\title{
Et poetis ipsis necessarium argentum / Humanistische Selbstdarstellungsstrategien auf dem Konzil von Konstanz
}

Dissertation zur Erlangung des philosophischen Doktorgrades an der Philosophischen Fakultät der

Georg-August-Universität Göttingen

vorgelegt von

Zsuzsanna Kiséry aus Debrecen

Göttingen 2009

1. Gutachter: Prof. Dr. Thomas Haye

2.

3. Gutachter: Prof. Dr. Johannes Helmrath

Tag der mündlichen Prüfung: 24. 11. 2010 


\section{Inhaltsverzeichnis}

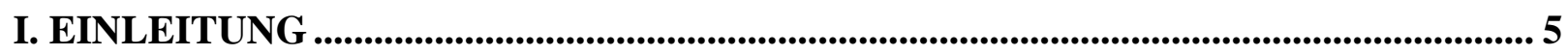

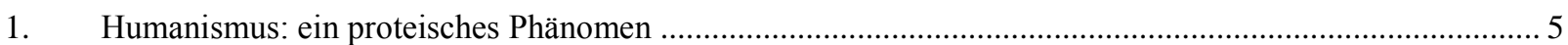

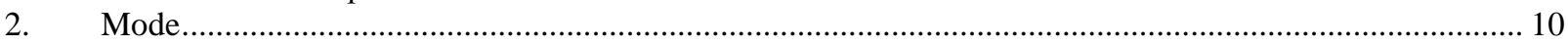

3. Die Rhetorik des Bruches und ihre Rolle in den Selbstdarstellungsstrategien ..................................... 13

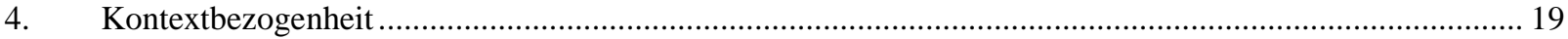

5. Wahrnehmung: Ein Spaziergang von den Humanisten bis zu den Hirnforschern und wieder zurück ......... 20

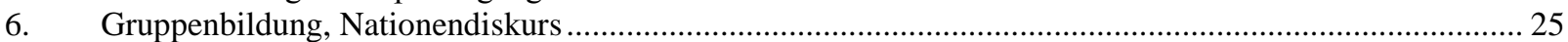

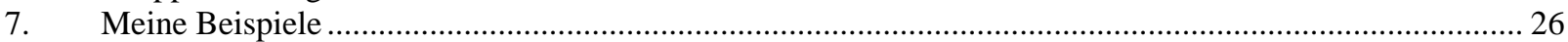

\section{VOM NUTZEN DER TOTEN: EULOGIEN AN DEN TOTEN KARDINAL FRANCESCO ZABARELLA ALS INSTRUMENTE HUMANISTISCHER SELBSTDARSTELLUNG................................................................................................... 31}

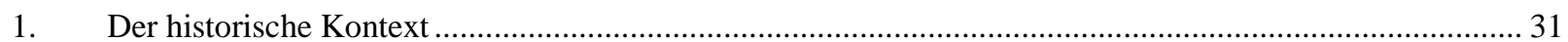

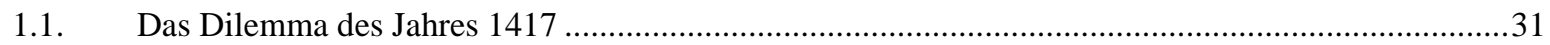

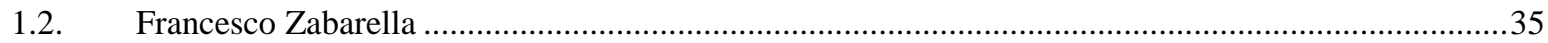

1.3. Die Eulogien zum Anlass des Todes des Francesco Zabarella ............................................................36

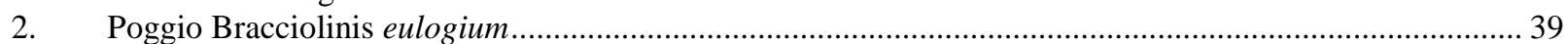

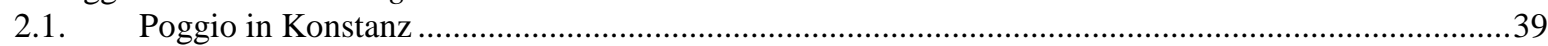

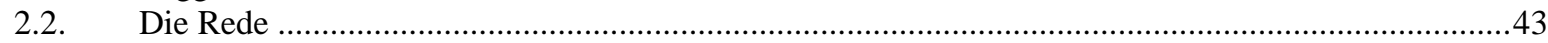

2.2.1. Die Strategie des orators: die Dramatisierung von Zabarellas Gestalt ......................................43

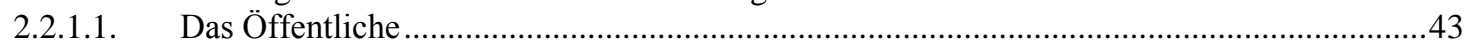

2.2.1.1.1. Vom Bescheidenheitstopos zur Selbstdarstellung als Meister des genus grande ........... 43

2.2.1.1.2. Der Höhepunkt: Zabarellas Vergegenwärtigung ……………………………………...... 47

2.2.1.1.2.1. Die Heraufbeschwörung des toten Kardinals ........................................................ 47

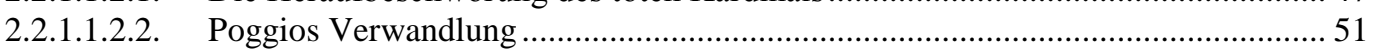

2.2.1.2. Poggios Entdeckungen als Folie für seine Rede und Instrument seiner

Selbstdarstellung: der wiedererweckte Cicero ………………...............................................54

2.2.1.3. Die Rede als Denkmal ............................................................................................57

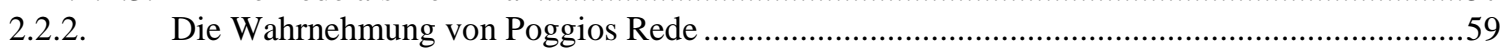

2.2.2.1. Über die Frage, ob die Rede tatsächlich gehalten wurde ..................................................59

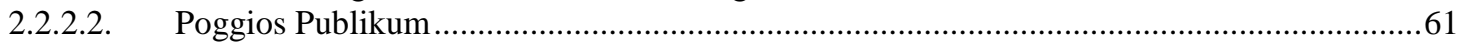

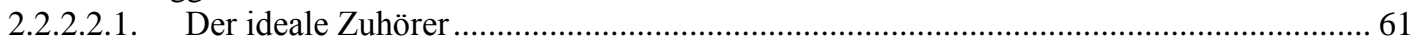

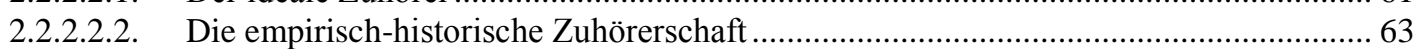

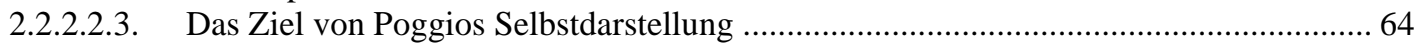

2.2.2.3. Das Ringen um die Toten - Poggios Denkmal für Zabarella: von den Forschern übernommen, von Poggio relativiert ................................................................................66

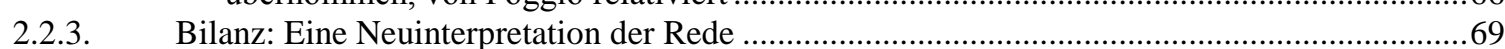

2.2.3.1. Poggios Agenda - Der orator als Verkünder von Zabarellas politischem Testament ..........69

2.2.3.2. Wer sind Poggios „,Feinde"? ............................................................................................71

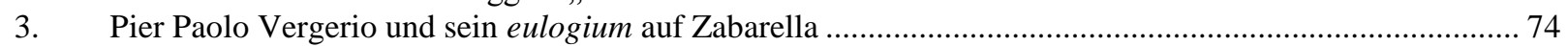

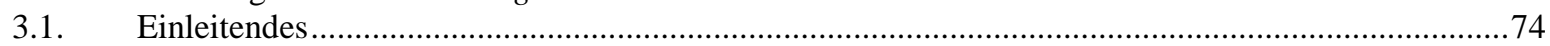

3.1.1. Sein Leben im kurzen Überblick ...................................................................................

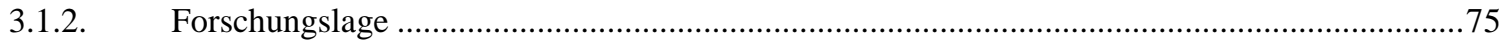

3.2. Vergerios Engagement für Sigismund von Luxemburg in Konstanz im Spiegel der

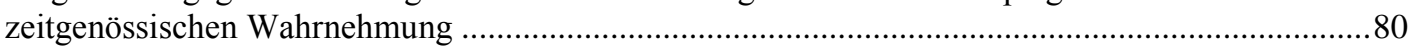

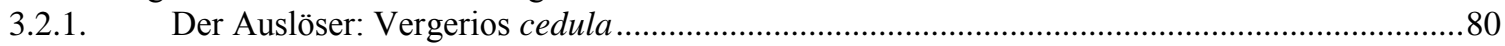

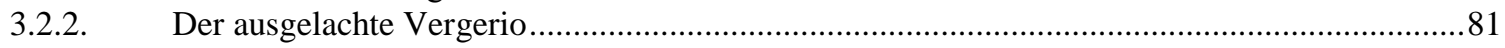

3.2.3. Der ,utriusque iuris ac medicine doctor" und gekrönte Dichter .................................................. 85

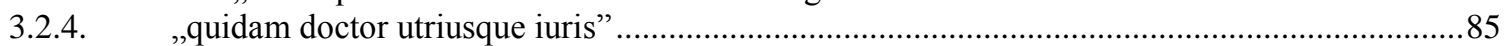

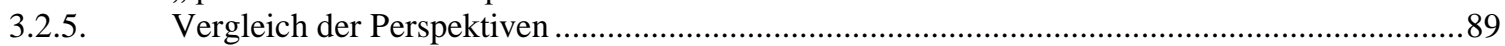

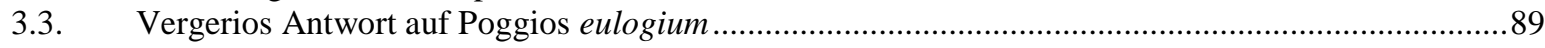

3.3.1. Die Strategie des Briefeschreibers und Freundes: Die Entdramatisierung von Zabarellas

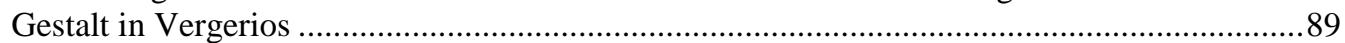

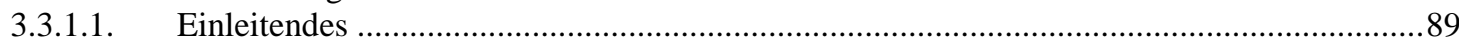

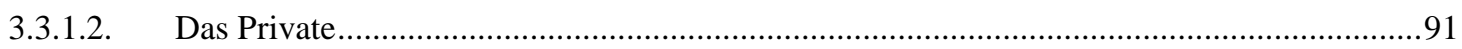

3.3.1.2.1. Freundschaft: ein wichtiger Baustein humanistischer Selbstdarstellung ....................... 91

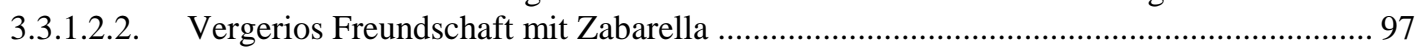


3.3.1.2.3. Vergerios Bild von seiner Freundschaft mit Zabarella in seinem eulogium ................. 98

3.3.1.2.3.1. Die Selbstfiktion der Briefform als Rahmen für den Diskurs des Privaten............ 98

3.3.1.2.3.2. Die Erzählung des Lebens als Erzählung einer Freundschaft ............................ 100

3.3.1.2.3.3. „Apud nos": ein , wir” wird kreiert ............................................................. 100

3.3.1.2.3.4. Vergerio als Begünstigter in Zabarellas Testament: Der geerbte Cicero ............. 102

3.3.1.2.3.5. Ciceros De amicitia als Folie zu Vergerios eulogium ........................................ 104

3.3.1.3. Die Entdramatisierung von Zabarellas Gestalt .......................................................... 110

3.3.1.3.1. Eine gar nicht harmlose Anapher...................................................................... 110

3.3.1.3.2. Zabarella als Vermittler .................................................................................. 114

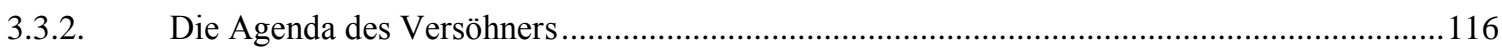

3.4. Zabarella, der „Humanist”: eine Bilanz ................................................................................ 118

III. PIER PAOLO VERGERIO: DIE KARRIERE EINES HUMANISTEN .................. 122

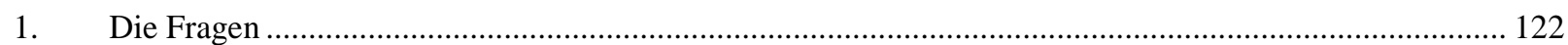

2. Vergerios Karrieremuster vor dem Konzil von Konstanz: in Petrarcas Fußstapfen ............................... 122

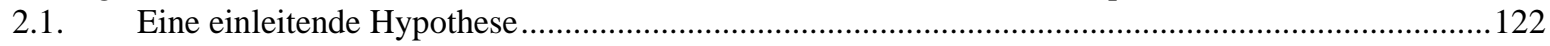

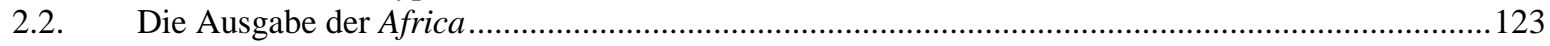

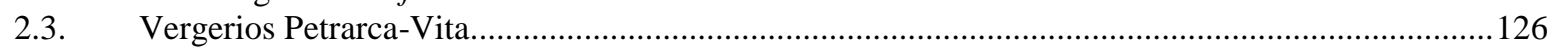

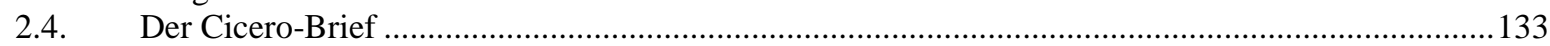

2.4.1. Vergerios angeblicher Republikanismus: Die früheren Deutungen des Briefes und deren

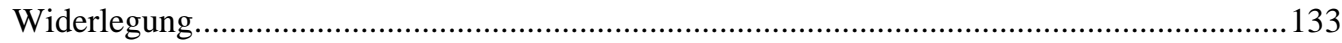

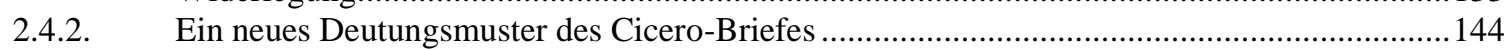

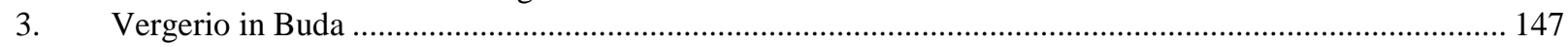

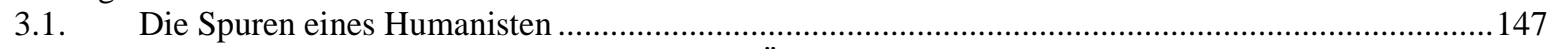

3.2. Eine missglückte Repräsentation: Vergerios Übersetzung von Arrian .......................................151

3.2.1. Die Wahrnehmung von Vergerios Übersetzung ............................................................. 151

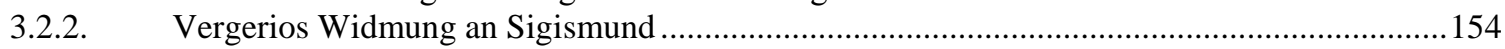

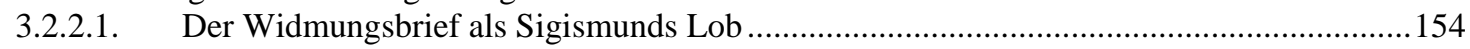

3.2.2.2. Vergerios Selbstlob in seinem Widmungsbrief und der Topos des Humanisten als

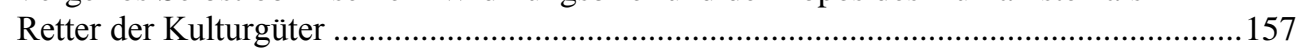

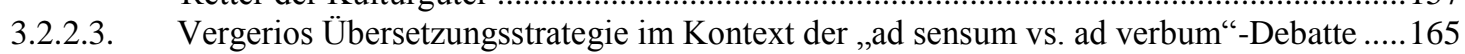

3.2.3. Ein Vergleich von Vergerios und Facios Übersetzungen der Alexander-Vita.......................170

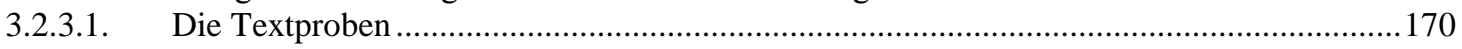

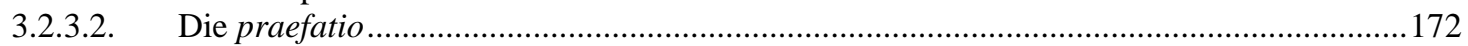

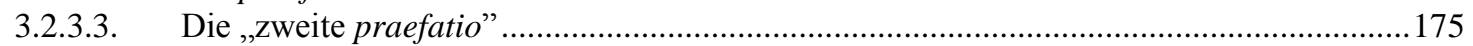

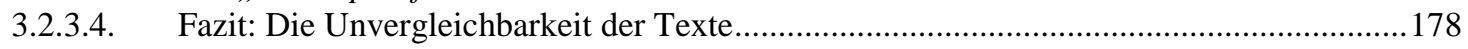

3.2.4. Projektionen: Der Herrscher und sein Humanist........................................................... 180

IV. BENEDETTO DA PIGLIO: EIN HUMANIST?.............................................................. 185

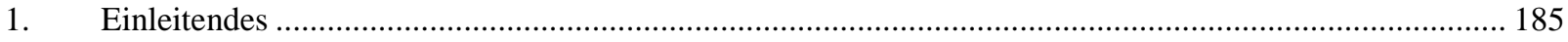

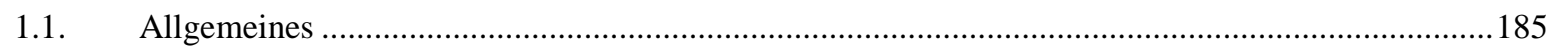

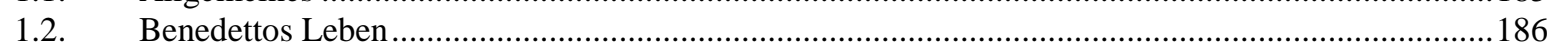

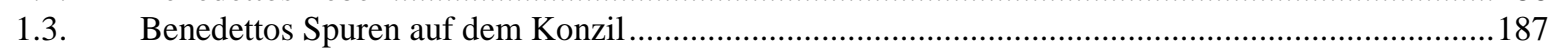

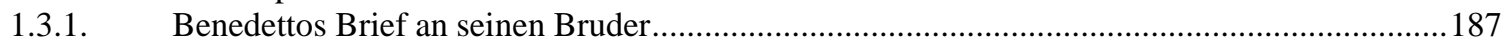

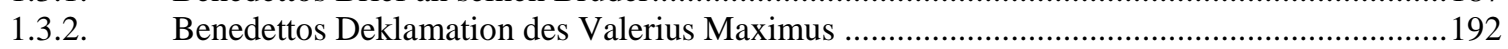

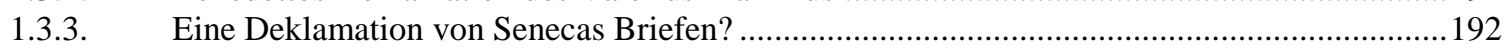

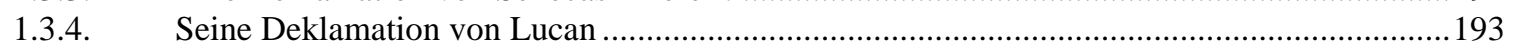

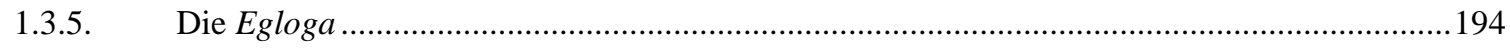

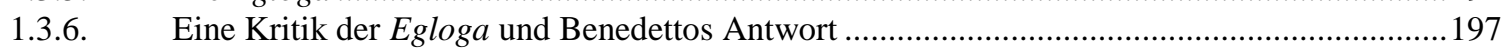

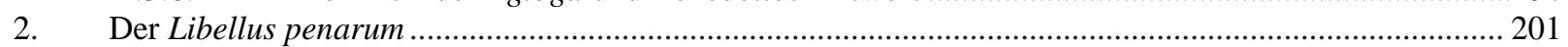

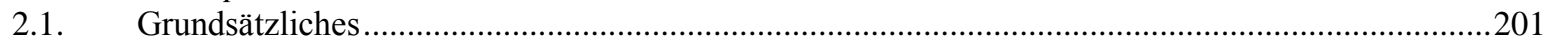

2.1.1. Die Struktur und Schreibsituation (nach der Fiktion) ...................................................201

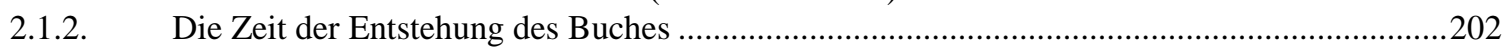

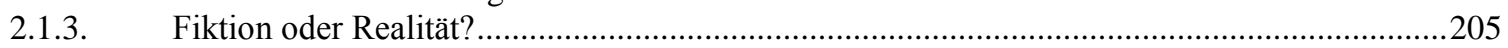

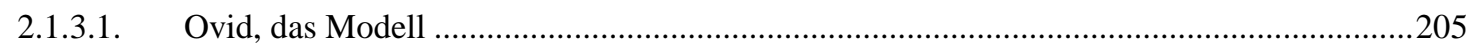

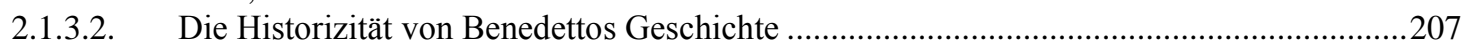

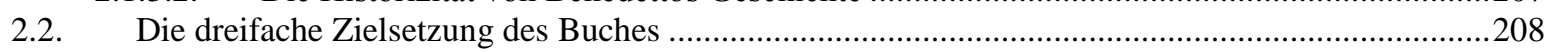

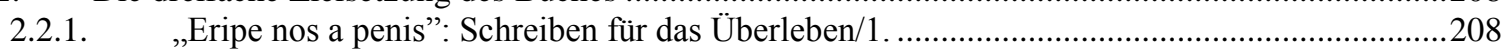

2.2.2. „otium sine litteris mors est”: Schreiben für das Überleben/2 . ..........................................209 
2.2.3. „fama per Italiam clara perennis erit”: Schreiben für das Überleben/3 .............................210

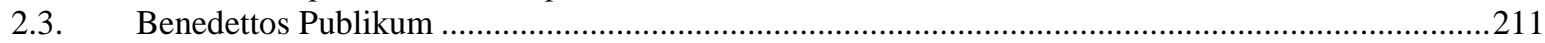

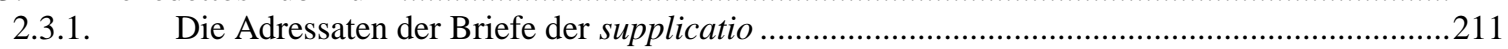

2.3.2. Benedettos Brüder als Adressaten des Libellus...........................................................213

2.3.3. Benedettos „Freunde”: Eine Lesergemeinschaft..........................................................213

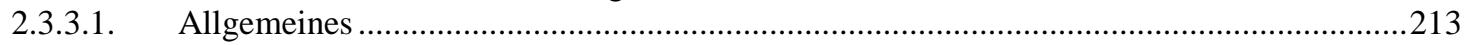

2.3.3.2. Die Öffentlichkeit des Konstanzer Konzils ................................................................2 214

2.4. Benedettos Selbstpositionierung mit seinem Libellus: Unter Sigismunds Ägide?.......................216

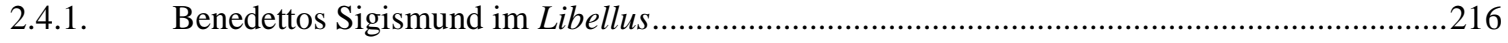

2.4.2. „O si nunc Caesar consurgere posset ab umbris” - Benedettos Rom-Invektive .....................217

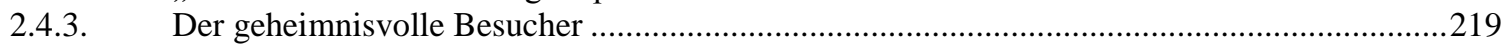

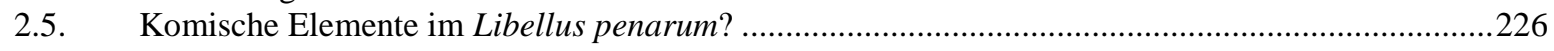

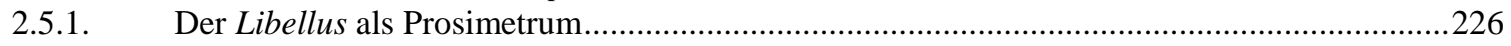

2.5.2. Die als komisch oder selbstironisch deutbaren Stellen im Libellus penarum .......................229

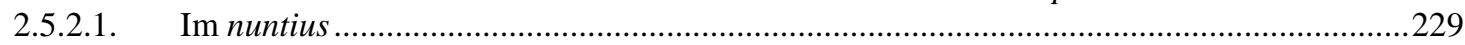

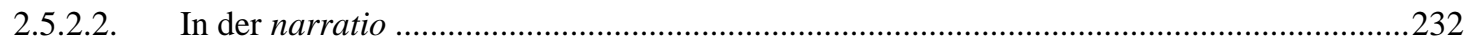

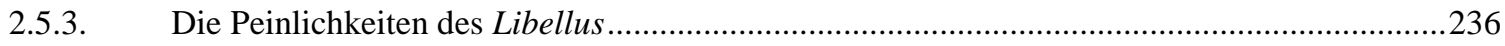

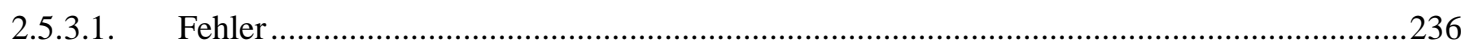

2.5.3.2. Ungeschicklichkeiten im nuntius .............................................................................2236

2.5.3.3. Die Durchsuchung: eine peinliche Szene und eine missglückte Stelle in der narratio.......240

2.5.3.4. Ein Versuch im Stil der „Bewanderten”. Stilistisches Scheitern in der supplicatio: die

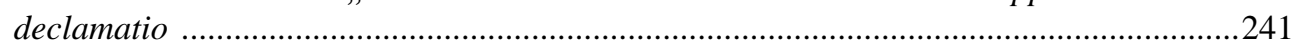

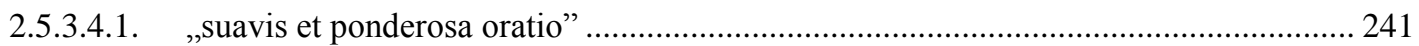

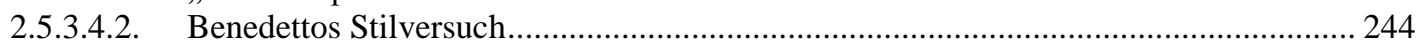

2.5.3.4.3. Benedettos Perspektive ............................................................................... 248

2.5.4. Benedettos Reflexionen über die Qualität des eigenen Textes ............................................249

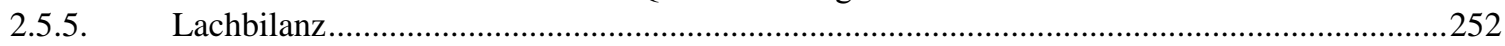

2.6. Benedettos Rekurs auf humanistische Praktiken.....................................................................25

2.6.1. Der Diskurs der Dichterkrönung im Libellus und sein Florentiner Kontext ..........................254

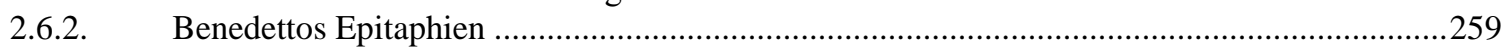

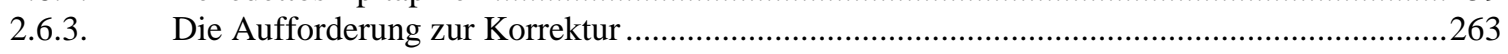

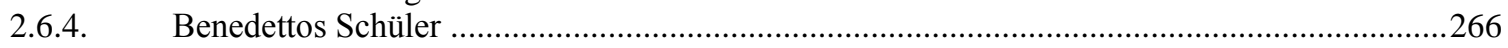

2.6.5. Zusammenfassung: Benedettos Haltung gegenüber dem Humanist-Sein ..............................267

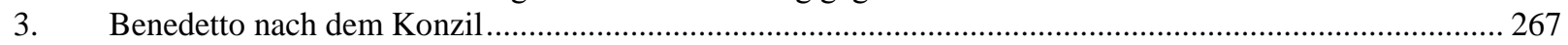

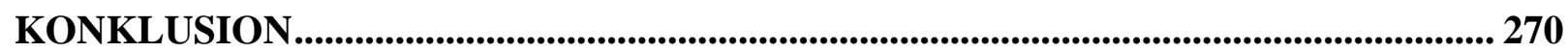

Eine Vorbemerkung: Das Paradoxon des Humanismus ......................................................................2 270

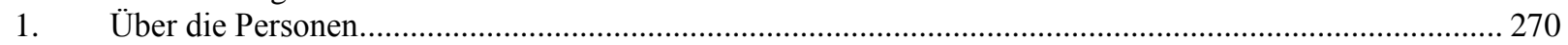

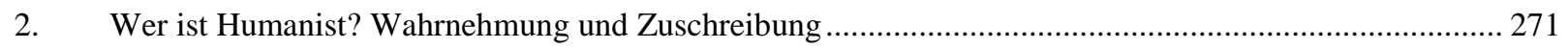

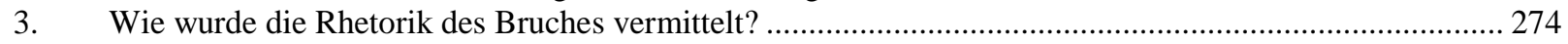

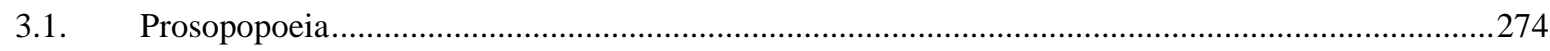

3.2. Diskurs der Dichterkrönung: Ein Schlüsseldiskurs am Anfang des 15. Jahrhunderts? .....................275

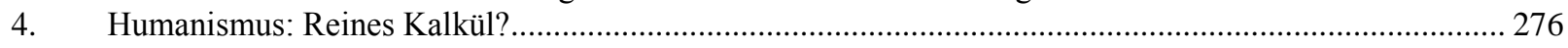

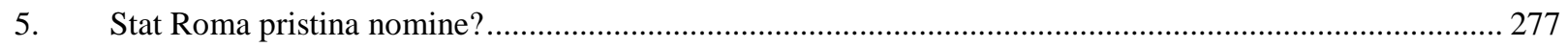

ANHANG 1: DIE MEIST BENUTZTEN TROPEN IN POGGIOS NARRATIO ........... 278

ANHANG 2: VERGERIOS UND FACIOS ÜBERSETZUNG DER PRAEFATIO, UND DER ,ZWEITEN PRAEFATIO” DER ALEXANDER-VITA ARRIANS............... 280

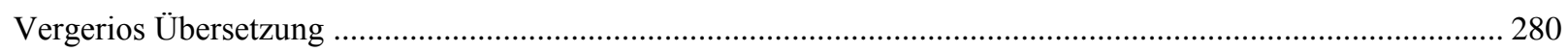

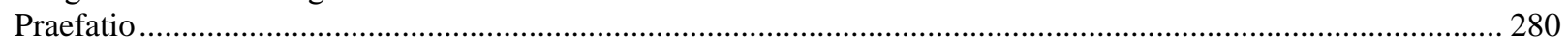

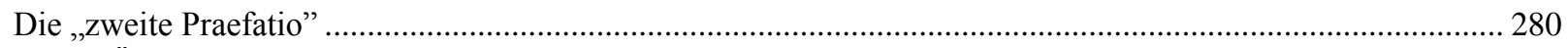

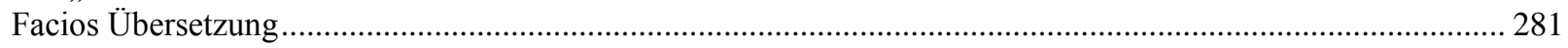

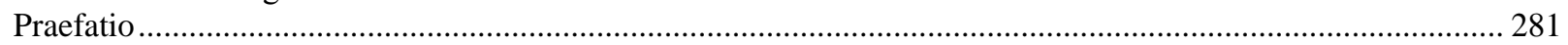

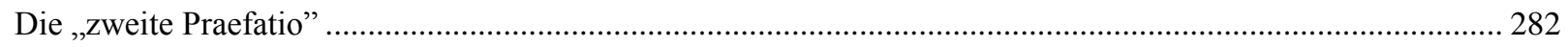

ANHANG 3: DER TEXT VON BENEDETTOS DECLAMATIO .................................... 283 
ANHANG 4: DIE BIOGRAPHISCHEN PERSONEN DER LESERGEMEINSCHAFT BENEDETTOS ................................................................................................................ 286

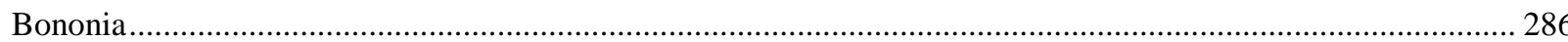

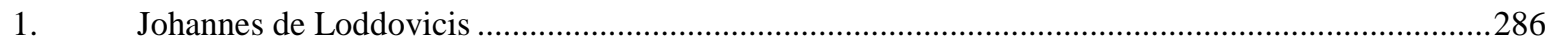

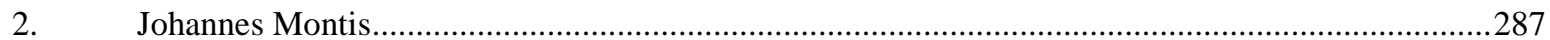

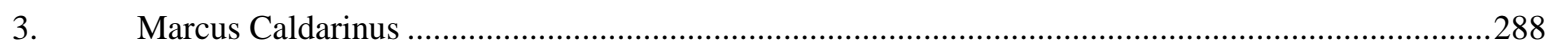

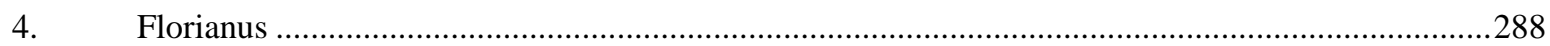

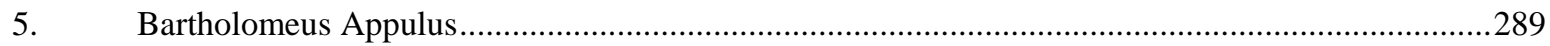

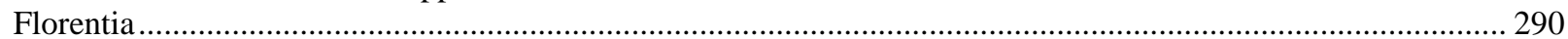

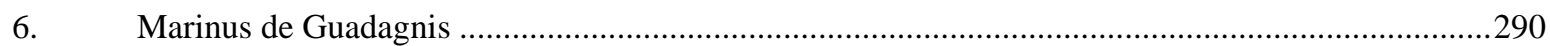

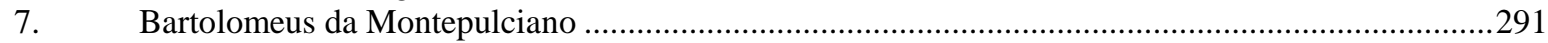

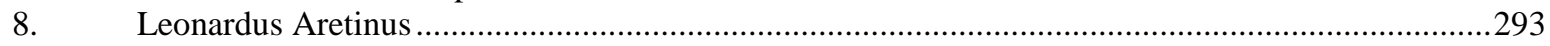

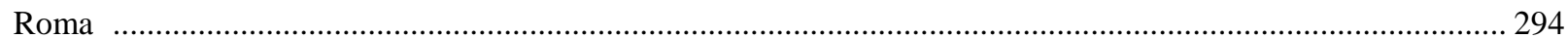

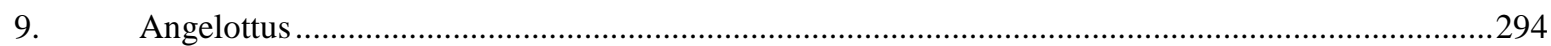

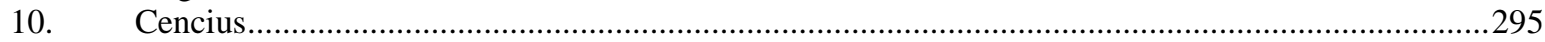

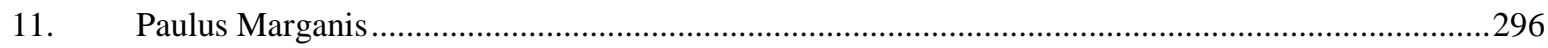

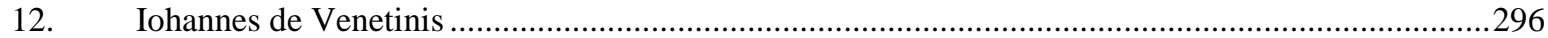

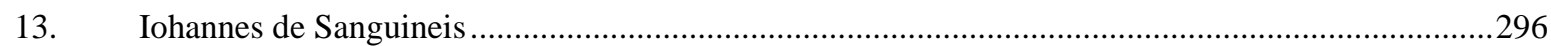

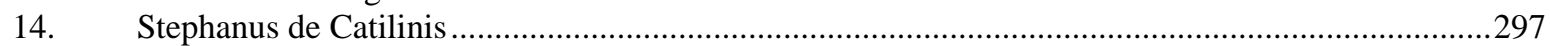

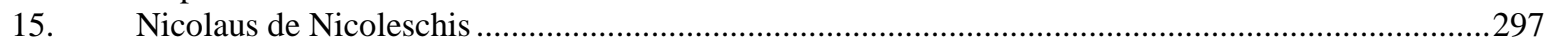

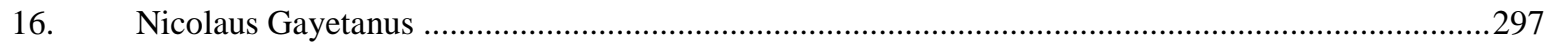

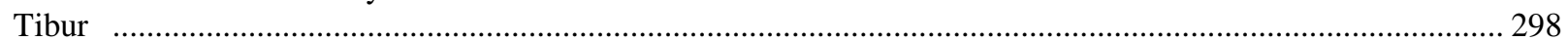

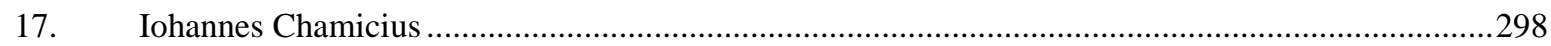

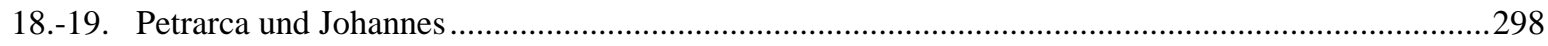

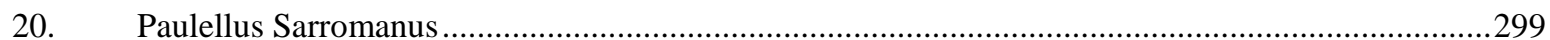

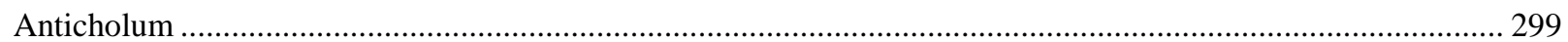

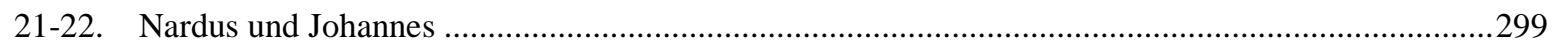

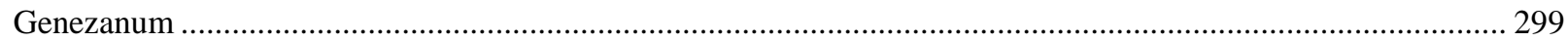

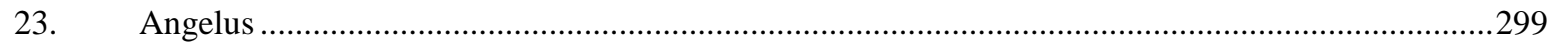

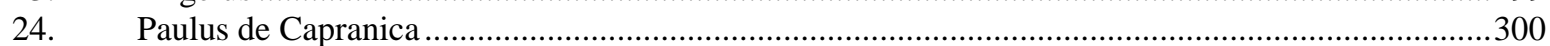

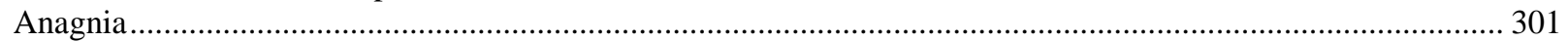

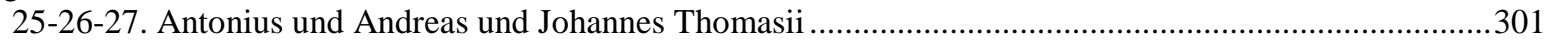

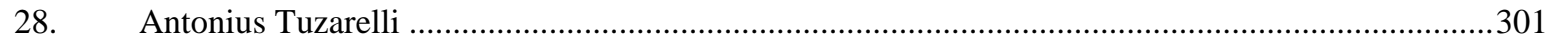

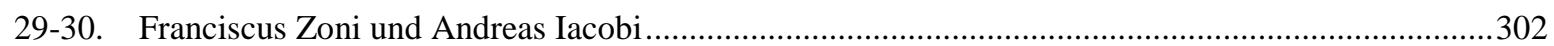

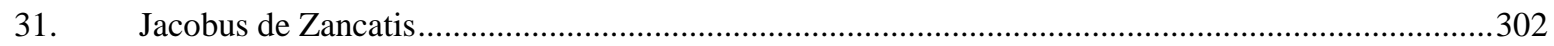

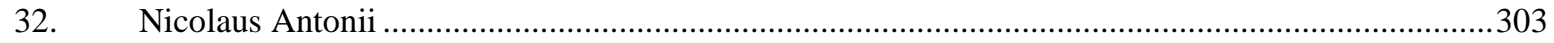

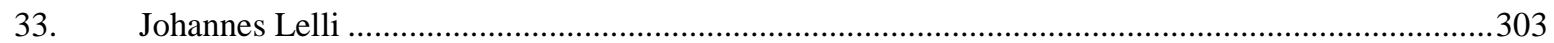

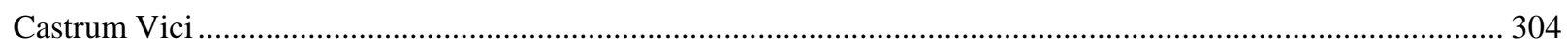

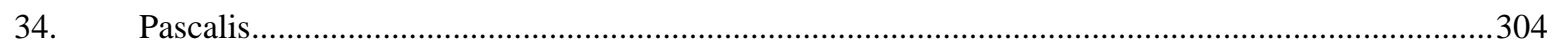

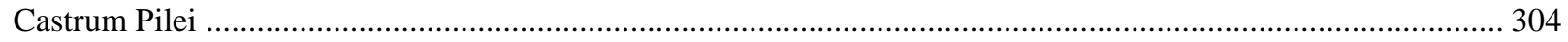

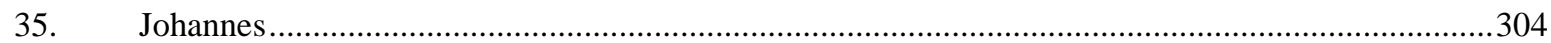

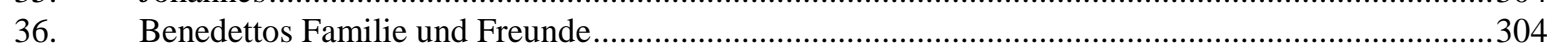

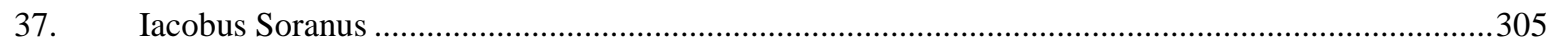

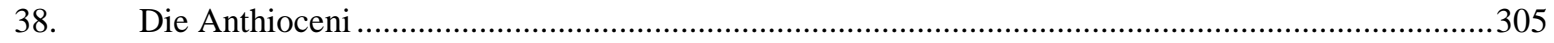

BIBLIOGRAPHIE ................................................................................................................................ 307

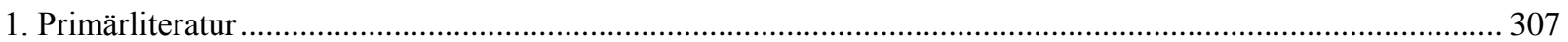

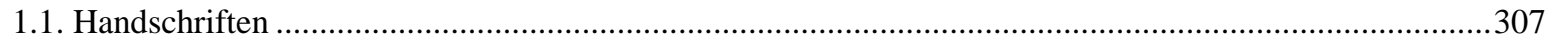

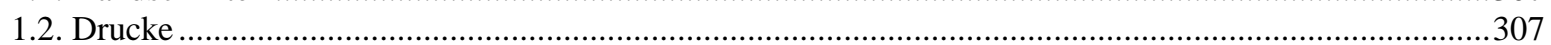

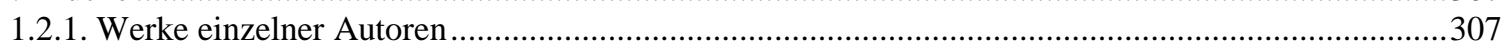

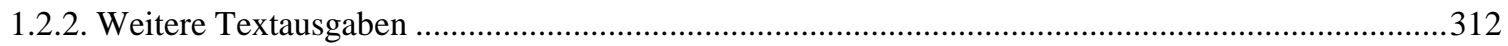

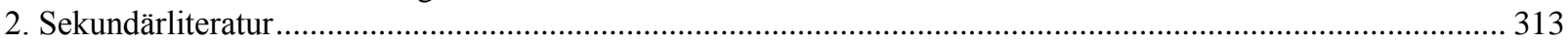

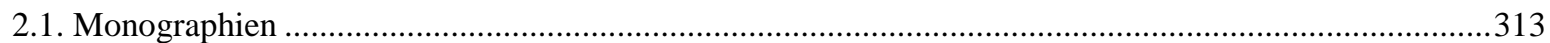

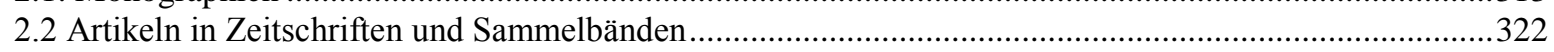

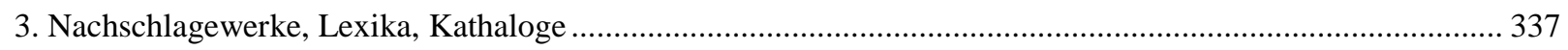

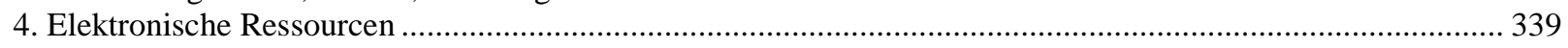




\section{Einleitung}

\section{Humanismus: ein proteisches Phänomen}

„...et così dell'Humanista, alli quali è lecito trattar, o legger quel che piú gli piace”: „und genauso [werde ich nicht berichten] über den Humanisten, dem es erlaubt ist, das zu behandeln oder in einer Vorlesung vorzutragen, was ihm am besten gefällt" schreibt Giovanni Francesco Trincavello, ein Student der Universität von Padua, 1552 in einem Bericht über die Universität. ${ }^{1}$ Paul F. Grendler zitiert diesen Satz in seiner Monografie über die Universitätsgeschichte der italienischen Renaissance mit der Erklärung, dass der Grund, warum Humanisten bei deren Lehr- und Forschungstätigkeit an den Universitäten für Unabhängigkeit prädestiniert waren, in der Tatsache zu suchen sei, dass die meisten von ihnen als Studenten eher wenig Zeit an Universitäten verbrachten und über keinen Universitätsabschluss verfügten. ${ }^{2}$

In dieser Arbeit geht es um Humanismus und Humanisten. Wenn man die Frage, wie man Humanismus und Humanisten definieren sollte, auf Grund des oben zitierten Beispiels beziehungsweise im Kontext der Universitätsgeschichte $\mathrm{zu}$ beantworten versucht, so ergibt sich folgerichtig eine Definition ex negativo. Humanisten seien die Leute, die auch ohne einen Abschluss an einer Universität unterrichten konnten. Gelehrte, die in anderen Kontexten als Humanisten bezeichnet werden, die aber mit einem ,,anständigen” Abschluss an einer Universität tätig waren, wie zum Beispiel Pier Paolo Vergerio, der, im Besitz des Doktorgrades ,,in scienciis suprascriptis arcium et medicine, iurisque canonici et civilis"3, an der Universität von Bologna unterrichtete, werden in diesem Zusammenhang oft nicht als „Humanisten” beschrieben, weil sie an der Universität, wo sie unterrichteten, auch nicht als „Humanisten” eingestellt wurden: Vergerio unterrichtete Logik und nicht die für Humanisten typischen Fächer der Rhetorik oder Poetik. Als Parallelbeispiel kann ein Phänomen genannt werden, das von Studien, die den Humanismus sozialgeschichtlich untersuchen, oft ins Blickfeld gerückt

1 Der Bericht ist in einer Sammelhandschrift zu finden, die Schriften über die Geschichte der Universität von Padua enthält, die vom Bibliothekar der Biblioteca Marciana, Jacopo Morelli, gesammelt worden sind. Der Bericht ist gedruckt in: Rodolfo Gallo, „Due informazioni sullo studio di Padova della metà del Cinquecento", Archivio Veneto 73, (1963): 17-100.

2 „Moreover, the Humanists' outlook disposed them to independence in teaching and research, possibly because they spent little time as university students. Filelfo, Poliziano, and Sigonio lacked degrees, and Muret acquired his by examination at the age of forty-six. Of this illustrious group only Poliziano and Sigonio even studied at universities." Vgl. Paul F. Grendler, The Universities of the Italian Renaissance (Baltimore und London: The Johns Hopkins University Press, 2002), [im Weiteren: „The Universities”], hier S. 236.

3 Gaspare Zonta und Giovanni Brotto, Hrsg., Acta Graduum Academicorum Gymnasii Patavini ab anno MCCCCVI ad annum MCCCCL (Padua: Typis seminarii Patavii, 1922), hier S. 483 f. 
wird $^{4}$ : der Gebrauch des Titels poeta laureatus auf deutschem Gebiet im 16. Jahrhundert. Er wird oft nur dann gebraucht, wenn kein höherer Titel vorhanden ist. Mit anderen Worten, wenn jemand, nachdem er als Dichter gekrönt worden war, noch einen Abschluss in Theologie oder Recht machte, bezeichnete er sich oft nicht mehr als poeta laureatus.

Gegen eine solche Definition von Humanisten kann sich sofort der Einwand erheben, dass sie mit einem Kontext arbeitet, der eine andere Definitionsmöglichkeit von vornherein ausschließt: Humanismus und die ars humanitatis hatte im spätmittelalterlichen Universitätssystem sachlich und institutionell einen extraordinären Status ${ }^{5}$. Dementsprechend kann Humanismus, von diesem Gesichtspunkt aus betrachtet, nur negativ beschrieben werden, als etwas, das mit dem alten System nicht kompatibel ist. Auf diesen Einwand kann man wiederum antworten, dass Humanismus selbstverständlich immer nur kontextbezogen beschrieben werden kann, weil er nur in Wahrnehmungen und Darstellungen existiert, was $a b$ ovo mehrere Interpretationen und Definitionen impliziert. Dementsprechend kann man die oben zitierte, unter den Trägern der etablierten Kultur geläufige kritische Meinung - der Satz des Jurastudenten über einen Humanisten, der lehren und forschen kann, was er will, und über den der Berichterstatter kein weiteres Wort verlieren möchte, impliziert keine besonders schmeichelhafte Meinung über die Vertreter der neuen Kultur - als eine Definition unter den anderen gelten lassen.

Die ältere Humanismusforschung hatte oft die Tendenz, die Selbstdarstellung der Humanisten für bare Münze zu nehmen, als Ausgangspunkt für eine objektive Definition zu nutzen, ohne den Status solcher Selbstaussagen zu hinterfragen. ${ }^{6}$

4 Dieter Mertens, „Zu Sozialgeschichte und Funktion des poeta laureatus im Zeitalter Maximilians I.”, in Gelehrte im Reich. Zur Sozial- und Wirkungsgeschichte akademischer Eliten des 14. bis 16. Jahrhunderts, hrsg. v. Rainer Christoph Schwinges (Berlin: Duncker\&Humblot, 1996), 327-348, hier besonders S. 340341; und John L. Flood, „Viridibus lauri ramis et foliis decoratus. Zur Geschichte der kaiserlichen Dichterkrönungen", in Reichspersonal. Funktionsträger für Kaiser und Reich, hrsg. v. Anette Baumann, Peter Oestmann, Stephan Wendehorst und Siegrid Westphal (Köln, Weimar, und Wien: Böhlau, 2004), 353-377, hier besonders S. $372 \mathrm{f}$.

5 Zur Frage vgl. Franz Josef Worstbrock, „Hartmann Schedels „Index Librorum”. Wissenschaftssystem und Humanismus um 1500", in Studien zum 15. Jahrhundert. Festschrift für Erich Meuthen, hrsg. v. Johannes Helmrath, Heribert Müller und Helmut Wolff (München: Oldenbourg, 1994), 697-717.

6 Hier kann man zum Beispiel an die alte Petrarca-Forschung denken, die Petrarcas Selbstaussagen für bare Münze nahm. Die Naivität der Forschung hatte in diesem Fall besonders auffällige Konsequenzen, weil sie sogar die Datierung der Petrarcaschen Werke beeinflusste: Petrarca datierte seine Werke in manchen Fällen nicht realitätsgemäß, um auf diese Weise eine idealisierte, aus diesen Datierungen herauslesbare Autobiographie konzipieren zu können. Ein Streit zwischen den Forschern, die Petrarca glauben, und denen, die seine Behauptungen hinterfragen und damit zu völlig anderen Ergebnissen zur Frage über die Datierung eines Petrarca-Werkes gelangen, kann durch die Debatte über das Entstehungsdatum des Secretums exemplifiziert werden. Für erstere Position vgl. Carlo Calcaterra, „Sant Agostino nelle opere di Dante e Petrarca", in Nella selva del Petrarca (Bologna: Editore Licinio Cappelli, 1942), 291-306; und Remigio Sabbadini, „Note filologiche sul Secretum del Petrarca”, Rivista di Filologia e di istruzione classica 45 (1917): 24-37. Für die zweite Position vgl. Francisco Rico, Vida u obra de Petrarca. I. Lectura del Secretum (Padua: Antenore, 1974), dessen Studie als Wendepunkt gesehen werden kann. 
Durch die Analyse meiner Beispiele werde ich der Frage nachgehen, was das Spezifische und das Neue der humanistischen Rhetorik war. Welche textuelle Strategie kann als eine typisch humanistische verstanden werden? Trotz der scheinbaren Banalität dieser Frage gilt sie in der Humanismusforschung meines Erachtens nicht als beantwortet. Die Selbstverständlichkeit, mit der man über Humanismus und Humanisten schreibt, verdeckt manchmal die Tatsache, dass bis heute keine eindeutige Antwort auf die Frage gegeben wurde, worin eigentlich Humanismus besteht.

In der Debatte über Humanismus sind nicht nur verschiedene Definitionen geläufig. Manchmal halten es die Forscher sogar für nötig, selbst um die Anerkennung der Existenz der Renaissance und des Humanismus zu kämpfen.

Improved techniques of lighting have affected not only our homes and offices, but the Middle Ages as well. The darkness of the mediaeval blackout has all but disappeared. Certain mediaeval centuries indeed are said by some to be nearly as bright as day, for we now speak of a renaissance in the ninth century and another in the twelfth. Consequently the dazzling brightness of what used to be the Renaissance to those who came to it from the medieval blackout now seems to have less candle power.[...] Then too we have discovered a spiritual kinship with the Middle Ages, a discovery which has led to some rather remarkable results in the last thirty years. Among them is a deprecation of the Renaissance. This chapter will be regarded as a reactionary by some because it assumes the fundamental importance of the revival of literature and the classics in the formation of the Renaissance. ${ }^{7}$

Außer Ullmans offensichtlicher Aversion gegenüber dem Mittelalter, die als ein Zeichen für seine Übernahme der humanistischen Rhetorik des Bruches zu verstehen ist, spürt man auch die Angst aus seinen kämpferisch-ironischen Worten heraus, dass die Betonung von Kontinuität zwischen Mittelalter und Renaissance die Existenz der Letzteren hinterfragen könnte. Wenn man bedenkt, dass es Anfang der vierziger Jahre noch keine so erbarmungslosen Kontinuitätsverfechter wie Robert Black $^{8}$ gab, um wenigstens ein Beispiel zu nennen, ist der Ton von Ullmans Kritik noch auffälliger. Er richtet seine Kritik gegen die Vertreter der These, es

7 Berthold Louis Ullman, „Some Aspects of the Origin of Italian Humanism”, in Studies in the Italian Renaissance, Storia e Letteratura 51, hrsg. v. Berthold Louis Ullman (Rom: Edizioni di Storia e Letteratura, 1955), 27-40, hier S. 27.

8 Für eine bündige Darstellung von Blacks Humanismusdefinition vgl. Robert Black, „Humanism”, in The New Cambridge Medieval History c. 1415-c. 1500, The New Cambridge Medieval History 7, hrsg. v. Christopher Allmand (Cambridge: Cambridge University Press, 1998), 243-277, [im Weiteren „Humanism"]. Auch in seiner Monographie über die Schule in der italienischen Renaissance argumentiert er für eine eindeutige Kontinuität zwischen dem Mittelalter und der Renaissance: Robert Black, Humanism and Education in Medieval and Renaissance Italy: Tradition and Innovation in Latin Schools from the Twelfth to the Fifteenth Century (Cambridge: Cambridge University Press, 2001), [im Weiteren: „Humanism and Education"]. 
habe so etwas gegeben wie die Renaissance des neunten oder zwölften Jahrhunderts. ${ }^{9}$ Im Vergleich mit der Situation, gegen die Ullman es für nötig hielt, seine Worte zu richten, wimmelt es in der heutigen Forschungslandschaft regelrecht von den Gegnern der von Ullman vertretenen und von ihm selbst als „,reaktionär” bezeichneten Position.

Heute entzünden sich die Gemüter mancher Humanismusforscher zum Beispiel an Robert Blacks Ansichten, und zwar aus einem Ullmans Befürchtungen ähnlichen Grund. Paul F. Grendler zum Beispiel fasst Blacks Ansichten folgender Weise zusammen:

He denies the existence of significant curricular change in Latin schooling in Italy before 1500. More generally, he diminishes the importance of Renaissance humanism and its impact. [...] His overall argument is part of an interpretative stance that denies the existence of the Renaissance. ${ }^{10}$

Eine Skepsis an der Möglichkeit einer eindeutigen Trennung zwischen Humanistischem und Nichthumanistischem scheint zum Beispiel auch in Gebiete eingedrungen zu sein, in denen früher die Abgrenzung eindeutiger schien, wie zum Beispiel in die Paläographie. ${ }^{11}$ Auch auf eine gewisse Kontinuität zwischen Humanistenlatein und mittelalterlichem Latein wurde bereits in den siebziger und achtziger Jahren hingewiesen. ${ }^{12}$

Die Schwierigkeiten der Definition von Humanismus und Humanisten sind zum Teil auf die Schwankungen der zeitgenössischen Wahrnehmung des Phänomens zurückzuführen. Es ist bekannt, dass die Meinungen darüber, welcher Autor als Urheber der neuen Kultur gelten kann, unter den Trägern derselben Kultur recht verschieden waren. Paolo Cortesi nimmt $(1465-1510)^{13}$ in seinem Dialog De hominibus doctis Manuel Chrysoloras als Ausgangspunkt für seinen Überblick über die homines docti, die die Kultur, die 1000 Jahre lang in

9 Seine Attacke richtet sich also hauptsächlich gegen: Jean-Jacques Ampére, Histoire Littéraire de la France avant le douzième Siècle (Paris: Hachette, 1839); Charles Homer Haskins, The Renaissance of the Twelfth Century, (Cambridge: Harvard University Press, 1927); und Gérard Paré, Adrien Brunet und Pierre Tremblay, La renaissance du XIIe siècle. Les écoles et l'enseignement (Ottawa und Paris: Vrin, Institut d'études médiévales, 1933).

10 Paul F. Grendler, „Reply to Robert Black”, Journal of the History of Ideas 52 (1991): 335-337, hier S. 335.

11 Johann Peter Gumbert zum Beispiel hat in seiner Studie auf die Tatsache hingewiesen, dass gotische und humanistische Schriften nicht so eindeutig von einander zu trennen sind, wie es oft angenommen wird: Johann Peter Gumbert, „Italienische Schrift - humanistische Schrift - Humanistenschrift”, in Renaissance und Humanistenschriften, Schriften des Historischen Kollegs, Kolloquien 13, hrsg. v. Johannes Autenrieth, (München: R. Oldenburg Verlag, 1988), 63-71.

12 Vgl. die Studien: Franz Blatt, „Die letzte Phase der lateinischen Sprache”, Archivium Latinitatis Medii Aevi 40 (1975): 65-75; und Jozef IJsewijn, „Mittelalterliches Latein und Humanistenlatein”. In Die Rezeption der Antike. Zum Problem der Kontinuität zwischen Mittelalter und Renaissance, Wolfenbütteler Abhandlungen zur Renaissanceforschung 1, hrsg. v. August Buck (Hamburg: Hauswedell, 1981) 71-83.

13 Dieter Girgensohn zitiert Paolo Cortesis Werk als ein Beispiel für die wechselnde Optik der verschiedenen Generationen der Humanisten hinsichtlich deren Urteil über die Urheber der neuen Kultur: Dieter Girgensohn, „Studenti e tradizione delle opere di Francesco Zabarella nell'Europa centrale”. In Studenti, università, città nella storia padovana. Atti del convengo, Padova 6-8 Febbraio 1998, Contributi alla storia dell'Università di Padova 34, hrsg. v. Francesco Piovan and Sitran Rea Luciana (Triest: Lint, 2001), 127176, [im Weiteren: „Studenti e tradizione”], hier S. 168. 
Vergessenheit gewesen sei, wiederentdeckt haben. ${ }^{14}$ Über Petrarcas Latein, der von vielen Humanisten der früheren Generationen, wenn es um eine ähnliche Auflistung der Initiatoren der Wiederbelebung der lange vergessenen antiken Tradition ging, noch eindeutig als erster genannt wurde, ${ }^{15}$ hat Cortesi ein weniger schmeichelhaftes Urteil: „Huius sermo nec est Latinus et aliquando horridior; sententiae autem multae sunt sed concisae, verba abiecta, res compositae diligentius quam elegantius."16

Diese Kritik an Petrarca und die Tatsache, dass er in Cortesis Werk nicht als der Ausgangspunkt genannt wird, kann den Leser zur Annahme bewegen, dass Cortesi die Anfänge des Humanismus nicht auf Petrarca zurückführt und dass er Petrarca sogar aus dem Kreis der Humanisten ,ausschließt”. ${ }^{17}$ Gegen eine solche Annahme kann man aber einwenden, dass Cortesis nächster Satz viel von der Schärfe seines Urteils zurücknimmt:

Fuit in illo [Petrarca] ingenii atque memoriae tanta magnitudo, ut primum ausus sit eloquentiae studia in lucem revocare. Nam huius ingenii affluentia primum Italia exhilarata, et tanquam ad studia impulsa atque incensa est. ${ }^{18}$

Hält Cortesi Petrarca für „dazugehörend” oder nicht? Seine Haltung ist zwiespältig: er stellt zwar Petrarca nicht an den Anfang seiner enumeratio, erkennt aber trotzdem seinen hervorgehobenen Status an und sieht ihn als den ersten, der es überhaupt gewagt hat, sich den Studien der antiken Literatur zu widmen. Die Sekundärliteratur zitiert oft entweder den einen oder den anderen Satz Cortesis, je nach der zu beweisenden Annahme. Studien, die Petrarca als eine für die Humanisten unerschütterliche Autorität darstellen, zitieren oft nur den Teil der Aussage, den Cortesi dem Teilnehmer seines Dialogs in den Mund legt, der für Petrarca schmeichelhaft ausfällt. ${ }^{19}$ Es gibt aber Auffassungen, für die der Teil von Cortesis Text

14 ,id esse nuper ab ingeniis nostrorum hominum vel inventum vel illustratum quod mille iam prope annos ignoratum sit”: Paolo Cortesi, De hominibus doctis dialogus, L’ippogrifo 1, hrsg. v. Maria Teresa Graziosi (Rom: Bonacci, 1973), [im Weiteren: „Dialogus”], hier S. 72.

15 Um ein Beispiel von den Autoren zu nennen, um die es in meiner Arbeit geht: Als Pier Paolo Vergerio eine Invektive gegen Carlo Malatesta schrieb, der Vergils Statue in Mantua abreißen ließ, schrieb er über den hochgeschätzten Status der antiken Dichter, und gleich nach den antiken Beispielen nennt er Petrarca: qui post tot secula unicus vates emersit: Pier Paolo Vergerio, Epistolario, Fonti per la storia d'Italia. Epistolari. Secolo XIV-XV 74, hrsg. v. Leonardo Smith (Rom: Istituto Storico Italiano, 1971), [im Weiteren: „Epistolario"], hier S. 200.

Cortesi, Dialogus, S. 18.

Girgensohn, Studenti e tradizione, S. 168: „esclude espressamente Petrarca”.

Cortesi, Dialogus, S. 18.

Henry David Jocelyn in seinem Artikel: Henry David Jocelyn, „Petrarch and the Classical Drama”, in Petrarca e la cultura europea, hrsg. v. Luisa Rotondi Secchi Tarugi (Mailand: Nuovi Orizzonti, 1997), 3154, hier S. 31. Schon der Titel, und so das Thema des Buches, indem es Petrarca als einen Begründer der neuen Kultur ins Zentrum des Diskurses über Humanismus stellt, erhöht die Wahrscheinlichkeit, dass in der im Buch veröffentlichten Studie der „unproblematischere” Teil von Cortesis Aussage über ihn zitiert wird, der Petrarca als den ersten nennt, der sich überhaupt getraut habe, sich mit der antiken Erbschaft der Rhetorik auseinanderzusetzen. 
willkommener ist, in dem Petrarcas Stil getadelt wird, ${ }^{20}$ weil damit vor Augen geführt werden kann, dass sogar die Urteile über die Autoren, die man heute als „Humanisten” bezeichnet, im 14.-15. Jahrhundert sehr unterschiedlich sein konnten. ${ }^{21}$ Von diesen zwei angeführten Beispielen aus der Sekundärliteratur, obwohl beide die Cortesi-Stelle nur zur Hälfte zitieren, scheint die Zielsetzung der historisch arbeitenden Richtung die fruchtbringendere zu sein, derjenigen also, die es sich vornimmt, die Wechselhaftigkeit des Phänomens zu untersuchen, statt mit absolut gesetzten Kategorien zu arbeiten. ${ }^{22}$ Der in Cortesis Schrift präsente Zwiespalt im Urteil über Petrarca ist ein Beweis dafür, wie wenig eindeutig entscheidbar es ist, und schon immer war, ob jemand als Humanist zu bezeichnen sei/war oder nicht.

\section{Mode}

Für die Analyse meiner Fallbeispiele und für die Deutung des Phänomens Humanismus bekam meine Arbeit wichtige Impulse von der Kristellers Ansätze weiterführenden Auffassung von Robert Black. ${ }^{23}$ Er erklärt den Erfolg des Humanismus mit dem argumentativen Geschick der ihm zu Grunde liegenden Fiktion, laut der eine klassische Bildung jedem eine essentielle Qualifikation liefere, der nach einer führenden Position strebt. Dieses Bildungsideal könne auf jedes politische System angewendet werden. Black stützt sich in seiner Argumentation auf Gombrich ${ }^{24}$ und Grey $^{25}$ als Exponenten eines ähnlichen Erklärungsmusters, die

20 Wie zum Beispiel Girgensohn, Studenti e tradizione, S. 168.

21 Es geht selbstverständlich nicht um das Wort „humanista”, dessen erste Anwendungsbeispiele erst von einer späteren Zeit überliefert worden sind, als die von mir untersuchten Dezennien. In meiner Arbeit, wie in so vielen anderen Arbeiten über den Humanismus, geht es um Humanisten avant la lettre. Für die Geschichte dieser Bezeichnung selbst vgl. Rino Avesani, „La professione dell'Umanista” nel Cinquecento”, Italia Medioevale e Umanistica, 13 (1970): 205-232; Giuseppe Billanovich, „Auctorista, humanista, orator”, Rivista di cultura classica medioevale 7 (1965): 143-163, [im Weiteren: „Auctorista”]; und Augusto Campana, „The Origin of the Word „Humanist”, Journal of the Warburg and Courtauld Institutes 9 (1946): 60-73.

22 Auch ich benutze Cortesis Schrift in diesem Sinne: als Teil einer Argumentation für die Wechselhaftigkeit des Phänomens. Wenn ich die ganze Stelle zitiere, also auch den Teil, der Petrarcas Lob enthält, nicht weglasse, so gefährdet es die Argumentation nicht. Der einzige Unterschied ist, dass das Zitieren der ganzen Stelle - mit ihrer Uneindeutigkeit - einen Beweis für die Unentschiedenheit über Petrarcas Stellung in der humanistischen Gelehrsamkeit innerhalb desselben Textes bietet, also eine synchrone, statt eine rein diachrone Beweisführung ermöglicht.

23 In seiner Zusammenfassung der Erklärungsversuche von Humanismus nennt Black Kristellers Studie von 1979 als „the single most influential article on Renaissance humanism written this century”: Black, Humanism, S. 246. Es handelt sich um die Studie: Paul Oskar Kristeller, „Humanism and Scholasticism”, in Renaissance Thought and its Sources, hrsg. v. Michael Mooney (New York: Columbia University Press, 1979), 85-105, in der Kristeller vorschlägt, die Humanisten nicht als Philosophen zu betrachten (in der viel zitierten Formulierung: „I should like to suggest that the Italian humanists on the whole were either good nor bad philosophers, but no philosophers at all." S. 91.)

24 Ernst H. Gombrich, „Antike Regeln und objektive Kriterien. Von der Schrift- und Sprachreform zur Kunst der Renaissance: Niccolo Niccoli und Filippo Brunelleschi”, in Die Entdeckung des Sichtbaren. Zur Kunst der Renaissance Bd. 3 (Stuttgart: Klett, 1987), 114-135.

25 Hannah H. Gray, ,Renaissance Humanism: The Pursuit of Eloquence”, Journal of the History of Ideas 24, (1963): 497-514. Die Autorin betont ,the subjective consciousness of novelty” der Humanisten: S. 500. 
in den Gründen der Erfolgsgeschichte des Humanismus seine Überzeugungskraft sehen, die es den Humanisten selbst glaubhaft machen konnte, dass sie einen sichereren Weg zur Tugend bieten als ihre Vorgänger. Diese Sichtweise beschreibt Humanismus als eine Mode. ${ }^{26}$ Mit dem Wort „Mode” geht Black sehr vorsichtig um, und fügt gleich hinzu, dass es sich wahrscheinlich doch um etwas mehr handeln sollte. ${ }^{27}$ Wenn er es am Ende doch vermeidet, Humanismus als eine „Mode” abzustempeln, dann tut er das wahrscheinlich, weil „Mode” für ihn einen pejorativen Nebengeschmack hat. Wenn man versucht, „Mode” zu definieren und ihre wichtigsten Merkmale zu benennen, dann kann man ihr Wesen durch drei Züge beschreiben: Zirkularität, Ephemerität, und die Behauptung des Neuen. Wenn man an die lange Erfolgsgeschichte des Humanismus denkt, dann fällt Ephemerität als Merkmal ganz bestimmt weg. Eine gewisse Zirkularität dieses Phänomens kann man aber nicht verleugnen: ohne einen fassbaren, konkreten Grund setzt sich der neue Geschmack durch. Ab dieser unerklärlichen Origo setzt sich ein Mechanismus in Bewegung, der als zirkulär zu beschreiben ist: als Herrscher sollte man im 15-16. Jahrhundert ein paar Humanisten um sich haben, weil es die anderen auch so machen. ${ }^{28}$ Die Beweggründe können selbstverständlich nicht alleine auf den Willen, up to date zu sein, zurückgeführt werden, dieser Wille aber dürfte eine große Rolle in der Motivation der Herrscher, sich mit Humanisten zu umgeben, gespielt haben. Zum richtigen Marketing von Modegegenständen gehört auch eine Begründung, die den Bedarf dieser Gegenstände mit Vernunftgründen legitimiert. Im Fall des Humanismus spielte die Erklärung des Zusammenhangs zwischen der Bildung durch das Lesen der klassischen Autoren und der Tugendhaftigkeit eine ähnliche Rolle. ${ }^{29}$ Die Toposhaf-

26 Johannes Helmrath zitiert allerdings Blacks und Gombrichs Vorschläge als verwendbare Modelle für die Beschreibung des Prozesses seiner Verbreitung: Johannes Helmrath, „Diffusion des Humanismus. Zur Einführung", in Diffusion des Humanismus, hrsg. v. Johannes Helmrath (Göttingen: Wallstein Verlag, 2002), [im Weiteren: „Diffusion”], 9-29, hier S. 10-11. Im Zusammenhang mit diesem Begriff setze ich den Akzent anders: ich erkläre damit nicht nur die Verbreitung des Humanismus, sondern auch seine „Geburt”, bzw. mit dem Vorschlag, Humanismus als eine Mode zu betrachten, verzichte ich gewissermaßen auf die Beantwortung der Frage nach dem Warum.

„Was this just a fashion, and indeed a fashion which was to last for centuries? Surely they must have expected something more tangible than just virtue or one-manship for all the money, effort and time spent." Black, Humanism, S. 273.

28 Auch Witt - ohne explizit für eine Deutung dieses Phänomens als Mode zu argumentieren - formuliert eine ähnliche These über den möglichen Grund des Erfolges des Humanismus: "The success can be explained in part by the existence of a new audience, already generated by the movement." Ronald G. Witt, In the Footsteps of the Ancients, Studies in Medieval and Reformation Thought 74 (Leiden: Brill, 2000), [im Weiteren „In the Footsteps"], hier S. 371.

29 Kann man wirklich behaupten, dass Menschen durch Humanismus besser geworden sind als früher? Diese scheinbar naive Frage lässt sich nicht vermeiden, wenn man über die vermeintlichen Zusammenhänge zwischen klassischer Bildung und Tugend nachdenkt. Man könnte antworten, dass man nicht gleich mit absoluten Kategorien argumentieren sollte wie ,gut” und „schlecht”, sondern stattdessen lediglich danach fragen, ob Menschen anders geworden sind durch die andere Bildung. Auf eine auf diese Weise formulierte Frage kann man wahrscheinlich mit einem ,ja” antworten. Das Problem ist, dass die Verfechter der These, Humanismus und Renaissance hätten ganz neue Inhalte mit sich gebracht, zugleich oft annehmen, dass 
tigkeit dieser Argumentation verlangt große Vorsicht beim Umgang mit einschlägigem Quellenmaterial. In seiner Besprechung von Blacks Buch geht Grendler auf einen vermeintlichen Widerspruch in Blacks Argumentation ein:

This book repeats the interpretations that Black offered in his 2001 book, including his claim that schools did not teach good morals. On the other hand, he quotes several teacher contracts in which communes ordered school masters to teach good morals. Did teachers ignore the wishes of their employers at the peril of their jobs? ${ }^{30}$

Von der Formulierung good moral in den zwischen den Kommunen und Lehrern abgeschlossenen Verträgen ausgehend zieht Grendler die Schlussfolgerung in Bezug auf die humanistischen Inhalte des Unterrichts. Vom Text eines Arbeitsvertrags auf die tatsächlich vermittelten Inhalte des Unterrichts zu schließen, ist aber vielleicht eine Vereinfachung, die nicht nur die Kontextbezogenheit des zu untersuchenden Textes außer Acht lässt, sondern eine ,zeitlose” Zielsetzung der schulischen Erziehung überstrapaziert.

Die Auffassung vom Humanismus als einer Mode böte sich als der dritte Weg an, neben den in Johannes Helmraths Studie implizierten Möglichkeiten, Humanismus zu verstehen.

Antikes, so die These dieses Bandes, wurde in der Renaissance nicht nur idealistisch-zweckfrei und integral rezipiert, weil es antik war, sondern auch, weil ein „Bedarf an Antike” bestand, weil man sie zur Lösung von spezifischen Problemen der Gegenwart brauchte und gebrauchte. ${ }^{31}$

In Johannes Helmraths Worten sind zwei Möglichkeiten impliziert, wie man Humanismus deuten könnte: die eine Möglichkeit ist eine Sichtweise, die den Umgang von Humanismus mit der antiken Kultur - und damit eigentlich Humanismus als ganzes - als idealistisch und zweckfrei interpretiert. Die andere dagegen wäre die Interpretationsmöglichkeit, die von der Annahme ausgeht, dass Humanismus einen bestehenden „Bedarf“ gedeckt haben könnte. Der dritte Weg wäre es, weder idealistisch, noch funktionalistisch zu argumentieren, sondern anzunehmen, dass der Bedarf, den Humanismus zu decken hatte, von den Humanisten selbst geweckt und suggeriert wurde. Dieser zirkuläre Aspekt ist es, der uns Humanismus als Mode interpretieren lässt. Dementsprechend ist der Grund ihrer Entstehung viel mehr mit der Motivation ihrer Urheber zu erklären, als mit einem in der Gesellschaft vorhandenen Bedarf, der

diese Inhalte etwas Besseres dargestellt haben als die früheren Bildungsinhalte. Als Beispiel dafür können Ullmans oben zitierte Worte genannt werden.

30 Paul F. Grendler, „Education and Society in Florentine Tuscany: Teachers, Pupils and Schools, c. 12501500 (Besprechung)", Renaissance Quarterly 61 (2008): 509-511.

31 Johannes Helmrath, „Der Europäische Humanismus und die Funktionen der Rhetorik”, in Funktionen des Humanismus. Studien zum Nutzen des Neuen in der humanistischen Kultur, hrsg. v. Thomas Maissen and Gerrit Walter (Göttingen: Wallstein, 2006), 18-48, hier S. 21. 
eine Lösung verlangte, die nur die neue Kultur hätte bieten können. Alan Stewart geht in seinem Buch über homoerotische Lehrer-Schüler Beziehungen im Humanismus von der gleichen Annahme aus:

The tacit assumption of most critical writings is that certain innovations - in diplomacy and printing, for example - made textual skills necessary in new areas, and that the humanists conveniently stepped in to fill this gap. I challenge this model and argue instead that humanism worked consistently to produce this gap, that humanism deliberately created the perceived need for humanism. ${ }^{32}$

Überzeugende Argumente dafür, dass „die technischen Spezialkompetenzen” der Humanisten „existentiell gefragt” waren, dass also die Neuerungen der Humanisten nicht l'art pour l'art waren, holt Helmrath aus dem fünften Dezennium des 15. Jahrhunderts, und zwar aus dem Florentinum, aus einer Zeit also, die eine etwas spätere Phase darstellt als die, die von mir untersucht wird. ${ }^{33}$ Damit ist die Frage der Entstehung noch nicht beantwortet.

\section{Die Rhetorik des Bruches ${ }^{34}$ und ihre Rolle in den Selbstdarstellungsstrategien}

Ohne den Anspruch zu erheben, eine ultimative Antwort auf die wahrscheinlich unbeantwortbaren Fragen „Warum Humanismus?” und „Warum am Anfang des 15. Jahrhunderts?" zu geben, möchte ich untersuchen, was Humanisten gegebenenfalls instrumentalisierbar gemacht hat, was die Humanisten ihrem Publikum zu bieten hatten, was sie attraktiv machen konnte. Diese Fragestellung steht scheinbar im Widerspruch mit meinem Ausgangspunkt, wonach ich es zu bestreiten versuche, dass Humanismus sein Entstehen einem reell bestehenden Bedarf zu verdanken hatte. In Wirklichkeit stehen aber die zwei Annahmen - also einerseits, dass kein derartiger Bedarf vorhanden war, andererseits, dass die Humanisten, um sich als Bildungselite etablieren zu können, etwas zu bieten haben mussten, was sie unentbehrlich erscheinen ließ - nicht im Gegensatz zueinander. Um den scheinbaren Widerspruch aufzulösen, ist es nötig, zu definieren, was unter „Bedarf” zu verstehen wäre.

In Helmraths Argumentation bedeutet „Bedarf” eine konkrete Nachfrage nach den konkreten beruflichen Fertigkeiten der Humanisten, und zwar vor allem nach ihrer philologi-

32 Alan Stewart, Close Readers: Humanism and Sodomy in Early Modern England, (Princeton, N.J.: Princeton University Press, 1997), hier XXV.

33 Johannes Helmrath, „Diffusion des Humanismus und Antikrezeption auf den Konzilen von Konstanz, Basel und Ferrara/Florenz", in Die Präsenz der Antike im Übergang vom Mittelalter zur Frühen Neuzeit. Bericht über Kolloquien der Kommission zur Erforschung der Kultur des Spätmittelalters 1999-2002, Abhandlungen der Akademie der Wissenschaften zu Göttingen, Philologisch-Historische Klasse, 3. Folge, 263, hrsg. v. Ludger Grenzmann, Klaus Grubmüller, Fidel Rädle und Martin Staehlin (Göttingen: Vandenhoeck \& Ruprecht, 2004), 8-56, [im Weiteren: „Diffusion des Humanismus und Antikrezeption”], hier 45-47.

34 Für den Ursprung der Rhetorik des Bruches vgl. Theodore E. Mommsen, „Petrarch's Conception of the 'Dark Ages'." Speculum 17 (1942): 226-242. 
schen Kompetenz, nach ihrer übersetzerischen Tätigkeit. In einer anderen Studie von Johannes Helmrath über Piccolomini als „Apostel” des Humanismus, identifiziert er „sieben literarische Aktionskomplexe”, „in denen Humanisten, so auch Enea Silvio, charakteristisch zu wirken pflegten". In dieser Studie untersucht der Autor dementsprechend Enea in den folgenden Rollen: 1. als Briefschreiber, 2. als Redner. 3. als Handschriftenjäger und Editor, 4. als Prinzenerzieher, 5. als Lehrer und arbiter des Lateinischen, 6. als Förderer der humanistischen Schrift, 7. als Deutschsprecher. ${ }^{35}$

Wenn man diese Punkte auf einen gemeinsamen Nenner bringen möchte, bis auf den letzten Punkt (in dem man aber auch Enea „als Ausfall bezeichnen”36 muss), so könnte man das Hauptgeschäft des Humanisten in seiner Antikerezeption sehen. Da Antikerezeption am Anfang des 15. Jahrhunderts aber nichts Neues war, muss man diese Ansicht etwas verfeinern und auf die folgende Frage eine Antwort finden: Was war in der Antikerezeption der so genannten Humanisten neu und anders im Vergleich zur Auseinandersetzung mit der antiken Kultur früherer Generationen? Mit Walter Rüeggs Worten: „Humanismus ist auch nicht die Beschäftigung mit der Antike an und für sich, sie mag noch so vertieft oder bewusst sein: sonst wären die Altertumswissenschaftler die größten Humanisten, was durchaus nicht der Fall ist.",37

Versteht man die Betonung, zu der neuen Generation zu gehören, die eine vergessene Tradition (die Antike) wiederherstellt, also das Behaupten eines Bruches zwischen der alten und der neuen Kultur als die wichtigste Geste der Humanisten, so sind die philologischen Fertigkeiten eher als sine qua non, und nicht als sicheres Merkmal für einen Humanisten zu verstehen. Man hätte die gleichen Aufgaben, für deren Lösung die Humanisten die Zuständigkeit für sich beanspruchten, auch ohne ein Humanist zu sein lösen können. Was Humanisten nach meiner Hypothese attraktiv machte, war gerade deren Anspruch, die neuen, die richtigen Hüter des antiken Erbes zu sein. Die Behauptung, die Neuen und die Richtigen zu sein, impli-

35 Johannes Helmrath, „Vestigia Aeneae imitari. Enea Silvio Piccolomini als „Apostel” des Humanismus. Formen und Wege seiner Diffusion”, in Diffusion, 99-141, [im Weiteren: „Vestigia”], hier S. 117.

36 Helmrath, Vestigia, S. 132. Dass Helmrath bei dieser Liste über „literarische Aktionskomplexe” spricht, erlaubt die Annahme der Komplexität dieser Tätigkeitsfelder nicht nur im Sinne der Deckung, sondern auch der Generierung der Nachfrage.

37 Walter Rüegg, Cicero und Humanismus. Formale Untersuchungen über Petrarca und Erasmus (Winterthur: Buchdruckerei Winterthur AG., 1946), [im Weiteren „Cicero”], hier S. 6. Rüegg entwickelt auf Grund seiner Unterscheidung zwischen Humanismus und den Phänomenen (wie Klassizismus oder Platonismus), die in seiner Sicht damit verwechselt werden, eine Definition von Humanismus, in der das gewisse Plus im Vergleich mit diesen eine bestimmte Haltung bedeutet, die der Autor folgendermaßen zusammenfasst: „Hier steht der Mensch als eine aus der gemeinsamen metaphysischen Irrationalität dem Menschen der Vergangenheit, Gegenwart und Zukunft verpflichtete Persönlichkeit im Mittelpunkt des Bemühens und findet in dieser Verpflichtung seine geistige Gestalt, seine Form.” Rüegg, Cicero, S. 63. Diese Argumentation ist selbstverständlich eine essentialistische, die das Phänomen „Humanismus” mit dem Erscheinen neuer Inhalte identifiziert. Die Aussage aber, dass Humanismus nicht mit Altphilologie gleichgesetzt werden kann, ist auch für meine Untersuchungen ein wichtiger Ausgangspunkt. 
ziert die Existenz eines Gegenübers, von dem man sich abgrenzen muss. Abgrenzung ist ein wichtiger Bestandteil von Selbstdarstellung ${ }^{38}$, deswegen ist unter anderem die Rhetorik des Bruches des Humanismus so erfolgreich.

Im Folgenden werde ich an drei Beispielen zu zeigen versuchen, wie diese Abgrenzungsversuche bzw. eben das Fehlen dieser Versuche auf die zeitgenössische bzw. die wissenschaftliche Einordnung einzelner Gelehrter zurückwirken konnte.

Mein erstes Beispiel ist der Fall von Johannes Gerson, Theologieprofessor und Kanzler der Pariser Universität, der über eine Bildung verfügte, die der humanistischen vergleichbar war, und dessen Humanist-Sein trotzdem immer wieder hinterfragt bzw. bezweifelt wird. $^{39}$

Wenn man zum Beispiel seine auf dem Konzil verfasste Schrift De discretione spirituum liest, versteht man die Skepsis derer, die bezweifeln, dass er ein Humanist gewesen sei. Der ursprünglich als Rede konzipierte Traktat erweckt den Eindruck, dass er Elemente des humanistischen Diskurses aufschnappt, die er aber diesmal in einem völlig traditionellen Kontext, das heißt in einem scholastischen Traktat benutzt, in dem er für die Unentbehrlichkeit der Theologen in Kanonisationsprozessen argumentiert.

Quoniam omisso divinarum scripturarum studio, magna pars Christianorum ad has visiones, ideo placentiores quia recentiores, converteret oculos et aures prurientes. Sicque necessaria nescirent, quod iuxta Senecae verbum, supervacua didicissent. Sint oportet in omni revelatione Moses et Helias, hoc est, secundum venerabilem Richardum, testimonia legis et Prophetarum. Per totum alioquin suspecta est. Et inde sit perspicuum, quam necessarii sint Theologi in Canonizationibus sanctorum et examinatione doctrinarum. [...] Habet praeterea quaelibet passio profunda suam laesionem, suam ebrietatem, suum, ut Origines loquitur, daemonium. Patet in philotypis, philocaptis, in zelotypis et iracundia, in invidiis et avaris. Unde poeta: An, quia amant sibi somnia fingunt $?^{40}$

38 Dazu mehr in: Stephen Greenblatt, Renaissance Self-Fashioning: From More to Shakespeare (Chicago, London: University of Chicago Press, 1980), [im Weiteren: „Self-Fashioning”], hier: „Self-fashioning is achieved in relation to something perceived as alien, strange, or hostile", S. 9.

39 Der Zwang, es immer wieder unter Beweis zu stellen, dass er doch ein Humanist war, kann als Beweis gelten, dass eine solche Bezeichnung in seinem Fall keine opinio communis ist. Der Forscher, der in seinen Schriften immer wieder für Gersons Humanist-Sein argumentiert, ist Gilbert Ouy, der 2006 in einer Studie eine Zusammenfassung seiner früheren Forschungsergebnisse bezüglich Gerson darstellte: Gilbert Ouy, „Discovering Gerson the Humanist”, in A Companion to Gerson, Brill's Companions to the Christian Tradition 3, hrsg. v. Brian Patrick McGuire, (Leiden, Boston: Brill, 2006), 79-132, [im Weiteren: „Discovering Gerson”]. Ouy schreibt über einen Humanismus „stricto sensu”, der im erneuten Interesse an der Antike zu sehen sei, er schreibt aber auch über einen Humanismus „lato sensu”, den er nach den ,von Burckhardt aufgestellten Kriterien” beschreibt. Die Merkmale von diesem Humanismus „lato sensu” seien: ,the new importance given to personality", ,interest in the vernacular”, ,a new interest in the situation of women”, und ,a new attitude towards religion”: Ouy, Discovering Gerson, S. 126-132.

40 Johannes Gerson, „De probatione spirituum”, [im Weiteren: „De probatione”], in Magnum oecumenicum Constantiense Concilium de universali ecclesiae reformatione, unione, et fide VI. tomis comprehensum, 
Aus bestimmten anderen Anlässen zeigte sich der Autor dieser Zeilen vielleicht als ein Nachahmer Petrarcas, indem er sein Vorbild perfekt nachahmende Eklogen ${ }^{41}$ dichtete, es gab aber genug Anlässe, in denen der Theologieprofessor und Kanzler der Universität Paris eine andere Strategie der Selbstdarstellung verfolgte. Was den Beweiszwang der Forschung, sein Humanist-Sein zu betonen, mobilisiert, ist vielleicht bei ihm eben das Fehlen der Rhetorik des Bruches. Man kann natürlich über „humanistische” Elemente seiner Bildung reden. Es ist aber schwierig, ein „Minimum an Humanismus” festzulegen, das jemand haben muss, um als Humanist bezeichnet zu werden. Wenn man davon ausgeht, dass die Rhetorik des Bruches eines der wesentlichen Merkmale der humanistischen Selbstdarstellung ist, so würde dies die Beantwortung einer solchen Frage, wenn man sie schon stellt, etwas erleichtern. In einer Studie über den französischen Humanismus in der Zeit des Konstanzer Konzils formuliert Patrick Gilli eine ähnliche These über das Wesen des ersten französischen Humanismus. ${ }^{42}$ Nach seiner Meinung konnte sich Humanismus am Anfang des 15. Jahrhunderts in Frankreich deswegen nur oberflächlich ${ }^{43}$ etablieren, weil einerseits, im Gegensatz zu dem den Geist der aemulatio begünstigenden politischen Polyzentrismus Italiens, Frankreich monozentrisch war. Andererseits war auch die universitäre Umgebung gegenüber dem Humanismus eher indifferent und nicht feindlich. Fillastres Integrationsversuche der neuen Texte (Platos Gorgias zum Beispiel) können nach Ansicht des Autors nicht nur als Zeichen der Toleranz bewundert werden, sondern auch als eine Verharmlosung des Textes verstanden werden, die ihn um sein Wesen bringt. ${ }^{44}$

Mein zweites Beispiel für die „Wirksamkeit” der ostentativen Selbstbehauptung der Humanisten ist ein Vorkommnis, in dem sich die neue Konfrontationslust in Bezug auf die lateinische Sprache artikulierte. Außer expliziten Aussagen war das thematisierte Benutzen des ,richtigen” Lateins das sicherste Medium, durch das man den Bruch mit der alten Kultur vermitteln konnte. Der Vorwurf, dass etwas in schlechtem Latein geschrieben wurde, bedeutet für die res publica litteraria das Diskreditieren des Autors und seines Werkes. Ein „gutes”, das heißt klassischen Modellen folgendes Latein ist für diese Lesergemeinschaft das Hauptkriterium in der Entscheidung, ob ein Autor dieser res publica angehört oder nicht. Dass das Urteil über die Qualität der Lateinkenntnisse als Kreditierungs- und Diskreditie-

hrsg. v. Hermann von der Hardt (Frankfurt: In officina Genschii, 1697), [im Weiteren: „Magnum Concilium"], Bd. 3, 28-38, hier S. $31 \mathrm{f}$.

41 Vgl. Ouy, Discovering Gerson, S. 90-94.

42 Patrick Gilli, „L'humanisme français au temps du concile de Constance”, in Humanisme et culture géographique à l'époque du concile de Constance autour de Guillaume Fillastre, Actes du Colloque de l'Université de Reims 18-19 Novembre 1999, History of the Representation of Space in Text and Image 3, hrsg. v. Didier Marcotte (Turnhout: Brepols, 2002), 41-62.

43 „Diffusion pelliculaire”: S. 60, „,un mode mal enracinée”: S. 61.

44 Gilli benutzt das Wort „,demasculation”: S. 61. 
rungsmittel funktionieren konnte, war keine humanistische Erfindung. Auch in mittelalterlichen Quellen gibt es reichlich Beispiele für die Instrumentalisierung des Urteiles über das Latein der zu diffamierenden Person. ${ }^{45}$ Die Neuigkeit, die die humanistischen Beispiele für das gleiche Phänomen von den alten unterscheidet, liegt erstens in der Tatsache, dass in der neuen Kultur Sprach- und Stilniveau plötzlich das wichtigste, oder sogar oft das einzige Kriterium der Zugehörigkeit bedeuteten.

Für die Vehemenz, mit der Humanisten für das ,gute” Latein gekämpft haben (und dafür, dass in diesem Fall das Wort „,kämpfen” keine Übertreibung ist) steht eine Anekdote über Vallas Provokation der Rechtsstudenten in Pavia. ${ }^{46}$ Im Jahre 1433, während des öffentlichen Examens in der Kathedrale, als nach den Vorschriften jeder, der etwas gegen die Verleihung des akademischen Grades hatte, es mitteilen konnte, hatte Valla sich tatsächlich zu Wort gemeldet, und den Legisten wegen seines barbarischen Lateins lächerlich gemacht. Der Humanist habe damit eine solche Wut der Juristen ausgelöst, dass diese ihn aus der Kathedrale gejagt haben. Die Geschichte kann unabhängig von ihrer Wahrheit als exemplarisch angesehen werden. Selbst wenn sie in der Tat eine Anekdote sein sollte, die die Spannungen zwischen dem Humanisten Valla und der traditionellen Umgebung der Universität von Padua mit einer erfundenen Geschichte zu illustrieren versucht - im Gegensatz zu Anekdoten muss ein Konflikt im realen Leben nicht unbedingt in Handgreiflichkeiten gipfeln -, sagt sie vieles über die Rolle, die Lateinkenntnisse und Stil für Humanisten gespielt haben. Über einen Humanisten im 15. Jahrhundert war eine solche Anekdote nur erzählbar, weil sie einen Realitätsbezug hatte. Der Humanist mit seinem Steckenpferd des guten Lateins musste ein für das Publikum bekannter Gemeinplatz sein. Der zweite Unterschied zwischen der alten und der neuen Art, Lateinkenntnisse als Mittel der Diskreditierung zu instrumentalisieren, ist einfach die Akzentsetzung des Reinen, Ursprünglichen und Klassischen, mit anderen Worten die Rhetorik des Bruches. Man solle zu dem Latein der antiken Autoren zurückkehren und die Sprache von den Barbarismen der dazwischenliegenden Epoche befreien. In den mittelalterlichen Beispielen zu dem gleichen Phänomen dagegen ist die Idee des korrekten Sprachgebrauches nicht unbedingt mit der einer Rückkehr ad fontes verbunden.

45 „Da Latein als eine Prestigesprache gilt, ist die individuelle lateinische (In-) Kompetenz potentiell auch ein Aspekt und Instrument der Diskreditierung", bemerkt Thomas Haye in seinem Buch über lateinische Oralität: Thomas Haye, Lateinische Oralität. Gelehrte Sprache in der mündlichen Kommunikation des hohen und späten Mittelalters (Berlin, New York: Walter de Gruyter, 2005), [im Weiteren: „Lateinische Oralität”], hier S. 9. Für dieses Phänomen nennt er mehrere Beispiele im Kapitel „Das korrekte Latein”, S. 9-15.

46 Erwähnt in Grendler, The Universities, S. 210-211. Näher: Mario Speroni, „Lorenzo Valla a Pavia: Il Libellus Contro Bartolo", Quellen und Forschungen aus italienischen Archiven und Bibliotheken 59 (1979): 453-467. 
Die Rhetorik des Bruches kann als eine neue Geste gesehen werden, eine Selbstdarstellungsstrategie, durch die die Autoren ihre Neuheit betonen und sich selbst als die Vertreter eines neuen Paradigmas definieren. So beißt sich die Argumentation wieder in den eigenen Schwanz. Man landet wieder bei der Selbstdarstellung als einem zentralen Begriff im Humanismusdiskurs. Selbstdarstellung wird in dieser Arbeit nicht als etwas Sekundäres betrachtet dies würde bedeuten, sie als Vermittlerin von vermeintlich wichtigeren Inhalten zu verstehen -, sondern als etwas Grundsätzliches, als ein den Humanismus entscheidend bestimmendes Phänomen. Das wichtigste Merkmal eines Humanisten wäre dementsprechend, dass er als solcher wahrgenommen werden möchte. Im Gegensatz zu der Betonung eines Bedarfs an Humanisten und ihrer beruflichen Kompetenzen in bestimmten Tätigkeitskreisen setze ich den Akzent etwas anders und stelle das Bedürfnis von Selbstlegitimation und Selbstrepräsentation als motivierende Kräfte im Entstehungsprozess der neuen exklusiven Bildungselite in den Vordergrund.

Ein letztes Beispiel für eine - diesmal etwas fehlgeschlagene - Betonung dessen, dass man sich als Humanist nicht mit der unmittelbaren, sondern mit der antiken Vergangenheit verbunden fühlte, wird in Poggios Facetiae überliefert. In der Facetia 82 wird Ciriaco d'Ancona wegen seiner etwas übertriebenen Sorge um den Fall des römischen Imperiums ausgelacht: „Ciriacus Anconitanus, homo verbosus et nimium loquax, deplorabat aliquando, astantibus nobis, casum atque eversionem Imperii Romani, inque ea re vehementius angi videbatur". ${ }^{47}$ Er wird von Loschi mit dem Mann verglichen, der wegen Rolands Tod ganz traurig geworden war, als er über diesen im Vortrag eines Sängers gehört hatte. Ciriacos Versuch, durch das Aufgreifen eines Themas, das seiner Meinung nach für Humanisten eine Herzenssache sein sollte, sich als jemanden darzustellen, der zu der gelehrten Gesellschaft gehört, hat den entgegen gesetzten Effekt erzeugt: er wurde ausgelacht. Humanist-Sein war wegen seines inhärenten Selbstdarstellungszwanges ein anscheinend heikles Geschäft. In dieser Arbeit geht es um die Frage, wie die hier als Fallbeispiele dargestellten Gelehrten auf dieser kurvenreichen Bahn zurecht gekommen sind.

47 Poggio Braciolini, Facezie, Biblioteca Universale Rizzoli L 418, hrsg. v. Marcello Ciccuto (Mailand: Biblioteca Universale Rizzoli, 1983), hier S. 200. 


\section{Kontextbezogenheit}

Wenn man Selbstlegitimation und Selbstdarstellung als zentrale Begriffe für die Deutung des Humanismus benutzt, wenn man also nicht davon ausgeht, dass Humanist-Sein ein konstantes Merkmal eines Menschen wäre, sondern die Fragen stellt, wer, wann, unter welchen Umständen sich bemühte, sich als Humanist darzustellen, so folgt aus dieser Perspektive auch die Akzentsetzung auf die Kontextbezogenheit des Humanismus.

Die Betonung der Kontextbezogenheit muss nicht zwangläufig ein essentialistisches Erklärungsmuster ausschließen: es wäre durchaus vorstellbar, über bestimmte, auf ein homogenes Ideologiesystem zurückzuführende „humanistische” Merkmale zu sprechen, mit denen sich die Akteure aber nur in bestimmten Situationen schmücken. In der Praxis der Forschung scheinen sich diese zwei Herangehensweisen aber meistens auszuschließen. Essentialistisch argumentierende Forscher gehen nicht von einem homogenen Ideologiesystem des Humanismus als einem Schatzkasten aus, aus dem die einzelnen Autoren je nach Bedarf ihre Profile schöpfen, sondern sie setzen oft auch die Homogenität des Euvres der einzelnen Autoren voraus: ein Humanist muss immer ein Humanist sein, und wenn er auch Schriften produziert, die nach der Meinung der Forscher nicht mit dem humanistischen Wertesystem zu vereinbaren sind, so suchen die Forscher nach den Ursachen der ,fehlerhaften” Heterogenität der Schriftenproduktion. ${ }^{48}$

Die Ursache eines solchen plötzlichen Sinneswandels wird oft mit der Verwendung des Begriffes „Einfluss” erklärt. ${ }^{49}$ Ich halte es für kontrollierbarer, statt in Kategorien wie „Einfluss” oder „Tiefe und Ehrlichkeit einer Überzeugung” zu reden, eher über motivierte ${ }^{50}$ und deswegen kontextbezogene Aneignungen literarischer Modelle nachzudenken.

48 Für diese Herangehensweise sind die Erklärungen für Vergerios angeblichen Sinneswandel (von Republikanismus zum Monarchismus) ein gutes Beispiel. Auf die diesbezügliche Debatte werde ich im Kapitel über Vergerio eingehen.

49 Laut Robeys später vorzuführender Interpretation habe Vergerio manche „republikanisch” gesinnte Schriften verfasst, weil er in der Zeit vom florentinischen Gedankenklima beeinflusst worden sei. Vgl. David Robey, „P. P. Vergerio the Elder: Republicanism and Civic Values in the Work of an Early Humanist”, Past and Present 58 (1973): 3-37, [im Weiteren: „Republicanism”].

50 Die Frage nach der Motivation ist in der heutigen Forschung kein Tabu mehr. Wie groß dieser Sichtwechsel vom idealisierenden zur etwas pragmatischeren Sichtweise ist, merkt man, wenn man Aussagen liest, wie Sabbadinis enthusiastische Worte über den Enthusiasmus der Humanisten: ,il pregio fondamentale di quella brava gente era l'amore disinteressato agli studi, era l'entusiasmo per l'antichità da essi così pazientemente dissepolta: amore e entusiasmo, che affrattellavano il più umile copista al più fortunato scopritore di codici.” Remigio Sabbadini, Il metodo degli umanisti (Florenz: Le Monnier, 1920), hier S. 87. 


\section{Wahrnehmung: Ein Spaziergang von den Humanisten bis zu den Hirnforschern und wieder zurück}

Eine die Rolle der Selbstdarstellung betonende Beschreibung von Humanismus muss zwangsläufig auch einen weiteren Aspekt des Phänomens „Humanismus” miteinbeziehen. Das Untersuchen der Wahrnehmung von Humanismus und Humanisten ist die andere Seite der Frage nach der Selbstdarstellung: Selbstdarstellung ist immer für ein Publikum konzipiert, sie funktioniert nur, wenn sie wahrgenommen wird. ${ }^{51} \mathrm{Um}$ die Symmetrie dieser zwei zu untersuchenden Aspekte (Selbstdarstellung und Wahrnehmung) noch mehr hervorzuheben, kann man feststellen, dass nicht nur Selbstdarstellung, sondern auch Wahrnehmung immer motiviert ist. ${ }^{52}$

Wahrnehmung ist laut der Erkenntnis der Hirnforschung die erste Station der Interpretations- und Deformationskette der Verarbeitung und Tradierung der persönlichen Eindrücke, gefolgt von der Speicherung in das und dem Abrufen aus dem Gedächtnis, und dann von der Wiedergabe, dem Weitererzählen. ${ }^{53}$ Natürlich kann erst Letzteres eine bewusste Verfälschung

51 Wahrnehmung ist natürlich auch generell in jedem Versuch der Rekonstruktion von Ereignissen ein unvermeidbarer Aspekt: die beschreibenden Quellen sind nichts anderes als schriftlich fixierte Wahrnehmungen.

52 An dieser Stelle muss man auf die Ergebnisse der interdisziplinären Hirnforschung verweisen, deren wichtigste Lehre für die Historiker die Feststellung ist, dass, selbst wenn man von aufrichtigen Beobachtern ausgeht, sowohl das Wahrnehmen als auch das Erinnern von den Interessen des Beobachters gesteuerte Interpretationsprozesse und demzufolge Deformationsprozesse sind. Für eine bündige Zusammenfassung und Einleitung zum Thema vgl. den Eröffnungsvortrag Wolf Singers, Direktor des Max Planck-Instituts für Hirnforschung, am 43. Deutschen Historikertag in Aachen: Wolf Singer, „Wahrnehmen, Erinnern, Vergessen”, in Eine Welt - Eine Geschichte? 43. Deutscher Historikertag in Aachen. Berichtsband, hrsg. v. Max Kerner (München: Oldenbourg Wissenschaftsverlag, 2001), S. 18-27. „Geschichte hat demnach die charakteristischen Eigenschaften eines selbstreferentiellen, ja vielleicht sogar evolutionären Prozesses, in dem alles untrennbar miteinander verwoben ist und sich gegenseitig beeinflusst, was die Akteure des Systems, in unserem Fall die Menschen, hervorbringen - ihre Taten, Wahrnehmungen, Erinnerungen, Empfindungen, Schlußfolgerungen und Bewertungen - und natürlich auch die Geschichten, die sie unwissentlich fortwährend erfinden. Ein Proze $\beta$ also, in dem es keine sinnvolle Trennung zwischen Akteuren und Beobachtern gibt, weil die Beobachtung den Prozeß beeinflußt, selbst Teil des Prozesses wird. Und so scheint mir, daß es weder die Außenperspektive noch den idealen Beobachter geben kann, die beide erforderlich wären, um so etwas wie die eigentliche, die wahre, die tatsächliche Geschichte zu rekonstruieren. Wenn dem so sein sollte, dann können wir im Prinzip nicht wissen, welcher der möglichen Rekonstruktionsversuche der vermuteten ,wahren” Geschichte am nächsten kommt. Und so wird jeweils in die Geschichte als Tatsache eingehen, was die Mehrheit derer, die sich gegenseitig Kompetenz zuschreiben, für das Zutreffendste halten. Unbeantwortbar bleibt dabei, wie nahe diese Feststellungen der idealen Beschreibung kommen, weil es diese aus unserer Perspektive nicht geben kann." Singer, S. 27. Weitere Einführungen in das Thema sind Johannes Frieds Aufsatz, der als eine kurze Zusammenfassung des Problems und Aufruf zur Weiterarbeit auf dem Gebiet gelten kann: Johannes Fried, „Geschichte und Gehirn: Irritationen der Geschichtswissenschaft durch Gedächtniskritik", Abhandlungen der Geistes- und Sozialwissenschaftlichen Klasse / Akademie der Wissenschaften und der Literatur 7 (2003): 5-43, [im Weiteren: „Geschichte und Gehirm”]; und sein Buch: Johannes Fried, Der Schleier der Erinnerung. Grundzüge einer historischen Memorik, (München: C. H. Beck, 2004), [im Weiteren: „Der Schleier”], in dem er die im Untertitel angedeuteten Grundzüge einer historischen Memorik anhand von zahlreichen Fallbeispielen erläutert.

53 Für eine auch graphische Darstellung des Weges ,,vom Faktum zu dessen Darstellung in der Quelle” vgl. Hans Werner Goetz, ,'Wahrnehmung' der Arbeit als Erkenntnisobjekt der Geschichtswissenschaft”, in Arbeit im Mittelalter. Vorstellungen und Wirklichkeiten, hrsg. v. Verena Postel (Berlin: Akademie Verlag, 2006), 21-35, [im Weiteren: „Wahrnehmung”]. 
der erinnerten Inhalte sein, das heißt aber nicht, dass die anderen Glieder dieser Kette automatische, vom Subjekt des Wahrnehmenden oder Sich-Erinnernden unabhängige Prozesse sind. Wahrnehmung ist dementsprechend nicht als wertneutral und unvoreingenommen, sondern als ein von den eigenen Interessen gesteuerter Vorgang zu sehen. Weitere, konkretere Ergebnisse, die mehr als eine auf die Gefahr des naiven Umganges mit den Quellen hinweisende Warnung wären, kann man aus diesem Ansatz nicht gewinnen. Die Fallstudien, deren Beispiele mit den Ergebnissen der modernen Gedächtnis- und Hirnforschung konfrontiert werden, führen oft nicht aus dem Bereich einer vernünftigen, klassischen Quellenkritik hinaus. Einer der Gründe dafür ist darin zu sehen, dass alle die zu überprüfenden Inhalte (das heißt alle Quellen) schon durch das Sieb (oder den Fleischwolf, je nach Präferenzen innerhalb der Küchenmetaphorik) sämtlicher Deformationsprozesse gegangen sind. Alle die Quellen, die man als Historiker oder Philologe untersucht, sind nicht einfach wahrgenommene, sondern erzählte Inhalte. Es gibt keine Möglichkeit, einen Inhalt vor dieser Deformationsstufe zu untersuchen, mit anderen Worten: man kann es in Disziplinen, die sich mit der Vergangenheit auseinandersetzten, nicht festmachen, woran sich der Erzählende erinnert, oder wie er etwas wahrgenommen hat. Man kann nur erfahren, wie er es weitererzählt. Deswegen scheint der von Johannes Fried formulierte Anspruch dieser Studien schwer zu verwirklichen:

Literalität, der Gebrauch literarischer Muster und die Realisierung spezieller Darstellungsziele, überlagert dann die Erinnerungskonstrukte noch einmal und überzieht sie mit einem zweiten Verformungsraster; beide Verformungskräfte wirken wechselseitig aufeinander ein. Doch wird der literarische Prozess hier nicht eigens untersucht, sondern nur beiläufig vermerkt. ${ }^{54}$

Das im Zitat angegebene Ziel dieser Forschung, den Hauptakzent auf die Untersuchung der Erinnerungsinhalte zu setzen und Literalität nur beiläufig zu untersuchen, ist meines Erachtens illusorisch. Das einzig Untersuchbare ist nämlich gerade die ganz konkrete Form, die Literalität, und die Inhalte sind nur in der Form zugänglich, in der sie durch dieses zweite Verformungsraster hindurch vermittelt wurden. Deswegen ist rhetorische Analyse ein unvermeidbares Mittel nicht nur der literarischen, sondern auch der historischen Untersuchung. Eine sehr einfache, aber einleuchtende Lösung der Frage, wie die Informationen, die in den Werken eines Autors zu finden sind, auf das reale Leben zu beziehen sind, gibt Lawrence Lipking:

Poetry cannot tell us whether the author was a happy person, or a sinner, or justified in his politics, or suffering from bad dreams; but it can tell us all we need to know

$54 \quad$ Fried, Der Schleier, S. 334. 
about the author's ability to convert his experience into vision. Here - not in the creative process or some irrecoverable unconscious - life and poetry intersect. Thus, whatever else we know about Dante's life, we can be certain about one fact, he actually did achieve the vision recorded in the final canto of the Commedia. ${ }^{55}$

Lipkings Aussage kann man natürlich nicht nur auf Dichtung beziehen, sondern auf alle Textsorten. Es gibt dementsprechend immer einen Punkt, wo das, was man historische Wirklichkeit nennen kann, und der Text einander überschneiden: dieser Punkt kann erfasst werden, indem man den Text selbst als historisches Faktum betrachtet, das heißt, dass man die Tatsache, dass ein Text genau in der Form geschrieben wurde, zum Ausgangspunkt der Untersuchung nimmt. Eine solche, das heißt eine die Textualität, und damit die Fiktionalität aller Textsorten ins Zentrum stellende Untersuchung, muss dementsprechend andere Fragen stellen als Untersuchungen, die die Texte als direkte Quellen für eine extratextuelle Wirklichkeit benutzen. Anders formuliert: Man gelangt nicht durch den Text zur Erkenntnis von extratextuellen Fakten, sondern man muss den Text selbst als historisches Faktum behandeln. Wenn der Text selbst zum Faktum wird, so werden seine Gestaltungsmechanismen nicht mehr als sekundär angesehen werden.

Dieser Punkt kann an einem Beispiel aus Johannes Frieds Buch erläutert werden. Eines seiner Fallbeispiele ist der Fall „Chlodwig” als Beispiel für die konstruktive Kraft des literarischen Gedächtnisses. ${ }^{56}$ In dieser Fallstudie stellt Fried eine Diskrepanz zwischen den Quellen bezüglich der Geschichte von Chlodwigs Taufe fest. Während in den zeitgenössischen Quellen Chlodwig als fidelis ante fidem dargestellt wird, findet man in der späteren Tradition von Tours die Geschichte mit einem neuen Element angereichert: sie wird als Bekehrungsgeschichte dargestellt. Am Ende der Studie wird der Grund der Abweichungen der turonischen Version der Geschichte im Vergleich mit den zeitgenössischen Quellen angegeben:

Abermals wird ein Erinnerungshorizont fassbar, dem der Geschichtsschreiber nun selbst verpflichtet ist, der Horizont nämlich der Kollaboration katholischer Römer im arianischen Westgotenreich mit den Franken und der nachdrücklichen Empfehlung ihrer himmlischen Helfer an die zur Abfassungszeit regierenden Herrscher und Nachfahren Chlodwigs. ${ }^{57}$

\footnotetext{
55 Lawrence Lipking, The Life of the Poet. Beginning and Ending Poetic Careers (Chicago, London: The University of Chicago Press, 1981), hier S. X.

56 Fried, Der Schleier, S. 335-344.

57 Fried, Der Schleier, S. 343.
} 
Die turonische Tradition über Chlodwigs Taufe wird also als geschehensfernes Gedächtniskonstrukt bezeichnet, von dem man mehr über die Entstehungszeit dieser Schriften erfahren kann als über die Chlodwigs.

Die in dieser Fallstudie implizierte Schlussfolgerung (wenn man Gregor von Tours über Chlodwig liest, erfährt man mehr über den Autor als über den König) scheint schmerzhaft plausibel zu sein. Es gibt aber zwei Punkte, die nicht geklärt worden sind. Erstens glaubt der Autor, obwohl er in seinen Arbeiten über die potentielle Zusammenarbeit der Historiker und Gedächtnisforscher oft darauf hinweist, dass ein viel höherer Grad von Skepsis gegenüber überlieferten Gedächtnisdaten nötig wäre, ${ }^{58}$ an die Möglichkeit einer neutralen, faktentreuen Erinnerungskontrolle ${ }^{59}$ : in Chlodwigs Fall sind es die zeitgenössischen Quellen, die diese Rolle übernehmen können. Diese werden nämlich nicht als Gedächtniskonstrukt apostrophiert. An dieser Stelle sollte man vielleicht auf die Notwendigkeit einer noch tiefer greifenden Skepsis hinweisen und die Aussage riskieren, dass es wahrscheinlich keine neutralen Quellen gibt. Es gibt keine unbeteiligten Erzähler: jede Erzählung hat ein Ziel, ein anvisiertes Publikum, für das die Erzählung etwas beweisen soll. Deswegen bleibt eine neutrale Erinnerungskontrolle weiterhin ein Traum. Hinter dem Schleier der Erinnerung, so könnte man Frieds Ansatz aber verstehen, gibt es immer noch die Geschichte „an sich”, die wahren Fakten, die mit Hilfe einer neutralen Kontrollinstanz erkennbar zu sein scheinen, was auch das Ziel historischer Forschung sein könne. Die Alternative dazu wäre, nicht mehr „nach dem Faktum [zu] fahnden"60, sondern den vom Faktum zu dessen Darstellung führenden Prozess selbst zum Gegenstand der Untersuchung zu machen. Selbst dieser Vorschlag impliziert aber nicht die Hinterfragung der Existenz einer wahren Geschichte, die vielleicht schwer erkennbar sei, aber die es immerhin noch gäbe. Wenn man noch skeptischer ist, so könnte man theoretisch eine mit der gorgianischen Skepsistriade vergleichbare Skepsis hegen: es gibt so etwas wie wahre Geschichte nicht; wenn es so etwas geben würde, könnte man es nicht erkennen; wenn man es erkennen könnte, könnte man es nicht vermitteln. Eine bis zur letzten Stufe dieser „Triade” gelangende Skepsis ist allerdings aus moralischen Gründen schwer haltbar. ${ }^{61} \mathrm{Ob}$ es hinter dem Schleier der Erinnerung eine eindeutig rekonstruierbare Geschichte gibt, gehört meines Erachtens zu den Glaubensfragen, die man aus ihrem Wesen

58 Zum Beispiel: Fried, Geschichte und Gehirn, S. 42.

59 „Der Geschichtsforscher bedarf ferner, auch das erweist unser Beispiel als eine unverzichtbare Voraussetzung historischer Analyse, neutraler Kontrollmöglichkeiten, mithin weiterer Zeugnisse, die unabhängig von den Beteiligten deren Erinnerungsleistungen zu überprüfen gestatten.” Fried, Geschichte und Gehirn, S. 25.

60 Dieser ist der von Hans-Werner Goetz vorgeschlagene Weg. Vgl. Goetz, Wahrnehmung, S. 25.

61 Die problematische Vertretbarkeit der absoluten Skepsis kann durch Beispiele der jüngsten Geschichte am deutlichsten anschaulich gemacht werden. Sie könnte zum Beispiel zur Relativierung bzw. Verleugnung von Kriminaltaten benutzt werden. 
heraus nie klären kann. Goetz‘ elegante Lösung, nach der eine scharfe Trennung zwischen historischer Realität und den menschlichen Auffassungen davon nicht nötig sei, weil letztere auch zur historischen Realität gehörten, ${ }^{62}$ könnte man als eine Zwischenlösung in einer Debatte nehmen, die wahrscheinlich, weil es, wie schon angedeutet wurde, um eine Glaubensfrage geht, nie ein Ende nehmen wird.

Die zweite mögliche Bemerkung zu diesem Ansatz ist, dass Frieds Kritik der turonischen Tradition über Chlodwigs Taufe nichts mit den Neuronen zu tun hat: es geht um bewusste Veränderungen, um die Anpassung eines Stoffes an literarische Schemata, die das Ziel des Neuschreibens von Chlodwigs Geschichte und die dahinter steckenden Interessen zu verfolgen scheint. Es geht also um Rhetorik, und nicht um Gregor von Tours' Erinnerungsvermögen.

Was folgt aus diesem Beispiel? Dass kein Text als neutrale Kontrollinstanz gelten kann, und dass die wichtigsten Fragen, die man in jedem Einzelfall stellen muss, die folgenden sind: Wie ist der Text geschrieben? Welche Interessen verfolgt eine solche Art der Darstellung des Stoffes? Kurz gefragt: Cui bono? Die Cui-bono-Frage kann aber nicht unabhängig von der rhetorischen Beschaffenheit des Textes beantwortet werden. Deswegen scheint der im Vorwort angekündigte Verzicht ${ }^{63}$ Frieds auf die Untersuchung der Literalität, des Gebrauches literarischer Muster und der Realisierung spezieller Darstellungsziele, die die Erinnerungskonstrukte überlagern, riskant und schwer realisierbar zu sein.

Selbst ohne auf die Ergebnisse der Hirnforschung näher einzugehen, kann man aber feststellen, dass die Wahrnehmung und Darstellung eines anderen als Humanisten, also als zu der gleichen Leser- und Interessengemeinschaft gehörend, nicht unabhängig von den persönlichen Motivationen und Interessen geschieht. Bei der Wahrnehmung eines anderen als zur gleichen Gruppe Gehörenden geht es natürlich nicht nur um die Positionierung des anderen, sondern auch um Selbstpositionierung. Die Wahrnehmung und Darstellung des anderen ist gleichzeitig immer Teil der Arbeit an der eigenen Selbstdarstellung. 


\section{Gruppenbildung, Nationendiskurs}

Als Guarino 1417 einen „Empfehlungsbrief” an Poggio für seinen Freund Franciscus Bracchus schrieb, fasste er seine Charakterisierung des Freundes auf folgende Weise zusammen: „quid multa? Nostri ,gregis”, ut Terentius diceret, et elegans quidem est”. ${ }^{64}$ Die Gründe, die Guarino dafür angibt, warum er seinen Freund mit gutem Gewissen für einen Posten in der Kuria weiterempfiehlt, sind symptomatisch für den Mechanismus der humanistischen Gemeinschaftsbildung. Erstens wird es klar, dass sich Humanisten bereits am Anfang des 15. Jahrhundert als Mitglieder einer Gemeinschaft empfunden haben, und dass die Zugehörigkeit zu dieser Gemeinschaft gewissermaßen als Garantie für die Qualitäten der betroffenen Person funktionieren konnte. Zweitens wird im kurzen Satz auch ein Grund genannt, der bei der Beurteilung des Betroffenen wahrscheinlich eine entscheidende Rolle gespielt hat: „elegans quidem est”. Das Wort „elegans” kann schwer mit einem Wort wiedergegeben werden, eines kann aber auf jeden Fall festgestellt werden: es deutet auf Qualitäten hin, die von sprachlichen Kompetenzen nicht zu trennen sind.

Um die Aspekte der Gruppenbildung aus dem Gesichtspunkt der Forschung zu formulieren, die das soziale Handeln der Humanisten untersucht, die also ihren Schwerpunkt auf das Bilden und Funktionieren von Personengruppen und Kommunikationsnetzen setzt, kann man die folgende Formulierung zitieren: „Humanist ist hier, wer mit anderen Humanisten im Gespräch ist und bleibt". ${ }^{65}$ Harald Müller versteht Humanisten als eine intellektuelle Konsensgemeinschaft. Er nimmt als Motto seiner Arbeit die modifizierte Version des Titels einer Studie: „An Humanisten Humanismus verstehen”. Der von Müller modifizierte Satz lautet: „an Humanisten Humanismus erkennen”. ${ }^{66}$ Wenn man sich aber, mit dem von diesem Motto genannten Erkenntnisinteresse bewaffnet, auf die Suche nach Humanismus macht, hat man mit der folgenden Schwierigkeit zu kämpfen: man muss wenigstens wissen, wen man als $\mathrm{Hu}-$ manisten bezeichnen kann. Wie es Cortesis Beispiel verdeutlicht haben mag, ist genau diese Frage gar nicht so einfach zu beantworten.

Ein anderer Ansatz, der die Funktion des Humanismus hauptsächlich als eine Selbstdarstellungsstrategie sieht, und zwar im Kontext des europäischen Nationdiskurses, muss an dieser Stelle auch erwähnt werden: „Die Humanisten bauten kulturelle Wälle gegen Norden, da militärische Wälle fehlten”. So könnte man Caspar Hirschis überzeugend dargelegte

64 Für den Brief 86 vgl. Guarino Veronese, L'epistolario, Miscellanea di storia veneta 11, hrsg. v. Remigio Sabbadini, Bd. 1 (Venedig: R. Deputazione Veneta di Storia Patria, 1915), [im Weiteren: „L'epistolario”], hier S. 161.

65 Harald Müller, Habit und Habitus. Mönche und Humanisten im Dialog, Spätmittelalter und Reformation N. R. 32 (Tübingen: Mohr Siebeck, 2006), [im Weiteren: „Habit”], hier S. 77.

66 Müller, Habit, S. 10. 
Position in der Humanismusdebatte kurz zusammenfassen. ${ }^{67}$ Die Funktion der Vergötterung der eloquentia und die Barbarenrhetorik sei die der Selbstabgrenzung gewesen: eine These, die auch in dieser Arbeit als Ausgangspunkt genommen wird, denn, wo es um Erbschaften geht, und das ist hier der Fall, im konkreten wie im übertragenen Sinne des Wortes, dort hat man es immer auch mit Ausschließlichkeit und Konkurrenz zu tun, weil Erbschaft ein Eigentumsverhältnis ist. Im Unterschied zu Hirschis erkenntnisleitendem Interesse spielt aber in dieser Arbeit der Diskurs um die Nationen keine zentrale Rolle: einige meiner Fallbeispiele haben - zumindest auf den ersten Blick - eine Identität, die man sogar als „transnational” bezeichnen könnte.

\section{Meine Beispiele}

Ich nehme meine Beispiele aus dem Kontext des Konstanzer Konzils (1414-1418). In der Konzilstadt hielten sich für längere oder kürzere Zeit viele Humanisten auf: Chrysoloras, Bruni und Poggio sind die größten Eminenzen der neuen Kultur, deren Aufenthalt in Konstanz in der Sekundärliteratur erwähnt wird. ${ }^{68}$ Dieses Ereignis liefert reichliche Quellen für eine Untersuchung von Selbstdarstellungsstrategien, weil das Konzil offensichtlich als eine ideale Plattform für Selbstdarsteller diente, die nach einer neuen Anstellung suchten. Andererseits ermöglicht es - wegen seines Charakters als Treffpunkt von Trägern verschiedenster Traditionen - die Beobachtung unterschiedlicher Wahrnehmungsmuster. Meine Beispiele sind Texte von Poggio Bracciolini, Pier Paolo Vergerio und Benedetto da Piglio, drei Personen, deren Leben auf dem Konzil eine Wendung nimmt.

Die Begriffe „Selbstdarstellung” und „Selbstlegitimation” benutze ich im Kontext des Konstanzer Konzils für beide Seiten: sowohl für die Humanisten, als auch für ihre potentiellen oder reellen Brotgeber. Die Selbstdarstellungsversuche der Humanisten sind letzten Endes

67 Caspar Hirschi, Wettkampf der Nationen. Konstruktionen einer deutschen Ehrgemeinschaft an der Wende vom Mittelalter zur Neuzeit (Göttingen: Wallstein, 2005), hier S. 184.

68 Die zwei wichtigsten Überblicke des Themas „Humanismus auf dem Konstanzer Konzil” sind: Helmraths bereits (Vgl. Anm. 33) erwähnte Studie: Diffusion des Humanismus und Antikerezeption und Alexander Patschovsky, Der italienische Humanismus auf dem Konstanzer Konzil (1414-1418), (Konstanz: Universitätsverlag Konstanz, 1999). Zu den Konzilien als europäische Foren intellektueller Kommunikation vgl.: Jürgen Miethke, „Die Konzilien als Forum der öffentlichen Meinung im 15. Jahrhundert“, in DA 37 (1981) 736-773 und ders., „Die großen Konzilien des 15. Jahrhunderts als Medienereignis: Kommunikation und intellektueller Fortschritt auf den Großtagungn“, in: University, Council, City. Intellectual culture on the Rhine (1300-1559), hrsg. v. Laurent Cesalli und Nadja Germann (Turnhout: Brepols, 2007), 291-322; Johannes Helmrath, „Kommunikation auf den spätmittelalterlichen Konzilien“, in Die Bedeutung der Kommunikation für Wirtschaft und Gesellschaft, hrsg. von Hans Pohl, (Stuttgart: Franz Steiner Verlag, 1989), 116-172; Thomas Rathmann, „Beobachtung ohne Beobachter? Der schwierige Umgang mit dem historischen Ereignis am Beispiel des Konstanzer Konzils“, in Die Konzilien von Pisa (1409), Konstanz (1414-1418) und Basel (1431-1449), hrsg. von Heribert Müller und Johannes Helmrath, (Ostfildern: Thorbecke, 2007), 95-106. 
auf einen einfachen Grund zurückzuführen: auf die Suche nach eben diesen potentiellen Brotherren. Unter diesen möglichen Brotherren gehören die ersten Plätze dem zukünftigen Papst und dem römisch-deutschen König, Sigismund von Luxemburg.

Dafür, dass eine humanistisch gefärbte Selbstdarstellung in der kurialen Umgebung erfolgreich sein konnte, ist selbst der Grund für die Anwesenheit der meisten Humanisten der beste Beweis. Die meisten von ihnen kamen in die Konzilstadt als kuriale Schreibkräfte. Ein weiterer Beweis für die engen Verflechtungen zwischen päpstlichen Machtträgern und Humanismus ist die Tatsache, dass beide große Toten, die von den Humanisten auf dem Konzil begraben worden sind, Chrysoloras und Zabarella, auch als mögliche Kandidaten für den päpstlichen Titel betrauert wurden. Humanist-Sein konnte dementsprechend als ein Merkmal des zukünftigen Papstes dargestellt werden. Die Projizierung der Rhetorik des Bruches auf die Verhältnisse der Kirche hatte ihre Anfänge bei Petrarca. Seine Bemühungen, den Papst zu überzeugen, dass er seinen Sitz wieder nach Rom legen sollte, waren mit der Idee von der Wiedergeburt Roms verbunden. ${ }^{69}$

Sigismunds Motivation für Selbstdarstellung generell kann erstens mit dem allgemeinen, kontinuierlichen Bedarf des Machttragenden an Selbstlegitimation erklärt werden. Macht ist nicht etwas Stabiles, das, wenn es einmal sich zu etablieren wusste, keine weiteren Selbstdarstellungsstrategien mehr bräuchte. Macht muss sich kontinuierlich neu behaupten. Mit Stephen Greenblatt könnte man sagen, dass das wichtigste Merkmal von Macht darin bestehe, dass sie fähig sei, ihre eigene Fiktion der Welt aufzuzwingen. „The quintessential sign of power is the ability to impose one's fictions upon the world. The more outrageous the fiction, the more impressive the manifestation of power." ${ }^{70}$ Man könnte sogar einen Schritt weiter gehen und behaupten, dass das Bemühen, die eigene Fiktion der Welt aufzuzwingen, nicht nur ein Merkmal der Macht, sondern sogar ihre Essenz ist. Wenn man also Macht als einen Prozess des Sich-Darstellens versteht, ist das Bedürfnis der Selbstrepräsentation im Allgemeinen selbsterklärend. Für Sigismunds konkreten Fall kann man aber sogar weiter mit einem extrem hohen Legitimationsbedarf argumentieren.

Außer seiner wohlbekannten Geldnot war auch sein Anspruch auf den kaiserlichen Thron nicht ganz problemlos vertretbar: seine Wahl zum römisch-deutschen König gelingt ihm erst beim zweiten Versuch, ${ }^{71}$ und zwar mit Hilfe einer Abmachung zwischen Sigismund

69 Charles Calvert Bayley, „Petrarch, Charles IV, and the „Renovatio Imperii””, Speculum 17 (1942): 323 341, [im Weiteren: „Petrarch, Charles IV'].

70 Greenblatt, Self-Fashioning, S. 13.

71 Jörg K. Hoensch, Kaiser Sigismund. Herrscher an der Schwelle zur Neuzeit 1368-1437 (München: Beck, 1996), [im Weiteren „Sigismund”], hier S. 148-161. Eine approbatio personae und confirmatio electionis von Seite des Papstes erfolgte erst am 23. Januar 1418: Hoensch, Sigismund, S. 156 f. 
und seinem Bruder Wenzel, laut der der Preis des römisch-deutschen Thrones für Sigismund der Kaisertitel war: nach dieser Vereinbarung hätte Sigismund den Titel des römischdeutschen Königs erhalten unter der Bedingung, dass er dafür seinem Bruder Wenzel helfen würde, den Kaisertitel zu erhalten. ${ }^{72}$ Selbst wenn Sigismund diese Vereinbarung keine Minute lang als verbindlich betrachtet hätte, ist sie ein Zeichen dafür, dass schon in der Zeit das Trennen der zwei Titel, des römisch-deutschen Königs und des Kaisers, nicht für unmöglich gehalten wurde, und dass dementsprechend Sigismunds Wahl als römisch-deutscher König noch keine Versicherung für seine Kaiserkrönung bedeutete. Man muss dementsprechend in Sigismunds Fall von einem erhöhten Bedarf an Selbstdarstellung und Propaganda ${ }^{73}$ ausgehen.

Die Anwesenheit von Humanisten in Sigismunds Umgebung - auf Grund des Rufs, den sein Vater, Karl IV., als Herrscher hatte, der sich gerne mit der Anwesenheit von Humanisten, wie zum Beispiel Petrarca, schmückte, war eine der möglichen Strategien, sich als wahrer Erbe seines Vaters zu behaupten. Die humanistische Idee der renovatio studii war ein Gedanke, der sein politisches Pendant hatte, die renovatio imperii. Dass Sigismund den Rückgriff auf seine antiken Vorläufer als ein mögliches Mittel für die Gestaltung seines eigenen Image gehalten hatte, ist zum Beispiel durch einen Brief belegt, von dem man erfährt, dass Sigismund auf dem Konzil einem Humanisten den Auftrag gegeben hatte, ein vollständiges Exemplar der Gesta Iulii Cesaris zu besorgen. ${ }^{74}$ Wenn Sigismund, der römischdeutsche König - und nach seinen Erwartungen bald Kaiser - auf dem Konzil Iulius Cäsar lesen will, so ist dieser Akt in erster Linie nicht als seine private Angelegenheit, sondern eher als des Königs Erkennen des Repräsentationspotentials dieser Schrift zu sehen.

Eine Szene zwischen Ciriaco d'Ancona und Sigismund zeigt, dass Sigismund selbst als Projektionsfläche für humanistische Selbstdarstellungsstrategien fungieren konnte. Ciriaco d'Ancona zeigte Sigismund, als er zu seiner Krönung in Rom war, die Ruinen und ein anderes

\footnotetext{
72 Hoensch, Sigismund, S. 155 f.
}

73 Eine klare Trennung zwischen Selbstdarstellung und Propaganda ist schwierig. Dies wird auch im Fall von Hruzas Vorschlägen für einen Gebrauch des Begriffes der Propaganda klar. Die Schlüsselwörter seiner Beschreibung sind: Öffentlichkeit, gesellschaftspolitische Relevanz, Handlungsappelle, Gruppe als gezieltes Publikum. An dem Punkt, wo er über Handlungsappelle schreibt, bemerkt er folgendes: „Diese Wirkung zu erreichen, muß nicht nur durch direkte bzw. offensichtliche, sondern kann auch durch subtile und ,unauffällige” Überzeugungsarbeit unternommen werden. Vgl. Karel Hruza, „Propaganda, Kommunikation und Öffentlichkeit im Mittelalter”, in Propaganda, Kommunikation und Öffentlichkeit (11.-16. Jahrhundert), Forschungen zur Geschichte des Mittelalters 6, hrsg. v. Karel Hruza (Wien: Verlag der Österreichischen Akademie der Wissenschaften, 2002), S. 9-26, hier S. 25.

74 Es handelt sich um den Brief des Bartolomeo della Capra an Uberto Decembrio, den er 1416 aus Konstanz geschrieben hatte. Der Brief wird zitiert von: Florio Bánfi, „Pier Paolo Vergerio il Vecchio in Ungheria 12", Archivio di Scienze, Lettere ed Arti della Società Italo-Ungherese 1 und 2 (1939-1940): 1-30, und 1729, [im Weiteren: „PPV'], hier Teil 2., S. 15, Anm. 38. 
Mal, in Siena, überreichte er dem Kaiser eine Trajan-Münze. ${ }^{75}$ Diese Geste kann als eine Anspielung auf eine ähnliche Szene zwischen Karl IV. und Petrarca verstanden werden. Petrarca hat Karl IV. ebenfalls antike Münzen überreicht und den Kaiser dabei an seine Vorbilder erinnert. Wenn Ciriaco das Gleiche tut, ist es also eine doppelte Anspielung: einerseits auf Petrarca und Karl IV., andererseits auf die antiken Vorbilder.

Dass humanistische Selbstdarstellungsstrategien in beiden Kontexten - im kaiserlichen und kurialen - gleich wirksam sein konnten, ist ein Zeichen für das von Black betonte Merkmal des Humanismus: seine universale Verwendbarkeit.

In den ersten zwei Kapiteln werde ich am Beispiel einer vergleichenden Analyse der Frage nach den Zusammenhängen zwischen den jeweiligen persönlichen Präferenzen, politischen Motivationen und Selbstdarstellungsstrategien nachgehen. Die aus Anlass von Zabarellas Tod geschriebenen Eulogien von Poggio und Vergerio boten sich deswegen als ideale Gegenstände dieser Untersuchung an, weil in diesen Stücken - schon wegen des Genres - das Thema Erbschaft (in meiner Interpretation ein zentrales Anliegen der neuen Kultur) mit besonderer Intensität und auf verschiedenen Ebenen thematisiert wird, und zwar in einem politisch zugespitzten Moment, in dem zwei einander entgegensetzte Gruppen ihre jeweiligen Interessen - hinsichtlich der Frage der Papstwahl - mit größter Vehemenz artikulierten.

Im Kapitel über Vergerio werde ich versuchen, die Motivationen seiner Einstellung bei Sigismund zu erkennen, und zu untersuchen, ob seine Wahl, Sigismund zu dienen, tatsächlich, wie es in der Sekundärliteratur angenommen wird, als ein Gesinnungswandel zu sehen wäre. Im Kapitel über seinen Aufenthalt in Buda habe ich die einzige längere Schrift des Vergerio aus dieser Zeit, die Übersetzung der Alexander-Vita Arrians und ihre Wahrnehmung in den Humanistenkreisen analysiert. Dies schien mir erforderlich, weil diesen Jahren seines Lebens bis jetzt nur wenig Aufmerksamkeit geschenkt wurde, trotz der schwungvollen Theorien über seine Rolle als Apostel des Humanismus in Ungarn und Ost-Europa.

Benedetto da Piglio, der Protagonist des vierten Kapitels, schien gerade wegen seiner Marginalität (unter den Humanisten und in der Forschung) interessant für diese Analyse über humanistische Selbstdarstellungsstrategien und deren Wahrnehmung. Die Marginalität seiner Figur ermöglicht es, den humanistischen Diskurs von einer quasi Außenseiterperspektive zu

75 Francesco Scalamonti, Vita viri clarissimi et famosissimi Kyriaci Anconitani, For Promoting Useful Knowledge 86 Pt 4, hrsg. v. Charles Mitchell und Edward W. Bodnar (Philadelphia: American Philosophical Society, 1996), [im Weiteren: „Vita Kyriaci”], hier S. 67. Die Szene zwischen Petrarca und Karl IV. ist in Petrarcas Darstellung zu lesen: Francesco Petrarca, Le Familiari, 4 Bde., Edizione Nazionale delle Opere di Francesco Petrarca 10-13, hrsg. v. Vittorio Rossi (Florenz: Sansoni, 1865-1938), [im Weiteren: „Familiari”], Brief 19. 3, Bd. 3, S. 310-318, für die Szene der Überreichung der Münzen: S. 315. 
beobachten. Auch weil es im Fall seines Libellus penarum um einen bis jetzt unedierten Text geht, hielt ich eine nähere Betrachtung dieser Schrift für fruchtbringend.

In den Textanalysen dieser Arbeit wird untersucht, mit welchen Techniken die Humanisten den Bruch zwischen dem Alten und dem Neuen, bzw. die Grenze zwischen sich selbst und den anderen zum Ausdruck gebracht haben. Welche rhetorischen Strategien wurden angewendet? Ein anderes für die Beantwortung dieser Frage zu untersuchendes Phänomen ist das Benutzen des Titels poeta laureatus. Die Hypothese, dass ,sich die Identität des Humanisten in den Praktiken der poetae laureati manifestiert", ist der Ausgangspunkt von Albert Schirrmeisters Arbeit über die gekrönten Dichter des 16. Jahrhundert. ${ }^{76}$ Dieser Titel bot einerseits durch das Wiedererwecken eines angeblich antiken Gebrauches den Humanisten des 16. Jahrhunderts eine Möglichkeit, die Antike performativ nachzuahmen, und diese Nachahmung zur Schau zu stellen, andererseits verlieh er durch seinen institutionellen und kaiserverbundenen Charakter dem humanistischen Image eine gewisse Stabilität. ${ }^{77}$ Konnte dieser Titel auch am Anfang des 15. Jahrhunderts eine ähnliche Funktion erfüllen?

In den Analysen der Texte dieser Autoren und Akteure ${ }^{78}$ werde ich die jeweilige Rhetorik und die Motivation von deren Urhebern untersuchen. In meiner Untersuchung konzentriere ich mich auf die möglichen Folien der Texte, die ich in einen mit Berücksichtigung des Erwartungshorizontes der anvisierten Zuhörerschaft festgestellten Kontext der Intertextualität zu platzieren versuche.

76 Albert Schirrmeister, Triumph des Dichters. Gekrönte Intellektuelle im 16. Jahrhundert, Frühneuzeitstudien N. F. 3. (Köln, Weimar und Wien: Böhlau, 2003), [im Weiteren: „Triumph”].

77 Zur Einschränkung muss man aber auch bemerken, dass die zwei Gruppen: Humanisten und gekrönte Dichter auch später nicht identisch waren, was bedeutet, dass die Stabilität nur den Trägern des Titels zu Teil wurde, und dass deren Zugehörigkeit zur Gruppe, bzw. deren Berechtigung von den anderen Mitglieder trotz des Titels hinterfragt werden konnte.

78 Mit dieser Wendung wird Rathmanns später ausführlicher zu erörternde Auffassung von der Textualität des Konzils angesprochen: Autoren sind gleichzeitig auch Akteure, das Ereignis wird in deren Schriften nicht einfach widergespiegelt, sondern auch mit konstituiert. Vgl. Thomas Rathmann, Geschehen und Geschichten des Konstanzer Konzils. Chroniken, Briefe, Lieder und Sprüche als Konstituenten eines Ereignisses, Forschungen zur Geschichte der älteren deutschen Literatur 20 (München: Wilhelm Fink Verlag, 2000), [im Weiteren: „Geschehen”]. 


\section{Vom Nutzen der Toten: Eulogien an den toten Kardinal Francesco Zabarella als Instrumente humanistischer Selbstdarstellung}

Im Jahre 1417, am 26. September, im vorletzten Jahr des Konstanzer Konzils, starb Francesco Zabarella, der florentinische Kardinal, in der Konzilstadt. Es wurden vier Schriften tradiert, die sich gleich nach seinem Tod vornahmen, seine memoria zu erarbeiten, mit anderen Worten, für den Toten ein Monument zu erstellen. Parallel zum Stiften der memoria des Toten versuchten die Autoren, sich durch ihre Selbstdarstellungsstrategien im politischen Raum zu positionieren. Die Darstellung des Toten und die Selbstdarstellung der Autoren der Reden lassen sich voneinander nicht trennen. Wenn der Redner ein Monument für den Toten erbaut, errichtet er damit gleichzeitig das Fundament für die eigene Karriere unter den gegebenen Machtverhältnissen.

Durch das Beispiel der in diesem Kapitel untersuchten Eulogien werde ich versuchen, für eine Deutung des Phänomens „Humanismus” zu argumentieren, die Humanismus nicht als ein ideologisch homogenes Gebilde versteht. Die Humanisten, deren Schriften ich analysieren werde, haben sich unterschiedlich unter den in Konstanz gegebenen Machtverhältnissen positioniert, sie haben sich für einander entgegengesetzte Seiten entschieden und diese Entscheidung in ihren Schriften deutlich gemacht.

\section{Der historische Kontext}

\subsection{Das Dilemma des Jahres 1417}

Im Jahre 1417 war die dringendste Frage, über die das Konzil zu befinden hatte, die folgende: Was ist der nächste Schritt nach der erfolgreichen Absetzung der drei Päpste? Soll das Konzil so schnell wie möglich den neuen Papst wählen, oder sollten erst Reformen der Kirche (reformatio in capite et membris) erfolgen $?^{79}$ Die erste Version durchzusetzen - nach der erst die Papstwahl, und dann die Reformen durchzuziehen waren - stand im Interesse der Kardinäle, während Sigismund und die ihn unterstützenden Nationen (die deutsche und die englische Nation) für die Verzögerung der Papstwahl plädierten.

Warum war es Sigismund so wichtig, dass die Reformen vor der Papstwahl verwirklicht wurden? Man könnte benevolent mit der Wichtigkeit der Reformen selbst argumentieren und einfach behaupten, dass es dem König am Herzen lag, dass die Kirche auf jeden Fall re-

79 Zur Geschichte des Konstanzer Konzil im Allgemeinen: Walter Brandmüller, Hrsg., Das Konzil von Konstanz 1414-1418, 2 Bde, Konziliengeschichte Reihe A (Paderborn, München, Wien, Zürich: Ferdinand Schöning, 1991, 1997), [im Weiteren: „Konstanz”], hier Bd. 2. S. 276-357. 
formiert wurde, und dass er die Erfüllung seiner Reformforderungen nach einer Papstwahl nicht mehr gesichert sah. ${ }^{80}$

Wenn man aber nach dem Nutzen fragt, den die Verzögerung der Papstwahl für Sigismund mit sich bringen konnte, dann kann man erstens den allgemeinen Prestigegewinn hervorheben und antworten, dass der römisch-deutsche König so lange Schirmherr des Konzils bleiben konnte, bis ein neuer Papst gewählt wurde.

Erst Elemér Mályusz’ Buch über die Zusammenhänge des ungarischen Patronatsrechts hat die Frage wirklich klären können. ${ }^{81}$ (Diese Antwort übernimmt Brandmüller in seiner Schilderung der Ereignisse des Jahres 1417. ${ }^{82}$ ) Sigismund hatte einen ganz konkreten Grund, warum er die Papstwahl so lange wie möglich hinauszuzögern versuchte. Er wollte seine Herrschaft über die kirchlichen Güter im ungarischen Königreich erhalten, die ihm durch das königliche Patronatsrecht zugesichert war: alle päpstlichen Ernennungen und Verordnungen in Ungarn unterstanden der königlichem Konzession. 1404 erließ Sigismund das Dekret placitum regium, in dem der König seine Beschlüsse von 1394 und 1397 wiederholte. ${ }^{83}$ Am Konzil von Konstanz musste Sigismund das königliche Patronatsrecht, das er bei Papst Bonifaz IX. schon durchgesetzt hatte, wieder so absichern, dass der zukünftige Papst auf keinen Fall etwas dagegen unternehmen konnte. $\mathrm{Zu}$ einer Vereinbarung zwischen dem König und dem Kardinalskollegium kam es am 19. September 1417. Über eine Vereinbarung liest man auch in Fillastres Tagebüchern ${ }^{84}$, aber was diese genau bedeutete, worin der Kompromiss genau bestand und welchen Preis die Kardinäle dafür zahlen mussten, dass der König versprach, der Papstwahl keine weiteren Hindernisse in den Weg zu legen, war bis Mályusz' Veröffentlichung des Textes ${ }^{85}$ der Kardinalsurkunde unklar. In der Hauptquelle für diese Ereignisse, Fillastres Konzilstagebücher, wird nämlich der Inhalt dieser Vereinbarung nicht wiedergegeben.

80 Eine solche, wohlwollende Interpretation von Sigismunds Motivation liest man bei Hollnsteiner. Johannes Hollnsteiner, „König Sigismund auf dem Konstanzer Konzil. Nach den Tagebuchaufzeichnungen des Kardinal Fillastre", Mitteilungen des Österreichischen Instituts für Geschichtsforschung 41 (1926): 185200, [im Weiteren: „Sigismund”]. Auf Seite 200: „Aber wenn man bedenkt, dass der ihm übelwollende Franzose gewiß keine Schattenseite zu zeichnen vergessen, tritt auch die Bedeutung Sigismunds für das Konzil, für die Union und wenigstens für den Versuch einer Kirchenreform in ein helles Licht. Hätte sich Sigismund mit seiner Forderung: Kirchenreform vor der Papstwahl, durchsetzen können, wäre vielleicht die Entwicklung der abendländischen Geschichte eine andere geworden."

81 Elemér Mályusz, Das Konstanzer Konzil und das königliche Patronatsrecht in Ungarn, Studia Historica 18 (Budapest: Akadémiai Kiadó, 1959), [im Weiteren: „Patronatsrecht”].

82 Brandmüller, Konstanz, S. 319.

83 Mályusz, Patronatsrecht, S. 72.

84 Guillaume Fillastre, „Gesta concilii Constantiensis”, [im Weiteren: „Gesta”], in: Acta Concilii Constantiensis, 4 Bde., hrsg. v. Heinrich Finke, Johannes Hollnsteiner und Hermann Heimpel (Münster i. W.: Regensberg, 1896-1928), [im Weiteren: „ACC'], Bd. 2, 13-170.

85 Mályusz, Patronatsrecht, S. $8 \mathrm{f}$. 
Es war aber nicht nur die Prioritätsdebatte, die der Wahl des neuen Papstes im Wege stand. Die andere ungeklärte Frage betraf das Wahlverfahren: Wer konnte als legitimer Wähler gelten, wenn mit der Ausnahme von Benedikt XIII. selbst alle Kardinäle von Schismapäpsten ernannt worden waren $?^{86}$ Philip H. Stump bestreitet sogar, dass das Hauptthema in den Debatten im Jahre 1417 die Frage der Priorität der Papstwahl oder der Reform gewesen sei. Seiner Meinung nach war die Hauptfrage die Frage des Wahlmodus, wie also der Papst gewählt werden müsste. ${ }^{87}$ Stump kritisiert auch die allzu polarisierende Sichtweise der Sekundärliteratur, die der Hauptquelle zum Thema, d. h. Fillastres Tagebüchern zu verdanken sei, die die Ereignisse des Sommers 1417 selbst als einen Kampf zwischen Sigismund und den Kardinälen schildern. ${ }^{88}$ Die Situation sei nicht so einfach gewesen. Auch viele der Kardinäle seien für die Reformen gewesen, sie haben sich gegen die Reformen geäußert, als sie die Vorrechte der Kirche in Gefahr gesehen hätten. Trotz all der Verfeinerungen, die man am Bild vom Sommer 1417 anbringen muss, halte ich es für berechtigt, eine polarisierende Schilderungsweise zu verwenden, und zwar aus dem folgenden Grund: Wenn die Hauptquelle eine solche Sichtweise suggeriert, muss es heißen, dass der zeitgenössische Verfasser der Schrift, Kardinal Guillaume Fillastre, selber aktiver Teilnehmer des Konzils, die von ihm geschilderten Ereignisse so wahrgenommen hat. Die Gegenüberstellung der zwei Parteien, Sigismund und die Kardinäle, ist so präsent in seinem Text, dass man ihn, wenn schon nicht als faktentreue Darstellung, dann wenigstens - und es ist nicht wenig, was man damit gewinnt - als ein Beispiel zeitgenössischer Wahrnehmung dieser Ereignisse ernst zu nehmen hat. ${ }^{89}$ Weiterhin, wenn man damit nicht zufrieden ist, mit Fillastres Tagebüchern ein Beispiel der Wahrnehmung der Ereignisse zu haben, wird aus dem Text evident, dass eine polarisierende Gegenüberstellung der Interessen des Königs und der Kardinäle, wenn übertrieben, aber bestimmt nicht ganz fiktiv ist. $\mathrm{Ob}$ diese Interessenunterschiede sich bezüglich des Prioritätsstreits oder des Wahlmodus artikuliert haben, ist eine weitere Frage. Beide Parteien haben die eigenen Interessen und Vorrechte verteidigt, beide wollten, dass der Papst nach ihren Vorstellungen gewählt werde. Die Kardinäle hatten Angst, dass Sigismund durch Akklamation, ohne die Kardinäle in die

86 Brandmüller, Konstanz, S. 322 f..

87 „The principal struggle in the summer of 1417 was not between a reform party and an anti-reform party. The main bone of contention was the election." Philip H. Stump, The Reforms of the Council of Constance, Studies in the History of Christian Thought 53 (Leiden, New York, Köln: Brill, 1994), [im Weiteren: „Reforms"], hier S. 42.

88 Stump, Reforms, S. 31.

89 Wenn man etwas skeptisch formulieren wollte, so könnte man behaupten, dass die Ereignisse generell immer nur durch die Wahrnehmung und weitere Transformationsprozesse gefiltert zum Forscher gelangen. Vgl. das fünfte Unterkapitel der Einleitung dieser Arbeit: „Wahrnehmung: Ein Spaziergang von den Humanisten bis zu den Hirnforschern und wieder zurück." 
Entscheidung mit einzubeziehen, einen neuen Papst wählen ließe, Sigismund wiederum wollte eine ausschließlich den Interessen der Kardinäle dienende Papstwahl verhindern. ${ }^{90}$

Um ein durch seine Handfestigkeit (im konkretesten Sinne des Wortes) immer zum Zitieren einladendes und deswegen auch häufig zitiertes Bild zu nennen, erwähne ich als ein Beispiel für die konkrete Form, die die Meinungsunterschiede zwischen Sigismund und den Kardinälen annehmen konnten, die folgende, in Fillastres Tagebüchern überlieferte Szene: Wir sind im September 1417. Alle nationes haben schon ihre Vertreter für die Verhandlungen über die Papstwahl gewählt, es fehlen nur die Germani, die es noch nicht getan haben, um die Papstwahl zu verzögern. Als ein Kardinal den Anwesenden eine Aufforderung zur Wahl dieser Vertreter vorlesen lassen will, wird dieser Versuch auf folgende Weise verhindert:

Hiis dictis cardinalis Pisanus alta voce loquens Germanis dixit: Ecce, domini Germani, omnes naciones preter vos dederunt deputatos. Detis, ut ceteri! Et quia nullus respondebat, tradidit archiepiscopo Bituricensi requisicionem et protestacionem in scriptis legendam, qui illam cepit legere. Et tunc rex surrexit et factus est tumultus. Iterum incepit legere. Rex alta voce dixit: Per deum, vos non legetis! Et tunc tumultus major factus est et rex recedit. Loquens tunc unus prothonotarius Ytalicus dixit: Ponantur ista in valvis! Rex hoc audiens reversus ad illum dixit: tu habebis in valvis! Et ut asserunt dictus prothonotarius et plures episcopi, percussit illum prothonotarium de pugno sub mento et in pectore; recedens dicebat: isti Ytalici et Gallici volunt nobis dare papam! Per deum, ipsi non facient hoc! ${ }^{91}$

Die Vereinbarungen bezüglich des Wahlmodus wurden erst am 30. Oktober 1417 abgeschlossen, und Oddo di Colonna wurde am 11. November zum Papst gewählt. Das Datum von Francesco Zabarellas Tod (der 26. September) und von seinen Trauerfeierlichkeiten fällt in die noch für beide Seiten mit existentiellen Fragen beladene Zeit, als noch alles offen war.

90 Am Ende wurde ein Kompromiss gefunden: der Papst sollte von den Kardinälen und von den sechs Vertretern der jeweiligen Nationen gemeinsam gewählt werden. Zur Wahl waren zwei Drittel der Voten der Kardinäle und zwei Drittel der Voten der einzelnen Nationen nötig. Zu den Debatten über den Wahlmodus vgl. Karl August Fink, „Die Wahl Martins V.”, in Das Konstanzer Konzil, Wege der Forschung 415, hrsg. v. Remigius Bäumer (Darmstadt: Wissenschaftliche Buchgesellschaft, 1977), 306-22, [im Weiteren: „Die Wahl'], hier besonders S. 308-310.

91 Fillastre, Gesta, S. 139. Ob der grammatisch fehlerhafte Satz in Sigismunds Antwort (,Tu habebis in valvis") ein Schreibfehler oder ein bewusst verwendetes Mittel der Komik ist, kann hier nicht entschieden werden. 


\subsection{Francesco Zabarella}

Kardinal Francesco Zabarella (1360-1417), der auch als einer der berühmtesten Kanonisten seiner Zeit galt, war eine zentrale Figur des Konstanzer Konzils. ${ }^{92}$ Er galt als Autorität in den Fragen hinsichtlich des Schismas, da er der Verfasser des Tractatus de schismate (1402-1408) war, in dem er als Lösung der Kirchenspaltung den konziliaren Weg vorgeschlagen hatte. Er spielte eine wichtige Rolle in den Vorbereitungen des Konzils 1413-1414, sowie 1415 in der Formulierung des Dekrets Haec sancta ${ }^{93}$, des Konziliarismus-Dekrets, das die oberste Autorität des Konzils in der Kirche bestätigt. In seinen Konzilsreden ${ }^{94}$ formuliert er die doppelte Zielsetzung des Konzils: beides, die Reformen und die Einheit der Kirche, sind die Ziele, die das Konzil verwirklichen muss.

Seine Beziehung zu Sigismund ist von Morrissey als ein Wechselspiel der Unterstützung und Anerkennung einerseits und der Kritik andererseits dargestellt worden. ${ }^{95}$ Der Grund für den Wechsel in seiner Haltung gegenüber Sigismund sei dessen zunehmend aggressiv und explizit werdender Anspruch auf einen direkten Einfluss auf das Konzil und auf die Papstwahl gewesen. ${ }^{96}$ Zabarella nannte den Kaiser in seinem Traktat einen Advokaten und Verteidiger der Kirche. ${ }^{97}$ Er sah es als die Aufgabe des Kaisers, das Konzil einzuberufen, sobald aber das Konzil versammelt war, sollte es frei entscheiden können, ohne von der königlichen Willkür bedroht zu werden. ${ }^{98}$ Auch Stump stellt Zabarellas Stellung zur Reform als wechselhaft dar: er unterstreicht seine reformfeindliche Haltung während der Arbeiten an dem Text des Haec-sancta-Dekrets, obwohl Zabarella auf dem Konzil selbst viele Reformen

92 Um die wichtigsten Beiträge zu Zabarellas Leben und seiner Tätigkeit auf dem Konstanzer Konzil zu nennen: Dieter Girgensohn, „Francesco Zabarella. Gelehrsamkeit und politisches Wirken eines Rechtsprofessors während des großen abendländischen Schismas", Zeitschrift der Savigny-Stiftung für Rechtsgeschichte, Kanonistische Abteilung 79=110=123 (1993): 232-277; ders., "Die Stellung Francesco Zabarellas im Humanismus", in Prusy - Polska - Europa. Studia z dziejów sredniowiecza i czasów nowozaytnych. Prace poswiecone profesorowi Zenonowi Hubertowi Nowakowi w szesndziesieciopieciolecie urodzin $i$ czterdziestolecie pracy naukowej, hrsg. v. Anrzej Radziminski und Janusz Tandecki, (Torun: Wydawnictwo Naukowe Umk, 1999) 57-72; Thomas Edward Morrissey, „Emperor-Elect Sigismund, Cardinal Zabarella, and the Council of Constance", The Catholic Historical Review 69 (1983): 353-70, [im Weiteren: „Emperor-Elect”]; Thomas Edward Morrissey, „The Call for Unity at the Council of Constance: Sermons and Addresses of Cardinal Zabarella, 1415-1417', Church History 53. (1984): 307-318, [im Weiteren: „Unity”]; und Gasparo Zonta, Francesco Zabarella (Padua: Tipografia del seminario, 1915).

93 Über Zabarellas Rolle bei der Formulierung und Interpretation des Dekrets siehe: Thomas Edward Morrissey, „The Decree Haec Sancta and the Cardinal Zabarella: His Role in Its Formulation and Interpretation”, Annuarium Historiae Conciliorum 10 (1978): 145-76, [im Weiteren: „The Decree”].

94 Über diese Reden, deren doppelte Zielsetzung, und über die Ironie der intertextuellen Zusammenhänge zwischen einer Rede Zabarellas und der Bulle von Bonifaz VIII., Unam Sanctam, schreibt Morrissey in seinem Artikel von 1984: Vgl. Morrissey, Unity, S. 314 f.

95 Morrissey, Emperor-Elect, S. 361.

96 Dieser Prozess und Zabarellas Reaktionen darauf werden in Morrisseys Studie Emperor-Elect dargestellt.

97 Morrissey, Emperor-Elect, S. 356 f.

98 Morrissey, Emperor-Elect, S. 370. 
vorgeschlagen habe. Ihm sei es um die Interessen und Vorrechte der Kirche gegangen: wenn er diese nicht gesichert gesehen habe, habe er gegen die Reformen gearbeitet. ${ }^{99}$

Im Jahre 1417 war Zabarella einer der schärfsten Kritiker Sigismunds. Sein letzter Auftritt ist auf den 11. September 1417 datiert, als er gegen die exzessiven säkularen Machtansprüche des Königs protestiert haben soll. ${ }^{100}$ Er starb am 26. September 1417, am Konzil, nach langer Krankheit. Der Tod des Kardinals, der auf Grund seiner Bestrebungen vor und an dem Konzil als Symbolfigur für die wiederherzustellende Einheit der Kirche gesehen werden konnte, bot Anlass zur Artikulierung der verschiedenen Meinungen der 1417 einander gegenüber stehenden Seiten - der des Kardinalskollegs und der des Königs. Im Folgenden werde ich zeigen, dass im eulogischen Schrifttum ein Raum geschaffen wurde, wo die Akteure pro und contra argumentieren konnten, also der von den Lobreden gebildete Raum als ein Forum der im Jahre 1417 aktuellen Debatten gesehen werden kann.

\subsection{Die Eulogien zum Anlass des Todes des Francesco Zabarella}

Es sind vier Eulogien überliefert, die zum Anlass des Todes des Kardinals geschrieben wurden: Poggio Bracciolinis Grabrede, die er am 27. September hielt ${ }^{101}$, Richard Flemings am 2. Oktober gehaltene Thema-Predigt ${ }^{102}$, Pietro Donatos Grabrede, die er auf den Trauerfeierlichkeiten in Padua hielt ${ }^{103}$, und ein Brief, den Pier Paolo Vergerio aus dem

99 Laut Stump war es Zabarella zu verdanken, dass das Konzil an dem Text des Dekrets Haec sancta auch an der fünften Sitzung arbeiten musste, weil er, als er den Text des Dekrets vorlas, die Wörter ,reformatio in capite et in membris" weggelassen hatte. Der Beleg, auf den Stumps Urteil beruht (den er aber nicht erwähnt), ist Fillastres Bemerkung in seinen Tagebüchern: vgl. Fillastre, Gesta, S. 27-28. Stump, Reforms, S. 43. Im Gegensatz zu Stump beurteilt Morrissey in seinem Artikel (The Decree) über das Haec-SanctaDekret Zabarellas Teilnahme an den Arbeiten an dem Text des Dekrets viel wohlwollender und detaillierter. Seiner Meinung nach waren Zabarellas Vorbehalte für eine präzisere Formulierung des Textes nötig. Für die konkreten Quellen für die verschiedenen Phasen der Überarbeitungen des Textes sowie für die Zusammenfassung der Diskussion in der Sekundärliteratur über Zabarellas Rolle in der Formulierung siehe Morrissey, The Decree, S. 146-151.

100 Vgl. Anm. 225.

101 Poggio Bracciolini, „Oratio in funere domini Francisci cardinalis Florentini”, [im Weiteren: „Oratio”], in Opera omnia, 3 Bde., hrsg. v. Riccardo Fubini (Turin: Bottega d'Erasmo, 1964), Bd. 1, S. 252-261. Für die Datierung der Rede vgl. das Unterkapitel: 2.2.2.1. „Über die Frage, ob die Rede tatsächlich gehalten wurde" dieser Arbeit. Eine kritische Ausgabe der Oratio fehlt bislang. John M. McManamon, der ausgewiesene Forscher des Themas, schickte mir freundlicherweise in einer email (John M. McManamon, E-Mail Nachricht an die Autorin, 23. 05. 2008) seinen unveröffentlichten „Census laudationum duarum (1417-18)" mit einer Liste der 40 Handschriften, die Poggios Oratio über Zabarella enthalten.

102 Eine kritische Ausgabe des Textes ist von Chris L. Nighman angefertigt worden. Seine Dissertation enthält die Rede als Anhang der Arbeit: Chris Nighman, „Reform and Humanism in the Sermons of Richard Fleming at the Council of Constance (1417)" (PhD Diss., University of Toronto, 1996), [im Weiteren: „Reform and Humanism"], die online zugänglich ist: National Library of Canada: http://www.nlcbnc.ca/obj/s4/f2/dsk3/ ftp04/NQ41569.pdf. Der Text befindet sich auf den Seiten 405-426. monasterii S. Michaelis Venetiarum prope Murianum, hrsg. v. Iohannes-Benedictus Mittarelli (Venedig: Typ. Fentiana, 1779), Sp. 1236. 
gleichen Anlass an Ludovico Buzzacarini (oder Leonardo Bruni) ${ }^{104}$ schrieb. In diesem Vergleich werden von den vier Eulogien nur zwei untersucht: Poggios Grabrede und Vergerios Brief. Der Grund dieser Einschränkung liegt darin, dass der kompetitive Charakter der (Selbst)-Darstellung in diesen beiden Schriften am markantesten fassbar wird. In diesen beiden Eulogien kann man eine unterschwellige Debatte rekonstruieren. Dagegen entstand die Grabrede des Venezianers Pietro Donato in einem anderen Kontext, in Padua. Dementsprechend waren die Animositäten, die zwischen den in Konstanz arbeitenden Humanisten wirkten, für diesen Autor ohne Interesse. ${ }^{105}$

Der Engländer Fleming seinerseits war in die Debatte weniger involviert. Sie konnte in der Intensität, wie sie aus den Eulogien Poggios und Vergerios zu rekonstruieren ist, anscheinend nur unter Menschen entstehen, die aus einem als gemeinsam gefühlten Kulturgut schöpften. Flemings Rede wurde in McManamons Monographie über humanistische Traueroratorik ${ }^{106}$ mit Poggios eulogium verglichen. ${ }^{107}$ Er benutzt Flemings Text im Sinne einer Kontrastierung: von Flemings sermo als Themenpredigt, es sei ein Beispiel für die der humanistischen oratio entgegengesetzte Tradition. Chris Nighman dagegen sieht in Flemings sermo ein eindeutiges Zeichen dafür, dass der Engländer sich auf dem Konzil als Humanist dargestellt habe. ${ }^{108}$ Nicht nur die antiken Zitate, sondern auch der starke Akzent auf dem Ruhm soll ein Beweis dafür sein. Nighman sieht die Motivation für eine solche Schreibweise in Flemings Wunsch, in der Umgebung des zukünftigen Papstes Karriere zu machen. ${ }^{109}$ Sowohl Flemings Rede selbst als auch seine Beurteilung bei McManamon und Nighman können als Beispiel für die Kontextbezogenheit der humanistischen Selbstdarstellungsstrategien und deren Wahrnehmung genannt werden. Einerseits verfolgt Flemings Rede eine offensichtlich andere Strategie als seine anderen Reden, andererseits sind die Akzente der Forscher in der Darstellung seiner Rede auch kontextabhängig. Wenn sein Text als Kontrast

104 Die von Smith untersuchten Handschriften sind sich, was den Adressaten des Briefes betrifft, nicht einig. Smith vertraut der Gruppe, die als Adressaten Buzzacarini angibt, aus zwei Gründen. Erstens seien diese Handschriften vertrauenswürdiger, zweitens sei die Freundschaft zwischen Vergerio, Zabarella und Buzzacarini seit dem Jahre 1398 ein Argument dafür, dass Vergerio sein eulogium Zabarellas an Buzzacarini gerichtet habe. Auch was das Datum des Briefes betrifft, liefern die Handschriften zwei Versionen: „VI. kal. nov.” und „VI. nov.” Nach Smiths Meinung ist das zweite Datum, also die Datierung des Briefes auf den 6. November 1417, wahrscheinlicher, weil das von Vergerio erwähnte Dekret über die Wahl des Papstes erst am 30. Oktober vorgelesen wurde. Vgl. Smith, Epistolario, S. 362-363, Anm. 1.

105 Für eine zusammenfassende Darstellung dieser Rede vgl. Girgensohn, Studenti e tradizione, S. 128 und 165 f.

106 John M. McManamon, Funeral Oratory and the Cultural Ideals of Italian Humanism (Chapel Hill, London: University of North Carolina Press, 1989), [im Weiteren: „Funeral'].

107 McManamons Vergleich der Reden für Zabarellas Tod: Funeral, S. 11-16.

108 Nighman, Reform and Humanism, besonders S. 220-238.

109 Obwohl Nighman mit einer anderen, mehr an Inhalte gebundenen Definition von Humanismus arbeitet als diese Arbeit, zeigt seine Fragestellung Ähnlichkeiten mit der hier verfolgten, bis auf den Unterschied, dass er die Frage, ob nun Fleming wirklich ein Humanist war oder nicht, für objektiv entscheidbar hält. 
zu den „richtigen” humanistischen Reden dienen soll (wie bei McManamon), so wird seine Traditionalität betont, wenn er aber im Kontext seiner Biographie und seiner anderen Schriften untersucht wird (wie bei Nighman), so werden eher die Züge seiner Rede wahrgenommen, die etwas Neues und Anderes darstellen als seine anderen Schriften.

Über die Sekundärliteratur zu den zum Anlass von Zabarellas Tod geschriebenen Eulogien liefert Johannes Helmrath einen sehr informativen Überblick ${ }^{110}$ in seinem Kapitel über „Performative Antike: Humanistische Konzilsreden”. Mit dem Vergleich der Eulogien hat sich am ausführlichsten McManamon in seinem Buch über humanistische Totenreden befasst, in dem er die wichtigsten Neuerungen der humanistischen Grabreden gegenüber den traditionellen, „mittelalterlichen” Leichenpredigten exemplifiziert. Nach McManamon kann die Neuheit der humanistischen Oratorik auf diesem Gebiet zusammenfassend als ein Wechsel von den als „erweiterte Syllogismen" ${ }^{111}$ bezeichneten Themenpredigten zu den das Leben des Verstorbenen ins Zentrum stellenden, klassizisierenden Reden erfasst werden.

Ich werde in meiner Analyse dieser Schriften von der McManamons in einem wichtigen Punkt abweichen. Weil er sich auf die Merkmale konzentriert, die humanistisches Schrifttum vom nichthumanistischen unterscheiden, verwischt er unvermeidlich die Aspekte, die die „humanistischen” Stücke wiederum voneinander unterscheiden. Dies folgt aus seiner Grundannahme, nach der es nach exakten Richtlinien zu entscheiden wäre, ob eine Schrift als humanistisch oder eine Person als Humanist zu bezeichnen wäre. ${ }^{112}$ Meine Absicht ist es, Humanismus nicht als ein mit objektiven Merkmalen beschreibbares Phänomen darzustellen, sondern der Frage nachzugehen, wer, wann, warum und unter welchen Umständen sich als Humanist dargestellt hatte, beziehungsweise als Humanist wahrgenommen wurde.

Ich betrachte Humanismus als einen Diskurs, der sich immer wieder neu formuliert, und der sich aus Darstellungs- und Selbstdarstellungsstrategien zusammensetzt. Dieser Sichtweise folgend ist es nötig, die verschiedenen Stimmen, aus denen der Diskurs entsteht, in ihrer Verschiedenheit darzustellen. Ich möchte mit der folgenden Analyse beweisen, dass $\mathrm{Hu}-$ manisten nicht zwangsweise „Reformdenker” waren, und dass sie zum Beispiel in der Prioritätsdebatte von 1417 verschiedene Positionen einnehmen und für die jeweiligen Positionen mit unterschiedlichen rhetorischen Strategien argumentieren konnten. Meine kritische Aus-

\footnotetext{
110 Helmrath, Diffusion des Humanismus und Antikerezeption, S. 30 f..

111 McManamon, Funeral, S. 10: McManamon benutzt hier den Ausdruck „extended syllogism” für die von Francesco Zabarella und Giovanni Ludovico de' Lambertazzi für Francesco il Vecchio da Carrara gehaltenen traditionellen Leichenpredigten.

112 Dazu vgl. das Kapitel „Humanismus: ein proteisches Phänomen”.
} 
einandersetzung mit McManamons Argumentation, sowie mit den über das Thema vorzufindenden weiteren Beiträgen folgt in den einzelnen Unterkapiteln.

\section{Poggio Bracciolinis eulogium}

\subsection{Poggio in Konstanz}

Es war Poggio Bracciolini, der als secretarius apostolicus des Papstes Johannes XXIII. nach Konstanz reiste ${ }^{113}$ und dessen Name im Kontext des Konstanzer Konzils meistens im Zusammenhang mit seinen „Entdeckungen” von antiken Autoren erwähnt wird ${ }^{114}$, der als erster eine Grabrede auf Zabarella hielt. ${ }^{115}$

Die Beurteilung der modernen Sekundärliteratur von Poggios Aufenthalt an dem Konzil scheint oft das Bild von Humanisten als welt- und politikfremden Forschern antiker Literatur zu übernehmen: Humanisten seien in erster Linie mit ihren antiken Lektüren beschäftigt, in den Hader der Politik wollen sie nicht hineingezogen werden. Im Kapitel seiner Monographie über die Konstanzer Jahre beschreibt Walser Poggios Aufenthalt auf dem Konzil in zwei Abschnitten. Erst handelt er über „das äußere Schicksal von Poggios Glücksschifflein”, um nach dieser Schilderung der politischen Geschehnisse des Konzils sich der literarischen Tätigkeit Poggios zuzuwenden. ${ }^{116}$ Im Rahmen der Beschreibung der Leistungen folgt die detaillierte Schilderung der Entdeckungen Poggios, und dann eine kurze Beschreibung der von Poggio auf dem Konzil verfassten Schriften: sein Brief an Niccoli über die Bäder von Baden, sein Brief vom Tod des Hieronymos von Prag und seine Grabrede über den Kardinal Francesco Zabarella. Die Walser leitende Frage bei der Paraphrasierung der drei Schriften ist,

113 Für Poggios Ernennungen in der Kurie vgl. Walther von Hofman, Forschungen zur Geschichte der kurialen Behörden: vom Schisma bis zur Reformation, 2 Bde. (Rom: Verlag von Loescher\& C., 1914), [im Weiteren: „Forschungen”], Bd 2, S. 110. Phyllis Goodhart Gordon's Beitrag, der den vielversprechenden Titel „Poggio at the Curia” trägt, ist eine Zusammenfassung von bekannten Daten aus Poggios Leben und trägt wenig zu den bereits in den bekannten Poggio-Biographien mitgeteilten Daten bei. Vgl. Phyllis Goodhart Gordan, „Poggio at the Curia”, in Umanesimo a Roma nel Quattrocento, hrsg. v. Paolo Brezzi und Maristella de Panizza Lorch (Rom, New York: Istituto di Studi Romani, Barnard College, 1984), 113127.

114 Poggios „Entdeckungen” werden detailliert geschildert in Walsers Monographie über den Humanisten: Ernst Walser, Poggius Florentinus. Leben und Werke, Beiträge zur Kulturgeschichte des Mittelalters und der Renaissance 14, hrsg. v. Walter Goetz (Leipzig, Berlin: Teubner, 1914), [im Weiteren: „Poggius”], zu den Entdeckungen vgl. S. 49-61. Für genaue Informationen darüber, welche Autoren wem in welcher Fassung zugänglich waren siehe: Remigio Sabbadini, Storia e critica di testi latini (Padua: Antenore, 1971). Zu diesem Aspekt des Humanismus auf dem Konzil im Allgemeinen vgl. Paul Lehmann, „Konstanz und Basel als Büchermärkte während der grossen Kirchenversammlungen”, in Erforschung des Mittelalters. Ausgewählte Abhandlungen und Aufsätze, 5 Bde., hrsg. v. Paul Lehmann (Stuttgart: Hirsemann 1941-1962) Bd. 1, 253-280; und Helmrath, Diffusion des Humanismus und Antikerezeption, S. 18-24. 
ob Poggio ein Epikureer war. ${ }^{117}$ Der Brief über den Tod des Hieronymus, „voll von erhabenem, tödlichem Ernst" ${ }^{\text {"18 }}$, und die Grabrede Zabarellas sollen zum Ausgleich zu der „heiteren Lust des Badenerbriefes"119 stehen, und zusammen mit den 1418-22 aus England geschriebenen Briefen beweisen, „wie tief religiös Bracciolini dachte, wie harmonisch bei ihm und seiner Zeit sich froher Lebensgenuß mit äußerer und innerer Rechtgläubigkeit vereinigte." ${ }^{120}$ Politik als Hintergrund, als das ,äußere Schicksal” einerseits, und die von der Politik unabhängigen literarischen Leistungen des Gelehrten andererseits sind die zwei Komponenten von Walsers Schilderung. Poggio als Mitwirkender, als Mitgestalter des politischen Diskurses wird überhaupt nicht wahrgenommen.

Ein Grund, warum das Politische in Walsers Schilderung zu kurz kommen musste, besteht darin, dass er die Attribution eines Werkes an Poggio nicht akzeptiert, das die Möglichkeit böte, über die Zusammenhänge zwischen Humanismus und Politik nachzudenken. Gemeint ist hier die irgendwann zwischen dem Mai 1415 und November 1417 gehaltene Oratio ad patres reverendissimos, dessen Autor die Zustände des Klerus kritisiert $^{121}$. Es war Riccardo Fubini, der der Attribution der Überlieferung des Textes an Poggio zugestimmt hat. ${ }^{122}$ Fubini hat seine Entscheidung mit den aus dem Kontext von Poggios anderen Schriften genommenen Argumenten begründet: die Oratio füge sich gut in Poggios antiklerikale Polemik, deren Zeugen seine anderen Schriften seien: De avaritia, Contra hypocritas, einige Briefe und seine Oratio in funere Cardinalis florentini. Fubini verzichtet in seiner Darstellung auf die Analyse der aktuellen politischen Zusammenhänge, sein Erkenntnisinteresse besteht in der Erfassung von Poggios Grundhaltung gegenüber dem Klerus, die er als mehr oder weniger unverändert sieht, und die er manchmal mit einer zum Psychologisieren neigenden Begrifflichkeit beschreibt. ${ }^{123}$ Zum Beweis der Zusammenhänge der zwei Reden (der Oratio in funere Cardinalis florentini und der Oratio ad patres reverendissimos) hat aber Fubini keine detaillierte vergleichende Analyse der Reden

Walser, Poggius, S. 61.

Walser, Poggius, S. 65.

ebda

ebda

Die moderne Ausgabe des Textes dieser Oratio ist veröffentlicht in einer Studie von Fubini. Vgl. Riccardo Fubini, „Il 'teatro del mondo' nelle prospettive morali e storico-politiche di Poggio Bracciolini”, [im Weiteren: „Teatro”], in Poggio Bracciolini 1380-1980. Nel VI Centenario della nascita, Studi e testi / Istituto Nazionale di Studi sul Rinascimento 8, hrsg. v. Riccardo Fubini und Cesare Vasoli (Florenz: Sansoni, 1982), 1-135.

122 Vgl. dazu Fubinis Studie: „Un’ orazione di Poggio Bracciolini sui vizi del clero scritta al tempo del concilio di Costanza”, Giornale storico della letteratura italiana 142 (1965): 24-33, [im Weiteren: „Sui vizi'].

123 Ein Beispiel für diese Begrifflichkeit aus der Passage, in der Fubini auf die Ähnlichkeit zwischen dem Seelenzustand, in dem Poggio seine Oratio ad patres reverendissimos und seine Briefe, die er an Barbaro und Pizzolpasso geschrieben haben dürfte, hindeutet: „Riteniamo di non essere lontani dalla verità nel riferire a tale stato d'animo la Oratio ad patres reverendissimos [...]”, Fubini, Sui vizi, S. 30. 
durchgeführt, die Grabrede wird nur kurz erwähnt. ${ }^{124}$ Die Gründe dieses als evident dargestellten Zusammenhangs erklärt Fubini nicht weiter. Als der einzig konkrete Beweis wird die für die Rezeptionsgeschichte der Reden in der Tat wichtige Tatsache erwähnt, dass im Codex Arundel 70 die zwei Reden unmittelbar aufeinander folgen, was darauf schließen lässt, dass der Schreiber des Codex die zwei Texte als zusammengehörend betrachtet hatte.

In seiner Poggios Leben und Werk bearbeitenden Dissertation betont James Donald Folts ${ }^{125}$ Poggios Interesse an den Geschehnissen des Konzils. Folts erwähnt in diesem Zusammenhang Poggios Grabrede an Zabarella, seine Briefe an seine Freunde über das Konzil, und die, von ihm am ausführlichsten beschriebene Oratio ad patres reverendissimos. Die Grabrede wird auch in dieser Arbeit nur als Beweis für das Interesse des Humanisten erwähnt, eine Analyse des Textes fehlt aber auch bei Folts.

Wie aus diesem knappen Überblick über die Sekundärliteratur erkennbar wird, wurde Poggios Rede über Zabarellas Tod immer wegen ihrer ähnlichen Züge im Vergleich mit Poggios anderen Werken (Walser, Fubini, Folts), oder mit anderen humanistischen Werken (McManamon) erwähnt oder kurz analysiert. Bei einer solchen Herangehensweise, die homogen vorausgesetzte Einheiten wie „humanistisches Schrifttum” oder „das Euvre” eines Autors zum Ausgangspunkt nimmt, läuft der Interpret Gefahr, die Besonderheiten eines Textes und dessen konkreten Entstehungskontext zu übersehen. Im Folgenden werde ich versuchen zu analysieren, wie die memoria des Kardinals in der Rede konstruiert wird, mit welchen rhetorischen Mitteln Poggio erreicht, dass er in seiner Trauerrede durch seine Schilderung des Lebens von Zabarella gleichzeitig für die von ihm in der Prioritätsdebatte eingenommene Position plädiert. In den weiteren Kapiteln werde ich Poggios Rhetorik mit Vergerios eulogium vergleichen und neben den unbestreitbaren Ähnlichkeiten auch Besonderheiten und Unterschiede in den jeweiligen Konstruktionen der memoria Zabarellas suchen. Besonderheiten und Unterschiede, die meines Erachtens der jeweiligen politischen Agenda, die die Autoren verfolgen, zu verdanken sind.

Der unmittelbare Entstehungskontext der Rede ist der Prioritätsstreit, in dem Poggio, wie die meisten Italiener, auf der Seite des Kardinalskollegiums stand. Eine seiner konkreten Motivationen für das Schreiben seiner Rede ist wahrscheinlich in der Tatsache zu suchen, dass der Humanist ab 1412 als secretarius apostolicus tätig war: eine möglichst zügige Papstwahl war für ihn eine existentielle Frage. Dass für die Schar der ehemaligen päpstlichen Sek-

\footnotetext{
124 „Certo essa appare in relazione abbastanza stretta pure con l'orazione funebre del card. Zabarella, pronunciata da Poggio a Costanza all'indomani della morte del suo illustro protettore": Fubini, Sui vizi, S. 30.

125 James Donald Folts, „In Search of The 'Civil Life': An Intellectual Biography of Poggio Bracciolini” (PhD Diss., University of Rochester, 1976), [im Weiteren: „Civil Life”].
} 
retäre und Notare die Konzilstadt als ein für die Suche eines neuen Brotherrens ideales Forum betrachtet wurde, versteht man auch, wenn man einen Brief liest, in dem Bruni 1415 Poggios Erwähnung des Andrangs der Schreiber des Papstes Gregor XII. und des Petrus de Luna beantwortete:

Faecem piceni agri atque flaminii in possessiones nostras scribis impetum fecisse. $\mathrm{O}$ rem acerbam! Quid ergo posthac non timendum? Jungentur jam gryphes equis aevoque sequenti / cum canibus timidi venient ad pocula damae ${ }^{126}$ Ego praeter hos et lunaticos expecto, quod si fiat, vides plane integram legionem. ${ }^{127}$

Poggios Brief kennt man heute nicht mehr, aber aus Brunis Antwort wird klar, dass Poggio sich Sorgen um die Konkurrenz machte.

Die Wahl Martins V. brachte ihm nicht die Bekräftigung seines früheren Status, sondern einen Verlust an Renommee: er wurde nur als scriptor eingestellt. ${ }^{128}$ Von seiner, in einem Brief an Francesco Barbaro geäußerten Enttäuschung kann man auf die Erwartungen scließen, die er gegenüber der Papstwahl gehegt hatte. Er klagt über seine neue Situation mit einem aus Cicero (Ad fam. 7. 3, 4) stammenden Sprichwort: „ubi non sis, qui esse soleas, non esse, cur esse velis." ${ }^{129}$ Er beschreibt den neuen Papst als „Iupiter tonans” und „fulminans”, dem er bald entfliehen wird: „Aliquando vindicabo me in libertatem, ut ne Iovem quidem tonantem aut fulminantem pertimescam.” ${ }^{130}$ Den Papst als „Iupiter tonans ac fulminans“ zu bezeichnen wäre an und für sich noch nicht als Kritik zu verstehen, der Kontext macht es aber eindeutig, dass Poggio seinen Status als scriptor beim neuen Papst nicht befriedigend empfand. Wenn man glauben kann, was Poggio über Zabarella sagt, dass der Kardinal nämlich nach der Meinung von allen Konzilsteilnehmern als Kandidat für das Papsttum in Frage kam, so darf man Poggios Erwartungen sogar als begründet betrachten: Zabarella war sein Patron; so hätte der Humanist wahrscheinlich gute Chancen gehabt, in seiner Position zu bleiben, wenn der Kardinal tatsächlich zum Papst gewählt worden wäre. Nach Zabarellas Tod war diese Position nicht mehr so sicher, es stand aber weiterhin in Poggios Interesse, die Wahl des neuen Papstes zu beschleunigen. Als er seine Rede im Rahmen von Zabarellas

\footnotetext{
126 Verg. ecl. 8,27-28.

127 Leonardo Bruni, Epistolarum libri VIII, 2 Bde., hrsg. v. Lorenzo Mehus (Florenz: Paperinus, 1741), ND hrsg. v. James Hankins (Rom: Edizioni Storia e Letteratura, 2007), [im Weiteren: „Epistolae”], Brief IV. 4, hier Bd. 1, S. 110. Die Stelle wird auch in Walsers Poggio-Biographie zitiert: Walser, Poggius, S. 43.

128 Hofman, Forschungen, S. 110.

129 Bracciolinis Brief an Barbaro wurde von Albert C. Clark veröffentlicht, in den früheren Briefsammlungen von Poggio und in Harths Ausgabe ist der Brief nicht enthalten. Vgl. Albert C. Clark, „The Literary Discoveries of Poggio”, Classical Review 13 (1899): 119-130, [im Weiteren: „Discoveries”], hier S. 125.

130 Clark, Discoveries, S. 125. Clark ist der Meinung, dass Poggios Brief teilweise deswegen unvollständig überliefert worden ist, weil er Martin V. mit solchen unvorsichtigen Ausdrücken bezeichnet hatte. Clark, Discoveries, S. 124.
} 
Trauerfeierlichkeiten hielt (am 27. September), war die Vereinbarung zwischen Sigismund und dem Kardinalskollegium (am 19. September) noch ganz frisch, und die Aussichten auf eine baldige Papstwahl waren - wegen der Unstimmigkeiten betreffend des Wahlverfahrens immer noch nicht ganz ungetrübt.

\subsection{Die Rede}

\subsubsection{Die Strategie des orators: die Dramatisierung von Zabarellas Gestalt}

\subsubsection{Das Öffentliche}

\subsection{Vom Bescheidenheitstopos zur Selbstdarstellung als Meister des genus grande}

Die Grabrede Poggios ist „ein typisches Produkt humanistischer Traueroratorik”, bemerkt McManamon ${ }^{131}$, und er begründet diese Behauptung damit, dass Zabarellas eulogium in klassizisierendem Latein geschrieben wurde, dass es aus den in klassischen Handbüchern für Panegyrik vorgeschriebenen drei Teilen besteht (exordium, Lob, peroratio), und dass Poggio die drei Stilarten nach dem emotionalen Rhythmus der Redeteile variiert. ${ }^{132}$

Poggio fängt seine Oratio mit einem Hinweis auf die persönliche Art an, wie er über Zabarella reden wird: Obwohl es ihm wegen der großen Trauer und des Schmerzes schwer fällt ,„(Etsi plurimo luctu doloreque impedior“) ${ }^{133}$, muss er an seine Aufgabe denken (,non doloris tantum mei, quantum officii rationem me habere oportet" ${ }^{134}$. Gleich am Anfang, mit der Gegenüberstellung des persönlichen Schmerzes und der zu leistenden Aufgabe (dolor meus - officium), die Poggio als Redner hat, wird das Öffentliche mit dem Privaten konfrontiert. Der Redner sieht seine Aufgabe darin, sich an der Grenze dieser zwei Sphären zu bewegen (,Itaque in publicum munus, quod extremum a nobis mortuo praestatur, aestimavi mihi etiam privatum_aliquid honoris esse adiicendum“"). ${ }^{135}$ Wie diese zwei Sphären gegeneinander ausgespielt werden und sich miteinander vermischen, wie konstruiert also das „Persönliche” in der Rede ist, wird in meiner Analyse später anschaulich gemacht.

Im zweiten Teil des exordiums folgt der Demutstopos: der Redner wolle mit seiner Rede ein sehr bescheidenes Ziel verfolgen. Mit seiner Erzählung von den Dingen, die ihm zum Thema einfallen, denke er einerseits seinen eigenen Wunsch zu erfüllen, und andererseits den anderen Material zu liefern für den Fall, dass jemand etwas Größeres, Erhabeneres über

\footnotetext{
131 Seine kurze Analyse der Rede: McManamon, Funeral, S. 12-14, der oben zitierte Satz: S. 12.

132 McManamon identifiziert und beschreibt die drei Teile der Rede und er fasst deren Inhalt zusammen. In meiner Arbeit wird die Richtigkeit von McManamons formaler Beschreibung des Textes nicht bestritten, meine Fragestellung erfordert aber eine tiefer gehende Analyse der Rede. 
das Thema vortragen wird: („Illud enim arbitratus sum, cum haec quae in mentem veniunt paucis recensuissem, et satisfacturum me desiderio meo, et simul quasi materiam quandam praebiturum reliquis maiora atque ampliora quaedam dicendi.“ $)^{136}$ Poggio stellt mit diesem Satz seine Rede als Ausgangspunkt dar, die nur als Rohstoff für die anderen, für deren eigene Reden dienen könnte, eine Fundgrube also, die den anderen in der Phase der inventio hilfreich sein könne. Poggio rechnet mit der Möglichkeit, dass später jemand etwas Größeres über Zabarella vortragen wird. Mit „maiora atque ampliora dicendi” ist aber nicht nur etwas Größeres im allgemeinen Sinne des Wortes gemeint: es ist eine Anspielung auf den erhabenen, den großen Stil, der einer der unter anderem von Cicero beschriebenen drei Stile ist. In der antiken Stillehre sind die drei Stile gleich wertvoll. Die grundlegende Regel ist, dass der Redner die Tugend des aptum vor Augen zu halten hat, die die Aufgabe des Redners dahingehend definiert, immer den passenden Stil zu benutzen. ${ }^{137}$ Der Stil soll Thema, Redner und Publikum angepasst werden. Aus dieser Überlegung könnte man darauf folgern, dass der große Stil literarisch nicht wertvoller sei als der stilus mediocris oder der stilus humilis, weil das einzige, das von Wichtigkeit sei, die Angemessenheit der Verwendung des jeweiligen Stils sei. Cicero bemerkt im Orator, dass der Redner alle drei Stile benutzen soll ${ }^{138}$, Quintilian schreibt dasselbe, mit dem Unterschied, dass er betont, dass sogar in den verschiedenen Teilen derselben Rede verschiedene Stile zu benutzen sind. ${ }^{139}$ Trotz dieser, aus der Logik des aptum folgenden, scheinbaren Gleichsetzung der Stile, ist in der rhetorischen Literatur auch deren Hierarchisierung zu erkennen. Cicero nennt den Redner des großen Stils princeps, allerdings mit der Einschränkung, dass sein Können nichts taugen wird, wenn er nur im großen Stil bewandert ist. ${ }^{140}$ Quintilian sagt, wenn man einen der Stile ${ }^{141}$ wählen müsste, würde man natürlich den großen Stil wählen, der zu den größten Gegenständen passe.

Wenn die für die Stilarten benutzten Benennungen jedoch für die Beschreibung des Talentes des Redners verwendet werden, so haben die gleichen Wörter eine andere Bedeutung, sie sind nämlich in diesem Kontext eindeutig in hierarchischem Sinne zu

\section{ebda}

137 Die Tugend des aptum wird von Quintilian beschrieben: Quint. Inst. 11.1. 1-93. Für die drei genera dicendi: Quint. Inst. 12. 10.58.

138 „Is erit igitur eloquens, ut idem illud iteremus, qui poterit parva summisse, modica temperate, magna graviter dicere.” Cic. Orat. 29.

139 „Plures igitur etiam eloquentiae facies, sed stultissimum quaerere, ad quam se recturus sit orator, cum omnis species, quae modo recta est, habeat usum, atque id ipsum non sit oratoris, quod vulgo genus dicendi vocant. Utetur enim ut res exiget, omnibus, nec pro causa modo, sed pro partibus causae.” Quint. Inst. 12. 10. 69.

140 „At vero hic noster, quem principem ponimus, gravis, acer, ardens, si ad hoc unum est natus aut in hoc solo se exercuit aut huic generi studuit uni nec suam copiam cum illis duobus generibus temperavit, maxime est contemnendus." Cic. Orat. 28.

141 „Quare si ex tribus his generibus necessario sit eligendum unum, quis dubitet hoc praeferre omnibus, et validissimum alioqui et magnis quibusque causis accommodatissimum?” Quint. Inst. 12. 10. 63. 
verstehen. Dieser andere, hierarchische Sinn der Bezeichnung mediocris ist auch bei Cicero präsent, der in seinem De optimo genere dicendi, in seiner Darstellung des perfekten Redners bemerkt, dass er die Redner nicht wie die Stilarten oder wie die Schriftsteller für kategorisierbar hält. Die Redner unterscheiden sich nicht, wie die Schriftsteller Terenz und Accius, nach Stilarten voneinander, sondern nur durch Qualität. ${ }^{142}$ Cicero benutzt das Wort mediocris für den Redner, und zwar selbstverständlich als eine Bezeichnung der Qualität, im Sinne von Mittelmäßigkeit. ${ }^{143}$

Die Tatsache, dass Poggio die gesteigerten Formen der beiden Adjektive benutzt, lässt darauf schließen, dass diese neben dem Hinweis auf den großen Stil gleichzeitig auch in hierarchischem Sinne benutzt werden. Diese Behauptung scheint noch begründeter zu sein, wenn man den nächsten Satz liest: „Non enim usitato genere orationis, non mediocri eloquentia virtus sua contenta est, sed postulat excellens ingenium, atque exquisitum et eximium dicendi genus." Zabarellas virtus sei nicht mit der üblichen Art und mit der mittelmäßigen Redekunst Genüge getan, sondern es verlange ein herausragendes Talent und den feinen und hohen Stil. Das Wort mediocris wird in diesem Zusammenhang nicht als ein wertneutraler Ausdruck für einen der drei Stile verwendet, es bedeutet etwas weniger Wertvolles, es bedeutet das Übliche, das Mittelmäßige.

Poggio spielt mit der Doppeldeutigkeit der in der antiken Stillehre benutzten Benennungen der Stile, er lässt beide Deutungsmöglichkeiten von grandis und mediocris in seinem Text wirken, indem er nicht immer klar erkennen lässt, ob er über das Talent des Redners oder über den anzuwendenden Stil redet. Die Syntagmen, in denen er die Wörter maiora, ampliora verwendet (,maiora atque ampliora quaedam dicendi”), können auf beide Weisen verstanden werden. Stilebene und das Talent des Redners sind durch die oben beschriebene Doppeldeutigkeit in engste Verbindung gebracht. Der große Stil wäre der adäquate, der zur Situation passen würde: den kann aber nur ein Redner von herausragendem Talent verwenden. Petrarcas Urteil über seine Zeitgenossen, nach dem die meisten nicht mehr in der Lage seien, den großen Stil anzuwenden, ist aus dem oft zitierten Satz bekannt: „Horum primus nostra etate pene nullorum est; proximus paucorum; ultimus multorum ". ${ }^{144}$ Poggio schreibt nicht explizit, dass er dieses Talent nicht habe, aber in seiner Geste der Verwendung des Demutstopos (er liefere mit seiner Rede Rohstoff für die anderen) ist eine ähnliche

\footnotetext{
142 „Oratorem genere non divido; perfectum enim quaero. Unum est autem genus perfecti, a quo qui absunt, non genere differunt, ut Terentius ab Accio, sed in eodem genere non sunt pares.'. Cic. Opt. Gen. 1.3.

143 „Ea igitur omnia in quo summa erunt, erit perfectissimus orator; in quo media, mediocris; in quo minima, deterrimus. Et appellabuntur omnes oratores, ut pictores appellantur etiam mali, nec generibus inter sese, sed facultatibus different." Cic. Opt. Gen. 2.6. 
Behauptung impliziert. Die ganze Rede ist selbstverständlich so konzipiert, dass sie gegen diese implizierte Selbsterniedrigung arbeitet. Am Ende der Rede müssen die Zuhörer der Meinung sein, dass der perfekte Orator von herausragendem Talent (excellens ingenium), der fähig ist, das genus grande zu verwenden, niemand anders als Poggio Bracciolini sei.

Ein weiteres Thema, das im exordium angesprochen wird, ist die memoria. Das Thema der memoria ist ein wesentlicher Bestandteil von Poggios Strategie, seine Selbstdarstellung in seiner Oratio von dem im Demutstopos dargestellten Bild von sich selbst als einen Redner, der mit seiner Rede eigentlich nur Rohstoff für die anderen liefern möchte, bis zur Selbstdarstellung als der ideale Redner hin zu bewegen.

Poggio habe, nach seiner Selbstdarstellung im exordium, einen ganz kleinen Anteil an der Arbeit an der memoria Zabarellas: er erzähle, was ihm zum Thema einfalle (,haec quae in mentem veniunt recensuissem”). Der Satz ist ein Hinweis auf die memoria naturalis, auf das natürliche Gedächtnisvermögen. Als ob Poggios Erzählung nicht ein künstlerisch gestaltetes Endprodukt all der fünf Bearbeitungsphasen der Redekunst (inventio, dispositio, elocutio, memoria, pronuntiatio), sondern etwas Halbfertiges wäre, das nicht einmal die erste Bearbeitungsphase, d. h. die inventio hinter sich habe: jeder der antiken Rhetorik kundige Zuhörer wusste ganz genau, dass selbst die inventio nicht mit dem natürlichen Gedächtnis gleichzusetzen ist, da sie auch ein von der Zielsetzung der Rede, von dem zu Beweisenden gesteuerter Vorgang ist. „Inventio est excogitatio rerum verarum aut veri similium, quae causam probabilem reddunt", steht in der Rhetorica ad Herennium. ${ }^{145}$ Wenn Poggio seine Rede mit den Sachen identifiziert, die ihm spontan eingefallen sind, dann setzt er seine Rede außerhalb des Bereiches der ars rhetorica, und simuliert eine von Kunst unberührte Natürlichkeit. Der Topos der Dissimulation der Redekunst ist selbstverständlich allen in der Redekunst nur halbwegs Bewanderten wohl bekannt, und wird in vielen Reden benutzt. Eine genauere Untersuchung dessen, wie genau dieser Topos von Poggio angewendet wird, ist trotzdem erforderlich, weil gerade diese Dissimulation und deren Verkehrung eine wichtige Rolle in seinen Selbstdarstellungsstrategien spielen wird. ${ }^{146}$

\footnotetext{
145 Rhet. Her. 1.2.3.

146 Auf die späteren Rekurse auf das Thema memoria in der Rede werde ich in der Analyse später zurückkommen.
} 


\subsection{Der Höhepunkt: Zabarellas Vergegenwärtigung}

\subsection{Die Heraufbeschwörung des toten Kardinals}

Der Hauptteil der Rede enthält die Beschreibung von Zabarellas Leben und Tugenden. Dass Zabarellas Leben und Taten in aller Ausführlichkeit erzählt werden, ist die große Erneuerung des humanistischen eulogischen Schrifttums, wie es auch McManamon betont. Keine der Tugenden (die intellektuellen Tugenden wie seine sapientia und prudentia und die aktiven Tugenden wie seine iustitia, liberalitas, beneficentia, modestia, temperantia, continentia, fortitudo, constantia) wird abstrakt, ohne Bezugnahme auf das Leben des Verstorbenen dargestellt, sondern sie werden immer mit Beispielen beleuchtet. Der an biographischen Details reiche zweite Teil des Lobes bildet mit dem ersten Teil, d. h. mit der Beschreibung des Lebens des toten Kardinals, eine Einheit, trotz Poggios Hinweis darauf, dass er jetzt zu einem neuen Kapitel in seiner Erzählung kommt ${ }^{147}$. Das überall gegenwärtige Biographische, das von McManamon für eines der wesentlichen Merkmale der humanistischen Grabreden bezeichnet wurde, das den bedeutendsten Unterschied zur traditionellen Leichenpredigt darstelle, ist auch in Poggios Grabrede intensiv präsent.

Die Zusammenfassung von diesem Teil der Rede ergäbe praktisch eine Biographie Zabarellas, deswegen werde ich mich darauf beschränken, auf die Vielfalt von rhetorischen Figuren hinzuweisen, mit denen Poggio seine Beschreibung schmückt. ${ }^{148}$

Auf diesen Teil folgt der absolute Höhepunkt der Rede, wobei die im exordium angesprochenen Themen wieder aufgenommen werden. Hier werden die im exordium angedeuteten Doppeldeutigkeiten und Unsicherheiten, was den Wert von Poggios rednerischen Leistungen betrifft, aufgelöst: Poggio benutzt hier den großen Stil. Er greift zu den dramatischsten Mitteln der Rhetorik. Es ist derjenige Teil der Rede, in dem dem Publikum Zabarellas letzter öffentlicher Auftritt, seine letzten Tage und sein Tod vor Augen geführt werden. Die Schilderung der Umstände des Todes der zu lobenden Person folgt nicht einfach der Logik der Chronologie des darzustellenden Lebens. Nach den Handbüchern der Rhetorik ist es auch eines der Mittel, mit denen der Redner den Gegenstand seines Lobes preisen kann. Priscianus erwähnt die Beschreibung der Umstände des Todes unter den argumenta a persona:

\footnotetext{
147 Nunc ad reliquam partem, quae mihi de virtutibus suis proposita erat, veniendum est. Poggio, Oratio, S. 256.

148 Vgl. Anhang 1 dieser Arbeit. McManamon gibt einen kurzen Überblick des Inhaltes der Rede, eine rhetorische Analyse ist von ihm nicht vollzogen worden. Auch hier muss auf Vollständigkeit verzichtet werden. Die Liste des Anhangs soll nur auf die von Poggio am häufigsten benutzten Figuren hinweisen.
} 
Ad haec a qualitate mortis, ut pro patria pugnans, vel si quid mirabile in ipsa morte evenit, vel etiam ab eo, qui interfecit, ut Achilles ab Apolline interfectus est; exquires etiam, quae secuta post mortem, si certamina in honorem eius sunt celebrata, quomodo Patroclo ab Achille et Anchisae ab Aenea; si oraculum aliquod datum est de ossibus eius, quomodo de Oreste et Palinuro; si laudabiles filios habuit, quomodo Achilles Pyrrhum; maximam vero occasionem in huiuscemodi orationibus suppeditant comparationes. ${ }^{149}$

Welchem der von Priscianus aufgelisteten Umstände entspricht Zabarellas Tod? Poggios Beschreibung lässt keinen Zweifel. Es handelt sich um die an erster Stelle erwähnte Möglichkeit der zum Lob „verwendbaren” Todesarten: um den Fall, wenn der Tod den Gelobten trifft, als er für seine Heimat kämpft, „ut pro patria pugnans”. Im Fall des Kardinals muss natürlich diese für einen Kleriker etwas zu martialische Todesart im übertragenen Sinne verstanden werden. Zabarellas Engagement für die Einheit der Kirche und insbesondere seine letzte Rede, die er dieser Angelegenheit gewidmet hatte, werden als Taten gedeutet, mit denen er den gleichen Lob und Ruhm verdient hat, wie diejenigen, die für das Vaterland gestorben sind: „eorum gloriam et laudem adeptus, qui quondam pro salute patriae mortem obiere”. ${ }^{150}$ Am Ende der Rede bemerkt Poggio, dass Zabarella eigentlich ein Denkmal verdient hätte, auf dem eine goldene Statue stehen sollte, mit der Inschrift auf dem Postament: parenti patriae. Der Titel parens patriae war im antiken Rom eine Auszeichnung, die, laut römischer Geschichtsschreiber wie Livius, oft in Verbindung mit dem Titel des dictator gegeben wurde. $^{151}$ Den Titel pater patriae $\mathrm{zu}$ haben, hieß gleichzeitig, der neue Romulus, der Neubegründer des Staates zu sein. ${ }^{152}$ Als Neugründung wurden Ereignisse bezeichnet, mit denen der Staat vor einer großen Gefahr gerettet wurde. Diese Gefahr war oft eine Kriegsgefahr: der Titel wurde im Altertum also oft Männern gegeben, die ihre Heimat - oft im ganz konkreten Sinne des Wortes, im Krieg - verteidigt haben. ${ }^{153} \mathrm{Zu}$ dem großen Beispiel des zumindest im konkreten Sinne des Wortes weniger bellikosen pater patriae (Cicero) werde ich später kommen.

\section{Prisc. Praeex. 7.}

150 Poggio, Oratio, S. 259.

151 Dieser Zusammenhang zwischen dem Titel des dictator und dem Titel pater/parens patriae wird am Beispiel von Camillus anschaulich: ,dictator recuperata ex hostibus patria triumphans in urbem redit inter iocos militaris, quos inconditos iaciunt, Romulus ac parens patriae conditorque alter urbis haud vanis laudibus appellabatur" Liv. 5.49.7.

152 Über diesen Aspekt des Titels pater patriae vgl. Andreas Alföldi, Der Vater des Vaterlandes im römischen Denken, Libelli 261 (Darmstadt: Wissenschaftliche Buchgesellschaft, 1972), [im Weiteren: „Vater”].

153 „Wenn wir auf die unten gegebene Liste der römischen Größen einen Blick werfen, die vor Augustus das Prädikat des Landesvaters erhielten, dann muß es auffallen, daß sie nicht etwa wegen ihres warmen Herzens und väterlichen Wesens, nicht für ihr Wohlwollen und ihre Fürsorge für friedliche Bürger so gefeiert worden sind, sondern für eine befreiende Tat im Krieg oder wegen der Unterdrückung einer Revolution, was ebenso wenig aus der Eigenart des Hausvater-Begriffs fließt, aus welchem man den Titel pater patriae direkt ableiten wollte, wie es auch unserem Vater-Begriff zuwider läuft.” Alföldi, Vater, S. 46 f. 
Die Darstellung der letzten Rede Zabarellas beginnt mit dem Wort „mementote“. Mit der Imperativform wird an die elementarste Aufgabe des Redners und des Publikums einer Grabrede hingewiesen: in Erinnerung zu rufen und sich zu erinnern. Im Laufe der Rede hat Poggio nur zweimal Ausdrücke benutzt, die zum gleichen semantischen Feld (der memoria) gehören: im exordium: „quae in mentem veniunt" ${ }^{, 154}$ und in den Sätzen, mit denen er den zweiten, Zabarellas Tugenden beschreibenden Teil seines Lobes einführt: „virtutum suarum commemoratione ${ }^{\prime 155}$. Bis zur Klimax scheint er eher sparsam mit den an die memoria des Verstorbenen hinweisenden Wörtern umzugehen. Umso größer ist der Kontrast zwischen dem übrigen Verlauf der oratio und deren Höhepunkt, in dem das Publikum in zwei nacheinander folgenden Sätzen dreimal aufgefordert wird, sich die Umstände seines Todes in Erinnerung zu rufen:

Mementote illius turbulentissimi diei, Paters Conscripti, et eum ponite ante oculos vestros illius temporis, ut vere dicam, tumultum, cum frequentes omnium aetatum, ordinum, nationum homines in illam concionem convenissent. Revocate animis vestris gravitatem rei (de suprema enim salute agebatur), ${ }^{156}$ dissensiones et varias multorum sententias ac non nullorum trepidationem. ${ }^{157}$

Poggio dramatisiert seine Beschreibung (die so keine eigentliche Beschreibung bleibt), indem er mit der Figur der exclamatio besonders großzügig umgeht. Exclamatio gehört zum Instrumentarium des großen Stils, zusammen mit den anderen affektischen Figuren, die besonders geeignet sind, das Publikum zu bewegen. Quintilian schreibt in folgender Weise über diese Art von Figuren:

Quae vero sunt augendis adfectibus accomodatae figurae, constant maxime simulatione. Namque et irasci nos et gaudere et timere et admirari et dolere et indignari et optare quaeque sunt similia his fingimus. Unde sunt illa: „liberatus sum, respiravi” et „bene habet”, et „quae amentia est hec?” et „o tempora, o mores!” et „miserum me! Consumptis enim lacrimis infixus tamen pectori haeret dolor”, et „magnae nunc hiscite terrae”. Quod exclamationem quidam vocant ponuntque inter figuras orationis. Haec quotiens vera sunt, non sunt in ea forma, de qua nunc loquimur: at simulata et arte composita procul dubio schemata sunt existimanda. ${ }^{158}$

Der Redner muss die Affekte simulieren, um das Publikum zu bewegen. Dies (das movere, also das Bewegen) steht in den Rhetorikbüchern als das officium des großen Stils: ,, secundum

Poggio, Oratio, S. 256.

Die Behauptung, dass Zabarella die Kirche (als res publica bezeichnet) vor der extremsten Gefahr gerettet hat, ist ein weiterer Baustein des Monuments Zabarellas, des „parens patriae”.

157 Poggio, Oratio, S. 259.

158 Quint. Inst. 9.2.26 f. 
[sc. genus grande atque robustum] movendi [...] praestare videatur officium". ${ }^{159}$ Dieses officium ist das wichtigste der jeweiligen officia der Stile: ,probare necessitatis est, delectare suavitatis, flectere victoriae". ${ }^{160}$ Auf Zabarellas letzte Rede wird erst mit der Figur der exclamatio, und zwar mit vier Staccato-Sätzen hingewiesen: „Quis enim vultus! Quanta significatio animi et constantiae! Qualis illa oratio! Quam plena dignitatis et prudentiae!" 161 Poggio will in diesem Teil seiner Rede ganz konkrete Bilder in das Gedächtnis seiner Zuhörerschaft prägen: „ponite ante oculos illius temporis, ut vere dicam tumultum”162; „quis enim fuit vultus!"163; „videbamus pallorem vultus, oris macilentiam, ac totius debilitatem corporis"164. Das anschauliche Vorführen von Einzelheiten wird von Quintilian in folgender Weise beschrieben:

Insequitur 'Evóp $\gamma_{\varepsilon \imath} \alpha$, quae a Cicerone inlustratio et evidentia nominatur, quae non tam dicere videtur quam ostendere, et adfectus non aliter, quam si rebus ipsis intersimus, sequentur. [...] ubi vero miseratione opus erit, nobis ea, de quibus queremur, accidisse credamus atque id animo nostro persuadeamus. Nos illi simus, quos gravia, indigna, tristia passos queremur, nec agamus rem quasi alienam, sed adsumamus parumper illum dolorem. ${ }^{165}$

Die Veranschaulichung soll einen so hohen Grad erreichen, dass der Redner mit seinem darzustellenden Gegenstand praktisch identisch wird. Er muss die gleichen Affekte simulieren, die dieser in der Situation, in der er dargestellt wird, gefühlt haben konnte. Das alles ist nötig, um das Mitgefühl der Zuhörerschaft zu erwecken.

Auf dem absoluten Höhepunkt der Rede wird Zabarella selbst angesprochen:

$\mathrm{O}$ virum ingentem, et fama dignum immortali, quae nam tanta esse posset copia dicendi, ut te digne oraret pro meritis operum tuorum? Tu perfugium calamitosorum, subsidium inpotum, bonorum sustentaculum fuisti. Tu splendor Italiae, decus nationum, ornamentum concilii, lumen seculi extitisti. Tu sanctissimum omnium virtutum exemplar ostendisti. ${ }^{166}$

Quint. Inst. 12. 10. 59.

Cic. Orat. 21

Poggio, Oratio, S. 259.

ebda

ebda

Poggio, Oratio, S. 260.

Quint. Inst. 6.2. 32-34.

Poggio, Oratio, S. 259. Die Anrede des Toten erinnert den Leser gleich an den Agricola des Tacitus, dessen vorletztes Kaput eine ähnliche Anrede des toten Agricola enthält: „tu vero felix, Agricola”. Um es zu vermeiden, sich von verlockenden Spekulationen verleiten zu lassen, muss man gleich bemerken, dass Poggio den Text des Agricola um diese Zeit noch nicht kannte. Er schreibt am 3. November 1425 über den Agricola als über ein bislang noch unbekanntes Werk (,aliqua opera Cornelii Taciti nobis ignota”) von Tacitus. Vgl. Remigio Sabbadini, Storia e critica di testi latini (Padua: Antenore, 1971), [im Weiteren: „Storia”], hier S. 263. 
Die Apostrophe, die Abwendung des Redners von seiner ursprünglichen Zuhörerschaft, ist auch in dem Fall, wenn ein Lebender angesprochen wird, ein Mittel, das zur Dramatisierung der Rede beiträgt. Umso erschütternder muss dieses Mittel wirken, wenn die Anrede an einen Toten gerichtet ist. Die Toten zu evozieren gehört zum Instrumentarium des großen Stils: „hic orator et defunctos excitabit ut Appium Claudium Caecum”, sagt Quintilian. ${ }^{167}$

\subsection{Poggios Verwandlung}

Zabarella wird im letzten Abschnitt der Rede mit mehreren Stilmitteln vergegenwärtigt. Er wird mit der anaphorisch verwendeten Tu-Form persönlich evoziert. Die oben in Quintilians Beschreibung dargestellte inlustratio oder evidentia dient dem gleichen Zweck: die Anwesenheit des nicht Anwesenden zu simulieren. Wie aus Quintilians Schilderung hervorgeht, muss der Redner mit dem Gegenstand seiner Rede eins werden. An einem bestimmten Punkt, so Quintilian, müsse die Beschreibung in eine performative Simulation umschlagen. Im Fall Zabarellas fiel Poggio diese Simulation wahrscheinlich nicht schwer: es handelte sich nämlich um die Darstellung Zabarellas als Redner. Der Höhepunkt von Poggios Rede ist nämlich die Darstellung von Zabarellas letzter Rede, die von Poggio als der Höhepunkt Zabarellas rhetorischer Leistungen und seiner Bemühungen am Konzil, die Einheit der Kirche wieder herzustellen, gedeutet wird: „Cygnea vox illa fuit, et futurae mortis praesagium. Nam dixit luculentius quam antea unquam" - steht in der oratio über Zabarellas letzte Rede. Diese Übereinstimmung (die Darstellung einer Rede als Höhepunkt der eigenen Rede) macht eine Identifikation der zwei Redner besonders leicht. Poggio wird auf diesem Höhepunkt gleichsam zu Zabarella. Er beschreibt nicht Zabarellas Rede, er ahmt sie performativ nach. In der Klimax wird seine Beschreibung zur Prosopopoeia: er macht Zabarella zum Sprechenden. Wenn er redet, so spricht eigentlich Zabarella zum Publikum. Auch die pronuntiatio, das Vortragen der beiden Reden (Zabarellas und Poggios) ist an diesem Punkt wahrscheinlich identisch: Zabarella erhebt seine Stimme am Ende seiner Rede: „et postremis verbis clamans"168, sagt Poggio auf dem Höhepunkt seiner Rede. Und er muss es laut gesagt haben, wenn er sich an die Vorschriften der Rhetorik hielt. Quintilian und Cicero schreiben ausführlich darüber, wie der Redner mit seiner Stimme umzugehen hat: man müsse sie immer

167 Quint. Inst. 12. 10. 61.: Quintilians Feststellung ist eigentlich ein doppelter Hinweis an Cicero. Erstens: Cicero selbst schreibt über den Redner des einfachen Stils, wie folgt: „Non faciet rem publicam loquentem, nec ab inferis mortuos excitabit" (Cic. Orat. 25). Zweitens bezieht sich Quintilians Feststellung auf Ciceros Rede pro Caelio, wo er Appius Claudius Caecus sprechen lässt. 
an den Gegenstand anpassen und Monotonie vermeiden. ${ }^{169}$ Die Evokation des Toten ist perfekt vollzogen: das Publikum, während es Poggio zuhört, hört Zabarella sprechen. Dieser Höhepunkt wird in der Rede vorbereitet. Im ersten Teil des Lobes, das hauptsächlich den mittleren Stil verwendet, wo Poggio Zabarellas rednerische Fähigkeiten beschreibt, tut er es mittels einer Metapher: „ex eius ore melle dulcior (sicut de Nestore inquit Homerus) fluere videretur oratio". ${ }^{170}$ Quintilian benutzt die Metapher der Rede, die süßer als der Honig fließt, wenn er über den mittleren Stil sagt: „nam et Homerus [...] ex ore Nestoris dixit „dulciorem melle profluere sermonem" ${ }^{\prime 17}$. Im Text Quintilians wird nicht klar, ob er für den mittleren Stil Homer oder Nestor als Beispiel zitiert. Der Satz ist doppeldeutig: Homer beschreibt Nestor mit der Wendung „dulcior melle profluere sermonem” als einen Redner, der den mittleren Stil verwendet. In diesem Kapitel zeigt Quintilian, dass Homer in seinem Text alle drei genera dicendi verwendet hatte. Nach der Logik der Quintilian-Stelle muss das Homer-Zitat ein Beispiel für den mittleren Stil sein. Dementsprechend ist der Ausdruck ,dulcior melle profluere sermonem" gleichzeitig die Beschreibung eines Stils und die Nachahmung desselben Stils. Es ist ein Satz im mittleren Stil über den mittleren Stil. Wenn Poggio denselben Satz für Zabarellas Stil verwendet, so beschreibt er Zabarella als Redner des mittleren Stils mit einem Satz im mittleren Stil.

Diese Identifizierung der Rhetorik des Redners Poggio mit der von ihm beschriebenen Rhetorik Zabarellas wird auf dem Höhepunkt der Rede noch offensichtlicher.

Das Ineinanderfließen der Figuren Poggios und Zabarellas lässt auch deren Tränen ineinander fließen. Tränen, echte und erzählte, sind auch ein bekanntes Mittel der Redekunst. Sie werden auch oft beschrieben als Zeichen dafür, dass der Redner das Publikum bewegen konnte. Sie gehören zum großen Stil: ein Redner, der den verwendet, muss Tränen erzwingen von seinen Zuhörern: „hoc dicente iudex pallebit et flebit”, sagt Quintilian über den Redner des genus grande. ${ }^{172}$ Und er kann es am besten, indem er selber die gleichen Gefühle fühlt und vorzeigt, die er zu beschreiben hat. In der oben zitierten Beschreibung der inlustratio schreibt Quintilian über Tränen als Zeichen dafür, dass der Redner sich mit dem Gegenstand seiner Beschreibung so weit wie möglich identifiziert hat. Er schreibt dabei über seine eigenen Tränen.

\footnotetext{
169 Quint. Inst. 11.3. 14-65 und 11.3. 150-176. besonders aber 11.3. 166.: ,accendendi iudicis plures sunt gradus. Summus ille et quo nullus est in oratore acutior: „suscepto bello, Caesar, gesto etiam ex parte magna”, Praedixit enim: ,quantum potero voce contendam, ut populus hoc Romanus exaudiat.” 
Vidi ego saepe histriones atque comoedos, cum ex aliquo graviore actu personam deposuissent, flentes adhuc egredi. Quod si in alienis scriptis sola pronuntiatio ita falsis accendit affectibus, quid nos faciemus, qui illa cogitare debemus, ut moveri periclitantium vice possimus? Sed in schola quoque rebus ipsis adfici convenit easque veras sibi fingere, hoc magis quod illic ut litigatores loquimur frequentius quam ut advocati: orbum agimus et naufragum et periclitantem, quorum induere personas quid attinet, nisi adfectus adsumimus? Haec dissimulanda mihi non fuerunt, quibus ipse, quantusculumque sum aut fui, pervenisse me ad aliquod nomen ingenii credo: frequenter motus sum, ut me non lacrimae solum deprenderent, sed pallor et veri similis dolor. ${ }^{173}$

Die Intimität ist allerdings, dem gerade schilderten Thema gemäß, eine simulierte: Quintilian übernimmt nämlich eine Stelle von Ciceros De Oratore, wo Antonius eine ähnlich ,,persönliche", sogar intime Bemerkung macht:

De me autem causa nulla est, cur apud homines prudentissimos atque amicissimos mentiar: non, me hercule, umquam apud iudices dolorem aut misericordiam aut invidiam aut odium dicendo excitare volui, quin ipse in commovendis iudicibus eis ipsis sensibus, ad quos illos adducere vellem, permoverer. ${ }^{174}$

Aus der Fortsetzung geht auch bei Cicero hervor, dass Weinen zum Instrumentarium der Rhetorik gehört. Redner, wenn sie Mitleid erwecken wollen, müssen selbst die signa doloris vorzeigen: „Neque ad misericordiam adducetur, nisi tu ei signa doloris tui verbis, sententiis, voce, vultu, conlacrimatione denique ostenderis." ${ }^{~} 175$ Conlacrimatio wird auf dieser Liste nicht zufällig an der letzten Stelle erwähnt. Die signa doloris sind in ansteigernder Weise aufgeführt. Tränen stehen deswegen an letzter Stelle: sie sind die kräftigsten Mittel des Überzeugungsinstrumentariums.

In Poggios Rede liest man über Tränen erst in der Klimax. Im exordium, das mit der Erwähnung des Schmerzes (,„etsi plurimo luctu doloreque impedior“") ${ }^{176}$ beginnt, wird dieser Schmerz noch nicht mit den konkreten Bildern des Weinens anschaulich gemacht. An einer weiteren Stelle der Rede wird dolor noch einmal erwähnt, auch diesmal als ein mögliches Hindernis der Rede, das der Redner überwinden muss, um seine oratio halten zu können. Um allzu großen Schmerz zu vermeiden, muss er auf die Schilderung bestimmter Einzelheiten verzichten: „Illud praeterea vereor, ne quo plura enumerem illius bene facta, eo magis recrudescat dolor, qui et me impediat dicendo, et vos reddat in audiendo tardiores." ${ }^{\text {(177 }}$ Diese Erwähnung von Tränen ist insofern anders als die des exordiums, als hier auch das Publikum

\footnotetext{
173 Quint. Inst. 6.2.36.

174 Cic. de Orat. 2. 189.

175 Cic. de Orat. 2. 190.

176 Poggio, Oratio, S. 252.

177 Poggio, Oratio, S. 255.
} 
miteinbezogen wird. Eine allzu große Trauer, die der Redner verursacht, würde die Zuhörer daran hindern, die Rede richtig aufzunehmen. Wenn Poggio über diese Angst schreibt, er könne allzu große Gefühle im Publikum erzeugen, impliziert er gleichzeitig auch die Hoffnung aller Redner: seine Rede sei so überwältigend, dass sich die Zuhörer auf keinen Fall ihrer Wirkung entziehen können. Sie empfänden den gleichen Schmerz wie der Redner selbst. Das ist eigentlich das Ziel einer Rede, auch Poggios oratio hat vor allem vor, die Zuhörerschaft zu bewegen. Es muss aber am richtigen Punkt passieren: erst auf dem Höhepunkt der Rede, wo die Tränen zu fließen beginnen. Es sind aber nicht immer dieselben Tränen: „Atque ita expiravit ut nequeam recordatione illius temporis, quo reddebat animam continere lachrymas". ${ }^{178}$ Es sind Poggios Tränen, die ihm zu fließen beginnen, wenn er an den Tag denkt, an dem Zabarella gestorben ist, die zuerst erwähnt werden. Gleich im nächsten Satz aber sehen die Zuhörer Zabarellas Tränen fließen: „Oculis ipsis et aspectu nos hortari, et lachrymis quas plurimas fudit commonefacere videbatur, ut instar sui causam publicam susciperemus". ${ }^{179}$ Es dürfte kein Zufall sein, dass Poggios Tränen in unmittelbarer Nähe zu Zabarellas Augen stehen: Der Satz, der Poggios Tränen erwähnt, endet mit dem Wort „lachrymas“ und der nächste, Zabarellas Tränen enthaltende Satz fängt mit dem Wort „oculis“ an. Als absoluter Höhepunkt des Zusammenschmelzens der zwei Figuren fließen sogar deren Tränen zusammen.

\subsubsection{Poggios Entdeckungen als Folie für seine Rede und Instrument seiner Selbstdarstellung: der wiedererweckte Cicero}

Zabarellas Figur als Redner ist aber nicht die einzige Folie, auf die sich Poggios Selbstdarstellung in seiner Rede bezieht. Zu seiner Imagebildung nutzt er meines Erachtens auch seinen Ruhm als „Entdecker” antiker Handschriften. Während seines Aufenthaltes in Konstanz fand Poggio viele Texte antiker Autoren, von deren Existenz man teilweise nichts wusste, oder die man, wenigstens in Italien, bis zu ihrer Wiederentdeckung durch Poggio nur fragmentarisch kannte. Die zwei Autoren, deren Texte man in diesem Kontext erwähnen soll, sind Quintilian und Cicero.

Quintilian kannten die Humanisten bis zu Poggios Wiederentdeckung des Textes im Jahr 1416 in St. Gallen nur fragmentarisch. ${ }^{180}$ Nach Sabbadinis Meinung gab es, obwohl die

\footnotetext{
178 Poggio, Oratio, S. 260.

ebda

Für die Sekundärliteratur zur Frage vgl. die Anm. 183.
} 
meist verwendeten Fassungen viele Lakunen enthielten, ${ }^{181}$ eine vollständigere Fassung des Textes, die Andreolo Arese schon 1396 in seinem Besitz hatte. ${ }^{182}$ Diese Behauptung wird von Boskoff und Winterbottom widerlegt. ${ }^{183}$ Selbst wenn Sabbadini Recht haben sollte, würde die Existenz einer vollständigen, aber unter den Italienern unbekannten Fassung nichts daran ändern, dass Poggios „Entdeckung” ihn vor den Italienern, und vor sich selbst in der Rolle des Retters des antiken Rhetoriklehrers - um die personifizierende Art, wie Poggio über seine Begegnung mit Quintilian schreibt, aufzugreifen - prahlen ließ. Er selbst beschreibt seine Entdeckung, und die Florentiner scheinen dieses Selbstbildnis Poggios angenommen und sogar weiterentwickelt zu haben. Poggio an Guarini am 16. Dezember 1416:

Quid nunc agere docti homines debent, et praesertim studiosi eloquentiae, cum singulare et unicum lumen Romani nominis, quo extincto nihil praeter Ciceronem supererat, et eum modo simili lacerum ac dispersum, non tantum ab exilio, sed $a b$ ipso paene interitu revocaverimus? Nam mehercule nisi nos auxilium tulissemus, necesse erat illum propediem interiturum. ${ }^{184}$

Barbaro feiert in seinem Brief an Poggio den Adressaten nicht einfach als den Retter Quintilians, sondern sogar als denjenigen, der antike Autoren wiederauferstehen ließ:

Tu Tertulianum, tu M. Fabium Quintilianum, tu Q. Asconium Pedianum, tu Lucretium, Sylium Italicum, Marcellinum, tu Manilium astronomicum, Lucium Septimium, Valerium Flacchum, tu Caprum Eutichium Probum, grammaticos, tu compluros alios, Bartholomeo collega tuo adiutore, vel fato functos vita donastis vel longo, ut aiunt, postliminio in Latium reduxistis. [...] qui tot illustris ac sapientissimos viros mortuos in perpetuum resuscitastis.

181 Sabbadini listet diese Lakunen in seinem Kapitel über Quintilian auf: Inst. 1. 1, 1-6; 5. 14., 12.-8. 3. $64 . ;$ 8. 6. 17-8. 6. 67.; 9. 3. 2-10. 1. 107.; 11. 2. 33.; ab 12. 10. 43 bis zum Ende des Textes. Vgl. Sabbadini, Storia, S. 283.

182 Mehr dazu siehe: Sabbadini, Storia, S. 283 f.

183 Sabbadini argumentiert für seine Behauptung mit einem Brief von Nicolas de Clémanges, in dem der Autor Quintilian-Stellen zitiert, die in der mutili-Tradition nicht vorhanden waren. Boskoff widerlegt dieses Argument mit dem Hinweis, dass die von Nicolas zitierten Stellen in einer fragmentarischen Handschrift vorzufinden waren. Dementsprechend muss Nicolas keine integere Fassung des Quintilians gekannt haben. Priscilla F. Boskoff, „Quintilian in the Middle Age” Speculum 27 (1952): 71-78, hier S. 75 f. Winterbottom übernimmt Boskoffs Skeptizismus gegenüber Sabbadinis Behauptung. Er ist auch der Meinung Boskoffs, dass zwar auch eine Tradition von Quintilian existierte, die integre Texte hervorbrachte (die an den Bambergensis zurückgeht), diese Tradition war jedoch denen, die Quintilian am Anfang des 15. Jahrhunderts lesen wollten, unbekannt (escaped scholarly detection). Vgl. Michael Winterbottom, „Fifteenth-Century Manuscripts of Quintilian”, The Classical Quarterly n. s. 17. (1967): 339-369, hier S. 339.

184 Für die berühmte Beschreibung von Poggios Entdeckung von Quintilian: Poggio Bracciolini, Lettere, 3 Bde., Istituto nazionale di studi sul Rinascimento / Carteggi umanistici 1-3, hrsg. v. Helene Harth (Florenz: Leo S. Olschi Editore, 1984-1987), hier Bd. 2. S. 154 f.

185 Francesco Barbaros Brief an Poggio Bracciolini in: Francesco Barbaro, Epistolario, 2 Bde., Istituto nazionale di studi sul Rinascimento / Carteggi umanistici 5-6, hrsg. v. Claudio Griggio (Florenz: Leo S. Olschki Editore, 1999), [im Weiteren: „Epistolario”], Bd. 2, S. 71-79, hier S. 72 und 73. 
Der andere von Poggio aus dem Grab errettete Autor ist Cicero. Während seines Aufenthaltes in Konstanz fand Poggio acht bislang unbekannte Reden von Cicero: in Langres die Rede pro Caecina, in der Dombibliothek zu Köln die pro Roscio Comoedo, die drei Reden de lege agraria contra Rullum, pro Rabirio perduellionis reo, in Pisonem und pro Rabirio postumo. ${ }^{186}$ In Barbaros Liste sucht man vergeblich nach Ciceros Namen. Der Grund dafür ist, dass die Nachricht von Poggios Entdeckung der Cicero-Reden erst im September 1417 in Florenz angekommen war. Die erste Reaktion der Italiener darauf, die überliefert worden ist, ist ein Brief von Traversari an Barbaro, den er Anfang Oktober schrieb. ${ }^{187}$

Wie sich auch im Brief von Barbaro anschaulich zeigt, hatte Poggio unter seinen Kollegen in Italien den Ruf des Erretters antiker Autoren, unter anderen auch Quintilians und (ab September) Ciceros, der beiden Autoritäten antiker Rhetorik. Meines Erachtens gaben Zabarellas Trauerfeierlichkeiten Poggio die Möglichkeit, sich in der Rolle des Wiederweckers nicht nur allgemein antiker Literatur, sondern besonders antiker Rhetorik zu behaupten. Welches Ausmaß des Feierns wegen seiner Funde Poggio von der res publica litteraria ${ }^{188}$ erwartet haben konnte, was also die Reaktion auf solche Entdeckungen gewesen sein konnte, zeigt Barbaros oben zitierter Brief, den er in Form einer exhortatio schrieb. Im Brief wird Poggio für würdig gehalten, dass zu seiner Ehre eine Statue errichtet wird, oder dass die dank seiner Arbeit nach Italien zurückgekehrten Schriften als poggiana genannt werden. Barbaros Vorschlag des Aufstellens einer Statue zu Ehren Poggios kann als ein weiterer Beweis dafür gesehen werden, dass Poggio, wenn er über eine für Zabarella aufzustellende Statue und über Zabarellas Verehrung spricht, gleichzeitig für sich eine gleiche Reputation beansprucht. Es spielt keine Rolle, dass Barbaros Lob eine Sammlung rhetorischer Topoi ist. Wichtig ist die Tatsache, dass Poggios Entdeckungen im Auge derjenigen, denen die neue Kultur nicht völlig fremd und unbekannt war, als Anlass für solche Würdigungen galten, das heißt, dass ein Teil von Poggios Publikum diese Topoi mit Poggios Figur assoziiert haben dürfte.

Im Kontext von Poggios Selbststilisierung ist die Tatsache besonders erwähnenswert, dass unter Poggios Entdeckungen auch jene acht Reden von Cicero zu finden sind. Wenn Poggio bemerkt, dass Zabarella es verdient hätte, dass man ihm ein Denkmal mit einer Statue errichtet, deren Postament die Inschrift parenti patriae trägt, ist es eine eindeutige Anspielung auf den antiken pater patriae schlechthin, auf Cicero. ${ }^{189}$ Zabarella hat, ähnlich wie Cicero,

\footnotetext{
186 Vgl. Walser, Poggius, S. 58 f, Sabbadini, Storia S. 35-39.

187 Vgl. Sabbadini, Storia, S. 36.

188 Das erste überlieferte Zeugnis für den Ausdruck res publica litteraria ist in diesem Brief Barbaros zu finden: „Quos autem orno? Eos nempe, qui huic litterariae rei publicae plurima adiumenta atque ornamenta contulerunt." Barbaro, Epistolario, Bd. 2. S. 75.

Poggio, Oratio, S. 259
} 
diesen Titel mit seiner rednerischen Tätigkeit verdient. Wie damals Cicero die res publica vor dem Untergang (in Ciceros Selbststilisierung bekam die Verschwörung Catilinas diese Bedeutung) durch seine der Nachwelt als Reden bekannten Maßnahmen gegen die Verschwörung gerettet hatte, so versuchte auch Zabarella ebenfalls mit Hilfe der Beredsamkeit, die res publica christiana vor der Gefahr der Uneinigkeit zu retten. Wenn Poggio sich in seiner Rede in Zabarella verwandelt, so verwandelt er sich gleichzeitig in Cicero. Mit dieser Verwandlung ruft er seiner Zuhörerschaft seine Entdeckung von Ciceros Reden in Erinnerung. Die Rolle eines zweiten Ciceros passt gut zu jemandem, der seine Schriften vor der Vergessenheit bewahrt hat.

Er wies auf seine Entdeckungen natürlich nicht explizit hin, es wäre in einer Trauerrede eine eher wenig elegante Geste gewesen. Außerdem war es auch nicht nötig, viele im Publikum wussten bestimmt bereits von ihnen.

\subsubsection{Die Rede als Denkmal}

Wie aus dieser Analyse hervorgeht, bewegt sich Poggio in seiner Rede von einem scheinbar privaten Auftakt in die Richtung eines öffentlichen Tons. Am Anfang der Rede dominiert noch der Ton der fingierten Privatheit: der Redner muss, um seine öffentliche Aufgabe erfüllen zu können, seinen Schmerz überwinden. Am Ende der Rede wird die Gegenüberstellung des privaten, persönlichen Schmerzes und der öffentlichen Aufgabe aufgelöst: die Tränen, mit denen man als Zeichen des Trauerns einen hohen Grad der Intimität assoziiert, werden zum Mittel eines öffentlichen Aufrufs. Wenn auf dem Höhepunkt der Rede die Tränen Zabarellas und Poggios zusammenfließen, so ist es keinesfalls eine private Angelegenheit, und nicht nur, weil sie in einer öffentlichen Rede inszeniert ist. Zabarellas Tränen werden in engstem Zusammenhang mit Poggios Aufruf dargestellt, Zabarellas letzten Willen zu erfüllen und an der Wiederherstellung der Einheit der Kirche zu arbeiten. Die Eröffnung von Zabarellas Testament ist ein öffentlicher Akt.

Die gleiche Verschiebung von der privaten zur öffentlichen Aufgabe ist im Wechsel der Wortwahl für die Beschreibung der Errichtung von Zabarellas memoria zu beobachten. Im exordium der Rede suggerieren die Ausdrücke, mit denen Poggio über die Erinnerungsarbeit schreibt, Spontaneität, und so muss der Zuhörer auf den persönlichen, privaten Charakter von Poggios Darstellung assoziieren: Poggio sage in der Rede, was ihm gerade über Zabarella einfalle. Am Ende der Rede befindet sich ein eindeutiger Hinweis darauf, dass die Arbeit an Zabarellas memoria als vollendet angesehen werden kann. Aus der Fiktion der am Anfang als spontan beschriebenen Erinnerungen wird am Ende der Rede ein für Zabarellas 
memoria erstelltes Monument: Poggio überlegt, dass man für Zabarella eigentlich ein Denkmal bauen sollte:

Et quoniam pompa funeris haberi satis digna non potuit propter difficultatem temporum, diligentior habenda est ratio monumenti. Curandum est enim si grati volumus existimari, ut sepulchrum sibi ex publico aere aedificetur quam magnificum, in quo scribatur breviarium gestorum eius, prout solitum est fieri his, qui pro patria occubuissent. Superinponenda esset sepulchro aurea statua more priscorum, cuius in basi esset scriptum Parenti patriae. ${ }^{190}$

Da aber dieser Brauch nicht mehr gängig sei, müsse man wenigstens ein Grabmal mit einer Inschrift errichten, die zu Zabarellas Ehre und als Mahnmal für die Nachwelt stehen sollte, seinem Beispiel nachzuahmen:

Sed quia hic mos venit in desuetudinem, satis erit constitui sepulchrum, ornarique ad modum maiorum nostrorum, cum inscriptione honorifica quae sit ad honorem ipsius, et ad imitationem posterorum.

Eigentlich habe aber Zabarella selbst ein Monument für sich errichtet, es liegt an den Zuhörern, dass ihr eigener Ruhm mit Zabarellas Ehre zusammen erhalten wird. Sie müssen Zabarellas Beispiel folgen, und seine Erinnerung bewahren:

Nam quamvis ipse sibi vivus monumentum extruxerit aere perennius ${ }^{191}$, quod nulla unquam disturbatura sit vetustas, tamen gratitudinis vestrae erit, in virum de vobis bene meritum vestri iudicii memoriam extare, ut una cum gloria sua vestrisque officii perpetuo sit fama coniuncta. Quod reliquum est, vos oro obtestorque Patres primum, ut illius virtutem imitari velitis in omni vita, quem tantopere comprobatis. Deinde ut eius memoriam vestris animis defixis perpetuo conservetis. ${ }^{192}$

Wenn der Redner, der gerade das Leben des Verstorbenen dargestellt hat, das Publikum aufruft, dessen Erinnerung zu bewahren, so bezieht sich seine Aufforderung auf seine eigene zentrale Rolle beim Errichten der memoria des Toten. Ein solcher Aufruf am Ende der Rede kann nämlich nur so verstanden werden, dass die Zuhörer Zabarellas Erinnerung auf Grund von Poggios Rede bewahren sollten. Die Rede übernimmt so die Funktion des zu errichtenden Monuments. Poggios Rede wird das Monument, mit dessen auch etymologisch fassbarer doppelter Funktion: „moneo“, das Verb von dem die Substantivform „monumentum“ abzuleiten ist, kann in zwei Bedeutungen verwendet werden: jemanden an eine Tatsache erinnern, oder jemanden erinnern, etwas zu tun. Poggios Rede erfüllt diese zwei Funktionen. Sie ruft seiner

\footnotetext{
190 Poggio, Oratio, S. $260 \mathrm{f}$.

191 Hor. carm. 3, 30.

192 Poggio, Oratio, S. 261.
} 
Zuhörerschaft Zabarellas Leben und Tugenden in Erinnerung, und gleichzeitig mahnt sie, seinem Beispiel zu folgen.

Das Monument, das die Zuhörer in ihren Herzen tragen sollen, ist das von Poggio erstellte Monument. Es geht also nicht nur darum, dass am Ende der Rede der Demutstopos in sein Gegenteil umschlägt. Außer dem Umschlagen von Demut in Selbsterhebung ereignet sich in der Rede auch eine Verschiebung vom privaten Ton in die Richtung der öffentlichen Aufgabe.

\subsubsection{Die Wahrnehmung von Poggios Rede}

\subsubsection{1. Über die Frage, ob die Rede tatsächlich gehalten wurde}

Um sauber zu argumentieren, muss man an dieser Stelle ein Problem ansprechen, das in rein philologischen Arbeiten oft vernachlässigt wird. Nach der alten Regel der praemunitio ist es aber ratsam, mögliche Vorbehalte und Einwände des Publikums vorwegzunehmen. Es geht um die Frage, ob man sicher sein kann, dass die Reden, die schriftlich überliefert sind, tatsächlich vorgetragen wurden. In Poggios Fall könnte man hier einen kurzen Hinweis auf eine Stelle in den von Finke herausgegebenen, sogenannten „Akten” des Konzils machen. ${ }^{193}$ Für einen Leser, der nicht nachprüft, könnte man damit den Eindruck erwecken, dass es um eine feste, historische „Quelle” geht, um einen Fakt, der also keiner weiteren Beweise bedürftig ist. Finkes Angabe des Datums der von Poggio gehaltenen Rede basiert aber wahrscheinlich auf Hardts Ausgabe, weil er keine Quelle für seine Datierung angibt. Hardt schreibt an einer Stelle über Zabarellas Tod und über die für den Kardinal gehaltenen Trauerfeierlichkeiten. Für den Tag des 27. September steht in seinem Bericht der folgende Eintrag:

Cum pridie obiisset, exenteratus atque aromatibus conditus, hodie terra conditus est, inter sacra publica magno cum splendore, praesente Caesare, Principibusque omnibus, nec non universo clero, in choro templi Franciscanorum. [...] Floridissimus Concilii orator Poggius Florentinus praeclara oratione funebri merita viri celebravit. Dedimus illam supra Tom. I. f. 537. ${ }^{194}$

Das Datum von Poggios Rede ist im nächsten Eintrag noch einmal wiederholt: „Peroraverat Poggius Florentinus nuper die 27. Septembris cum funus efferretur”.

Wenn die Sekundärliteratur Poggios Rede mit Selbstverständlichkeit als die erste von den für Zabarella gehaltenen Reden bespricht ${ }^{195}$, übernimmt sie Hardts Datierung - oft nur

Finke, $A C C, \mathrm{Bd} .2,516$.

Hardt, Magnum Concilium, Bd. 4, S. 1431.

Wie zum Beispiel McManamon, 1989, S. 169, Fn. 31: „Poggio delivered his oration on 27 September 1417." 
durch Finke vermittelt. Hardt gibt als Quelle seiner Erzählung der Trauerfeierlichkeiten Zabarellas zwei Handschriften an: einen Braunschweiger und einen Leipziger Codex, ohne präzise Beschreibung von deren Format oder genauem Inhalt. ${ }^{196}$ Unter den von Finke identifizierten Constantiensia-Handschriften findet man den Leipziger Codex Lat. 1316, den Hardt laut Finkes Bemerkung benutzte. In dieser Handschrift fehlen leider die Einträge zwischen dem 24. September und dem 9. Oktober ${ }^{197}$, also genau die Beschreibung von Zabarellas Trauerfeierlichkeiten. Auf Finkes Liste der Handschriften findet man keinen Codex, den man mit Hardts Braunschweiger Codex identifizieren könnte. Demzufolge sind die Quellen von Hardts Erzählung dem heutigen Leser nicht zugänglich. Wenn man also die Kette der Referenzen bis zum letzten Glied verfolgt, hat man das gleiche Problem wie im Fall von Zabarellas letzter Rede: Hardts Quelle für seine Angabe bleibt unbekannt, man hat keine zeitgenössischen Referenzen, mit denen man die Aussagen über das Vortragen der Rede sauber und sicher belegen könnte. Streng genommen ist die einzige, heute zugängliche zeitgenössische Quelle für Zabarellas Beerdigung Richentals Chronik, die aber keine konkreten Angaben für die dort gehaltenen Reden überliefert.

Worauf man sich stützen kann, ist erstens das Plausibilitätsprinzip. Warum sollte ein Redner seine für einen ganz konkreten Anlass geschriebene Rede nicht vorgetragen haben? Zweitens kann man mit der allgemeinen Praxis argumentieren. Im Fall von anderen humanistischen Reden hat man manchmal äußere Beweise für das konkrete Vortragen dieser Reden, das heißt, dass es sich im Fall von humanistischer Traueroratorik meistens nicht um eine reine Fiktion handelt. Drittens kann man auf einen Fakt hinweisen, der wieder nicht als Beweis angeführt werden kann, aber die Annahme, dass die Rede tatsächlich vorgetragen wurde, plausibel macht. Es geht um das Phänomen, das ich in einem späteren Unterkapitel als „das Ringen um den Toten" beschreiben werde. Wenn die Trauerreden (für Chrysoloras und für Zabarella) nicht gehalten worden wären, wäre es nicht nötig gewesen, die Zuständigkeiten für die Toten und die für sie geschriebenen Reden ,aufzuteilen”. Im Fall einer nicht gehaltenen Rede, die also nur nach ihrer Selbstfiktion eine Rede ist, könnten gleichzeitig mehrere $\mathrm{Hu}$ manisten zur Feder greifen, die Idee der aemulatio würde ein solches Wetteifern sogar ermu-

\footnotetext{
196 Über Hardts Ausgabe vgl. Ansgar Frenken, „Die Quellen des Konstanzer Konzils in den Sammlungen des 17. und 18. Jahrhunderts", Annuarium Historiae Conciliorum 30 (1998): 416-439. Für die Identifizierung der von Hardt benutzten Handschriften vgl. Finke, ACC, Bd. 6, S. III-CIII, und: Heinrich Finke, „Das Quellenmaterial zur Geschichte des Konstanzer Konzils”, Zeitschrift für die Geschichte des Oberrheins 70, (1916): 253-275.

197 An der Stelle, wo diese Einträge folgen sollten, findet man fünf leere Folios: 428r-432v.
} 
tigen. Wenn die Humanisten aber die diesbezüglichen Aufgaben unter sich aufzuteilen versuchten, so deutet es darauf hin, dass diese Reden in der Tat auch gehalten wurden. ${ }^{198}$

Wenn man sich aber ausschließlich mit harten Fakten zufrieden gibt und die plausible Annahme, nach der Poggios Rede tatsächlich gehalten wurde, nicht akzeptiert, so ist natürlich vieles von der Argumentation über Poggios Motivation für das Schreiben (und Halten) seiner Rede gefährdet. Vieles, aber nicht alles: selbst wenn Poggio seine Rede für Zabarellas Tod nicht gehalten haben sollte, hat er einen Text geschrieben (den Text der Rede), der für ein breites Publikum gemeint war. Humanistische Reden, genauso wie Briefe, wurden kopiert und gelesen und keineswegs für die „Schublade” geschrieben. Man könnte auch an dieser Stelle einen Einwand vorbringen, nach dem, wenn es um eine Rede geht, die nur nach ihrer Selbstfiktion eine ist, der Text zu jeder beliebigen Zeit geschrieben worden sein kann, weil der zwingende Umstand der Zeitwahl, mit dem man bei einer Rede zu rechnen hat, entfällt. Diesen Vorbehalt kann man wiederum mit einem Hinweis auf Plausibilität beantworten: selbst eine fiktive Rede hat einen Sinn, wenn sie eine bestimmte Aktualität hat. Ausnahmen sind natürlich exemplarische Figuren der Vergangenheit; über Iulius Cäsars Tod kann man jeder Zeit eine Rede schreiben, Zabarellas Fall ist aber, trotz seines Ruhms unter seinen Zeitgenossen, ein ganz anderer.

\subsubsection{Poggios Publikum}

\subsection{Der ideale Zuhörer}

Mit dem Hinweis auf das Publikum wird eine immer grundlegende, aber in einer Argumentation über Selbstdarstellungsstrategien besonders elementare Frage angesprochen: die Frage der anvisierten Zuhörerschaft und des Ziels der Selbstdarstellung. Es geht hier um die Frage, was das Publikum verstand, worunter in diesem Fall nicht nur eine Frage der Sprachkompetenz der Zuhörschaft ${ }^{199} \mathrm{zu}$ verstehen ist. Poggios Zuhörer mussten auch über stilistische Kompetenzen verfügen, um die Rede richtig schätzen oder um sie überhaupt verstehen zu können. Sie verfolgte nämlich ein ganz anderes Muster als die traditionellen Leichenreden, und so konnte diese neue Ausdrucksweise auch zum Hindernis des Verständnisses werden.

198 Als letztes Argument darf vielleicht hinzugefügt werden, dass es unwahrscheinlich ist, dass Hardt seine Angaben gefälscht hat. Selbst wenn seine Vorlage in diesem Fall nicht mehr zugänglich ist, darf man seine Abschrift der Braunschweiger Handschrift doch für aussagekräftig halten.

199 Zur Frage des Verständnisses des Publikums einer auf Latein verfassten Rede vgl. Hayes einleuchtende Beispiele vom Ende des 11. Jahrhunderts, die zeigen, wie verschiedene Zuhörerschaften mit derselben Rede angesprochen werden konnten: Haye, Lateinische Oralität, S. 20-24. 
Um die konkrete Frage nach Poggios Zuhörerschaft und dem Ziel seiner Selbstdarstellung zu beantworten, ist es nötig, die Ergebnisse meiner Analyse dieser Strategie zusammenzufassen.

In meiner Analyse habe ich dafür argumentiert, dass Poggio in seiner Rede eine Strategie verwendet, die die Figur des Redners mit dem Gegenstand seiner Rede, das heißt mit Zabarellas Figur, verschmelzen lässt. Da Zabarella auf dem Höhepunkt der Rede als Redner dargestellt wird, impliziert die Verschmelzung der zwei Figuren, dass der Redner (Poggio) ein genauso guter Rhetoriker sein muss, wie es Zabarella war. Diese Selbstprofilierung wandelt den im exordium benutzten Demutstopos in seinen absoluten Gegensatz um, in das Selbstbildnis des Redners des großen Stils, der mit seinem rhetorischen Können sogar die Toten einerseits Zabarella, andererseits Cicero und Quintilian - aus deren Gräbern zum Leben erwecken kann. Wenn man Petrarcas oben zitiertes Urteil - das in einer anderen viel gelesenen Schrift, in Vergerios De ingenuis moribus et liberalibus adolescentiae studiis liber auch wiederholt wurde ${ }^{200}$ - über die Unfähigkeit der meisten seiner Zeitgenossen vor Augen behält, in dem er (Petrarca) den Mangel an Könnern auf diesem Gebiet mit der Vorstellung über die Unterlegenheit seiner eigenen Zeit gegenüber der Antike verbindet, so lässt sich Poggios auf die Untergrabung des am Anfang angewendeten Demutstopos basierende Selbstdarstellung, die ihn als den auch den großen Stil beherrschenden Redner darstellt, als eine typisch humanistische Strategie deuten. Sie impliziert nämlich eine Kluft zwischen der Mehrheit, die das genus grande zu meistern nicht mehr fähig sei, und dem Redner, der es kann, und der demzufolge über ein Können verfüge, das in der Zeit zwischen der Antike und seiner eigenen Zeit in Vergessenheit geraten sei.

Wer könnte als anvisiertes Publikum für Poggios Selbstdarstellung gelten? Man kann sich dieser Frage aus drei Richtungen annähern. Die erste Möglichkeit ist, den Erwartungshorizont des idealen Lesers (Zuhörers) des Textes aus dem Text selbst zu rekonstruieren. Eine vereinfachende, aber vielleicht nicht ganz verkehrte Lösung dieser Aufgabe wäre die Feststellung, dass Poggios Selbstdarstellung an einen idealen Zuhörer gerichtet war, der in der Rhetorik bis zu einem bestimmten Grad bewandert war, und der die Erfüllung der von Quintilian und Cicero gestellten Erwartungen gegenüber dem idealen Redner zu schätzen wusste. Je präziser die Rhetorikkenntnisse des Zuhörers waren, desto größer konnte seine Be-

200 „Verum ea, cum nobilium hominum studiis celebrari olim consuevisset, nunc paene prorsus obsolevit.” Pier Paolo Vergerio, „De ingenuis moribus et liberalibus adolescentiae studiis liber”, in Humanist educational treatises, I Tatti renaissance Library 5, hrsg. v. Craig Kallendorf (Cambridge, Massachusetts, London: Harvard University Press, 2002), 2-91, [im Weiteren: „De studiis”], hier S. 50. Vergerio schreibt zwar nicht über das genus grande, sondern generell über den Niedergang der ars rhetorica, es geht aber in beiden Fällen um das rhetorische Können der Zeitgenossen, das beiden Beobachtern unzureichend zu sein schien. 
geisterung für Poggios Umsetzung der theoretischen Lehre der Rhetorik in die Praxis gewesen sein. Reden sind aber nicht nur für die wenigen konzipiert, die alle ihre Facetten schätzen können. Der ideale Zuhörer ist zwar in jedem Fall jemand, der exakt die gleiche Kultur hat wie der Autor des Textes - und demzufolge zu den gleichen Assoziationen fähig ist - es sind aber wahrscheinlich auch diejenigen als Zuhörer mitgedacht, die nur einen Teil der im Text implizierten Allusionen verstehen.

\subsection{Die empirisch-historische Zuhörerschaft}

Als zweiter Weg böte sich die Rekonstruktion der empirisch-historischen Zuhörerschaft der Rede an. Das Publikum der Konstanzer Konzilsreden war sehr gemischt: angefangen bei dem deutschen, aus Konstanz stammenden, wegen seiner Schreibfehler von Francesco Barbaro als ignorantissimus omnium viventium gestempelten Schreiber (den Poggio auf seine Entdeckungsreisen mitnahm, dessen mangelnde Lateinkenntnisse es ihm aber wahrscheinlich nicht ermöglichten, sich für Poggios rhetorische Leistungen besonders zu begeistern), bis zur internationalen Bildungselite, welche die in den Text der Rede eingeschriebene Leserrolle am meisten zu erfüllen vermochte. Die potentiellen Zuhörer Poggios sind also auf einer breiten Skala der lateinischen Sprachkompetenz und der Vertrautheit mit antiker Rhetorik einzuordnen. Die konkrete Zuhörerschaft von Poggios Rede zu rekonstruieren ist leider nicht möglich. Aus Richenthals Chronik erfährt man auch nicht viel: „und trug man in in das closter zu den Parfußen in den chor zu der linggen siten, und giengen damit all pfafhait und all herren, gaistlich und weltlich, wie vorgeschriben ist, wann er gar ain gelerter man was.“ ‘201 Da es sich aber um einen Kardinal handelte, ist davon auszugehen, dass die hohen kirchlichen Amtsträger und die Kardinäle auf jeden Fall an den Trauerfeierlichkeiten teilnahmen. Zur Frage des Bildungsniveaus dieser Amtsträger kann die Tatsache erwähnt werden, dass eines der Kriterien, die bei den Kardinalsernennungen überlegt wurden, die Gelehrsamkeit des Kandidaten war. ${ }^{202}$ Obwohl Gelehrsamkeit nicht unbedingt eine humanistisch gefärbte Bildung bedeutet, ein Universitätsabschluss utriusque iuris zum Beispiel erhöht die Chancen, dass derjenige, der diesen Abschluss hat, mit einer klassizisierenden, auf antike Vorlagen

201 Ulrich von Richental, Das Konzil zu Konstanz, 2 Bde., hrsg. v. Otto Feger (Starnberg: Keller/Thorbecke, 1964).

202 Dieter Girgensohn nennt fünf Motive, die bei Kardinalserhebungen eine Rolle spielten: politische Beziehungen, Herkunft aus einer ,guten” Familie, hohe Stellung innerhalb der kirchlichen Hierarchie, Gelehrsamkeit, Erfahrung in den Geschäften der Kurie. Vgl. Dieter Girgensohn, „Wie wird man Kardinal? Kuriale und außerkuriale Karrieren an der Wende des 14. zum 15. Jahrhundert", Quellen und Forschungen aus italienischen Archiven und Bibliotheken 57 (1977): 138-62. 
anspielenden Oratio mehr anzufangen weiß als der erwähnte deutsche Schreiber, den Poggio auf seine Entdeckungsreisen mitnahm.

\subsection{Das Ziel von Poggios Selbstdarstellung}

Die dritte Richtung, über die Zuhörerschaft der Rede nachzudenken, führt uns zur folgenden Fragestellung: Was konnte das Ziel dieser Selbstdarstellung sein? Im Allgemeinen Ruhm und Ehre als Redner zu erlangen ist eine der möglichen Antworten. Poggio hatte aber wahrscheinlich konkretere Ziele vor Augen. Im Hinblick auf den bereits geschilderten biographischen Entstehungskontext der Rede lässt sich eine plausible Hypothese über dieses Ziel aufstellen: Poggio brauchte einen neuen Brotherrn. Da es sehr wahrscheinlich war, dass der zukünftige Papst unter den Zuhörern war, kann Poggios Grabrede als eine Art Bewerbung für seine zukünftige Arbeit bei seinem zukünftigen Arbeitgeber aufgefasst werden.

Poggio selbst artikuliert explizit keine solchen Hoffnungen in dieser Zeit, andere Zeugnisse beweisen aber zweifelsohne diese selbst ohne konkrete Beweise offensichtliche Annahme. Dass Poggios Ruhm als Wiedererwecker antiker Literatur seine konkreten Erwartungen gegenüber dem neuen Papst erweckt haben könnte, dass also eine solche Verknüpfung zwischen dem Ruhm als homo eruditus und einer üppigen Belohnung nicht ungewohnt war, veranschaulicht Barbaros Brief, in dem er seine Hoffnungen bezüglich Poggios Belohnung ausdrückt.:

Accedet ad gratiam, cum uberrimam laborum tuorum mercedem suscepturus sis, si quando, quod maxime vellem, is in universam rem p. summam potestatem habebit, cui in doctrina cui in virtute cui in laude percipienda ab ineunte etate plurimum studii fuit et temporis. Erit enim sapientis pontificis maximi beneficia vestra memoria prosequi et magna vobis prestare, quandoquidem non parva in hoc genere a vobis accepit, quin eo maiora iudicio meo censeri debent, quo minus erant expectata. $^{203}$

Barbaro sagt, dass der neue Papst Poggios Bemühungen reichlich belohnen wird, wenn derjenige als Papst gewählt wird, der seit seiner Jugend nach Gelehrsamkeit, Tugend und Lob gestrebt hatte. Er nennt seinen Kandidaten nicht, es ist aber plausibel, davon auszugehen, ${ }^{204}$ dass dieser nur Zabarella gewesen sein konnte. ${ }^{205}$

Es reicht ein kurzer Überblick des Diskurses über Zabarella in den Briefen der beiden Humanisten (Poggios und Barbaros) zu der Zeit, um einzusehen, dass diese Annahme der

\footnotetext{
203 Barbaro, Epistolario, Bd. 2., S. 77.

Vgl. Walser, Poggius, S. 61.

Der Brief wurde nämlich verfasst, als Zabarella noch lebte.
} 
Wahrheit entspricht. Poggios Brief an Barbaro vom Dezember 1417 (Anm. 129-130) macht diese Hypothese plausibel. Er schreibt, dass er Guarino, der ihn wahrscheinlich darum bat, dass Poggio ihn in der Kuria weiterempfiehlt, leider nicht helfen kann, weil dort alles unsicher geworden ist.

Antea pecuniis, nunc ambitione certatum, tantaque est suffragiorum ac tribuum varietas, ut nedum Cato, sed Paulus repulsam ferret. Obiit ille, qui doctorum omnium erat asylum. ${ }^{206}$

Der Grund dafür, dass Poggio seine Position in Gefahr sieht und dass er deswegen auch Guarino nicht helfen kann, ist, dass der „Zufluchtsort” aller Gelehrten gestorben ist. In seiner Grabrede, in dem Absatz, der Zabarellas liberalitas und beneficentia beschreibt, hat Poggio den Kardinal als asylum bezeichnet. Wenn er im Brief an Barbaro kurz nach Zabarellas Tod über den „Zufluchtsort” aller Gelehrten schreibt, dann kann er damit nur den Kardinal gemeint haben. Der Satz ist eine eindeutige Anspielung und Antwort auf die in Barbaros Brief formulierte Hoffnung bezüglich der Person des neuen Papstes. Zabarella ist tot, er wurde nicht Papst, alles ist verloren. ${ }^{207}$ In diesem Kontext betrachtet, scheint es plausibel zu sein, dass auch Barbaro Zabarella meinte, als er über den zukünftigen Papst schrieb. Poggio schrieb seine Antwort im Dezember 1417, als er bei dem neuen Papst als scriptor eingestellt wurde. Er war tief enttäuscht wegen dieses Prestigeverlustes.

Als er aber seine Rede nach Zabarellas Tod hielt, da war noch alles offen, da hatte er noch die Hoffnung, bei dem neuen Papst weiter als secretarius arbeiten zu dürfen. Ein Beweis dafür, wie sorgfältig und systematisch seine Suche nach einem potentiellen Brotherrn war, ist die Tatsache, dass er seinen zukünftigen Herrn, den Bischof von Winchester, Henry Beaufort, bereits während des Konzils kennen gelernt hatte. Nach seiner Enttäuschung verließ Poggio den Kontinent, um in England für den Bischof zu arbeiten. Seine Motivation dazu, dass er auf dem Konzil einen intensiven Kontakt mit dem Bischof pflegte, könnte vielleicht in Beauforts Ambitionen gesehen werden, zum Papst gewählt zu werden. ${ }^{208}$ Poggio musste seinen zukünftigen Brotherrn von seinen Fähigkeiten überzeugen und seine Aufmerksamkeit mit

206 Clark, Discoveries, S. 125.

207 Dass Zabarella, wenn er weiter gelebt hätte, Papst geworden wäre, ist auch in Poggios Oratio erwähnt: „Nec vero dubium est, quin si vixisset diutius, summo sacerdotio functus esset. Nam omnes summi, infimi, mediocres culmen illud pontificium ad eum uno ore deferebant illum maxime dignum asseverantes, qui ecclesiasticae rei publicae gubernaculum teneret." Poggio, Oratio, S. 255-256. Über die möglichen Gründe für Poggios Übersiedlung nach England, so unter anderen auch seine Enttäuschung nach der Papstwahl, vgl. Folts, Civic Life, S. 108-112.

208 Vgl. Fillastre, Gesta, S. 152. Folts begründet Poggios Annäherung an den Bischof damit, dass Poggio generell gern die Nähe der Mächtigen suchte: „Poggio liked to be associated with powerful and successful individuals", Folts, Civic Life, S. 109. Über die weiteren Kandidaten für das Papsttum vgl. Fink, Die Wahl, S. 310 . 
rhetorischem Geschick noch einmal auf seine Entdeckungen lenken. Dies hatte er in seiner Oratio auch getan.

Indem Poggio sich durch die Verknüpfung des privaten mit dem öffentlichen Diskurs in beiden Rollen darstellt, in der des Freundes, und in der einer öffentlichen Persönlichkeit, argumentiert er doppelt für seine Anstellung: einerseits sei er ein guter Freund Zabarellas, und Zabarella der Spitzenkandidat für den päpstlichen Thron. Seine Zuhörer brauchten keine hermeneutische Spitzfindigkeit, um auf die von der Rede suggerierte Schlussfolgerung zu kommen, dass Poggio in der Kurie, wenn Zabarella es hätte erleben können, zum Papst gewählt zu werden, einen sicheren Broterwerb bekommen hätte. Andererseits, indem Poggio sich als eine öffentliche Persönlichkeit schlechthin, das heißt als Redner darstellt, beweist er, dass ihn seine Bildung, sein kulturelles Kapital gewissermaßen generell dazu befähigen, in der päpstlichen Kurie einen lukrativen Posten zu besetzen.

Wenn man die Erwägungen der drei möglichen, nach Poggios Publikum tastenden Fragen (nach dem idealen Zuhörer, nach den empirisch-historischen Zuhörern und nach der Zielsetzung Poggios) rekapituliert, so kann der obere Klerus als das von Poggio anvisierte Publikum definiert werden. Seine Mitglieder erfüllen sämtliche drei Kriterien. Ihr Bildungsniveau entsprach den vom Text gestellten Erwartungen, sie müssen bei Zabarellas Beerdigung anwesend gewesen sein und schließlich waren sie durch ihre Position potentiell in der Lage (wenigstens einer von ihnen in der Zukunft, nämlich der zukünftige Papst), Poggios persönlichen Erwartungen bezüglich seiner Karriere entgegenzukommen.

\subsubsection{Das Ringen um die Toten - Poggios Denkmal für Zabarella: von den For- schern übernommen, von Poggio relativiert}

Es ist interessant zu beobachten, wie stark die aus dem Anlass von Zabarellas Tod verfassten Texte die modernen Darstellungen beeinflussen: „But he had seen what was most important for him, he had climbed the mountain and seen the dream: the goal of Christian unity as a reality in the West" so Morrissey am Ende seiner Studie. ${ }^{209}$

Walsers Darstellung von Poggios Rede über Zabarella ist ein lehrreiches Beispiel dafür, wie sich der Autor, wie auch Poggio selbst in seiner Rede, allmählich mit seinem Gegenstand identifiziert, und wie er seine Worte mit denen seines Gegenstandes verschmelzen lässt. Am Anfang macht Walser noch klar, dass er Poggios Rede über Zabarella beschreibt, und dass nicht er selbst, Ernst Walser, über Zabarella meint: „mit kräftigen 
Strichen zeichnet der Redner erst das Leben Zabarellas" ${ }^{210}$. In seinen weiteren Sätzen fasst er Poggios Beschreibung zusammen, allerdings nicht im Konjunktiv, sondern im Indikativ, und auch ohne jegliche Zeichen von Distanz Poggios Worten gegenüber. Er schließt sein Kapitel über Poggios Konstanzer Zeit mit folgenden Sätzen:

Und besser als durch eine goldene Statue mit der Inschrift: Dem Vater des Vaterlandes, wie er nach antiker Sitte wahrlich verdient hätte, pflegen wir sein edles Andenken durch tatkräftige Nachahmung seiner Tugenden.

Walser kehrt nicht mehr auf Poggio zurück und hinterlässt in seinen Lesern den Eindruck, nicht über Poggios Rede über Zabarella, sondern Walsers eulogium, seinen eigenen Aufruf zum Bewahren von Zabarellas memoria gelesen zu haben.

Umso überraschender ist es, Poggios Brief an Guarino Veronese 38 Jahre später zu lesen, in dem der Humanist selbst das von ihm erstellte Denkmal relativiert:

Libentius profecto Manuelis quam cardinalis Florentini laudandi tunc officium sumpsissem. Uberior enim dabatur in laudibus suis vagandi campus. Nam et patria complectenda erat, de cuius laudibus infinita pene enarrari possunt, et doctrina singularis et eius viri eximia in omni genere virtus, tum mores probatissmimi, tum castissimma vita. Utilitas preterea, quam latinis litteris attulit, que ante suum adventum mute, mance, debiles videbantur. Excitata sunt eius opere ingenia ad grecarum litterarum studia, que magnum doctrine lumen nostro seculo attulerunt. Tum ad eloquentiam commoti sunt permulti, in qua pristinum fere dicendi ornatum recuperatum videmus. Hec tot tantaque in eum virum congesta amplam laudandi materiam prebuissent. ${ }^{211}$

Poggio sagt, dass er eigentlich viel lieber ein eulogium über den ebenfalls auf dem Konzil gestorbenen Manuel Chrysoloras als über Zabarella geschrieben hätte, weil es ihm mehr Möglichkeiten zum Lob geboten hätte. Es geht hier ganz kühl und sachlich um die Kunst. Der Redner will einen Gegenstand haben, der ihm möglichst viel Stoff liefert.

Aus demselben Brief geht deutlich hervor, dass es zwischen den Humanisten manchmal ein regelrechtes Ringen um die Toten gab: Poggio konnte keine Grabrede für Chrysoloras halten, weil sein Freund Cencio Rustici, mit dem er auch seine berühmten Entdeckungsreisen in die Bibliotheken unternahm, diesen Anlass für sich beanspruchte. So musste Poggio auf die von Chrysoloras‘ Tod gebotene Möglichkeit verzichten, mit seiner rednerischen Kunst vor dem Konstanzer Publikum zu prahlen. Umso ärgerlicher sei es gewesen, dass sein Freund am Ende die Rede doch nicht geschrieben habe (,sed et ipse nihil edidit et mihi scribendi sustulit

210 Walser, Poggius, S. 70.

211 Poggio, Lettere, Bd. 3, S. 347-349. 
facultatem“). Jahre später wiederum hatte Poggio das Vorrecht, eine laudatio über Antonio Loschi zu halten, so musste dieses Mal Cencio seine Finger vom Stoff lassen:

Hoc idem in morte clarissimi viri Antonii Lusci contigit, cuius laudationem cum me scripturum professus essem et iam scribere coeperam, Cincius quoque se id omnino destinasse dixit quasi egre laturus, si quid a me scriberetur. At et ipse tacuit, et me reddidit mutum. Alios tamen postea in funere ornando laudavi, pro quibus scripte extant orationes. $^{212}$

Pier Paolo Vergerio ist der dritte Humanist, dessen Name in diesem Zusammenhang zu erwähnen ist. Er forderte Guarino Veronese auf, ein eulogium auf Chrysoloras zu schreiben. Vergerios Brief ist nicht erhalten, über seine Aufforderung erfährt man in Guarinos Antwort vom 27. August 1415, in der er Vergerio ermutigt, diese Aufgabe selber zu erfüllen. ${ }^{213}$ Vergerio verfasst keine Grabrede (die Grabrede, die für Chrysoloras' Tod überliefert wurde, stammt von Andrea Giuliano, in Venedig gehalten), sondern den Text des Epitaphiums für das Grab von Chrysoloras. Der Text lautet:

\begin{abstract}
Ante aram situs est Manuel Chrisoloras, miles Constantinopolitanus ex vetusto genere Romanorum, qui cum Constantino imperatore migrarunt. Vir doctissimus, prudentissimus, optimus, qui tempore generalis Concilii Constanciensis diem obiit ea existimatione ut ab omnibus summo sacerdocio dignus haberetur. Die XV Aprilis conditus est MCCCCXV. ${ }^{214}$
\end{abstract}

Die zweite Möglichkeit, auf dem Konzil für einen prominenten Toten ein Denkmal zu erbauen, wurde durch Zabarellas Tod geboten. Da sich Chrysoloras Tod 1415 und die Arbeit an

Poggio, Lettere, Bd. 3, S. 349.

Guarino, L'epistolario, Bd. 1, S. 72-75.

Wenn man hier liest, dass also auch Chrysoloras von allen für würdig befunden wurde, zum Papst gewählt zu werden, wird man den Verdacht nicht ganz los, dass es sich hier möglicherweise um einen Topos handelt (vgl. Anm. 207). Der Text des Epitaphiums wurde ediert: Emile Louis Jean Legrand, Louis Petit, Hubert Octave Pernot, Hrsg., Bibliographie Hellénique ou, Description raisonnée des ouvrages publiés par des Grecs aux XV et XVI siècle (Paris, G. P. Maisonneuve \& Larose, 1885), Bd. I, S. xxvi und von Smith wieder veröffentlicht: Vergerio, Epistolario, S. 357, Anm. 1. Heute ist eine Kopie des Epitaphiums zu sehen im ehemaligen Dominikanerkonvent in Konstanz, dessen Gebäude heute als Hotel (Hotel Insel) funktioniert. Für eine Dekonstruktion des Mythos, dass Chrysoloras im Konstanzer Dominikanerkloster beigesetzt gewesen sei, vgl. Lydia Thorn-Wickert, Manuel Chrysoloras (ca. 1350-1415). Eine Biographie des byzantinischen Intellektuellen vor dem Hintergrund der hellenistischen Studien in der italienischen Renaissance, Bonner romanistische Arbeiten 62 (Frankfurt am Main, Berlin, Bern, Bruxelles, New York, Oxford, Wien: Peter Lang, 2006), [im Weiteren: „Chrysolora”], hier S. 111-114. Der Text des Epigramms ist auch in einem Brief des Guarino erhalten, den er an Iacopo de Fabris geschrieben hat: Guarino, L'epistolario, Bd. 1, S. 114. Vergerios Text wurde auch in späteren Epitaphiensammlungen überliefert, wie zum Beispiel in der vom deutschen Student Johannes Hasenbeyn 1450 in Padua zusammengestellten humanistischen Anthologie (München, Clm, 6720, f. 187. r), deren Epygrammata in Necchis Artikel veröffentlicht wurden: Elena Necchi, „Una silloge epigrafica Padovana: gli epigrammata illustrium virorum di Iohannes Hasenbeyn", Italia Medioevale e Umanistica 35 (1992): 123-177. Über die verschiedenen Versionen der Inschrift und über Guarinos Chrysolorina vgl.: Giuseppe Cammelli, Manuele Crisolora, i dotti bizantini e le origini dell'Umanesimo (Florenz: Valecchi Editore, 1941), S. 167-177. Der ausführlichste und kritischste Bericht über die zu Ehren des Chrysoloras entstandenen Schriften ist von Thorn-Wickert geliefert worden: Thorn-Wickert, Chrysoloras, S. 114-128. 
seiner memoria anhand der ganz konkreten und expliziten Äußerungen in Poggios Brief als ein Anlass für humanistischen Konkurrenzkampf interpretieren lässt, verstehe ich auch die Eulogien, die aus dem Anlass von Zabarellas Tod geschrieben wurden, als Plattform für einen ähnlichen Konkurrenzkampf zwischen den Humanisten, welcher in Poggios und Vergerios Fall - man denke an den Tod Chrysoloras - sich auch nicht ganz ohne Vorgeschichte abspielte.

\subsubsection{Bilanz: Eine Neuinterpretation der Rede}

\subsubsection{Poggios Agenda - Der orator als Verkünder von Zabarellas politischem Testament}

Diese Interpretation stellt das traditionelle Erklärungsmuster des Textes in Frage. Die Sekundärliteratur sieht Poggios Rede im engsten Zusammenhang mit seiner so genannten Reformrede, der Oratio ad patres reverendissimos. Während Poggio in seiner Reformrede die Laster des Klerus angreife, kämpfe er in seiner Grabrede über Zabarella für das gleiche Ziel mit anderen Mitteln. Statt die schlechten Beispiele zu zeigen und gegen sie anzukämpfen, stelle er ein positives Beispiel in den Mittelpunkt, nämlich den Kardinal Zabarella, der in jeder Hinsicht das Gegenteil der Moral verkörpert, die Poggio in seiner Reformrede beschreibt und attackiert. Dieser Meinung sind Fubini ${ }^{215}$ und McManamon. Der letztere verwischt dabei die Haltung der drei Humanisten, die über Zabarella Eulogien geschrieben haben. Er konzentriert sich auf die Gemeinsamkeiten und projiziert eine gemeinsame, „humanistische” Haltung in die drei Autoren:

Poggio, Vergerio, and Donato transformed him, from a friend of the humanists whose own culture remained little influenced by humanism, to an exemplar of its value for the Church. Zabarella the institutional reformer of Church structures became Zabarella the humanist reformer of individual morals. ${ }^{216}$

Es ist selbstverständlich nicht meine Absicht, die Gemeinsamkeiten der drei humanistischen Eulogien in Frage zu stellen, wie zum Beispiel die Tatsache, dass alle drei Humanisten Zabarella als den Prototyp des humanistischen Gelehrten dargestellt haben. Der Punkt, wo ich Möglichkeiten für ein weiteres Verfeinern des Bildes sehe, ist die Frage der persönlichen Motivationen und der politischen Präferenzen, die von diesen persönlichen Interessen gesteuert werden. Wenn die neue Kultur problemlos ganz verschieden gesinnte Argumenta-

\footnotetext{
215 Vgl. Fubini, Sui vizi.

216 McManamon, Funeral, S. 68. Eine andere Stelle, die Vergerio, Poggio und Donato als Beispiele für dieselbe Haltung auflistet: S. 66.
} 
tionen zur gleichen Frage ermöglichte, ist es schwierig, diese an irgendwelchen gemeinsamen Inhalten festmachen zu wollen. Diese Unsicherheit (worin Humanismus bestehe: in der klassizisierenden Form oder in irgendwelchen gemeinsamen Inhalten) wird auch bei McManamon sichtbar: Wenn er die Gemeinsamkeiten der drei humanistischen Reden beschreibt, nennt er immer die drei Humanisten Poggio, Vergerio und Donato als Stifter eines humanistisch gestalteten Bildes von Zabarella. In den Fußnoten, in denen er die für seine Beweisführung relevanten Stellen auflistet, nennt er aber auch die bezüglichen Stellen von Fleming, dessen Rede er im Haupttext als Musterbeispiel für eine scholastische Predigt beschrieben hat. Wenn es also um die Form geht, dann gehört Fleming zu den NichtHumanisten, in der Schilderung gemeinsamer Inhalte wird jedoch plötzlich die Trennlinie zwischen Humanisten und Nicht-Humanisten nicht mehr so deutlich. ${ }^{217}$

Poggio stilisierte sich, wie ich es in meiner Analyse zu beweisen versuchte, erstens zu einem perfekten Redner, um seinem erhofften, zukünftigen Brotherrn zu imponieren. Diese Selbststilisierung als der Redner des großen Stils und als Humanist durch die Figur der Prosopopoeia und durch seine Verwandlung in Zabarella kann natürlich nur funktionieren, wenn er Zabarella als großen Redner und Humanisten darstellt, wie es in der Rede auch geschieht. Zabarellas Stilisierung zum Humanisten ist die Grundvoraussetzung für Poggios Selbststilisierung.

Zweitens: Es stand in seinem Interesse, wenn er sich seine Zukunft in der Kuria vorstellte, seine Position (selbstverständlich an der Seite der Kardinäle) in den Debatten des Sommers 1417 zu artikulieren. Er tut es auch in seiner Rede: wenn er sich in seiner Oratio mit Zabarella verschmelzen lässt, bedeutet es nicht nur, sich zu einem großen Redner zu stilisieren. Es bedeutet auch, sich als den Befürworter und Fortführer von Zabarellas Bestrebungen, das heißt als den Förderer der Union der Kirche darzustellen. Wenn er über Zabarellas letzte Rede spricht, nennt er diese das Testament Zabarellas: ,, et postremis verbis clamans, inquit, eam orationem suum fuisse testamentum, cum sese ita comparasset, ut in unitate ecclesiae vellet animam profundere. ${ }^{, 18}$ Indem Poggio Zabarellas letzte Rede vergegenwärtigt, eröffnet er praktisch sein Testament. Er mahnt seine Zuhörer, Zabarellas Erbe zu hüten, ihm treu zu bleiben und seinen letzten Willen zu erfüllen, indem sie in seinem Sinne agieren und die Papstwahl beschleunigen. Poggios Rede ist im Gegensatz zu früheren Deutungen nicht mit Poggios Reformfreundlichkeit zu erklären. Poggio nimmt mit seiner Mahnung eine eindeutige Position in der Prioritätsdebatte ein, und zwar eine Position, deren Vertreter eine schnelle Papstwahl augenblicklich für dringlicher gehalten haben, als die Durchsetzung der Reformen der Kirche. Die Analyse von Vergerios eulogium wird ein Beispiel dafür liefern, dass die von

217 Vgl. McManamon, Funeral, S. 200-201, Anmerkungen: 16, 23, 24.

218 Poggio, Oratio, S. 259. 
Poggio eingenommene Position nicht die einzig mögliche für einen Humanisten war. Humanist-Sein erweist sich in diesem Fall als nicht an inhaltliche Fragen gebunden.

\subsubsection{Wer sind Poggios „Feinde”?}

Selbstprofilierung braucht immer einen Antipoden, von dem man sich abgrenzen kann, gegen den man seine eigene Identität aufbauen kann. Wenn man diese fast banale Aussage mit einer Autorität unterstützen möchte, so könnte man auf Stephen Greenblatts Kriterien für Self-fashioning hinweisen, unter denen auch das Erfordernis von einem Kontrahenten für die eigene Selbstdarstellung erwähnt wird: „Self-fashinonig is achieved in relation to something perceived as alien, strange, or hostile. This threatening Other - heretic, savage, witch, adulteress, traitor, Antichrist - must be discovered or invented in order to be attacked and destroyed." ${ }^{219}$ Dieser Wirkungsmechanismus von Attacke wurde - um eine zeitgenössische Beschreibung zu zitieren - in Bartolomeo Facios (ebenfalls nach diesen Regeln funktionierender) Invektive gegen Lorenzo Valla zusammengefasst:

Denique neque vivo, nec mortuo cuiquam parcis, scilicet in id studens, ut tibi ex aliena vituperatione laudem vendices. ${ }^{220}$

Dass auch die oben dargestellte Selbstprofilierung Poggios mit einem Antipoden arbeitet, erklärt sich nicht nur aus dem Entstehungskontext eindeutig. Poggio macht selbst unverkennbar deutlich, dass er sich mit seiner Rede in einem von einander gegenüberstehenden Kräften beherrschten politischen Raum bewegt. Gegen wen richtet sich Poggios Attacke? Von wem versucht er sich abzugrenzen? Sollte man Poggios Text im Kontext seines vermeintlichen Antiklerikalismus lesen, wie es in der Sekundärliteratur manchmal vorgeschlagen wird? ${ }^{221}$

Unmittelbar nach dem Höhepunkt der Rede schlägt seine Trauer in Verwünschung um: es sei ungerecht vom Schicksal, dass ausgerechnet Zabarella sterben musste, denn es gäbe so viele an dem Konzil, deren Tod wünschenswert sei.

Nonne satius fuerat, cum tot nepharii, improbi, seditiosi (quorum magna semper est copia), in hoc consilio versarentur, qui omnia permisceant ac perturbent, nonne inquam hos omnes satius erat perditum ire, ex quorum interitu salus omnis parabatur

\footnotetext{
219 Greenblatt, Self-Fashioning, S. 9. Die Stelle wurde, etwas kürzer, in dieser Arbeit bereits zitiert, vgl. Anm. 38.

220 Bartolomeo Facio, „Le invettive di Bartolomeo Facio contro Lorenzo Valla”, hrsg. v. Robert Valentini und I. Guidi, Rendiconti della Reale Accademia dei Lincei. Classe di scienze, morali, storiche s. 5.15 (1906): 493-550, hier S. 523.

221 Fubini, Sui vizi, S. 30.
} 
orbi, quam hunc virum privari vita, ex cuius incolumitate salus omnis pendere videbatur? $^{222}$

Es sind die „nepharii, improbi, seditiosi” deren Tod Poggio am Ende der Rede wünscht, die alles „,verstören und verwirren”. Schimpfwörter, die sich auf eine aufwühlerische Tätigkeit bezogen, wurden in der Zeit viel benutzt, von beiden Seiten. ${ }^{223}$ In Vergerios cedula, in der er für die Hinauszögerung der Papstwahl plädiert ${ }^{224}$, sind mit den Worten „turbatores concilii, autores et fautores scismatum" diejenigen gemeint, die für eine schnelle Papstwahl waren, also genau jene, auf deren Seite unter anderen auch Poggio stand. Wenn Poggio ähnliche Ausdrücke benutzt, dann meint er diejenigen, die sich auf Sigismunds Seite für das Hinauszögern der Papstwahl engagiert haben. Poggios „,nepharii, improbi, seditiosi” kann als eine Antwort auf Vergerios „turbatores concilii, autores et fautores scismatum” gelesen werden. Genau an dem Tag, an dem Zabarella seine letzte Rede hielt, kam es zu äußerst dramatischen Ereignissen. ${ }^{225}$ Am 11. September, zwei Tage nach der am Anfang dieses Kapitels zitierten königlichen Schlägerei (Anm. 91), nach dem Tag also, an dem Sigismund das Verlesen der cedula verhindert hatte, in der die deutsche Nation aufgefordert wurde, ihre deputati zu den Bespre-

222 Poggio, Oratio, S. 260.

223 Laut Fillastre von Sigismunds Seite für die Kardinäle benutzt: „contra cardinales et alios, quos vocabant turbatores concili ": Fillastre, Gesta, S. 142.

224 Vgl. das Kapitel 3.2. „Vergerios Engagement für Sigismund von Luxemburg in Konstanz im Spiegel der zeitgenössischen Wahrnehmung” und besonders das Unterkapitel: III. 3.2.1. „Der Auslöser: Vergerios cedula" dieser Arbeit.

225 Die Datierung von Zabarellas letzter Rede - da Poggio kein Datum angibt - basiert auf Hardts Beschreibung der Ereignisse dieses Tages: „ea vehementior, aegro licet corpore, Caesaris et germanorum pro reformanda prius Ecclesia studium impugnavit, ut et concertationem intentissimam ultimam aestimaret loco testamenti vocem, et brevi post expiraret." Hardt, Magnum Concilium, Bd. 4, S. 1417. Diese Worte stehen aber in Hardts Beschreibung nicht als Zitat, sondern als eigener Text, dessen Quelle Hardt leider nicht angibt, die aber wahrscheinlich in Poggios Oratio zu suchen ist. Trotzdem wird in der Sekundärliteratur auf diese Stelle als vertrauenswürdige historische Quelle hingewiesen; wie zum Beispiel Zonta, Zabarella, S. 111, oder bei Thomas Edward Morrissey, „Franciscus de Zabarellis (1360-1417) and the conciliarist traditions” (PhD Diss., Cornell University, 1973), [im Weiteren: „Franciscus de Zabarellis”], hier:, Bd. 2. S. 596. Eine andere Stelle von den „Konzilsakten”, die die Sekundärliteratur als Beweis dafür angibt, dass Zabarella seine Rede am 11. September gehalten hat, befindet sich in Finkes Werk. Es handelt sich um die Stelle Finke, ACC, Bd. 2, S. 513 (zitiert unter anderen in: Morrissey, Franciscus de Zabarellis, S. 607). In diesem Teil seines Werkes listet Finke die Reden auf, die auf dem Konzil gehalten worden sind. Er beschränkt sich aber nicht auf die Reden, deren Text überliefert wurde, sondern nimmt auch Einträge auf, über deren Existenz man nur von Erwähnungen etwas weiß. Zu diesen Reden gehört auch Zabarellas Rede vom 11. September 1417. Als Referenz gibt Finke Poggios Trauerrede an. Dementsprechend darf seine Angabe mit etwas Skepsis betrachtet werden, da Poggio kein Datum für Zabarellas letzte Rede angibt. Der Hinweis auf Finke kann den Leser der Sekundärliteratur irreführen, da der Titel dieses Werkes („Acta”) suggeriert, dass es sich ausschließlich um vertrauenswürdige Quellen handelt, in Wirklichkeit verwischt sich aber manchmal die Grenze zwischen Finkes Interpretation von äußeren Hinweisen und den Quellen, die tatsächlich in der Form überliefert worden sind, wie man sie in Finkes Werk findet. Da aber Zabarella in den Konzilsakten in der Tat sehr häufig als Hauptvertreter der Interessen des Kardinalkollegs genannt wurde, scheint es doch plausibel zu sein, dass er sich für die von ihm vertretenen Ansichten auch an dem turbulenten 11. September 1417 eingesetzt hat. Dass Poggio diesen Auftritt zu einem „Schwanenlied” stilisiert darstellt und Zabarellas Rede damit etwas mehr Wichtigkeit zubilligt, als diese in der Realität vielleicht besaß, kann natürlich sein. Es ist aber weiterhin davon auszugehen, dass Zabarella in diesen Tagen eine Rede hielt, es stand nämlich nicht in Poggios Interesse, auf ein Ereignis hinzuweisen, das völlig aus der Luft gegriffen war: er hätte damit seinen Zuhörern keinen guten Eindruck vermitteln können. 
chungen über den Wahlmodus zu ernennen, wurde diese cedula doch verlesen. In Fillastres Tagebüchern steht über diesen Tag, dass es zum Aufruhr kam, als der Kardinal die cedula verlesen wollte:

Et ab utraque parte fiebat sermo, et ab utraque tumultus magnus finaliter. Cardinalis alta multum voce legens non cessavit, et alii recesserunt et dixerunt postea, quod venerant pro bono pacis, et quod fuit eis facta magna injuria, et quod aliqui vocaverunt eos hereticos, et eciam regem Romanorum. Et inde magnum odium ortum est, et gravis discordia. ${ }^{226}$

Es passierte an diesem Tag, dass Sigismund aus Angst davor, dass die Kardinäle das Konzil mit ihrem Fortgang boykottieren würden, bewaffnete Männer in die Stadt, an das Ufer und auf die Schiffe schickte, damit sie die Flucht der Kardinäle aus der Stadt verhindern konnten. Die Männer des Königs erkannten einander im Dunkeln der Nacht nicht wieder, und die eigenen Männer für die fliehenden Kardinäle haltend, griffen sie diese an. ${ }^{227}$ Diese Geschehnisse dürften Poggios Zuhörerschaft nicht unbekannt gewesen sein. Wenn Poggio in seiner Rede über nepharii lästert, die alles durcheinanderbringen, so konnte es seinem Publikum unter anderen diese von Fillastre überlieferte Szene in Erinnerung gerufen haben.

Poggios Attacke richtet sich in seiner Rede in erster Linie nicht gegen den korrupten Klerus, sondern gegen Sigismunds Partei, gegen die nepharii, improbi, seditiosi, die es versucht haben, die Papstwahl so lange wie möglich hinauszuzögern. Seine Oratio ist meines Erachtens nicht, wie es die Vertreter der älteren, die Humanisten auf jeden Fall als reformfreudig beschreibenden Forschung meinen, als Teil seiner antiklerikalen Polemik zu sehen, sondern vielmehr als die Rede eines Humanisten, der seine Zukunft in einer überaus klerikalen Umgebung zu sichern versucht.

\footnotetext{
226 Fillastre, Gesta, S. 140 f.
}

227 Fillastre, Gesta, S. 141. 


\section{Pier Paolo Vergerio und sein eulogium auf Zabarella}

\subsection{Einleitendes}

\subsubsection{Sein Leben im kurzen Überblick}

Einer der Bausteine des von Poggio für sich selbst errichteten Monuments ist seine oben geschilderte Attacke auf die ,nepharii, improbi, seditiosi (quorum magna semper est copia), in hoc consilio versarentur, qui omnia permisceant ac perturbent" ${ }^{228}$. Es ist plausibel anzunehmen, dass Poggio im Herbst des Jahres 1417 unter den „Unruhestiftern” Sigismunds Partei verstand, die Leute also, die sich für die Hinauszögerung der Papstwahl einsetzten.

Unter diesen Leuten findet man auch Pier Paolo Vergerio, der zu dieser Zeit schon ein angesehenes Mitglied der humanistischen Gemeinschaft war ${ }^{229}$ : der im Jahre 1370 in Capodistria (Koper, Iustinopolis) geborene Vergerio studierte in Padua, Florenz und Bologna und erwarb den Doktortitel 1405. ${ }^{230}$ In Florenz lernte er Coluccio Salutati ${ }^{231}$ und seinen Kreis, außerdem Francesco Zabarella kennen. Während eines späteren Aufenthaltes in Florenz lernte er Griechisch von Manuel Chrysoloras, und schloss Freundschaft mit Leonardo Bruni, der ihm seinen bekannten Dialogus ad Petrum Paulum Istrum Dialogus widmete. ${ }^{232}$ In Padua schloss er sich dem Kreis von Giovanni da Ravenna an, hier lernte er Ognibene da Scola kennen, den er später auch in Ungarn traf, als die beiden im Dienst von Sigismund von Luxemburg standen. ${ }^{233} 1405$ ging er nach Rom, wo er bis 1409 in der Kurie (erst bei Innozenz VII., und dann bei Gregor XII.) diente. Um die gleiche Zeit waren noch Poggio Bracciolini, Leonardo Bruni, Francesco da Fiano, und etwas später (unter Gregor XII.) Antonio

228 Poggio, Oratio, S. 260.

229 Die neueste Monographie über Vergerio wurde von McManamon geschrieben: John M. McManamon, Pierpaolo Vergerio the Elder. The Humanist as Orator, Medieval and Renaissance Texts and Studies 163 (Tempe: Arizona Center for Medieval and Renaissance Studies, 1996), [im Weiteren: „Vergerio”]. Über seine Reden, die er über den Heiligen Hieronymus geschrieben hat, vgl. vom gleichen Autor: Pierpaolo Vergerio the Elder and Saint Jerome: An Edition and Translation of ,, Sermones pro Sancto Hieronymo”, Medieval and Renaissance Texts and Studies 177 (Tempe: Arizona Center for Medieval and Renaissance Studies, 1999), [im Weiteren: „PPV and Jerome”]. Diese Ausgabe enthält außer den Texten und der englischen Übersetzung der Reden auch eine Liste von Vergerios Werken mit deren gesamter dem Autor der Monographie bekannten handschriftlichen Überlieferung und modernen Ausgaben. Eine, was den Umfang betrifft, bescheidenere, aber bezüglich der Angabe primärer Quellen an manchen Stellen genauere Darstellung von Vergerios Leben bieten zwei ältere Studien: Bánfis bereits erwähnte (vgl. Anm. 74) Studie und Leonardo Smiths Einleitung zu seiner kritischen Ausgabe der Briefe Vergerios: Leonardo Smith, Vorwort zum Epistolario von Pier Paolo Vergerio, L. IX-XXX. Siehe Anm. 3.

231 Über die Korrespondenz zwischen Vergerio und Salutati vgl. Milán Solymosi, „Pier Paolo Vergerio e Coluccio Salutati”, Verbum. Analecta Neolatina 4 (2002): 147-163.

232 Die kritische Ausgabe des Dialogs: Leonardo Bruni, Dialogi ad Petrum Paulum Histrum, Istituto Nazionale di Studi sul Rinascimento / Studi e testi 35, hrsg. v. Stefano Ugo Baldassarri. Florenz: Leo S. Olschi, 1994.

233 Ognibene della Scola war legum et artium doctor, wahrscheinlich trat er 1415 in Sigismunds Dienst. Vgl. Gisella Beinhoff, Die Italiener am Hof Kaiser Sigismunds (1410-1437), Geschichte und ihre Hilfswissenschaften 620 (Frankfurt am Main, Berlin, Bern, New York, Paris, Wien: Peter Lang, 1995), [im Weiteren: „Die Italiener”], S. 225-228. 
Loschi in der Kurie tätig. Vergerio geriet in Konflikt mit den anderen Humanisten, als diese auf dem Pisaner Konzil statt Gregor XII. zu bestätigen, Alexander V. zum Papst gewählt haben. Nach Alexanders Tod (1410) suchte Vergerio erneut die Freundschaft der anderen Humanisten und unterstützte zusammen mit ihnen den Nachfolger Alexanders, den neuen Pisaner Papst, Johannes XXIII. Nach Konstanz zum Konzil kam er 1414 wie viele Humanisten in Zabarellas Gefolge. In Konstanz trat er in Sigismunds Dienst, dem er nach dem Konzil nach Buda folgte, wo er bis zu seinem Lebensende blieb. Er starb in Buda $1444 .^{234}$

\subsubsection{Forschungslage}

Vergerios Leben kann in zwei große Abschnitte aufgeteilt werden: die Jahre in Italien und Konstanz, und sein zweiter Lebensabschnitt, den er in Buda verbrachte. Zwei Umstände machen diese Aufteilung plausibel: einerseits die Tatsache, dass die Intensität seiner literarischen Produktion in seiner Ungarnphase deutlich nachließ. Der zweite Grund für eine solche Aufteilung ist nicht ganz unabhängig von dem ersten und liegt in der Forschungslage selbst. Die Forschung behandelt Vergerios zwei Lebensabschnitte oft so getrennt, als ob es nicht um die gleiche Person gehen würde. Während nicht-ungarische Forscher sich oft auf die Untersuchung der Laufbahn Vergerios bis zu dem Punkt beschränken, als Vergerio nach Buda aufbrach, um Sigismund zu dienen, ${ }^{235}$ stellen ungarische Forscher meistens die Frage nach Vergerios Rolle in der „Verbreitung” humanistischer Kultur in Ungarn. Diese Forschungstradition misst Vergerio eine symbolische Bedeutung bei:

234 Hier muss ich auf die Tatsache verweisen, dass die Benutzung der Form „Budapest” bis 1873, dem Jahr, als die drei Städte: Buda (Ofen), Óbuda (Alt-Ofen) und Pest vereinigt worden sind und so Budapest entstanden ist, ein in der Sekundärliteratur leider allzu oft auffindbarer Anachronismus ist, der sich aber so erfolgreich durchgesetzt hat, dass man sogar in ernstzunehmenden Nachschlagewerken die Behauptung findet, Vergerio sei in Budapest gestorben. Vgl. zum Beispiel: Ansgar Frenken, „Pier Paolo Vergerio (der Ältere)", in Biographisch-Bibliographisches Kirchenlexikon, Hrsg. Friedrich Wilhelm Bautz (ab Band 3 fortgeführt von Traugott Bautz), (Herzberg: Verlag Traugott Bautz, 1975-), Bd. 14, Spalten 1572-1576, oder Herbert Jaumann, „Pier Paolo Vergerio der Ältere” in Herbert Jaumann, Handbuch Gelehrtenkultur der Frühen Neuzeit, Band 1: Bio-bibliographisches Repertorium, hrsg. v. Herbert Jaumann (Berlin, New York: Walter de Gruyter 2004), S. 677.

235 Vgl. zum Beispiel den schon oben zitierten Lexikonartikel von Herbert Jaumann, der seine Zusammenfassung von Vergerios Leben mit der Information beendet, dass Vergerio auf dem Konzil zum Stimmenzähler gewählt wurde. Der Leser des Artikels fragt sich, wo der Humanist für die nächsten 26 Jahre seines Lebens verblieben ist. Auch Bischoff erzählt Vergerios Geschichte nur bis zu seinem Verschwinden im ,fernen Osten”. Sein letzter Satz lautet: „Er ist nach dem Schluss des Konzils in der schönen Bodenseestadt nicht mehr nach dem sonnigen Italien gezogen, das ihm allerdings weniger Licht als Schatten gebracht hatte, sondern seinem königlichen Gönner und Freunde Sigismund nach dem fernen Osten ins Ungarnland gefolgt." Vgl. Conrad Bischoff, Studien zu P. P. Vergerio dem Älteren, Abhandlungen zur Mittleren und Neueren Geschichte 15 (Berlin und Leipzig: Dr. Walther Rothschild, 1909), [im Weiteren: „Studien”], S. 78. Eine Ausnahme ist McManamons bereits erwähnte Biographie (vgl. Anm. 150: McManamon, Vergerio). 
Ohne Vergerio kann ich für die humanistischen Züge des János Vitéz ${ }^{236}$ keine Erklärung geben: der Schlüssel für die rätselhafte Genese seiner humanistischen Charakterzüge kann alleine hier sein. Ich denke, dass es ohne Vergerio keinen János Vitéz gibt, ohne János Vitéz keinen Janus Pannonius, ohne die beiden gibt es den weltberühmten Hof des Königs Matthias nicht, und all das, was wir mit gerechtem Stolz ungarisches Quattrocento nennen. ${ }^{237}$

Diese überschwänglichen Worte ${ }^{238}$ des ungarischen Forschers Huszti exemplifizieren die Spannung zwischen dem augenscheinlich fehlenden Beweismaterial, das ermöglichen würde, über Vergerios Rolle als Kulturvermittler einerseits etwas Näheres zu sagen und der sich trotz dieser Unsicherheit fest etablierten Meinung, die Präsenz des italienischen Humanisten habe bei der Gründung humanistischer Kultur in Ungarn doch eine Schlüsselrolle spielen müssen. Die Schwierigkeiten, etwas Konkretes über Vergerios Zeit in Ungarn zu sagen, sind ursächlich der Dürftigkeit der diesbezüglichen Quellen zu verdanken. Die nach 1418 entstandenen Schriften Vergerios, die man heute zur Verfügung hat, sind zwei Briefe ${ }^{239}$, eine Über-

236 Johannes Vitéz de Zredna (Vitéz János, Ivan Vitez od Sredne) war Onkel des Dichters und Humanisten Janus Pannonius (Csezmicei János, Ivan Česmički), tätig in den Kanzleien des Königs Sigismunds, Ladislaus I., des Gubernators Johann Hunyadi (Hunyadi János) und des Königs Matthias, ab 1445 Bischof von Großwardein (Várad, Oradea), ab 1465 Erzbischof von Gran (Esztergom). Er spielte eine entscheidende Rolle bei der Gründung der Academia Istropolitana, der Universität von Pressburg (Pozsony, Bratislava). Seine Briefe gegen die drohende Gefahr von Seiten des osmanischen Reiches wurden von seinem Freund Pál Ivanich gesammelt, kopiert und kommentiert. Vgl. Johannes Vitez de Zredna, Opera quae supersunt, Bibliotheca Scriptorum Medii Recentisque Aevorum 3, hrsg. v. Iván Boronkai (Budapest: Akadémiai Kiadó, 1980).

237 József Huszti, Janus Pannonius (Pécs: Janus Pannonius Társaság [Janus Pannonius Gesellschaft], 1931), S. 7. Die Übersetzung ist von Zs. K. Ein anderer prominenter Forscher der neulateinischen Literatur in Ungarn, Tibor Kardos, stellt die gleiche Frage wie Huszti und ist mit dem gleichen Problem konfrontiert: auch sein Anliegen ist es, das fehlende Glied der Traditionskette zu finden, nachzuweisen also, mit welcher Vermittlung die humanistische Kultur in Ungarn sich etabliert hat. Auch seine Artikel bezeugen einerseits die feste Überzeugung, was Vergerios Rolle in diesem Vermittlungsprozess betrifft, andererseits aber auch eine Unsicherheit, die sich mit dem Mangel der handfesten Beweise für diese Rolle erklären lässt. Kardos schreibt über Vergerios ,große Verdienste” in der Ausbildung eines neuen Kreises der Hofbeamten und in der „Gründung eines neuen Lebensideals”, ohne aber konkrete Beweise für diese Annahme anzugeben. Sein einziger Beweis ist, dass nach seiner Meinung die Episteln von Vitéz János eindeutig auf die Kenntnis der Episteln Petrarcas hindeuten. Vgl. Tibor Kardos, „Petrarca e la formazione dell'umanesimo Ungherese", in Italia ed Ungheria. Dieci secoli di rapporti letterari, hrsg. v. Mátyás Horányi und Tibor Klaniczay (Budapest: Akadémiai Kiadó, 1967), 67-89, [im Weiteren: „Petrarca”], hier besonders S. 72 f. Eine ähnliche Argumentation findet man bei: Tibor Kardos, A magyarországi humanizmus kora [Das Zeitalter des ungarischen Humanismus] (Budapest: Akadémiai Kiadó, 1955), [im Weiteren: „Humanizmus”], hier besonders S. 84-105. Auch McManamon übernimmt diese Annahme, was teilweise auch der Dynamik des von ihm gewählten Genres, des biographischen Portraits, zu verdanken ist. Ein großes Narrativ kann nur so erstellt werden, dass man die Lücken, für die man nur wenig Beweismaterial zur Verfügung hat, mit großzügigen Annahmen füllt. Für diese Überbrückung fand McManamon die Hypothesen der ungarischen Forscher vor. In einer Fußnote gibt er auch die Hinweise auf die Sekundärliteratur, die die Rolle Vergerios in der Verbreitung des Humanismus in Ost-und Mitteleuropa beschreibt: McManamon, Vergerio, S. $158 \mathrm{f}$.

238 Die suggestive und großzügige Formulierung wurde letztens auch in einem populärwissenschaftlichen Buch zitiert: Marcus Tanner, The Raven King. Matthias Corvinus and the Fate of his Lost Library (New Haven, London: Yale University Press, 2008), S. 73.

239 Beide wurden veröffentlicht in Vergerio, Epistolario: S. 384-387 und 388-395. Den einen Brief schrieb er an einen Unbekannten, laut Smiths Datierung nach 1420. Hier erzählt er eine Anekdote über einen Böhmen, der einem Polen seinen Hut wegnimmt. Als dieser seinen „captur” (seinen Hut in seiner Muttersprache) zurückverlangt, unterstellt ihm der Böhme, dass es verrückt sei, was er in der Hand halte, 
setzung der Alexander-Vita Arrians, der dazu verfasste Widmungsbrief an Sigismund und sein Testament ${ }^{240}$. Von einer Biographie Sigismunds ist außer deren Titel De gestis Sigismundi regis Pannoniae nichts erhalten geblieben. ${ }^{241}$ Dementsprechend müssen Versuche, Vergerio als den aktiven Vermittler humanistischer Kultur in Ungarn darzustellen, als nicht fundiert in Frage gestellt werden.

Die Annahme, dass Vergerio seine Bücher Vitéz vermacht habe, ist Teil dieses Gründungsmythos. ${ }^{242}$ Eine andere Annahme, die Vergerio als das fehlende Glied der Transferkette zwischen dem italienischen Humanismus und der humanistisch geprägten Kultur des Hofes

sei ein „cluca” (oder „cucla”: der Hut in seiner Muttersprache). Auch Wucherer verfolgen dieselbe Strategie, indem sie ihre Tätigkeit statt als „usurae” als „cambium” bezeichnen. Mit dieser Praktik können sie die Ahnungslosen irreführen. Der letzte Satz des Briefes bezieht die Geschichte auf die ,artes honestissime”: auch diese seien nicht mehr wie früher: „nam honestissime quidem artes in vilissimum ministerium, philosophiam in philargyriam, oratoriam in nummulariam, ipsasque grecas litteras quas dicunt cambii, per malum cambium converterunt". Die Logik dieses Vergleiches hapert etwas: in der Anekdote ging es um einen Wechsel der Benennung derselben Sache, genauso wie im Fall der Praktik der Wucherer. Die Wucherer nennen ihre Tätigkeit, die aber dieselbe bleibt, anders, um sie zu veredeln. Im Fall der artes und der litterae geht es eigentlich um das Gegenteil: die Benennung bleibt dieselbe, trotz der veränderten Qualität und Motivation von deren Praktikern. Den anderen Brief schrieb Vergerio laut Smiths Datierung zwischen 1432 und 1436 an den Bischof von Segna (Zengg, Senj), Ioannes de Dominis. Auch dieser Brief ist ein Beispiel für eine facetia: hier erzählt Vergerio über den Heuchler namens Tuscanellus, der sich als Arzt ausgab und so sein Geld verdiente und über einen Bauern, der seine unreifen Feigen loswerden wollte und diese unter die reifen mischte. Die Moral der Geschichten ist hier ebenfalls am Ende des Briefes zusammengefasst: ,precari bona, deprecari mala; de bonis gratias agere [Deo] quod dedit, de malis gratias agere quod peiora non dedit." Über die Motivation für das Schreiben der beiden Briefe kann man nichts Konkretes sagen, da sie Geschichten erzählen, die wegen ihrer Anekdotenhaftigkeit schlecht kontextualisierbar sind.

240 Verfasst in Buda, veröffentlicht: Vergerio, Epistolario, S. 463-471.

241 Die Annahme, dass Vergerio eine solche Biographie geschrieben habe, basiert auf einem Brief aus dem Jahre 1509, den ein ferner Verwandter Vergerios, Giovanni Andrea Favonio aus Rom schrieb. Der Brief wurde veröffentlicht in: Vergerio, Epistolario, S. LVII. Für Ziliottos Skepsis vgl. Baccio Ziliotto, La cultura letteraria di Trieste e dell'Istria (Trieste: Vram, 1913), [im Weiteren: „La cultura”], S. 82 f. In diesem Brief bittet der Verwandte seinen Freund, Scipione Carteromacho Fortiguerra darum, nach den Werken Vergerios in Bologna zu suchen, weil er selbst nur ein einziges Werk von seinem Verwandten gefunden habe. Auf seiner Liste der Werke Vergerios, nach denen er suchte, befindet sich auch der Titel De gestis Sigismundi regis Pannoniae. Obwohl Giovanni Andrea Favonio Vergerios Quelle für seine Liste nicht bekannt ist und kein weiterer Beweis für die Existenz eines solchen Werkes vorliegt, scheint die Forschung, abgesehen von der von Ziliotto vertretenenen Skepsis, mit der Annahme, dass Vergerio eine Biographie Sigismunds geschrieben habe, als Tatsache umzugehen. Vgl. Elemér Mályusz, Zsigmond király uralma Magyarországon 1387-1437, [König Sigismund in Ungarn 1387-1437] (Budapest: Gondolat, 1984), [im Weiteren: „Zsigmond”], S. 271-272. Mályusz' Annahme der Existenz einer solchen Schrift wurde auch in jüngeren Arbeiten zitiert, wie zum Beispiel von Gisela Beinhoff, Die Italiener, S. 233. Beinhoff übernimmt auch die fehlerhafte Annahme von Mályusz, dass Sigismund Vergerio als den Verfasser der Trauerrede für Zabarella kennengelernt hätte. Vgl. Mályusz, Zsigmond, S. 271, Beinhoff, Die Italiener, S. 231.

Diese Annahme hat sich in der Forschung durch die folgenden Studien eingebürgert: József Huszti, „Pier Paolo Vergerio és a magyar humanizmus kezdetei” [Pier Paolo Vergerio und die Anfänge des ungarischen Humanismus], Filológiai Közlöny 1 (1955): 521-533, Tibor Kardos, Humanizmus, 118 f; Klára, Csapodi Gárdonyi, Die Bibliothek des Johannes Vitéz (Budapest, Akadémiai Kiadó, 1984), S. 23-28. Klára Pajorin ist aber in ihren fundierten Studien der Meinung, dass diese Annahme nicht bewiesen werden kann. Vgl. Klára, Pajorin, „A magyar humanizmus Zsigmond-kori alapjai [Die Anfänge des ungarischen Humanismus im Zeitalter von Sigismund von Luxemburg]", in Müvészet Zsigmond korában 1387-1437 [Kunst im Zeitalter von Sigismund von Luxemburg] hrsg. v. László Beke, Ernő Marosi, Tünde Wehli (Budapest: Művészettörténeti Kutatócsoport, 1987), 193-211, [im Weiteren: „A magyar humanizmus”]; und Klára Pajorin, „Vitéz János múveltsége [Die Bildung von Vitéz János]”, Irodalomtörténeti Közlemények [Literaturhistorische Mitteilungen] 108 (2004): 533-540, [im Weiteren: „Vitéz”]. 
König Matthias' zu definieren versucht, die aber nach einer gründlichen Prüfung der Quelle, auf der sie basiert, unhaltbar zu sein scheint, ist die Behauptung, dass Vergerio, zusammen mit Filippo Podocataro, János Vitéz und Gregor von Sanok Mitglied eines humanistischen Kreises gewesen sei. Die Erzählung, auf die sich eine solche Hypothese stützt (die aber oft als Fakt vermittelt wurde), ist die Schrift Vita et mores Gregorii Sanocei des Filippo Buonaccorsi (Philippus Callimachus Experiens). ${ }^{243}$ In der Vita des Erzbischofs von Lwow (Lemberg), der, bevor er Erzbischof wurde, eine Zeitlang in Ungarn wohnte und zusammen mit Vitéz als Erzieher der Hunyadi-Brüder László und Mátyás (des späteren Königs Matthias) tätig war, liest man über das regelmäßige Treffen von den vier oben genannten Humanisten. Wenn man aber die Lebensdaten, die man von den Protagonisten der Erzählung zur Verfügung hat, mit der Erzählung vergleicht, wird deutlich, dass solche Treffen in der Form, wie darüber der italienische Humanist berichtet, gar nicht zustande kommen konnten. ${ }^{244}$ Es wäre vielleicht sinnvoll, bevor man anfängt, Buonaccorsis Erzählung zu korrigieren und so einige von ihm erwähnte Fakten für die Genealogie des Humanismus in Ungarn zu retten, über Buonaccorsis Motivation für das Schreiben der Vita nachzudenken. Buonaccorsi war früher Mitglied der Akademie des Pomponio Leto in Rom, bis ein schwerer Konflikt zwischen dem Papst und den Akademikern ausbrach und er wegen der Beschuldigung, an einer Verschwörung gegen den Papst teilgenommen zu haben, gezwungen wurde, ins Exil zu gehen. Er fand bei dem Erzbischof von Lwow, Gregor von Sanok, in Dunajow Zuflucht. ${ }^{245}$ Eine humanistische Vita des Gregor von Sanok zu schreiben, war die für den italienischen Humanisten selbstverständliche Gegenleistung für seine Aufnahme an dem Hof des Erzbischofs. Buonaccorsi vollendete die Vita, als die darzustellende Person schon gestorben war, und widmete sie Sbignew Olessnicki, dem Sekretär des Königs, Neffe des Kardinals Olessnicki. Sbignew Olessnicki war sein nächster Patron, dem Buonaccorsi wahrscheinlich von Gregor

243 Für Buonaccorsis Biografie vgl. Gioacchino Paparelli, Callimaco Esperiente (Filippo Buonaccorsi) (Salerno: Edizioni Beta, 1971).

244 Über die chronologischen Widersprüche der Erzählung hat Tibor Klaniczay berichtet. Vgl. Tibor Klaniczay, A magyarországi akadémiai mozgalom elötörténete [Die Vorgeschichte der ungarischen akademischen Bewegungen], Humanizmus és Reformáció 20 (Budapest: Balassi Kiadó, 1993), hier S. 27 35. Nichtdestotrotz bewertet er die Information über die Existenz eines solchen Kreises als vertrauenswürdig und sucht nach einer Möglichkeit, die Geschichte mit einigen Korrekturen im Großen und Ganzen als haltbar beizubehalten. Diese Bemühung ist mit seinem Erkenntnisinteresse erklärbar: wie es auch der Titel seiner Studie offenlegt, will Klaniczay die Vorgeschichte akademischer Bewegungen in Ungarn darstellen. Für das Schreiben einer solchen Geschichte ist es natürlich verlockend, die Anfänge dieser Vorgeschichte auf einen so frühen Zeitpunkt wie möglich zu datieren und mit großen Namen zu verbinden. Klára Pajorin ist in ihrer schon zitierten Studie (Pajorin, Vitéz) kritischer und schlägt vor, darauf ganz zu verzichten, dass man Vitéz und Vergerio auf solche Weise zusammenbringt. Damit hinterfragt sie, genauso wie mit ihrer Skepsis gegenüber dem Schicksal von Vergerios Bibliothek, Vergerios Rolle als das fehlende Glied der Transferkette.

245 Über das den Buonaccorsi in Polen umgebende Netzwerk vgl. Jacek Wiesiołowski, „Gli amici e i mecenati di Callimaco in Polonia", in Callimaco Esperiente. Poeta e politico del '400, hrsg. v. Gian Carlo Garfagnini (Florenz: Leo S. Olschi Editore, 1987), 91-104. 
von Sanok empfohlen worden war. Die Geste, die Vita seines vorherigen Patrons dem neuen Patron $\mathrm{zu}$ widmen, ist auch als eine Geste der Selbstpositionierung zu deuten. Genauso selbstverständlich war es, diese Vita den Regeln der humanistischen Tradition gemäß zu schreiben, das heißt, Gregor von Sanok als Humanisten darzustellen. Den Erzbischof als Mitglied eines humanistischen, mit der römischen Akademie vergleichbaren Kreises zu zeigen, kann als Bestandteil eines humanistisch konzipierten Porträts gesehen werden. Diese Tatsache mahnt meines Erachtens zur Vorsicht bei der Erwägung der Vertrauenswürdigkeit der Erzählung Buonaccorsis.

Die Erzählung als bare Münze zu nehmen, und dementsprechend Vergerio als einen aktiven Missionar des Humanismus in Ungarn zu sehen, ist vielleicht Folge des Wunsches, für die Genealogie des ungarischen Humanismus eine mit Enea Silvio Piccolomini vergleichbare Stiftungsfigur zu finden. ${ }^{246}$

Welche fast an Parodie grenzenden Züge die Bewertungen des Wendepunkts in Vergerios Karriere annehmen können, zeigen die Darstellungen, die diese Bewertungen mit einem Hinweis auf die klimatischen Verhältnisse verknüpfen: Während Bischoff, der Vergerios Zeit in Buda nicht der Erzählung wert gehalten hat, in seinen letzten Satz die wohlbekannte Gegenüberstellung des sonnigen Italien mit dem fernliegenden Osten einfließen lässt und damit den Topos des kalten, sonnenlosen Barbarenlandes impliziert ${ }^{247}$, sieht es der ungarische Forscher Kardos genau umgekehrt. Den Grund dafür, dass Vergerio sich in Ungarn wohl gefühlt haben musste, sucht er ebenfalls im Klima: Vergerio habe sich in Ungarn unter anderem deswegen wohl gefühlt, weil ihm dessen Klima von seiner Heimat her, das heißt von Istrien, vertraut gewesen sei. ${ }^{248}$

Zusammenfassend kann man feststellen, dass von den zwei Richtungen: der Tendenz der ungarischen Forschung, die Vergerio eine aktive Rolle in der „Gründung” oder „Verbreitung" des Humanismus in Ungarn - je nach der Metapher, die man bevorzugt - zuzuteilen versucht, und Vergerios Tätigkeit als Humanist lieber als ununterbrochen sehen möchte, und der Tendenz der nicht-ungarischen Forschung, die eine Zäsur zwischen seiner Zeit in Italien und in Ungarn betont, auf Grund der zur Verfügung stehenden Quellen eher die letztere begründet zu sein scheint. Das bedeutet aber keineswegs, dass Vergerios Beispiel nicht die

246 Diese Bestrebung erscheint manchmal ganz offen, wie zum Beispiel in der Studie von Tibor Kardos, in der zwischen den zwei Humanisten eine Parallele gezogen wird. Aus dem schnellen Vergleich geht allerdings Vergerio als Sieger hervor: „Gli [Vergerio] può essere paragonato solo Enea Silvio Piccolomini, il quale lavora nella cancelleria dell'imperatore Federigo III, e il quale più tardi diventa papa Pio II, un altro ingegno cospicuo, anche se non sia una figura di pioniero tanto prominente quanto il Vergerio." Vgl. Kardos, Petrarca, S. 72.

247 Vgl. Anm. 235 dieser Arbeit.

248 Kardos, Humanizmus, S. 101. 
Möglichkeit bieten könnte, über die Karriereaussichten und die damit verbundenen Selbstdarstellungsstrategien der Humanisten nachzudenken: es gilt weiterhin zu fragen, welche Motivationen beiderseits - von der Seite Sigismunds und Vergerios - dafür genannt werden können, dass der Humanist in Sigismunds Dienst trat, und welche Selbstdarstellungsstrategien dafür verwendet wurden, diese Karrierevorstellungen zu verwirklichen.

\subsection{Vergerios Engagement für Sigismund von Luxemburg in Konstanz im Spiegel der zeitgenössischen Wahrnehmung}

\subsubsection{Der Auslöser: Vergerios cedula}

Der 1414 in Zabarellas Begleitung in Konstanz ankommende Vergerio wurde nicht immer als ein würdiger Nachfolger Petrarcas wahrgenommen, er wurde auf dem Konzil einmal sogar ausgelacht. Wie kam es zu dieser Peinlichkeit? Vergerio stand in der Prioritätsdebatte nicht auf der Seite, auf der wir Poggio und Zabarella sahen: er versuchte nämlich Sigismunds Interessen zu vertreten. In einer cedula, die als die Ankündigung einer disputatio konzipiert wurde, und die an die Kirchentüren von Konstanz geschlagen wurde, verkündete Vergerio in Form von questiones, responsiones und correlaria seinen Standpunkt in der Debatte. $^{249}$ Seine erste Frage ist, ob diejenigen, die für eine schnelle Papstwahl sind, als „turbatores concilii, autores fautores scismatum et vehementer de heresi suspecti” seien. Die zweite Frage ist, ob die „reformacio ecclesie in capite” ein ausreichender Grund für die Verschiebung der Papstwahl sei. Drittens fragt er, ob selbst die Verhandlungen über den Wahlmodus aus dem gleichen Grunde verschoben werden sollten. Seine Antworten auf alle drei Fragen sind selbstverständlich positiv. Zum Schluss bemerkt er, dass alle, die aus der Hoffnung auf ,privata commoda” für die schnelle Papstwahl sind, eine große Sünde begehen. Mit dieser Bemerkung war wahrscheinlich unter anderen auch das Schreibervolk der ehemaligen Päpste gemeint, das von einer zügigen Wahl des neuen Papstes die Lösung der eigenen existentiellen Unsicherheit erhofft hatte, und dem auch Poggio angehörte.

Die Sprache der cedula wird durch die gewählte Form der scholastischen questiones bestimmt: Vergerio benutzt in dieser Schrift lateinische Ausdrücke, nach denen man in seinen Briefen vergebens suchen würde, wie zum Beispiel „de presenti”, oder „necessitas necessaria".

Sein Engagement für den König muss für einen großen Aufruhr gesorgt haben, es fand nämlich Resonanz in mehreren Schriften, die auf dem Konzil entstanden sind. Als Erstes kann

249 Der Text der cedula wurde veröffentlicht in: Finke, ACC, Bd. 3, S. 667-669. 
hier eine direkte Antwort auf Vergerios questiones genannt werden. ${ }^{250}$ In dieser Antwortschrift wird Vergerios cedula ein ,libellus famosus et iniuriosus” genannt, und die dort erörterten Fragen im entgegengesetzten Sinn beantwortet. Dementsprechend werden in dieser Schrift die Personen, die gegen eine unmittelbare Papstwahl sind, als Anhänger der Huss'schen, häretischen doctrina und als „fautores pravitatis scismatice” abgestempelt.

\title{
3.2.2. Der ausgelachte Vergerio
}

In Fillastres Konzilstagebüchern ist die Geschichte wie folgt geschildert:

\begin{abstract}
Hiis diebus multi adherentes regi visi sunt cedulam per collegium cardinalium oblatam suprascriptam impugnare, inter quos unus doctor Petrus Paulus Ytalicus. Ille obtulit se publice impugnaturum die veneris post festum corporis Christi, que fuit XI. Junii, in loco nacionis Germanie. Et super hoc posuit cedulas in valvis ecclesiarum, propter quod cardinales aliqui et plures ex nacionibus Ytalie et Gallie propter hoc congregati constituerunt de qualibet illarum nacionum sex doctores, tres theologos et tres iuristas, ex quibus debebant dictam cedulam comprobare et respondere argumentis illius et alii assistere. Dicta autem die veneris comparuerunt plures in dicto loco; sed illi de nacione Germanie prohibuerunt ibi fieri disputacionem. Et nichil fuit factum, quod multum regi displicuit, quia volebat hoc fieri. Ymo creditur, quod hoc fieri faciebat. Ille autem Petrus Paulus fuit reputatus a pluribus temerarius et derisus. ${ }^{251}$
\end{abstract}

Vergerio wurde laut dieses Berichtes für dreist gehalten und ausgelacht, weil er sich so eifrig für Sigismund eingesetzt hatte und weil dieser Versuch dann ausgerechnet an dem Widerstand der deutschen Nation scheiterte. Die mit viel Wirbel angekündigte Disputation, zu der sich viele versammelt hatten, fiel aus.

Dies ist natürlich nicht die einzige Szene, in der Fillastre etwas maliziös über die die Papstwahl hinauszögernden Versuche von Sigismunds Partei berichtet. In den vorherigen Kapiteln wurden bereits die folgenden Szenen erwähnt: der Bericht über die königlichen Faustschläge, eine Szene, wo Sigismund möglicherweise nicht nur wegen der zu seiner Position unpassenden Handgreiflichkeit lächerlich gemacht wird, sondern auch wegen seiner bescheidenen Lateinkenntnisse, und die mit eleganter Zurückhaltung erfasste und deswegen umso effektiver wirkende Schilderung des Kampfes gegen die eigenen Kräfte, die im Dunkeln für fliehende Kardinäle gehalten wurden. Dies sind Beschreibungen von Vorfällen, die wegen Sigismunds Leuten im tumultus endeten: „tumultus magnus, gravis discordia”252. An einer anderen Stelle wird der tumultus sogar unmittelbar mit der Person des Königs in

\footnotetext{
250 Diese Schrift wurde ebenfalls von Finke veröffentlicht: Finke, ACC, Bd. 3, S. 669 f.

251 Fillastre, Gesta, S. 112

252 Fillastre, Gesta, S. 140 f.
} 
Zusammenhang gebracht: „Et tunc rex surrexit et factus est tumultus” ${ }^{, 253}$. Die Spannung zwischen den zwei Teilen des Satzes kommt von der Enttäuschung über den König, also von der Unangemessenheit seines Verhaltens her: wenn ein König sich erhebt, sollte kein tumultus ausbrechen, sondern im Gegenteil, der König, als Schirmherr des Konzils, sollte eigentlich eher Ruhe und Effektivität stiften. Wenn stattdessen Unruhe, Aufruhr und Chaos entsteht, so bedeutet es verkehrte Verhältnisse, was als ein Mittel von Komik bezeichnet werden kann. Taten, die nicht $\mathrm{zu}$ der eigenen Situation und dem eigenen Rang passen, lassen einen lächerlich erscheinen. Sigismund und seine Leute sorgen also nicht nur für Chaos auf dem Konzil, sondern auch für Lachen.

Dass es in Fillastres Interesse stand, Vergerio als Zielscheibe der Lächerlichkeit darzustellen, ist keinesfalls überraschend. Erstens stand Vergerio auf Sigismunds Seite, was schon allein ein Grund für Fillastres Antipathie gewesen sein musste. Dass Fillastres Aufzeichnungen keineswegs als ein unvoreingenommener Bericht der Geschehnisse am Konzil gelesen werden können, versteht sich eigentlich von selbst. Fillastre berichtet aus einer typisch französischen Perspektive über das Konzil, was Sigismund nicht besonders positiv erscheinen lässt. Dies ist auch in der Sekundärliteratur mehrmals bemerkt worden: Thomas Rathmann widmet diesem Problem ein ganzes Kapitel in seiner Monographie, die sich mit der Textualität des Konzils befasst. Er arbeitet stärker die Perspektivität, Intertextualität und Narrativität heraus. ${ }^{254}$

Zweitens war Vergerio Italiener, was von Fillastre auch betont wurde (,unus doctor Petrus Paulus Ytalicus”). Nach Petrarcas furiosen Attacken gegen die Galli, die er als Barbaren abgestempelt hatte, hatten die Franzosen einen guten Grund, Italienern gegenüber ein wenig misstrauisch zu sein. Darunter darf man sich natürlich keineswegs eine eindeutige Missachtung der Italiener von Seiten der Franzosen vorstellen. Nicht nur, weil jede Verallgemeinerung gefährlich und meistens ungerecht ist, sondern auch weil dieser spezielle Fall viel komplizierter ist, als dass man ihn mit einer einfachen Aussage abtun könnte. Französische

253 Fillastre, Gesta, S. 139.

254 Vgl. Rathmann, Geschehen. Rathmanns Argumentation ist sehr überzeugend: er beschreibt Fillastres Strategie nicht als „Mangel”, er findet es nicht angemessen, Fillastre auf Grund unseres neuzeitlichen Wahrheitsanspruches zur Rechenschaft zu ziehen. Dies sollte nach dem neuen Geschichtsverständnis, das die Konstruiertheit der Geschichte betont, keine Überraschung sein. Der Ansatz des Autors ist, das Konzil als ein diskursives Ereignis zu beschreiben, das selbst durch die Texte, die es darstellen, immer neu konstituiert wird. Dieser Ansatz scheint mir einleuchtend zu sein und dem diskursiven Verständnis von Humanismus, das in dieser Arbeit vertreten wird, steht er auch nahe. Das einzig Problematische daran ist, dass die These, die er widerlegt (Fillastres Schreiben sei dem ersten Anschein nach ein objektiver Bericht), eigentlich von niemandem vertreten worden ist. Bereits Hollnsteiner schreibt über den „Mangel an Objektivität" bei Fillastre, und dass er in seinen Aufzeichnungen ,überall der Franzose” sei. Auch in Bezug auf Sigismund stellt er fest, dass Fillastre ein ,ihm übel wollender Franzose” gewesen sei: vgl. Hollnsteiner, Sigismund, S. 187 und 200. Bei Rathmann ist neu, dass er Fillastres Voreingenommenheit nicht als Negativum abstempelt. 
Humanisten der ersten Generation haben Petrarca viel intensiver nachgeahmt, als es sich aus ihren expliziten Aussagen vermuten lässt. Sie haben seinen Namen oft, wahrscheinlich verärgert über seine vernichtenden Aussagen über Franzosen, zwar verschwiegen, aber seine Werke trotzdem gelesen und nachgeahmt. ${ }^{255}$ Italienische Humanisten und deren französische Sinnverwandte hatten demzufolge ein zwiespältiges Verhältnis, dessen Koordinaten einerseits von Agonalität, andererseits aber von einer sich formenden, die Agenten der neuen Kultur miteinander verbindenden Gruppenidentität bestimmt wurde. ${ }^{256}$

Eine andere Frage, die Fillastres Beschreibung von Vergerios Auftritt auf dem Konzil aufwirft, ist eine persönlichere, deren Beantwortung aber auch viel über die allgemeinen Züge der französisch-italienischen Beziehungen aussagen könnte: wenn Fillastre über Vergerio als über „unus doctor Petrus Paulus Ytalicus” schreibt, so impliziert diese Formulierung, dass er diesen Petrus Paulus früher nicht gekannt hatte. Kannte Fillastre Vergerio tatsächlich nicht? Vergerio war um diese Zeit durch seinen De ingenuis moribus et liberalibus adulescentiae studiis liber ein durchaus bekannter und angesehener Autor; so ist es nicht auszuschließen, dass sein Ruhm bis nach Frankreich gereicht haben konnte. Ein weiterer Fakt, der darauf hinweist, dass Vergerio Fillastre nicht völlig unbekannt gewesen sein konnte, besteht darin, dass Fillastre sich 1415-16 auf dem Konzil Brunis Dialogi ad Petrum Histrum, zusammen mit einer großen Auswahl von Ciceros Werken in einen Pergamentcodex kopieren ließ. ${ }^{257}$ Wenn also Fillastre Vergerio kannte, konnte er ihn vielleicht mit dem Wichtigtuer an Sigismunds Seite nicht identifizieren? Die dritte und meines Erachtens wahrscheinlichste Möglichkeit

255 Diese Meinung stammt von Gilbert Ouy, der zu dieser Einsicht nach aufwendigem Studium des handschriftlichen Quellenmaterials gelangt ist. Vgl. Ouy, Discovering Gerson, S. 94-96.

256 Man konnte auf Petrarcas Kritik als Franzose vielleicht auf einer gewissen Ebene sogar stolz sein. Das Prestige, das die Person des Kritikers seiner Aussage gegeben hatte, war wahrscheinlich größer als der Prestigeverlust, der aus dem Inhalt seiner Kritik zu befürchten war. Die Kontextgebundenheit dieser Kritik spielt auch eine wichtige Rolle bei dieser Erwägung: Invektiven gehörten zum Instrumentarium literarischer Kommunikation der neuen Kultur. Zielscheibe einer Invektive zu sein, bedeutete ironischer Weise auch eine gewisse Zugehörigkeit, also Teil eines Kreises zu sein, dessen „Mitglieder” voneinander wissen und miteinander kommunizieren. Invektiven sind nicht nur Waffen, nicht nur Instrumente der Ausgrenzung, sondern auch Werkzeuge beim Ausbauen eines literarischen Raums, dessen Wohnrecht nicht nur der Autor der Invectiva, sondern auch die Zielperson für sich beanspruchen kann. Es ist natürlich kein Zufall, dass Petrarca seine Invektiven nicht gegen ungarische literati geschrieben hatte. Andererseits die Tatsache zu leugnen, dass es sich bei diesem Genre um Attacken handelt, würde natürlich ebenso dessen Wesen verfälschen und wäre deswegen unangebracht. Miteinander in freundschaftlicher Korrespondenz zu stehen bedeutet natürlich eine wesentlich angenehmere und sicherere Art der Zugehörigkeit.

257 Über Fillastres Bibliothek vgl. Jeudys Rekonstruktion von Fillastres Bibliothek: Colette Jeudy, „La bibliothèque de Guillaume Fillastre", in Humanisme et culture géographique à l'époque du concile de Constance autour de Guillaume Fillastre, Actes du Colloque de l'Université de Reims 18-19 Novembre 1999, History of the Representation of Space in Text and Image 3, hrsg. v. Didier Marcotte (Turnhout: Brepols, 2002), 245-91. Auf der von Jeudy rekonstruierten Liste, die nur die erhaltenen Bücher Fillastres enthält, befinden sich acht Bücher, die in Konstanz, während des Konzils kopiert worden sind. Unter den Werken findet man viele antike Autoren, und von den modernen Werken auch einige, die für ein Interesse des Kardinals für die neue Kultur sprechen: Quintilians Declamationes maiores, vieles von Cicero, Zanobi della Stradas Oratio zu seiner Dichterkrönung. Unter seinen Kodices findet man weiterhin mehrere, die Brunis Übersetzungen aus dem Griechischen enthalten. 
wäre, dass Fillastre genau wusste, wen er in seinen Tagebüchern als eine in seiner Wichtigtuerei gescheiterte und deswegen lächerliche Figur dargestellt hatte. In diesem Fall könnte man seine fingierte Ignoranz dahingehend interpretieren, dass er Vergerio ein Schnippchen schlagen wollte.

Fillastre schrieb seine Aufzeichnungen ganz gewiss nicht nur für sich, obwohl die von Finke diesen Schriften zugeteilte Bezeichnung „Tagebücher” eher einen privaten Charakter dieser Aufzeichnungen suggeriert. Sein Bericht wurde Ende 1431 in einem Konsistorium von Kardinal Juan Cervantes, mit der Titularkirche San Pietro in Vincoli, vorgelesen, als er aufgefordert wurde, die Bulle Papst Eugens IV. über die Auflösung des Basler Konzils zu unterschreiben. Er zeigte den Anwesenden Fillastres Text als einen Beweis für die Existenz des auf dem Konzil von Konstanz verabschiedeten Dekrets Haec sancta vor:

De illo autem decreto fecerat sibi specialem noticiam, penes se habens originalem librum de gestis synodi illius, editum a bone memorie Guillermo tituli sancti Marci cardinali biennio ante defuncto, negareque id fuisse decretum synodale coram eo audebat nullus, promptissime cunctis ostendente librum illum, minusque refragari conditoris auctoritatem et in illo concilio, prout illius gesta testificantur, et in Romana curia usque diem obitus singulari habitum veneracione. ${ }^{258}$

Die Autorität des Buches (die von der Autorität seines Autors stammt) wurde dazu benutzt, die Versuche, das Konzil von Basel aufzulösen, zum Scheitern zu bringen. Dass Fillastres Buch ein so großes Ansehen hatte und als autoritätsstiftende Instanz benutzt wurde, könnte theoretisch eine von der Intention des Autors unabhängige Tatsache sein, erweckt aber eher den Eindruck, dass Fillastre sein Buch von vornherein nicht für private Ziele konzipiert hatte, und dass der Kardinal beim Schreiben und mit seiner Strategie der Darstellung der Geschehnisse des Konzils ein ganz bestimmtes Publikum vor Augen hatte. ${ }^{259}$

258 Joannes de Segovia, Historia gestorum generalis synodi basiliensis, Monumenta conciliorum generalium seculi decimi quinti, Tomus. 3., pars 5 und Tomus 4, hrsg. v. Ernestius Birk (Wien: Typis C. R. Officinae Typographicae Aulae et Status, 1873), hier S. 75.

259 Die Frage des Publikums, für das Fillastre seine Schrift verfasst hatte, wird von Rathmann leider nicht erörtert, obwohl es aus seiner Fragestellung folgen würde: wenn man, Rathmanns überzeugender Argumentation folgend, annimmt, dass die Tagebücher nicht als objektive Widerspiegelung der Konzilsgeschehnisse zu verstehen sind, sondern vielmehr als Bestandteil dieser Geschehnisse, und dass sie als solche selbst auf die Ereignisse eingewirkt haben, so wäre die Frage nach der Intention und dem anvisierten Publikum dieser Schrift nicht uninteressant. 


\subsubsection{Der „utriusque iuris ac medicine doctor" und gekrönte Dichter}

Secuntur aliquod questiones cum ipsarum responsionibus et correlariis facte per dominum Petrum Paulum utriusque iuris ac medicine doctorem necnon laureatum poetam, affixe valvis ecclesiarum in die sancti Laurencii anno etc. XVII. ${ }^{260}$

Von wem die Bezeichnung Vergerios als „dominus Petrus Paulus utriusque iuris ac medicine doctor necnon laureatus poeta" stammt, kann nicht mit Sicherheit entschieden werden. Die Zeilen leiten die Abschrift der von Vergerio an die Kirchentüren angeschlagenen questiones ein. Der Satz, der Vergerios Bezeichnungen trägt, ist nicht Teil des abgeschriebenen Textes, er bildet die Einleitung zu diesem Text („Secuntur”). Aus diesem Grund könnte man davon ausgehen, dass die Auflistung der Titel Vergerios dem Kopisten zu verdanken ist, der die questiones in den Codex ${ }^{261}$ eingetragen hatte. Seine Quelle konnte aber die von ihm kopierte cedula sein, auf der Vergerio sich selbst vielleicht mit diesen Titeln dargestellt hatte. Dies scheint deswegen wahrscheinlich, weil der Kopist sonst möglicherweise nicht über die Information von Vergerios Dichterkrönung verfügt hätte. Vergerios Dichterkrönung fand höchstwahrscheinlich auf dem Konzil selbst statt, weil er diesen Titel früher nicht geführt hatte. Die einzige Quelle über die Dichterkrönung Vergerios ist eben diese Abschrift. Wenn die Bezeichnung auf die cedula zurückgeht, so hat man es mit einer Selbstbezeichnung zu tun, deren Nutzen aus der Situation gut erklärbar wäre: Vergerio hätte in diesem Fall seine sämtlichen Titel aufgelistet, um dem von ihm propagierten Ereignis der disputatio mehr Gewicht zu verleihen. In seinem diesbezüglichen Eifer nimmt Vergerio eine Diskrepanz zwischen dem scholastischen Kontext der questio und der Bezeichnung des poeta laureatus in Kauf.

\subsection{4. „quidam doctor utriusque iuris"}

Nach diesen zwei sowohl in ihrem Genre als auch in ihrer Bewertung sehr verschiedenen Berichten über Vergerios Aktion scheint die Beschreibung Peters von Pulkau des gleichen Ereignisses ein regelrecht unparteiischer Bericht zu sein. Der Gesandte der Wiener Universität berichtet folgendes an die Universität Wien, die den Theologieprofessor damit beauf-

\footnotetext{
260 ACC 3, S.668.

261 Die zwei Handschriften, die Finke als Quelle seiner Ausgabe angibt, sind: Stuttgart, Landesbibliothek, Theol. et Philos. 317, fol. 176, und München, Staatsbibliothek, 5596, fol. 95. Ich habe die Münchener Handschrift angesehen, auf eine Anfrage an die Landesbibliothek Stuttgart habe ich leider keine Antwort bekommen. Im Münchener Codex Cod. Lat. 5595, fol. 95r. wird Vergerio nur als ,venerandisssimus et eximius doctor” und „utriusque juris magister” bezeichnet. Deswegen ist davon auszugehen, dass die von Finke veröffentlichte Variante auf die Stuttgarter Handschrift zurückgeht.
} 
tragt hatte, seinen Auftraggeber über die Geschehnisse auf dem Konzil regelmäßig zu informieren $^{262}$ :

Item in festo sacramenti quidam doctor utriusque iuris intimavit se in crastino de materia cedulae disputaturum ipsam impugnando et alius vel alii ex adverso ipsam defendere per certas conciones de haeresi intimationem faciendo. Unde nacio nostra timens rumorem et scandala conclusit, quod non esset hoc admittendum in loco nationis nostrae, quo intimatum fuerat ad cavendum scandala et sui suspicionem, ne crederetur hoc ordinasse, hinc mane, dum tumultosissime cum protestationibus convenisset multitudo maxima, praesidens noster m. Petrus Dekinger ipsis conclusionem nationis insinuavit et cum maximo tumultu solvebatur conventus. ${ }^{263}$

Das officium, das die Grundlinien des von der Universität erwarteten Verhaltens der Gesandten, Petrus de Pulkau und des Juristen Kaspar Maiselstein, festlegte, legte den Professoren außer den praktischen Hinweisen, dass sie bis zum Ende des Konzils zu bleiben und dass sie den Rest des Geldes nach ihrer Rückkehr innerhalb eines Monats zurückzubezahlen haben, die Treue zum Konzil und zum neu erwählten Papst ans Herz. ${ }^{264}$ Es stand im Interesse der Universität, dass ihre Gesandten sich für die Reform der Kirche engagierten. Der Grund der Ermutigungen der Gesandten zu einem solchen Engagement war wahrscheinlich u.a. die Hoffnung auf eine bessere Position der Graduierten bei der Vergabe der kirchlichen Benefizien. $^{265}$

Petrus de Pulkau hielt sich in seinen Berichten an die Universität an seine Aufgabe und berichtete getreulich über die Geschehnisse auf dem Konzil. Girgensohn verteidigt Pulkau gegenüber dem Vorwurf des Utilitarismus mit der Bemerkung, dass er in seinen Reden auf dem Konzil einen weniger engen Blickwinkel gehabt zu haben scheint als in seinen Briefen. ${ }^{266}$ Der Unterschied ist meines Erachtens auch den unterschiedlichen Genres geschuldet: Berichte an einen Auftrag-(und Geld-)geber sollten möglichst gezielt sein, während in einer Rede die gleiche Zielstrebigkeit (das heißt in diesem Fall: über die Reform

262 Über Petrus de Pulkau und seine Gesandtschaft auf dem Konstanzer Konzil vgl. Dieter Girgensohns Arbeiten: Peter von Pulkau und die Wiedereinführung des Laienkelches. Leben und Wirken eines Wiener Theologen in der Zeit des Großen Schismas, Veröffentlichungen des Max-Planck-Instituts für Geschichte 12 (Göttingen: Vandenhoeck\&Ruprecht, 1964), [im Weiteren: „Pulkau”], hier besonders S. 49-66, und Dieter Girgensohn, „Die Universität Wien und das Konstanzer Konzil”. In: Das Konzil von Konstanz. Beiträge zu seiner Geschichte und Theologie. Festschrift unter dem Protektorat seiner Exzellenz des hochwürdigsten Herrn Erzbischofs Dr. Hermann Schäufele, hrsg. v. August Franzen and Wolfgang Müller (Freiburg, Basel, Wien: Herder, 1964), 252-281, [im Weiteren: „Die Universität”]. Die Briefe von Petrus de Pulkau an die Universität Wien wurden herausgegeben: Friedrich Firnhaber, „Petrus de Pulka, Abgesandter der Wiener Universität am Concilium zu Constanz”, Archiv für österreichische Geschichte 15 (1856): 1-70, [im Weiteren: „Pulka”], hier Nr. XXIII, 16. Juni 1417, S. 52. Girgensohn, Pulkau, S. 52 f. In seiner Studie über die Universität Wien auf dem Konzil veröffentlicht Girgensohn den Text des Officiums: Girgensohn, Die Universität, S. 279 f. 
der Kirche nur in dem einen Zusammenhang der Benefizienverleihung zu sprechen) eher unangebracht und sogar kontraproduktiv gewesen wäre.

Die andere Perspektive, die sich aus Pulkaus Briefen erkennen lässt, ist eine ganz persönliche und konkrete. Es lohnt sich, sie in Girgensohns Formulierung zusammenzufassen: „Wer fühlt nicht mit dem einsamen Professor, der krank und von allen Geldmitteln entblößt in der Fremde bleiben muss, obgleich es ihn nach mehr als dreijähriger Abwesenheit nur zu sehr in die Heimat zieht!"267 Pulkaus Lebenslage, die aus seinen Bitten und Bemerkungen deutlich wird, und die einen Historiker aus dem 20. Jahrhundert zu solchem Mitgefühl führen, erklärt, warum es in seinen Berichten für Bemerkungen, die nicht eng mit seinem Auftrag oder mit den ganz praktischen Seiten seiner Gesandtschaft zusammenhängen, keinen Platz gibt. Es handelt sich um einen Professor, der mit seiner Arbeit an der Universität zufrieden war, und der das Konzil eher als ein sorgfältiger, braver, aber nicht besonders neugieriger Beobachter erlebt hatte. Er wollte sich keinesfalls umorientieren, nach einem neuen Brotgeber suchen oder seinen persönlichen Passionen nachgehen, wie manche Humanisten, von denen diese Arbeit handelt. Pulkau hat seine Aufgabe erfüllt, seine Präsenzpflicht aber manchmal sogar eher als Last empfunden. Wissensdurst und Neugierde mögen persönliche Charakterzüge sein, deren Erörterung eher Aufgabe der Psychologie sein dürfte, und den auf dem Gebiet der Geschichtswissenschaften arbeitenden Forscher auf einen unsicheren Boden führen, sie sind aber auch (und mit der folgenden Bemerkung kann man die Vulgärpsychologisierung doch nicht vermeiden) von persönlichen Interessen gesteuerte Eigenschaften, und als solche haben sie doch einen Platz in der Schilderung von Pulkaus Lage auf dem Konzil. Er war an der Beobachtung all der kleinen Details oder großen Zusammenhänge, die nicht unmittelbar mit seinem Auftrag zu tun hatten, nicht sonderlich interessiert. Dass er kein Mensch der Repräsentation war, lässt sich aus der Tatsache erkennen, dass er nicht die Möglichkeit ergriffen hatte, seine Universität im Konklave zu repräsentieren: nicht er, der einzige offizielle Vertreter der Universität Wien (1415 ist Kaspar Maiselstein heimgekehrt) ${ }^{268}$, sondern unter anderen sein Wiener Kollege Nikolaus von Dinkelsbühl als Gesandter Herzog Albrechts V. vertrat die deutsche Nation bei der Papstwahl. Wie Girgensohn feststellt, lässt sich kein Neid von Pulkaus Seite wegen dieser Angelegenheit bemerken, er ist eher stolz auf die Ehre, die durch Dinkelsbühls Teilnahme an der Konklave auch der Universität zu Teil 
wird. ${ }^{269}$ Er ist also keinesfalls ein public face der Universität Wien, wie es über Jean Gerson, Vertreter der Pariser Universität, mit Recht behauptet werden kann. ${ }^{270}$

Auch im Zusammenhang mit seinem Stil kann man von einer ähnlichen Zweckmäßigkeit sprechen - er selbst entschuldigt sich oft dafür, dass er lepor gar nicht anstrebt: „Prebete, queso, veniam de diffusis et incultis scriptis, quia non quero leporem, cuius me nostis ignarum, sed expressionem simplicem veritatis."271 Wenn man Pulkaus Briefe liest, vergewissert man sich sofort darüber, dass es sich in diesem Fall um keinen reinen Demutstopos handelt. Dass Pulkau kein Humanist war, wie auch immer man einen Humanisten definieren mag, ist gar keine Frage. Es gab andere, die, obwohl sie nicht als Humanisten galten, trotzdem mit der neuen Mode für manche Anlässe „kokettiert” haben, wie Fleming, um ein in dieser Arbeit erwähntes Beispiel zu nennen. Pulkau dagegen hat die neue Mode einfach überhaupt nicht interessiert. Es ist kein Zufall, dass er von der Nachwelt sogar als ein Gegenbeispiel für die humanistische Haltung angefürt wurde. Im Briefwechsel zwischen Konrad Säldner, Professor der Theologie in Wien, der die neue Mode aus Italien eher mit Skepsis beobachtete, und dem Augsburger Patrizier Sigismund Grossembrot, der die „Poeten” und das neue Bildungsideal hoch schätzte, wurde über den Nutzen des neuen Stils diskutiert. Grossembrots verlorengegangener Brief war höchstwahrscheinlich ein Plädoyer für die studia humanitatis und die „Dichter” des neuen Stils, worauf Säldner seine Antwort verfasste, die sich als eine Attacke gegen die neue Mode und eine Rechtfertigung der alten Bildung zusammenfassen lässt. In seiner Argumentation darüber, dass Theologie der antiken Autoren nicht bedürfe, erwähnt er Petrus de Pulkaus Namen als einen Beweis dafür, dass es viele große Männer gibt, die berühmt geworden sind, ohne in der neuen Mode bewandert zu sein. $^{272}$

Petrus de Pulkau hat Vergerio als Humanisten oder prominente Persönlichkeit überhaupt nicht wahrgenommen. Für ihn ist er weder ein lächerlicher Wichtigtuer, noch ein ehrwürdiger poeta laureatus. Seine Ignoranz ist keine fingierte wie die Fillastres. Seine Perspektive kann erstens als die eines braven Beamten beschrieben werden, zweitens kann man auch feststellen, dass er die Episode aus dem Blickwinkel der deutschen Nation darstellt. Was ihn interessiert, ist der Grund, warum die Disputation ausgefallen ist:

\footnotetext{
269 Girgensohn, Pulkau, S. 60.

270 Daniel Hobbins, „The Schoolman as Public Intellectual: Jean Gerson and the Late Medieval Tract”, The American Historical Review 108 (2003): 45 pars. 2 Mar. 2008, http://www.historycooperative.org/journals/ ahr/ 108.5/hobbins.html.

271 Firnhaber, Pulka, S. 70, zitiert von Girgensohn, Pulkau, S. 59.

272 Wilhelm Wattenbach, „Sigismund Grossembrot als Vorkämpfer der Humanisten und seine Gegner”, Zeitschrift für die Geschichte des Oberrheins 25 (1873): 36-69, hier S. 39.
} 
Unde nacio nostra timens rumorem et scandala conclusit, quod non esset hoc admittendum in loco nationis nostrae, quo intimatum fuerat ad cavendum scandala et sui suspicionem, ne crederetur hoc ordinasse. ${ }^{273}$

Die Disputation fiel aus, weil die deutsche Nation Angst vor einem möglichen Skandal hatte und sich nicht dem Gerücht aussetzen wollte, selbst die Disputation organisiert zu haben.

\subsubsection{Vergleich der Perspektiven}

Die drei Schilderungen von Vergerios Auftritt auf dem Konzil zeigen verschiedene Haltungen dem Humanisten gegenüber: die unkritische Übernahme der Bezeichnung poeta laureatus als eines würdevollen Titels; die spöttische Zurückweisung der italienischen Wichtigtuerei aus der Perspektive eines Franzosen, der Bescheid weiß und selbst - weil er up to date sein möchte - auch kulturelle Interessen hegt, die humanistisch gefärbt genannt werden können, und die völlige Immunität gegenüber der neuen Mode eines bequemen Theologieprofessors, der als braver Gesandter seiner Brotgeber sich in erster Linie auf seinen Auftrag konzentriert. Man kann also über kein einheitliches Vergerio-Bild sprechen: ob er als poeta laureatus und Doktor der beiden Rechte, oder einfach als irgendein Italiener, der sich mit seinem Übereifer lächerlich machte, wahrgenommen und geschildert wurde, scheint sehr vom jeweiligen Beobachter abhängig gewesen zu sein und somit ein Beispiel dafür zu liefern, dass es schwierig ist, festzustellen, ob jemand ein Humanist gewesen sei oder nicht, und dass es viel mehr darum geht, ob, von wem und warum jemand als solcher wahrgenommen wurde.

\subsection{Vergerios Antwort auf Poggios eulogium}

\subsubsection{Die Strategie des Briefeschreibers und Freundes / Die Entdramatisierung von Zabarellas Gestalt}

\subsubsection{Einleitendes}

Auf diese Einleitung, die zeigte, wie verschieden die Wahrnehmung des Humanisten und seiner Propagandatätigkeit für das von Sigismund bevorzugte Szenario des Konzils gesehen werden konnte, folgt die Erörterung eines Schreibens Vergerios das ebenfalls mit dessen Engagement für Sigismund zu tun hat: sein eulogium auf Zabarella. Ich werde hier versuchen zu zeigen, wie Vergerios eulogium auf Poggios Rede ,antwortet”, was seine Strategie ist, Zabarella darzustellen und gleichzeitig sich selbst zu profilieren, wie er sich und

\footnotetext{
273 Vgl. Anm. 268.
} 
die von ihm erbaute memoria Zabarellas von Poggios Darstellung und Selbstdarstellung distanziert, und wie dieses Schreiben mit Vergerios Propagandatätigkeit zusammenhängt.

Aus Vergerios Position, die er in der Prioritätsdebatte vertrat und die den meisten Italienern und selbst Zabarella entgegengesetzt war, folgt, dass er es schwerer hatte, wenn er ein eulogium auf Zabarella schreiben wollte: er musste den Kardinal so loben, dass er seine eigene Position trotzdem beibehalten konnte. Dies tut er mit einer Strategie, die auf Poggios Selbstdarstellungsstrategie resoniert und sich davon abgrenzt.

Dass ein Brief und eine Rede trotz der gattungsbedingten Unterschiede Darstellungsrahmen sind, die miteinander verglichen werden können, ist nicht nur den in diesem Fall vorhandenen thematischen Gemeinsamkeiten zu verdanken. Einerseits wurden Reden, nachdem sie vorgetragen worden sind, kopiert und gelesen (manchmal sogar ausschließlich schriftlich überliefert und überhaupt nicht vorgetragen), während umgekehrt Briefe auch vorgelesen werden können. Beweise dafür, dass die ähnliche Überlieferungssituation die Unterschiede der Gattungen für den Rezipienten entschärfen konnte, gibt es auch für diesen konkreten Fall. Erstens gibt es einen Codex ${ }^{274}$, in dem die beiden Texte (Poggios Rede und Vergerios Brief) direkt aufeinander folgen. Das ist selbstverständlich nichts Überraschendes, auch die Chrysolorina, um ein zeitgenössisches Beispiel zu zitieren, sammelt Lobschriften, die für eine Person geschrieben worden sind, ohne eine Trennung der Gattungen. ${ }^{275}$ Trotz der Selbstverständlichkeit der Logik, die dahintersteckt, ist diese Praxis erwähnenswert als ein Beispiel für die Verschmelzung der Gattungen im Prozess ihrer Perzeption. Ein weiterer Beweis für das gleiche Phänomen ist ein spanischer Codex, in dem Poggios Rede über Zabarella als epistola bezeichnet wird. ${ }^{276}$ Dass die Briefform wegen der Unterschiedlichkeit der zu erörternden Themen nicht auf eine einzige Stillage festgelegt werden, und dass sie aus dem gleichen Grund Verwandtschaft mit mehreren Gattungen haben kann, je nach dem behandelten Thema, ist eine schon von Erasmus vertretene These, die aber auch in der modernen Sekundärliteratur Resonanz gefunden hat und weiterentwickelt wurde. So ist Helene Harth der Meinung, „die Verherrlichung berühmter Zeitgenossen oder die Austragung gelehrter philologischer Kontroversen verbinden den humanistischen Brief mit der Lobrede,

274 Es handelt sich um den Codex 97. der Biblioteca Guarneriana in San Daniele. Die Information stammt von der Webseite der Bibliothek: Inventario die Manoscritti della Biblioteca Guarneriana di San Daniele del Friuli, http://www.guarneriana.it/inventario-manoscritti.html (letzte Einsicht am 03. 01. 2017).

275 Die Sammlung enthielt neben Briefen auch die Grabrede für Chrysoloras. Vgl. Anm. 214.

276 Der Codex der Nationalbibliothek in Madrid (11557) gibt Poggios Schrift den folgenden Titel: Epistola Pogii super funere Cardinalis de Zanbarelis [sic!] Constancie". Vgl. Paul Oskar Kristeller, Hrsg., Iter Italicum: a Finding List of Uncatalogued or Incompletely Catalogued Humanistic Manuscripts of the Renaissance in Italian and other Libraries, 6 Bde., (London: The Warburg Institute und Leiden: Brill, 1963-1992), [im Weiteren: „Iter”], Bd. 4, S. 570 b. 
der Leichenrede oder der Invektive." ${ }^{277}$ Der Fall der für Zabarella geschriebenen Lobschriften kann als ein Beispiel für diese These gesehen werden.

\subsubsection{Das Private ${ }^{278}$}

\subsection{Freundschaft: ein wichtiger Baustein humanistischer Selbstdarstellung}

Vergerios Selbstdarstellung bedient sich Mittel, die, im Gegensatz zu Poggios Rede, die sich vom scheinbar privaten Auftakt bis zur implizierten Selbstbehauptung als öffentlicher Stifter des für Zabarella erstellten monumentum bewegt, einen eindeutigen Akzent auf das Private setzten. Diese Wahl ist leicht nachvollziehbar: er konnte sich und Zabarella, was ihre öffentlichen Tätigkeiten betrifft, nicht als Sinnesverwandte darstellen, und musste betonen, dass er und der Kardinal, obwohl sie in den letzten Jahren verschiedene Interessen vertreten hatten, sich auf einer anderen Ebene weiterhin gut verstanden hatten, also Freunde geblieben sind.

Dass unter Freundschaft in der humanistischen Literatur in erster Linie keineswegs ein spontanes, auf Emotionen beruhendes Verhältnis der Beteiligten zu verstehen ist, ist in der Forschung eine schon längst etablierte Einsicht. ${ }^{279}$ Die Kultivierung der amicitia hat auch ihre antiken Vorbilder und dementsprechend eine doppelte Erbschaft. Auf der einen Seite gab es eine von der Moralphilosophie erarbeitete Dimension der Freundschaft. Der Haupttext dieser Tradition, Ciceros De amicitia, wurde von den Humanisten reichlich kopiert und übersetzt. Auf der anderen Seite geht es um ein geregeltes System von Verhältnissen, in dem die Beteiligten Aufgaben (officia) zu erfüllen hatten und einander gegenseitige Gefälligkeiten (beneficia) erwidert hatten. ${ }^{280}$ Ähnlich dem antiken System der amicitia funktioniert ihre vor-

277 Helene Harth, „Überlegungen zur Öffentlichkeit des humanistischen Briefs am Beispiel der Poggio-Korrespondenz", in Kommunikationspraxis und Korrespondenzwesen im Mittelalter und in der Renaissance, hrsg. v. Heinz-Dieter Heimann, Ivan Hlaváček (Paderborn: Ferdinand Schöningh, 1998), 127-137, [im Weiteren: „Überlegungen”], hier S. 133.

278 Ich benutze das Wort „privat" nicht in seinem absoluten Sinne, es gibt unter den Quellen, mit denen ich arbeite, selbstverständlich nichts, das im absoluten Sinne des Wortes „privat” wäre: es geht um literarische Kommunikation, dementsprechend ist alles für eine Öffentlichkeit (natürlich nicht im Habermas'schen Sinne) gedacht. Das „Private” hat hier nur einen Sinn im Vergleich mit Poggios Geste, sich an eine breite Öffentlichkeit zu wenden und als einen Stifter der memoria Zabarellas darzustellen.

279 Über Freundschaft als ein Institutionalität und Expressivität vereinigendes Phänomen im Burgund des 15. Jahrhunderts vgl. Klaus Oschema, Freundschaft und Nähe im spätmittelalterlichen Burgund. Studien zum Spannungsfeld von Emotion und Institution, Norm und Struktur 26 (Köln, Weimar, Wien: Böhlau, 2006).

280 Über die Mechanismen, wie die antike amicitia funktionierte, wie ihr Vokabular für die Beschreibung von patronus-cliens Beziehungen benutzt wurde und die Frage, ob die Dichter in diesem Beziehungssystem einen besonderen Status hatten vgl. die folgende Studie: Peter White, ,Amicitia and the Profession of Poetry in Early Imperial Rome", The Journal of Roman Studies 68 (1978): 74-92, [im Weiteren: „Amicitia”]. Für einen guten Überblick über die Probleme und Forschungstendenzen kann die Einleitung der Monographie von Mauro Reali konsultiert werden. Mauro Reali, Il contributo dell'epigrafia latina allo studio dell'amicitia: il caso della Cisalpina, Pubblicazione della Facoltà di lettere dell'Università degli studi di Milano 176 (Florenz: La Nuova Italia Editrice, 1998), S. 1-19. Hier wird unter anderem auch das 
moderne Form insofern, als ihr Vokabular oft schwer von dem der Gönnerschaft zu unterscheiden ist. ${ }^{281}$ Die wahrscheinlich pragmatischste antike Beschreibung der Freundschaftsregel ist eine unter dem Namen von Quintus Tullius Cicero (und im Anhang an Marcus Tullius Ciceros Briefe) überlieferte Schrift: das Commentariolum petitionis. In dieser Beschreibung der amicitia spielen ausschließlich die Nützlichkeitserwägungen eine Rolle. Da der Brief für die Leser des 15. Jahrhunderts zugänglich war, kann man davon ausgehen, dass das doppelte Gesicht der Freundschaft, sogar in Verbindung mit derselben Person (Cicero), im 15. Jahrhundert eine Selbstverständlichkeit war.

Was eine wesentliche Neuigkeit des humanistischen Gebrauches der amicitia zu sein scheint, ist die textuelle Beschaffenheit des Phänomens: es geht um literarische Freundschaften, die durch Texte - in denen es meistens wiederum um Texte geht - funktionieren, die manchmal sogar in diesen Texten konzipiert werden. ${ }^{282}$ Die üblichsten Benefizien, die im antiken Rom zwischen amici ausgetauscht worden $\operatorname{sind}^{283}$, werden bei den Humanisten auf das geschriebene Wort bezogen. Eine Liste der unter amici üblichen Gefälligkeiten stellt Peter White zusammen. 1: Erbschaften, 2: an bestimmte Ereignisse gebundene Geldgaben (wie Reisegeld und Mitgift), 3. Geldanleihe ohne Zinsen, 4. das Schenken eines Hauses oder eines Landguts, 5. Gastfreundlichkeit, Unterkunft im eigenen Haus, 6. das Arrangieren einer gut bezahlten Stelle für den Freund, 7. das Arrangieren einer Heirat für den Freund. Von den sieben Formen der Wohltaten gibt es vier, die mit Büchern oder mit der Schreibtätigkeit verbunden werden konnten: Bücher kann man vererben, ausleihen oder schenken. Das Arrangieren einer Stelle für einen Freund war auch eine übliche Bitte der Humanisten an ihre Freunde, welche insofern mit der Schreibtätigkeit in Verbindung gebracht werden kann, als dass die Stellen, um die es ging, meistens mit Tätigkeiten zusammenhingen, die die Humanisten als ihren eigenen Wissensbereich für sich beansprucht haben.

Problem der unscharfen Trennung zwischen ,clientela” und ,,amicitia” angesprochen. Interessant ist Realis Bemerkung, nach der das Benutzen des Wortes ,amicus” - von Horaz auf Maecenas bezogen - ein Akt der Fiktionalisierung sei, durch die ein Verhältnis, das wegen der Ungleichheit der Beteiligten eigentlich als „,clientela” zu bezeichnen wäre, dennoch als ,amicitia” bezeichnet wird: S. 11.

281 Über die Zusammenhänge der beiden Systeme vgl. Guy Fitch Lytle, „Friendship and Patronage”, in Patronage, Art, and Society in Renaissance Italy, hrsg. v. Francis W. Kent und Patricia Simons (Oxford, Canberra: Humanities Research Center, Clarendon Press, 1987), 47-61.

Ein markantes Beispiel dafür ist Petrarcas Freundschaft zu seinem „Socrates”, die laut Papys Studie als eine teils fiktive, in den Texten der Briefe hochstilisierte Freundschaft zu verstehen ist. Die Stilisierung der Figur des Freundes erreicht hier einen so hohen Grad, dass, trotz der Existenz der historischen Figur des mit Sokrates identifizierten Ludovicus Sanctus von Beringen (Lodewijk Heyligen van Beringen), es sinnvoll ist, über ein Konstrukt zu sprechen bzw. über eine Freundschaft, die von Petrarca als eine der Freundschaft zwischen Cicero und Atticus ähnliche Bindung wahrgenommen und dargestellt wurde. Vgl. Jan Papy, „Creating an Italian Friendship: From Petrarch's Ideal Literary Critic „Socrate” to the Historical Reader Ludovicus Sanctus of Berlingen", in Petrarch and his Readers in the Renaissance, Intersections: Yearbook for Early Modern Studies 6, hrsg. v. Karl A. E. Enenkel und Jan Papy (Leiden, Boston: Brill, 2006), 13-30.

283 Vgl. White, Amicitia, S. 90-92. 
Während die Dichter des antiken Rom keine Sonderstellung unter den „Freunden” eines wohlhabenden Menschen hatten ${ }^{284}$, diente amicitia bei den Humanisten als ein Mittel des Ausdruckes von Gruppenzusammenhörigkeit, die durch das geteilte Interesse an der antiken Literatur gestiftet wurde. ${ }^{285}$ Freunde $\mathrm{zu}$ sein, bedeutete in diesem Kontext, dazugehörig zu sein, es qualifizierte also die beteiligten Personen. Wer wen als seinen Freund bezeichnet, sagt viel über einen aus, indem es die Koordinaten im öffentlichen Raum festlegt. Die Freundschaft ist ein mit Bourdieus Vokabular gut beschreibbares soziales Phänomen. ${ }^{286}$ Die teilweise auch mit „Freundschaft” bezeichneten Kontakte gehören zum sozialen Kapital, das die Akteure gegebenenfalls in ökonomisches Kapital umwandeln können. Die Umwandelbarkeit des Kulturkapitals in soziales und ökonomisches Kapital, ein indirekter Zusammenhang also zwischen dichterischer Leistung, der Freundschaft mit den Richtigen, und finanzieller Unterstützung, den Bourdieus Theorie von der Umtauschbarkeit der verschiedenen Kapitalarten nahe legt, könnte Whites Konklusion etwas modifizieren. Die Dichter haben als solche von ihren amici nur durch die Möglichkeit, ihre Gedichte vortragen zu können durch ein von der Klientel des amicus geformtes Publikum profitiert. ${ }^{287}$ Mit Bourdieu könnte man versuchen dieses Bild zu modifizieren und annehmen, dass es, wenn keinen direkten, aber wahrscheinlich doch einen indirekten Zusammenhang zwischen dichterischer Tätigkeit und Lohn gab. Dass Dichter zu der Klientel eines wohlhabenderen Freundes gehören konnten, war teilweise wahrscheinlich auch deren Beruf zu verdanken.

Ohne eine detaillierte Analyse über das Netz der Freundschaften zwischen Intellektuellen kann man vielleicht trotzdem die Aussage riskieren, dass für die Rolle der Freundschaft zwischen Intellektuellen im 15. Jahrhundert ein ähnliches Erklärungsmuster vorstellbar ist: das durch Freundschaften genährte soziale Kapital konnte durch den Aufwand der Transformationsarbeit zu einem Wachstum des ökonomischen Kapitals führen. In manchen Fällen ist der Umtausch ein direkter: der Freund arrangiert zum Beispiel für seinen Freund eine gut bezahlte Stelle. In manchen Fällen ist der Wert der Freundschaft viel indirekter umwandelbar: durch die Freundschaft mit den „Richtigen” nimmt das eigene Renommee zu und dieser Gewinn an Ansehen wird später vielleicht dahin führen können, in eine bessere Position zu gelangen.

\footnotetext{
284 Whites Konklusion ist, dass Dichter nicht als solche an beneficia beteiligt waren. Vgl. im nächsten Absatz.

285 Dies wird an einem Beispiel im nächsten Unterkapitel exemplifiziert.

286 Für eine kurze Zusammenfassung über die Theorie der Kapitalarten und deren Umwandlungen vgl. Pierre Bourdieu, „Ökonomisches Kapital, kulturelles Kapital, soziales Kapital”, in Soziale Ungleichheiten, Soziale Welt, Sonderband 2, hrsg. v. Reinhard Kreckel (Göttingen: Verlag Otto Schwartz \& Co. 1983), 183-198, [im Weiteren: „Kapital’].

287 Die Konklusion gilt nur für das Material, das mit folgenden Einschränkungen festgelegt wurde: White untersucht lateinisch schreibende Dichter ab der Mitte des ersten bis zur Mitte des zweiten Jahrhunderts nach Christi Geburt. Dichter aus kaiserlicher Umgebung schließt er aus seiner Untersuchung aus.
} 
Glücklicherweise sind aus der Zeit unmittelbar vor dem Konzil drei Briefe überliefert worden, an denen die gerade beschriebenen Eigenschaften und Mechanismen exemplifiziert werden können. Es geht um einen Briefwechsel zwischen Vergerio, Gasparino Barzizza und Zabarella.

Der erste der drei Briefe wurde Ende Juli des Jahres 1414 von Vergerio an Barzizza geschrieben. ${ }^{288}$ Vergerio schreibt nach eigener Angabe auf Zabarellas Ermunterung, er solle sich ihn zum Freund wählen: ,iussit, ut te deligerem"289. Zabarella habe über Barzizza nicht nur viel erzählt, sondern auch einen Brief von ihm gezeigt, so konnte sich Vergerio selbst davon überzeugen, dass Barzizza ein guter und gelehrter Mann sei: „in qua maxime, velut in speculo vir bonus et doctus haud ambiguis signis eluceret. ${ }^{, 290}$ Am Ende des Briefes bietet sich Vergerio Barzizza als Freund an. Der Grund dafür, dass er sich als Barzizzas debitor fühlt, sei dessen virtus und der Gewinn, den seine Lehrtätigkeit für alle bringt. Dass er sich ihm nicht nur als „Schuldner” anbieten möchte, sondern auch als einen nahestehenden Menschen, sei dem Umstand zu verdanken, dass Barzizza Zabarellas Freund sei: „pro eo autem quod illius es, cuius iussu ad te nunc scribo, non tantum debitorem, verum etiam tuum hominem me credas velim." ${ }^{291}$

Auf Vergerios Brief folgt Barzizzas Antwort vom 4. August, in der er Vergerios Freundschafts-Angebot annimmt. ${ }^{292}$ Die Begründung besteht wieder aus großen humanistischen Höflichkeitsgesten: außer Zabarellas auctoritas, seien allein Vergerios allen bekannte studia und sein Brief, den er an Barzizza geschrieben hat, ein hinreichender Grund, Barzizza davon zu überzeugen, dass Vergerio es verdient habe, von den Guten geliebt zu werden:

Cum enim auctoritas Francisci Zabarelle cardinalis Florentini tanta apud me sit, quanta hominis apud hominem esse potest, tamen studia tua omnibus nota et litterae, ut amicissimae, ita doctissimae, ad me scriptae satis persuadent te dignum esse a bono viro etiam ultro ameris. ${ }^{293}$

Dieser Begründung folgt die explizite Bestätigung der Freundschaft: „Quod vero ad me attinet, omni studio contendam ut, postquam totus meus es, ego itidem totus sim tuus, et ,par pro pari” referam." 294 Er lobt Zabarella und erwähnt, dass er ihm auch private Gefälligkeiten erwiesen habe (,,alia sunt multa eius in me officia, quae privata sunt” ${ }^{, 295}$ ). Zabarellas Freund-

\footnotetext{
Vergerio, Epistolario, S. $351 \mathrm{f}$.

Vergerio, Epistolario, S. 352.

ebda

ebda

Vergerio, Epistolario, S. 353 f.

Vergerio, Epistolario, S. 353.

Vergerio, Epistolario, S. 354.

ebda
} 
schaft habe ihm schon viele Freunde erworben, weil diese, wie Vergerio auch, gedacht haben, dass der Freund eines so guten Menschen kein schlechter Mensch sein könnte: „quae res, ut nuper te ipsum, ita saepe alios multos mihi amicos fecit, cum sibi coniecturam faciunt eum non malum hominem esse, qui ipse ab optimo viro ametur" ${ }^{\text {"296 }}$. Am Ende seines Briefes bietet sich Barzizza Vergerio nochmals an, dieser könne über ihn disponieren, wie es ihm gefalle, und er bevorzuge in Freundschaft niemanden vor ihm.

Im dritten Brief bedankt sich Barzizza bei Zabarella dafür, dass er ihn mit Vergerio bekannt gemacht habe, er preist Zabarella wegen der vielen Zeichen seiner Freundschaft, von denen das größte Vergerios Freundschaftsangebot sei, da es außer Zabarella keinen besseren und gelehrteren Menschen gäbe, als Vergerio. Barzizza schließt seinen Brief mit einer beinahe übertrieben detaillierten Metapher, in der er Vergerios Selbstbezeichnung als debitor aufgreift. Es lohnt sich, diese in ihrer ganzen Länge zu zitieren:

Tantum ergo hac re tibi debeo, quanti amicitiam hominis et eruditissimi facio. Qui si solvendo essem, non differrem in diem, sed statim hoc alieno aere me exolverem. Nunc vero cum nihil dicere mihi religio sit, ut verbis poete comici utar, et me ipsum superiori tempore pro multis aliis meritis tuis insolutum dederim, faciam, quod debitores non mali solent. Qui non suppetentes sunt, unde suis creditoribus reddant, saltem hoc curant, ut diligenter calculi rationem habeant. Conficiam ergo novos calendarios; nam priores tuis creditis iam omnes sunt pleni; et a capite libri in albo, ut dicitur, scribam: „in receptum Petrum Paulum Vergerium nostrum”; summam autem non taxabo; est enim mea sententia inextimabilis. Tu, quanti voles, taxabis, et ego ratum habebo. ${ }^{297}$

Dass sich Barzizza bei der Danksagung ausgerechnet einer Metapher aus dem Feld der Finanzen bedient, und er seine Beziehung zu Zabarella mit Fachtermini wie „debitor”, „creditor” „,in receptum”, „se insolutum dare”, „taxare”, „ratum habere” beschreibt, verdient besondere Aufmerksamkeit, weil Freundschaft, wenigstens nach ihrem Selbstverständnis, nichts mit finanziellem Gewinn zu tun haben dürfte. ${ }^{298}$ Obwohl Barzizza mit einem Hinweis eben auf die Unmöglichkeit des Umtausches von ideellem Wert in finanziellen Gewinn die Strenge der Metapher und so die Absurdität der Sinnbindung auflockert, bleibt die Spannung zwischen der Denotation und der Konnotation der Metapher enorm. Dies ist aber wahrscheinlich auch beabsichtigt, die Quelle des Humors liegt genau in dieser Spannung. Die

ebda

Vergerio, Epistolario, S. 355 f.

Über Großzügigkeit und darüber, dass der Ertrag der Freundschaft schon in der Liebe selbst bestehen sollte vgl. zum Beispiel: Cic. Amic. 31.: „Ut enim benefici liberalesque sumus, non ut exigamus gratiam - neque enim beneficium faeneramur, sed natura propensi ad liberalitatem sumus-, sic amicitiam non spe mercedis adducti, sed quod omnis eius fructus in ipso amore inest, expetendam putamus." 
Möglichkeit einer Umwandlung der Kapitalarten wird hier durch eine humorvoll überspitzte Offenlegung verschleiert, die die zu verheimlichende Realität als Absurdes darstellt.

Freundschaft hatte in der Antike, wie auch im frühneuzeitlichen Kontext immer einen sehr konkreten, praktischen, vom finanziellen Gewinn nicht ganz unabhängigen Aspekt. Dass dies auch für den Fall von Zabarella, Vergerio und Barzizza gelten dürfte, geht erstens aus Barzizzas Bemerkung, nach der Zabarella ihm in mehreren privaten Angelegenheiten geholfen habe, hervor. Zweitens wird diese These von einer externen Evidenz unterstützt. Barzizza wird am 13. August desselben Jahres, also wenige Tage später, vom Papst Johannes XXIII. zum secretarius apostolicus ernannt. Seine Ernennung hatte Barzizza sehr wahrscheinlich Zabarellas Mitwirken zu verdanken. ${ }^{299}$ Zabarella baute also in diesen Monaten ein Netzwerk auf. Er war es nämlich, der wahrscheinlich genau in dieser Zeit auch Vergerio angeboten hatte, sich der Entourage des Papstes Johannes XXIII. anzuschließen und auf das Konzil in Konstanz mitzufahren. ${ }^{300}$ Im Rahmen dessen ermunterte er wahrscheinlich Vergerio, Barzizza anzuschreiben, damit die zwei Humanisten, die auf der gleichen Seite zu kämpfen hatten, einander ihres gegenseitigen Wohlwollens gewiss sein könnten. Seine vernetzende Tätigkeit war beiden Humanisten von Nutzen und diente gleichzeitig wahrscheinlich auch des Kardinals Interessen. Je mehr Leute er für seine Seite gewinnen konnte, desto gesicherter konnte er sich und die von ihm vertretene Seite auf dem Konzil wissen.

Die Realität hinter dem Ideal der Freundschaft war dementsprechend eine Interessengemeinschaft: ein Mächtiger lud zur Mitarbeit ein und ermutigte seine Klienten-Freunde miteinander in Verbindung zu treten. Für die „Freunde” bedeutete dies einen doppelten Gewinn, dessen beide Seiten miteinander im engsten Zusammenhang standen. Erstens einen Prestigegewinn, was auch als ein Gewinn am Netzwerk-Kapital gesehen werden kann, zweitens aber, durch die Umwandelbarkeit der Kapitalarten, auch einen möglichen Gewinn an ökonomischem Kapital. Die erste der beiden Gewinnarten wird im Brief auch angesprochen: im System der Schmeicheleien werden alle Möglichkeiten durchgespielt. Die beiden Freunde Zabarellas schmeicheln einander mit der Behauptung, der andere sei schon dadurch, dass er vom Zabarella empfohlen wurde, ganz gewiss ein guter Mensch, und dass das eigene Ansehen durch die Freundschaft des anderen wachsen wird. Die ökonomische Seite wird aber nach den Spielregeln des großen humanistischen Gemeinschaftsspiels „Freundschaft” selbstverständlich verschwiegen. Wenn Barzizza das Thema am Ende des Briefes mit der

\footnotetext{
299 Vergerio, Epistolario, S. 351 f, Anm. 1; Remigio Sabbadini, „Dalle nuove lettere di Gasparino Barzizza”, Rendiconti del R. Istituto Lombardo di Scienze e Lettere 62 (1929): 881-890, S. 885; und Domenico Magni, „Gasparino Barzizza, una figura del primo umanesimo”, Bergomum, 31 (1937) 104-118, 143-70, und 205222.

300 Vergerio, Epistolario, S. 351, Anm. 1, und McManamon,Vergerio, S. 148.
} 
Schuldner-Metapher trotzdem anspricht, so funktioniert diese Geste nicht als Erklärung einer Wahrheit, sondern viel mehr als eine Verharmlosung dieser im Ernst nicht ansprechbaren Seite der Freundschaft. Die Inkompatibilität der beiden Teile der Metapher, ihre Denotation und Konnotation, also Geld und Freundschaft, impliziert die Unmöglichkeit eines Zusammenhangs: der im realen Leben allzu präsente Zusammenhang wird dadurch verhüllt.

Vergerio war Zabarellas Freund, sowie Teil des vom Kardinal ausgebauten Netzwerks, und diese Verbindung hatte mehrere Attribute einer humanistischen Freundschaft. Eine von diesen Attributen war seine von Zabarella veranlasste Integration in das Freundschaftsnetzwerk. Weitere Attribute der von Vergerio erzählten Freundschaft werden in den nächsten Kapiteln besprochen.

\subsection{Vergerios Freundschaft mit Zabarella}

„Eum iugiter michi amicum optimum et patrem amantissimum sensi” ${ }^{301}$ bemerkt Vergerio über den Kardinal in seinem eulogium. Hier erzählt er die Geschichte dieser Bindung. Er habe Zabarella in Florenz vor ungefähr dreißig Jahren kennen gelernt, als er wegen seines Studiums in der Stadt war, wo Zabarella kanonisches Recht unterrichtete. Nachdem er ihn besser kannte, sei seine Verehrung (reverentia) immer mehr gewachsen, und je mehr er ihn kennen gelernt habe, desto größer und besser sei er ihm erschienen. Er habe bei ihm auch gewohnt (,interdum quidem ei domesticus fui“), sei ihm aber sowieso immer ein familiaris gewesen. Später wird im Brief ${ }^{302}$, um die Geschichte dieser Freundschaft zu Ende zu erzählen, betont, dass Zabarellas Freundschaft zu Vergerio trotz der verschiedenen Meinungen, die die beiden am Konzil über die Papstwahl hatten - weswegen Vergerio vielen verhasst wurde (,,apud multos gravi odio laborarem“303) - unverändert blieb (,,illesa mansit apud eum benivolentie gratia“). Aus der Erzählung Vergerios wird eindeutig ersichtlich, dass ihm viel daran lag, sich bis zum Lebensende des Kardinals für Zabarellas Freund halten zu können.

Es gibt auch äußere, also nicht von Vergerio gelieferte Zeugnisse, die Vergerios Freundschaft mit Zabarella beweisen: ${ }^{304}$ der gemeinsam geschriebene Traktat De arte metrica $^{305}$, Zabarellas Widmung seines De felicitate an Vergerio ${ }^{306}$ und Vergerios Epigramm,

\footnotetext{
301 Der Brief an Lodovico Buzzacarini wurde von Leonardo Smith herausgegeben: Vergerio, Epistolario, S. 362-378, hier S. 365.

302 Vergerio, Epistolario, S. 370.

303 ebda

304 Die „Beweise” dieser Freundschaft wurden von Bischoff im Kapitel „Die literarischen Beziehungen Vergerios und Zabarellas" gesammelt: Bischoff, Studien, S. 85-88.

305 Die Einleitung, in der Zabarella den Namen seines Mitarbeiters (,vir doctissimus Petrus Paulus Vergerius de Justinopoli”) erwähnt, wurde veröffentlicht von Vedova, Memorie, S. 114, und Bischoff, Studien, S. 86.

306 Zabarellas Worte an Vergerio werden zitiert von Bischoff, Studien, S. 87.
} 
das er seiner Abschrift von De felicitate hinzufügte. In diesem Epigramm bedankt er sich bei Zabarella dafür, dass er diese Schrift ihm gewidmet hatte. ${ }^{307}$

\subsection{Vergerios Bild von seiner Freundschaft mit Zabarella in seinem eulogium}

\subsection{Die Selbstfiktion der Briefform als Rahmen für den Diskurs des Privaten}

Außer der expliziten Erwähnung der Freundschaft zu Zabarella verwendet Vergerio verschiedene Strategien, die auf diese hinweisen und die explizite Aussage unterstützen.

Als Erstes muss die Wahl des Genres erwähnt werden: die Briefform ist - wenigstens laut ihrer Selbstfiktion - eine private Gattung. ${ }^{308}$ Sie passt gut zum Thema „Freundschaft”, die - wenigstens laut ihrer Selbstfiktion - auch eine private Angelegenheit ist. Man kann aber als ein Argument gegen die Interpretation, die die Wahl der Briefform als einen strategischen Akt sehen möchte, einwenden, dass diese Wahl von der Situation selbst bestimmt worden war, und dass es sich dementsprechend auch um keine Wahl handelte, sondern um eine Notwendigkeit: Vergerio habe keine andere Möglichkeit gehabt, als über Zabarella in Briefform zu schreiben, weil die öffentliche Rede schon von Poggio gehalten worden war. So muss man die Aussage folgendermaßen präzisieren: Vergerio hatte keine andere Möglichkeit, als über Zabarella in Briefform zu schreiben, und der Akzent auf dem „Privaten” folgt aus dieser Gattung.

Dies war bestimmt ein Kompromiss für einen Humanisten, der bekannt für seine Reden sein musste. ${ }^{309}$ Mit der Rede auf den Tod des Francesco da Carrara eröffnet Vergerio eine Reihe von Begräbnisreden, die nach dem neuen, antikisierenden Ideal konzipiert wurden. ${ }^{310}$ McManamon liefert für seine These, nach der Vergerio der erste gewesen sei, der

307 Er baut in sein Gedicht auch den Topos ein, nach dem Freunde alles gemeinsam haben: „omnia iandudum cum sint communia nobis..." Das Epigramm ist veröffentlicht in einer Fußnote von Smith. Vgl. Vergerio, Epistolario, S. 367, Anm. 1.

308 Über den Öffentlichkeitscharakter humanistischer Korrespondenz vgl. den schon zitierten (Anm. 199) Artikel von Helen Harth (Überlegungen). Harth argumentiert anhand der Poggio-Korrespondenz für die große öffentliche Wirkung humanistischer Briefe und deutet diese Wirkung als Produkt eines Kommunikationsrituals.

309 Seine Rede von 1393 auf den Tod des Francesco da Carrara ist in 11 Handschriften überliefert worden. Vgl. McManamon, PPV and Jerome, S. $270 \mathrm{f}$.

310 Über Vergerios Rede als die erste humanistische Begräbnisrede vgl. John M. McManamon, „Innovation in Early Humanist Rhetoric: The Oratory of Pier Paolo Vergerio the Elder", Rinascimento 2. s. 22 (1982): 332, [im Weiteren: „Innovation”], hier S. 31. Hier wird Vergerio noch etwas weniger eindeutig als der „erste” genannt, der die neue Form in der Oratorik eingeführt haben soll, während sich der Autor in seiner späteren Monographie über Vergerios Rolle als „Begründer” humanistischer Oratorik sicher zu sein scheint. Vgl. McManamon, Funeral, S. 11 und passim. Grendler übernimmt McManamons These und schreibt über Vergerios Begräbnisrede: „a funeral oration that might have been the first completely classical oration since the end of antiquity." Paul F. Grendler, Schooling in Renaissance Italy: Literacy and learning 1300-1600 (Baltimore: Johns Hopkins University Press, 1989), [im Weiteren: „Schooling”], S. 207. Witt dagegen hält es für wichtig, den Unterschied zwischen Vergerios Vorhaben und dem Gelingen seines Planes festzuhalten. Nach Witts Meinung sind Vergerios Reden zwar als humanistisch, aber nicht als 
die antikisierende Form für Oratorik benutzt haben sollte, ausschließlich den Beweis, dass seine Rede von 1393 als erstes Item auf seiner Liste der Begräbnisreden steht, die dem neuen Stil folgen. Er unterstützt seine Behauptung mit keinen Beispielen der zeitgenössischen Wahrnehmung Vergerios als des Erneuerers der Traueroratorik. Auf diesen Aspekt des Phänomens (d. h.: seine zeitgenössische Wahrnehmung) scheint er keinen besonderen Akzent zu legen. Was trotzdem die Wahrscheinlichkeit der Annahme erhöht, dass Vergerios Rede von 1393 seinen Zeitgenossen aufgefallen sein muss, und dass ihr Autor als ein wichtiger Erneuerer dieser Gattung gelten durfte, ist seine Schilderung der Lage der Oratorik in seinem meist bekannten Werk De ingenuis moribus (1402/3). Hier werden nämlich die Konturen einer von ihm für ideal gehaltenen Oratorik deutlich, die er bei seinen Zeitgenossen vermisst, und welchem Idealbild er in seiner Rede nahezukommen sucht. ${ }^{311}$ Für jemanden, der beide Texte kannte, muss der Zusammenhang zwischen Theorie (De ingenuis) und Praxis (die von Vergerio gehaltene Rede) aufgefallen sein.

Dementsprechend kann man annehmen, dass Vergerio wahrscheinlich als ein Redner angesehen werden konnte, der als erster oder wenigstens als einer der Ersten versuchte, die Regeln antiker Rhetorik in der Praxis der Oratorik zu verwenden. Wenn man sich dies vor Augen hält, so kann man Poggios Rede, die sich von der üblichen, älteren Praxis der Traueroratorik ostentativ abgrenzt, als ein für Vergerio irritierendes Ereignis deuten. Vergerio hatte zwar selbstverständlich kein ausschließliches Vorrecht, diese Art von Oratorik zu praktizieren, aber die Tatsache, dass er sich in Poggios Rede sogar noch als Zielscheibe einer verhüllten Attacke gesehen haben dürfte, hat seine Sensibilität für die Begebenheit, dass diese Attacke mit seinen eigenen Waffen geführt wurde, wahrscheinlich erhöht. Warum hielt nicht Vergerio die Rede, die Poggio gehalten hatte? Er war, selbst wenn man die aus seiner Strategie folgenden Übertreibungen über die Freundschaft zwischen ihm und Zabarella wegzulassen versucht, wahrscheinlich tatsächlich ein guter Freund des Kardinals, außerdem war er ein Humanist, dessen Name auch im Zusammenhang mit Traueroratorik bekannt war. Die Antwort liegt wohl auf der Hand. Seine Stellungnahme an Sigismunds Seite in der Prioritätsdebatte hat ihn als einen Redner zu diesem Anlass disqualifiziert. Er musste, wenn er trotzdem zu dem Anlass etwas schreiben wollte, die Briefform wählen.

ciceronianisch zu betrachten. Vgl. Witt, In the Footsteps, S. 370-387. Die Unterschiede in der Beurteilung von Vergerios Rolle bei der Wiederbelebung der antiken Oratorik bei Witt und McManamon sind den unterschiedlichen Erzählstrategien der jeweiligen Darstellungen zu verdanken: Während McManamon einen Bruch zwischen dem Traditionellen und dem Humanistischen sieht, stellt Witt die Ciceronianische Rhetorik der Humanisten als einen Entwicklungsprozess dar. Vergerio steht in Witts Narrativ am Anfang dieses Prozesses.

311 Wenn man die Chronologie beachtet, so wird klar, dass Vergerio zuerst seine Rede (1393) geschrieben hatte, und erst nachher (1402-03) seine Aussagen über die Lage der zeitgenössischen Oratorik formulierte. 


\subsection{Die Erzählung des Lebens als Erzählung einer Freundschaft}

Als zweites Mittel, mit denen Vergerio den privaten Raum schafft, in dem seine Beziehung zu Zabarella zu platzieren ist, kann der von ihm gewählte Rahmen für die Erzählung von Zabarellas Leben genannt werden. Er erzählt dieses Leben in engster Verbindung mit der Erzählung seiner Freundschaft mit dem Kardinal. Seine Darstellung des Lebens von Zabarella beginnt nicht mit seiner Abstammung, sondern erst mit dem Jahr, als sie sich kennen gelernt hatten: „Florentie illum primum novi ante triginta fere annos, cum ibi studiorum causa versarer, ille vero canonica iura traderet." ${ }^{\prime 312}$ Weitere Erwähnungen der Geschichte der Freundschaft mit Zabarella sind in Zabarellas Lebensbeschreibung eingewoben. Die bereits zitierte Aussage über die Freundschaft der beiden befindet sich auch in diesem Kontext. Auch während Zabarellas Romreise findet der Leser Vergerio an Zabarellas Seite. ${ }^{313}$ Im Vergleich zu Poggios Darstellung ist Vergerios Beschreibung viel persönlicher, nicht nur durch die Erwähnung der Freundschaft mit Zabarella, sondern auch dadurch, dass in Vergerios Fall der Erzähler tatsächlich der sich erinnernde Freund ist:

Nam illius quidem sincere mentis, recti animi, suavissime conversationis atque integerrime vite, que mihi per tot annos perspecta sunt, non ante oblivisci, quam mei ipsius potero, non antea desinere predicare, quam me vita deserere ceperit. 314

Poggio dagegen leitete den Teil seiner Rede, der Zabarellas Leben erzählt, folgendermaßen ein:

Quare a vobis peto Patres Conscripti, ut cum pauca de ipsius vita et moribus, pro ut tempus fert dixero, me de virtutibus suis dicentem benigne, sicut coepistis, attenteque audiatis. ${ }^{315}$

\subsection{3. „Apud nos": ein ,wir” wird kreiert}

Vergerio schafft nicht nur für sich einen Platz in Zabarellas Leben, er schafft auch dieser Freundschaft ein Umfeld, in dem diese zu sehen sei: „omnium vero libros oratorum et poetarum, historicorum quoque, qui sunt apud nos cogniti et habentur in usu, ita diligenter legerat, ut etiam familiares haberet". ${ }^{316}$ Mit diesem Satz wird eine Zusammengehörigkeit gestiftet, die auf der Basis von gemeinsamen Lesestoffen beruht. Im Kontext einer sich kristalli-

\footnotetext{
Vergerio, Epistolario, S. 364.

Vergerio, Epistolario, S. 365.

Vergerio, Epistolario, S. 364.

Poggio, Oratio, S. 252.

Vergerio, Epistolario, S. 368.
} 
sierenden Gruppenidentität, die keinen Konsens über eine einheitliche Selbstbezeichnung kennt, hat eine solche Geste eine besondere Bedeutung. Die Autoren, um deren Werke es hier geht, werden als oratores, poetae und historici bezeichnet, Bezeichnungen, welche auf Tätigkeitsfelder hindeuten, die üblicherweise für typisch ,humanistisch” gehalten werden. Zabarella wird aber nicht nur als Leser, sondern auch als Autor dargestellt: „extant autem ornatissime orationes plurime, quas variis de rebus inter presentes habuit, itemque alio volumine elegantiores epistole collecte, quas scripsit ad absentes." ${ }^{317}$ Die zwei als schlechthin humanistisch geltenden Gattungen werden hier also genannt, in denen der Kardinal selbst tätig gewesen sein soll. Vor diesen Sätzen befindet sich die Schilderung von Zabarellas Lehrtätigkeit: er habe in allen freien Künsten sich bestens ausgekannt und diese unterrichten können, insbesondere aber habe er sich der naturalis philosophia und oratoria gewidmet, so dass er , de natura rerum acutissime disputare poterat, und omnia quecunque vellet accuratissime disserere“. 318

Zabarellas Lehrtätigkeit wird also mit den Verben sapere und docere eingeleitet, und dann mit disputare und disserere präzisiert, während seine Reden und Briefe (für die er als Autor), und die Werke der Redner, Dichter und Geschichtsschreiber (als deren Leser er dargestellt wurde), einer anderen Sphäre angehören, die nicht unmittelbar mit seiner Lehrtätigkeit zusammenhängt. Die zwei Sphären sind voneinander mit einem autem getrennt. Dass Zabarella in der zweiten, eher extrauniversitären Umgebung mit humanistischen Interessen bekleidet wird, welche einen Kreis von Lesern schaffen, zu welchem sich Vergerio zugehörig darstellt, ist ein gutes Beispiel dafür, wie Darstellung und Selbstdarstellung miteinander verbunden sind. Vergerio, der Humanist, stellt Zabarella auch als einen Gelehrten dar, der ähnliche Interessen hegte. In diesem Punkt ist seine Strategie der von Poggio ähnlich. Während aber Poggio seine Darstellung auf Zabarellas rednerische Fähigkeiten zuspitzt, erwähnt Vergerio auch seine Briefe als mit den Reden gleichrangige Stücke, wobei die Gleichrangigkeit durch die Symmetrie der zwei Satzteile geschaffen wird (,extant autem ornatissime orationes plurime, quas variis de rebus inter presentes habuit, itemque alio volumine elegantiores epistole collecte, quas scripsit ad absentes") ${ }^{319}$. Auch die Oratorik bekommt einen anderen Akzent bei Vergerio als bei Poggio. Bei Letzterem wurde Zabarellas Tätigkeit als Redner den Zuhörern hauptsächlich durch seine letzte Rede vergegenwärtigt, während bei Ersterem Reden und Briefe ähnliche Funktionen haben; der Unterschied besteht darin, dass Briefe an Abwesende, Reden an Anwesende geschrieben werden. Indem er Briefe und Reden

\footnotetext{
317 ebda

318 Vergerio, Epistolario, S. 367 f.

319 Vergerio, Epistolario, S. 368.
} 
als miteinander vergleichbare Kommunikationskanäle darstellt, entdramatisiert Vergerio die von Poggio extrem dramatisch gefärbte Gattung der Rede einerseits, während er dem Brief einen in der Gattungshierarchie mit der Rede vergleichbaren Status zuschreibt. Dies ist von der Tatsache, dass er sein eulogium in Briefform verfasst, wahrscheinlich nicht ganz unabhängig: er qualifiziert damit sein eigenes Schreiben über Zabarella als mit einer Festrede gleichrangiges Schriftstück.

\subsection{Vergerio als Begünstigter in Zabarellas Testament: Der geerbte Cicero}

Auch die Erwähnung von Zabarellas Testament, das in Poggios Rede als ein öffentlicher Aufruf zur Aufhebung des Schismas und zu einer schnellen Papstwahl erschien, findet Widerhall in Vergerios Text. Das von ihm erwähnte Testament ist aber Zabarellas privates Testament, in dem er seine Bücher Vergerio hinterlässt:

Sed et illud quoque, ut oblivioni minime michi tradendum, ita nec committendum silentio, quod post plurima variis temporibus officia beneficiaque in me collata, postremo cum testamentum conderet, quorundam etiam librorum legato me honoravit. $^{320}$

Erbschaft ist eine der üblichsten beneficia unter Freunden. Unter Gelehrten besteht das Erbgut teilweise aus Büchern. Die Geste, die eigenen Bücher jemandem zu vererben, hat außer dem nicht $\mathrm{zu}$ unterschätzenden finanziellen Wert auch einen symbolischen. Sie ist als eine Freundschaftserklärung zu verstehen, weil sie eine Sinnesverwandschaft der beiden Personen und die Wertschätzung des Erben von Seiten des Verstorbenen impliziert. Sie folgt aus der Logik der Freundschaft: Freunde haben, so ist spätestens seit Plato bekannt, alles gemeinsam. ${ }^{321}$ Das Sprichwort wird von Poggio in seiner Rede zitiert, an der Stelle, wo er über Zabarellas Tugenden, mit besonderem Akzent auf seine Großzügigkeit, schreibt. ${ }^{322}$ Während Poggio über Zabarellas selbstloses Verhalten gegenüber seinen Freunden als Teil der allgemeinen Darstellung des Kardinals schreibt, wird Freundschaft bei Vergerio das Hauptthema seines Briefes, ohne diese als solches explizit zu nennen. Wenn Vergerio das Sprichwort (welches zu zitieren in diesem Kontext selbstverständlich gewesen wäre) nicht zitiert, dann tut er es höchstwahrscheinlich, weil Poggio es schon getan hatte. Vergerio wollte

\footnotetext{
320 Vergerio, Epistolario, S. 373.

321 Zum Sprichwort ,amicorum omnia communia” von Platos Leg. 739 c., über Terenz Adelph. 803 und Cicero Off. 1. 51. bis zu seinen englischen und spanischen Entsprechungen vgl. Kuratorium Singer der Schweizerischer Akademie der Geistes- und Sozialwissenschaften, Hrsg., Thesaurus Proverbiorum Medii Aevi, 13 Bde. (Berlin-New York: Walter de Gruyter, 1996-2007), [im Weiteren: „TPMA”] Bd. 4, S. 25.

322 Es sind mehrere Tugenden, die in diese Richtung hindeuten, wie seine liberalitas, beneficentia, bonitas, charitas und misericordia: vgl. Poggio, Oratio, S. 258.
} 
in seiner Antwort einer anderen Strategie folgen, die nicht mit Allgemeinwahrheiten arbeitet, die jedem Redner als erste Wahl der Topoi zum Thema „Freundschaft” eingefallen wären. ${ }^{323}$

Unter den Büchern, die Zabarella Vergerio vermachte, befindet sich auch Ciceros Laelius de amicitia. ${ }^{324}$ Dadurch wird die Geste, die auch ohne diesen Text als ein unübersehbares Eingeständnis der Freundschaft von Zabarella Vergerio gegenüber gesehen werden darf, noch eindeutiger.

Dafür, dass Cicero - neben Petrarca - eines der „Hauptthemen” der Freundschaft zwischen Vergerio und Zabarella war, hat Agostino Sottili mit Hilfe eines Briefes argumentiert, den ein bestimmter „Franciscus” an Cicero adressiert hatte, und dessen Autor Sottili mit Zabarella identifiziert. Nach seiner Meinung war dieser Brief die Vorlage für Vergerios (hier später ausführlich analysierten) Brief an Petrarca. ${ }^{325}$

323 In seinem Epigramm deutet Vergerio auch auf diese Sentenz hin, vgl. Anm. 308.

324 Die Bücher, die Vergerio von Zabarella erbte, sind: „Ciceronem de Tusculanis ligatum simul cum Epistolis Plinii, et ipsas etiam Epistolas P., Ciceronem de Officiis. Item alium de Amicitia et de Senectute cum quibusdam eius Orationibus in alio volumine. Aliud insuper parvum volumen, in quo novem Orationes eiusdem, et Rethoricam novam et veterem: Libros etiam hos Petrarce: Africam, Epistolas metricas, De secreto Conflictu, De Vita solitaria, De Ocio religioso, De Remediis utriusque fortune.": Giuseppe Vedova, Memorie intorno alla vita ed alle opere del cardinale Francesco Zabarella (Padua: Minerva, 1829), [im Weiteren: „Memorie"], 130. McManamon stellt eine Liste von Vergerios Büchern zusammen: PPV and Jerome, S. 59-66. Auf dieser Liste befindet sich auch der Codex Nr. 20 der Universitätsbibliothek von Budapest, der mehrere Schriften von Cicero enthält, unter anderem auch den Laelius. McManamon erwähnt in einer Fußnote ( $P P V$ and Jerome, S. 265) zu diesem Codex, dass Vergerio von Zabarella einen Codex geerbt hatte, der die Werke Ciceros enthielt, die in diesem Budapester Codex enthalten sind, der nach McManamons Angabe (die auf Csapodis Buch über die Bibliothek von János Vitéz basiert) Vergerio gehörte. McManamons Erwähnung dieser inhaltlichen Ähnlichkeit der zwei codices suggeriert dem Leser, dass es möglich sein könnte, dass der Budapester Codex identisch mit dem von Zabarella geerbten Codex sein könnte. Nach neuesten Untersuchungsergebnissen gehörte aber der Codex 20 nicht Vergerio, weil das von Csapodiné verwendete Argument dafür, nämlich, dass im Codex manche Marginalnotizen von János Vitéz stammen, als unbegründet zurückzuweisen ist. Auch der andere Grund, weswegen man überhaupt auf den Gedanken der Zuschreibung des Codex an Vergerio gekommen ist, nämlich, dass es sich im Fall des Codex um eine Corvine handeln sollte (der aus Vergerios Bibliothek durch János Vitéz in die Bibliothek des Matthias gelangt sei), nach neueren kodikologischen Untersuchungen nicht bestätigt werden konnte. Vgl. András Németh, „Az Egyetemi Könyvtár Cod. Lat. 20. kódexének új vizsgálata és a benne Szereplö Phalarisz-levél fordítása [Die neue Untersuchung des Codex Nr. 20 der Universitätsbibliothek von Budapest und die Übersetzung des darin zu findenden Phalaris-Briefes]", Az Egyetemi Könyvtár Évkönyvei [Die Jahrbücher der Universitätsbibliothek von Budapest] 12 (2005): 61-92. Dementsprechend bleibt die Identität des von Zabarella geerbten Codex weiterhin unbekannt.

325 Agostino Sottili, „La questione ciceroniana in una lettera di Francesco Zabarella a Francesco Petrarca”, Quaderni per la storia dell'università di Padova 6 (1973): 25-59, [im Weiteren: „La questione”]. Den Text des Briefes veröffentlicht er im Anhang zu seiner Studie. Der wesentliche Unterschied zwischen Zabarellas und Vergerios Antwort auf Petrarcas Brief an Cicero ist, dass Zabarella seinen Brief, im Gegensatz zu Vergerio, in seinem eigenen Namen schreibt („Franciscus Francisco Petrarce salutem”: Sottili, La questione, S. 122). Aus diesem Unterschied folgt der im Ton: Vergerio, weil er im Namen Ciceros schrieb, den Petrarcas Kritik persönlich getroffen hat, benutzt einen leidenschaftlicheren Ton. Zabarella, der die Distanz zwischen sich selbst und Cicero nicht verschleierte, ist wesentlich kompromissbereiter und zeigt auch mehr Verständnis für Petrarcas Standpunkt. Indem er im eigenen Namen schreibt, kann er sich als einen Richter in den „Streitigkeiten” seiner beiden Idole zeigen. Am Ende des Briefes schreibt er, dass er auch an Petrarcas Lebensstil nichts zu tadeln hat: „Nam tuam illam singularem solitariamque vitam, quia tibi sufficiens ferventissimus studiorum floci fecisti regum opes, minime carpo": Sottili, La questione, S. 124. 


\subsection{Ciceros De amicitia als Folie zu Vergerios eulogium}

Ciceros Text galt als einer der wichtigsten, die bei der Konstruktion des humanistischen Freundschaftsmythos eine Schlüsselrolle spielten. Außer diesem herausragenden Status von Ciceros Text unter den von Humanisten geschätzten Schriften antiker Autoren und seinem aus diesem Status folgenden Signalwert unter den von Zabarella vererbten Büchern hat De amicitia eine konkrete Funktion bei Vergerios Bemühung, seinem eulogium die richtigen Koordinaten im gewaltigen Gewebe der Texte antiker und zeitgenössischer Autoren zu geben. Er benutzt De amicitia gewissermaßen als Folie für das Schreiben seines eigenen Freundschaftstextes.

Vor der Erörterung der Gemeinsamkeiten der beiden Texte, oder besser gesagt, der Elemente, die Vergerio von Ciceros Text in sein eulogium einbaut, ist es nötig, die offensichtlichen Differenzen zu markieren. Hier sei zuerst die Zugehörigkeit zu unterschiedlichen Genres genannt. Ciceros moralphilosophischem Dialog steht Vergerios Brief gegenüber. Ein anderer Unterschied betrifft den „Narrator” und den Rahmen der jeweiligen Schriften, die vieles entscheidende Frage: „Wer spricht?” In Vergerios Brief ist die narrative Situation ziemlich unkompliziert, der Erzähler ist mit dem biografischen Autor gleichzusetzen.

Trotz dieser relativen Unkompliziertheit des Erzählrahmens in Vergerios Fall ist eine kurze Bemerkung zu diesem Thema zu machen. Das Gleichsetzen des biografischen Autors mit dem „Erzähler” eines Textes ist immer nur mit größter Vorsicht vorzunehmen, da man in literarischen Texten immer mit einer Unterscheidung zwischen dem Autor und dem Narrator rechnen muss. Selbst in der ,privaten” Gattung des Briefes gibt es Beispiele dafür, wie irreführend es sein kann, wenn man den biografischen Autor des Briefes mit dem Erzähler gleichsetzt. ${ }^{326}$ Ein absolutes Zusammenfallen des Autors und des Narrators ist nur im Falle von Texten möglich, die mit Sicherheit als nicht fiktional $\mathrm{zu}$ bezeichnen sind. Die Qualifikation eines Textes als eine rein faktuale Erzählung ist äußerst schwierig, wenn man die Sprache nicht als transparentes Medium der Wahrheitswiderspiegelung definiert. Deswegen ist es vielleicht sinnvoller, statt von einer Dichotomie der Fiktionalität und der Faktualität eher von einem Kontinuum auszugehen, auf dessen Polen sich diese zwei Qualitäten be-

326 Petrarcas Briefe wurden in der älteren Forschung als „faktuale Narrationen” verstanden, ganz zu schweigen von Schriften, die nicht einmal mit ihrem Genre eine solche Vertrauenswürdigkeit suggerieren, wie - um nur ein Beispiel dafür zu nennen - der Dialog Secretum, der oft als ein Beweis, als ein Dokument für Petrarcas Krise wahrgenommen wurde. In Folge der Aufklärung vieler Unstimmigkeiten (im Fall des Secretums war es einfach das Datum des Schreibens des Dialogs) wurde allmählich akzeptiert, dass vieles vom Erzählten nicht dem entspricht, was man aus anderen, externen Beweisen über Petrarcas Leben zu wissen glaubt. Diese Tatsache kann einen dazu führen, die in den Briefen dargestellte Realität als „Lüge” abzustempeln, die andere, m. E. sinnvollere Möglichkeit wäre aber einfach die Einsicht, dass man literarische Dokumente nur mit Einschränkungen zur Rekonstruktion des Lebens des biografischen Autors benutzen darf. 
finden und innerhalb dessen alle Texte unterzubringen sind. Vergerios Brief würde sich in diesem Fall näher dem Pol der „Faktualität” befinden, und so darf man das vom Autor suggerierte Nicht-Unterscheiden zwischen Autor und Narrator akzeptieren und davon ausgehen, dass in diesem Fall diese zwei Funktionen nahezu zusammenfallen.

Im Gegensatz zu der relativ einfachen Erzählsituation in Vergerios Text hat Ciceros De amicitia eine komplizierte Struktur, was die erzählenden Stimmen betrifft. In der an Atticus gerichteten Einleitung meint Cicero, dass er im Folgenden die Erzählung des Augurs Quintus Mucius Scaevola rekonstruiert, in welcher ein Gespräch wiedergegeben wurde, dessen Gegenstand die Freundschaft war, zwischen Laelius, dem erzählenden Scaevola und Caius Fannius. Der Hauptsprecher ist Laelius, es geht um seine disputatio über die Freundschaft, seine Worte werden aber durch einen zweistufigen Übertragungsvorgang präsentiert: Cicero vermittelt sie auf Grund der Erzählung des Scaevola. Von Polyphonie ist aber nicht nur wegen der mehrschichtigen Vermittlung zu reden, sondern auch in der synchronen Achse des Dialogs gibt es dafür Indizien. Man hört nicht nur Laelius' Stimme, sondern, wenn auch eher nur aus dem Hintergrund, in der Funktion der Fragenden, zudem die der Gesprächspartner Scaevola und Fannius. Ein dritter Aspekt der Polyphonie ist in derselben disputatio des Laelius' zu finden, weil er in seiner Rede die Meinungen der verschiedenen philosophischen Schulen miteinander konfrontiert. Dementsprechend wäre es schwierig, zu versuchen, aus dem Text Ciceros persönliche Einstellung herauszudestillieren. Aus Vergerios Perspektive ist diese Polyphonie aber weniger von Bedeutung, weil sie von den Lesern des frühen 15. Jahrhunderts anscheinend nicht problematisiert wurde. De amicitia galt als ein autoritativer Text, der das antike Modell von Freundschaft exemplarisch darstellte.

Die Gemeinsamkeiten der beiden Schriften betreffen erstens die Ausgangssituation des Freundeslobes. In beiden Fällen ist der Freund, der Gegenstand des Lobes, gerade gestorben. Der Tod des jeweiligen Freundes liefert den Anlass für einen Text, in dem es um die Freundschaft geht. In Ciceros Fall handelt es sich um einen philosophischen Dialog, in dem Freundschaft im Allgemeinen thematisiert wird. In Vergerios Fall ist Freundschaft als Hauptthema nicht so offensichtlich. Sie wird nicht thematisiert, aber unterschwellig ist sie trotzdem das, worum es im ganzen Text geht. Freundschaft wird hier nicht theoretisch beschrieben, sondern sie wird behauptet. Sie wird, durch die teilweise schon oben behandelten Strategien konstruiert ${ }^{327}$, damit Vergerio genau mit diesem Konstrukt sein Ziel

327 Das Wort „Konstruktion” verstehe ich nicht im Kontext der Dychotomie von „wahr” und „gelogen”, wo es auf dem Pol „gelogen” zu platzieren wäre. Ich verstehe es als einen Verweis auf die textuelle Beschaffenheit des eulogiums, mit anderen Worten: auf die Tatsache, dass Texte in jedem Fall, und so auch Vergerios eulogium, die Welt nicht widerspiegeln, sondern aus verschiedenen Elementen neu aufbauen, neu schaffen. Für diesen konkreten Fall bedeutet es, dass Vergerios Freundschaft mit Zabarella im eulogium auf jeden 
erreicht, das ihn zum Schreiben motivierte, nämlich, dass er trotz seines Engagements an der Seite Sigismunds weiterhin ein „Mitglied” der humanistischen Gemeinschaft bleibe. Der tote Freund, in Ciceros Fall Scipio Africanus, in Vergerios Zabarella, ist ein mächtiger, einflussreicher und selbstverständlich tugendhafter Mensch. Die Behauptung der Tugendhaftigkeit des anderen folgt erstens aus der Tatsache, dass beide Schriften Lobschriften sind, zweitens aber auch aus der ciceronischen Definition der Freundschaft, nach der virtus Freundschaften zustande bringt und konserviert.

Virtus, virtus, inquam, C. Fanni, et tu, Q. Muci, et conciliat amicitias et conservat. In ea est enim convenientia rerum, in ea stabilitas, in ea constantia; quae cum se extulit et ostendit suum lumen et idem aspexit agnovitque in alio, ad id se admovet vicissimque accipit illud, quod in altero est; ex quo exardescit sive amor sive amicitia; utrumque enim dictum est ab amando; amare autem nihil est aliud nisi eum ipsum diligere, quem ames, nulla indigentia, nulla utilitate quaesita; quae tamen ipsa efflorescit ex amicitia, etiamsi tu eam minus secutus sis. ${ }^{328}$

Ein Freund kann demzufolge per definitionem nur ein tugendhafter Mensch sein. Es ist die Tugend, die einem den anderen liebenswert macht, und zwar dadurch, dass der eigene virtus die gleiche Eigenschaft im Anderen erkennt und sich zu dem anderen hingezogen fühlt. Virtus funktioniert wie ein in den Menschen eingepflanzter Magnet, der die Menschen, die über diesen verfügen, zueinander zieht. Damit wird aber auch die eigene Tugendhaftigkeit behauptet. Dass sich Freunde zwangsläufig ähnlich sind, wird in Ciceros Text auch explizit erklärt: „Verum enim amicum qui intuetur, tamquam exemplar aliquod intuetur sui." ${ }^{329}$ Wenn man annimmt, dass es Vergerios Absicht war, Ciceros Text seinen Lesern in Erinnerung zu rufen (für diese Behauptung werden im Folgenden weitere Beweise ausführlicher erörtert), so dürfte man annehmen, dass er damit gerechnet hat, dass sein anvisiertes Publikum bei dem Lesen seines eulogium s Ciceros De amicitia als Folie, als Bezugspunkt ständig im Hinterkopf hat. Dieser ideale Leser musste also beim Lesen von Vergerios Lob des Zabarella auch den oben zitierten Satz von Cicero präsent haben, nach dem es genauso sei, wenn man seinen wahren Freund betrachtet, als ob man sein eigenes Abbild betrachten würde. Wenn der Leser den Syllogismus zu Ende zu führen vermochte, so konnte er feststellen, dass Vergerio selbst ein genauso großartiger, tugendhafter und gelehrter Mann sei wie der von ihm gelobte Zabarella,

Fall eine Konstruktion ist, unabhängig davon, ob Vergerio und Zabarella im realen Leben wirklich Freunde waren oder nicht.

329 Cic. Amic. 23. 
sonst hätten die beiden nicht Freunde gewesen sein können. Freundschaftslob ist, wenn man es vor diesem Hintergrund betrachtet, immer gleichzeitig auch Selbstlob. ${ }^{330}$

Dass in Ciceros Fall dieser mächtige Mann kein anderer als Scipio war, kam Vergerio gelegen. So wurde die Identifikation Zabarellas mit Scipio für den Leser leicht gemacht. Der Politiker, der von Cicero als der Retter der res publica gefeiert wurde, ${ }^{331}$ ein Lob, in welchem wieder ein verstecktes Selbstlob von Laelius (also ein Lob des Laelius von Ciceros Seite) mitschwingt, ${ }^{332}$ war auch als Unterstützer mehrerer Dichter bekannt. Eine Tatsache, auf welche Cicero mit seiner Wahl von Zitaten hinweist: der zu dem Scipiokreis gehörende Terenz wird zum Beispiel zweimal im Dialog zitiert. Im Folgenden werden die entsprechenden Stellen aus beiden Texten zitiert, in denen Scipio und Zabarella charakterisiert werden. Zabarella entspricht dem gleichen Ideal vom weisen Mann, den Scipio für Cicero verkörpert: er kümmerte sich um seine Familie und Freunde. Für Scipio: „Quid dicam de moribus facillimis, de pietate in matrem, liberalitate in sorores, bonitate in suos, iustitia in omnes?",333 Während für Zabarella: „Itaque vix ullus pater a filiis ita diligitur, ut ipse erat suis discipulis carus, quoniam ita docebat, ut plane videretur non ambitioni proprie eum studere, sed illorum utilitati”334 und „nec vero in me unum, sed in omnes supra modum pene hac suarum facultatum largitione liberalis erat... propensius vero in miserabiles personas ferebatur, quas

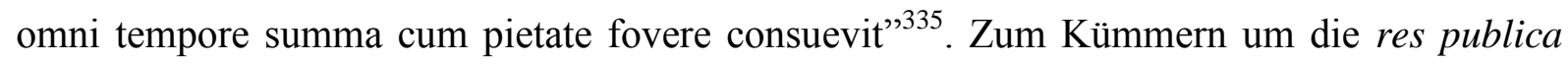
heiß es für Scipio: ,rei publicae paene sero, qui duabus urbibus eversis inimicissimis huic imperio non modo praesentia verum etiam futura bella delevit "336, sowie für Zabarella: ,,cum hoc tempore ego illi de re maxima publice adversarer, et uterque communi bono studeret”337, und „fructum suorum laborum,...quos novissime in hoc concilium pro reintegranda Ecclesia

330 In Ciceros Fall ist - dank der komplexeren Erzählsituation - das Selbstlob etwas indirekter. Da Scipios Lob in Laelius' Mund gelegt wird, ist das Lob des Scipio ein fiktives Selbstlob von Seiten des Laelius. Dass dieses wiederum doch auch im Kontext von Ciceros Selbstdarstellung zu deuten ist, ist mit seiner Positionierung im politischen Gewebe zu erklären: der Dialog fängt mit dieser Selbstpositionierung an. Cicero sei nach dem Anlegen der toga virilis von seinem Vater in Scaevolas Obhut gegeben worden, der ihm viel über seinen Schwiegervater Laelius erzählt habe. Wenn man die Verbindungen Schritt für Schritt zurückverfolgt, so kommt man zum Ergebnis, dass Cicero - natürlich mit einer Generationsverschiebung quasi zur gleichen familia gehört wie Laelius. Auf jeden Fall gehöre Cicero zur guten Seite, wo all die großen Männer zu finden sind, die als Beispiele für ideale Freundschaft und Tugendhaftigkeit dienen. „...factus consul est bis, primum ante tempus, iterum sibi suo tempore, rei publicae paene sero, qui duabus urbibus eversis inimicissimis huic imperio non modo praesentia verum etiam futura bella delevit.": Cic. Amic. 11.

332 Weil Scaevola Scipios Sorge um die res publica wie alles andere ebenfalls geteilt hat: „Sed tamen recordatione nostrae amicitiae sic fruor, ut beate vixisse videar, quia cum Scipione vixerim, quocum mihi coniuncta cura de publica re et de privata militia communis et, id in quo est omnis vis amicitiae, voluntatum, studiorum, sententiarum summa consensio.": Cic. Amic. 15.

333 Cic. Amic. 11.

334 Vergerio, Epistolario, S. $368 \mathrm{f}$.

335 Vergerio, Epistolario, S. 374.

336 Cic. Amic. 11.

337 Vergerio, Epistolario, S. 370. 
contulit”,338. Weswegen sie von allen geschätzt und geliebt wurden: für Zabarella: „,quisquis esset rerum status, fides ei permaxima apud omnes haberetur, essetque semper unus inprimis acceptus et carus omnibus”, ${ }^{\text {,39 }}$, nam quisquis illum semel novit, dilexit semper; odisse nemo potuit, nisi extreme malus" ${ }^{340}$, und dessen Tod deswegen ein Verlust für die ganze Menschheit ist: für Scipio: „Quam autem civitati carus fuerit, maerore funeris indicatum est”341, für Zabarella: „eo moriente tanto lumine privatus est mundus, ... docti omnes et quicunque aliquo virtutis genere valerent, tam benivolum patrem amiserunt" ${ }^{342}$.

Jedem Mitglied der Lesergemeinschaft, deren gemeinsamer Nenner die antike Literatur und in erster Linie Cicero war, galt Scipio mit großer Wahrscheinlichkeit als Vorbild für eine vor großer Öffentlichkeit tätige und literarische Interessen hegende Persönlichkeit. Diese Selbstverständlichkeit konnte für Vergerio beim Schaffen seines Zabarella-Bilds behilflich sein und dazu benutzt werden, Ciceros Freundschaftstext unter anderem auch mit dieser Assoziation seinen Lesern in Erinnerung zu rufen.

Eine andere Gemeinsamkeit der beiden Texte ist, dass sie nicht nur von einem großen Freund handeln (aus dem Anlass des Verlustes dieses Freundes), sondern auch einem Freund gewidmet wurden: Cicero schreibt den Dialog an Atticus, während Vergerio seine Worte wahrscheinlich an seinen Humanistenfreund Ludovico Buzzacarini richtet. ${ }^{343}$

Das Politikum der humanistischen Gemeinschaftsbildung in Vergerios Fall wurde in dieser Arbeit schon angesprochen. Für Cicero lässt sich ein noch offensichtlicherer politischer Hintergrund der Freundschaftsschrift feststellen. Er lässt Laelius betonen, dass er das Thema Freundschaft nicht im abstrakten Sinne erörtern möchte, sondern in seiner alltäglichen Realisierung. ${ }^{344}$ Dementsprechend ist sein Monolog ausgestattet mit positiven sowie auch mit negativen exempla für die Freundschaft. Die positiven Beispiele stammen meistens aus dem Scipionenkreis, während die negativen von der Seite populärer „Staatsfeinde” wie den Gracchen stammen. Durch die vielen negativen exempla schildert Cicero den Zustand des römischen Staates äußerst kritisch. Ciceros Agenda ist in seiner Freundschaftsschrift keineswegs eine versteckte. Demzufolge kann man vielleicht davon ausgehen, dass das Politikum für einen in der antiken Literatur bewanderten Leser des frühen 15. Jahrhunderts kaum zu übersehen war, die Namen im Dialog standen bestimmt nicht in einem Vakuum, sonst könnte

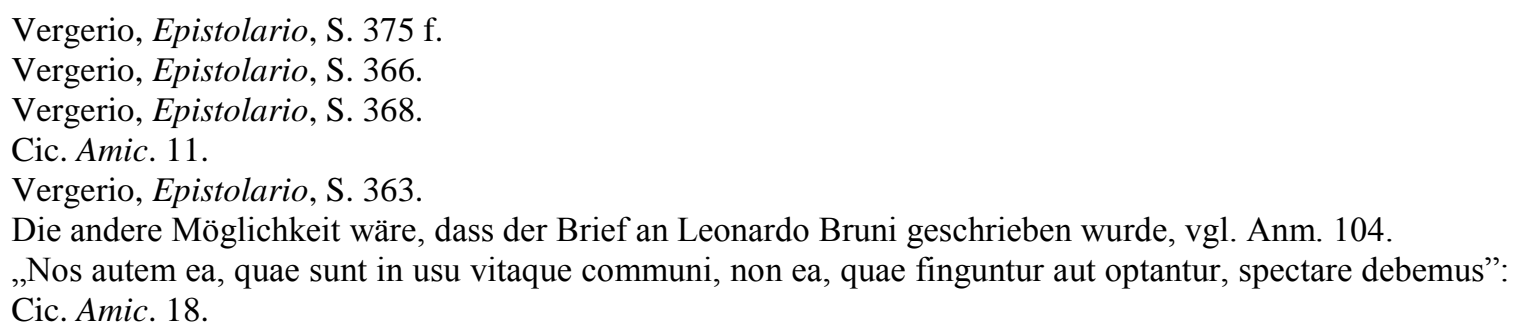


man nicht behaupten, dass ein (implizierter) Vergleich Zabarellas mit Scipio von Vergerio überhaupt durchsetzbar war.

Aber De amicitia war für Vergerio wahrscheinlich trotzdem in erster Linie nicht wegen seines politischen Hintergrunds interessant. Wenn diese Schrift zitiert wurde, dann meistens doch wegen ihrer sprichwortartigen Aussagen. ${ }^{345}$ Vergerio zitiert in zwei Briefen Ciceros Laelius mit einer allgemeinen Wahrheit über Freundschaft. Einmal in seinem Brief an Santo dei Pellegrini 1389, den er mit einer Entschuldigung für sein langes Schweigen anfängt. Er entschuldigt sich mit dem Gemeinplatz über Freundschaft, dass man den anderen selbst dann nicht vergisst, wenn man ihn lange Zeit nicht sieht, und dass richtige Freundschaften sogar über den Tod hinaus dauern: „Reor enim me talem tecum amicitiam sanxisse, que nec absentia, nec quovis humano casu, imo nec possit morte deleri”,346. Dieser Gedanke ist auch in Ciceros Laelius zu finden: „Quocirca et absentes adsunt et egentes abundant et imbecilli valent et, quod difficilius dictu est, mortui vivunt." ${ }^{347}$ Nach dieser Paraphrase zitiert Vergerio die antike Freundschaftsautorität auch wörtlich, um zu deklarieren, dass Freundschaft das Kostbarste sei, was man von den Göttern bekommen habe: „nichil a diis immortalibus melius habemus". 348 Nach dieser Einleitung setzt der Schreiber des Briefes seinen Freundschaftsdiskurs in einem anderen, etwas pragmatischeren Register fort, indem er ein Buch, das Santo einmal mitgenommen habe: „ne autem longior mea te afficiat oratio, te rogatum velim, ut reddas quod debes, scilicet librum Bucolicorum quem tecum tulisti cum Glemona (Gemona del Friuli) recederes... 349 Obwohl das Organisieren des Bücherverkehrs

345 Als Beispiel sollen hier Stellen aus Poggios Briefen stehen: „Scis enim virtutem tanti esse, ut nos ad eorum, etiam quos nunquam vidimus, benivolentiam compellat.” Poggio, Lettere, Bd. 2, S. 222 (vgl.: Cic. Amic. 28 „Nihil est enim virtute amabilius, nihil quod magis adliciat ad diligendum, quippe cum propter virtutem et probitatem etiam eos, quos numquam vidimus, quodam modo diligamus.") Die gleiche Stelle wird auch in zwei weiteren Briefen Poggios paraphrasiert: „Etenim cum omnium benivolentia appetenda est, ut nature officio pareamus, maxime, in quibus virtutis splendor eluceat, que solet nos cogere ad amorem etiam ignotorum.” Poggio, Lettere, Bd. 3, S. 175, und: „Si enim quos nunquam vidimus etiam diligimus propter eorum virtutem, quanto maiori affectione esse debemus erga illos, quos presentes conspicimus...": Poggio, Lettere, Bd. 3. S. 215. Es kommt auch vor, dass Poggio einen ganzen Brief auf eine Laelius-Stelle aufbaut. Es handelt sich um eine kurze Danksagung. Ciceros Laelius scheint für eine solche Höflichkeitsrunde auch die ideale Topos-Sammlung zu sein: „Quanvis, pater et domine mi reverendissime, dubitetur a sapientibus viris, an inter admodum dispares dignitatis gradus amicitia esse possit, tamen volunt caritatem et benivolentiam esse posse, que et ipse usu sunt et consuetudine conservande.": Poggio, Lettere, Bd. 3, S. 168, „dispares enim mores disparia studia sequuntur, quorum dissimilitudo dissociat amicitias”: Cic. Amic. 74. Manchmal funktioniert aber der Text des De amicitia wie eine Fundgrube für allgemeine Wahrheiten, auch wenn es nicht um Freundschaft geht: „,vetus est sententia: omnia preclara rara.”: Poggio, Lettere, Bd. 2, S. 229; „et quidem omnia praeclara rara.” Cic. Amic. 21. Laelius-Stellen in Salutatis Briefwechsel: Coluccio Salutati, Epistolario, 4 Bde., hrsg. v. Francesco Novati (Rom: Tipografi del Senato, 1891-1911). Bd. 1, S. 59, 83, 185, 199, 210, 211 und 229, Bd. 3, S. 185, 376, 447, 468 und 491, Bd. 4, S. 19, 138 und 302.

346 Vergerio, Epistolario, S. 16.

347 Cic. Amic. 23.

348 Vergerio, Epistolario, S. 16. Cic. Amic. 20.

349 Vergerio, Epistolario, S. 16. 
zwischen diesen Gelehrten eines der Hauptthemen ihrer Korrespondenz war, also eigentlich quasi ein Muss in einem Humanistenbrief, wirkt diese ausgesprochen brüske Aufforderung nach dem antikisierenden Freundschaftsschwur trotzdem etwas ernüchternd.

Der zweite Brief mit einem Zitat aus dem Laelius ging an den Arzt Antonio Baruffaldi, in dem Vergerio den Freund ermuntert, die heiligen Bänder der Freundschaft nicht zu vernachlässigen, weil man ohne sie nicht glücklich leben könne: „sine quo, ut ait Cicero, nullus eligeret vivere", 350

Man kann also feststellen, dass Ciceros De amicitia als eine Art obligatorische Autorität funktionierte, wenn es um das Thema Freundschaft ging. Was Cicero in diesem Fall interessant machte, war in erster Linie nicht das Politische, nicht also das für Ciceros Zeit Spezifische, sondern gerade das, was man eigentlich von jedem anderen Autor hätte zitieren können. Man nahm aber Cicero, weil es sich so gehörte, weil er (neben Seneca) als der Freundschaftsexperte galt. Diese wahrscheinlich eher wenig überraschende Bemerkung unterstützt aber (und deswegen war sie vielleicht doch nicht ganz ohne Interesse) die These, dass die Tatsache, dass Vergerio von Zabarella auch diese Schrift geerbt hatte, für eine symbolische Geste gehalten werden darf, man zweitens damit rechnen kann, dass sie auch als solche wahrgenommen wurde, und letztens, dass in Vergerios eulogium von einer unterschwelligen Präsenz dieses Schlüsseltextes des humanistischen Freundschaftsdiskurses auszugehen ist.

Für die letztere Hypothese habe ich bis jetzt damit argumentiert, dass die Ausgangssituation in Vergerios Fall eine ähnliche ist. Der Anlass für das Freundeslob ist der Tod eines mächtigen, einflussreichen Freundes, was einen Vergleich der zwei großen Toten impliziert und damit einen weiteren Baustein für das von Vergerio errichtete Monument für Zabarella darstellt. Es gibt aber weitere Stellen in Vergerios Text, die eine Assoziation mit Ciceros Laelius ermöglichen. Sie werden in den nächsten Abschnitten erläutert. Außer den oben geschilderten Verbindungen der beiden Texte sehe ich eine von diesen getrennte Erörterung der weiteren intertextuellen Zusammenhänge deswegen als nötig an, weil diese gleichzeitig auch auf Poggios Text antworten und die Hauptaussage von Vergerios eulogium bilden.

\subsubsection{Die Entdramatisierung von Zabarellas Gestalt}

\subsection{Eine gar nicht harmlose Anapher}

Neben der Betonung der ,privaten” Bindungen zwischen sich und Zabarella ist die Hervorhebung seiner Rolle als Vermittler zwischen den beiden „Parteien” der Debatte ein weiterer Bestandteil des von Vergerio gezeichneten Zabarella-Bildes. Während Poggio das

\footnotetext{
350 Vergerio, Epistolario, S. 17, und Cic. Amic. 52. und 86 f.
} 
Konzil beinahe zu einem Krieg stilisiert, in dem die zwei entgegengesetzten Parteien miteinander einen richtigen Kampf führten und seinen Zabarella als einen Vorkämpfer der einen Seite darstellt, entdramatisiert Vergerio Zabarellas Gestalt.

Der Höhepunkt von Poggios Rede mit seiner dramatischen, anaphorischen Anrede Zabarellas („Tu ... tu ... tu“) hat in Vergerios Brief eine Parallelstelle. Auch Vergerio verwendet auf dem Höhepunkt seines Briefes die Figur der Anapher. Sein Höhepunkt (und so sein Gebrauch der Anapher) ist aber viel weniger dramatisch als Poggios. Er wiederholt nicht Zabarellas Anrede, wie es Poggio tut (,tu”), sondern das Wort „vidit”. In diesem Absatz geht es darum, dass es eine iniuria memoriae, eine Beleidigung der memoria des Verstorbenen wäre, seinen Tod zu beweinen. Es wäre ein Zeichen von Neid, denn Zabarella sei glücklich gestorben, umgeben von seinen Schülern, auf dem Gipfel seiner Karriere:

Quamobrem, etsi durum est nobis eo carere, qui superstites sumus, tamen ita mortuus est, ut maxime perciperet hoc tempore fructum suorum laborum, sive illorum, quos longis temporibus prius docendo pertulit, sive horum, quos novissime in hoc concilium pro reintegranda Ecclesia contulit. ${ }^{351}$

Mit den auf diesen Absatz folgenden anaphorischen Sätzen, die das Wort „vidit” wiederholen, werden diese glücklichen Umstände von Zabarellas Tod zusammengefasst:

Vidit enim uno tempore tot discipulos suos ex toto orbe terrarum in unum locum congregatos, qui diversis temporibus eum audiendo profecerant, quique ad varias dignitates merito sue doctrine promoti erant; ut non temere pre omnibus, qui in concilio erant, gloriari posset se unum esse, qui tot tantosque filios in doctrina genuisset, eaque gloria omnes anteacte vite voluptates iure visa sit superare. Vidit insuper, quod erat in rebus huius concilii maximum factuque difficillimum, vacare apud omnes apostolicam sedem et ex tribus contendentibus de papatu unum quidem sponte renunciasse, reliquos vero duos legitime depositos, actaque cetera usque in diem obitus sui.[...] vidit tamen, antequam moreretur, unitam Ecclesiam in uno generali concilio; vidit ad hoc amplius nichil restare, quam summi pontificis electionem. ${ }^{352}$

Auf die ersten zwei mit „,vidit” eingeleiteten Sätzen folgt der Gemeinplatz, nach dem man sich nicht um den Verstorbenen sorgen muss, sondern um sich selbst, weil man mit dem Tod des Freundes selbst vieles verloren habe: „quamobrem, si neque communi neque nostra propria, illius tamen causa consolari debemus, ne aut invidere felicitati eius aut iniuriam memorie facere videamur."353

351 Vergerio, Epistolario, S. 375 f.

352 Vergerio, Epistolario, S. 376-378.

353 Vergerio, Epistolario, S. 376. Mit dieser Anspielung auf Poggios Rede, in der viele Tränen vergossen worden sind, diskreditiert also Vergerio Poggios Rede als eine iniuria memoriae. Poggio habe, statt ein Denkmal für Zabarella zu errichten, das Gegenteil getan, nämlich ein Verbrechen begangen: die iniuria 
Dass man im Fall des Todes eines guten Freundes sich selbst beweinen muss und nicht den Verstorbenen, gehört zum stoischen Allgemeingut, derselbe Gedanke wird auch im Laelius deutlich vernehmbar:

Moveor enim tali amico orbatus qualis, ut arbitror, nemo umquam erit, ut confirmare possum, nemo certe fuit; sed non egeo medicina, me ipse consolor et maxime illo solacio, quod eo errore careo, quo amicorum decessu plerique angi solent. Nihil mali accidisse Scipioni puto, mihi accidit, si quid accidit; suis autem incommodis graviter angi non amicum, sed se ipsum amantis est. ${ }^{354}$

Eine solche Aussage scheint ein dermaßen verbreiteter Gemeinplatz zu sein, dass sie zum Einwand gegen die Behauptung bewegen könnte, sie sei als eine Anspielung auf Ciceros De amicitia zu deuten. Was diese Hypothese trotzdem plausibel macht, ist erstens der Kontext der anderen Berührungspunkte zwischen den zwei Texten, zweitens aber die Tatsache, dass auch die Begründung, warum man Zabarella wegen der Umstände seines Todes eher glücklich schätzen kann als ihn zu bemitleiden, dem Cicero-Text zu folgen scheint. Zabarellas Tod sei beneidenswert, weil er, wie schon oben angedeutet, auf dem Gipfel seiner Karriere gestorben sei:

Qui [dies obitus sui] etsi nobis quidem intempestivus visus est, qui eum precipue dileximus, communi vero saluti, que persepe paucorum vita continetur, non immerito damnosus apparuit; ipsi certe obeunti, si recte volumus existimare, gloriosus evenit, quoniam quicquid desiderari potest bene morienti ad huius temporis gloriam, omnia fere certe maxima sit moriendo consecutus. ${ }^{355}$

Ciceros Scipio sei auch nicht einfach nur ruhmreich gestorben, sondern an dem Tag, als seine langjährige politische Aktivität ihren Gipfel erreicht zu haben schien. Am Vorabend seines Todes sei er umgeben von den Senatoren, vom Volk, von den Bundesgenossen und den Latinern heimgekehrt. Diese Ehre scheint nicht mehr zu steigern zu sein, was den Politiker quasi direkt zu den Göttern geführt habe. Alles andere wäre nach diesem Höhepunkt fast als Rückfall zu deuten:

Quam ob rem vita quidem talis fuit vel fortuna vel gloria, ut nihil posset accedere, moriendi autem sensum celeritas abstulit; quo de genere mortis difficile dictu est; quid homines suspicentur, videtis; hoc vere tamen licet dicere, P. Scipioni ex multis

(oder um bei der Bildhauermetaphorik zu bleiben: damnatio) memoriae. Die Assoziation auf diese Sanktion post mortem passt zu der Bildhauermetapher (die memoria als ein Denkmal beschreibt), weil in der damnatio memoriae die Verstümmelung oder Zerstörung der Statuen der inkriminierten Person mit inbegriffen sein konnte. Über diese Institution in der Spätantike vgl. Charles Hedricks Buch, das damnatio memoriae in ihrem breiten kulturellen Kontext erörtert: History and Silence: Purge and Rehabilitation of Memory in Late Antiquity (Austin: University of Texas Press, 2000). 
diebus, quos in vita celeberrimos laetissimosque viderit, illum diem clarissimum fuisse, cum senatu dimisso domum reductus ad vesperum est a patribus conscriptis, populo Romano, sociis et Latinis, pridie quam excessit e vita, ut ex tam alto dignitatis gradu ad superos videatur deos potius quam ad inferos pervenisse. ${ }^{356}$

Zabarellas Tod scheint sogar aus dieser Hinsicht Scipios Triumphzug in den Himmel fast noch zu übertreffen, weil in seinem Fall das Umgeben-Werden von seinen Schülern im Moment seines Todes noch konkreter und direkter ist: um das Wetteifern zwischen den zwei ruhmreichen Sterbenden noch zu überspitzen, kann man feststellen, dass Vergerio, während Scipio die oben beschriebene Ehre am Vorabend seines Todes passiert sei, in Zabarellas Fall (unabhängig davon, unter welchen Umständen er in Wirklichkeit gestorben ist) betont, dass er inmitten des größten Weltereignisses schlechthin, also während des Konzils gestorben sei:

Quando enim contigere illi poterat unquam gloriosius mori, quam hoc tempore, cum est congregatum hoc generale concilium, quo nullum vel scriptis vel memoria hominum fuisse traditur insignium virorum frequentia magis celebre? Nam preter eos, qui prelati sunt ecclesiarum, aut ecclesiastici viri, omnium insuper regum christianorum legationes adsunt; omnes fere principes Europe, ipsi quidem quandoque per se, per legatos autem semper, interfuerunt. Imperator quoque Grecorum, qui nimis diuturno atque utinam non perpetuo scismate a nobis divisus est, insignem legationem hic continuam habuit, spe reconciliationis data; quoque magis mirum est, etiam usque Ethiopia quidam privatim ad tanti concilii famam venerunt. Nullum diuturnius fuisse certe constat, ut quod iam triennio integro perseveraverit, nescio an ullum pro causa graviori convocatum, quippe ut tolleretur ante omnia hoc pestiferum scisma, quod iam per XL annos, clericorum favoribus studiisque nutritum, in consensum secularium et regum mentes ita irrepserat, ut propemodum sine spe perficiendi tentata sit Ecclesie reintegratio. ${ }^{357}$

Das Konzil wird in Vergerios Darstellung zum Größten, was sich in der ganzen Weltgeschichte ereignet habe. Seine Beschreibung fängt mit der Würdigung der Dimensionen an. Die Konferenz umfasse ganz Europa, die ganze christliche Welt, zu der auch die Griechen zu zählen seien. Mit der Erwähnung der äthiopischen Teilnahme gewinnt das Konzil eine Dimension, die sogar über die Grenzen Europas hinausgeht. ${ }^{358}$ Das Konzil sei nicht nur wegen seines Umfanges großartig, sondern auch wegen seiner Dauer und wegen der Gewichtigkeit des zu lösenden Problems. Bei der Erwähnung dieses dritten Grundes, weswegen das Konzil

\section{Cic. Amic. 12.}

\section{Vergerio, Epistolario, S. 376 f.}

358 In einer Fußnote bemerkt Smith (vgl. Vergerio, Epistolario, S. 377, Anm. 1), dass die Äthiopier an den Sitzungen nicht teilnahmen, was Vergerio selbst mit dem Wort „privatim” angibt. Die Erwähnung der Äthiopier geschieht selbstverständlich aus rhetorischen Gründen. Ebenfalls mit Vorsicht muss Ulrich Richenthals Bericht über die Zahl der Teilnehmer gelesen und für die historische Rekonstruktion benutzt werden. Auch er hat, wahrscheinlich aus lokalpatriotischem Stolz, die Teilnehmerzahl etwas großzügiger berechnet. 
von Konstanz von unvergleichbarer Größe sei, kann sich Vergerio einen Seitenhieb gegen den Klerus (,pestiferum schisma [...] clericorum favoribus studiisque nutritum”) nicht verkneifen.

Zum beneidenswerten Tod kommt noch die Tatsache hinzu, das Zabarella von seinen vielen Söhnen (das heißt, von seinen Schülern) begraben werden konnte: „nichil vero desiderabilius quam tot filiorum presentium manibus sepeliri, quod in nullo aliorum locorum nulloque alio tempore contingere ei poterat". ${ }^{359}$ Die Betonung der Anwesenheit der Schüler Zabarellas in seiner Nähe als einem der Umstände, die seinen Tod beneidenswert machen, ist ein weiteres Mittel der Selbsterhebung Vergerios, der sich ja, im Gegensatz zu Poggio, zu Zabarellas Schülern zählen konnte.

\subsection{Zabarella als Vermittler}

Außer der Entdramatisierung von Zabarellas Tod macht Vergerio auch seinen Standpunkt, was Zabarellas Rolle auf dem Konzil betrifft, explizit: „cunctarum enim discordiarum atque contentionum, que plurime in hoc sacro concilio, instigante diabolo, exorte sunt, solus pre omnibus mediator atque arbiter constituebatur" ${ }^{360}$. Zabarella habe also über den ganzen Streitigkeiten gestanden, und diese eher zu schlichten versucht. Nicht die eine Seite, wie bei Poggio, wird als schlecht und böse dargestellt, sondern die Tatsache selbst, dass es zu solchen Kämpfen gekommen ist, sei dem Werkzeug des Teufels zu verdanken. Damit wird der Ball gewissermaßen zu Poggio zurückgeworfen. Wenn er das Konzil nach dem Schema von zwei entgegengesetzten Parteien schildert, so sei er eigentlich ein Mitanstifter der Unruhe und damit auf der „bösen” Seite. Wie ich anschaulich zu machen versuchte, hat auch Vergerio mit der Dichotomie zweier Seiten arbeitet. Der Unterschied zu Poggio besteht darin, dass der Autor des Briefes die Trennlinie zwischen den Seiten anders zieht. Es geht bei ihm nicht um den Kampf zwischen den Positionen in der Prioritätsdebatte, sondern viel mehr zwischen denen, die das Problem, weswegen das Konzil einberufen wurde, lösen wollen und denen, die nur Aufruhr anstiften. Mit dieser Neubestimmung der Seiten stellt er sich mit Zabarella auf die gleiche Seite. Auch Sigismund wird an dieser Stelle erwähnt als der andere Mitwirkende der Einberufung des Konzils, auf der gleichen, „guten” Seite also wie Zabarella:

Nam, ut omittam, quod hieme media in Alpes, que Italie imminent, forte enim

Sigismundus, Romanorum imperator, in ea regione tunc agebat; profectus est,

\footnotetext{
$359 \quad$ Vergerio, Epistolario, S. 378.

360 Vergerio, Epistolario, 375.
} 
apostolice sedis legatus, ut communi consensus utriusque potestatis de congregandi concilii loco convenirentur $[\ldots] .^{361}$

Der Satz über das Treffen der beiden, als sie den Ort des Konzils gemeinsam bestimmt haben, wird mit der folgenden Bemerkung eingeleitet: „negari enim nequit plus unum illum opere laborisque posuisse in hoc concilium sive congregandum sive dirigendum, quam ex ordine clericorum alium quenpiam"362. Mit dieser Einschränkung wird die Möglichkeit offen gelassen, den nicht zu den Klerikern gehörenden Sigismund als die andere Schlüsselfigur des Konzils zu sehen. Seine mit Zabarella vergleichbare Rolle wird durch die symmetrisierende Darstellung betont. Bei Vergerio werden nur Zabarella und Sigismund als die Vertreter der zwei Mächte genannt, die sich getroffen und vereinbart haben. In Wirklichkeit waren auch Antoine de Challant und Manuel Chrysoloras bei dem Treffen anwesend. ${ }^{363}$ Dass Sigismunds Rolle beim Organisieren des Konzils wichtig war, mag selbstverständlich sein, seine Erwähnung in Vergerios eulogium hat trotzdem eine besondere Bedeutung. Denn Sigismund wird in Poggios Rede einfach verschwiegen. Seine Erzählung der Vorbereitungen des Konzils hat einen einzigen Protagonisten, den Kardinal Zabarella:

Nam simul ut est factus cardinalis, videns se in publici consilii convovactionem delectum, omnem quoque meditationem suam in procuratione causae publicae collocavit. Quod et multis in rebus antea ostendit, et tunc praesertim cum ad deligendum locum pro praesenti concilio missus est. Nam fuit in primis autor huius loci statuendi, qui discordiis et dissentionibus fidelium fatalis esset futurus. ${ }^{364}$

Vergerio als Italiener, dessen kaiserfreundliche Haltung für seine Konpatrioten etwas irritierend sein musste, lobt Sigismund ganz vorsichtig, er würdigt den König hier nicht offen. Allein die Erwähnung des Königs ist schon ein deutlicher Unterschied zu und eine Antwort auf Poggios Darstellung.

Durch die oben geschilderte Strategie und die konkrete Aussage über Zabarellas Rolle als eines zwischen den Parteien stehenden Vermittlers werden die Spannung und die Feindseligkeit zwischen den zwei Seiten entschärft (zumindest auf der Oberfläche: wie bereits bemerkt, arbeitet auch Vergerio mit einer Gegenüberstellung vom Guten und Bösen). Mit dieser verharmlosenden Schilderung verfolgt Vergerio sein Vorhaben, seine eigene Position vor den Italienern zu entschuldigen. Er und Zabarella hätten das gleiche Ziel gehabt, nämlich das Ge-

Vergerio, Epistolario, S. 374 f.

Vergerio, Epistolario, S. 374.

Über die Konferenz von Como vgl. Brandmüller, Konstanz, Bd. 1, S. 49-58.

Poggio, Oratio, S. 255. 
meinwohl zu fördern (,,et uterque communi bono studeret”365) und so seien ihre Meinungsunterschiede nicht von Bedeutung gewesen, wenn man den guten Zweck, wonach sie beide gestrebt haben, vor Augen behält. „Verae amicitae sempiternae sunt”366, bemerkt Cicero in seinem Laelius. In seinen einleitenden Höflichkeitsformeln im Brief an Santo dei Pellegrini (Anm. 348-349 und 350) zitiert Vergerio Cicero wegen des gleichen Gedankens. Im eulogium wird zwar Ciceros Laelius überhaupt nicht zitiert, diese Sentenz könnte trotzdem als Motto für den Text stehen, der durch das oben beschriebene Gewebe der Anspielungen genau die gleiche Aussage hat.

\subsubsection{Die Agenda des Versöhners}

An zwei Stellen des Briefes wird Vergerios Position ganz unverkennbar. Genauso wie Poggio in seiner Rede erwähnt er die Tatsache, dass Zabarella von allen als der geeignete Kandidat für die päpstliche Tiara angesehen wurde. Bei ihm aber wird dieser Umstand anders gedeutet als in Poggios dramatischer Schilderung:

Quo quidem gradu [summi pontificis], quod primum est et maius, dignus erat; quod proximum, ita extimabatur,; quod vero non ultimum, ut illo potiretur, desiderabant omnes. Igitur, tametsi ei merito debebatur, tamen eligibilius fuit in hoc concilio mori cum ea extimatione ac desiderio hominum sine papatu quam, quod antea multis accidit, ignotum concilio papatum obtinuisse. Et defuit quidem illi quod minus erat; quod vero maximum et quod proximum ac omnino quod aliquid erat, habuit. Nam meo iudicio longe gloriosius est desiderari digne ab omnibus, quam a paucis consequi id, quod multi vel indigni consequi possunt. ${ }^{367}$

Es sei viel ruhmvoller, für einen Posten von allen berechtigterweise gewünscht zu werden, als diesen durch die Voten von wenigen unverdient zu erreichen. Der Satz enthält eine klare Kritik an einer übereilten Papstwahl ${ }^{368}$, die, wie es Vergerio nahe legt, einem Unwürdigen das höchste Amt in der Kirche zukommen lassen könnte.

Vergerio schließt seinen Brief und seine Liste der Umstände, die Zabarellas Tod als einen schönen, ruhmreichen Tod erkennen lassen, mit der Erwähnung, dass Sigismund, der

365 Vergerio, Epistolario, S. 370. Dass die beiden trotz dieses Meinungsunterschieds Freunde blieben, ist ein Beweis der Kraft ihrer Freundschaft, und kein Hindernis, weil sich beide um das Wohl der res publica bemüht haben.

366 Cic. Amic. 32.

367 Vergerio, Epistolario, S. 378. Der Satz geht weiter mit der schon oben zitierten Aussage über die Ehre, die Zabarella durch die Anwesenheit seiner Schüler zu Teil wurde („nichil vero desiderabilius quam tot filiorum presentium minibus sepeliri“'). In diesem Kontext erhält die Betonung der Rolle der Schüler ein besonderes Gewicht, da sie mit der Ehre verglichen wird, die Zabarella mit seiner Wahl zum Papst hätte erreichen können.

Dies wurde auch von Smith bemerkt: Vergerio, Epistolario, S. 378, Anm. 1. 
ihn hoch schätzte, würdigte und liebte, an seinen Trauerfeierlichkeiten bis zum Ende teilgenommen hat:

Postremo, ne quid deesset officiorum, que certatim ab omni genere hominum in honorem funeris congesta sunt, Sigismundus, qui eum plurimi faciebat, venerabatur et amabat, cum efferretur, comitatus est funus, et insuper, ipsa exequiarum die, omnibus gestis usque ad extremum assiduus interfuit. ${ }^{369}$

Durch die hoch akzentuierte Position der erneuten Erwähnung Sigismunds erhält die Figur des Königs eine besondere Bedeutung. Seine Hervorhebung wird mit den Worten „postremo” und „,insuper” weiter gesteigert, die die Funktion haben, Sigismunds Anwesenheit als eine die ganze Trauerfeier krönende Geste darzustellen. Die königliche Präsenz wird am Ende der Beschreibung mit der Wortgruppe „usque ad extremum assiduus interfuit” nachdrücklich gewichtet.

Mit diesen Sätzen geht nicht nur die in jenen vergegenwärtigte Zeremonie zu Ende, sondern eben diese Sätze bilden auch den Briefschluss. Das Vergegenwärtigte und das zu Vergegenwärtigende werden damit für einen Moment ein und dasselbe, der performative Akt des Beschreibens wird selbst zum Ereignis: Vergerios Brief wird selbst in den Rang einer Trauerfeier erhoben.

Wie aus der Analyse des Textes hervorgeht, ist auch Vergerios eulogium keine Erzählung ohne Motivation und ohne ein Ziel, das dessen Autor mit dem Schreiben verfolgt. Poggio hat seine Rede aus der Perspektive der italienischen, mit Sigismund keineswegs sympathisierenden Seite geschrieben. Weiterhin ist seine persönliche Motivation für die Rede vielleicht in seiner Auftragssuche (möglichst in Papstnähe) zu sehen.

Auch Vergerio wollte, ebenso wie Poggio, sein Publikum bewegen (movere), im doppelten Sinn des Wortes: rühren und anregen. Vergerio hat sich zur Zeit des Schreibens des Briefes Sigismund verpflichtet. Mit seinem eulogium wollte er sich meiner Ansicht nach als Humanist profilieren. Sich als den Freund des Verstorbenen zu schildern, der in beiden Darstellungen als ein Gelehrter mit humanistischen Interessen beschrieben wird, impliziert nach der Logik der Freundschaft (nämlich, dass Freunde ähnlich sein sollen) und im Sinne der Humanismusforschung (die die humanistische Identität als ein Phänomen der Gemeinschaftsbildung erklärt und die Kontakthaltung mit den anderen Humanisten als Grundvoraussetzung dafür ausweist, um selbst ein Humanist zu bleiben ${ }^{370}$ ), dass Vergerio selbst, trotz seines ihm von vielen Hass einbringenden Engagements für Sigismund in der

\footnotetext{
369 Vergerio, Epistolario, S. 378.

370 Vgl. den in der Einleitung zitierten Satz Müllers: „Humanist ist hier, wer mit anderen Humanisten im Gespräch ist und bleibt.” (Vgl. Müller, Habit, S. 10, und Anm. 65 dieser Arbeit.)
} 
Prioritätsdebatte (,ob eam causam apud multos gravi odio laborarem ${ }^{371}$ ), ein Humanist war und blieb. Dies war sein fundamentales Interesse, weswegen es ein wichtiger Bestandteil seiner Selbstdarstellung und Selbstpromotion bildete, mit der er erreichen wollte, dass die italienischen Humanisten ihn weiterhin als ein Mitglied der humanistischen Gemeinschaft wahrnehmen.

\subsection{Zabarella, der „Humanist”: eine Bilanz}

Wie die Unterschiede der beiden Darstellungen Zabarellas aus den unterschiedlichen Motivationen folgen (die Tatsache, dass Zabarella bei Vergerio eher als ein Vermittler zwischen den beiden Seiten und bei Poggio als der Hauptvertreter der Kardinalspartei dargestellt wurde), so sind die Ähnlichkeiten ihren Berührungspunkten zu verdanken. Sowohl Poggio als auch Vergerio wollten sich als Humanisten darstellen, dementsprechend haben sie Zabarella zu einem Humanisten stilisiert.

Poggios Brief $^{372}$, in dem er sagt, er hätte viel lieber zum Anlass des Todes von Chrysoloras eine Rede geliefert, ist nicht der einzige Text, in dem die Frage der Rolle der Eulogien als Medien humanistischer Selbstdarstellung angesprochen wird. Leon Battista Albertis Canis, Musca und Defunctus sind auch diesem Phänomen gewidmet, ${ }^{373}$ und auch Bruni schreibt in einem Brief in Bezug auf seine Laudatio über die Wichtigkeit der Unterscheidung zwischen Geschichtsschreibung, in der man nach der Wahrheit streben solle, und Lobreden, in denen man die Erwartungen des Publikums und den Erfolg, den man erreichen möchte, vor Augen hat. ${ }^{374}$ Auch diese Beispiele sprechen dafür, dass humanistische Topoi mit ihrer offensichtich zwangsläufigen Tendenz zur Übertreibung in der Mitte des 15. Jahrhunderts ein Gemeinplatz waren.

Vergerio, Epistolario, S. 370.

Vgl. Anm. 211.

Die Texte Albertis sind veröffentlicht: Leon Battista Alberti, „Canis”, in Apologhi ed elogi, hrsg. v. Luigi Malerba (Genua: Costa \& Nolan, 1982), 142-69, Leon Battista Alberti, „Musca”, in Aploghi ed elogi, hrsg. v. Luigi Malerba (Genua: Costa \& Nolan, 1982), 172-95; und Leon Battista Alberti, „Defunctus”, in Dinner Pieces, hrsg. v. David Marsh (Binghamton: Medieval and Renaissance Texts and Studies in conjunction with the Renaissance Society of America, 1987), 98-125. McManamon zitiert in seiner Monographie den Canis als Beispiel für eine Parodie humanistischer Traueroratorik: McManomon, Funeral, S. 5.

$374, \ldots$ id Graeci panegyricum vocant, nec ad subtilitatem disserendi, sed ad plausum multitudinis accomodandi, omnisque laudandi occasio arripienda est in eo genere, ac verbis extollenda.... Aliud est enim historia, aliud laudatio. Historia quidem veritatem sequi debet, laudatio vero multa supra veritatem extollit." Bruni, Epistulae, Bd. 2, S. 111-112. Um dieser Aussage über das Genre der laudatio gerecht zu werden, darf man nicht verschweigen, dass diese Sätze Teile eines Briefes sind, in dem sich Bruni gegenüber jemandem verteidigt, der seine Lobschrift auf Florenz angegriffen hatte. So gesehen werden seine Argumente über die Verschiedenheit der Geschichte und der Lobschrift etwas relativiert. Er wehrt sich im Brief gegen Vorwürfe, die - wie aus Brunis Brief hervorgeht - die Wahrhaftigkeit von Brunis Darstellung in Frage stellten. 
An dieser Stelle kann auf einen von Paul Gerhard Schmidt beschriebenen Unterschied zwischen mittelalterlichen und humanistischen Darstellungsweisen hingewiesen werden. ${ }^{375}$ Nach Schmidts Beobachtungen verträgt ,die mittelalterliche deskriptive Topographie einer Stadt [...] individuelle(n) Anekdoten, die mit der ganz anderen stilistischen Ebene des humanistischen Stadtlobs unvereinbar schienen". ${ }^{376}$ Als Beispiel nennt er Bonvesin de la Rivas Beschreibung Mailands, in der der Autor über einen „vir illustris” seiner Stadt, Uberto della Croce, ganz viele kleine Details überliefert hat, die ein Humanist über den Gegenstand seiner Darstellung in einem ähnlichen Kontext nie berichtet hätte (dass er zum Beispiel 32 Eier bei einer Mahlzeit verspeisen konnte). Andererseits bemerkt er auch, dass in den humanistischen Beschreibungen einer Stadt die Kategorie der „viri illustres” eine „stärkere Resonanz” findet. ${ }^{377}$ Den Akzent auf die Gruppe der „viri illustres” und die abnehmende Detailfreudigkeit ihrer Darstellung kann man damit erklären, dass, wie Schmidt bemerkt, „die Kriterien für die Aufnahme in die Gruppe der „,viri illustres” geändert werden, im Sinn einer rigoroseren Auswahl". ${ }^{378}$ Wenn man den Gedanken des von Schmidt angesprochenen Unterschieds weiterdenkt, so kann man zusammenfassend feststellen, dass humanistische Porträts trotz ihres Akzents auf dem Biographischen gewissermaßen schablonenhaft sind. ${ }^{379}$

Wie schon erwähnt ${ }^{380}$, haben manche Zabarella-Forscher vieles kritiklos von Poggios Lobrede und Vergerios Brief übernommen, ohne Rücksicht auf die Eigenschaften des Genres, die den Leser der Lobschriften zu mehr Vorsicht mahnen. ${ }^{381}$ Weil es in dieser Arbeit um die Frage der Wahrnehmung von Humanisten geht, will ich mit der Begründung, dass es erstens vielleicht einfacher ist, darüber zu sprechen, wer für einen Humanisten gehalten wurde, als darüber, wer ein Humanist war, sowie andererseits, weil die zweite Frage wegen des in dieser

375 Vgl. Paul Gerhard Schmidt, „Mittelalterliches und humanistisches Städtelob”, in Die Rezeption der Antike. Zum Problem der Kontinuität zwischen Mittelalter und Renaissance, hrsg. v. August Buck (Hamburg: Dr. Ernst Hauswedell \& Co., 1981), 119-129, [im Weiteren: „Städtelob”].

376 Schmidt, Städtelob, S. 125.

377 Schmidt, Städtelob, S. 124.

378 ebda

379 Es sei angemerkt, dass wahrscheinlich auch die lustigen Details, die Bonvesin seinen Lesern über Uberto mitteilt, nicht weniger schablonhaft sind: es ist einfach eine andere Schablone, die Bonvesin benutzt. Alle die von Schmidt zitierten Einzelheiten, mit denen Bonvesin seinen vir illustris charakterisiert, fügen sich in das Bild eines robusten, starken Mannes. Den Unterschied zwischen seinem Helden und dem humanistischen Ideal eines vir illustris kann man mit dem Eliasschen Modell des Prozesses der Zivilisation erklären.

380 Im Unterkapitel: II. 2.2.2.3. „Das Ringen um die Toten - Poggios Denkmal für Zabarella: von den Forschern übernommen, von Poggio relativiert" dieser Arbeit.

381 Neben dem Beispiel von Walsers Narrativ kann man Zontas Schilderung von Zabarellas Engagement auf dem Konzil nennen. Zonta zitiert Poggios Beschreibung der letzten Rede Zabarellas als Beweis für die „Redekunst” und „Vehemenz” des Kardinals als Redner (,stupebant omnes, admirabantur... pro unitate ecclesiae vellet animam profundere“). Unmittelbar nach dem zitierten Absatz folgt Zontas Kommentar: „Sigismondo dovette cedere”. Zonta benutzt Poggios Worte, um seine Leser davon zu überzeugen, dass es Zabarellas Verdienst war, dass Sigismund sich am Ende der Prioritätsdebatte doch flexibler gezeigt und nachgegeben hatte. Zonta, Zabarella, S. 111-112. 
Arbeit behaupteten Wesens des Humanismus wahrscheinlich auch wenig Sinn hat, auf die Frage, inwieweit Zabarella dem von ihm kreierten Bild entsprochen hatte, inwiefern also seine Schriften und seine Interessen als „humanistisch” bezeichnet werden können, keine definitive Antwort geben. ${ }^{382}$

McManamon, der in diesem Punkt eine Entscheidung zu treffen versuchte, scheint der Meinung zu sein, es sei am Zutreffendsten, von Zabarellas Interesse für die neue Kultur zu sprechen, nicht aber von seiner aktiven Aneignung derselben. Er schreibt über Zabarella als über einen Freund der Humanisten, dessen eigene Kultur aber vom Humanismus unbeeinflusst blieb. ${ }^{383}$ In seinem Artikel, in dem er Vergerio als den ersten Humanisten beschreibt, der seine Reden nach antiken Vorbildern geschrieben habe, stellt er eine Liste der Trauerreden auf, die zwischen 1373 und 1420 geschrieben wurden, und teilt die Reden in drei Kategorien ein: „klassizisierend”, „thematisch” und „gemischt”. Zabarellas Rede, die er aus Anlass des Todes von Francesco da Carrara il Vecchio geschrieben hat, bekommt die Etikette „gemischt". ${ }^{384}$ Zonta macht auch einen kurzen Vergleich zwischen Zabarellas und Salutatis Stil in deren Briefen und stellt fest, dass Zabarella Salutatis Eleganz trotz aller Anstrengungen nicht erreicht habe. Der Kanoniker habe die neue Bewegung mit Sympathie betrachtet und selbst aber nur bis zu dem Punkt verfolgt, bis zu welchem es die Verschiedenheit seiner beruflichen Tätigkeiten und Studien erlaubt hat. ${ }^{385}$

Dieter Girgensohn dagegen vertritt die Meinung, dass Zabarella auf jeden Fall als ein Anhänger der humanistischen Bewegung bezeichnet werden kann. Als Lackmustest benutzt er nicht dessen Latein und dessen Stil, wie McManamon und Zonta es tun, sondern einerseits die Disziplinen aus Parentucellis Katalog, feststellend, dass Zabarella in den fünf Wissensbereichen der Humaniora (Grammatik, Rhetorik, Poetik, Geschichtsschreibung und Moralphilosophie) Interessen hegte und darin bewandert war $^{386}$, andererseits aber auch die Verbindungen $\mathrm{zu}$ anderen Humanisten und seinen Ruhm als Redner und Stilist. $^{387}$ In

382 Ohne in dieser Frage entscheiden zu wollen, kann man vielleicht doch bemerken, dass einige Äußerungen Zabarellas seine Wahrnehmung als Humanist unter seinen Zeitgenossen wahrscheinlich problematisch gemacht haben konnten: „Litterati quam plurimi, Petre Paule, suorum quisque temporum deflevit inertiam atque infelicitatem. Id attestantur eorum volumina, quibus fere omnibus priora tempora laudibus complevere, sua execrationibus. Horum dicere soleo lacrimas inanes falsamque existimationem" - schreibt er an einer von Bischoff zitierten Stelle seines Buches De felicitate. Vgl. Bischoff, Studien, S. 87. Seine Kritik kann als gegen die in seiner Meinung von den Humanisten etwas überstrapazierte Rhetorik des Bruches gerichtet verstanden werden. Andererseits: Zabarellas führende Rolle im paduaner Petrarca-Kreis, was als ein wichtiger Aspekt seines literarischen Profils betrachtet werden kann, wird im nächsten Kapitel (im Unterkapitel: III. 2.2. „Die Ausgabe der Africa” und 2.3. „Vergerios Petrarca-Vita”) erörtert.

383 McManamon, Funeral, S. 68.

384 McManamon, Innovation, S. 20.

385 Zonta, Zabarella, S. 9.

386 Girgensohn, Studenti e tradizione, S. 162.

387 Girgensohn, Studenti e tradizione, S. 164-167. 
Girgensohns Argumentation sind nicht nur die Kriterien überzeugend, nach denen er seine Entscheidung getroffen hat, sondern auch der Kontext seiner Fragestellung: er stellt die Frage, ob Zabarella tatsächlich als ein Humanist bezeichnet werden kann, nicht um der Frage willen, nicht also aus einem einfachen Zwang der Kategorisierung, sondern um eine andere beantworten zu können. Warum Zabarellas Reden hauptsächlich nördlich der Alpen überliefert worden sind. Seine Antwort ist, dass die Sammlung von Zabarellas Reden als „rhetorisches Musterbuch” für die „,braven Deutschen, Niederländer, Schweizer und Österreicher" gedient haben konnte, die nicht bemerkt haben, dass diese in einem Latein geschrieben worden waren, das inzwischen in Italien als überholt galt. Girgensohn geht von einem sich schnell ändernden Stilideal des Humanismus aus, womit er das Obsolet-Werden von Zabarellas Schriften erklärt. Die italienischen Humanisten der zweiten Hälfte des 15. Jahrhunderts haben die Schriften des Rechtsprofessors nicht mehr gelesen. ${ }^{388} \mathrm{Um}$ Girgensohns Meinung über den Humanismus kurz zusammenzufassen: Zabarella konnte auch als Humanist bezeichnet werden, aber er wurde als solcher in Italien nur von seinen unmittelbaren Zeitgenossen, und später nur ausserhalb von Italien wahrgenommen.

Um noch einmal, diesmal in Bezug auf die Frage von Zabarellas Ruhm als Humanist, auf Poggios Brief zurückzukommen: der Autor der oratio funebris fasst Zabarellas Wahrnehmung als Humanist selbst am besten zusammen. Er konnte als Humanist gelobt werden (sonst hätte Poggio eine Lobrede in diesem Sinne gar nicht riskiert), es gab aber Kandidaten (wie etwa Chrysoloras), die mehr Anlass zu einer Stilisierung zum Humanisten geboten hätten.

388 Girgensohn, Studenti e tradizione, S. 173. 


\section{Pier Paolo Vergerio: die Karriere eines Humanisten}

\section{Die Fragen}

Wie kam es nun zu Vergerios Einstellung bei Sigismund? Was hatte der König davon und warum war es eine verlockende Perspektive für den Humanisten? Eine vorläufige Antwort ist schnell bei der Hand. Dass ein König einen Humanisten an seinem Hof halten mochte, scheint eine Selbstverständlichkeit zu sein, genauso wie das Umgekehrte, nämlich dass für einen Humanisten in der Umgebung von Machtträgern zu arbeiten, eine nahe liegende Möglichkeit des Broterwerbs war. Da aber Vergerio einer der ersten „Exporthumanisten” war, eines der ersten Beispiele für die Einstellung eines Humanisten nördlich der Alpen, lohnt es sich, das Bild etwas zu verfeinern, um es weniger zeit- und kontextlos zu gestalten. Denn auf Grund dieses Beispiels könnte man eine der möglichen Antworten auf die Frage nach der Funktion des Humanismus und den Mechanismen seines Exportes zu finden hoffen. Die weiterführenden Fragen sind dementsprechend: Was war Vergerios Funktion in Sigismunds Dienst? Welche konkreten Aufgaben hatte er in den vielen Jahren, die er in Buda verbrachte? Warum genau stand die Einstellung Vergerios in Sigismunds Interesse? Welche Modelle wurden von Seiten Sigismunds und Vergerios verfolgt? Wie fügte sich der Dienst bei einem König (mit Erwartungen auf den Kaiserthron) in die Karriere eines italienischen Humanisten? Diese Fragen werde ich in zwei Abschnitten zu beantworten versuchen. Im ersten Teil werde ich den möglichen Erwartungen nachgehen, die Sigismund und Vergerio einander gegenüber gehabt haben konnten. Im zweiten Abschnitt werde ich untersuchen, ob und wie Vergerio diese ursprünglichen Erwartungen erfüllte und ob seine Zeit in Buda für ihn zufriedenstellend war.

\section{Vergerios Karrieremuster vor dem Konzil von Konstanz: in Petrarcas Fuß- stapfen}

\subsection{Eine einleitende Hypothese}

Es scheint plausibel zu sein, Vergerios und Sigismunds gegenseitige Erwartungen als Folge der Nachahmung der jeweiligen Modelle - von Vergerios Seite Petrarcas, von Sigismunds Seite Karls IV. - zu interpretieren. Laut meiner Hypothese war einer der möglichen Gründe, warum Vergerio für den römisch-deutschen König attraktiv sein konnte, seine Strategie, sich als einen „zweiten Petrarca” darzustellen. Petrarcas Beziehung zu Karl IV. war dessem Sohn Sigismund bestimmt nicht unbekannt. Sigismunds Wiederbelebung der 
Tradition der Dichterkrönung kann als ein Beweis dafür genannt werden, dass er die Praktiken seines Vaters teilweise zu übernehmen versuchte, mit denen Karl IV. sich als Musenfreund darstellte. Er krönte aller Wahrscheinlichkeit nach Vergerio zum Dichter auf dem Konzil. ${ }^{389}$ Wenn er sich als den legitimen Nachfolger seines Vaters auf dem Kaiserthron darstellen wollte (und der Legitimationsbedarf in Folge der Unstimmigkeiten um seine Königswahl erforderte es, jedes Mittel zu ergreifen), war für den noch nicht gekrönten Kaiser ein Humanist wie Vergerio, der auf Grund seiner Schriften den Ruf haben musste, ein Nachfolger Petrarcas zu sein, wahrscheinlich nicht uninteressant.

Für die oben formulierte Hypothese kann man mit der Analyse einer Gruppe von Vergerios Schriften argumentieren, die der Pflege des Petrarcaschen Erbes gewidmet sind.

\subsection{Die Ausgabe der Africa}

Vergerio hatte die Ehre, Petrarcas Africa veröffentlichen zu dürfen. Ein Epos, dem, solange es nicht bekannt war, die Humanisten große Erwartungen entgegengebracht hatten.

Der Mythos des Epos entstand in Folge von Petrarcas Weigerung, seinen Text auch nur einem begrenzten Publikum zugänglich zu machen. Um das Recht der Veröffentlichung der Africa, ein Unternehmen, welches von Billanovich als riskant und prekär bezeichnet wurde, ${ }^{390}$ haben mehrere Gelehrte den Verwalter von Petrarcas Nachlass mit Bitten bedrängt $^{391}$ - ein Enthusiasmus, welcher nach der Veröffentlichung des Textes in Enttäuschung umschlug, wie es, um das bekannteste Beispiel zu nennen, in Brunis Dialoghi anschaulich $\mathrm{zu}$ erkennen ist. ${ }^{392}$ In den diesbezüglichen Briefen der Florentiner werden Vorbehalte gegenüber den Paduaner Verwaltern dieser Erbschaft sichtbar. Es geht hier nicht einfach um ein brennendes Verlangen nach dem Lesen eines vermuteten Meisterwerkes,

389 Vgl. dazu das Kapitel „Der utriusque iuris ac medicine doctor und gekrönte Dichter”. Vielleicht hatte Sigismund sogar den unter dem Namen seines Vaters tradierten und viele Petrarca-Zitate enthaltenden Fürstenspiegel gelesen. Der Text wurde veröffentlicht: Samuel Steinherz, Ein Fürstenspiegel Karls IV., Quellen und Forschungen aus dem Gebiete der Geschichte 3 (Prag: Verlag der Deutschen Gesellschaft der Wissenschaften und Künste für die Tschechoslowakische Republik, 1925). Für seinen Eifer für Dichterkrönungen vgl. Beccadellis Dichterkrönungsdiploma, in dem diese kaiserliche Bestrebung folgendermaßen ausformuliert wurde: „... nos vero cupientes antecessorum nostrorum gloriosa imitari vestigia...” Teile des Textes des Dichterkrönungsdiplomas wurden zitiert von: Joseph Burney Trapp, „The Owl's Ivy and the Poet's Bays. An Enquiry into Poetic Garlands", Journal of the Warburg and Courtauld Institutes 21 (1958): 227-255, hier S. 236, Anm. 45.

390 Giuseppe Billanovich, Gli inizi della fortuna di Francesco Petrarca (Rom: Edizioni di Storia e Letteratura, 1947), [im Weiteren: „Gli inizi”], S. 11.

391 Die Geschichte wird in Festas einleitender Studie zu seiner kritischen Edition des Africa wiedergegeben: Nicola Festa, „Prefazione”, in Francesco Petrarca, Africa, Edizione Nazionale delle Opere di Francesco Petrarca 1, hrsg. v. Nicola Festa (Florenz: Sansoni, 1926), [im Weiteren: „Prefazione”], S. XI-LXX, hier besonders das Unterkapitel „Per la storia del testo”, S. XXXV-LXIV.

392 Ob mit „ridiculus mus” die eigentliche Meinung Niccolis oder Brunis wiedergegeben wurde oder nicht, spielt hier keine Rolle. Was zählt ist, dass eine solche Meinung überhaupt, auch wenn in einem fiktiven Rahmen, als vertretbar erschien. 
sondern um eine Prestigefrage: um einen Kampf um die Erbschaft Petrarcas. Boccaccio bringt in einem Brief seine Hoffnung zum Ausdruck, dass das Schicksal dieser Erbschaft nicht von Juristen entschieden wird, die sich nur in den Gesetzen auskennen, jedoch denken, dass sie auch in anderen Fragen kompetent seien. ${ }^{393} \mathrm{Ihm}$ wurde von Lombardo della Seta die Möglichkeit versprochen, eine Kopie vom Text anfertigen zu dürfen, er starb aber, bevor dieses Versprechen hätte eingelöst werden können. Auch Coluccio Salutati drückte seine die Africa betreffenden Besorgnisse aus, nach denen der Text schlecht behandelt und deswegen beschädigt werden könnte. ${ }^{394}$ In einem Brief vom 28. Januar 1377 an Franceschino da Brossano bedankt sich Salutati für die Kopie der Africa. In demselben Brief betrauert er aber die von Franceschino gestellten Bedingungen. Er schreibt hier auch über seine Pläne mit dem (vorher doch korrigierten! ${ }^{395}$ ) Text. Es sollten nach Bologna, Paris und England jeweils eine Kopie geschickt, und in Florenz ein Exemplar für die Öffentlichkeit zugänglich gemacht werden. Wenn dieses Vorhaben nicht verwirklicht werden konnte, so war der Grund wahrscheinlich, so vermutet Festa, dass Salutati eine Veröffentlichung des Textes seitens der Paduaner ausdrücklich verboten wurde. ${ }^{396}$

Mit der Herausgabe des Textes wurde schließlich der zu jener Zeit in Padua an der Universität tätige Vergerio beauftragt. Billanovich sieht den Grund für diese Wahl des Herausgebers in der Tatsache, dass Vergerio ein Protégé Zabarellas, der zentralen Figur des Paduaner Petrarca-Kreises, war. Der italienische Forscher hegt keine große Sympathie für Vergerio. Sein Urteil scheint die oben zitierten florentinischen Vorbehalte gegenüber den Paduaner Juristen zu wiederholen. In Bezug auf Vergerios Antwort auf Petrarcas Brief an Cicero, den er als „una sua invenzione pesantemente scolastica"397 bezeichnet, und einen anderen Brief, in dem er Petrarca nachgeahmt hatte, schreibt er über Vergerios „debolezza di fantasia e di stile”398. Er versagt Vergerio die Bezeichnung „Humanist” und nennt ihn stattdessen „il recente dottore di arti e di medicina e scolaro di diritto”. 399

393 Vgl. seinen auch von Festa (Festa, Prefazione, S. XLII) zitierten Brief vom 24. November des Jahres 1374 : „Heu michi, timeo, ne juristis commissum sit, qui, quum leges noverint et eas potissime, quas impudico ore aiunt esse de pane lucrando, se arbitrantur eruditos in omnibus."

„Nec dubito quod si quem tanta amentia invaserit, ut audeat opera sacra sua lacerando corrigere, quanquam forte sibi videatur corticem levigasse, omnium consensu sensa perverteret et comptum ordinem comarum calamistris inuret. Sed faciant quidquid eorum cordibus sederit. Sive integram sive laceratam, Africam promant; quod facturi sunt, cito absolvant, et nos hac spe et metu liberent.": Zitiert von Festa, Prefazione, S. XLIV. Salutati, Epistolario, Bd. 1, S. 202 f. In dem Moment, in dem er den Text gesehen hat, hielt er Korrekturen doch für nötig.

Vgl. Festa, Prefazione, S. L-LI.

Billanovich, Gli inizi, S. 50.

ebda

Billanovich, Gli inizi, S. 50 f. 
Festa identifiziert in seiner einleitenden Studie einen Wolfenbütteler Codex als das Autograf der vergerianischen Ausgabe der Africa. ${ }^{400}$ Vincenzo Fera dagegen, der den verschiedenen Ausgaben der Africa im 14-15. Jahrhundert ein ganzes Buch widmet, bestreitet diese Annahme. ${ }^{401} \mathrm{Er}$ argumentiert auf Grund der späteren Ausgaben der Africa, Vergerios eigener Aussagen über den Text und eines Briefes des Pasquino Capelli, den er über die Africa-Ausgabe schrieb, überzeugend dafür, dass man, obwohl die vergerianische Ausgabe aus keiner der überlieferten Handschriften bekannt ist, davon ausgehen kann, dass Vergerio eine diplomatische Ausgabe angefertigt hatte, ohne die Lücken füllen und kleine Imperfektionen verbessern $\mathrm{zu}$ wollen. Die Tatsache, dass Vergerios Ausgabe in ihrer ursprünglichen Form heute nicht mehr vorhanden ist, sondern nur mit Korrektur- und Verbesserungsvorschlägen versehen, die teilweise auf Salutatis Scholien zurückgehen, ist laut Fera selbst dem Wesen der vergerianischen Ausgabe zu verdanken. Sie war, gerade wegen des von Vergerio gewählten Wegs, diesen Text zu edieren, also wegen der mangelnden Personalisierung der Ausgabe in der weiteren Überlieferungstradition schwer identifizierbar und den Verbesserungsvorschlägen der späteren Leser ausgeliefert. ${ }^{402}$

Obwohl Feras Argumentation einleuchtet, wäre es hier doch nicht angemessen, Vergerios Herangehensweise in seiner Ausgabe, die den heutigen Lesern nicht zur Verfügung steht, auf der Basis einer noch so überzeugenden Hypothese ausführlich zu interpretieren. Man dürfte vielleicht trotzdem eine Bemerkung wagen. Wenn Feras Hypothese stimmt, so kann man in Vergerios Geste, den Text der Africa ohne Emendationen und Ergänzungen dem Publikum zu zeigen, nur scheinbar einen neutralen Akt sehen. Die Geste, an dem Text der Africa dezidiert keine Veränderungen vorzunehmen und ihn den Lesern so darzustellen, wie Petrarca ihn geschrieben hatte, kann einerseits als Ausdruck seines Anspruches verstanden werden, der berechtigte Hüter des Erbes Petrarcas zu sein. Mit diesem Akt half Vergerio aber andererseits, Petrarcas Image seinem Vorbild Vergil anzunähern. Daher konnte die Geschichte der Veröffentlichung der Africa nach dem vergilianischen Muster verlaufen. ${ }^{403}$

\footnotetext{
$400 \quad$ Festa, Prefazione, S. LIII.

401 Vincenzo Fera, Antichi editori e lettori dell'Africa, Itinerari Eruditi 2 (Messina: Centro di Studi Umanistici, 1984), [im Weiteren: „Antichi editori’], vgl. das Kapitel: L'edizione Vergeriana, S. 83-105.

402 Fera, Antichi editori, S. 104.

403 Varius und Tucca haben bekanntlich auch darauf verzichtet, die unvollendeten Verse der Aeneis zu vollenden zu versuchen. Dass von den Zeitgenossen Parallelen zwischen dem unvollendeten Zustand der Aeneis und dem der Africa gezogen wurden, wird von mehreren Dokumenten bezeugt, welche in Festas oben erwähnter Studie zitiert werden.
} 


\subsection{Vergerios Petrarca-Vita}

Der Sermo de vita moribus et doctrina illustris et laureati poetae Francisci Petrarcae wurde von Vergerio wahrscheinlich ursprünglich für die aus Anlass des Geburtstages von Petrarca gehaltenen Feierlichkeiten im Dom von Padua geschrieben, deren Kanoniker der Dichter selbst gewesen war. ${ }^{404}$ Diese Feierlichkeiten wurden auch von Zabarella gepflegt, der ab 1397 Archipresbyter an demselben Dom war. Ein von Billanovich ${ }^{405}$ zitiertes Dokument spricht über diese Feiern ab dem Jahr 1400. Der Gelehrte Antonio Comin, der im 18. Jahrhundert der Kapitularbibliothek vorstand, machte Notizen aus den Registern der Sagrestia Maggiore über dieses jährliche Gedenken an Petrarca und schrieb, dass er es für wahrscheinlich hielt, dass diese Feiern schon im 14. Jahrhundert stattgefunden haben. Es handelt sich um ein alljährliches Ereignis, für das Petrarca dem Paduaner Dom in seinem Testament zweihundert Dukaten hinterlassen hatte. Von dieser Summe sollte ein Landgut gekauft werden, von dessen Erträgen diese jährliche Messe für Petrarca gehalten werden konnte: „lego ipsi ecclesie Paduane ducatos ducentos auri ad emendum aliquantulum terre, ubi melius fieri poterit, de cuius proventibus perpetuum anniversarium anime mee fiat." ${ }^{\text {"406 }}$ Demzufolge wurde diese Zeremonie wahrscheinlich nicht erst von Zabarella eingeführt ${ }^{407}$. Seine Bewunderung des Humanisten, die unter anderem auch von seiner großen Sammlung der Werke desselben bewiesen wird, lässt jedoch vermuten, dass in der Zeitspanne, in der er Archipresbyter am Dom war, diesen Feiern mehr Gewicht beigemessen wurde als unter seinen Vorgängern.

Der (überarbeitete) Text des Sermo de vita Francisci Petrarcha fungierte später als Vorwort zur Africa-Ausgabe Vergerios ${ }^{408}$ sowie als Einleitung zu Petrarcas Werken. Auch Tomasini bringt den Sermo als Vorwort zu seiner Ausgabe von $1650 .{ }^{409}$

404 Dass der Sermo mit den metrischen Inhaltsangaben der Hauptwerke Petrarcas, die der Lebensbeschreibung des Dichters folgen, in der Paduaner Kathedralkirche vorgetragen wurde, wird von einer Olmützer Handschrift (Nr. 509) bezeugt, die von Konrad Burdach ausführlich beschrieben wurde: Konrad Burdach, Aus Petrarcas ältestem deutschen Schülerkreise. Texte und Untersuchungen, Vom Mittelalter zur Reformation 4 (Berlin: Weidmannsche Buchhandlung, 1929), [im Weiteren: „Aus Petrarcas Schülerkreise”], S. 175. Diese Handschrift enthält den folgenden Vermerk: „Hos libros dominus Petrus Paulus doctor arcium, licentiatus in medicinis, studens iuris canonici metrice comprehendit et recitavit in sermone in ecclesias kathedrali. Qui fuit michi amicus et favorabilis et hunc sermonem michi prestitit rescribendum." Im Olmützer Codex befindet sich eine unvollständige Fassung der Vita, die Petrarcas Leben nur bis zu seinem Aufenthalt in Parma enthält, auch die Würdigung des Africa und die Argumente für dessen Bücher fehlen hier. Burdach ist der Auffassung, dass letztere erst spätere Ergänzungen zur Vita seien, sie nähmen „unverhältnismäßig großen Raum” ein, und fielen ,aus dem Rahmen der sonst so summarischen Biographie" heraus. Burdach, Aus Petrarcas Schülerkreise, S. 22.

408 Zum Beispiel: Florenz, Bibl. Laurenziana, cod. Acquisti e Doni 441 (Kristeller, Iter, Bd. 1, S. 105b); Venedig, Bibl. Nazionale Marciana, cod. Marc. lat. XII. 17. (3944) (Kristeller, Iter, Bd. 2, S. 240b); Neapel, 
Die reiche handschriftliche Überlieferung der Petrarca-Vita Vergerios ${ }^{410}$ beweist, dass es sich um eine weit verbreitete und viel gelesene Schrift handelt, die Forschung freilich hat ihr wenig Aufmerksamkeit geschenkt. Der Grund dafür ist die Tatsache, dass Vergerio in seiner vita sehr eng Petrarcas autobiographischer Epistola ad posteros gefolgt war. Als historische "Quelle” betrachtet, konnte der Text lediglich einen sehr geringen Gewinn an neuen Informationen liefern, als literarischer Text verstanden, konnte er als eine Überarbeitung des Petrarcaschen Briefes abgetan werden. ${ }^{411}$ Billanovich versteht Vergerios Festhalten an Petrarcas Text und seine Vernachlässigung von Boccaccios De vita et moribus domini Francisci Petrarcae als Folge seiner Eile. ${ }^{412}$ Es gibt nur einen einzigen Artikel von Aurigemma, der sich mit Vergerios Text ausführlich auseinandersetzt. ${ }^{413}$

Vergerios „Abschreiben” des autobiographischen Briefes von Petrarca wurde von ihm selbst gar nicht geleugnet (angesichts der Bekanntheit des Textes Petrarcas hätte es auch wenig Sinn gehabt), sondern sogar betont:

...in quadam epistola, quam ad posteritatem de se, deque rebus suis scribit; ex qua haec pene omnia ad literam transtuli, certus, nec verius dicere me posse, quam quod ille de se, nec melius, quam quod ille dixisset. ${ }^{414}$

Aurigemma vergleicht Vergerios Text mit dessen Vorlage und beschreibt sowie begründet Vergerios Abweichungen von Petrarcas Brief. Ihm ist in den meisten Fällen auch zuzustimmen: etwa seine Erklärung zu der Passage, wo Vergerio in der Schilderung von Petrarcas unterbrochenem Jurastudium dessen kritische Bemerkungen zur Praxis der Juristen seiner Zeit weglässt. Hier geht Aurigemma ${ }^{415}$ von der persönlichen Betroffenheit Vergerios aus und nennt diese als Grund für die Veränderung des Textes (Vergerio selbst hat sein Jurastudium zu Ende gebracht). Weiterhin bezieht er auch vitae von florentinischen Autoren in seine Analyse ein und stellt Unterschiede fest, die aus der unterschiedlichen Verbundenheit stammen. An einem Punkt scheint er vielleicht nicht Recht zu haben, und zwar mit seiner

Bibl. Nazionale, cod. V. E. 40, (Kristeller, Iter, Bd. 1, S. 401b); Greifswald, Universitätsbibliothek, cod. 682 (Kristeller, Iter, Bd. 3, S. 403b).

410 McManamon kennt 45 Handschriften mit dem Text des Sermo, vgl. McManamon, PPV. and Jerome, S. 308-310.

411 Vgl. die von Smith geschriebene Fußnote: „che è poco più di un rimaneggiamento dell'Epistola ad posteros del Petrarca": Vergerio, Epistolario, S. 204, Anm. 3.

412 „Benchè il frettoloso Vergerio lo abbia usato molto poco...”: Billanovich, Gli inizi, S. 59.

413 "Marcello Aurigemma, „Il „Sermo de vita Francisci Petrarcha” di Pier Paolo Vergerio”, in Studi filologici, letterari e storici in memoria di Guido Favati, hrsg. v. Giorgio Varanini (Padua: Antenore, 1977), 33-53, [im Weiteren: „Il Sermo"].

414 Den Text des Sermo zitiere ich aus der folgenden Ausgabe: Angelo Solerti, Hrsg., Le vite di Dante, Petrarca e Boccaccio scritte fino al secolo decimosesto, Storia letteraria d'Italia 54 (Mailand: Vallardi, 1905), [im Weiteren: „Le vite”], 294-302, hier S. 300.

415 Aurigemma, Il Sermo, S. 38. 
Erklärung der Tatsache, dass Vergerio in den Formulierungen Petrarcas, die im Original einen Demutstopos enthielten, diesen weggelassen hat, wie zum Beispiel den Anfang des Briefes, wo Petrarca über seine Zweifel spricht, ob der Leser seinen Namen überhaupt schon gehört haben könnte („Fuerit tibi forsitan de me aliquid auditum-quamquam et hoc dubium sit, an exiguum et obscurum longe nomen seu locorum, seu temporum perventurum sit..."). ${ }^{416}$ Aurigemma erklärt, Vergerio habe mit gutem psychologischen Gespür verstanden, dass es hier um eine besondere Eigenschaft Petrarcas ging, nämlich dass er mit seinen Demutstopoi lediglich die hochmütige Absicht zu kontrastieren versuchte, die schon daraus eindeutig hervorgeht, dass er für die Nachwelt schreibt. ${ }^{417}$

Es wäre an dieser Stelle vielleicht nicht verkehrt, statt mit dem psychologischen Gespür Vergerios eher mit einer banalen rhetorischen Regel zu argumentieren. Ein Demutstopos kann per definitionem nur in der ersten Person verwendet werden, wenn man ihn in eine Erzählung in der dritten Person übernimmt, verwandelt er sich in eine Beleidigung. Wenn also das zu überarbeitende Original einen solchen Topos enthält, muss der Erzähler, der es in die dritte Person umsetzen möchte, den Topos entweder ganz weglassen (wie im Fall des Anfanges des Petrarca-Briefes, in Vergerios Umformulierung) oder die Formulierung umgestalten (wie etwa in dem Fall, wo Petrarca sich in einer Litotes als „,non inverecundus” bezeichnet und Vergerio „,verecundus” schreibt). ${ }^{418}$ Oder seinen Inhalt leugnen, wie es bei der Behandlung der Africa passiert, wo er nach seiner Würdigung des Epos schreibt: ,sed nescio quam ob causam male de eo auctor suus senserit". 419

Warum geht Vergerio in diesem letzten Fall auf Petrarcas „Selbstkritik” ein? Ein möglicher Grund dafür ist, dass die Frage nach der Qualität des Epos Africa unter den Zeitgenossenen höchst umstritten war. Vergerio konnte den Wind aus den Segeln der Kritiker nehmen, indem er Petrarcas selbstkritische Stellung zu seinem Werk erwähnte. Die Würdigung des Epos stand schließlich in seinem Interesse als Herausgeber des Textes. ${ }^{420}$ Es gibt aber noch einen weiteren Grund dafür, dass Vergerio Petrarcas Demutstopos an dieser Stelle nicht einfach weggelassen, sondern erwähnt und sogar zitiert hat. Dieser Grund ist die Herkunft des Petrarcaschen Zitates:

416 Karl A. E. Enenkel, „A Critical Edition of Petrarch's Epistola Posteritati”, in Modelling the Individual. Biography and Portrait in the Renaissance, Studies in Literature 23, hrsg. v. Betsy De Jong-Crane, Karl A. E. Enenkel und Peter Liebregts (Amsterdam, Atlanta: Rodopi, 1998), 243-82, [im Weiteren: „Ad posteros"], hier S. 256.

417 Aurigemma, Il Sermo, S. 37.

418 Wie auch Aurigemma bemerkt: vgl. Aurigemma, Il Sermo, S. 37

419 Solerti, Le vite, S. 300.

420 Dass Vergerios Interesse in der Würdigung der Africa in der eigenen Biographie des Petrarca teilweise mit der Tatsache zu erklären ist, dass er selbst der Herausgeber des Textes war, wurde auch von Aurigemma bemerkt: Aurigemma, Il Sermo, S. 36. 
In ea [epistola] siquidem ad marginem (nam dudum illius manum notissimam habeo) ita scribit: „Raro unquam pater aliquis tam moestus filium unicum in rogum misit, ut ego librum illum, quem multo labori mihi genueram..."421

Vergerio zitiert hier nämlich eine autographe Marginalnote von Petrarca. Obwohl man über einen Kult des Autographen in dieser Zeit noch nicht sprechen kann, konnte sich Vergerio mit der Erwähnung einer Randbemerkung, die nicht in allen zirkulierenden Exemplaren der Epistula zu lesen und somit nicht allen Lesern des Petrarca-Briefes zugänglich war, als „,insider” im Thema „Petrarca” profilieren. Zudem hat er sich so die Möglichkeit geschaffen, ganz nebenbei erwähnen zu können, dass er die Handschrift dieses Humanisten sehr gut kenne, was man als einen Hinweis auf seine Africa-Ausgabe verstehen kann.

Diese Strategie der Selbstprofilierung Vergerios spielt in meiner Analyse die Hauptrolle. Nicht nur, weil es sich in meine allgemeine Fragestellung fügt, sondern weil es ein Aspekt eben dieses Sermo ist, mit dessen Klärung man die Frage nach Vergerios Umgang mit seiner Vorlage erläutern kann. Dies ist auch die Frage, deren Details Aurigemma nachgeht. Vergerios Präferenz für Quellen, die von Petrarca selbst stammen, bewertet er einfach als ein Zeichen dafür, dass Vergerio seine eigene, von der florentinischen Tradition unabhängige Version der Geschichte Petrarcas schreiben wollte. ${ }^{422}$ Aurigemmas Betonung der Rolle des paduanischen Umfeldes bei der Entstehung von Vergerios Text ist einleuchtend. Ein Element der Selbstdarstellung Vergerios ist aber vielleicht nicht nachdrücklich genug betont worden, nämlich, dass Vergerio strikt den Petrarcaschen Quellen folgt (oder besser gesagt: ostentativ behauptet, ihnen zu folgen). Da diese Präferenz Vergerios nur festgestellt und nicht kommentiert wird, könnte man denken, dass sie nach Meinung Aurigemmas mit Vergerios unvoreingenommener Suche nach der Wahrheit zu erklären sei. ${ }^{423}$ Teilweise könnte man ihm sogar zustimmen, allerdings mit einer wichtigen Ergänzung: Vergerios Suche nach dem „wahren” Petrarca ist genauso Teil seiner Selbstdarstellungsstrategien wie seine Würdigung der Africa. Indem er seinen Lesern einen Petrarca vorstellt, den er mit den authentischsten Quellen, die es gibt (die Schriften desselben Petrarcas, mit seinen eigenen Randnotizen) rekonstruiert hatte, stellt er sich als den einzigen wahren Hüter seines Erbes dar.

Diesem Ziel wird auch der Umgang mit seinen Quellen untergeordnet. Er ist mit dem Erwähnen seiner Quellen selektiv: er benutzt nicht ausschließlich Petrarca, sondern auch Boccaccios De vita et moribus domini Fransisci Petracchi. Wenn er Petrarca zitiert, gibt er

$421 \quad$ Solerti, Le vite, S. 300.

422 Aurigemma, Il Sermo, S. 51.

423 Dass Vergerios Perspektive eine objektivere sei, weil aus Padua, wird von Aurigemma behauptet: „con l'objettività del non fiorentino": Aurigemma, Il Sermo, S. 37. Außerdem findet man noch weitere Formulierungen im Artikel, die bezeugen, dass dessen Autor von einer ,redlichen” Suche nach der Wahrheit ausgeht, wie zum Beispiel: ,il solito amore del vero”: Aurigemma, Il Sermo, S. 44. 
seine Quelle an, andernfalls wird die Herkunft seiner Vorlage verschwiegen. Zwei dieser Stellen, in denen Vergerio Boccaccios Erzählung folgt, wurden von Billanovich ${ }^{424}$ identifiziert.

Die erste ist die Stelle, in der es um Petrarcas Liebe geht. Hier hat Vergerio, im Gegensatz zu Petrarcas Autobiographie, eine Verbindung zwischen dem Namen Lauras und Petrarcas Liebesdichtung bzw. dem Streben nach Ruhm geschaffen. ${ }^{425}$ Man könnte hier den Einwand erheben, dass diese Verbindung (das Wortspiel „Laura-laurus“) auf Petrarca zurückgeht (der es oft verwendet hatte, nicht aber in der Epistola ad posteros), und nicht auf Boccaccio. Die Tatsache aber, dass Vergerio das Wortspiel in seine vita genauso einbaut, wie es Boccaccio in seine gefügt hatte, deutet doch auf eine Inspiration durch Boccaccio hin. Ein wesentlicher Unterschied ${ }^{426}$ besteht aber darin, dass Boccaccio in seiner Version die Diminutivform „Lauretta” benutzt. Aurigemma wertet Vergerios Lösung, die dies nicht tut, als ein Zeichen einer „gravità intellettualistica”. Boccaccios dagegen soll „eine lebendigere Präsenz des Weiblichen" erzeugen. Auf jeden Fall kann meines Erachtens Vergerios Geste, das bekannte Wortspiel in seinen Text einzubauen, jedoch anstelle der Boccaccio „Lauretta”Formulierung mit Petrarcas Form „Laura”, als eine Korrektur von Boccaccios Version gedeutet werden. Eine Korrektur, die den Text in die Nähe der Texte mit voller Autorität, d. h. in die Nähe der von Petrarca selbst geschriebenen bringt.

Die zweite Stelle, die Vergerio in seinen Text (überarbeitet) übernommen hat, ist Boccaccios Phrase über die Unaufzählbarkeit der vielen Werke Petrarcas: „Si que... composuerit opuscula...conarer exprimere, „Ante diem clauso componet vesper Olimpo. „427 Billanovich vergleicht diesen Satz mit Vergerios Einleitung zur Liste von Petrarcas Werken: „si enim omnia persequi contenderimus, et dies et facultas narranti audentique deficiet” ${ }^{428}$.

Dass Vergerio auch Boccaccio für seinen Sermo benutzt hatte, ist eigentlich keine große Überraschung. Boccaccios Text, wenn man nicht die Autorität des Autors, sondern einfach die Entstehung der beiden Schriften (Petrarcas und Boccaccios) bedenkt, war gar nichts Sekundäres im Vergleich zu Petrarcas Epistula ad posteros. Denn es war doch Boccaccio, dessen Biographie von Petrarca für seinen eigenen autobiographischen Brief als Vorlage gedient hat, und nicht umgekehrt. ${ }^{429}$ In einem bestimmten Sinne ist paradoxer Weise

424 Billanovich, Gli inizi, S. 59.

425 Für Boccaccio: Solerti, Le vite, S. 262, für Vergerio: Solerti, Le vite, S. 298.

426 Bemerkt von Aurigemma, Il Sermo, S. 45.

427 Solerti, Le vite, S. 264.

428 Solerti, Le vite, S. 298.

429 Vgl. mit Enenkels Analyse der beiden Schriften: Karl A. E. Enenkel, „Modelling the Humanist: Petrarch's Letter to Posterity and Boccaccio's Biography of the Poet Laureate", in Modelling the Individual. Biography and Portrait in the Renaissance, Studies in Literature 23, hrsg. v. Betsy De Jong-Crane, Karl A. 
Boccaccios Text das Original und Petrarcas Schrift seine Überarbeitung. Vergerio konnte mit gutem Gewissen Boccaccios Text benutzen, ohne Bedenken tragen zu müssen, er greife auf etwas Sekundäres zurück. Dass er Boccaccio nicht erwähnt, ist ebenso wieder verständlich, wenn man sein Vorhaben, sich als den Darsteller des wahren, des originalen Petrarca zu profilieren, im Auge behält.

Petrarcas Leben auf Grund seiner Autobiographie nachzuerzählen brachte für Vergerio außer dem allgemeinen Prestigegewinn auch die Möglichkeit, das Haus Carrara zu glorifizieren. Dies geschieht dank der komplexen Erzählsituation des Sermo auf eine raffinierte Weise. Den Lesern (und Zuhörern) von Vergerios Text war bekannt, dass sich Vergerio eng an seine Vorlage (den Brief ad posteros) gehalten hat und dessen Formulierungen an vielen Stellen einfach wörtlich übernommen hat. In der Rede, die er im Dom von Padua gehalten hat, muss dies bedeutet haben, dass er für sein Publikum ein Sprachrohr Petrarcas geworden ist. Er hat Petrarcas Worte über sich selbst den Zuhörern vermittelt (eine prosopopoetische Situation schlechthin). Die Zuhörer wussten, dass sie, indem sie Vergerio zuhören, eigentlich Petrarca selbst sprechen hören. Auch das Lob des Hauses Carrara muss in diesem Kontext verstanden werden. Vergerio macht, wenn er die Carrara würdigt, eigentlich nichts anderes, als Petrarcas Worte zu wiederholen: „Itaque Patavium veniens ab illo clarissimae memoriae viro, non humane tantum, sed sicut coelum felices animae recipiuntur, acceptus est." ${ }^{430}$ Zum Vergleich soll hier Petrarcas Formulierung stehen:

Itaque sero quidem Patavium veni, ubi ab illo clarissime memorie viro non humane tantum, sed sicut in celum felices anime recipiuntur, acceptus sum, tanto cum gaudio tamque inextimabili caritate ac pietate, ut, quia equare eam verbis posse non spero, silentio opprimenda sit. ${ }^{431}$

Wenn Vergerio den zweiten Teil von Petrarcas Satz weglässt, tut er dies deswegen, weil dieser zweite Teil eigentlich als eine persönliche Danksagung Petrarcas zu verstehen ist (,equare eam verbis posse non spero”), dessen Übernahme in eine Erzählung in der dritten Person einfach inadäquat gewesen wäre.

Über Petrarcas nächsten Aufenthalt in Padua, diesmal während der Herrschaft des Sohnes des oben gewürdigten Giacomo da Carrara, meint Vergerio: „,...] tandem Patavii sedem fixit, ubi a magnificentissimo et prudentissimo viro Francisco seniore, eius Jacobi filio,

E. Enenkel und Peter Liebregts (Amsterdam, Atlanta: Rodopi, 1998), 11-49. Enenkel erklärt auch die Fragmentarität von Petrarcas Brief mit der Tatsache, dass die Vorlage dazu Boccaccios Schrift war.

431 Enenkel, Ad posteros, S. 280. 
per paterna vestigia et honoratus et dilectus. ${ }^{, 432}$ Die Vorlage zu seiner Formulierung war in diesem Fall:

Et licet sibi filius successerit, prudentissimus et clarissimus vir et qui me per paterna vestigia carum semper atque honoratum habuit, ego tamen, illo amisso, cum quo magis michi presertim de etate convenerat, redii rursus in Gallias... ${ }^{433}$

Hier hat Vergerio eine größere Veränderung vorgenommen. Während Petrarca - bei aller Achtung dem Sohn, Francesco, gegenüber - schreibt, dass er sich eigentlich eher dem Vater, Jacopo, verbunden fühlte und dass er deswegen nicht in Padua geblieben, sondern nach Frankreich zurückgekehrt sei, berichtet Vergerio über einen Aufenthalt („Patavii sedem fixit”) in Padua. Er lässt den zweiten, auf „tamen” folgenden Teil des Satzes, in dem Petrarca sagt, dass er nach dem Tod des Franciscus nicht mehr in Padua bleiben wollte, einfach weg. Der Grund dafür ist, dass es sich um zwei verschiedene Zeitpunkte handelt: Petrarca schreibt eigentlich über seine Abreise aus der Stadt, trotz der Möglichkeit, weiterhin in Padua zu leben, weil der Sohn des Jacopos ihn wie sein Vater geschätzt habe. Petrarca schreibt also über das Jahr 1352, über das Jahr seiner Reise in die Provence, Vergerio hingegen über das Jahr 1368, über Petrarcas Rückkehr nach Padua. Über diesen späteren Aufenthalt in Padua hat Petrarca selbst nicht geschrieben, der Brief endet nämlich mit dem oben zitierten Satz. Vergerios Zitieren von Petrarcas Worten in dieser Angelegenheit ist dementsprechend eigentlich nicht ganz korrekt, weil es in Petrarcas Original um etwas anderes ging. Vergerio wollte aber Petrarcas würdigende Worte beibehalten, ohne aber Petrarcas Hierarchisierung seiner Freundschaften zu Vater und Sohn (das heißt, dass er eigentlich eher mit Jacopo befreundet war) zu erwähnen. Ein solcher Vergleich, in dem Francesco da Carrara il Vecchio (der Vater von Francesco Novello, der in Vergerios Zeiten in Padua herrschte) etwas kurz gekommen, wäre für Vergerio weniger günstig gewesen.

Mit dieser geschickten kleinen Veränderung konnte Vergerio das Haus Carrara mit den Worten Petrarcas, aber doch in erster Person Singular würdigen, als Pier Paolo Vergerio. Er hat zwar Petrarca fast wörtlich zitiert, aber weil er den Sermo in seinem eigenen Namen schrieb, wurden Petrarcas Worte zu seinen eigenen und so Petrarcas Lob des Hauses Carrara zu seinem eigenen der Herrscherfamilie der Stadt, in der er sich just zu dieser Zeit zu etablieren versuchte. 


\subsection{Der Cicero-Brief}

\subsubsection{Vergerios angeblicher Republikanismus: Die früheren Deutungen des Briefes und deren Widerlegung}

Das dritte Stück der Textgruppe, die aus Vergerios Petrarca-Ehrung erwuchs, ist der Brief, den der Humanist in Ciceros Namen an Petrarca schrieb. ${ }^{434}$ Dieser Brief erfüllt eine Doppelfunktion. Er ist einerseits eine Antwort auf Petrarcas Brief an Cicero, andererseits eine Antwort auf Zabarellas Brief, den dieser ebenfalls als Antwort auf Petrarcas Cicero-Brief formuliert hatte. ${ }^{435}$ Ich deute diesen Brief als eine Geste, mit deren Hilfe Vergerio sich in denselben Kanon einschreibt, in den sich Petrarca schon eingeschrieben hatte. Indem Petrarca einen Brief an Cicero schreibt, hebt er sich auf den gleichen Rang mit dem Adressaten. Vergerio wiederum stellt sich mit Petrarca und dadurch ebenfalls mit Cicero in einer Reihe dar.

Den Brief in erster Linie als eine solche Geste $\mathrm{zu}$ verstehen, bedeutet die Hinterfragung des in der Interpretation des Briefes entstandenen Konsenses. Laut diesem wäre der Brief als ein Träger republikanischer Ideen zu verstehen. Diese Deutung würde eine für meine Argumentation ungemütliche Frage aufwerfen: Kann ein Text, in dem für republikanische Ideen plädiert wird, als Pinselzug in einem Image gedeutet werden, das später den römisch-deutschen König ansprechen wird? Wenn Vergerio unter anderem wegen seines Briefes an Petrarca als „Republikaner” angesehen werden konnte, so würde das meine Hypothese fast untergraben.

Der einflussreichste Vertreter der These über den Republikanismus des Briefes ist Hans Baron, der in seinem Werk über den „Bürgerhumanismus“ auch Vergerios Brief erörtert. ${ }^{436}$ Dass Baron in vielem deswegen für einen heutigen Leser nicht differenziert genug argumentieren konnte, weil er das 15. Jahrhundert sehr stark durch seine in der Weimarer Republik herausgebildete Perspektive betrachtete und weil er in Leonardo Bruni, den Protagonisten seiner Geschichte, ein anachronistisches Idealbild eines dem Republikanismus verpflichteten Ideologen projiziert hat, ist heute vielleicht die opinio communis der Forschung. Bruni wird in den Studien, die Barons These nicht oder nur unter Vorbehalten annehmen, vielmehr als ein professioneller Rhetoriker dargestellt. ${ }^{437}$

\footnotetext{
434 Vergerio, Epistolario, S. 436-445.

435 Petrarca, Le Familiari, Brief 24. 3, Bd. 4, S. 225-227.

436 Die „These” Barons hat die bekannteste Ausformulierung in seinem Buch: Hans Baron, The Crisis of the Italian Renaissance. Civic Humanism and Republican Liberty in an Age of Classicism and Tyranny (Princeton, New Jersey: Princeton University Press, 1955), [im Weiteren: „The Crisis”].

437 Eine Zusammenfassung der Kritik dieser These stammt von James Hankins. Vgl. James Hankins, „The „Baron Thesis” After Forty Years and Some Recent Studies of Leonardo Bruni”, Journal of the History of
} 
Ohne alle die Punkte, die von Barons Kritikern angesprochen worden sind, zu erwähnen, muss ich auf einen Punkt hinweisen, der zwar die „Baron-These” im Allgemeinen betrifft, aber auch in der Interpretation des Briefes von Vergerio eine wichtige Rolle spielen wird: es geht um die Verwendung des Wortes „republic”. Wie auch von David Wootton bemerkt wird, projiziert Baron ein „republikanisches” Vokabular in Brunis Laudatio urbis florentinae und die Dialogi, die er als die Gründungsschriften des florentinischen Republikanismus deutet. ${ }^{438}$ Baron liest in seinen Quellen „res publica” und „imperium” als Antonyme, obwohl, wie Wootton bemerkt, sie in Brunis Schriften noch als Synonyme zu verstehen sind. Wootton identifiziert die erste Verwendung von „res publica” mit dem neuen Sinn, das heißt für eine konkrete Staatsform, statt allgemein für den Staat in einem Text aus dem Jahr 1496, in Bartolomeo Scalas Apologia contra vituperatores civitatis Florentinae. Woottons Beispiele mahnen zur Vorsicht mit den Projektionen aus der heutigen Bedeutung des Wortes „Republik” heraus: die Dichotomie von Ideologien, die viele Forscher als „republikanisch” und „monarchistisch" bezeichnen, scheint nach einem gründlicheren Lesen der Texte, bei dem man die ursprüngliche Bedeutung des Wortes res publica vor Augen hält, ihre Gültigkeit zu verlieren. Die Trennungslinie zwischen ,gut” und „böse” scheint wie in der auch von Wootton zitierten $^{439}$ ciceronischen Staatstheorie oft statt zwischen den drei verschiedenen Staatsformen eher zwischen legitimen und illegitimen Herrschaftsformen gezogen worden zu sein.

Ganz in diesem Sinn hinterfragt meine Interpretation den Konsens über den Republikanismus des Briefes, der sich trotz der allgemeinen Verbreitung einer kritischeren Einstellung zu Barons These immer noch zu halten scheint. Aus meiner Sicht ist der Brief Vergerios nicht als Träger republikanischer Ideen zu betrachten.

Ideas 56 (1995): 309-38, [im Weiteren: „The Baron Thesis”]. Hankins behauptet, Barons Bruni sei eher einer Holzpuppe ähnlich als dem Portrait eines Mannes: Hankins, The Baron Thesis, S. 320. Für die Betonung der Rolle der Rhetorizität in Brunis Schriften durch das Beispiel von den Dialogi vgl. Jerrold E. Seigel, „Civic Humanism“ or Ciceronian Rhetoric? The Culture of Petrarch and Bruni”, Past and Present 34 (1966): 3-48, [im Weiteren: „Ciceronian Rhetoric?”]. Daraus, dass er bei der Beschreibung von Ereignissen des 15. Jahrhunderts Parallelbeispiele aus dem 19. und 20. Jahrhundert im Kopf hatte, macht Baron in seinem Buch kein Geheimnis: einmal vergleicht er Giangaleazzo Visconti sogar mit Napoleon und Hitler (Baron, The Crisis, S. 32). Obwohl es in diesem expliziten Vergleich um die Taktik des Wartenlassens des Gegners geht, ist es in Barons Narrativ völlig klar, in welche Richtung seine Sympathien und Antipathien gehen, und dass diese Neigungen und Abneigungen teilweise Projektionen von zeitgenössischen Verhältnissen in das 15. Jahrhundert zu verdanken sind. Die Abneigung gegenüber der Mailänder „Tyrannei” ist auf jeder Seite des Buches offensichtlich: Pamphlete von der Mailänder Seite werden zum Beispiel immer als für Viscontinisches Geld geschriebene Propagandaschriften abgetan, während man kein Wort über florentinische Propaganda liest.

438 David Wootton, ,The True Origins of Republicanism: The Disciples of Baron and the Counter-Example of Venturi", in Il repubblicanesimo moderno. L'idea di repubblica nella riflessione storica di Franco Venturi, Serie Studi 31, hrsg. v. Manuela Albertone (Neapel: Bibliopolis, 2006), 271-305, [im Weiteren: „The True Origins"].

439 Wootton, The True Origins, S. 372. 
Baron erörtert Vergerios Brief vor den Kulissen des titanischen Kampfes zwischen Republikanern und Monarchisten, zwischen ehrenvollen Humanisten und skrupellosen Schreiberlingen. Barons kurze Beschreibung der Karriere Vergerios scheint den Charakter einer Erzählung des Streites von Gutem und Bösem um die Seele des Humanisten zu haben. ${ }^{440}$ Vergerio habe den Brief im Namen Ciceros unter dem (guten) Einfluss von Salutati verfasst. Unmittelbar nach der (noch zu erörternden republikanischen) Paraphrase des Briefes stellt Baron die Frage, wieso Vergerio nach solch einer klaren Sicht des römischen bürgerhumanistischen Geistes wieder zu seiner mittelalterlichen, monarchistischen Sichtweise zurückkehren konnte. ${ }^{441}$ Baron erklärt diese von ihm bedauerte Tatsache mit der Tragödie des Jahres 1405, als Padua unter venezianische Herrschaft geriet, was Vergerios Karriere als Humanist zerstört habe: „Before long, one of the best minds of the pioneering generation of the early Quattrocento was lost to the humanistic cause." ${ }^{442}$ Aber Vergerio sei wegen seiner Umgebung sowieso zum Monarchismus prädestiniert gewesen und hätte selbst ohne die Ereignisse des Jahres 1405 kein ordentlicher Republikaner werden können. Padua sei, weil es sich um eine typische norditalienische Renaissance-Tyrannei handelte, kein idealer Ort für republikanische Humanisten gewesen. Während Salutatis Schüler Bruni in Florenz seine Laudatio Florentinae Urbis und die Historiae Florentini Populi schrieb, habe Vergerio statt der Geschichte des paduanischen Volkes die Vitae Principum Carrarensium geschrieben, ein Werk, durchtränkt von der Bewunderung der rücksichtslosen Machtpolitik der CarraraFamilie. ${ }^{443}$ Am Ende seines Vergerio-Kapitels erwähnt Baron Petrarcas Africa als ein republikanisches Schriftstück und die Tatsache, dass Vergerio unter den ersten war, die das Epos von Petrarca lesen durften, und er den Text sogar ediert hat. In Barons Erzählkontext erscheint dieser Text als eine von Vergerio versäumte Möglichkeit, sich wieder zum Republikanismus zu bekehren. Der Republikanismus der Africa als die Erinnerung an Salutatis Philosophie des Bürgerhumanismus habe sich nicht mehr gegen die Realität von Vergerios paduanischer Umgebung durchsetzen können. ${ }^{444}$

Baron fasst seine Interpretation des Briefes in den ersten Sätzen seiner Paraphrase zusammen:

\footnotetext{
440 Baron, The Crisis, S. 101-109.

441 Baron, The Crisis, S. 104. Auch Witt betrachtet das Schreiben des „De Monarchia” als einen Sinneswandel von Vergerios Seite: „Paradoxically, Vergerio's 'Ciceronianism' laid the groundwork for what would become 'signorial' civic humanism.”: Witt, In the Footsteps, S. 386.

442 Baron, The Crisis, S. 105.

443 Baron, The Crisis, S. 108.

444 Baron, The Crisis, S. 109.
} 
As Petrarch had examined the political situation at the end of the Roman civil wars through the eyes of the partisans of Caesar, so Vergerio revived Cicero's and Brutus' faith in the continued vitality of republican liberty-their firm conviction that the Roman civic spirit had not been destroyed for good by the corruption of the moment. Never during then periode of Cicero's participation in the civil wars, Salutati's disciple asserts, had Roman freedom „fallen so low that it was beyond the possibility of revival through wisdom and through force". ${ }^{445}$

Mit seiner Formulierung stellt er die Meinungsunterschiede zwischen Petrarca und Vergerios Cicero als einen Konflikt zwischen monarchistischer und republikanischer Ideologie dar. Der erste aus dem Brief zitierte Satz, den Baron zur Unterstützung seiner These in seine Paraphrase einbaut, soll den Optimismus der Republikaner beweisen, die fest an das Weiterleben der „republikanischen Freiheit” glauben. Wenn man eine Paraphrase mit einem eingebauten Zitat liest, so geht man davon aus, dass nicht nur das Zitat aus dem Text kommt, um den es geht, sondern dass auch sein Umfeld den Sinn der ursprünglichen Umgebung des zitierten Satzes wiedergibt. Wenn man jedoch in Vergerios Text nach ,republikanischer Freiheit" sucht, bleibt die Suche ohne Ergebnis. Wenn man die ursprüngliche Umgebung von Barons Zitat, das heißt, den Satz vor dem zitierten Satz liest, so findet man die republikanische Seite nicht mehr so einheitlich:

Brutus autem meus, quem tu michi impinges, si tam presens in conservanda republica quam acer et promptus in acquirenda fuisset, aut si tam armis, quod faciliter poterat, quam ego lingua, pugnasset, rempublicam, quam nullam quidem antequam morerer infelix vidi, aut optimam aut certe aliquam reliquissem. ${ }^{446}$

Zum weiteren Verständnis soll hier auch der auf diesen Satz folgende, von Baron nur halb zitierte Satz ganz stehen: „Nunquam enim, quando a me in Italia $<\mathrm{m}>$ accersebatur, tantum corruerat libertas, quin manu et consilio erigi posset.” Baron lässt die Übersetzung von „quando a me in Itali $<\mathrm{m}>$ accersebatur” weg, er paraphrasiert es als ,während Ciceros Teilnahme an dem Bürgerkrieg”. Auch in den Anmerkungen gibt er bloß den von ihm übersetzten Teil des lateinischen Satzes an und lässt den Teil weg, der von ihm nur paraphrasiert wurde. Das Original ist etwas konkreter als seine Paraphrase. Es handelt sich darum, dass der historische Cicero Brutus mehrmals aufgefordert hatte, nach Italien zurückzukehren. Damals hätte Brutus die res publica noch retten können, weil noch nicht alles verloren war. Er war aber, wie aus den vorangehenden Sätzen klar wird, ,acer” und „promptus”, als es darum ging, die Macht über die öffentlichen Angelegenheiten zu ergreifen, und er war nicht da, als es darum ging, sie zu behalten. Es geht hier um Ciceros Vorwurf, Brutus habe nicht zu den

445 Baron, The Crisis, S. 103.

446 Vergerio, Epistolario, S. 442. 
Waffen gegriffen, um die res publica zu retten, und nicht um eine optimistische Aussage darüber, dass der römische „Bürgergeist” („,civic spirit”) nicht zerstört wurde.

Wenn man in Petrarcas Brief nach dem Vorwurf sucht, auf den die oben zitierten Sätze antworten, findet man dort Folgendes:

Sed quis te furor in Antonium impegit? Amor credo reipublice, quam funditus iam corruisse fatebaris. Quodsi pura fides, si libertas te trahebat, quid tibi tam familiare cum Augusto? Quid enim Bruto tuo responsurus es? ${ }^{447}$

Antonius ist aber nicht der erste in der Reihe der römischen Persönlichkeiten, die Petrarca in seinem Brief aufzählt. Der Absatz, der mit der Frage, was Cicero in Bezug auf seine Stellungnahme für Octavianus seinem Brutus antworten würde, fängt mit Dionysius an:

Omitto Dionysium, omitto fratrem tuum ac nepotem, omitto, si placet, ipsum etiam Dolabellam, quos nunc laudibus ad caelum effers, nunc repentinis maledictis laceras. Fuerint haec tolerabilia fortassis. Iulium quoque Caesarem praetervehor, cuius spectata clementia ipsum lacessentibus portus erat; Magnum praeterea Pompeium sileo, cum quo iure quodam familiaritatis quilibet posse videbare. ${ }^{448}$

Petrarca wirft Cicero nicht seinen „Republikanismus” vor, nicht also seine Stellungnahme für eine als „republikanisch” identifizierbare Seite im Bürgerkrieg, sondern seine Inkonsequenz. Mal habe er diese, mal die andere Seite unterstützt, die gleichen Personen manchmal gelobt, manchmal getadelt. Was Petrarca an Cicero weiterhin auszusetzen hat, ist überhaupt seine Teilnahme an der Politik. Petrarcas Briefanfang fasst seine späteren Vorwürfe gleich zusammen:

Audivi multa te dicentem, multa deplorantem, multa variantem, Marce Tulli, et qui iampridem qualis preceptor aliis fuisses noveram, nunc tandem, quis tu tibi esses, agnovi. [...] $\mathrm{O}$ inquiete semper atque anxie, vel ut verba tua recognoscas, o preceps et calamitose senex, quid tibi tot contentionibus et prorsum nihil profuturis simultatibus voluisti? Ubi et etati et professioni et fortune tue conveniens otium reliquisti? ${ }^{449}$

Vergerios Brief im Namen Ciceros bietet genau auf diese Vorwürfe eine Antwort: der Tenor des Briefes könnte so zusammengefasst werden. Vergerio/Cicero gibt zu, er habe seine Meinung und seine „Rede” oft geändert, es sei aber nötig gewesen in einer Zeit, in der sich alles ständig geändert habe: „quam ob causam ut variarem necesse fuit aliquando et animum

\footnotetext{
447 Petrarca, Le Familiari, Brief 24. 3, Bd. 4, S. 226.

448 ebda

449 Petrarca, Le Familiari, Brief 24. 3, Bd. 4, S. 225 f.
} 
et orationem, quando tanta erat in rebus, tanta in moribus hominum variatio." ${ }^{450}$ Am Ende des Briefes fasst der Autor seinen Standpunkt in Bezug auf vita activa versus vita contemplativa zusammen:

ea enim michi matura semper et prestans philosophia visa est, que in urbibus habitat et solitudimen fugit, que cum sibi tum communibus studet commodes, et prodesse quam plurimis cupit, atque ita de perpetua quidem, non de mortali, non de exigua vita cogitat. ${ }^{451}$

Die Verteidigung der vita activa muss aber keine republikanische Einstellung bedeuten. Da Bürgerhumanismus („civic humanism”) in Barons einflussreichem Buch immer in Verbindung mit Republikanismus steht, werden die beiden Erscheinungen (,civic humanism” und Republikanismus) miteinander oft fast automatisch verbunden. Dass der Ausdruck „civic humanism” entweder nicht mehr oder nur mit Vorsicht benutzt werden sollte und ohne eine Verbindung mit Republikanismus, wird auch von Hankins vorgeschlagen. Die Wertschätzung der Rhetorik und der Bemühungen für das Gemeinwohl sind nach Hankins’ Beweisführung unter anderem auch in einer Schrift des Humanisten am Hof des Filippo Maria Visconti, Uberto Decembrio, nicht weniger präsent als in Brunis Schriften. ${ }^{452}$

Selbst aber die Würdigung der vita activa gegenüber der vita contemplativa muss nicht unbedingt für Vergerios persönliche Meinung gehalten werden, die er in allen seinen Schriften vertreten hat. Damit meine ich aber nicht, dass er seine Position in dieser Frage geändert habe und dass auf eine Phase, in der er für das eine war, eine Phase folgte, in der er eher für das andere argumentierte. In seinem oben erörterten Sermo, den er ungefähr zur gleichen Zeit geschrieben hat wie seinen Brief in Ciceros Namen, scheint Vergerio ganz anderer Meinung zu sein. In dieser Schrift verteidigt er Petrarca gegenüber seinen Kritikern, die ihn wegen seiner angeblich inkonsistenten Haltung seinen „Herren” gegenüber verurteilt haben:

Quamobrem obiecta est ei saepe a maledicis inconstancia, multumque diu, et clam et palam hoc telo impetitus est. Quod cum cognovisset, maledicta eorum ita refellebat: videri se sibi et caeteris, qui recte iudicassent, constantissimum, quod eius semper propositi fuisset, nec abstineri ab eo ulla ratione posse, quin quietem sectaretur, seque numquam quieturum, donec quietis locum invenisset. ${ }^{453}$

Man könnte meinen, dass Vergerio hier nur Petrarca zitiert habe (,ita refellebat"), und dass er eine ganz andere Meinung haben konnte. Auf eine Distanzierung von der Seite Vergerios

450 Vergerio, Epistolario, S. 439.

451 Vergerio, Epistolario, S. 444.

452 Hankins, The Baron Thesis, S. 327-330.

453 Solerti, Le vite, S. 297. 
gegenüber Petrarcas Selbstverteidigung deutet aber im Text nichts hin, er relativiert Petrarcas Aussage nicht. Außerdem nennt er Petrarcas Kritiker selbst „maledici“, was keineswegs eine wertneutrale Bezeichnung ist. Die „maledici“ sind immer diejenigen, die jemanden zu Unrecht angreifen. Vergerio scheint im Sermo Petrarcas Partei zu ergreifen. Wenn man die Entstehungsgeschichte des Sermo bedenkt, der ursprünglich als eine im Paduaner Dom zu haltende Festrede für Petrarcas Geburtstag gedacht war (Anm. 406), dann stellt man fest, dass eine andere Haltung von Vergerio fehl am Platz gewesen wäre. Es besteht immer noch die Möglichkeit zu sagen, dass Vergerio seinen Sermo nicht aus Überzeugung, nicht ernsthaft geschrieben habe, während er seine eigentliche, eigene Meinung im Brief in Ciceros Namen ausformuliert habe. Solche Behauptungen stehen aber auf einem unsicheren Boden. Es ist viel sinnvoller, in diesem Fall statt mit moralischen Begriffen wie „Ehrlichkeit” eher mit der kontextuellen Gebundenheit der Texte zu argumentieren. In einer Festrede für Petrarca ergreift man für ihn Partei (zumal, wenn man, wie ich oben argumentierte, diese Rede mit den Worten desselben Petrarca geschrieben hat); in einem Brief dagegen, den man als Antwort auf Petrarcas Schreiben an Cicero im Namen Ciceros schreibt, versucht man die Argumente zu finden, mit denen ein Cicero sich hätte gegenüber Petrarcas Kritik wehren können. Vergerio muss sich in dem einen Fall in Petrarca, in dem anderen in Cicero verwandeln, um den richtigen Ton treffen zu können. ${ }^{454}$

Um ein letztes Beispiel für eine Baronsche Paraphrase zu nennen, sei hier die Stelle zitiert, wo er über Cäsars Beurteilung des Cicero-Vergerio schreibt: „Our fight, Vergerio’s Cicero explains, was against Caesar's monarchical position, not against his person." ${ }^{\text {455 }}$ Der Satz, der auf diese Weise zusammengefasst wurde, lautet im Original wie folgt:

Placuit siquidem Cesar, quandiu non potentiam suam, sed utilitatem publicam querere visus est, quandiu sibi incolumitas urbis et civile otium placuit; postea vero quam subvertit omnia et libidine sua potitus est, nequaquam de eo bene dixi. ${ }^{456}$

Wie es aus dem Original ersichtlich wird, wird Cäsar von Cicero/Vergerio nicht wegen seines „Monarch-Seins” verurteilt, wie man es auf Grund von Barons Paraphrase denken könnte, sondern weil er nicht mehr das Gemeinwohl vor Augen gehabt, seiner „libido” nachgegeben und, statt für Frieden zu sorgen, alles auf den Kopf gestellt habe. Es kommt zwar kein auf Alleinherrschaft hinweisendes Wort in Vergerios Text vor, wenn man ihn unbedingt mit

\footnotetext{
454 Dass solche rhetorischen Übungen, in denen man mal für die eine, mal für die andere Seite argumentieren musste, in der Antike verbreitet waren, ist bekannt und von den Forschern auch betont worden, die die Inkongruenzen der Schriften einzelner Humanisten mit deren Rhetorizität erklären, wie zum Beispiel in Seigels bereits erwähnter (Anm. 437) Studie (Civic Humanism).

456 Vergerio, Epistolario, S. 440.
} 
einem Hinweis auf Cäsars Monarch-Sein paraphrasieren möchte, könnte man den Sinn des Satzes so zusammenfassen: Vergerio/Cicero verurteilt Cäsar nicht als Monarchen, sondern als „schlechten” Monarchen, als einen Tyrannen. Im Gegensatz zu dem Sinn, den Barons Analyse in den Satz hineinprojiziert, schließt der Originaltext des Briefes die Möglichkeit eines guten Monarchen nicht aus.

Dass ein Herrscher seinem eigenen Verlangen nachgibt, statt das Gemeinwohl vor Augen zu haben, ist auch in einem anderen Text Vergerios ein Merkmal des schlechten Herrschers. In seiner De monarchia sive de optimo principatu liest man eine knappe Zusammenfassung der Unterschiede zwischen einem guten und einem schlechten Herrscher:

Si sit itaque rex bonus, si iustus, si clemens, et, quo plus legibus potest, eo magis legibus subsit, ibi certa pax, ibi vera libertas. Ex adverso autem nichil esse deterius potest, quam cum in unius perditi hominis libidine collata sunt capita multorum, et perniciose voluntati iuncta est facultas nocendi. ${ }^{457}$

Auch in De monarchia sind wie im Cicero-Brief die zwei Schlüsselwerte, über die die res publica verfügen soll, pax und libertas. In De monarchia wird es im zitierten Satz deutlich, während es im Brief mehrere Stellen gibt, mit denen man die Behauptung, pax und libertas seien Grundwerte, die die res publica unbedingt behalten soll, unterstützen kann: „.. pax, cuius auctor semper fueram stabiliende..." ${ }^{458}$; ,placuit Caesar, ...quandiu sibi incolumitas urbis et civile otium placuit" ${ }^{459}$; „,...in libera civitate..."460; „nunquam enim... tantum corruerat libertas..."461, , ,libertatem, que bonum omnibus commune est”462.

Weiterhin soll der gute Herrscher desto mehr den Gesetzen unterworfen sein, je mehr Macht er durch diese hat. Den gleichen Gedanken findet man auch im Cicero-Brief, in jenem Satz, der auf Petrarcas Vorwurf antwortet, nach dem Cicero selbst Cäsars clementia nicht richtig geschätzt habe („Iulium quoque Caesarem praetervehor, cuius spectata clementia ipsum lacessantibus portus erat."):

Neque enim spectatam eius clementiam placebat plus legibus aut senatu valere; nam, ut in libera civitate nomen ipsum crudelitatis odiosum est, ita et clementie invidiosum, nec facile solemus quenquam clementem dicere, nisi qui et crudelis impune esse possit. ${ }^{463}$

Das Fragment De monarchia sive de optimo principatu wurde auch von Smith, in Vergerios Epistolario, ediert: Vergerio, Epistolario, S. 447-450, hier S. 447.

458 Vergerio, Epistolario, S. 440.

459 ebda

460 Vergerio, Epistolario, S. 441.

461 Vergerio, Epistolario, S. 442.

462 Vergerio, Epistolario, S. 443.

463 Vergerio, Epistolario, S. 441. 
Der erste Teil des Satzes steht in völligem Einklang mit der oben zitierten Stelle des Fragmentes De monarchia. Vergerio/Cicero habe es nicht gefallen, dass Cäsars „clementia“ wichtiger war, als die Gesetze und das Sagen des Senats. Wo die zwei Stellen etwas auseinanderzugehen scheinen, ist die Fortsetzung des Satzes, nach dem „clementia“ in einem freien Staat auf jeden Fall verhasst sein soll, weil man meistens jemanden nur in dem Fall als „clemens“ bezeichnen kann, wenn er gleichzeitig auch über die Möglichkeit verfügt, ungestraft „crudelis“ zu sein. In der Stelle in De monarchia ist dagegen „clementia“ eine der drei Haupttugenden des guten Herrschers. Wenn man aber etwas genauer liest, so erkennt man, dass die Sinndivergenzen der zwei Passagen doch nicht so groß sind: Einerseits betont auch De monarchia die Wichtigkeit dessen, dass der Herrscher den Gesetzen unterworfen sei, auch dieser Text verabsolutiert also „clementia“ nicht. Andererseits hat Cicero/Vergerio keinen Vorbehalt gegen „clementia“ selbst, was aus dem Anfang des Satzes klar wird (,neque enim spectatam eius clementiam placebat plus legibus aut senatu valere”), sondern dagegen, dass sie eine gewisse Unabhängigkeit des Herrschers von den Gesetzen impliziert: nur der habe die Möglichkeit zur Nachsicht und Großzügigkeit, der auch die Freiheit zur „,crudelitas“ habe. Diese Gefahr, die aus dem Wesen der Macht kommt, wird aber auch in De monarchia angesprochen: nachdem Vergerio einige Beispiele für einen schlechten Herrscher erwähnt hat (Caligula, Nero, Octavianus, als er noch jung war, Tiberius, Domitianus), meint er, dass man für diese Seite zahllose weitere Beispiele finden könnte, während für einen guten Herrscher die Beispiele seltener seien: ,sed deesse in hanc partem exempla non possunt. Illa rariora sunt, si meminisse clarorum principum volumus [...]". ${ }^{464}$ In einem späteren Absatz erörtert der Autor ausführlich, warum dies so sei, warum es also mehr schlechte als gute Herrscher gäbe: erstens, weil es überhaupt mehr schlechte als gute Menschen gäbe, zweitens, weil die Herrscher von den ersten Menschen stammten, die es geschafft hätten, die anderen Menschen zu regieren und zu einer zivilisierten Gemeinschaft zusammenzuführen. ${ }^{465}$ Die Abkömmlinge dieser ersten seien dann später auch als principes geachtet worden, obwohl diese verglichen mit ihren Vorfahren entartet gewesen seien: ,inde factum est, ut posteriores, crescentibus cum copia vitiis, a superioribus suis degenerent, et, quo plus posse se videant, eo magis insaniant." 466 Nach dem Vergerio des Fragmentes De monarchia besteht die Gefahr der Macht darin, dass sie auch von Unwürdigen ausgeübt werden kann. Wenn jemand aus eigenem Verdienst an die Macht kommt, wie die ersten Führer der Menschheit, so kann er die

\footnotetext{
464 Vergerio, Epistolario, S. 448.

465 Dass Vergerio wahrscheinlich eher auf Ciceros De officiis, als auf Aristoteles rekurriert, wie es Bischoff in seiner Studie (vgl. Bischoff, Studien, S. 31-35) nachzuweisen versucht, ist die Meinung von Smith, der es in einer Fußnote behauptet: Vergerio, Epistolario, S. 447, Anm. 1.

466

Vergerio, Epistolario, S. 449.
} 
Freiheit der Macht gut, im Dienst des Allgemeinwohls nutzen. Wie es aus dieser Erörterung, sogar schon aus der Fragestellung (warum es mehr schlechte als gute Herrscher gäbe) hervorgeht, ist Vergerio auch in seinem De monarchia nicht besonders optimistisch, was die Charakterzüge der Machtträger betrifft.

Die zwei Texte (De Monarchia und der Cicero-Brief) enthalten also ähnliche Gedanken: die Behauptung, dass ein Herrscher gut oder schlecht sein kann, dass er gut ist, wenn er das Gemeinwohl vor Augen hat und schlecht, wenn er als Sklave seiner eigenen libido agiert; unter einem guten Herrscher gebe es Frieden und Freiheit, unter einem schlechten werde alles auf den Kopf gestellt und sei die res publica nicht mehr frei. Der Cicero-Brief und das Fragment De monarchia sind nicht als Ausdrücke gegensätzlicher Einstellungen $\mathrm{zu}$ interpretieren, wie es Baron vorschlägt. Er behauptet sogar, Smiths Datierung des Fragmentes auf die Zeitspanne zwischen 1390 und 1404 könne nicht stimmen, und es müsse viel später geschrieben worden sein. ${ }^{467}$ Er schlägt 1394 als terminus post quem vor, das Jahr des Todes von Francesco da Carrara dem Älteren, der im Text als jemand, der erinnert wird (,memorie nostre”) vorkommt und demzufolge zur Zeit des Schreibens des Briefes tot sein musste. Diesen terminus post quem muss man auch akzeptieren. Wo man mit Baron nicht ohne Weiteres einverstanden sein kann, weil sich seine Argumentation auf schwache Beweise stützt, ist seine Behauptung, der Text müsse viel später als 1394 entstanden sein, weil der Ton des Absatzes über Francesco darauf hinweise, dass Francesco zur Zeit des Entstehens des Textes schon lange tot gewesen sei, und weil in der Mitte der neunziger Jahre, wie es sein Cicero-Brief bezeuge, Vergerios Attitüde noch eine ganz andere gewesen sei. Baron datiert De monarchia in die Zeit zwischen 1400 und 1405. Erstens sagt der „Ton” des Absatzes über Francesco da Carrara nichts über die Länge der Zeit, die er schon tot $\operatorname{sei}^{468}$, zweitens fällt das Argument, das sich auf die Unterschiedlichkeit der zwei Schriften stützt, auch weg, weil sie gar nicht so verschiedene Haltungen vermitteln. ${ }^{469}$

Wenn ich die Existenz mancher Berührungspunkte der zwei Texte - De monarchia und Cicero-Brief - betone, so will ich die Aussage der zwei Texte selbstverständlich nicht als identisch darstellen. Im Fall von De monarchia handelt es sich um eine Argumentation dafür, dass die beste Staatsform die Monarchie sei, während im Cicero-Brief Vergerio/Cicero - nach meiner Interpretation - keine Präferenzen für eine bestimmte Staatsform zu haben scheint.

\footnotetext{
467 Baron, The Crisis, S. 488, Anm. 25.

468 Dieser Punkt findet sich auch bei David Robey, dessen Kritik von Baron noch ausführlich erörtert wird: Robey, Republicanism, S. 22.

469 Drittens könnte man auch behaupten, dass es nicht auszuschließen ist, dass ein Humanist als ein professioneller Rhetoriker in der gleichen Zeitspanne pro und kontra die gleiche Sache argumentieren konnte.
} 
David Robeys Artikel über den Cicero-Brief Vergerios ist eine Antwort auf Hans Barons Ansichten. Was Robey bei dessen Vergerio-Interpretation kritisiert, ist die Annahme, dass Vergerio sich von seinem frühen Republikanismus, dessen Zeugnis sein Brief an Petrarca sei, später entfernt habe und zu dem konservativeren Monarchismus zurückgekehrt sei, und diese Änderung seiner politischen Präferenzen der Tatsache zu verdanken sei, dass er sich von der florentinischen Umgebung entfernt habe. Nach Robeys ist keine solche Entwicklungslinie bei Vergerio festzustellen. Der Republikanismus seines Briefes an Petrarca sei nicht indikativ für Vergerios frühe Phase. Was in seinen Briefen als das wichtigste Kriterium für eine gute Regierung zu bezeichnen wäre, sei die Frage der Legitimität der Herrschaft. Dementsprechend sei er nie ein überzeugter Republikaner oder Monarchist gewesen. Der Republikanismus des Petrarca-Briefes sei eher ein literarisches Phänomen und als solches nicht generell dem florentinischen Klima $\mathrm{zu}$ verdanken, sondern viel mehr Salutatis persönlichem und Ciceros literarischem Einfluss auf Vergerio. ${ }^{470}$ Robey mahnt vor der Überschätzung des „republikanischen Klimas” von Florenz ${ }^{471}$ und bezieht sich oft auf Ronald Witts Ergebnisse, wonach „libertas“ nicht unbedingt eine republikanische Bedeutung haben soll. ${ }^{472}$ Robeys Behauptung, dass Vergerio in seinen anderen Schriften weder Republikaner noch Monarchist war, sondern in seiner Beurteilung der Herrschaft die Legitimität die Hauptrolle spielte, ist überzeugend. Weniger nachvollziehbar erscheint seine These, Vergerios Absicht mit De Monarchia sei auf keinen Fall die Legitimierung von irgendeiner Form von monarchistischer Regierung gewesen. ${ }^{473}$ An einem Punkt hinterfragt er aber Barons Interpretation nicht. Auch Robey geht davon aus, dass der Cicero-Brief selbst republikanische Ideen enthalte. ${ }^{474}$ Dies ist der Punkt, an dem ich eine noch radikalere Revision von Barons Deutung des Cicero-Briefes vorschlage.

\footnotetext{
470 Robey, Republicanism, S. 24 f.

471 Robey, Republicanism, S. 5.

472 Robey, Republicanism, S. $10 \mathrm{f}$.

473 Robey, Republicanism, S. 18.

474 Robey benutzt an einer Stelle sogar den Ausdruck vom „offensichtlich militanten Republikanismus” (,apparently militant republicanism”): Robey, Republicanism, S. 12.
} 


\subsubsection{Ein neues Deutungsmuster des Cicero-Briefes}

Vergerios Werke, die er zwischen 1390 und 1397 schrieb, lassen darauf schließen, dass er die Absicht hatte, am Hof der Carrara Fuß $\mathrm{zu}$ fassen. McManamon fasst die Schriftproduktion Vergerios in dieser Zeit zusammen ${ }^{475}$ und gibt eine Übersicht über die Briefe, in denen Vergerio die Ereignisse des Krieges zwischen der Koalition gegen die Visconti-Herrschaft und Viscontis Alliierten kommentiert. Weiterhin betont er, dass Vergerio von dieser Zeit an versucht habe, seine humanistischen Studien in den Vordergrund zu stellen. ${ }^{476}$ Sehr überzeugend ist McManamons Erörterung des Briefwechsels Vergerios mit Salutati als ein Mittel humanistischer Selbstdarstellung. ${ }^{477}$ Salutatis Briefwechsel mit Petrarca sei eine Strategie gewesen, die Vergerio übernommen habe. Der Florentiner bekam zwar selbst nur einen einzigen Brief von Petrarca, aber wenigstens diesen konnte er in seine Briefsammlung einbauen. Durch diesen „Briefwechsel” und durch seine zwei Briefe, die er nach dem Tod Petrarcas über ihn geschrieben hatte, habe er den Eindruck erwecken können, sie seien Freunde gewesen. Vergerio habe dann auf ähnliche Weise Salutatis Nähe gesucht. Seine Briefe an jenen haben für Vergerios Ruf als Humanist gesorgt. ${ }^{478}$ Weiterhin überblickt der Forscher Vergerios Reden, die er zwischen 1392 und 1394 für Anlässe schrieb, die als Schlüsselereignisse im Konflikt zwischen den Carrara und Giangaleazzo Visconti gesehen werden können. ${ }^{479}$ Vergerios Brief im Namen Ciceros an Petrarca wird von McManamon in seinem nächsten Kapitel erörtert. ${ }^{480}$ In seiner Analyse bekommt berechtigter Weise Vergerios Verteidigung der vita activa den Hauptakzent. Am Ende beschreibt er den Cicero-Brief und De republica veneta als Werke Vergerios, in denen er das Modell oligarchischer Regierung verteidigt habe. Dies wird von McManamon als Zeichen des Pragmatismus eines arbeitslosen Intellektuellen verstanden, der bereit gewesen wäre, sowohl in einer „Republik” als auch für einen Fürsten $\mathrm{zu}$ arbeiten. McManamon scheint aber andererseits die republikanische Deutung des Briefes anzunehmen, ohne dass diese in seiner Analyse eine zentrale Rolle spielen würde. Er erwähnt auch Baron als den Stifter dieser Deutung, ohne sie zu hinterfragen. ${ }^{481}$ Wie auch aus der letzten Bemerkung des Kapitels eindeutig hervorgeht, versteht er aber Oligarchie und Republik als Synonyme und damit löst er das Problem, in

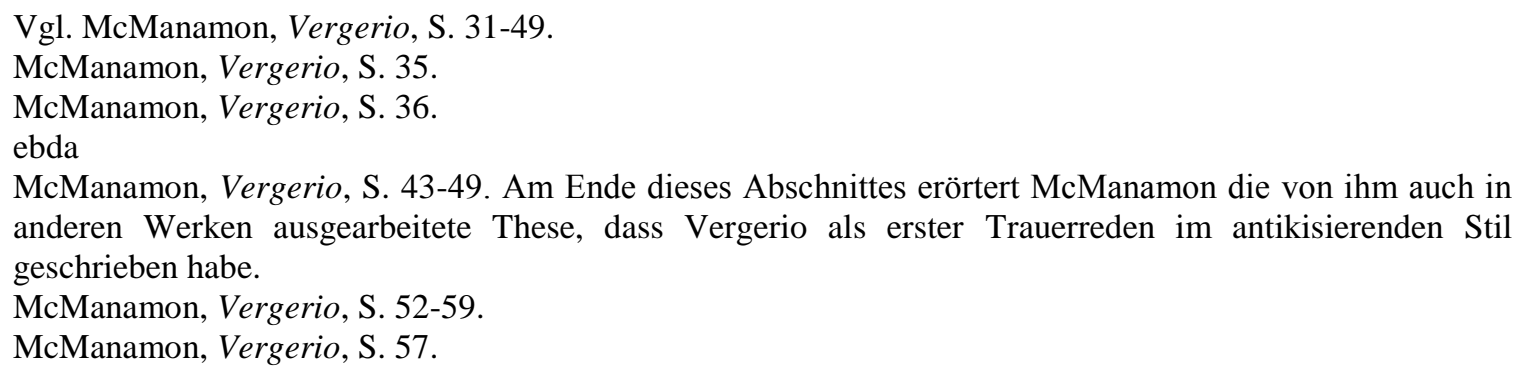
anderen Werken ausgearbeitete These, dass Vergerio als erster Trauerreden im antikisierenden Stil geschrieben habe. 
wieweit die Verteidigung „republikanischer” Ideen im Paduaner Kontext für die Arbeitssuche angebracht gewesen sein konnte: wenn Vergerio für Oligarchie plädiere, so könne er sich damit für beide Seiten, sowohl für Republiken, als auch für Fürsten, attraktiv zeigen. All dies ist aber in der Analyse nicht richtig geklärt, die Bezeichnungen ,republikanisch” und „oligarchisch” scheinen eher auf eine Weise benutzt zu werden, die die Konturen dieser Begriffe verwischt. Was aber sehr einleuchtet, ist Vergerios Stellungnahme in Bezug auf die soziale Rolle des Humanisten, und dass dieser politische Aktivismus nicht ganz ohne Eigennutz zu verstehen ist.

Der Ausgangspunkt für meine Interpretation ist die Behauptung, dass der Brief Alleinherrschaft nicht als solche verurteilt, sondern nur deren entartete Version: die Tyrannei. Meine Deutung setzt aber den Akzent nicht auf die Frage nach der von Vergerio bevorzugten Regierungsform, sondern auf eine Geste, die die Deutungsmöglichkeiten des Briefes auf einer anderen Ebene erweitert. Nach dieser Lesart kann Vergerios Cicero-Brief an Petrarca als einer der Versuche angesehen werden, sich als einen potenziellen Hofhumanisten zu profilieren. ${ }^{482}$ Meine Hypothese, die ich schon durch das Beispiel seiner Africa-Ausgabe und seiner Petrarca-Vita zu beweisen versuchte, ist, dass Vergerio sein Profil als Humanist unter anderem durch die Aneignung des Petrarca-Erbes geschaffen hat. Der Brief ist laut meiner Interpretation ein weiteres Beispiel für die Strategie, sich als einen zweiten Petrarca darzustellen. Die Bedeutung einer solchen Geste ist im Paduaner Kontext einfach zu erklären: sich als einen zweiten Petrarca zu profilieren, kann als ein Hinweis auf die Familientradition der Carrara, denen er gedient hat, verstanden werden - und so als implizite Aufforderung, ihn in Dienst zu nehmen.

Ein weiterer wichtiger Punkt, den ich neben dem angeblichen Republikanismus des Briefes hervorheben und modifizieren möchte, ist die von Baron wie auch von Robey und McManamon geteilte Auffassung, der Brief Vergerios solle in erster Linie und sogar ausschließlich als eine Kritik an Petrarca und als Verteidigung Ciceros gelesen werden. Was in dieser Sicht außer Acht gelassen wird, ist die Form des Briefes. Es ist ein Beispiel für eine Herangehensweise an Texte, die irgendwelche vermeintlich wichtigen „Inhalte” aus der vermeintlich weniger wichtigen „Form” herauszudestillieren versucht. Wenn man darauf achtet, wie Vergerio Cicero gegenüber Petrarca verteidigt, offenbart sich neben dem auf den

482 Bis zu diesem Punkt stimme ich McManamons Interpretation auch zu. Meine Argumentation basiert aber nicht wie McManamons auf der Annahme, dass Vergerio, um sich bei den Carrara attraktiv zu machen, mit seinem Brief für die Oligarchie plädiert hätte. Meine Hypothese bezieht sich auf eine andere Ebene des Imagebildens von Vergerio. 
ersten Blick evidenten Schema „Cicero und Vergerio gegen Petrarca” ein anderes Muster, das die drei Personen in eine völlig andere Beziehung zueinander stellt.

Das Schreiben des Briefes in Ciceros Namen ist ein Akt der Prosopopoeia. Vergerio redet durch Ciceros Stimme, er macht ihn zum Sprechenden. Die Figur der Prosopopoeia lässt den Leser immer zwei Stimmen hören: die von dem ins Leben gerufenen und die von dem ins Leben rufenden. In diesem Fall sind es Ciceros und Vergerios Stimmen, die sich im Brief vermischen. Um eine absolute Identifikation mit Cicero $\mathrm{zu}$ verhindern, um also die Simulation anzudeuten, hat Vergerio den Brief als Petrus Paulus Vergerius Iustinopolitanus unterzeichnet. ${ }^{483}$ Er wollte also das Spiel nicht ganz zu Ende spielen beziehungsweise sein Spiel als solches offenlegen. Seine Unterschrift ist nicht wegen ihres Informationswertes interessant, denn es überrascht natürlich keinen Leser des Briefes, dass er doch nicht von Cicero geschrieben wurde. Dass Vergerio das Spiel an diesem Punkt unterbricht, hat eine andere Funktion. Es ist als Hinweis für den Leser zu verstehen, die Worte Vergerios, die er in Ciceros Mund legt, gleichzeitig doch auch als die Worte Vergerios zu lesen. Wenn er hinter der Maske Ciceros über seine scheinbar wechselhafte Haltung und Position im politischen Feld schreibt, kann dies auch auf ihn selbst, also auf Vergerio bezogen werden.

Der Brief kann als ein Wechselspiel interpretiert werden, als ein Geflecht der zwei ineinander verwobenen Stimmen, in dem Ciceros Aussagen auch als Vergerios Aussagen verstanden werden müssen, und demzufolge Vergerios Verteidigung von Cicero als eine Strategie der Selbstverteidigung Vergerios verstanden werden soll. Vergerio/Cicero behauptet am Anfang des Briefes an Petrarca jenem gegenüber, dass jeder, der Kritik ausübt, auf ähnliche Kritik seitens der Nachwelt vorbereitet werden sollte:

Atque illud debueras animadvertere quod, si quippiam in te est rerum decus, quo plurimum redolet oratio tua, sive vives, sive morieris, rerum a te tuarum posteri rationem exigent. Neque enim impune quenquam carpimus; semper presto solet subsequi, qui nos corrodat. ${ }^{484}$

Diese Aussage bezieht sich nicht nur auf Cicero und Petrarca, wie man es auf den ersten Blick verstehen würde, und wie man es bis jetzt auch immer verstanden hat. Vergerio bezieht, wenn man annimmt, dass er seine eigene Stimme durch die des Cicero mitsprechen lässt, die Aussage auch auf sich selbst. Er kann Petrarca nicht kritisieren, ohne zu wissen, dass er auf

\footnotetext{
483 Aus Smiths Apparat wird klar, dass der Brief in zwei Codices so unterzeichnet worden ist, in dem L und C. In C. steht neben der Unterschrift auch das Datum „MCCCLXXXXIIII”. C. gehört nach Smiths Urteil zu den vertrauensswürdigen Codices. Für das Stemma vgl. Vergerio, Epistolario, S. LXI.

484 Vergerio, Epistolario, S. 438.
} 
die gleiche Kritik wie Petrarca vorbereitet sein muss. Die Kritik kann alle drei betreffen: Vergerio ist keine Ausnahme.

Die gleiche Verletzbarkeit und das gleiche Ausgeliefertsein bilden eine starke Gemeinsamkeit der drei Personen. Das Bedürfnis nach Selbstverteidigung und Selbstlegitimierung ist eine Verbundenheit, die mindestens genauso stark ist, wie die im Brief inszenierten Meinungsunterschiede. Vergerios Motivation zur von ihm im Brief deutlich gemachten Gemeinsamkeit kann als eine doppelte angesehen werden. Auf der einen Seite stellt er sich, indem er das von Petrarca angefangene Spiel weiterspielt, als einen zweiten Petrarca dar, was für einen am Hof der Familie Carrara sich zu etablieren suchenden Gelehrten nicht ganz unnütz sein sollte. Auf der anderen Seite entschuldigt er, indem er Ciceros wechselhafte Stellungnahmen entschuldigt, schließlich sich selbst und paradoxerweise auch Petrarca, an und gegen den der Brief gerichtet ist.

Laut meiner Interpretation ist Vergerios Brief kein Monument des „Republikanismus”, der sich mit seinen späteren Versuchen, am kaiserlichen Hof Fuß zu fassen, nicht vereinbaren liesse. Meines Erachtens ist der Brief viel mehr als ein Dokument von Vergerios Versuch zu deuten, sich als den berechtigten Hüter des Erbes Petrarcas oder sogar als einen zweiten Petrarca $^{485}$ darzustellen: ein Image, das genau so gut $\mathrm{zu}$ dem Paduaner wie zu dem kaiserlichen Hof passte und das dessen Träger in beiden Kontexten attraktiv machen konnte.

\section{Vergerio in Buda}

\subsection{Die Spuren eines Humanisten}

Um die Frage zu klären, in welcher Funktion er in Sigismunds Dienst stand, kann man folgende Details sammeln ${ }^{486}$ : die Bezeichnung seiner Funktion war nach einem Zeugnis des explicit der Kopie eines Briefes die eines „referendarius”. ${ }^{487} \mathrm{Da}$ es die einzige Spur einer Bezeichnung von Vergerios Funktion am Hof Sigismunds ist, muss man damit vorsichtig umgehen. Die ungarischen Forscher haben unterschiedliche Erklärungen für die Bedeutung dieses Titels gegeben. Koltay-Kastner gibt für seine Behauptung, Vergerio habe 27 Jahre lang der Kanzlei vorgestanden, zwar keine Quellen an, man kann aber davon ausgehen, dass er

485 Ein explizites Urteil über Vergerio, das ihn neben Petrarca stellt, ist erst aus der zweiten Hälfte des 15. Jahrhunderts überliefert worden. Bartolomeo Platina schreibt: „Romana enim lingua [...] tenebris supra septingentesimum annum iacuit: quam quidem Paulo ante Victorini aetatem, Franciscus Petrarcha et Paulus Vergerius in lucem quoquo modo deducere sunt visi." Zitiert von Witt, In the Footsteps, S. 339.

486 In diesem Absatz folge ich Florio Bánfis Artikel, der die präziseste Beschreibung von Vergerios Tätigkeit in Ungarn geliefert hat.

487 Das von Bánfi zitierte explicit lautet: „Finit feliciter Bononie per Petrum Paulum Vergerium virum summum, nunc Serenissimi Imperatoris referendarium.” (Barb. Lat. 1952 der Vaticana), vgl. Bánfi, PPV, Teil 2, S. 17. 
diese Annahme vielleicht auf den Titel „referendarius” stützte. ${ }^{488}$ Mályusz bemerkt, dass die Bedeutung der Bezeichnung „referendarius” unklar sei, sie deute aber auf jeden Fall darauf hin, dass Vergerio zu keinen Kanzleiarbeiten verpflichtet worden sei. ${ }^{489}$

Wem genau die Zuschreibung im explicit zu verdanken ist, ist nicht bekannt, ganz bestimmt aber nicht dem Kopisten des genannten $\operatorname{Codex}^{490}$, da dieser das explicit mit großer Wahrscheinlichkeit von seiner Vorlage abschrieb. ${ }^{491}$ Die Zuschreibung des Titels „referendarius” an Vergerio in der Vorlage kann auf einer gesicherten Information ruhen, ihren Ursprung aber auch einfach nur in dem Wenigen haben, was man über Vergerio nach dem Konzil gewusst hat. In diesem Fall würde „referendarius” einfach dafür stehen, dass er in Sigismunds Dienst stand.

Auch Bánfi stellt fest, dass die Bezeichnung „referendarius” dafür spricht, dass Vergerio von Sigismund als Kaiser und nicht als ungarischem König eingestellt wurde. Dies kann man aber selbst ohne diesen Titel feststellen. Wenn man vom explicit ausgeht, so sieht man, dass dort der Machtträger, in dessen Dienst Vergerio beschrieben wird, als Serenissimus Imperator bezeichnet wird. Wenn man sich aber die Umstände seiner Einstellung vor Augen hält, nämlich dass er Sigismund auf dem Konzil getroffen hatte und sein Dienst bei ihm dort begann, so kann man behaupten, dass er auf jeden Fall von Sigismund als römisch-deutschem König, dem Anwärter auf den Kaiserthron, eingestellt wurde. Genau dies war nämlich die Funktion, die Sigismund als „Schirmherren” des Konzils ausweisen ließ, und nicht die Tatsache, dass er König von Ungarn war.

Laut einer Studie über Sigismunds Kanzlei verfolgte der König in der Organisation seiner Kanzlei das Ziel, sich als würdigen Nachfolger seiner Vorläufer darzustellen: „durch die Kontinuität auf der höchsten Verwaltungsebene des Reiches repräsentierte das Königtum Sigismunds als würdiges Glied in einer langen Kette erlauchter Vorläufer" ${ }^{\text {492 }}$. Die Aufnahme

488 Koltay-Kastners Standpunkt wird von Bánfi erwähnt, vgl. Bánfi, $P P V$, Teil 2, S. 16.

489 Mályusz, Zsigmond, S. 232.

490 Der Brief, nach dessen Kopie der explicit steht, Vergerios Invektive gegen Carlo Malatesta, der Vergils Statue in Mantua abreißen ließ, ist eines der programmatischen Werke des Humanismus und gleichzeitig auch eines der meist gelesenen Werke Vergerios. Der Brief ist in einem humanistischen Sammelcodex zu finden, der unter anderem Poggios De nobilitate, Lukians De amicitia in Aurispas Übersetzung, humanistische Briefe (von Poggio, von Vergerio und von einem Anonymen) und Buonaccorsis De nobilitate enthält.

491 Der Kopist kann das explicit allerdings nicht selbst geschrieben haben, da ein post quem für das Schreiben des Codex unter anderem die Tatsache ist, dass es auch eine Oratio des Salimbene enthält, die im Jahre 1444 entstanden ist. Da Sigismund 1437 gestorben und Vergerio nach seinem Tod in Buda geblieben ist, kann er um die Zeit des Schreibens des Codex unmöglich im Dienst des Kaisers gestanden sein. Die Information des explicits stammt dementsprechend von der Vorlage des Kopisten. Hier verwischen sich die Spuren, da man über keine Angaben für die Identifikation dieser Vorlage verfügt.

492 Franz-Rainer Erkens, „Über Kanzlei und Kanzler König Sigismunds. Zum Kontinuitätsproblem in der deutschen Königskanzlei unter dem letzten Luxemburger”, Archiv für Diplomatik 33 (1987): 429-458, hier S. 458 . 
Vergerios in diese Kanzlei kann auch in diesem Sinne gedeutet werden. Genauso wie Karl IV. sich darum bemühte, mit Franceso Petrarca einen Gelehrten mit gut klingendem Namen wie für seine Dienste zu gewinnen, so hat sich Sigismund bemüht, seine Kanzlei so zu gestalten, dass sie auch prominente Figuren anzog. Dass man über Vergerios Tätigkeit als „referendarius“" sonst nichts erfährt, erweckt den Eindruck, dass seine Funktion eher in der Repräsentation als im alltäglichen Urkundenschreiben bestanden hat.

Eine weitere Spur seiner Tätigkeit in Sigismunds Dienst ist ein Bericht darüber, dass er nach der Niederlage des Kreuzzugs gegen die Hussiten am 14. März 1420 in den Verhandlungen über die vier Prager Artikel eine Schlüsselrolle spielte. Er war neben Paul von Prag der offizielle Redner, der Sigismunds Seite vertreten haben soll. Die Quelle dafür ist der Rundbrief der Hussiten vom 8. Februar 1421, in dem berichtet wird, wie Vergerio - der mit seinen rednerischen Fähigkeiten auf den Verfasser des Briefes anscheinend einen großen Eindruck gemacht hat (,nescimus si doctior an eloquentior”) - einen Konsens zwischen den zwei Seiten anstrebte, indem er behauptete, von den vier Artikeln gäbe es bloß einen einzigen, über den Uneinigkeit bestünde: , ,...] in hoc conclusive resedimus, quod ex quattuor punctis nobis per eos oblatis, videlicet primo, tercio et quarto, totaliter et ex integro concordamus". Doch selbst im zweiten Punkt sei die Uneinigkeit nur partiell:

sed de secundo, qui est de comunione eucharistie omnibus Christifidelibus porrigenda, partim sumus concordes et partim discordes; concordes quidem, quod predicta communio potest quidem licite et meritorie fieri et non fieri; sed in hoc, quod sit preceptum Domini, ibi discordamus. ${ }^{493}$

Weiterhin wird Vergerio in diversen Angelegenheiten als Zeuge genannt, man findet ihn immer wieder in Sigismunds Umgebung: $1418^{494}$, am 28. Juni $1424^{495}$, am 21. Juli $1424^{496}$, am 22. März $1425^{497}$ und am 27. März $1424 .^{498}$

493 Franz Palacky, Hrsg., Urkundliche Beiträge zur Geschichte des Hussitenkrieges, 2 Bde, (Prag: Tempsky, 1873, ND. Osnabrück: Biblio-Verlag, 1966), Bd. 2, S. 491 f., zitiert von Bánfi, PPV, S. 25 f, Anm. 8. Obwohl im Text des Briefes Vergerio nur als „Petrus Paulus” bezeichnet wird, kann man davon ausgehen, dass es in der Tat um Vergerio ging.

494 In Passau: vgl. Wilhelm Altmann, Johann Friedrich Böhmer, Die Urkunden Kaiser Sigismunds (14101437), 2 Bde., Regesta Imperii 11 (Hildesheim: Olms, 1968, Nd. 1896-1900), [im Weiteren: „RI’], hier Bd. 1, S. 261 (nr. 3714).

495 In Buda, als Sigismund die Streitigkeiten zwischen Kg. Erich v. Dänemark, Schweden u. Norwegen u. den Grr. Heinrich, Adolf u. Gerhard v. Holstein entscheidet. Vgl. Altmann, RI, Bd. 1, S. 418 (nr. 5894).

496 In Visegrád, als Sigismund einen Streit zwischen dem Erzbischof von Magdeburg und der Stadt Halle löst, vgl. Altmann, RI, Bd. 1, S. 419 (nr. 5911).

497 In Tata (Totis), als Sigismund auf Veranlassung des Dr. iur. Bartholus aus Pisa („,fisci nostri imperialis procurator") den Konrad v. Weinsberg u. den Ulrich v. Helfenstein beauftragt, dass sie die Söhne des Anton v. Burgund, Johann u. Philipp, welche sich das Herzogtum Brabant angemaßt haben, peremptorisch vor seinen Richterstuhl laden; die Citationen sollen in Lüttich und Aachen angeschlagen werden. Vgl. Altmann, RI, Bd. 2, S. 12 (nr. 6199). 
Über seine literarische Tätigkeit in diesen Jahren habe ich bereits berichtet. Wenn man diese zerstreuten Informationen zusammenzählt, scheint es nicht allzu viel zu sein für die fast 20 Jahre, die Vergerio in Sigismunds Dienst in Buda verbrachte. Man kann daraus natürlich trotzdem ein Narrativ aufbauen, wie es einige ungarische Forscher versucht haben, oder wie es McManamon tut, der behauptet, selbst aus diesen Bruchstücken gehe hervor, dass Sigismund die ganze Skala der Talente eines Humanisten genutzt hatte. ${ }^{499}$ Er schließt sein Narrativ mit der Erwähnung des Glockenturms der Dominikaner Kirche in Buda, in der der Humanist begraben werden wollte. Von dieser Kirche blieb nur der erwähnte Turm erhalten und McManamon stellt fest, dass Vergerios Grab genauso verlorengegangen ist, wie viele weitere Spuren aus den Jahren seines Dienstes beim Kaiser. ${ }^{500}$ Diese letzten zwei Sätze lassen sich als eine versteckte Metapher lesen, die Vergerios Tätigkeit als eine einst bedeutende „Kathedrale“ beschreibt, die heute nur noch in ihren wenigen Ruinen zu bewundern ist. Auf diesen Umgang mit den Quellen, auf die Annahme also, dass das Wenige, das man hat, eine zu etwas Größerem zu ergänzende Ruine sei, könnte man mit den Worten eines ungarischen Literaturhistorikers, eines Kenners der ungarischen Literatur des Mittelalters antworten. Dieser formuliert seine Skepsis gegenüber der Existenz eines höfischen Registers der ungarischen mittelalterlichen Literatur wie folgt: „Ich glaube nicht an gänzlich und spurlos versunkene literarische Kathedralen." ${ }^{501}$ Der Satz bedarf natürlich einer Modifizierung, damit er auf Vergerio anwendbar sein kann: dessen Anwesenheit in Ungarn ist nicht spurlos geblieben, der Literaturhistoriker muss diese Kathedrale nicht aus dem Nichts rekonstruieren. Das Ausmaß der zu rekonstruierenden Tätigkeit Vergerios als Humanist bleibt aber weiterhin eine Frage. Auch wenn man annimmt, dass Vergerio in Sigismunds Dienst außer den schon erwähnten auch weitere Verpflichtungen hatte, denen er nachgegangen war, wäre es nicht begründet, aus diesen Details das Bild eines aktiven Humanisten rekonstruieren zu wollen.

Man kann natürlich mit Recht behaupten, dass es nicht begründet ist, zwischen Tätigkeiten, denen ein Gelehrter als Humanist, und solchen, denen er nicht in dieser Funktion nachgegangen ist, zu unterscheiden. Wenn man nämlich davon ausgeht, dass ein Humanist eher eine repräsentative Funktion am Hof hatte, dann war er nicht nur wegen seiner eigentlichen Fertigkeiten gefragt, sondern wegen seines Ruhmes als Humanist. Demzufolge kann

498 In Tata, als Sigismund den Reichständen bekannt macht, dass er über die Stadt Halle auf Klage des Erzbischofs von Magdeburg die Acht verhängt habe. Vgl. Altmann, RI, Bd. 2, S. 14 f. (6247).

499 McManamon, Vergerio, S. 153: „Despite the sketchy character of the documentary evidence, it seems clear that Sigismund sought to utilize the full range of Vergerio's talents."

500 „Today, only the Gothic bell tower of the church still stands within the enclosure of the fortress. Vergerio's grave has been lost together with much of the material evidence from his years in imperial service.": McManamon, Vergerio, S. 167.

501 Ferenc Zemplényi, Az európai kultúra és a magyar irodalom, [Die europäische Kultur und die ungarische Literatur], Historia Litteraria 4 (Budapest: Universitas, 1998), hier S. 45. (Übersetzung von Zs. K.) 
selbst seine Anwesenheit bei öffentlichen Angelegenheiten als „Dienstleistung” verstanden werden. ${ }^{502}$ Andererseits war Humanist-Sein, wie aus dem Wesen des Frühhumanismus folgt, das meine Beispiele zu erläutern suchen, am Anfang des 15. Jahrhundert kein Status, der mit einem Titel mehr oder weniger gesichert gewesen wäre, sondern ein eher labiles und kontextbezogenes als ein konstantes Merkmal eines Gelehrten. So stand man als Humanist unter ständigem Beweisdruck. Um als Humanist wahrgenommen zu werden, musste man in den für Humanisten typischen Tätigkeitsfeldern aktiv sein und mit den anderen Humanisten ständig im Gespräch bleiben. Dementsprechend ist ein Humanist, der in diesen Tätigkeitsfeldern nicht mehr aktiv ist und mit den anderen Humanisten nicht mehr in Kontakt steht, kein eigentlicher Humanist mehr, und so kann er auch seine Vorzeigefunktion nicht erfüllen. Nach diesen Überlegungen muss man also feststellen, dass das Dabeisein in diesem Fall doch nicht alles war.

Gab Vergerio während seiner Zeit in Buda diesem Beweisdruck nach? Auf Grund seiner sehr stark zurückgegangenen literarischen Produktion würde man diese Frage eher verneinen. Man kann davon ausgehen, dass wenigstens von Vergerios Briefen, wenn er mit den italienischen Humanisten weiterhin in intensivem Kontakt geblieben wäre, mehr als die zwei, die heute aus diesen 26 Jahren zu lesen sind, erhalten geblieben wären. Vergerio konnte höchstwahrscheinlich den Kontakt mit anderen Humanisten nicht mehr aufrechterhalten und man fühlt sich geneigt, Vergerio, im Gegensatz zur früher erwähnten ungarischen Forschung, nicht als Mitbegründer des Humanismus zu zeigen, sondern eher in der Rolle eines isolierten und zum Teil vergessenen gelehrten Mannes.

\subsection{Eine missglückte Repräsentation: Vergerios Übersetzung von Arrian}

\subsubsection{Die Wahrnehmung von Vergerios Übersetzung}

Es stellt sich die Frage, warum das Pflegen der Kontakte mit den anderen Humanisten so wichtig war, wenn ein Humanist schon eine Anstellung gefunden hatte. Der Humanist habe doch schon gefunden, wonach er strebte, und seine Humanistenfreunde zur Auftragssuche nicht weiter gebraucht. Er könnte jetzt in Ruhe seine Werke schreiben, diese Tätigkeit könne man schließlich auch in der Isolation absolvieren. Auf diesen Einwand kann man antworten, dass die Arbeit an der Repräsentation des Brotherren nur funktioniert, wenn sie von den

502 Wenn ein vielleicht wenig schmeichelhafter, aber einleuchtender Vergleich hier erlaubt wäre, so könnte man diese repräsentative Funktion der Humanisten mit der jener Prachtpferde vergleichen, die man nicht wegen deren praktischen Nutzen gehalten hatte, sondern um zu zeigen, dass man es sich leisten konnte, eine bestimmte Anzahl von diesen eigentlich unnützen Geschöpfen zu halten, die aber ganz bestimmten „Vorschriften” entsprechen mussten. 
anderen Humanisten, die bei anderen Machtträgern in ähnlichen Funktionen eingestellt wurden, anerkannt wird.

Eine missglückte Repräsentation kann man Vergerios Übersetzung der Alexander-Vita Arrians nennen, wobei es in diesem Fall zur Wahrnehmung der Übersetzung von Seiten der humanistischen Gemeinschaft mit einer Zeitverschiebung kam. ${ }^{503}$ Die für Sigismund angefertigte Übersetzung hat Enea Silvio Piccolomini 1454 in Österreich entdeckt. Er schickte sie als Geschenk an Alfons, den König von Neapel. Im Begleitbrief meint er, dass vom Text nur zwei Kopien gemacht worden sind, eine für sich selbst und eine andere für Parentucelli, den späteren Nikolaus V., damals Bischof von Bologna, der sich als Gesandter am Hof des Kaisers aufhielt.

Piccolomini schrieb einen anderen Brief an den Hofhumanisten des Königs Alfons ‘, Antonio Beccadelli, in dem er sich, oder besser Vergerio für das grobe Latein der Übersetzung entschuldigt. Der Grund, warum Vergerio, der sonst in einem guten Latein schrieb, in dieser Übersetzung sich weniger elegant ausgedrückt habe, sei der, dass er sein Latein an Sigismunds Lateinkenntnisse anpassen wollte, der des höheren lateinischen Stils nicht mächtig gewesen sei:

Stylus neque altus neque admodum ornatus est, quamvis esset Paulus et facundissimus et elegantissimus, sicut eius edocent cetera, que scripsit opera. Sed voluit in hoc Sigismundo Cesari morem gerere, cuius iussu Arrianum transtulit. Neque enim sermonis capax sublimioris erat Sigismundus; Paulus, ut videbis, senio confractus est et ad sepulchrum festinat. Tuum est curare magno vati et tui simili, ut exequie digne fiant. ${ }^{504}$

Bartolomeo Facio hat mit Hilfe von Niccolò Sagundino und Teodoro Gaza den Text überarbeitet. In seiner kurzen vita Vergerios erwähnt er die Übersetzung (die natürlich viel länger erörtert wird als die anderen Werke Vergerios, da es der Text war, mit dem Facio am meisten zu tun hatte):

Sigismundi Imperatoris, ut ipse scribit, rogatu, Arrianum, qui res gestas Alexandri graece scripsit, e graeco in latinum vertit, nulla tamen elegantiae cura adhibita, idque

503 Smith datiert die Übersetzung auf die Zeit nach der Kaiserkrönung Sigismunds (nach 1433) mit der Begründung, dass die Humanisten in Rom bei der Kaiserkrönung darüber auf jeden Fall hätten informiert sein müssen und den Text wenigstens kritisiert, keinesfalls aber verschwiegen hätten. Vergerio, Epistolario, S. 381, Anm. 1.

504 Rudolf Wolkan, Der Briefwechsel des Eneas Silvio Piccolomini, 4 Bde, Fontes Rerum Austriacarum, Abt. 2, 61, 62, 67, 68 (Wien: Hölder, 1909-1918), [im Weiteren: „Der Briefwechsel’], Bd. 4. S. 433., zitiert auch bei Smith: Vergerio, Epistolario, S. 380, Anm. 1. 
de industria, ut scribit, ne Sigismundus, qui parum latine sciret, interpretis opera legens indigeret. ${ }^{505}$

Ähnlich wie Piccolomini mit der entschuldigenden Begründung des schlechten Lateins, erklärt Facios Text den Mangel an elegantia ausgesprochen als Vergerios Absicht, der seine Übersetzung nach seiner eigenen Angabe, so Facio, an Sigismunds bescheidene Lateinkenntnisse angepasst habe. Der Unterschied zwischen Piccolominis und Facios Urteilen besteht darin, dass Piccolomini keine Quelle für seine Behauptung angibt, Facio hingegen die Begründung, Vergerio habe seinen Stil an Sigismunds Lateinkenntnisse angepasst, Vergerio selbst in den Mund legt (,ut scribit”).

Facio schließt seine Vita mit einer Bemerkung über den alten Vergerio, der am Ende seines Lebens verrückt geworden sein soll: „Sub extremum vitae tempus mente captus est, ita tamen, ut nonnumquam resipisceret." Smith bemerkt ${ }^{506}$, dass es für das Verrücktwerden Vergerios keine anderen Angaben gibt und dass diese Information wahrscheinlich auf Piccolominis oben zitierte Behauptung zurückgeht.

Auch in der Widmung an König Alfons V. erwähnt Facio Vergerios angebliche Bemühung, seinen Stil Sigismunds schlechtem Latein anzupassen als Grund dafür, dass die erste Übersetzung der Alexander-Vita ,inculta” sei:

Caeterum, ut a Sigismundo imperatore Romano, qui parum doctus erat, sine cuiuspiam adiumento posset intelligi (sic enim ab eo scriptum repperi), hanc historiam ita inculte de industria traduxit. ${ }^{507}$

Aus der Fortsetzung des Textes wird klar, dass diese Erklärung des angeblichen schlechten Stils der ersten Übersetzung in Facios Schrift eine ganz konkrete Funktion hat:

Sed ut ille Sigismundi voluntati, qui exiguam grammaticae, nullam eloquentiae cognitionem haberet, gerere morem studuit, sic ego tentare volui, an hic noster labor Alfonso regi omni doctrina praedito probari posset, atque ut illa prior editio Germanis incultioribus relinqueretur, haec nostratium politiorum esset. ${ }^{508}$

Das Schlechtmachen von Vergerios Stil lief in Facios Argumentation also auf einen Vergleich der zwei Könige hinaus, aus welchem selbstverständlich der König Alfons als Sieger hervorging. Das Tadeln von Sigismunds fehlenden Kenntnissen der grammatica und eloquentia

\footnotetext{
505 Vergerio, Epistolario, S. 483.

506 Vergerio, Epistolario, S. 483, Anm. 1.

507 Der Text von Facios Widmung an den König Alfons wurde veröffentlicht in Philip A. Stadter, „Arrianus”, in Catalogus Translationum et Commentariorum: Mediaeval and Renaissance Latin Translations and Commentaries, hrsg. v. F. Edward Cranz, Virginia Brown und Paul Oskar Kristeller (Washington D. C.: The Catholic University of America Press, 1960-, 1976), Bd. 3, 1-20, [im Weiteren: „Arrianus”], hier S. 8. 
stellt eine Vergleichsfolie dar, vor der Alfons als ein „rex omni doctrina doctus” dargestellt werden kann.

\subsubsection{Vergerios Widmung an Sigismund}

\subsubsection{Der Widmungsbrief als Sigismunds Lob}

Es ist unumgänglich, Facios Worte über die absichtliche Anpassung an Sigismunds schlechtes Latein mit dem Widmungsbrief Vergerios zu konfrontieren, auf den sich Facios Bemerkung bezieht. Die Stelle, in der es um Vergerios Überlegungen über den anzuwendenden Stil geht, befindet sich am Ende seines Widmungsbriefes:

Qua in re licere michi sum arbitratus, tibi vero non futurum ingratum certus sum, si plano ac pene vulgari stilo sensus tantum, non verba transferrem, ut, eo nunc primum e Grecia redeunte et externa narrante, a Latinis quibusque vel indoctioribus rerum gestarum tenor possit agnosci. Ornatum autem orationis et dicendi elegantiam, quibus ille vel in aliena lingua plurimum eminet, si quis forsitan cum rerum notitia pariter desiderat, ea non a me, alieni sermonis interprete, sed ab ipso historie auctore et conditore requirat. ${ }^{509}$

Wie aus diesen Zeilen hervorgeht, beurteilt Vergerio die Lateinkenntnisse seines Auftraggebers keineswegs als gering. Es wäre eigentlich auch wenig angebracht gewesen, weil gegen die Regeln und die Logik des Genres, in einem Widmungsbrief zu behaupten, dass man seinen Text deswegen auf einem niedrigeren Sprachniveau verfasst hat, damit das Werk dem Auftraggeber trotz seines schlechten Lateins und ohne Übersetzer verständlich sei (,de industria, ut scribit, ne Sigismundus, qui parum latine sciret, interpretis opera legens indigeret"). Vergerio habe nach seiner Angabe den Sinn und nicht die einzelnen Wörter wiedergeben wollen, damit der Sinn auch für die Latini und auch für diejenigen, für die vielleicht die Geschichte nicht bekannt ist, verständlich werde. Entweder hat Facio den Absatz nur flüchtig durchgelesen und so ist für ihn aus den Wörtern „latinis”, ,indoctioribus” und später „interprete” unter dem Eindruck von Piccolominis Bemerkung ein neuer Sinn dieser Zeilen entstanden, oder es handelt sich um eine bewusste Verschiebung dessen, was er gelesen und richtig verstanden hatte.

Für ersteres, also für seine Unaufmerksamkeit, spricht, dass er bei dem Schreiben der kurzen vita des Vergerio nicht den Anschein erweckt, er sei seinen Behauptungen in jedem Fall penibel nachgegangen und hätte diese dann nach strengen Prinzipien geordnet: nicht nur die Erwähnung von Vergerios angeblichem Verrücktwerden scheint unbegründet zu sein, sondern auch die Behauptung, Vergerio habe mit seiner „Invektive” erreichen können, dass die

509 Vergerio, Epistolario, S. 383 f. 
Statue Vergils wieder hergerichtet worden sei („Carolum Malatestam invectus, Virgilii statua, quam ille Mantue in foro everterat, quoniam gentilis fuisset, ut ibidem restitueretur, effecit." ${ }^{210}$ ), entspricht nicht der Wahrheit. Weiterhin folgt seine Auflistung von Vergerios Werken keinen chronologischen Richtlinien und auch keinem anderen logischen Ordnungsprinzip. ${ }^{511}$

Vergerio hat Sigismund keinesfalls mit einer Unterstellung von fehlenden Sprachkenntnissen beleidigt. Er hat seinen Auftraggeber sogar gelobt und ihm geschmeichelt: es sei Sigismunds Befehl gewesen, Arrian übersetzen zu lassen, ein Werk, das im Gegensatz zu den vielen anderen Schriften über Alexander den Großen auf sicheren Quellen basiere und deswegen glaubwürdig sei: „quod Arrianus in eis describendis certiores secutus sit auctores, atque ideo fide dignus videatur" ${ }^{\prime 2}$. Die Konjunktivform neben dem „,quod” deutet darauf hin, dass es um die Wiedergabe der Behauptungen von einem anderen - in diesem Fall Sigismunds - geht. Damit wird die Begründung der Wahl von Arrian Sigismund zugeschrieben, und die oft als „typisch humanistisch” verstandene kritische Einstellung gegenüber den Quellen in den König projiziert. Ob man diese Zuschreibung wörtlich nehmen darf und wirklich glauben kann, dass sich Sigismund über die von Vergerio genannten Qualitäten Arrians als vertrauenswürdigen Geschichtsschreiber im Klaren war, ist nicht ganz sicher. Wahrscheinlich handelt es sich eher um die Konsequenzen der Logik der Widmungen, nach deren Regel der Autor die Initiative dem Auftraggeber zuschreibt, was die Möglichkeit bietet, den Auftraggeber für seinen Kenntnisreichtum zu loben. ${ }^{513}$ Dies geschieht auch in Vergerios Brief. Auf den Satz im Konjunktiv folgt eine Typologie der Schriften über Alexander, von denen viele eher in die Kategorie von fabula fallen:

Nam ex ceteris quidem historie scriptoribus, qui multi fuerunt multumque sibi invicem dissonantes, aliqui, vulgarem famam secuti, non que gessit Alexander, sed que de eo passim ferebantur, ea tanquam vere gesta conscripserunt. Alii favore gentis et domestice glorie studio in enarrandis ad laudem eius operibus modum excesserunt. Nonnulli e contra, odio vel invidia, sive ut aliis morem gererent, qui tanti nominis splendore offendebantur, detrahere rebus gestis conati sunt; quidam insuper, privatim ambitione querendi nominis et proprie laudis cupiditate, non quid

$510 \quad$ Vergerio, Epistolario, S. 483.

511 Es werden drei Werke des Humanisten erwähnt: erst das „De ingenuis moribus” von 1402-1403, wahrscheinlich weil diese seine bekannteste Schrift war, auf diese folgt seine Arrian-Übersetzung aus seiner Zeit in Buda, die ihre Erwähnung gleich nach dem „De ingenuis moribus” wohl dem bereits angedeuteten persönlichen Motiv zu verdanken hat. Die 1397 verfasste „Invektive” gegen Carlo Malatesta wird an der dritten Stelle genannt. Obwohl man gegenüber dem Autor der Vita selbstverständlich keine Erwartungen hinsichtlich einer strikten chronologischen Ordnung hegen darf, es hätte aber aus der Logik der Darstellung folgen können, dass er das späteste Werk Vergerios an der letzten Stelle erwähnt hätte, unmittelbar vor der Behauptung, er sei am Ende seines Lebens verrückt geworden.

512 Vergerio, Epistolario, S. $381 \mathrm{f}$.

513 Dementsprechend kann man die Richtigkeit des Begriffes „Auftraggeber” hinterfragen. 
gestum ab eo fuerit, sed quid decore de illo scriptum memorie posterorum mandari posset, hoc solum extimaverunt; nec tam veritatem rerum quam figmentorum lenocinium amplexi sunt. Atque hec tanta scribentium varietas perplexitatem legentibus afferre non modicam consuevit, cum essent incerti quibusnam fidem adhiberi pre ceteris conveniret, et fabulasve an historiam veram legerent. ${ }^{514}$

Selbst diese Typologisierung impliziert ein Lob Sigismunds, der, weil er Arrian genau lesen wolle, alle die Leser (und damit viele Herrscher), die sich mit den Schriften von mangelnder Vertrauenswürdigkeit zufriedengeben, übertreffe. Nach diesen Vorbereitungen kommt Vergerio zur offenen Würdigung des Königs:

Tu igitur hinc adductus, ea que Arrianus de gestis Alexandri scripsit tanquam veriora cupis agnoscere, laudandus profecto, sive quia veritati studes, que rebus omnibus preferenda est, sive quod historie notitia tantopere delectaris, ut domesticis non contentus etiam externa requiras. ${ }^{515}$

Mit dem Wort „hinc” fasst der Autor zusammen, was er in den vorigen Sätzen über die fragwürdige Wahrhaftigkeit der sonstigen Schriften über Alexander geschrieben hat und stellt seine Ausführung als Sigismunds Überlegung bei der Wahl von Arrians Text dar. Der König sei wegen seiner Bemühung um die Wahrheit und auch deswegen zu loben, weil er außer den römischen auch die „fremden” Beispiele der Geschichte kennenlernen wolle.

Decet autem omnes homines, sed eos precipue, qui magnis administrationibus presunt, ad utrunque conari laborareque summo studio, ut sciant se quidem inprimis; deinde, si quibus forte est in alios imperium, etiam subditos optimis rationibus regere, ac per honestas delectationes, quantum fieri potest, sine molestia vitam agere; te vero ante omnes, qui in supremo rerum culmine constitutus es, et qui magna semper animo volvis, curare convenit Alexandri Magni opera, que haud dubie magna fuerunt, certius agnoscere, et que ex eis digna sunt laude, ea non tam palpitando sectari velle, quam percurrendo superare. ${ }^{516}$

Der Bogen dieses Abschnittes geht vom Gedanken aus, dass sich jeder Mensch selbst erkennen solle, besonders aber diejenigen, die Machtträger sind, und dass diese sich um beides kümmern sollten: um die Untertanen und darum, dass sie selbst durch würdevolle Vergnügungen ein möglichst unbeschwertes Leben führen. Für Sigismund aber, der die oberste Position bekleidet und immer etwas Großes vorhat, sei es ganz besonders günstig, die Taten Alexanders kennenzulernen, damit er diese nicht einfach nur nachahmen, sondern sogar überflügeln möge. Der ursprüngliche Gedanke wird von der absoluten Allgemeinheit (,omnes homines”) über die Zwischenblendung einer „mittleren” Etappe (,qui magnis

\footnotetext{
514 Vergerio, Epistolario, S. 382.

515 Vergerio, Epistolario, S. 382 f.

516 Vergerio, Epistolario, S. 383.
} 
administrationibus presunt”) ganz genau auf Sigismund (,te vero ante omnes, qui in supremo rerum culmine constitutus es") präzisiert. Gleichzeitig zu dieser allmählichen Präzisierung, die schon an und für sich eine Steigerung bedeutet (allgemein vom Menschen bis zum obersten Haupt des Reiches), beinhalten diese Zeilen eine Steigerung auf einer anderen Ebene: vom sich Kennenlernen („ut sciant se quidem inprimis”), über das Kennenlernen der Taten des Alexander („Alexandri Magni opera [...] certius agnoscere”) mit der Erwähnung einer gleichzeitig auch auszuschließenden Etappe der Nachahmung dieser Taten (,ea non tam palpitando sectari velle”) zu deren Überflügelung (,ea [...] percurrendo superare”). Der Abschnitt erweist sich als ein durchdachtes Bauwerk. Innerhalb von wenigen Sätzen gelangt der Leser von einer verallgemeinernden Bemerkung über Selbsterkenntnis bis zum schmeichelhaften Aufruf des Kaisers, die Taten Alexanders des Großen, die viele Jahrhunderte hindurch als Lesestoff galten, zu überflügeln. Dass eine solche Ermunterung als ein Topos zu verstehen ist, nimmt nur wenig von der Bedeutung dieser Worte.

\subsubsection{Vergerios Selbstlob in seinem Widmungsbrief und der Topos des Humanisten als Retter der Kulturgüter}

Vergerio lobt aber nicht nur den Kaiser. Sein Brief enthält auch Elemente, die eindeutig als Selbstlob zu deuten sind. Den zweiten Teil des Briefes widmet der Humanist seiner eigenen Rolle als Kulturvermittler. Gleich nach dem den König feiernden, mit dem Wort „superare” endenden Absatz folgen diese Sätze:

Sed et michi quoque non est visum alienum, preter causas alias, que me ad hoc vel impulerunt vel coegerunt; nam, te quidem iubente, necesse erat parere; ut in honorem quoque scriptoris, qui Latinus fuit, laborem hunc non invitus assumerem, et que de rebus Grecorum grece scripsit, in latinum Latinus transferrem, illumque tibi traditum et michi per te commendatum, Latinis vero prorsus incognitum, tandem quasi longo postliminio in patriam revocarem, et suis utcunque darem agnoscendum. $^{517}$

Die Kulturvermittlung, die Adaptation literarischer Formen, wird bei Horaz nach einer überzeugenden Interpretation des Carmen III. 30 als ein Triumphzug gedeutet, in dem die Güter (die griechische Lyrik, durch die Adaptation der griechischen lyrischen Versmaße an die lateinische Sprache) der anderen Kultur zu eigen gemacht werden:

Dicar, qua violens obstrepit Aufidus / et qua pauper aquae Daunus agrestium/ regnavit populorum, ex humili potens, / princeps Aeolium carmen ad Italos /

517 Vergerio, Epistolario, S. 383. 
deduxisse modos. Sume superbiam / quaestam meritis et mihi Delphica / lauro cinge volens, Melpomene, comam. ${ }^{518}$

Selbst wenn Vergerio hier keine ausgeprägte Metapher der Militärsprache benutzt, lässt sich der Ausdruck ,postliminium” auch nicht ganz neutral deuten. In der Rechtssprache ist postliminium, oder ius postliminii das Recht, nach dem der römische Staatsbürger, wenn er in die Gewalt von Staatsfeinden gefallen war, nach seiner Rückkehr seinen alten Rechtsstand wiederbekommen hat. Im weiteren Sinne bedeutet postliminium die Wiederkehr in die eigene Heimat. In Richard de Burys Philobiblon wird das Wort in Bezug auf Bücher verwendet. Im Kapitel „Querimonia librorum contra bella” schreibt der Autor über die Rückkehr der Bücher nach Athen, die Xerxes nach Persien mitgenommen hatte: „O postliminium graciosum!”519 Die Anwendung des Wortes im Kontext einer Büchermetapher hat also ihre Vorgeschichte. In Vergerios Brief kann das Wort aber unmöglich „Wiederkehr” bedeuten: das Adjektivum, das mit dem Ablativ „postliminio” steht, ist „longo”. Man kann davon ausgehen, dass das „longum” sich hier nicht auf die Rückkehr, sondern auf die Abwesenheit beziehen lässt. ${ }^{520}$ Unabhängig davon, wo man den Ursprung der neuen Bedeutung des Wortes für das Gegenteil, das heißt für die Zeit der Abwesenheit, suchen soll, kann man feststellen, dass das Wort im humanistischen Kontext oft diese neue Bedeutung hat. Vergerio ist nämlich nicht der einzige Humanist, der das Wort in diesem Sinn und auf Bücher bezogen benutzt: Der bereits zitierte (Anm. 185) Brief Barbaros an Poggio, in dem er den Humanisten wegen seiner Entdeckungen während seines Aufenthaltes auf dem Konzil feiert, benutzt exakt das gleiche Syntagma für die Abwesenheit der Bücher, die endlich in ihre Heimat wiederkehren durften: „Tu Tertulianum, [...] tu compluros alios, Bartholomeo collega tuo adiutore, vel fato functos

518 Hor. Carm. 3. 30. Die Interpretation der letzten Zeilen des Gedichtes als eine Beschreibung des literarischen Triumphzuges des Dichters beruht auf dem Verständnis des Wortes „deducere”. István Borzsák argumentiert in seiner Studie mit Verweis auf die Testimonia des Thesaurus Linguae Latinae (Leipzig, Teubner, 1900-), [im Weiteren: „ThLL”] und auf mögliche Parallelstellen (Georg. 3. 10f), die für Horaz wahrscheinlich als Modell für sein Bild des Dichtertriumphes gedient haben, dass man „deducere” hier als „im Triumphzug als Kriegesbeute zu führen” übersetzen sollte. Nach Borzsáks Interpretation soll man dieses das Gedicht krönende Bild folgendermaßen verstehen. Der Dichter offeriert als sieghafter Heerführer nach seiner Kriegstat (die Entdeckung und Eroberung des aiolischen Liedes) seine wohlverdiente, stolze Beute statt auf dem Capitolium im Tempel des Jupiter, der Muse Melpomene. Vgl. István Borzsák, „Exegi Monumentum Aere Perennius...”, Antik Tanulmányok 11 (1964): 49-56. Bei Origenes und Augustinus findet man das christliche Pendent zu dieser Vorstellung: nach der typologischen Deutung einer Stelle von Exodus 3, 21-23 dürfen sich die Christen die Lehren der paganen Philosophie auf ähnliche Weise aneignen, wie die Israeliten bei dem Auszug aus Ägypten die Schätze der Ägypter mit sich genommen hatten. Origenes benutzt dieses Bild öfter in seinen Schriften. Das bekannteste Beispiel befindet sich im zweiten Kapitel seines Briefes an Gregor den Wundertäter: Orig. ep. Ad Greg. Thaumat. 2. Augustinus übernimmt diese typologische Deutung des Exodus 3, 21-23: Aug. doct. christ. 2, 60.

519 Riccardo da Bury, Philobiblon, hrsg. v. Antonio Altamura (Neapel: Fausto Fiorentino Libraio, 1954), S. 98.

520 Der ThLL liefert zwei Testimonia, die das Wort in diesem Sinne (,ipsum tempus peregrinationis vel intermissionis" benutzen: Hier. Epist. 128, 5, 4 quae ut ...post neces amicorum ... senex longo -o scriberem; vita Malchi 4 1. - o hereditarius possessor [is qui diu monachus fuit, sed nunc hereditatem adire vult]. Vgl. ThLL, Bd. 10, 2, Fasc. 2, S. 236. 
vita donastis vel longo, ut aiunt, postliminio in Latium reduxistis. "521 Als ein weiteres Beispiel für den humanistischen Nutzen des Wortes „postliminio” kann ein Brief Poggios gelten, in dem er sich über den Kardinal Giordano Orsini ärgert, weil dieser ihm einen Plautuscodex nicht ausleihen will:

Plautum hactenus non potui habere, nunc si possem, nollem, polliceorque tibi me nunquam amplius petiturum a cardinali, neque lecturum illum istis tribus annis etiam si ultro concederetur. Transcribitur modo, donoque mittetur duci Mediolani, qui eum per litteras postulavit. Marchio item Ferrariensis petiit; dabitur illis, sed ita corruptus, ut vere a barbaris redire postliminio videatur. Cui homo noster tanquam triumphi honorem ex hoc libro, ac si ipse illum suo studio aut impensa reperisset. ${ }^{522}$

Um Vergerios Übersetzung einen Schritt näher zu kommen, kann man ein weiteres Beispiel für das Benutzen des Wortes aus dem Bereich von Übersetzungen aus dem Griechischen nennen. Barbaro meint im Vorwort zu seiner Übersetzung der Aristides-Cato-Doppelvita des Plutarch im Jahr 1416 folgendes: ,et Catonem illum gravissimum longo, ut aiunt, postliminio ad nostros homines reducere mihi licuerit". 523

Italienische Humanisten haben Übersetzungen aus dem Griechischen oft als eine Rückkehr der Werke (oder noch besser: „Zurückführung”, die Humanisten haben ja ihre eigene Rolle in diesem Prozess betont) in ihre eigentliche Heimat dargestellt. Diese Strategie konnte mit verschiedenen Gründen legitimiert werden. Barbaro konnte seine Plutarch-Übersetzung wegen des Themas der Schrift (das Leben Catos) als eine Zurückeroberung darstellen. Die andere Strategie Barbaros für die Hervorhebung seiner Rolle als eines „Rückeroberers" einer Schrift für die Latini ist die Betonung der Tatsache, dass die griechische Schrift einmal schon ins Lateinische übersetzt wurde, diese Übersetzung aber verlorengegangen ist. Bruni sagt bei der Behandlung von Ciceros Schriften und Übersetzungen in seinem Cicero novus in einer kurzen Bemerkung über seine eigenen Übersetzungen von Demosthenes und Aeschines: „quae cum apud nostros negligenter custoditae iampridem ex Italia tamque peregrinae alienaeque aufugissent, nos Ciceronem imitati eas ex Graecia in Latinum nostra manu reduximus." ${ }^{24}$ Es scheint vielleicht übertrieben, eine lateinische Übersetzung eines griechischen Textes aus diesem Grund als Rückkehr darzustellen. Diese etwas willkürliche Begründung ist ein Zeichen dafür, dass der Topos der „Rückkehr” der

Vgl. Anm. 185.

$522 \quad$ Poggio, Lettere, Bd. 1, S. 97.

523 Joseph Smith, Bibliotheca Smithiana: seu catalogus librorum D. Josephi Smithii Angeli per cognomina authorum dispositus (Venedig: Typis Jo. Baptistae Pasquali, 1755). S. 335.

524 Auszüge aus dem „Cicero novus” wurden veröffentlicht von Hans Baron: Leonardo Bruni Aretino, Humanistisch-philosophische Schriften. Mit einer Chronologie seiner Werke und Briefe, hrsg. v. Hans Baron (Berlin, Leipzig: Teubner, 1928), ND, Wiesbaden: M. Sandig, 1967 [im Weiteren: „Schriften”], S. 113120, hier S. 116. 
Werke so verbreitet war, dass man ihn auch in Fällen anzuwenden versuchte, in denen die Metapher eigentlich nicht so richtig funktionieren konnte. Die große Verbreitung dieses Bildes ist wiederum möglicherweise auch als ein Ausdruck von Überlegenheitsgefühlen der lateinischen Seite gegenüber den Griechen zu verstehen, welche andererseits wahrscheinlich als Kompensierung von Minderwertigkeitskomplexen zu sehen sein könnten. Neben den üblichen vorurteilsgeladenen griechenfeindlichen Gemeinplätzen findet man bei den Humanisten oft auch Selbstverteidigungen gegenüber der möglichen Kritik, Latein sei im Vergleich mit dem Griechischen eine ärmere Sprache. ${ }^{525}$

In Barbaros und Poggios Fall funktioniert die Metapher mit der Rückkehr der Bücher und Autoren problemlos, weil sie über lateinisch schreibende Autoren oder über eine römische Persönlichkeit (Cato) schreiben. Vergerio musste, wenn er das gleiche Bild verwenden wollte, seinen Arrian als latinus verkaufen, und da er auf das Bild von sich als siegreichem Heerführer, der Schätze, die seit langer Zeit in der Fremde waren, wieder dorthin zurückführt, wo sie ursprünglich hingehören, nicht verzichten wollte, hat er Arrian in seiner Darstellung in der Tat zum latinus gemacht. ${ }^{526}$ So kann Vergerios Übersetzung ein viel größeres Gewicht beigemessen werden. Ein latinus wird den Lateinern zurückgegeben, indem er in seine eigentliche Heimat zurückgerufen wird.

Wenn man davon ausgeht, dass Vergerios Vorlage eine Abschrift von Aurispas Exemplar war, was sehr wahrscheinlich ist, da Aurispas Handschrift die erste heute bekannte Arrian-Handschrift ist, die nach Europa gebracht wurde, dann begann die Geschichte der „Rettung” Arrians bereits mit Aurispas Reise nach Konstantinopel im Jahr 1426. ${ }^{527}$ Aurispas Sammelwut darf man wahrscheinlich nicht so unpolitisch interpretieren, wie es oft doch geschieht, beziehungsweise wäre es durchaus sinnvoll, Aurispas Büchererwerbung in ihrem historischen Kontext zu sehen. ${ }^{528}$ In seinen Briefen sind die zwei Themen, die Situation in Konstantinopel einerseits und die von ihm erworbenen Klassiker andererseits, gar nicht so scharf voneinander getrennt. Im selben Brief, in dem er über seine Schätze berichtet, be-

525 Vgl. zum Beispiel Brunis an Salutati gerichtete Praefatio zu seiner Übersetzung von Plutarchs Vita des Marcus Antonius, die praktisch eine Verteidigungsschrift der Übersetzungsarbeit und der lateinischen Sprache ist. Der Text wurde veröffentlicht in Barons Ausgabe von Brunis kleineren Schriften: vgl. Bruni, Schriften, S. 102-104.

526 Der Grund dafür könnte die Tatsache sein, dass er römischer Staatsbürger war, wie auch Smith in seiner Fußnote bemerkt. Vgl. Vergerio, Epistolario, S. 383, Anm. 1.

527 Vgl. Stadter, Arrianus, S. 3.

528 Eine kurze Beschreibung der Reisen Aurispas nach Konstantinopel findet man in: Peter Schreiner, „Giovanni Aurispa in Konstantinopel. Schicksale griechischer Handschriften im 15. Jahrhundert”, in Studien zum 15. Jahrhundert. Festschrift für Erich Meuthen, 2 Bde., Hrsg. v. Johannes Helmrath und Heribert Müller (München: Oldenbourg, 1994), Bd. 2. S. 623-33. Der Klassiker Sabbadini erwähnt auch Aurispas Arrian: Remigio Sabbadini, Le scoperte dei codici latini e greci ne'secoli XIV e XV, 2 Bde. (Florenz: Casa Ed. Le lettere 1905-1914, ND Florenz 1967), hier Bd. 1, S. 46. 
schreibt er auch die Situation in der Hauptstadt von Byzanz: „dubium est an Turci urbem illam regiam capiant; id brevissime, utinam fallar, meo arbitratu fiet, ni Deus, ut solet, aliquid insperatum miserit." ${ }^{, 529}$ Aurispa scheint aber die Möglichkeit, sich als Retter der von den Türken bedrohten Schätze darzustellen, nicht genutzt zu haben. Trotzdem kann man annehmen, dass das Erwecken des Interesses an der griechischen Kultur und Sprache nicht ganz unabhängig von den zeitgenössischen Machtverhältnissen zu sehen ist: ${ }^{530}$ Chrysoloras, bei dem die Humanisten Griechisch gelernt haben, hatte in Italien neben seinen Lehrtätigkeiten auch diplomatische Aufgaben für Kaiser Manuel II. Palaiologos zu erfüllen, der sich in dieser Zeit bemüht hatte, für Byzanz Geld und Verbündete gegen die Türken zu sammeln. ${ }^{531}$ Das Thema,

529 Giovanni Aurispa, Carteggio, hrsg. v. Remigio Sabbadini (Rom: Tipografia del Senato, 1931), 10-15, hier S. 13.

530 Die Sekundärliteratur, die sich mit dem Zusammenhang zwischen dem Thema „Türkengefahr” und dem Humanismus beschäftigt, fokussiert meistens auf die Zeit nach dem Fall Konstantinopels am 29. Mai 1453, da der Diskurs seine Konturen verständlicherweise seit diesem Zeitpunkt erhalten hatte. Im Folgenden argumentiere ich jedoch dafür, dass dieser Diskurs selbstverständlich nicht aus dem Nichts entstanden ist. James Hankins befasst sich in seiner Studie mit der Frage, was das Spezielle an der humanistischen Kreuzzugsliteratur und den traditionellen Kreuzzugsschriften ist. Neben einer Kontinuität der alten Themen stellt er das Auftauchen neuer Elemente des Türkendiskurses fest, wie unter anderem eine neue Stereotypisierung, die die Türken statt in einer religiös fundierten Dichotomie vielmehr mit Hilfe der von der Antike geerbten Dichotomie von zivilisiert vs. barbarisch dargestellt haben. Vgl. James Hankins, „Renaissance Crusaders. Humanist Literature in the Age of Mehmed II.”, Dumberton Oaks Papers 49 (1995): 111-207. Meine Beispiele liefern einen Beweis dafür, dass die Verknüpfung der Diskurse (der alten Gegenüberstellung von barbarisch und zivilisiert und des Themas „Türkengefahr”) sich schon früher ereignet hatte, als in der zweiten Hälfte des 15. Jahrhunderts. Da die Sekundärliteratur zum Thema sehr reich ist und deren Erörterung den Rahmen dieses Unterkapitels sprengen würde, verweise ich hier auf die Studie von Johannes Helmrath, die außer seinem im Titel angekündigten Thema einen tieferen Einblick in das Thema im Allgemeinen ermöglicht und die dafür die weiterführende Literatur angibt. Vgl. Johannes Helmrath, „Pius II. und die Türken”, in Europa und die Türken in der Renaissance, hrsg. v. Bodo Guthmüller und Wilhelm Kühlmann (Tübingen: Max Niemeyer Verlag, 2000), 79-137. Ein anderer Kontext für das Thema dieses Unterkapitels ist die Geschichte der Griechischstudien in Italien im frühen 15. Jahrhundert. Die Sekundärliteratur dazu ist erstaunlicherweise etwas reicher, als man es vielleicht hoffen würde. Neben den (später teilweise auch zitierten) Artikeln zu den einzelnen Personen oder Detailfragen vermisst man jedoch eine zusammenfassende Erörterung des Themas, die aber über die Auflistung der biografischen Details der einzelnen Humanisten und deren Übersetzungen aus dem Griechischen hinausgeht und das Phänomen in seinem politischen Kontext eingebettet erörtert. Roberto Weiss' Behauptung über das Fehlen einer übergreifenden, vollständigen Geschichte der Griechischstudien im Europa des Mittelalters kann auf die Geschichte derselben Studien im Humanismus übertragen werden. Vgl. Roberto Weiss, „Greek in Western Europe at the End of the Middle Ages”, in Medieval and Humanist Greek, ders. (Padua: Antenore, 1977), 3-12, [im Weiteren: „Greek”], hier S. 4. Ein Beispiel für einen neueren Versuch, Griechischstudien der Humanisten monografisch darzustellen, ist Wilsons Buch: Nigel Guy Wilson, From Byzantium to Italy. Greek Studies in the Italian Renaissance (London: Duckworth, 1992). Da aber Wilson eine lange Periode in einer vergleichsmäßig kurzen Darstellung zu beschreiben versucht (seine Geschichte fängt mit Petrarca an und endet mit Marcus Musurus in der Mitte des 16. Jahrhunderts), ist er gezwungen, sich auf eine Wiedergabe der Grundinformationen zu beschränken. Es wäre vielleicht sinnvoll, dem Phänomen mit Hilfe des Modells des Kulturtransfers nachzugehen und über die Motivationen der Aneignung griechischer Kulturgüter von lateinischer Seite und der Übergabe von griechischer Seite, über die Transformationen, die die vermittelten Kulturgüter erlebten, sowie über deren Funktion im neuen Kontext nachzudenken. Weiss gibt in seinem Artikel eine knappe Zusammenfassung des Themas, in der auch die Motive dieser Studien entsprechend kurz ausfallen: „Sometimes it was a question of geography and sometimes a question of politics." Weiss, Greek, S. 3.

531 Für eine moderne Biographie über Chrysoloras vgl. das schon zitierte Buch von Lydia Thorn-Wickert (Anm. 136). Die Autorin unternimmt eine Korrektur der mythisierenden Darstellungen der Rolle des Chrysoloras in Italien. 
dass er bei seiner Werbung für griechische Literatur den Hintergedanken gehabt haben könnte, gleichzeitig auch die Aufmerksamkeit Europas auf die Notwendigkeit des Rettens von all den Schätzen dieser Kultur vor den „Barbaren” zu erwecken, wurde in der Sekundärliteratur des Öfteren angesprochen. Obwohl die politische Agenda hinter Chrysoloras' Lehrtätigkeit plausibel scheint, konnte sie nicht mit Quellen belegt werden, die auf eine solche Verknüpfung der zwei Ziele eindeutig hinweisen würden. ${ }^{532}$ In der italienischen Perzeption waren jedoch die Bedrohung, die die „Barbaren” darstellten, und die Figur von Chrysoloras als Retter der Kulturgüter einer bedrohten Zivilisation präsent. Vergerio schreibt in einem Brief an einen unbekannten Florentiner über den Griechischlehrer ganz in diesem Sinne. Er lobt die Stadt des Adressaten wegen der Griechischstudien, die in seiner Stadt blühten, und hebt dabei die Verdienste von Chrysoloras auf diesem Gebiet hervor, so dass der Brief über Florenz eigentlich eine Lobschrift Chrysoloras' wird. Die Stadt Florenz habe das Lob verdient, weil sie durch die Einladung von Chrysoloras nicht nur die griechischen Disziplinen wiederbelebt habe, sondern sogar die griechische Sprache und „Griechenland” selbst vor dem Untergang gerettet habe:

Qua quidem in re non tam, quod disciplinas Grecorum olim nostris maioribus familiares ad pristinum usum revocare visa est, laudem merebatur; quanquam esset tunc ea laus sibi propria soli; sed quod grecas litteras, imo vero Greciam ipsam pereuntem salvari, quo modo licebat, propagarique apud nos curavit. ${ }^{533}$

532 Ian Thomson, „Manuel Chrysoloras and the Early Italian Renaissance”, Greek, Roman and Byzantine Studies 7 (1966): 63-82, [im Weiteren: „,M. Chrysoloras”]. Der Autor begründet auch Chrysoloras' vorzeitige Unterbrechung seiner Lehrtätigkeit in Florenz damit, dass er es eingesehen habe, dass er dort doch nicht die Hilfe für sein Land finden konnte, die er sich erhofft habe (Thomson, M. Chrysoloras, S. 79). Er spekuliert sogar über die Gründe von Chrysoloras' Anwesenheit auf dem Konzil von Konstanz und hält es für vorstellbar, dass er mit der Hoffnung hingefahren sei, zum Papst gewählt zu werden, was die Annäherungsversuche der griechischen Kirche an Rom hätte fördern können (Thomson, M. Chrysoloras, S. 81). Der von Thomson zitierte textuelle Beweis für seine (durchaus plausible) These (Andrea Zulians Totenrede auf Chrysoloras) ist eher ein Beweis für die zeitgenössische Wahrnehmung von Chrysoloras' Lehrtätigkeit. Hankins zitiert einen weiteren Beweis, den Brief, den der griechische Gelehrte an Uberto Decembrio geschrieben hatte, in dem er als Grund seines Aufenthaltes in Italien die Hilfeleistung für seine Heimat nennt. Auch gegen diesen Beweis könnte man ins Treffen führen, dass es im Brief nicht um den Zusammenhang der Lehrtätigkeit von Chrysoloras und seiner politischen Mission geht, sondern um den Grund von Chrysoloras' Aufenthalt in Italien. Hankins nennt aber weitere Argumente für seine These: die Auswahl der Schriften, die Chrysoloras mit seinen Schülern gelesen hatte (die Tatsache, dass er zum Beispiel keine Dichtung unterrichtete, weil diese wegen der starken Präsenz mythologischer Themen die lateinischen Vorurteile gegenüber den Griechen hätte bekräftigen können), soll auch für seine politischen Hintergedanken sprechen. Nach Hankins' Meinung war Brunis Motivation in seinen Griechischstudien und Übersetzungen eine andere, und zwar eine typisch „lateinische”: anstatt die griechischen Autoren für sich selbst, als griechische Literatur zu lesen, hat er sie dazu benutzt, die römische Geschichte (also die italienische Vergangenheit) besser kennenzulernen und glorifizieren zu können. Vgl. James Hankins, „Manuel Chrysoloras and the Greek Studies of Leonardo Bruni”, in Humanism and Platonism in the Italian Renaissance, 2 Bd., Storia e letteratura 215, 220, ders. (Rom: Edizioni di Storia e Letteratura, 2003), Bd. 1, 243-66.

533 Vergerio, Epistolario, S. 244. 
Dass „Griechenland” von den Barbaren bedroht wird, wird an einer anderen Stelle des Briefes noch einmal angesprochen. Vergerio bemerkt, dass es schön wäre, wenn das Schisma beseitigt und das Papsttum Reformen unterzogen würde, damit Chrysoloras in Italien einen Ort finden könnte, der ihm würdig sei. Es sei peinlich, dass Chrysoloras, obwohl er „latinus” sein wolle, nicht nur Grieche bleibe, sondern ihm sogar Gefahr drohe, von den Barbaren gefangen genommen zu werden:

pudet tamen interea quod, cum cupiat esse Latinus, cogitur non tam Grecus perseverare quam perpetuo periculo subesse ne barbaris forsitan captivus fiat. Is est illarum partium status. 534

Interessant ist die implizite Bewertung des Griechentums als minderwertig gegenüber den Lateinern. Die unmittelbare Verknüpfung dieser Bewertung mit dem Thema „gefährliche Verhältnisse in Byzanz" suggeriert einen Zusammenhang zwischen den Vorurteilen gegenüber den Griechen und den Verhältnissen in Byzanz: die Griechen scheinen wegen ihrer Nähe zu den „Barbaren” von deren schlechtem Ruf etwas abzubekommen. Dass auf der in Vergerios Text implizierten Skala „Lateiner - Griechen - Barbaren” die Griechen näher bei den Barbaren stehen als die Lateiner, folgt vielleicht aus deren geografischer Nähe zu den Letzteren. ${ }^{535}$ An dieser impliziten Abwertung des Griechentums ändert Vergerios Bewunderung seines Griechischlehrers nichts. Er bedeutete eben die Ausnahme, die es nach Vergerios Meinung wahrscheinlich verdient hätte, selbst ein latinus zu werden. ${ }^{536}$ In der Geste, mit der Vergerio aus Arrian einen latinus macht, ist unter anderem auch diese nicht ausformulierte Abwertung des Griechentums präsent.

Die Vorstellung, dass in den Regionen, in denen die griechische Kultur einheimisch ist, gefährliche Verhältnisse herrschen, scheint bei Vergerio die Konsequenz zu haben, dass er Chrysoloras Lehrtätigkeit mit missionarischen Zügen ausgestattet darstellt. So kann man vielleicht davon ausgehen, dass die Übersetzungsarbeit an griechischen Texten bei Vergerio auch die Konnotation von der Rettung bedrohter Kulturgüter gewinnt. ${ }^{537}$

534 Vergerio, Epistolario, S. 245. Smith datiert den Brief in die Zeit, in der sich Chrysoloras in Konstantinopel aufhielt.

535 Über die Vorurteile der Italiener gegenüber den Griechen und die gesellschaftliche Diskriminierung, die demzufolge auch Chrysoloras zuteil geworden ist, als ein möglicher Grund für die vorzeitige Beendigung seines Lehrauftrags vgl. Thorn-Wickert, Chrysoloras, S. 51-54.

536 Wenn man die zitierten Zeilen Vergerios aufmerksam liest, wird klar, dass in ihnen auch dieser Gedanke präsent ist.

537 Diese Argumentation soll als Kontext für Vergerios Übersetzung aus dem Griechischen dienen, ohne die Behauptung, dass alle hier angesprochenen Aspekte des Übersetzens aus dem Griechischen in Vergerios Widmungsbrief auch präsent sind. Das Politikum des Übersetzens aus dem Griechischen ins Lateinische in der ersten Hälfte des 15. Jahrhunderts soll aber trotzdem unterstrichen werden. 
Die oben zitierten literarischen Beispiele für die Beschreibung der Aneignung fremder Kulturgüter oder für das Wiedergewinnen der eigenen haben eines gemeinsam: die Verwendung von Ausdrücken, deren ursprünglicher Kontext die Militärsprache ist. Im Horazschen Gedicht ist das Militärische nur durch die Allusion, die das Wort „deducere” beinhaltet, präsent, während es im Philobiblon auch ganz konkret um zwei Militäraktionen geht, durch die die Bücher von Athen nach Persien und dann wieder zurück nach Athen geführt werden. In diesem Fall wird es auch eindeutig, dass die wörtliche und die metaphorische Deutung der Gefangenschaft der Bücher oft zusammenhängen. Bücher bilden nicht nur das kulturelle Kapital einer Leser- (und Sprach-)Gemeinschaft, sondern können ganz konkret als Bestandteil des ökonomischen Kapitals gedeutet werden. Bei der Eroberung von Städten mit einer Bibliothek werden meistens auch die Bibliotheken geplündert. Dies kann man selbstverständlich auch als eine symbolische Geste deuten, man darf aber den konkreten, ökonomischen Wert der Bücher, die in solchen Aktionen geraubt werden, nicht unterschätzen.

Auch der humanistische Wortgebrauch „postliminium” kann nicht ganz harmlos gedeutet werden. Der Anspruch, den diese Humanisten damit zum Ausdruck bringen, ist der Anspruch von kultureller Überlegenheit. ${ }^{538}$ Mit dem Ausdruck „postliminium” konnte man nicht nur für die Notwendigkeit einer Übersetzung argumentieren, sondern generell für das „Rückgewinnen” von Kulturgütern durch das Abschreiben oder den Ankauf von Handschriften. Arrians Fall kann als ein Beispiel für beide Arten der „Rückkehr” interpretiert werden. Erst wurde der Codex von Aurispa nach Italien gebracht und dann auch dessen Text übersetzt.

Vergerio greift mit der Idee, er wolle einen latinus den Lateinern wiedergeben, einen humanistischen Topos auf, der sich wegen seiner Implikationen gut in einen „militärischen” Kontext einfügen lässt: der Übersetzer mit seiner Übersetzung habe eine mit Alexanders Eroberungen vergleichbare Aktion vollbracht. ${ }^{539}$ Mit dieser Strategie stellt er sich und den König in einem beinahe symmetrischen Konstrukt dar.

Die Symmetrie der Darstellung wird an einem weiteren Punkt offensichtlich. In Vergerios Liste der verschiedenen Mängel, die die Werke der meisten Autoren kennzeichnen, die über Alexander geschrieben hatten, stehen an der letzten Stelle diejenigen, die sich weniger um die Wahrheit bemüht hätten, sondern eher um den eigenen Ruhm und deswegen

\footnotetext{
538 In Poggios Fall z. B. implizierte diese Überlegenheit durch die Erwähnung von „,barbari” eine Opposition zwischen Barbarei und Zivilisation.

539 Dass die Symmetrie nicht ganz stimmt, weil Vergerios Anspruch im Gegensatz zu Alexanders Kriegstaten darin besteht, den „latini” etwas, was ursprünglich ihnen gehört hatte, zurückzugeben, muss nicht bedeuten, dass diese Interpretation zwangsläufig verfehlt wäre. Eine vollkommene Symmetrie ist auch im Vergleich zwischen den Kriegstaten Alexanders und denen des Sigismunds nicht möglich. Im Widmungsbrief Vergerios steht Alexander einfach für einen großen Staatsmann und Heerführer.
} 
eher darauf geachtet hätten, die Sachen zu verewigen, über die mit „decor” zu schreiben möglich war. Unter den von Vergerio aufgezählten Fehlern ist dieser der einzige, der sich auf den Übersetzer beziehen ließ. Wenn Vergerio sich durch eine Abgrenzung von den früheren Autoren behaupten wollte, dann konnte er es mit dem Hinweis auf diese letzte Fehlermöglichkeit tun, weil nur diese sich auf den Stil beziehen ließ. Der Humanist hat diese (von ihm selbst konstruierte) Möglichkeit auch genutzt. Im letzten Abschnitt des Briefes, in dem er die Wahl seines Stils begründet, gibt er zu, dass er in seiner Übersetzung auf die Übermittlung des „ornatus” und der „elegantia” verzichtet habe, diese müsse man im Original suchen. Diese Entscheidung wird mit Hilfe einer Gegenüberstellung von „verba” und „sensus" bzw. von „ornatus [...] orationis et dicendi elegantia” und „rerum notitia” gerechtfertigt. Aus der Kontrastierung gehen selbstverständlich „sensus” und „rerum notitia” als Sieger hervor. Vergerios Anspielung mit dieser Gegenüberstellung auf die schon früher erwähnte Fehlermöglichkeit hat die Funktion, darauf hinzuweisen, dass, genauso wie Sigismund mit seiner Wahl Arrians als Lesestoff aus der Reihe der üblichen Leser hervorsticht, auch er als Übersetzer mit seiner Wahl der Methode dazu beiträgt, dass das Lesestück den neuen, höheren Erwartungen entspricht und die üblichen Alexanderlektüren überflügelt. Er habe mit seiner stilistischen Entscheidung dazu beigetragen, dass Alexanders Taten dem Leser diesmal in einer faktentreuen, sich auf die Geschichte und nicht auf das rhetorische Ornament konzentrierenden Darstellung verfügbar geworden sind.

\subsubsection{Vergerios Übersetzungsstrategie im Kontext der ,ad sensum vs. ad verbum“- Debatte}

Wenn man Vergerios im Brief ausformulierte Prinzipien mit anderen Gemeinplätzen vergleicht, mit denen andere Übersetzer ihre Arbeit eingeleitet hatten, so kann man feststellen, dass er einen verbreiteten Topos benutzt hatte, um seine Methode darzustellen. Die Idee, dass man beim Übersetzen den Sinn eines Textes wiedergeben sollte und nicht die einzelnen Wörter, war keine Erfindung der Humanisten, selbst wenn man manchmal diesen Eindruck bei der Lektüre der humanistischen Schmähungen von früheren Übersetzungen desselben Textes bekommt. In Wirklichkeit handelt es sich um einen Gemeinplatz, den Übersetzer schon immer verwendet haben, wenn sie ihre Neuübersetzung eines Textes legitimieren wollten: der vorherige Übersetzer habe Wort für Wort übersetzt und nicht den Sinn des Textes wiedergegeben. ${ }^{540}$

540 Dieses Prinzip wird auf Grund eines Prologes des Cencio de' Rustici zu seiner Übersetzung der DionysosRede oft mit Chrysoloras' Namen verbunden. Thorn-Wickert hinterfragt (Chrysoloras, S. 110) mit Recht 
Die Gegenüberstellung von ad verbum- und ad sensum-Übersetzungen und die Behauptung, dass letztere die besseren seien, waren seit der Antike verbreitete Gemeinplätze. Diese Gedanken waren in der Horazschen Ars poetica genauso wie in Ciceros Werken ausformuliert. ${ }^{541}$ Hieronymus bezieht sich im Vorwort zu seiner Übersetzung von Eusebius und in seinem Brief an Pammachius ${ }^{542}$ auf Horaz und Cicero und behauptet, dass eine Wort-fürWort-Übertragung des Originaltextes nicht erwünscht sei, außer, wenn es sich um die Heiligen Schriften handelte. Während in vielen Werken über die Geschichte der Übersetzungstheorie auf Grund des Cicero- und Horaz-Zitates bei Hieronymus eine Kontinuität zwischen antiker Übersetzungstheorie und Hieronymus' Methode für seine Übersetzungen von nicht-biblischen Texten behauptet wird, untersucht Rita Copeland auch den jeweiligen Kontext der ciceronischen und hieronymischen Aussagen und stellt fest, dass Hieronymus zwar die antiken Autoritäten zitiert; aber dies tut er, um genau das Gegenteil zu behaupten, ohne aber auf diese Diskrepanz zwischen dem Zitat und seinen eigenen Behauptungen hinzuweisen. Laut Copeland handelt es sich im Fall von Hieronymus eigentlich um ein „Fehlzitat” der antiken Autoritäten. ${ }^{543}$ Da der Unterschied, der in Copelands Analyse nachgewiesen wird, auch im Fall von Vergerios Übersetzung eine wichtige Rolle spielen wird, lohnt es sich, die Argumentation der amerikanischen Autorin kurz zusammenzufassen.

Wenn Cicero eine ad verbum-Übersetzung des Originaltextes verwirft, so folgt diese Präferenz aus seiner Agenda, die nach Copelands Meinung die Betonung der Unabhängigkeit (und damit Gleichrangigkeit) der lateinischen Sprache und Philosophie der griechischen

diese Zuschreibung. Sie bemerkt, dass ad verbum-Übersetzungen schon seit den siebziger Jahren des 14. Jahrhunderts als unelegant galten. Diese Bemerkung entspricht auch der Wahrheit, sie bedarf nur einer Korrektion, und zwar, dass ad verbum-Übersetzungen schon viel früher kritisiert worden sind.

541 Zum Beispiel: „Nec verbum verbo curabis reddere interpres”: Hor. Ars p. 133; „Nec tamen exprimi verbum e verbo necesse erit, ut interpretes indiserti solent, cum sit verbum quod idem declaret magis usitatum.": Cic. De fin. 3.4.15.

542 Hieron. Ep. 57 ad Pamach. Eine deutsche Übersetzung von diesem Brief ist im Band „Das Problem des Übersetzens” enthalten, vgl. Hieronymus, „Brief an Pammachius”, in Das Problem des Übersetzens, Wege der Forschung 8, hrsg. v. Hans Joachim Störig (Darmstadt: Wissenschaftliche Buchgesellschaft, 1963), 1 13. Der Text veranschaulicht sehr gut die im Buch erörtere Thematik, weil hier das Übersetzen ein richtig großes Problem zu sein scheint. Er arbeitete aus einer Vorlage, die ich selbst nicht überprüft habe, die aber unmöglich so kontaminiert gewesen sein kann, dass allein die Kontamination all die Fehler, von denen es im Text wimmelt, erklären könnte. Die Probleme fangen gleich mit dem ersten Satz an, der in der Übersetzung exakt das Gegenteil von dem sagt, was Hieronymus schreibt: ,ich gebe nicht nur zu, sondern bekenne es mit lauter Stimme, dass ich bei der Übersetzung der Heiligen Schriften aus dem Griechischen, wo selbst die Wortstellung schon ein Mysterium ist, nicht Wort für Wort, sondern Sinn für Sinn ausgedrückt habe.” Hieronymus war bekanntlich der Meinung, dass man die Heiligen Schriften „Wort für Wort" übersetzen sollte, während alles andere ad sensum zu übertragen sei.

543 Rita Copeland, Rhetoric, Hermeneutics and Translation in the Middle Ages. Academic Traditions and Vernacular Texts (Cambridge: Cambridge University Press, 1991), [im Weiteren: „Rhetoric”], hier S. 4251. Copelands Argumentation wird von Vermeer übernommen: Hans J. Vermeer, Skizzen zu einer Geschichte der Translation. Anfänge von Mesopotamien bis Griechenland. Rom und das frühe Christentum bis Hieronymus, 2 Bde., Translatorisches Handeln - Wissenschaft 6 (Frankfurt am Main: Verlag für Interkulturelle Kommunikation, 1992), hier Bd. 1. S. 305. 
gegenüber sei. Cicero bestreitet die intellektuelle Hegemonie der griechischen Kultur. Bei Cicero spielen Sprache und Rhetorik keine zweitrangige Rolle, Ciceros Beschwörung der ad sensum Methode des Übersetzens ist Teil eines rhetorischen Wetteiferns mit den Griechen. Auch die lateinische Sprache sei fähig, ein mit dem Attizismus vergleichbares Modell zu entwickeln. Bei Hieronymus dagegen ist eine Wort-für-Wort-Übersetzung deswegen nicht erwünscht, weil das rhetorische Ornament die Aufmerksamkeit des Lesers (und des Übersetzers) von der eigentlichen Hauptsache, das heißt vom Sinn des Textes ablenken würde. ${ }^{544}$ Hieronymus benutzt in seiner Begründung ein antirhetorisches Modell. Sein Verständnis von Sprache und Rhetorik ist genau das Gegenteil des ciceronischen Sprachverständnisses.

Eine Forderung gegenüber der Übersetzung, die als typisch humanistisch bezeichnet werden kann, ist nicht die ad sensum-Übersetzung, die, wie aus Copelands Argumentation klar hervorgeht, sogar einander entgegengesetzte Theorien etikettieren konnte, sondern eher das Prinzip, nach dem der Übersetzer den Text auch stiltreu wiedergeben sollte, mit anderen Worten, das ciceronische Modell. Dieses wird von Bruni wieder aufgegriffen, der in seinem Traktat De interpretatione recta, einer Schrift, die er zur Legitimierung seiner AristotelesÜbersetzungen geschrieben hatte, seine Prinzipien der richtigen Übersetzung ausformulierte. Eine Gemeinsamkeit gibt es zwischen Brunis Übersetzungsprinzipien und dem von Vergerio benutzten Topos. Beide verwerfen die ad verbum-Übersetzung. Bruni gibt sich aber, im Gegensatz zu Vergerio, mit einer ad sensum-Übersetzung nicht zufrieden, der Stil des Originals ist für ihn auch etwas Wesentliches, den der Übersetzer auf jeden Fall wiedergeben muss. Wenn man diesen Gedanken mit Vergerios Ziel, den Sinn der Geschichte wiederzugeben, vergleicht, so würde eine schnelle Gegenüberstellung der zwei Zielsetzungen naheliegen, und man könnte denken, dass Vergerio einen weniger anspruchsvollen oder „fortschrittlichen" Weg eingeschlagen hatte. Vergerio adaptiert das ad sensum-Prinzip a la Hieronymus, während Bruni es im Sinne Ciceros benutzt. Wenn man aber den Kontext von Brunis Betonung der stilistischen Angemessenheit der Übersetzung im Auge behält, dann kann man feststellen, dass sich Brunis Aussagen auf seine Übersetzungen von Aristoteles beziehen. Bruni war von der Eloquenz dieses Philosophen überzeugt, ebenso, wie generell von der Untrennbarkeit von Philosophie und Eloquenz. ${ }^{545}$ Vor diesen Hintergrund gestellt bekommen Brunis Ansichten über den richtigen Weg des Übersetzens ihren Stellenwert. Mit

\footnotetext{
544 Für die genauen Stellen, auf die Copeland ihre Argumentation aufbaut vgl. das oben zitierte Kapitel in ihrem Buch.

545 Über diese Überzeugung Brunis, und über ihre Konsequenzen für Brunis Aristoteles-Übersetzungen vgl. Paul Botley, Latin Translation in the Renaissance. The Theory and Practice of Leonardo Bruni, Giannozzo Manetti and Desiderius Erasmus (Cambridge: Cambridge University Press, 2004), [im Weiteren, „Latin Translation"], hier S. 41-58.
} 
anderen Worten: Sie sind in erster Linie in ihrem Originalkontext und dementsprechend als Überlegungen zur Übersetzung philosophischer Werke zu verstehen.

Eine ähnlich vehemente Argumentation für die Wichtigkeit der stilgemäßen Übersetzung findet man in Brunis Vorworten zu seinen Übersetzungen aus der griechischen Geschichtsschreibung nicht. ${ }^{546}$ Ein gutes Beispiel für Brunis Auffassung von der Übersetzung historischer Werke liefert die von ihm erzählte Geschichte seines Unternehmens der Übersetzung von Plutarchs Cicero-Vita. In seiner an Niccoli gerichteten Praefatio ${ }^{547}$ zu seinem Cicero novus erzählt er, dass er eine lateinische Übersetzung dieser Schrift gelesen habe, die nach seiner Meinung von einem zwar guten, aber nicht genügend gelehrten Mann stamme. So habe er sich vorgenommen, eine eigene Übersetzung des griechischen Textes herzustellen. Beim Lesen des Originals sei ihm aber aufgefallen, dass Cicero in Plutarchs vergleichender Darstellung gegenüber Demosthenes etwas zu kurz kommt, weil der Autor vieles, das man zu Gunsten Ciceros hätte erzählen können, weggelassen habe. Er habe deswegen seine ursprüngliche Zielsetzung geändert und nicht eine Übersetzung des Textes von Plutarch angefertigt, sondern auf der Basis mehrerer Quellen ein eigenes Werk über Cicero geschrieben. ${ }^{548}$ Diese Geste impliziert eine Auffassung von Geschichtsschreibung, nach der eine historische Schrift in erster Linie nicht für sich selbst, als Text und nicht wegen seiner stilistischen Feinheiten, sondern als Informationsträger wertvoll ist. Warum Plutarch übersetzen, wenn man selbst eine vertrauenswürdigere Darstellung des Themas liefern kann?

Das Beispiel des Cicero novus ist für diese Untersuchung deswegen von großer Hilfe, weil es die Konsequenzen einer die Fakten in den Vordergrund stellenden Auffassung von Geschichtsschreibung für deren Übersetzung exemplifiziert: Übersetzungen historischer

546 Ich denke hier an die von Baron veröffentlichten Vorworte: an den „Prologus in Vita Quinti Sertorii ex Plutarcho traducta”: Baron, Schriften, S. 123-125, und an die „Praefatio in Vita M. Antonii ex Plutarcho traducta": Baron, Schriften, S. 102-104.

547 Der Text der Praefatio ist veröffentlicht worden in: Baron, Schriften, S. $113 \mathrm{f}$.

548 Über das Verhältnis zwischen Brunis Übersetzungen und seiner Geschichtsschreibung vgl. Gary Ianziti, „Bruni on Writing History”, Renaissance Quarterly 51 (1998): 367-91. Ianziti hebt folgenden Satz der Praefatio zum Cicero novus hervor: „[...]ex iis, quae vel apud nostros vel apud Graecos de Cicerone scripta legeramus, ab alio exorsi principio vitam et mores et res gestas eius maturiore digestione et pleniore notitia non ut interpretes, sed pro nostro arbitrio voluntateque descripsimus." Für Ianzitis Argumentation hat das Ende des Satzes eine besondere Bedeutung: ,pro nostro arbitrio voluntateque”. Er interpretiert diese Worte als indikativ für Brunis Auffassung von Geschichtsschreibung und der Rolle des Geschichtsschreibers: sie wiesen auf die interpretative Autonomie des Geschichtsschreibers hin. Ulrich Muhlack betont dagegen, dass in der humanistischen Geschichtsschreibung die Tätigkeit des Historikers eher ,empfangend und reproduktiv” sei: „Allerdings wird von Historikern eine gewisse subjektive Disposition gefordert. Sie soll ihn aber nicht zu einer schöpferischen oder produktiven Rolle befähigen, sondern gerade dazu, jene objektivistisch-realistische Erkenntnishaltung einzunehmen”. Vgl. Ulrich Muhlack, Geschichtswissenschaft im Humanismus und in der Aufklärung. Die Vorgeschichte des Historismus (München: C.H. Beck, 1991), S. 72-73. Was Muhlack unter ,gewisse subjektive Disposition” versteht, ist wahrscheinlich das Gleiche, worauf sich Brunis ,nostrum arbitrium voluntasque” bezieht. Als wie groß die mit den Worten ,,arbitrium voluntasque" beschriebene Freiheit des Historikers von Bruni verstanden wurde, ist schwer zu entscheiden: nach Ianzitis Interpretation auf jeden Fall größer als nach Muhlack. 
Werke haben nach dieser Auffassung die Funktion, den Leser über die im Originaltext erzählte Geschichte zu informieren und nicht über den Text der Originalfassung als solchen. Der Originaltext hat keinen eigenen Wert, sondern zählt lediglich als Vermittler der dargestellten Geschehnisse. Geschichte wird nicht für den Stil, sondern für die dargestellten Fakten gelesen und übersetzt. Diese zugespitzte Formulierung vindiziert für sich nicht das Recht, eine allgemeine Wahrheit über humanistische Auffassungen von Geschichtsschreibung generell $\mathrm{zu}$ formulieren. Sie mag aber vielleicht einen Aspekt dieses speziellen Falles erläutern. Plutarch interessiert Bruni in diesem Fall nicht seinetwegen, sondern wegen Cicero. Diese oben formulierte Aussage hat aber Gültigkeit mit der Einschränkung, die ich mit den Worten ,in diesem Fall” zum Ausdruck zu bringen versuchte. Am Anfang seiner Praefatio sagt Bruni nämlich, dass er Plutarchs Cicero-Vita schon des Öfteren gelesen habe. Dementsprechend kann man davon ausgehen, dass er Plutarch auch für den Text selbst zu schätzen wusste. Man kann seine Erzählung möglicherweise als einen Selbstlegitimierungsversuch verstehen, der graduell aufgebaut ist. Er legitimiert seine neue Cicero-Vita in zwei Schritten. Zuerst kritisiert er die lateinische Übersetzung, erst dann das Original selbst. Dass die oben beschriebene Auffassung von Geschichtsschreibung sich am Ende als eine Selbstlegitimationsstrategie entpuppt, ändert nichts an der Tatsache, dass eine solche Auffassung von Geschichtsschreibung in bestimmten Kontexten vertretbar zu sein schien. ${ }^{549}$

Es ist vor diesem Hintergrund durchaus vorstellbar, dass Vergerios Wahl der Stilebene mit dem Genre des zu übersetzenden Textes zu erklären ist. Für ihn waren die Verschiedenheit der Gattungen und die daraus zu ziehenden Konsequenzen eine Selbstverständlichkeit, genauso wie sie es nach dem Zeugnis eines (in Anm. 374 zitierten) Briefes für Bruni waren. Vergerio hat es deswegen für angemessen gehalten, sich im Fall einer Schrift aus dem Bereich der Geschichtsschreibung in erster Linie auf die Wiedergabe der Fakten zu konzentrieren. Er hat in seinem Widmungsbrief häufig auf eine Gegenüberstellung von fabula

549 Um noch ein Beispiel für Brunis Auffassung von Geschichtsschreibung und deren niedrigeren Grad von Rhetorizität zu nennen, sei hier eine Stelle aus seinem De studiis et litteris zitiert, wo er seinem Addressaten, Baptista de Malatestis, neben den zwei wichtigsten Studien (der religiösen Literatur und der Philosophie) die weiteren Studien nennt, die für die Bildung wichtig seien. Hier nennt er die Geschichtsschreibung, dann die Oratorik und an der letzten Stelle die Dichtung. Die drei Bereiche der Studien sind in einer Reihenfolge genannt, deren Logik in der wachsenden Komplexität der Textsorten zu sehen ist. Geschichtsschreibung steht am Anfang dieser Auflistung, weil diese Texte am einfachsten zu verstehen sind: „Neque enim subtilitas ulla in illis eruenda est aut quaestio enodanda, in narratione enim rerum facillimarum omnis constitit versaturque historia". Vgl. Vergerio, De studiis, S. 109. Vor einem Jahrhundert hätte ich nicht so ausführlich dafür argumentieren müssen, dass Historiographie möglicherweise, in manchen Kontexten sogar in erster Linie für die dargestellten Fakten gelesen und übersetzt wurde, und Stil eine zweitrangige Rolle gespielt haben konnte (dass „Stil” und „Fakten” überhaupt zu trennen wären). Heute aber, da die Rhetorizität der Geschichtsschreibung ein Gemeinplatz geworden ist, ist die Forschung für die Frage auch rückwirkend sensibel geworden und betont die rhetorische Beschaffenheit historiographischer Texte der Humanisten, was auch zweifellos aufschlussreich ist. 
und historia bestanden und darauf hingewiesen, dass Sigismunds Motivation zum Lesen Arrians in seinem löblichen Streben nach der Erkenntnis der Wahrheit bestünde. Dementsprechend folgt Vergerios Wahl der Methode des Übersetzens der inneren Logik des Widmungsbriefes und wird sowohl dem in den Bereich der historia gehörenden Text als auch dem „,nach der historischen Wahrheit strebenden” König gerecht.

Vergerios Brief ist bei weitem keine Beleidigung Sigismunds und auch keine Selbsterniedrigung. Im Gegenteil: Es handelt sich um ein Beispiel für humanistisches Schmeichelschreiben, in dem das Lob des Herrschers mit einem implizierten Selbstlob vermischt wird.

\subsubsection{Ein Vergleich von Vergerios und Facios Übersetzungen der Alexander-Vita}

\subsubsection{Die Textproben}

Die Sekundärliteratur übernimmt das negative Urteil Facios und Piccolominis, was die Qualität der Übersetzung Vergerios betrifft, ohne aber Vergerios Übersetzung selbst unter die Lupe zu nehmen und sie mit Facios Neuübersetzung zu vergleichen. ${ }^{550}$ Dies soll hier versucht werden. Die Länge der Alexander-Vita macht es nicht möglich, in diesem Rahmen die zwei Übersetzungen miteinander vollständig zu vergleichen. Ich nehme daher Textproben und vergleiche die Übersetzungen an jeweils zwei Textstellen miteinander. ${ }^{551}$

Die erste Stelle ist der Anfang des Textes. Diese Wahl muss nicht ausführlich begründet werden: Anfänge haben, außer der besonderen Bedeutung, die von ihrer Position herrührt, auch den Vorteil, dass sie wahrscheinlich von wesentlich mehr Lesern gelesen werden als der Rest des jeweiligen Textes. Eine besonders große Rolle musste diese Überlegung in Fällen von repräsentativen Aufträgen spielen, wo der Autor (Übersetzer) nicht davon ausgehen konnte, dass sein Auftraggeber den ganzen Text lesen wird. Außerdem werden in

550 Einige Beispiele seien hier angeführt: „Vergerio had produced his translation for Emperor Sigismund, who possessed only a limited grasp of Latin; though wellendowed with literary skills, Vergerio had perforce to present Arrian in a rather plain Latin dress.": Jerry H. Bentley, Politics and Culture in Renaissance Naples (Princeton: Princeton University Press, 1987), [im Weiteren: „Politics”], hier S. 107. „di sorta che rinunciò a rendere le eleganze del testo greco e s'attenne ad uno stile piano e disadorno, il solo che fosse accessibile alla mezzana cultura del re": Ziliotto, La cultura, S. 78. Seltsamerweise zitiert Ziliotto sogar Vergerio selbst in einer Fußnote zu seiner Bemerkung: „,ce lo dice il Vergerio stesso: Tibi vero non futurum ingratum certus sum...". Selbst McManamon, der im Vergleich mit den beiden oben zitierten Autoren noch am vorsichtigsten ist, und selbst behauptet, es sei selbstverständlich, eine Übersetzung zu schmähen, wenn man den Text selbst neu übersetzen möchte, schreibt über Vergerios Übersetzung: „Vergerios translation was so plodding that later humanists retranslated the works.” McManamon, Vergerio, S. 157.

551 Der Pariser Codex enthält, laut Smith, die Kopie, die für den späteren Papst Nikolaus V. hergestellt wurde: Paris Bibl. Nat, Nouv. Acq. Lat. 1302. Der Codex, der in der Vatikanischen Bibliothek zu finden ist (Cod. Vat. Lat. 5268), enthält die von Bartolommeo Facio revidierte Version. Dieser Codex, mit der neuen Version wurde an den König Matthias geschickt. Beide Übersetzungen sind unveröffentlicht. Ich habe für diese Analyse die Handschriften auf Mikrofilm gelesen. Die Transkription der hier untersuchten Textstellen befindet sich im Anhang 2. 
praefationes meistens grundsätzliche Fragen angesprochen, die auch Anlass zur Selbstprofilierung des Autors geben.

Die zweite von mir untersuchte Stelle ist die sogenannte „zweite Praefatio" der Anabasis. Es handelt sich um die berühmte Stelle, in der erzählt wird, dass Alexander Achilleus' Grab gekrönt und ihn als glücklich gepriesen habe, weil er in Homer den würdigen Verkünder seines Ruhmes gefunden habe. Auf Alexanders Makarismos an Achilleus folgt Arrians Selbstpositionierung in der griechischen, literarisch-historischen Tradition. Er habe vor, als erster über Alexander zu schreiben. Am Ende der zweiten Praefatio behauptet Arrian, dass er selbst würdig sei, Alexanders Taten als erster zu erzählen. Er zieht auch eine Parallele zwischen sich selbst und Alexander. Er sei unter den führenden Autoren in griechischer Sprache genauso der Erste, wie Alexander der Erste in Militärsachen gewesen sei. ${ }^{552}$ Wie Arrian sich mit der „zweiten Praefatio" auf verschiedene literarische Modelle bezieht und damit sich in einen literarischen Kanon hineinschreibt, der seinen Anfang bei Homer hat, wurde bereits in einer Analyse des griechischen Textes erörtert. ${ }^{553}$ Nach dieser Interpretation sei die Anabasis nach der Absicht des Autors als eine zweite Ilias zu verstehen ${ }^{554}$, dies sei in der Betonung von Homers Verewigung von Achilleus' Ruhm und der Feststellung, dass Alexander noch keinen ähnlichen Verkünder seiner Taten habe, impliziert. Der zweite wichtige Punkt dieser Interpretation ist die Bemerkung, dass die Anabasis sich nach der Logik der zweiten Praefatio als ein Enkomium verstehe: Alexanders Makarismos an Achilleus hebe das Fehlen eines ähnlichen Lobaktes für Alexander hervor. Wenn Arrian diese Lücke beseitigt, so müsse seine Geschichte einen ausgesprochen enkomiastischen Charakter haben. Für den Erstübersetzer des Textes bietet sich die Möglichkeit an, sich, ähnlich, wie der Autor des Textes, als jemanden, der eine Lücke beseitigt, darzustellen. Dies tut Vergerio auch in seiner Widmung an Sigismund, wie bereits gezeigt wurde. Die zweite Praefatio ist also die Stelle, an der der Autor des Textes sich selbst in seinen Text hineinschreibt ${ }^{555}$ und er seine eigene Position in der historisch-literarischen Tradition bestimmt. Demzufolge auch die Stelle, wo der Übersetzer besonders aufpassen musste, wenn er sich als ein vergleichbar wichtiges Glied der Traditionskette betrachten und darstellen wollte, wie der Autor selbst. Es ging hier auch ganz einfach um das alte Bild des „Dichters” als dispensator gloriae, der für

552 Arr. An.1. 12.5.

553 J. T. Moles, „The Interpretation of the „Second Preface” in Arrian's Anabasis”, The Journal of Hellenic Studies 105 (1985): 162-168, [im Weiteren: ,Second Preface”].

554 Moles, Second Preface, S. 163.

555 Dieser Aspekt der zweiten Praefatio war auch dem zeitgenössischen Leser der lateinischen Übersetzungen nicht verborgen: in beiden Handschriften findet man Randbemerkungen zu den Zeilen, in denen es um Arrian geht. In Bibl. Nat, Nouv. Acq. Lat. 1302 findet man fol. 11v. mit einer scheinbar zeitgenössischen Schrift Folgendes: „De se Arrianus loquitur”. Im Cod. Vat. Lat. 5268 fol. 21r steht: „Laus Arriani Historici Graeci”. 
jeden Gelehrten, der sich in der Nähe von Machtträgern positionieren wollte, ein lebensnotwendiger Topos war.

\subsubsection{Die praefatio ${ }^{556}$}

Was bei einem Vergleich der beiden Übersetzungen ${ }^{557}$ gleich im ersten Satz des ersten Kapitels auffällt, ist die Tatsache, dass Vergerio sich viel mehr an die Wortwahl und Wortfolge des Originals hält als Facio. Vergerio stellt das lateinische Äquivalent des griechischen

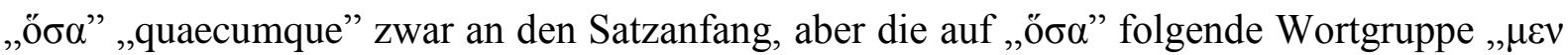

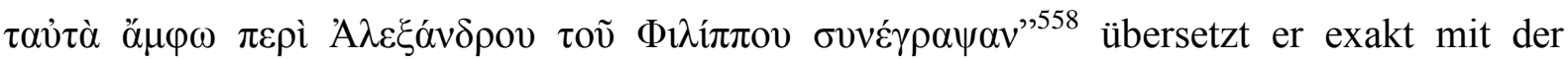
gleichen Wortfolge wie im Original: „eadem ambo de Alexandro Philippi conscripserunt”,559. Er versucht bei seiner Übersetzung die griechischen Wörter so nah wie möglich am Original wiederzugeben. Er übersetzt zum Beispiel „ő $\mu \varphi \omega ”$ mit „ambo”. Facio dagegen lässt in seinem lateinischen Text „ðپ $\mu \varphi \omega ”$ ganz weg, der lateinische Text funktioniert auch ohne dieses Wort,

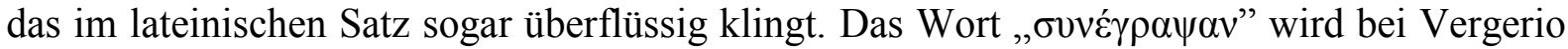
mit dessen Spiegelübersetzung als „conscripserunt” wiedergegeben ${ }^{560}$, was aber nicht als Notlösung von Seiten Vergerios betrachtet werden kann, da das lateinische Wort auch in antiken Texten als ein Terminus für das Schreiben eines Buches erscheint. ${ }^{561}$ Auch im

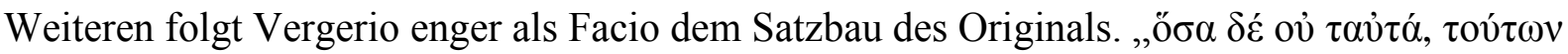

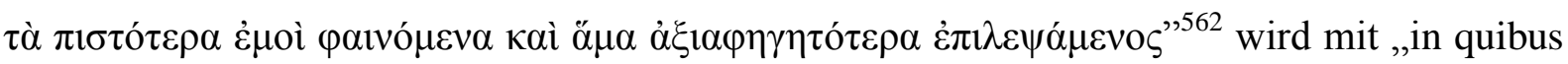
vero non convenient, ex illis ea quae visa sunt mihi probabiliora ac digniora narratu scribenda mihi elegi” ${ }^{563}$ wiedergegeben. Facio wählt hier statt Vergerios originalsnahem „visa sunt mihi” die Lösung ,existimavi”.

Facio geht mit seinen Emanzipationsbestrebungen des lateinischen Textes von seinem griechischen Original sogar so weit, dass er seinen Text mit „Ex omnibus Alexandri rerum scriptoribus" ${ }^{, 564}$ anfängt, während man im griechischen Original vergebens nach einem Äquivalent sucht. Die Übersetzung des griechischen Satzes lautet: „Alles, was Ptolemaios, der Sohn des Lagos, und Aristobulos, der Sohn des Aristobulos, über Alexander, den Sohn des Philippos, (miteinander) übereinstimmend geschrieben haben, schreibe ich als völlig

Arr. Anab. 1, Praef. 1-3.

Der Text der Praefatio befindet sich auf den folgenden Folios: in dem Vergerios Fassung enthaltenden Pariser Codex f. 2r, in dem Facios Version enthaltenden Vatikanischen Codex: 3r-4r.

558 Arr. Anab. 1. Praef. 1.

559 Lat. 1302, 2r.

560 Facio übersetzt das Wort mit „memoriae prodiderunt”.

561 Vgl. ThLL. Bd. 4, 375 f.

562 Arr. Anab. 1. Praef. 1.

563 Lat. 1302, 2r.

564 Vat. Lat. 5268, 3r. 
Wahres nieder, (von dem), was sie nicht übereinstimmend (geschrieben haben), wähle ich die (Sachen), die mir glaubwürdiger und erzählenswerter erscheinen." Dieser Sinn wird von Vergerio wiedergegeben, während Facio folgendes vorschlägt: „Von allen den über Alexander schreibenden Autoren schreibe ich die Sachen als am wahrhaftesten, die Ptolemaios, der Sohn des Lagos, und Aristobulos, der Sohn des Aristobulos, über den König miteinander übereinstimmend geschrieben haben.” Der Unterschied zwischen dem Original und Facios Übersetzung ist ein in Facios Übersetzung implizierter Vergleich zwischen allen den Autoren, die über das gleiche Thema geschrieben haben, aus welchem die zwei erwähnten Autoren als Gewinner angesehen werden müssten, aber auch sie nur in den Erzählungen von den Geschehnissen, die sie miteinander übereinstimmend beschrieben hätten. Im Originaltext geht es vom Anfang an nur um die beiden Autoren. Der Rest, dass also von den beiden nur das als wahrhaft übernommen wurde, was sie miteinander übereinstimmend erzählen, stimmt in Facios Übersetzung. Seine Veränderung dient wahrscheinlich dazu, dass auf diese Weise ein wohlklingenderer Textanfang geschaffen wurde, der die Vorlagen Arrians in einen universal klingenden („Ex omnibus”) Vergleichskontext stellt.

Im nächsten Satz kann man die unterschiedlichen Lösungen für das griechische

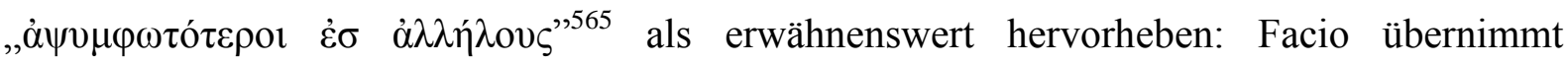
Vergerios „magis invicem discordantes” ${ }^{566}$ nicht, sondern schreibt stattdessen „minus inter se consentientes", 567 . In diesem Fall kann man seine Geste, ein anderes lateinisches Äquivalent zu suchen, nicht mit dem besseren, natürlicheren Klang seiner lateinischen Version erklären: Facios litotetische Lösung macht den Eindruck, dass der Umarbeiter der vergerianischen Übersetzung auf Grund seines eigenen Vorsatzes, den vorgefundenen Text umzuschreiben, voreingenommen mit Vergerios Übersetzung umging und ihn auch dort veränderte, wo eine Veränderung nichts zu einer Qualitätsverbesserung beigetragen hat.

Die erwähnten Beispiele lassen sich als Kategorien für einen Vergleich der beiden Übersetzungen nutzen. Im Folgenden können Facios Veränderungen seiner Vorlage, der Übersetzung Vergerios, in die folgenden Gruppen eingeteilt werden:

1. Veränderungen, die eine elegantere Lösung darbieten als Vergerios Version und dabei dem griechischen Text treu bleiben.

\footnotetext{
565 Arr. Anab. 1. Praef. 2.

566 Lat. 1302, 2r.

567 Vat. Lat. 5268, 3v.
} 
2. Veränderungen, die eine besser klingende Version vorschlagen, die aber vom Sinn des griechischen Originals abweichen.

3. Veränderungen, die nichts zur Sprachqualität des lateinischen Textes beitragen und eventuell auch mehr vom Griechischen abweichen als die erste Übersetzung, die also eher um der Veränderung willen eingeführt worden sind.

Warum eine vierte Gruppe, die Veränderungsvorschläge enthalten sollte, die dem griechischen Original besser und enger verbunden bleiben würden als Vergerios Übersetzung, hier nicht gebildet wird, wird später erklärt.

Im Weiteren werden die Auffälligkeiten der beiden Texte in die oben genannten Gruppen eingeteilt. Die Zuweisung der Ausdrücke zu den jeweiligen Gruppen ist mitunter schwer entscheidbar, es gibt zum Beispiel Fälle, in denen Facios Version zwar etwas eleganter ist, aber auch die von Vergerio benutzte Wendung nicht zu tadeln war.

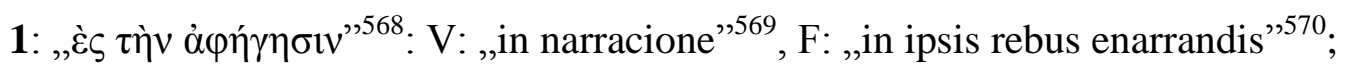

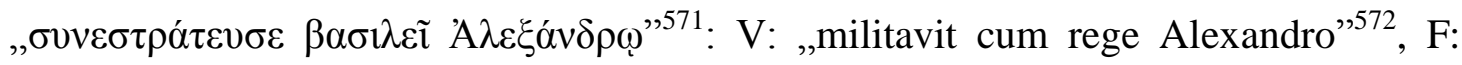
„regiae expeditionis socius fuit ${ }^{\text {}}{ }^{573}$;

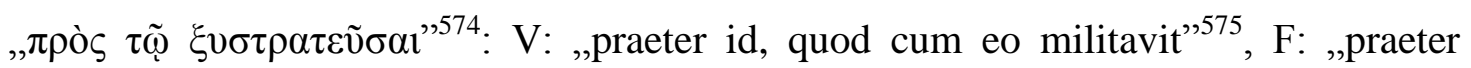
quam, quod et ipse regem bello secutus est" ${ }^{\text {"576; }}$

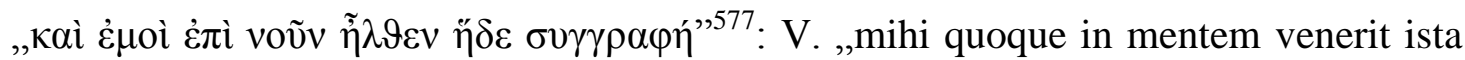
conscriptio" $^{, 578}$, F: ,ego quoque res eius scribere aggressus sum”,579;

\section{2:----}

Arr. Anab. 1. Praef. 2.

Lat. 1302, 2r.

Vat. Lat. 5268, 3v.

Arr. Anab. 1. Praef. 2.

Lat. 1302, 2r.

Vat. Lat. 5268, 3v.

Arr. Anab. 1. Praef. 2.

Lat. 1302, 2r.

Vat. Lat. 5268, 3v.

Arr. Anab. 1. Praef. 3.

Lat. 1302, 2r.

Vat. Lat. 5268, 3v. 


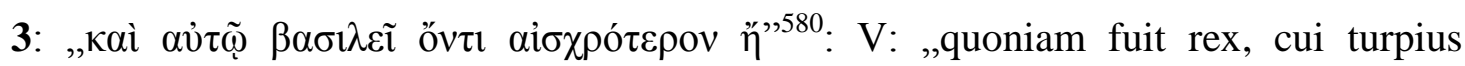

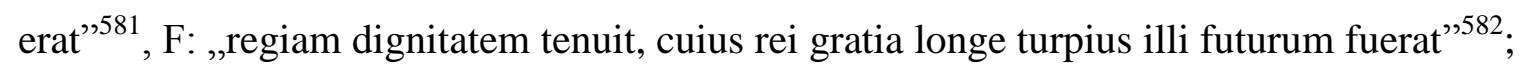

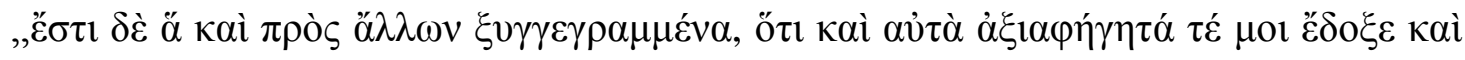

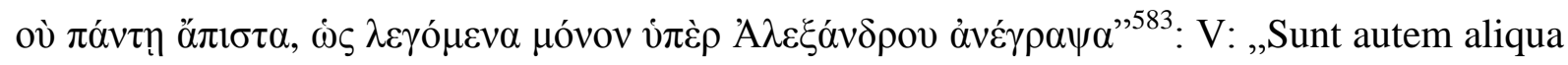
etiam ab aliis conscripta, que quando visa sunt mihi digna narratione et non penitus sine fide illa sola tanquam dicta de Alexandro, non tanquam vera conscripsi" ${ }^{584}$, F: „Quaedam praeterea et ab aliis scripta, quae ipse narratu digna iudicavi tanquam non penitus improbabilia, sed quod de Alexandro tradita sunt, adieci." ${ }^{255}$;

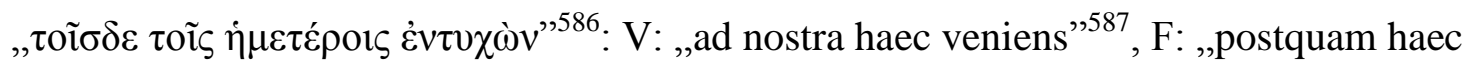
nostra legerit" ${ }^{, 588}$.

\subsubsection{Die ,zweite praefatio" ${ }^{, 589}$}

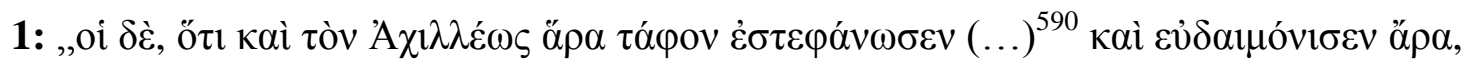

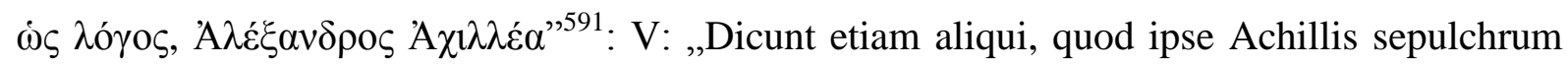
coronavit, felicemque in hoc eum dixit" ${ }^{\prime 592}, \mathrm{~F}$ : „Fertur quoque Achillis sepulchrum coronasse, et ob id felicem dixisse" ${ }^{, 593}$;

Arr. Anab. 1. Praef. 2.

Lat. 1302, 2r.

Vat. Lat. $5268,3 \mathrm{v}$.

Arr. Anab. 1. Praef. 3.

Lat. 1302, 2r. In diesem Fall ist es der sonst bündig formulierende Vergerio, der den Satz mit den Worten „,non tanquam vera” ergänzt, die zwar im griechischen Text nicht vorkommen, aber das Verständnis erleichtern.

Vat. Lat. 5268, 3v. Der Sinn des Satzes wird in Facios Version gar nicht wiedergegeben.

Arr. Anab. 1. Praef. 3.

Lat. 1302, 2r.

588 Vat. Lat. 5268, 3v-4r.

589 Arr. Anab. 1. 12. 1-5. Für den Text der Übersetzungen vgl. im Pariser Codex: 11r-v, im Vatikanischen: 20r21r.

590 Die in modernen Ausgaben vorhandene Erwähnung von Hephaistion, der nach Arrian Patroklos' Grab bekränzt haben soll, fehlt in beiden Übersetzungen, so dass man möglicherweise davon ausgehen kann, dass

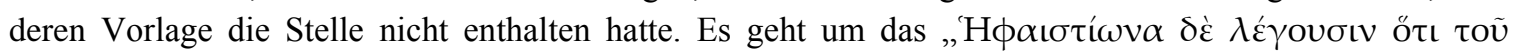

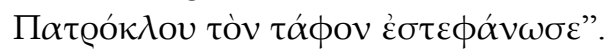




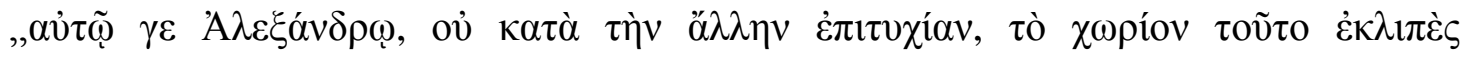

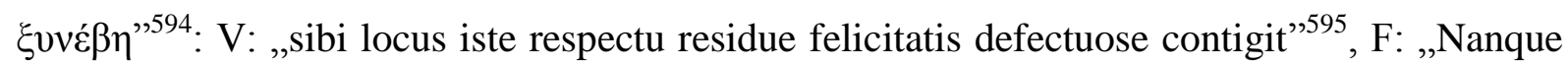
haec una pars tanto Regi ad cumulum felicitatis videtur defuisse" ${ }^{\text {} 596}$;

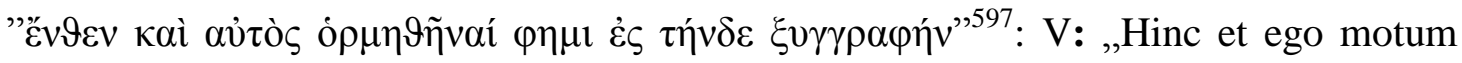
esse me dico in hanc conscriptionem faciendam”, ${ }^{\text {, }}$, F: „Qua primum causa adductus sum, ut eius res licet a pluribus scriptas scirem, et ipse litteris mandarem" ${ }^{499}$;

2: „ő $\tau 1$ O O posteros Homerum preconem habuerit”601, F: „quod Homerum rerum suarum preconem nactus esset" ${ }^{\prime 602}$;

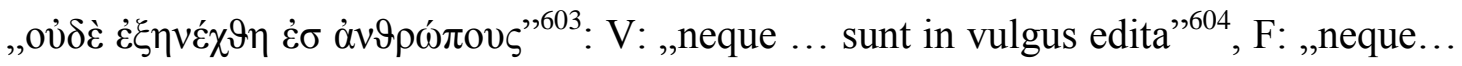
litteris proditae sunt" ${ }^{605}$;

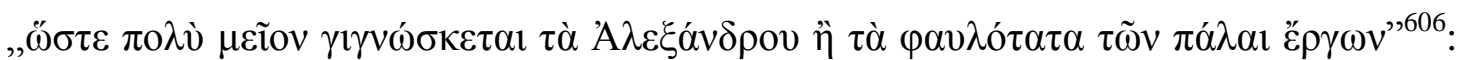
$\mathrm{V}$ : „itaque multo minus cognoscuntur Alexandri opera, quam vilia gestorum antiquorum "607, F: „ita est factum, ut nobis minus notae sunt Alexandri res magnae atque praeclare, quam multorum veterum infimae exigueque",608;

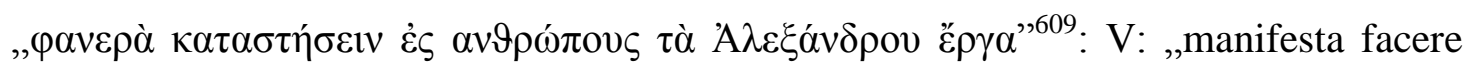
apud homines opera Alexandri" ${ }^{610} \mathrm{~F}$ : ,,res ab eo gestas conscriberem”, ${ }^{\text {, }}$

Arr. Anab. 1.12.2.

Lat. 1302, 11r.

596 Vat. Lat. 5268, 20r. Die Übersetzung Facios ist besser, aber mit der Einschränkung, dass „,tanto regi” im Original nicht vorhanden zu sein scheint.

597 Arr. Anab. 1.12.4.

598 Lat. 1302, 11v.

599 Vat. Lat. 5268, 20v-21r.

600 Arr. Anab. 1. 12. 1-2.

601 Lat. 1302, 11r.

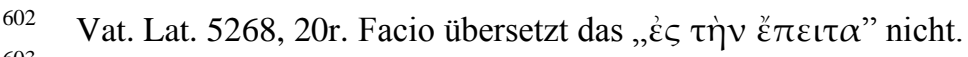

603 Arr. Anab. 1.12.2.

604 Lat. 1302, 11r.

605 Vat. Lat. 5268, 20r.

606 Arr. Anab. 1. 12. 2-3.

607 Lat. 1302, 11r.

608 Vat. Lat. 5268, 20v.

609 Arr. Anab. 1. 12. 4-5.

610 Lat. 1302, 11v.

611 Vat. Lat. 5268, 21r. 


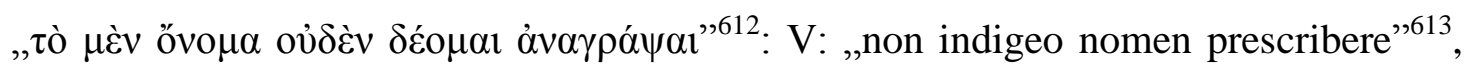
$\mathrm{F}$ : „,nomen profiteri non oportere existimo" ${ }^{, 614}$;

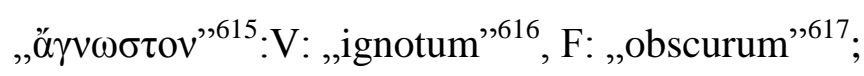

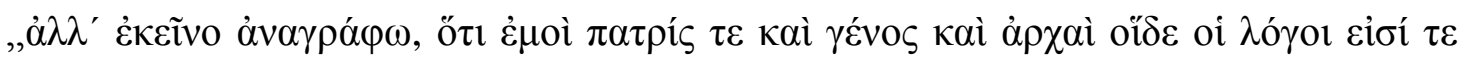

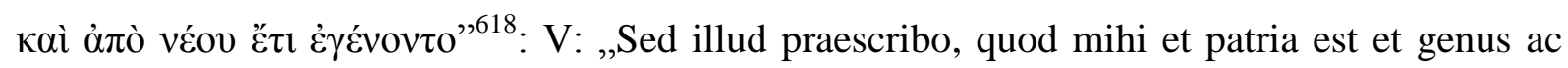
magistratus facultas autem sermonis et est et usque a iuventute fuit"619, F: „Illud dixisse satis fuerit, mihi patriam familiam magistratus ac bonas artes esse, et a puero semper fuisse" ${ }^{\text {620; }}$

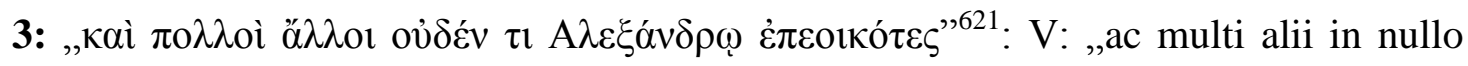
similes Alexandro"622, F: ,et alii plerique rebus gestis et Gloria haudquam pares"623;

612 Arr. Anab. 1.12.5

613 Lat. $1302,11 \mathrm{v}$

614 Vat. Lat. 5268, 21r. Facios Lösung ist eleganter als Vergerios wörtliche Wiedergabe, entfernt sich aber

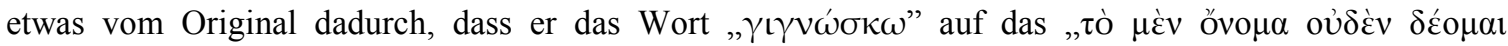

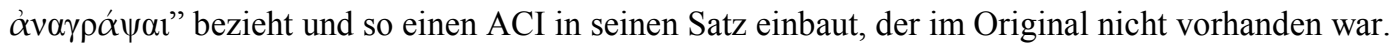

615 Arr. Anab. 1.12.5.

616 Lat. $1302,11 \mathrm{v}$

617 Vat. Lat. 5268, 21r. Facios Übersetzung des „ð̋ $\gamma v \omega \sigma \tau o v ”$ mit „obscurum”, mit dem Gegensatz zu „clarus” also, als Attribut des „övo $\mu$ ” ist ausdrucksvoller, als Vergerios wörtliche Wiedergabe, entfernt sich aber etwas mehr vom Original. Auch im Griechischen hätte es die Möglichkeit gegeben, ein Wort zu

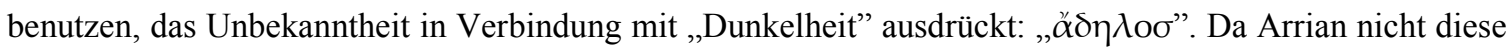
Möglichkeit benutzt hatte, ist Facios „obscurus” etwas weniger korrekt als Vergerios „,ignotum”. Arr. Anab. 1.12.5.

619 Lat. $1302,11 \mathrm{v}$

${ }^{620}$ Vat. Lat. 5268, 21r. Facios Formulierung ist hier wieder etwas eleganter als Vergerios mit "quod” einge-

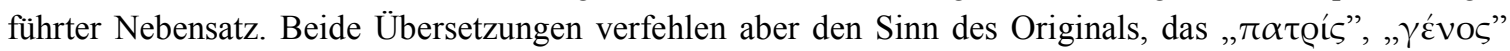

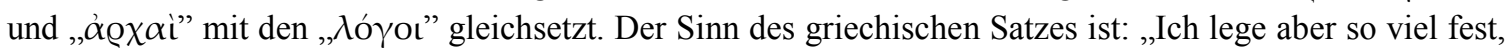
dass meine Heimat, meine Abkunft und meine Ämter sind und waren vom Anfang an diese Erforschungen.” Beide Übersetzungen verstehen den Satz so, dass Arrians Behauptung ist, dass er überhaupt über Heimat, Herkunft, Ämter und „bonae artes” verfüge. Der Unterschied zwischen den beiden Übersetzungen ist,

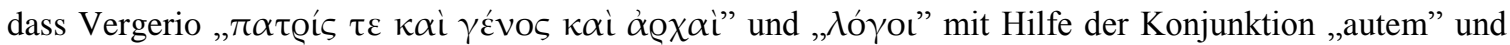
der Kontrastierung von „est”, bzw. „esse” mit „semper fuisse” einander gegenüberstellt (,,.. dass ich eine Heimat, Herkunft und Ämter besitze, und die Redekunst bereits seit meiner Jugend, schon immer besaß”); Facio dagegen macht zeitlich keinen Unterschied zwischen den verschiedenen „Gaben”: über alle diese Begabungen soll Arrian sowohl in der Gegenwart verfügen als auch schon immer verfügt haben. Die Tatsache, dass aber Vergerios grundlegendes Missverständnis des Satzes von Facio wiederholt wird, macht den Eindruck, dass er in seiner „Neuübersetzung” sich in erster Linie nicht auf das Original, sondern auf Vergerios lateinische Fassung gestützt hatte.

Arr. Anab. 1.12.2.

622 Lat. 1302, 11r.

623 Vat. Lat. 5268, 20v. Wahrscheinlich, um den ihm zu einfach erscheinenden Text zu schmücken, nahm Facio eine Ergänzung mit ,rebus gestis et Gloria” vor. Die einzige Erklärung wäre sonst, dass hier seine Vorlage anders gewesen wäre als die des Vergerio. Da die zwei Vorlagen sonst übereinzustimmen scheinen, ist das vielleicht doch nicht der Fall. 


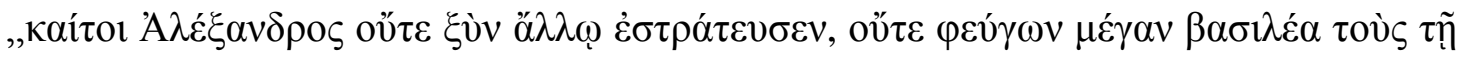

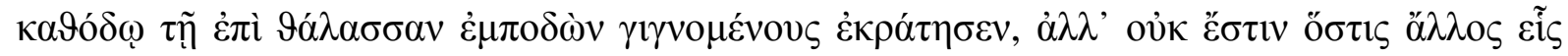

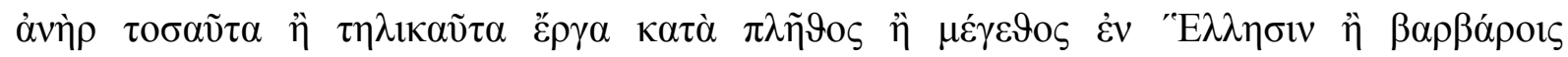
$\dot{\alpha} \pi \varepsilon \delta \varepsilon i \xi \alpha \tau 0^{0,624}: \mathrm{V}$ : „Atqui Alexander non militavit sub alio, neque fugiens magnum regem, eos vicit, qui impedimentum prestabant descensu versus mare, sed nec est aliquis alius unus homo, qui tot aut talia opera multitudine vel magnitudine in grecis aut barbaris quemadmodum Alexander (hinc: exp) effecerit.”,625, F: „At quamvis neque alieno ductu militaverit, neque persarum Regem fugiens vicerit, qui obstabant, quominus in maritinam regionem descenderet, tamen alius nemo mortalium est, sive graecus sive barbarus, vel multitudine rerum gestarum vel magnitudine conferendus". ${ }^{626}$

\subsubsection{Fazit: Die Unvergleichbarkeit der Texte}

Auf Grund dieses kurzen Vergleiches der ausgewählten Passagen der beiden Übersetzungen kann man feststellen, dass Facios Version oft in einem eleganteren Latein verfasst ist als Vergerios manchmal allzu wortnahe und deswegen etwas mühsam klingende Wiedergabe des griechischen Textes (vgl. die Beispiele in der Gruppe 1). Weiterhin spürt man aber oft den Drang des Neuübersetzers, seinen Vorläufer auf jeden Fall und immer korrigieren zu wollen, und zwar selbst in Fällen, in denen eine Korrektur nicht unbedingt nötig gewesen wäre. Diese nicht unbedingt nötigen Korrekturen ergeben dann entweder einen zwar auf Latein besser klingenden, aber dem griechischen Original weniger treuen Text (vgl. die Beispiele der Gruppe 2), oder sogar eine Übersetzung, die zur stilistischen Verbesserung des lateinischen Textes nichts beiträgt und auch dem Original weniger treu ist (vgl. die Beispiele der Gruppe 3). In den untersuchten Passagen gab es keine inhaltlich-grammatikalische Korrektur des vergerianischen Verständnisses des Originals, sondern ganz im Gegenteil. Es gab sogar ein

\footnotetext{
624 Arr. Anab. 1.12.4.

625 Lat. $1302,11 \mathrm{v}$.

626 Vat. Lat. 5268, 20v. Facio gibt den Sinn des Satzes nicht korrekt wieder: sein „quamvis - tamen” ergibt einen anderen Sinn als der griechische Satz. Facios Satz bedeutet: „obwohl Alexander nicht unter der Führung von jemandem Kriege führte (...) trotzdem gibt es niemanden unter Griechen oder Barbaren, den man

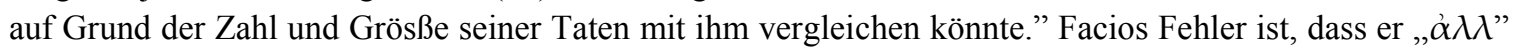
mit „tamen” (trotzdem), statt mit „sed” (sondern) übersetzt. Die richtige Übersetzung des Satzes wäre: „Und dies passiert (dass Alexander weniger bekannt ist, als viele Andere), obwohl Alexander nicht unter der Führung von jemandem anders Kriege geführt hat (...), sondern es gibt niemanden unter Griechen oder Barbaren, den man auf Grund der Zahl und Größe seiner Taten mit ihm vergleichen könnte." Die andere Lösung wäre, die Struktur des Satzes etwas aufzulockern, und „ $\alpha \lambda \lambda$ '” nicht unbedingt übersetzen zu wollen, sondern aus dem einen Satz zwei Sätze zu machen. Wichtig ist, dass es sich im griechischen Satz nicht um einen Widerspruch im Sinne von „obwohl-trotzdem” handelt, sondern um eine Korrektur im Sinne von: ,(obwohl) nicht-sondern”.
} 
Beispiel dafür, dass Facio Vergerios Missverständnis des Originals übernommen hatte (Anm. $623)$.

Es kann selbstverständlich kein richtiger Vergleich zweier Übersetzungen auf Grund von, wie es hier der Fall war, verhältnismäßig kurzen Abschnitten der Texte erstellt werden. Außer, dass eine solche Untersuchung der beiden Übersetzungen den Rahmen dieser Arbeit sprengen würde, besteht der Grund dafür, warum hier auf einen detaillierten Vergleich verzichtet wurde, auch in der Geschichte der Erstellung der zweiten „Übersetzung”. Wie bereits mit den Anführungsstrichen angedeutet wird, handelt es sich in dem Fall gar nicht um eine richtige Neuübersetzung des griechischen Textes. Facios Vorlage war nämlich nicht das griechische Original, sondern Vergerios lateinischer Text. Beweise dafür sind zwei Briefe: der Brief des Nicolaus Sagundinus an einen Freund, in dem er über seine Rolle in der Neuübersetzung des Textes schreibt, und darüber berichtet, dass er Vergerios Übersetzung mit dem griechischen Original verglichen habe. ${ }^{627}$ Der andere Brief stammt von Iacobus Curlus, der an Facios „Neuübersetzung” nach dessen Tod weitergearbeitet hatte und darüber berichtet, dass Facio für das Verständnis des vergerianischen Textes Nicolaus Sagundinus und Theodorus Thessalonicensis (also Theodor von Gaza) konsultiert hatte. ${ }^{628}$ Aus dieser Bemerkung wird klar, dass Facio nur in den Fällen an dem griechischen Original interessiert war, in denen er den von Vergerio erstellten Text nicht verstanden hatte.

Was er tat, kann eher eine stilistische Bearbeitung des lateinischen Textes als eine Neuübersetzung genannt werden. Mit dieser Tatsache lassen sich die Besonderheiten erklären, die die oben gegebenen kurzen, stichprobenartigen Beispiele zeigen. Wenn es das Ziel der Herstellung der neuen Version war, einen besser klingenden Text herzustellen (und in Facios Fall konnte es nicht anders sein), so ist es nicht überraschend, dass Facios Verbesserungsvorschläge immer in diese Richtung gehen. Bei diesem Versuch musste er sich selbstverständlich vom griechischen Original mehr entfernt haben als sein Vorläufer Vergerio, weil er dieses nur selten vor Augen hatte. Auch der Eifer, Stellen zu „,verbessern”, die es gar nicht unbedingt nötig hatten, lässt sich mit Facios Ansatz erklären: jemand, der einen neuen lateinischen Text produzieren möchte und der seinen Vorläufer für seine Version verleumdet hatte, will in seinen eigenen Text nichts von dem seines Vorläufers übernehmen, dies wäre ein Eingeständnis, dass Vergerios Text an manchen Stellen doch ganz brauchbar war.

Die Tatsache, dass Facio mit Vergerios lateinischem Text gearbeitet hatte, macht nicht nur die Besonderheiten seiner Version verständlich, sondern erübrigt sogar einen ausführlichen Vergleich der beiden Übersetzungen, weil es sich gar nicht um zwei Übersetzungen 
handelt, sondern um eine Übersetzung und ihre stilistische Umarbeitung. Die Unterschiede der zwei Texte, die oben erwähnt worden sind, sind demzufolge vorhersehbar, wie sie auch auf Grund der Aussagen beider Übersetzer vorhersehbar sind: Vergerio betont in seiner Widmung seine Absicht, sich auf die Tatsachen zu konzentrieren und Stilistisches zu vernachlässigen, während Facio sich in seiner Widmung an König Alfons als einen Stilisten darstellt, der die letzte Stufe der Latinisierung des Textes vollbringt. ${ }^{629}$

\subsubsection{Projektionen: Der Herrscher und sein Humanist}

Dass Facio, der Neuübersetzer des Textes, Vergerios Arbeit verschmäht, ist kein Wunder. Als „Neuübersetzer”, der noch dazu nicht mit dem Original gearbeitet hatte und sich somit auf die stilistischen Verbesserungen des lateinischen Textes beschränken musste, konnte er natürlich Vergerios Latein nur als ganz entsetzlich darstellen. ${ }^{630}$ Außerdem, wie bereits erwähnt wurde, diente das Tadeln von Sigismunds Unkultur, womit Facio Vergerios fehlende sprachliche Eleganz erklärte, als eine gute Vergleichsfolie für die Darstellung des Alfons.

Die treffendste Anekdote zur Frage von Sigismunds Latein scheint die Erzählung seiner grammatikalischen Blamage auf dem Konzil von Konstanz zu sein. Nach der Anekdote soll Sigismund das Wort Schisma als ein Maskulinum verwendet haben. Als er auf seinen Fehler hingewiesen wurde, soll er folgende Antwort gegeben haben: „Ego sum rex Romanus, et supra grammaticam" ${ }^{631}$. Paradoxerweise steht aber diese Anekdote in ihrem ursprünglichen Kontext nicht als Beweis der Unkultur des Königs, sondern ganz im Gegenteil: sie sollte seine Schlagfertigkeit demonstrieren. ${ }^{632}$ Es lohnt sich, die Anekdote in Cuspinianus' Erzählung wiederzugeben:

629 „Arrianus...latinus factus est”: Stadter, Arrianus, S. 9.

630 Für eine Zusammenfassung von Bartolomeo Facios Leben vgl. Paul Oskar Kristeller, „The Humanist Bartolomeo Facio and His Unknown Correspondence", in From the Renaissance to the CounterReformation, Essays in the honour of Garrett Mattingly, hrsg. v. Charles H. Carter (New York: Random House, 1965), 56-74, [im Weiteren: „Facio”]. Aus Kristellers Beschreibung geht eindeutig hervor, dass Facios finanzielle Situation sich erst mit seiner Anstellung bei dem König von Neapel, Alfons, verbessert hatte. Alfons war ein großzügiger Arbeitgeber, außer dem regelmäßigen Gehalt hat er für seine Aufträge zusätzlich bezahlt: Vgl. Kristeller, Facio, S. 60. Ein weiterer Beitrag zum Leben Facios ist in Bentleys Buch vorhanden: Bentley, Politics, S. 100-108. Bentley schreibt auch ausführlich über die Großzügigkeit von Alfons: Bentley, Politics, S. 51-62.

631 In dieser Form das erste Mal in: Matteo Castiglione, Elogi historici (Mantua: Osanna, 1606), S. 234. Der Satz wurde von Menzel ohne die Angabe der Quelle übernommen, durch diese Veröffentlichung fand Sigismunds Bonmot eine große Verbreitung. Vgl. Wolfgang Menzel, Geschichte der Deutschen bis auf die neusten Tage (Stuttgart, Tübingen: Cotta, 1837 (3. Aufl.), S. 477.

632 Eine der ersten Schriften, die diese Anekdote liefern, ist Cuspinianus' Sigismund-Vita: Johannes Cuspinianus, De Caesaribus atque imperatoribus romanis opus insigne (Argentorati [Strassburg]: Mylius, 1540), [im Weiteren: „De Caesaribus”]. Cuspinianus bezeichnet Sigismund als ,facetissimus et ingeniosissimus" (Cuspinianus, De Caesaribus, S. 601). 
Passim autem id de eo scribitur, cum in concilio Constantiensi lapsu forte linguae, alioqui disertus ac facundus, multarumque linguarum peritus, a Grammaticae regulis deerrasset, scismaque masculino non neutro genere (ut Grammatici docent) protulisset, esse tum a Placentino correptum Cardinale. Cui mox ex tempore dixit, Placentine, Placentine, si omnibus placeres, minime nobis places, qui minoris nos auctoritatis quam Priscianum Grammaticum, quem offendisse me asseris, existimas. Maximo omnium, qui aderant cachinno suscepta est Caesaris peccati commissi excusatio. Multarum enim linguarum scientia (ut scripsimus) claruit, et linguam Latinam observavit. ${ }^{633}$

Diese Erzählung stellt den Fehler als einen lapsus linguae und Sigismund als schlagfertig dar, der auf die Kritik des Kardinals ex tempore mit einem lateinischen Wortspiel zu antworten wusste. ${ }^{634}$

Um nach diesem kurzen Exkurs über Cuspinianus' Urteil über Sigismund zu Piccolominis Äußerungen zurückzukehren, kann man feststellen, dass Piccolomini in seinen Schriften auch ein eher positives Urteil über Sigismund gibt ${ }^{635}$. Auf Grund dieser Beispiele kann man davon ausgehen, dass die Beurteilung von Sigismunds Bildung bei Piccolomini und seinen Zeitgenossen nicht so negativ war, wie Piccolominis und Facios Bemerkungen bezüglich der Übersetzung Vergerios vermuten lassen. Er war andererseits auch nicht zu einem Philosophen-König und Bücherfreund stilisiert worden wie zum Beispiel Alfonso von Aragon. Auch durch Cuspinianus' Lob schimmert das Gefühl des Bedürfnisses durch, die Ehre des Königs, was seine sprachliche Kompetenz betrifft, zu retten.

Sigismunds Bemühungen, sich als einen Freund der Musen und einen Unterstützer der Dichter zu profilieren, werden in manchen Fällen karikaturenhaft dargestellt, wie zum Beispiel im Fall der Erwähnung der Dichterkrönung des Ugolino Pisani. Die Krönung wird von Angelo Camillo Decembrio in seinem Traktat De Politia litteraria ${ }^{636}$ verspottet. Ugolino wird als ein reisender Gelehrter porträtiert, der unordentlich aussieht, einen langen Bart hat

633 Cuspinianus, De Caesaribus, S. 601.

634 Die Anekdote lässt sich als eine Paraphrase früherer Erzählungen über Tiberius deuten (bei Dio Cass. Hist. Rom. 57, 17 und Suet. De gramm. 22). So entsteht der Verdacht, dass es hier um eine Anekdote geht, die vielleicht keinerlei historischen Kern hat.

635 Vgl. in seiner Europa: „princeps singulari prudentia”: Enea Silvio Piccolomini, De Europa, Studi e Testi 398, hrsg. v. Adrianus van Heck (Città del Vaticano: Biblioteca Apostolica Vaticana, 2001), S. 30. In De viris illustribus bezeichnet ihn Piccolomini als sermone facetus: Enea Silvio Piccolomini, De viris illustribus, Studi e Testi, 341, hrsg. v. Adrianus Van Heck (Città del Vaticano: Biblioteca Apostolica Vaticana, 1991), [im Weiteren: „De viris”], S. 54. Auch in seinen Kommentaren zu Beccadellis De dictis et factis Alphonsi Regis Aragonum et Neapolis stellt er den Herrscher an manchen Stellen als Beispiel für einen bildungsfreundlichen Herrscher dar. Er legt ihm nämlich den folgenden Satz in einer Anekdote in den Mund: „Stulte agis, qui literis militiam praefers.” Vgl. Enea Silvio Piccolomini, „Commentarii in libros Antonii Panormitae poetae de dictis et factis Alfonsi regis”, in Opera quae extant omnia (Basel: Henricpetri, 1551), 387-471, hier S. 494. Weiterhin stellt Piccolomini Sigismund an mehreren Stellen dieses Werkes als Urheber geistreicher Sprüche dar. Auch aus dem Kontext des Werkes wird klar, dass Piccolomini hier Sigismunds dicta et facta als mit denen des Alfons vergleichbar darstellt.

636 Angelo Camillo Decembrio, De politia litteraria, Beiträge zur Altertumskunde 169, hrsg. v. Norbert Witten (München/Leipzig: K. G. Saur, 2002), S. 398. 
und Nonsens schreibt. Er habe mit ein paar Zeilen bei Sigismund seine Dichterkrönung umstandslos bewirken können, weil der Herrscher sowieso dafür bekannt gewesen sei, leicht solche Titel zu verschenken.

Selbst die Darstellungen, die seine Bildung loben, heben auch nicht ihre Intensität, sondern eher ihre Extensität hervor, also die Tatsache, dass der König viele Sprachen beherrscht habe. Sein Bild in diesen Schriften seiner unmittelbaren Nachwelt ist das Bild eines bildungsfreundlichen, interessierten Königs, nicht aber eines typischen Humanistenkönigs. ${ }^{637}$ Dieses Urteil konnte von Kontext zu Kontext in die eine oder andere Richtung umkippen: in das Negative, wenn es um die Schmähung einer Vorlage für die eigene Übersetzung, und in das Positive, wenn es darum ging, ein exemplum über eine königliche facetia zu liefern. Mit anderen Worten: In einem Vergleich im Sinne von Parallelen hat man die Seiten hervorgehoben, die dem Vergleichsgegenstand ähnelten (wie im Fall von Piccolominis Anekdote in seinen Parallela Alfonsiana, vgl. Anm. 638), während in einem Vergleich im Sinne von Kontrastierung man die Gegensätze betont und Sigismund zum Beispiel als Vergleichsfolie für die Darstellung von Alfonsos Bildung benutzt hat (wie Facio in der Widmung an Alfonso).

Die Kritik, die Vergerios Übersetzung zuteil geworden ist, deutet darauf hin, dass Vergerio und Sigismund - unabhängig von der tatsächlichen Qualität des Textes - mit dieser Übersetzung (Vergerio mit der Übersetzungsarbeit, Sigismund mit dem Auftrag), wenigstens was die unmittelbare Nachwelt betrifft, nicht das gewünschte Ziel erreicht hatten. Die Übersetzung wurde nicht als ein Kunststück humanistischer Übersetzungskunst für einen humanistisch gebildeten König wahrgenommen. Aus Piccolominis Argumentation kann man auch folgern, dass der Ruhm des Herrschers und der seines Humanisten miteinander in engster Verbindung standen. Von Vergerios angeblich schlechtem Latein kam man unmittelbar auf Sigismunds fehlende Lateinkenntnisse und man nahm diese als Begründung für den Qualitätsmangel der Übersetzung. Diese Begründung, obwohl sie von Vergerio überhaupt nicht erwähnt wurde (weil Vergerio in seinem Widmungsbrief alles andere vorhatte, nur nicht sich für sein angeblich „schlechtes Latein” zu entschuldigen), wurde von Piccolomini Vergerio zugeschrieben und von Facio in seinen Mund gelegt. Es handelt sich wahrscheinlich

637 Der große Schritt von Erzählungen und Beschreibungen in die Richtung eines historischen Wahrheitskerns, also die Entscheidung, wie „humanistisch” Sigismunds Bildung in Wirklichkeit war, soll hier nicht riskiert werden. Zur Frage über Sigismunds Lateinkenntnisse darf hier trotzdem kurz der von Haye zitierte Fall erwähnt werden: In Stuhlweißenburg hat Sigismund eine längere lateinische Rede des Ambrosius Traversari ohne eine geschriebene Vorlage in der Hand zu haben, gehört (und darauf, wie es aus dem Kontext verständlich wird, auch gleich geantwortet): Gustav Beckmann, Hrsg., Deutsche Reichstagsakten unter Kaiser Sigmund. Sechste Abteilung. 1435-1437 (Göttingen: Vandenhoeck \& Ruprecht, 1957 [1901]), S. 13, zitiert bei: Haye, Lateinische Oralität, S. 24. 
viel mehr um den Einfluss des Renommees von Sigismund auf die Beurteilung des Vergerio. Man fand Vergerios Latein schlecht, weil er die Arbeit für Sigismund angefertigt hat. Die negative Beurteilung des Herrschers (welche durch einen Vergleich mit Alfonso motiviert war) warf einen Schatten auf den Ruhm seines Humanisten, auch wenn Letzterer entschuldigt wird (er hätte sich nur an Sigismunds Sprachkenntnisse angepasst): er habe trotzdem eine Übersetzung angefertigt, für deren schlechte Qualität man eine Erklärung suchen müsse.

Das Urteil der Forschung über Sigismunds Lateinkenntnisse und über seine Stellung zu Büchern scheint auch später, im Widerhall in wissenschaftlichen Arbeiten, schwankend zu sein. Manche sehen in ihm ein Beispiel für einen gelehrten König, der zum Beispiel zur „Verbreitung des Humanismus” viel beigetragen habe. ${ }^{638}$ In der Darstellung eines anderen ungarischen Forschers wird der gleiche König als „ein Mensch der verpassten Möglichkeiten” bezeichnet. ${ }^{639}$ In derselben Studie werden auch Sigismunds mangelhafte Lateinkenntnisse als Selbstverständlichkeit erwähnt ${ }^{640}$ und auch die Tatsache, „dass Beccadelli seine obszöne Gedichtsammlung, den Hermaphroditus, ausgerechnet Sigismund gewidmet hatte", spreche auch nicht besonders für Sigismund, so heißt es in dieser ausgesprochen feindseligen Darstellung. ${ }^{641}$ Es ist vielleicht Georg Voigt, dessen Urteil Sigismunds Einstellung am besten zusammenfasst: „Aber er ward jedes Mal ein anderer, wenn er in eine andere Atmosphäre kam, seit seiner Rückkehr aus Italien scheint er seine dortigen Liebhabereien vergessen zu haben.",642

Piccolomini beschreibt in seiner Schrift den Text der missglückten Übersetzung als den von Altersschwäche gebrochenen Körper des Übersetzers. In diesem metonymischen Konstrukt wird der Humanist ganz mit seinem Werk identifiziert. Dies mag zwar erstens ein rhetorischer Griff sein, zweitens spielt es auch auf die konkrete Tatsache an, dass Vergerio die Übersetzung als alter Mensch geschrieben hatte und dass er bereits tot war, als Piccolomini über ihn schrieb, drittens bringt er aber trotzdem etwas im Allgemeinen von der tatsächlichen Wahrnehmung von Humanisten und Humanisten-Sein zum Ausdruck. Ein Text, der - aus welchen Gründen auch immer - nicht den Erwartungen der humanistischen Gemeinschaft

638 Für diese Meinung ist zum Beispiel Klára Pajorins Studie zu zitieren: Pajorin, A magyar humanizmus.

639 Vgl. Csaba Csapodis Studie über Sigismund: „A magyar könyvkultúra Zsigmond korában [Ungarische Buchkultur im Zeitalter von Sigismund]", Magyar Könyvszemle 111 (1995): 1-14, [im Weiteren: „Könyvkultúra”], hier S. 13. Zitate übersetzt von Zs. K.

640 Csapodi, Könyvkultúra, S. 8.

641 Für den Stil der Studie, der von Csapodis persönlicher Aversion gegen Sigismund diktiert wird, sei hier deren letzter Satz zitiert: „Auch seine großen Bauprojekte waren Ausdruck nicht seiner Liebe zur Kunst, sondern seiner Megalomanie." Csapodi, Könyvkultúra, S. 14.

642 Georg Voigt, Die Renaissance: Die Wiederbelebung des classischen Alterthums, 2 Bde. (Berlin: Aretz, 1932), [im Weiteren: „Wiederbelebung”], Bd. 1, S. 279. Das Angenehme an Voigts Beschreibung ist, dass er diese Wechselhaftigkeit nicht von einem moralisierenden Gesichtspunkt aus darstellt. Was er beschreibt, ist einfach die Kontextbezogenheit von Sigismunds Interessen. 
entsprach, konnte „den Tod” des Ruhmes von dessen Autor bedeuten, auf jeden Fall aber seine Zugehörigkeit zur Gemeinschaft gefährden. Es ist eine Ironie des Schicksals, dass der „literarische Leichnam” eines Humanisten, der in seinem Leben unter anderem auch durch seine Werke an der memoria großer Verstorbener gearbeitet hatte, von Piccolomini gerade mit einem von ihm und von anderen Humanisten verrufenen Text identifiziert worden ist.

Man kann Vergerios Tätigkeiten folgendermaßen zusammenfassen: er lebte in Buda in Isolation. Er stand mit anderen Humanisten kaum in Kontakt. Heute ist ein einziger Brief, der in dieser Zeit (nach 1418) an ihn gerichtet wurde, zu lesen ${ }^{643}$ : der Brief des Nicolaus Venetus (Nicolo die Leonardi), in dem der Verfasser des Briefes kurz über sein Leben berichtet, ab dem Zeitpunkt, da er mit Vergerio nicht mehr in Briefkontakt stand: seit 8 Jahren sei er blind. Nicolaus berichtet sogar über Geschehnisse, die vor seinem Blindwerden sich ereignet haben. Dies bedeutet, dass die beiden zum Zeitpunkt des Schreibens dieses Briefes (1437) sich schon länger als acht Jahren nicht mehr geschrieben haben. Dementsprechend ist dieser Brief eher als ein Beweis für den Abbruch der Kontakte Vergerios mit seinen Freunden in Italien zu sehen, als als einer für seinen sporadischen Briefwechsel.

Das einzige Werk, das er für Sigismund angefertigt hatte und das uns heute noch zur Verfügung steht, ist von den anderen Humanisten als niveaulos verrufen worden, was nicht unbedingt nur mit der tatsächlichen Qualität der Übersetzung zu tun hat ${ }^{644}$, sondern eher mit dem Ruf des Übersetzers und noch viel mehr mit dem des Herrschers, der es übersetzen ließ. Aber selbst dieser Ruf hat etwas mit Humanisten-Sein zu tun: mit einer Existenz, in der Sein und Schein eng miteinander zusammenhängen. Vergerios schlechte Beurteilung ist teilweise seiner Isolation zu verdanken, in der er in Buda gelebt hat. Diese war so vollkommen, dass man ihn in Italien schon vor seinem Tod für tot gehalten hatte: ,errant igitur qui credunt eum iam diu vitam amisisse” - bemerkt der Verfasser einer vita des Vergerios. ${ }^{645}$ Positive Kritik wiederum hört man über seine Tätigkeit in Buda nicht. Wenn man davon ausgeht, dass Humanist-Sein kein Merkmal ist, das unbedingt ein Bestandteil der Persönlichkeit bleibt, sondern in Selbstdarstellungsstrategien immer neu konstruiert werden muss, so könnte man feststellen, dass Vergerios letzter Auftritt als Humanist 1421 war (Anm. 493), im Jahr, in dem er die Zuhörerschaft seines Diskurses über die vier Artikel der Hussiten mit seiner Eloquenz beeindruckte.

643 Vergerio, Epistolario, S. 395-398.

644 Ein weiterer Grund der negativen Beurteilung dieses Textes ist wahrscheinlich in einem von Girgensohn beschriebenen Phänomen zu suchen, und zwar in dem sich schnell ändernden Stilideal der Humanisten. Vgl. Anm. 390.

645 Die vita wurde herausgegeben in: Vergerio, Epistolario: S. 474 f. Smith datiert die Schrift für die Zeit zwischen 1444 und 1447. 


\section{Benedetto da Piglio: ein Humanist?}

\section{Einleitendes}

\subsection{Allgemeines}

Am 27. September des Jahres 1417, an dem Tag also, an dem Poggio Bracciolini seine Trauerrede für den Kardinal Zabarella vortrug, hielt ein Gelehrter Namens Benedetto da Piglio auf dem Konzil eine Deklamation von Lucan. ${ }^{646}$ Ähnlich wie Vergerio benutzte auch Benedetto das Konzil dazu, sich einen neuen Brotherren $\mathrm{zu}$ suchen und bemühte sich deswegen offensichtlich darum, sich als einen Humanisten darzustellen. Auch er wurde wie Vergerio zum Dichter gekrönt. Von seiner Krönung erfährt man wie bei jenem nur aus einem Kolophon, das ihn als poeta laureatus bezeichnet. Die Tatsache, dass er nirgendwo anders als Träger dieses Titels dargestellt wird, macht - genau wie in Vergerios Fall - die Annahme plausibel, dass die Krönung auf dem Konzil stattfand. Das Kolophon befindet sich in einem Codex, der die Abschrift von Benedettos Deklamation von Valerius Maximus enthält und lautet:

Finis Valerii Maximi, qui lectus est in Constancia civitate tempore generalis concilii per dominum Benedictum de Pilleo poetam laureatum, anno videlicet Domini $1416 .^{647}$

Die Spuren seiner Tätigkeit auf dem Konzil wurden von Bertalot gesammelt. Außer seinen Vorlesungen von Valerius Maximus und Lucan ${ }^{648}$ gibt es zwei Briefe ${ }^{649}$, eine „Egloga"650 über Sigismund und ein autobiographisches Werk, den Libellus penarum, von ihm, die auf dem Konzil entstanden.

646 Der Zusammenfall ist auch von Ludwig Bertalot bemerkt worden, vgl. Ludwig Bertalot, „Benedictus de Pileo in Konstanz", in Ludwig Bertalot, Studien zum italienischen und deutschen Humanismus, 2 Bde., Storia e Letteratura, Studi e Testi 130, hrsg. v. Paul Oskar Kristeller (Rom: Edizioni di Storia e Letteratura, 1975), 305-10, [im Weiteren: „Benedictus”], hier S. 310.

647 Es handelt sich um den Codex Lat. Fol. 585 der Berliner Staatsbibliothek, erwähnt auch bei Bertalot: Benedictus, S. 306.

648 Die Einleitung zu der Lucanvorlesung wurde von Bertalot im oben zitierten Artikel veröffentlicht: Bertalot, Benedictus, S. 307-310.

649 Der erste Brief ist an seinen Bruder gerichtet, diesen hat Wattenbach veröffentlicht: Wilhelm Wattenbach, „Benedictus de Pileo”, in Festschrift zur Begrüßung der 24. Versammlung deutscher Philologen zu Heidelberg (Leipzig: Engelmann, 1865), 97-131, [im Weiteren: „B. d. P. ”], hier S. 128-131. Den zweiten schrieb er an einen Kritiker seiner Ecloga auf Sigismund, ebenfalls von Wattenbach veröffentlicht: Wilhelm Wattenbach, „Benedictus de Pileo”, Anzeiger für Kunde der Deutschen Vorzeit 62 (1879): 225228, [im Weiteren: „de Pileo”].

650 Ed. Wattenbach, B. d. P., S. 124-127. 


\subsection{Benedettos Leben}

Über Benedettos Schicksal auf dem Konzil erfährt man im Libellus, von dem Wattenbach Auszüge veröffentlicht hat. ${ }^{651}$ Vor der ausführlicheren Erörterung des Werkes ist es sinnvoll, die wichtigsten Ereignisse dieses Lebens zusammenzufassen. ${ }^{652}$ Der aus Piglio stammende Gelehrte ${ }^{653}$, der seine Studien wahrscheinlich in Bologna absolvierte ${ }^{654}$ und der schon unter Alexander V. als scriptor in der Kurie gearbeitet hatte ${ }^{655}$, kam mit dem Papst Johannes XXIII. im Gefolge des Kardinals Pietro Stefaneschi degli Annibaldi auf das Konzil. 1415 begleitete er den Papst bei seinem Fluchtversuch von Konstanz und geriet dabei in Neufchâtel in Gefangenschaft. Er wurde hier gezwungen, acht Monate (ab dem 5. April bis zum 25. November) im Kerker zu verbringen. Nachdem er im November auf freien Fuß gesetzt worden war, ging er wieder nach Konstanz. Da der Kardinal Stefaneschi ${ }^{656}$ (der bei dem Fluchtversuch seine Leute trotz seines Versprechens nicht aus der Gefangenschaft befreite) verschwand, musste sich Benedetto nach einem anderen Brotgeber umschauen. Die Konzilsstadt war ideal für diese Arbeitssuche und so hat der italienische Gelehrte hier sein Glück versucht. Die Früchte seiner literarischen Tätigkeit lassen sich auf die Zeit datieren, die er mit der Suche nach einer Anstellung auf dem Konzil verbrachte.

651 Wattenbach, B. d. P.

652 Die meisten Daten dieses Lebens können auf Grund des Libellus rekonstruiert werden. Obwohl diese Praxis nicht ganz ohne Bedenken verwendet werden kann, kann man in diesem Fall mit großer Wahrscheinlichkeit annehmen, dass sie nicht ganz in die Irre führt: Obwohl auch im Libellus einiges erfunden zu sein scheint, stimmt wahrscheinlich die Ausgangssituation mit der historischen Wirklichkeit von Benedettos Leben überein. Die Fragen der Fiktionalität und Realität im Libellus werden später ausführlicher erörtert. Für eine kurze Zusammenfassung von seinem Leben, außer dem Artikel Wattenbachs (Wattenbach, B. d. P.) und Bertalots (Bertalot, Benedictus) vgl. Cecil Grayson, „Benedetto da Piglio”, [im Weiteren: „Benedetto”, in Dizionario Biografico degli Italiani, [im Weiteren: „DBI’], (Rom: Treccani), Bd. 8 (1966), S. 443-44. Sabbadini, Le scoperte, Bd. 1. S. 152-154, Hrsg., Neues Archiv der Gesellschaft für Ältere Deutsche Geschichtskunde Bd. 12 (1887), S. 607-608. Die erwähnten Zusammenfassungen gehen auf Wattenbachs Artikel (B. d. P.) zurück, der auf Grund des Libellus eine plausible Lebensbeschreibung Benedettos rekonstruiert hat. Birgit Studt, „Tamquam organum nostre mentis. Das Sekretariat als publizistisches Zentrum der Päpstlichen Außenwirkung", in Kurie und Region, hrsg. v. Brigitte Flug, Michael Matheus, Andreas Rehberg (Stuttgart: Franz Steiner Verlag, 2005), 73-92. Zu Benedetto gibt es auch einen C.A.L.M.A. Artikel: „Benedictus de Pileo“, C.A.L.M.A., Bd. 2., 008, S.227-228.

653 Für die Zeit seiner Geburt gibt es keine Hinweise.

654 Dies kann auf Grund der „Freunde” behauptet werden, die Benedetto selbst im Libellus aufzählt.

655 Ottenthal erwähnt ihn als „Scriptor und Abbreviator unter Alexander V., als Sekretär in Verwendung 1418 1422”; vgl. Emil von Ottenthal, „Die Bullenregister Martin V. und Eugen IV”, Mittheilungen des Instituts für Österreichische Geschichtsforschung 1. Ergänzungsband (1885) 401-589, [im Weiteren: „Bullenregister"], hier S. 474.

656 Stefaneschis Leben mit einer ausführlichen Bibliographie befindet sich in: Jörg Garms, Die mittelalterlichen Grabmäler in Rom und Latium vom 13. bis zum 15. Jahrhundert, 2 Bde. (Wien: Verlag der Österreichischen Akademie der Wissenschaften, 1981-1994), [im Weiteren: „Grabmäler”], Bd. 2, S. 126-129. 


\subsection{Benedettos Spuren auf dem Konzil}

\subsubsection{Benedettos Brief an seinen Bruder}

Der Wiener Codex ${ }^{657}$, in dem sein später zu erörternder Libellus überliefert wurde, enthält auch einen auf den 14. Februar 1415 datierten Brief, den Benedetto an seinen Bruder gerichtet hatte. Der Brief enthält die Beschreibung von Konstanz und fügt sich in die Tradition der Städtebeschreibung. Man kann Benedettos Bericht über Konstanz selbstverständlich nicht mit Brunis Laudatio urbis Florentie vergleichen. Es geht um eine fremde Stadt und nicht um die Gründung des Mythos der eigenen Stadt. Zweitens sind die Länge und das anvisierte Publikum auch zu verschieden, um einen Vergleich vornehmen zu können. Es bietet sich vielmehr an, Benedettos Beschreibung mit Brunis Brief an seinen Freund Niccoli zu vergleichen, in dem dieser 1414 Konstanz beschreibt. Beide Beschreibungen sind im Buch von Klaus Voigt analysiert worden. Der Autor beschränkt sich aber hauptsächlich auf die kurze Wiedergabe des Inhaltes der Briefe, deswegen ist hier ein kurzer Vergleich nicht überflüssig. ${ }^{658}$

Benedetto fängt seinen Brief mit der Beschreibung der ersten Sitzungen des Konzils an sowie der Bemerkung, dass sein Bruder diese Nachrichten an Giacomo Colonna (,tuo meoque domino Iacobo de Columna") und anderen Bekannten weitergeben könnte. Er fasst die Konzilsgeschehnisse kurz zusammen, bemerkt, dass bis zu dem Zeitpunkt der Niederschrift des Briefes noch nichts entschieden werden konnte, und berichtet über die Unstimmigkeiten in der Sache Wahlmodus auf dem Konzil. Nach dieser Zusammenfassung berichtet er flüchtig, durch die Figur der praeteritio, über einige Details, die noch interessant sein könnten: über die Besucher des Konzils und über die Spektakel. Er schreibt auch über die Königin Barbara von Cilly:

Pretereo augustam, cuius facies imperiali maiestati conformis inter suas Pantasileas et Camillas prefulget, quemadmodum Lucifer inter stellas aut carbunculus pretiosissmus inter gemmas. ${ }^{659}$

657 Wien ÖNB, CVP. 3529, 247r.-249v.

658 Seine Bemerkungen zu den Texten können folgenderweise zusammengefasst werden: In Brunis Brief konzentriert er sich auf das Phänomen „Landschaftsbeschreibung”. Er nennt weiterhin Pausanias als eine mögliche Quelle für die Form eines Itinerars, die im Brief angewendet wird. Bei Benedetto betont er einerseits die Tatsache, dass es ,an eigenwilligen Beobachtungen fehlt”, andererseits den „Optimismus” und die „Lebensfreude”, die nach seiner Meinung in Benedetto wohnen sollten, wenn er sich in Konstanz, ,zumal im Winter so wohlfühlte". Voigt, Berichte, S. 55.

659 Da der Brief von Wattenbach vollständig ediert wurde, gebe ich die Seitenzahlen seiner Ausgabe an: CVP. 3529, 247v-248r, Wattenbach, B. d. P., S. 129. Man muss hier bemerken, dass Benedetto, wenn er diesen Satz als Lob gemeint hat, nicht besonders geschickt war. 
Nach seinem Bericht über die Konstanzer „high society” setzt Benedetto seinen Brief mit der Stadtbeschreibung fort. Er berichtet zuerst über die Größe der Stadt und stellt fest, dass sie große Mengen von Menschen auffangen kann. In den nächsten Sätzen beschreibt er die Lage der Stadt und ihre Tore. Nach einer kurzen Unterbrechung, die ihm Anlass gibt, über seine Müdigkeit und sein fehlendes Talent zu klagen, die ihm das Schreiben erschweren, schreibt er über Nach- und Vorteile der Stadt. Unter den incommoda erwähnt er das Wetter. Es ist nicht so sehr die Kälte, über die er sich beschwert, sondern die Tatsache, dass man kaum die Sonne sehen kann, so dicht ist der Himmel immer mit Wolken bedeckt. Weiterhin erwähnt er, dass in Konstanz keine Feigen und keine Oliven wachsen, weswegen die Einwohner Öl aus fernen Gegenden heranschaffen müssen, und deswegen eher Butter benutzen. Unter commoda wird der Wein und das Essen gelobt und bemerkt, dass die Stadt alles zur Verfügung hat, was zur Verpflegung von Menschen und Tieren gebraucht wird. Diese copia wird im Text auch durch die Namen der Götter, die die Stadt wahrscheinlich als eigene betrachten, veranschaulicht, was auch einen guten Übergang zum Thema des Ursprunges der Stadt ermöglicht:

Sed nescio an mater Enee etiam hanc inter predilectas habuerit, illo forte respectu, quia a Constantio romano cive nomen sortita est. ${ }^{660}$

Er verweilt nicht lange bei dieser Frage und verbindet sie sogleich mit einem ovidianischen Zitat über Rom:

Tanta enim speciosissimarum et pulcerrimarum dominarum ac puellarum nivem candore vincentium multitudo datur hic conspici, ut decenter et huic loco convenire videatur ille Nasonis nostri versiculus de Roma compositus: Mater et Enee constat in urbe sua. ${ }^{661}$

Benedetto schließt den Brief mit seinem Urteil über die Führung der Stadt:

Accedit his, quod perrarum atque optimum est, hec civitas sub serenissimo atque optimo principe floret, ac sincera et vera fruitur libertate. ${ }^{662}$

Bruni fängt seinen Brief mit einer captatio benevolentiae an, er wolle seinen Leser mit den Nachrichten über den Konzilsablauf nicht langweilen, und sich an den Geschmack und die Interessen Niccolis anpassen:

Est autem, ut invitantis opus ad gustum convivarum epulas quaerere, sic scribentis ad amicum convenientem eius desiderio materiam sumere. ${ }^{663}$

\footnotetext{
660 Wien ÖNB, CVP. 3529, 249v; Wattenbach, B. d. P., S. 131.

661 ebda, Zitat: Ovid, ars I. 58

662 ebda
} 
Deswegen wolle er seinem Freund lieber seinen Weg nach Konstanz beschreiben. Weil der Brief hier als Vergleichsbeispiel zu Benedettos Brief beschrieben wird und weil Benedettos Brief keinen Bericht seiner ,,peregrinatio” nach Konstanz enthält, scheint es angebracht zu sein, gleich mit der Stelle in Brunis Brief anzufangen, die sich mit der Stadt Konstanz befasst. Nach einem knappen Auftakt („urbs non magna, sed opulenta atque formosa”664) leitet Bruni auf die Frage des Ursprungs der Stadt über. Er inszeniert sein Sammeln von Informationen als eine persönliche Befragung der Stadtbewohner:

De Constantiae antiquitate et origine, cum saepe a quibusdam civibus quaesissem, nemo adhuc michi occurrit, qui vel avi sui nomen et memoriam, nedum urbis tenere videretur. $^{665}$

Dass man Brunis Bericht über die Unkenntnis der Bewohner über die Vergangenheit von Konstanz nicht kritiklos glauben darf, geht aus der Fortsetzung eindeutig hervor:

Tabulam inveni marmoream, vetustas litteras continentem, ex quibus apparet a Constantio Constantini patre, qui a Diocletiano et Maximiliano Caesar dictus est, hanc urbem nomen coepisse, cum prius Vitudura nuncuparetur. Hanc tabulam nemo Constantiensium legere scit, tenetque vulgus opinio esse santuarium quoddam praecipuae religionis. Itaque mulierculae et cetera imperita turba fricandis per eam manibus iam litteras pene totas ex tabula deleverunt, cum tamen ibi scripta sint non Sanctorum Christi, sed persecutorum Christianae Fidei nomina. ${ }^{666}$

Bruni folgt hier offensichtlich Ciceros Erzählung der Tusculanae disputationes, in der dieser darüber berichtet, wie er als quaestor in Syrakus das Grab des Archimedes, den Bewohnern der Stadt unbekannt, selbst aufgefunden und den Syrakusanern gezeigt hatte. Der Unterschied ist, dass, während Bruni Konstanz und die anderen unterwegs gesehenen Gegenden als barbarisch betrachtet, der Hintergrund von Ciceros Stolz und Überlegenheit die implizit angedeutete Diskrepanz zwischen der großen Epoche der griechischen Kultur und seiner Gegenwart ist:

Ita nobilissima Graeciae civitas, quondam vero etiam doctissima, sui civis unius acutissimi monumentum ignorasset, nisi ab homine Arpinate didicisset. ${ }^{667}$

Auf diese Episode folgt bei Bruni ein detaillierter Bericht über die Regierung der Stadt. Obwohl er keine expliziten Vergleiche der florentinischen und der Konstanzer Stadtregierungsform macht, beantwortet er ähnliche Fragen in seiner Betrachtung der Konstanzer Regierung wie in seiner Laudatio. Er erwähnt nicht nur den Wahlmodus und die 
Länge der Regierungszeit, sondern auch die Tatsache, dass derjenige, der an der Macht ist, in seinem privaten Wohnhaus wohnt, was genau das Gegenteil des von ihm beschriebenen und hochgepriesenen Florentiner Usus ist. ${ }^{668} \mathrm{Er}$ vermerkt die Statik der gesellschaftlichen Struktur, die es den Reichen, die keine noble Herkunft haben, nicht erlaubt, sich mit den equites $\mathrm{zu}$ vermischen. Der letzte Satz des Briefes enthält die Etikettierung der Regierungsform der Stadt: „Gubernatio tamen reipublicae communis est plebeis et nobilibus." 669

Die Unterschiede zu Benedettos Beschreibung der Konzilsstadt sind offensichtlich. Brunis Perspektive ist sehr betont die eines stolzen Erben der antiken Kultur und eines Florentiners. Er hält sich an keine Muster der Stadtbeschreibung, sondern hebt nur die Punkte in seinem Bericht hervor, die kohärent mit seinem Image als Autor waren. Seine Beschreibung ist bei weitem nicht neutral. Sie enthält wesentlich mehr Tadel als Lob. Durch die Episode der von den Konstanzern missverstandenen Marmortafel wird die Frage des Ursprungs angesprochen. Das Lob des Ursprunges ist nach Quinitilanus eine der möglichen zu lobenden Aspekte einer Stadt: „laudantur autem urbes similiter atque homines. Nam pro parente est conditor, et multum auctoritatis adfert vetustas. ${ }^{, 670}$ Die Konstanzer zeigen sich als ihrer eigenen Vergangenheit unwürdig, weil sie sie überhaupt nicht kennen. Dies verwirklicht, was die Rhetorica ad Herennium über eine Tadelrede meint: „in vituperatione: si bono genere, dedecori maioribus fuisse." 671

Benedetto scheint sich an das Muster einer Stadtbeschreibung halten zu wollen. Dass er ein solches im Kopf hat, verrät er mit den Ausdrücken, mit denen er über sein Schreiben reflektiert. In der kurzen Klage über seine Müdigkeit schreibt er über sein Vorhaben als über einen Weg, den er zu bewältigen hat: „lento ac fesso pede iter hoc vincere "672 und dann fasst er kurz zusammen, was er noch in seinem Brief vor hat: „Amodo perstringam quedam incommoda et complura commoda huius loci." ${ }^{, 673}$ Man hat den Eindruck, als hätte er das Muster, das er über eine Stadtbeschreibung im Kopf hatte, unbedingt abarbeiten wollen. Sein Gesamturteil über Konstanz ist im Gegensatz zu Bruni positiv.

Was den Umgang mit dem Barbaren-Topos angeht, so lässt Bruni ihn viel ausführlicher in seinen Brief einfließen. Er berichtet zum Beispiel von unterwegs über die

\footnotetext{
668 „Hos igitur novem viros, quibus rei publice gubernacula commissa sunt, neque alibi quam in publica arce habitare voluit, quo ad rem publicam gerendam paratiores forent.” Hans Baron, „Bruni's Laudatio Florentinae Urbis". In From Petrarch to Leonardo Bruni. Studies in Humanistic and Political Literature, hrsg. v. Hans Baron (Chicago und London: The University of Chicago Press, 1968), 232-263, hier S. 259. Bruni, Epistolae, Bd. 1, S. 109.

Quint. Inst. 3.7.26.

Rhet. Her. 3. 13.

CVP. 3529, 248v; Wattenbach, B. d. P., S. 130.

CVP. 3529, 249r; Wattenbach, B. d. P., S. 130.
} 
Gewohnheit, in den Burgen die Hörner zu blasen, sobald eine größere Gruppe von Reisenden in der Gegend zu sehen ist, was er als „mos barbarum” bezeichnet. ${ }^{674}$ Auch Benedettos Erzählung enthält einige Bemerkungen, die auch als Topoi verstanden werden könnten. Diese sind aber gleichzeitig Bemerkungen, die trotz deren Geschichte in der römischhumanistischen Literatur über barbarische Gegenden vielleicht auch Wahrheiten enthalten. Es sei hier an die Bemerkungen über das Wetter und über die Abwesenheit von Feigen- und Lorbeerbäumen hingewiesen.

Für die Beantwortung der Frage, was in diesen Stadtbeschreibungen „humanistisch”, und was „mittelalterlich” (oder vorsichtiger formuliert: was neu und was traditionell) sei, kann man Paul Gerhard Schmidt heranziehen. ${ }^{675}$ Nach seiner Einsicht sind mittelalterliche Stadtbeschreibungen eher als „descriptiones”, die humanistischen eher als „declamationes” zu charakterisieren. Die mittelalterlichen Beispiele liefern eine viel detailliertere Beschreibung der darzustellenden Stadt, während die humanistischen Vertreter dieser Gattung die Aufzählung von Realien oft „den Anforderungen eines ausgewogenen Redeaufbaus” unterordnen. Benedettos Brief wäre nach dieser Typologie als „mittelalterlich” zu bezeichnen. Er beschreibt von den Stadttoren über das Wetter und bis hin zu den Lebensmitteln, die in der Stadt verzehrt werden, zwar alles flüchtig, aber möglichst konkret. Andererseits versucht er seinen Brief mit vielen antiken Verweisen zu schmücken: die Lebensmittel werden metonymisch durch Götternamen aufgelistet, es wird Ovid zitiert, die Lichtverhältnisse werden durch eine Anspielung auf eine Seneca Stelle beschrieben: die Bewohner von Konstanz „immeriti luunt et dant penas cene Thiestis"676, müssen also mit wenig Sonnenschein auskommen. Ob die Senecasche Allusion hier ganz treffend war, mag man bezweifeln, sie ist eher ein Zeichen für Benedettos Eifer, seine Belesenheit unter Beweis zu stellen. ${ }^{677}$ Was Benedettos historisches Interesse betrifft, so ist der Vergleich zwischen seinem ,a Constantio romano cive nomen sortita est" ${ }^{\$ 678}$ und Brunis Beschreibung der Marmortafel vielsagend. Zusammenfassend kann festgestellt werden, dass Brunis Text mit seiner Rhetorik der Abgrenzung gegenüber den unterwegs getroffenen barbari und der Einwohnerschaft der Konzilstadt, die ihre antike Vergangenheit verkenne, christianisiere und enthistorisiere, sich viel mehr in den

674 Bruni, Epistolae, Bd. 1, S. 105.

675 Schmidt, Städtelob. Für einen Überblick über die Geschichte des Genres in der Antike und im Mittelalter vgl. Carl Joachim Classen, Die Stadt im Spiegel der Descriptiones und Laudes urbium in der antiken und mittelalterlichen Literatur bis zum Ende des zwölften Jahrhunderts (Hildesheim, Zürich, New York: Georg Olms Verlag, 1986).

676 CVP. 3529, 249r; Wattenbach, B. d. P., S. 130.

677 Es ist ein Hinweis auf Sen. Thy. 815-827.

678 CVP. 3529, 249v; Wattenbach, B. d. P., S. 131. 
humanistischen Diskurs fügt, als die andere Stadtbeschreibung - trotz allen Eifers Piglios, seinen Text mit möglichst viel Antike zu schmücken.

\subsubsection{Benedettos Deklamation des Valerius Maximus}

Im Berliner Codex Lat. Fol. 585 befindet sich der Text des „liber valerii maximi factorum et dictorum memorabilium ad tyberium Cesarem"679. Das bereits erwähnte Kolophon mit dem wichtigen Hinweis auf Benedetto als gekrönten Dichter wurde von Mücke ${ }^{680}$, dem präzisen Beschreiber des Codex, in folgender Weise verstanden: Benedetto habe den Text „durchgesehen”. Daraus zieht er die Schlussfolgerung, dass die Hand, die die Glossen durchgehend im ganzen Codex geschrieben hat, vielleicht Benedettos Hand gewesen sein könnte. Mücke fügt aber auch hinzu, dass manche Glossen diese Annahme eigentlich untergraben, da sie nur von einem Deutschen stammen können.

Das Wort „lectus”, das für Mücke also für „,durchsehen” stehen würde, wurde von Bertalot als „vorgelesen” verstanden. ${ }^{681}$ Er hält den Text für den Niederschlag eines öffentlichen Vortrags von Benedetto da Piglio auf dem Konzil. ${ }^{682}$ Wenn man mit Bertalot davon ausgeht, dass Benedetto den Text auf dem Konzil vorgetragen hat, so kann man diesen Auftritt als eine Aktion sehen, mit der sich Benedetto als Humanist profiliert: Valerius Maximus, der einer der Autoren war, der im 14. Jahrhundert neu in die curricula gelangt ist, war ein Lieblingsautor der Humanisten. ${ }^{683}$

\subsubsection{Eine Deklamation von Senecas Briefen?}

Nach Bertalots Meinung darf man vielleicht auch in den Briefen Senecas, deren Abschrift in demselben Berliner Codex enthalten ist, „einen weiteren Gegenstand seiner [Benedettos] Lehrtätigkeit sehen”. Er habe dementsprechend auch diese öffentlich

679 Berlin, Staatsbibliothek, Lat. Fol. 585, f. 5v-204. Ich habe diesen Codex eingesehen.

680 Rudolf Mücke, „Die Ülzener Handschrift zu Senecas Briefen”. In Jahresbericht über die Königliche Klosterschule zu Ilfeld (Nordhausen: C. Kirchner's Buchdruckerei, 1895), 1-43, [im Weiteren: „Ülzener Handschrift'], hier S. 9.

681 Das Wort „lectus” wird von keinem der beiden Wissenschaftler problematisiert, sondern stillschweigend auf die eine oder andere Weise verstanden.

682 Bertalot, Benedictus, S. 306.

683 Sabbadini nennt ihn „caval di battaglia” der Leser: Sabbadini, Le scoperte, Bd. 1, S. 152. Über die Rezeption des Valerius Maximus kann man im Artikel des CTC einen Überblick bekommen: vgl. Dorothy M Schullian, „Valerius Maximus”. In Catalogus Translationum et Commentariorum: Mediaeval and Renaissance Latin Translations and Commentaries, hrsg. v. F. Edward Cranz and Paul Oskar Kristeller (Washington D. C.: The Catholic University of America Press, 1960-), Bd. 5 (1984), 287-403. In diesem Artikel werden zwei Kommentare genannt, deren Autoren in Bologna, in der Stadt also, in der Benedetto seine Studien absolvierte, tätig waren: Johannes de Ravenna und Benvenutus de Imola. 
vorgetragen. ${ }^{684}$ Diese Behauptung kann weder widerlegt, noch durch eindeutige Beweise unterstützt werden. ${ }^{685}$ Ein auf Benedetto hinweisendes Kolophon findet man im Berliner Codex nach diesen Briefen nicht.

\subsubsection{Seine Deklamation von Lucan}

Auf Grund eines Florentiner Codex (Riccard. 784) ${ }^{686}$ kann man jedoch sicher davon ausgehen, dass Benedetto eine Lucan-Vorlesung hielt. In diesem Codex befindet sich Benedettos Praefatio. Der Text selbst ist im Codex nicht enthalten, die Praefatio wurde von Bertalot veröffentlicht.

Der Text der Praefatio wurde bei Bertalot mit Recht als ein Zitatenmosaik bezeichnet. Die zitierten Autoren sind Valerius Maximus, Vergil, Cassiodor, Boethius, Ovid, Hieronymus, Aristoteles, Horaz, Cicero, Seneca, Augustinus und Quintilian. Von manchen dieser Autoritäten werden längere Sätze zitiert, und manche von ihnen lässt Benedetto sogar mehrmals sprechen. Wenn man die Länge der Praefatio im Auge behält (drei Seiten: f. 178v-9r), sieht man, dass Benedetto tatsächlich eine beträchtliche Menge von Zitaten in seinen Text eingebaut hat.

Er beginnt seine Rede, nach einem Bescheidenheitstopos samt Zitatenamalgam, über die Kraft der Rede. In diesem ersten langen Konditionalsatz leitet er die einzelnen Zitate jeweils mit „si” ein, um ihn dann mit einer Frage zu beenden: Warum vertrödelt man, wenn das alles so ist, die Zeit mit unnützen Tätigkeiten? Der Satz gibt den Sinn der ganzen Praefatio wieder: sie stellt eine Ermutigung der Zuhörerschaft dar, virtus anzustreben, ohne die „nec vir bonus esse, nec dicendi peritus potest”. ${ }^{687}$ Dass diese virtus durch Lesen anzueignen ist, geht aus der auf dieses Zitat folgenden Ermutigung zum Lesen eindeutig hervor. Außer diesem bei den Humanisten so oft aufgegriffenen Gedanken gibt es noch einen Punkt in Benedettos Rede, den er besonders stark betont: den Nutzen (und das Benutzen) des Wissens von Rhetorik als eines Mittels durch das man zu höheren Positionen gelangen kann.

Numquam satis admirari sufficio, maxime cum omnes homines natura scire desiderent $^{688}$, et per eloquentiam et sapientiam humillime condicionis viros ad summos honorum dignitatum et principatuum gradus adscendisse cernamus, at illi,

684 Bertalot, Benedictus, S. 306 f.

685 Nach Bertalot sei dies wegen der Tatsache wahrscheinlich, dass die Briefe Senecas auch im Pariser Codex enthalten sind, der außer weiteren Schriften Konstanzer Inhalts auch einen (hier später zu erörternden) Brief Benedettos enthält.

686 Diesen Codex habe ich nicht selbst eingesehen.

687 Hier zitiert Benedetto Quintilian: Instit. 12.2.1. Die Zitate sind in der Ausgabe Bertalots identifiziert.

688 Arist. metaph. 980. a in lateinischer Übersetzung („Omnes homines natura scire desiderant”), vgl. noch Dante, Conv. I. i. 1-2 (,Tutti gli uomini naturalmente desiderano di sapre”). 
qui iam hos honores dignitates et principatus adepti sunt, in eisdem per ipsas eloquentiam et sapientiam conservantur. ${ }^{689}$

Er sagt nicht nur, dass Leute von bescheidener Herkunft in hohe Positionen gelangen können, sondern dass diejenigen, die in diesen hohen Positionen sind (und hier redet er auch von principatuum gradus), diese mit Hilfe der Rhetorik und Weisheit (in dieser Reihenfolge!) sichern können. Dass auch die Herrscher etwas von den Antiken zu lernen haben könnten, bemerkt er auch später, am Ende seines Textes, in Bezug auf Lucan:

Hic habent maximi principes, quid imitentur in Cesare, sapientes in Catone, eloquentes in Tullio, fortes in Sceva ${ }^{690}$, fideles milites in Vulteio ${ }^{691,692}$

In der Rede konstruiert Benedetto sein Profil in mehreren Schritten. Indem er in der Praefatio konsequent die zweite Person Plural benutzt und ständig auf die gemeinsame Lektüre anspielt, konstruiert er eine Gruppe. In einem zweiten Schritt stellt er diese Gruppe als unentbehrlich dar. Wenn antike Schriften die Träger der anzueignenden virtus sind, dann sind damit die Personen, die sich mit diesen Schriften professionell beschäftigen, automatisch aufgewertet. Im dritten Schritt zeigt er sich sogar als einer, der ein Programm anzukündigen hat:

Eya ergo domini mei, de tenebris surgere, ignorantiam pro viribus fugare nitamur.

Und später:

Agite ergo, colite studia, audite, legite libros excellentium virorum. ${ }^{693}$

Mit diesen drei Schritten, in denen er gleichsam sein eigenes Image gezeichnet hat, sehen wir Benedetto nicht nur als jemanden, der zu einer Gruppe gehört, deren Nutzen außer Frage gestellt wurde, sondern als einen Programmgeber derselben Gruppe.

\subsubsection{Die Egloga}

Der Text der Egloga ist heute in zwei Handschriften zu lesen. Wattenbach veröffentlichte sie anhand eines Melker Codex, sie ist aber auch im Berliner Codex $585^{694}$ aufzu-

\footnotetext{
689 Bertalot, Benedictus, S. 307.

690 Marcus Cassius Scaeva, ein Centurio unter Caesar.

691 Vulteius, ein Kapitän Caesars, der in einer ausweglosen Situation seine Soldaten zu Massenselbstmord überredet.

692 Bertalot, Benedictus, S. 309 f.

693 Bertalot, Benedictus, S. $308 \mathrm{f}$.

694 Lat. Fol. 585, f. 204v-206r.
} 
finden. ${ }^{695}$ Hier folgt sie unmittelbar auf das die Abschrift des Valerius Maximus abschließende Kolophon. Wie bereits Mücke in seiner Beschreibung bemerkt hat, enthält die Abschrift der Egloga im Berliner Codex Randglossen, die Wattenbach nicht zur Verfügung standen (Wattenbach veröffentlichte den Text mit seinen Randglossen). ${ }^{696}$ Der Text ist nichts anderes als eine allegorisierende Beschreibung des Konzilverlaufs. Nach Benedettos Absicht sollte die bukolische Welt den Rahmen der Beschreibung darstellen: Konstanz ist der Wald („Forte sub umbrosa cepit Constancia silva” ${ }^{\text {697 }}$ ), die Konzilsväter sind die Hirten (das Wort „,pastores prelatos pro unione ecclesie" versehen). In weiteren Glossen werden in beiden Handschriften „Tirsis” mit „pap. Ioh. XXIII” ${ }^{999}$ und dessen „virga” als „dignitas pontificalis” erklärt. Sigismund wird als „Boreas”,700 vergegenwärtigt, der die Wolken vertreibt und den Himmel aufhellen lässt, dessen Kontrahent der Wind „Auster”,701 ist: „dux Friedericus Austrie”, wie es die Glossen in beiden Handschriften verraten.

Das bukolische Bild wird nicht ganz konsequent beibehalten. Wenn Benedetto über die Hoffnung schreibt, dass das Konzil das Schisma beseitigen wird, wechselt er unvermittelt zu einem anderen Bild und sagt: „Typhis et ipse suis deducet ductibus Argon”. Hier erklären die Glossen, dass Typhis der Steuermann des Schiffes Argo war: „Tiphis quondam magister prime navis nomine Argon" ${ }^{\text {,702 }}$, und sie geben zwei Möglichkeiten für die Identifikation seiner Figur an: „Christus vel pontifex”.

Benedetto nutzt das Gedicht nicht nur zur Glorifizierung Sigismunds, sondern auch zur Klärung der Fluchtgeschichte des Papstes Johannes, in die er selbst verwickelt war. Das Gedicht enthält nämlich eine Stelle, die als Benedettos Entschuldigung dafür verstanden werden kann, dass er mit Papst Johannes XXIII. die Konzilsstadt verließ. Als Johannes aufgefordert wurde, auf seine päpstliche Würde zu verzichten, sei er damit einverstanden gewesen:

Assensit, sed turba subit, que carpere lanas

Et mulgere greges illo regnante solebat,

Subvertitque virum furto tunc Thirsis ab omni

Se rapuit cetu fugiens et nocte sopora, ${ }^{703}$

695 Ich habe den Text in der Berliner Handschrift eingesehen.

696 Mücke, Ülzener Handschrift, S. 2.

697 Die Seitenzahlen gebe ich hier erst nach Wattenbachs Ausgabe (Wattenbach, B. d. P., S. 124-127) („W”) an und dann nach der Foliierung des Berliner Codex („B”). Ich zitiere die Stellen nach der Schreibweise der Berliner Handschrift. W: 125, B: 204v, 1. 
Sperans cuncta sibi ad votum cessura recessit.

Inde bona paucis fortassis mente secutis

Pastorem prefugum, multi mansere volentes

Armentum totumque gregem salvare, nec ipso Precipiente sequi. ${ }^{704}$

Dass die Worte „bona paucis fortassis mente secutis” als Benedettos Selbstentschuldigung zu verstehen sind, wird in der vom Autor verfassten Randglosse zu der Zeile im Berliner Codex verraten: „Si quis michi irascatur, quod dico fortassis, ipse se talem confiteatur esse, de quo sit dubitandum, an bona intentione secutus sit."705

Am Ende des Gedichtes fordert er seine Leser auf, Sigismund-Boreas zu feiern:

Illum ideo ${ }^{706}$ boream pueri iuvenesque senesque,

Per quem tranquille sperantur tempora vite,

Qua datur et poscit ratio, celebretis ovantes. ${ }^{707}$

Nach diesen Zeilen kommt die Sphragis, die nicht nur Benedettos Namen verrät, sondern durch das Zitieren des vergilianischen „tenui modulabar avena” sein Gedicht in eine literarische Tradition einordnet. Benedetto schließt seine Zeilen mit einer Aufforderung zur Korrektur:

Hec ego de Pileo Benedictus carmina nuper

Rustica, dum sedeo tenui modulabar avena. ${ }^{708}$

$\mathrm{Tu}$, qui pro meritis hauris Elicona virentem,

Castiga, si quos errantes videris agnos.

Sic tibi longeve donentur tempora vite,

Sic habeas faciles ad blanda precamina nymphas. ${ }^{709}$

Das Bild, mit dem Benedetto seinen Leser als „Dichter“ feiert, den er darum bittet, seinen Text zu korrigieren, ist ein wenig verwirrend. Das „hauris Elicona virentem” ist selbstverständlich so zu verstehen, dass der Dichter aus der sich auf dem Helikon befindenden Quelle trinken solle (,haurit”) und nicht etwa vom Helikon selbst, der bekanntlich kein Wasser, sondern ein Berg ist. Dies wäre ein wenig gelungenes Beispiel für das metonymische Nutzen des Helikons für die Quelle Hypokrene, das eher als eine Katachrese zu beschreiben wäre, wenn man vom unwahrscheinlichen Fall ausgehen würde, dass es sich hier um einen vom

W: $125, \mathrm{~B}: 204 \mathrm{v}, 6-14$

B: $204 v$

Bei Wattenbach: ,igitur".

W: 127, B: 205v 20-206r 1 .

Verg. ecl. I. 1.

W: 127, B: 206r 2-7. 
Autor beabsichtigten Bildbruch handelt. Gerade weil das Bild als ein poetisches gemeint war, fällt die Ungeschicklichkeit besonders auf.

\subsubsection{Eine Kritik der Egloga und Benedettos Antwort}

In einem von Wattenbach veröffentlichten Brief $^{710}$ verteidigt sich Benedetto gegen einen Kritiker, der seine Egloga angegriffen hatte. Über die Kritik selbst gibt es keine weiteren Informationen, auf ihren Inhalt kann man nur auf Grund von Benedettos Brief schließen. Der Brief ist an einen gewissen Bartolomeus gerichtet. Da im Text auch die Anrede „frater” vorkommt, vermutet Wattenbach, dass es sich um Benedettos Bruder handeln könnte. An ihn hat Benedetto auch seinen Libellus, wenigstens nach seiner Fiktion, geschickt, in dem er ihn auch aufgefordert hat, seinen Text zu korrigieren. Eine ähnliche Situation wäre auch im Fall der Egloga vorstellbar. Die andere Möglichkeit wäre, dass es sich um eine Fiktion handelt, die Benedetto die Möglichkeit geboten hatte, auf die Kritiken seiner Egloga zu reagieren, oder möglichen Kritiken im Voraus zu begegnen.

Laut des Briefes betraf der Angriff ausschließlich die Bezeichnung des Gedichtes als Egloga: „tota pugna si recte sentio contra nomen versatur" ${ }^{\text {,711 }}$. Dementsprechend geht es in Benedettos Antwort um die Erklärung, warum er seinen Rekurs auf die bukolische Tradition für gerechtfertigt hält. Diese Rechtfertigung wird von Wattenbach für „,recht geschickt”, ${ }^{\text {,12 }}$ gehalten. Benedettos Strategie ist die des Nutzens des Bescheidenheitstopos, aber auf eine Weise, die seine Wahl doch als richtig auszuweisen versucht, die also eigentlich den Bescheidenheitstopos untergräbt. Seine Begründung bezieht sich auf die aus der „rota Vergilii” bekannte Zuweisung von Stilebenen zu der jeweiligen vergilianischen Schrift.

Egloga namque carmen, cantum, eulogium caprinum vel rusticum sermonem sonare ab illustribus auctoribus traditur. Ego sum pastor indoctus, qui loquor ad omnes, sed signanter ad pueros, iuvenes, senes, ad te quoque et alios Pierii ingenii viros, quod circa finem egloge ipsius etiam parum sano potest aliunde patere. Dic, queso, quem michi dabis ex Faunis, quem ex Silvanis aut Satiris, quem ex hiis quos noster Naso Montana numina Panes ${ }^{713}$ apellat, qui me rusticior dici possit? ${ }^{714}$

Benedetto begründet seine Wahl der bukolischen Form mit seiner eigenen rusticitas. Diese Erklärung ist wahrscheinlich ironisch (selbstironisch) ${ }^{715} \mathrm{zu}$ verstehen. Wenn man das Beispiel

Vgl. Anm. 652.

Wattenbach, de Pileo, S. 227.

Wattenbach, de Pileo, S. 226.

Ov. epist. 4. 35.

Wattenbach, de Pileo, S. 227.

Die Frage der Ironie und Selbstironie wird später im Kontext des Libellus ausführlicher erörtert. 
des lateinischen Vorbildes Vergil vor Augen hatte, so konnte eine solche Deutung der Gattung, nach der die thematische rusticitas der Bukolik einfach von der persönlichen rusticitas des Autors stammen sollte, nicht ganz ernst genommen werden. Nach der auf den Vergil-Viten basierenden Theorie der sogenannnten „rota vergilii” sind die personae, die den drei Stilarten zugeordnet sind, nicht mit dem Autor, sondern mit dem behandelten Gegenstand gleichzusetzen. ${ }^{716}$ Dass Benedetto hier nicht ganz im Ernst spricht, wird auch durch das „loquor ad omnes, sed signanter ad pueros, iuvenes, senes” klar. Nach „signanter” würde man eine Einschränkung erwarten, stattdessen werden hier durch die Worte „pueros, juvenes, senes" beinahe alle Lebensalter als Adressaten aufgezählt. Benedetto weist also die Kritik mit diesem Scherz zurück, der gleichzeitig ein Bescheidenheitstopos ist. Dieser Topos selbst wird doppelt untergraben: wenn man ihn ernst nimmt, also in dem Sinne versteht, dass Benedetto hier in der Tat als pastor indoctus auftritt, dann wäre seine Wahl der Gattung nach der inneren Logik der Argumentation richtig, dementsprechend würde es sich um keinen Fehler handeln. Wenn man die Stelle ironisch deutet, so spräche genau die humorvolle Antwort gegen die im Topos angekündigte Einfalt des Autors.

Der andere Einwand scheint der Vorwurf zu sein, dass Benedettos Egloga nicht dialogisch gestaltet ist: Benedetto erklärt im nächsten Teil des Briefes, dass auch Vergils Eklogen nicht alle dialogisch aufgebaut sind.

Der Ton des Briefes ist freundlich und demütig, die im Bescheidenheitstopos festgestellte doppelte Haltung Benedettos für den ganzen Brief typisch. Einerseits verteidigt er sich gegen die Kritik des Bartolomeus, gibt aber andererseits immer wieder zu, dass er sein Gegenüber für wesentlich kompetenter hält. Dies gibt er bereits im ersten Satz seines Briefes zu verstehen:

Quid exercitum [...] adversus meam eglogam moves, quam enervam ac parvulam uno expugnare atque illo quidem gregario milite poteras? Quid perdis vulnera, quid Gnosiacam pharetram evacuas, cum una et eadem tenui tuo Appollineo arcu transmissa illam potueris sagitta prosterenere? An id agis, ut clarius pateat te non parum multa intelligere, scire ac posse? Recte me hercule! Cum his, qui ingenium non noverint tuum, mecum vero, qui ipsius acumen longa experiencia didici, supervacue ne dicam inutiliter factum judico. ${ }^{717}$

Die Passage ist deswegen interessant, weil Benedetto eigentlich das Gleiche tut, was er als Schreibweise seines Kritikers beschreibt. Auch Benedetto verschießt hier sein gesamtes rhe-

\footnotetext{
716 In manchen mittelalterlichen Betrachtungen des Themas wird das Personenschema auf das Publikum bezogen. Für die Theorie der genera dicendi vgl. Franz Quadlbauer, Die antike Theorie der genera dicendi im lateinischen Mittelalter (Wien: Hermann Böhlaus Nachf., 1962), [im Weiteren: „Die antike Theorie”]. Ein Beispiel für eine Umdeutung des Personenschemas: Quadlbauer, Die antike Theorie, S. 65. 
torisches Arsenal, um einen Bescheidenheitstopos über seine Wenigkeit, der aber gleichzeitig sein rhetorisches Können beweisen soll, auszuformulieren. Ähnlich also, wie die Rechtfertigung der gewählten Form Elemente enthält, die dieser Selbstverteidigung entgegenwirken (die Behauptung, dass Benedetto ein pastor indoctus sei, wirkt in die entgegengesetzte Richtung des eigentlichen Skopos der Selbstverteidigung), ist dieselbe doppelte Haltung innerhalb des am Briefanfang stehenden Bescheidenheitstopos präsent. Den Gegenpol zur Bescheidenheit bildet nicht allein die im Brief später erörterte Selbstverteidigung, sondern dieser ist bereits im rhetorischen Aufwand der Ausformulierung des Topos impliziert. Diese doppelte Haltung ist zwar in der Literatur ein ubiquitäres Phänomen und wahrscheinlich genauso alt wie die Bescheidenheitstopoi selbst, scheint aber bei Benedetto besonders oft zum Ausdruck gebracht zu werden, wie es in der Analyse des Libellus veranschaulicht wird.

In der Fortsetzung seines Briefes spielt Benedetto auf den Status seines Kritikers und vielleicht sogar auf den aktuellen Aufenthaltsort desselben an:

Nam cum tibi magnis et laudabilibus, cum michi parvis, tamen necessariis, hac in regione negociis occupato, longam et accuratam epistolam scribere non videtur opere precium, sed ut tue voluntati morem geram, lege benivole attenteque, quod sequitur. ${ }^{718}$

Zuerst ist die Frage des Aufenthaltsortes des Kritikers zu klären. Dies ist deswegen von Interesse, weil man, wenn man davon ausgeht, dass der Brief an Benedettos Bruder gerichtet ist, einen wichtigen Hinweis darauf gäbe, wo dieser Bruder, der gleichzeitig auch der Adressat des Libellus ist, sich zum Zeitpunkt aufhielt, als der Libellus entstand. Diese Information wird später bei der Entscheidung der Frage der Fiktionalität des Buches wichtig werden.

Wenn man den Satz auf die Weise versteht, dass sich die Worte ,hac in regione” auf die Geschäfte beider Personen, also auf die Benedettos und auch auf die des Bruders beziehen, dann könnte man davon ausgehen, dass der Bruder sich ebenfalls in der Konzilsstadt aufhielt. Diese Annahme kann vielleicht damit gerechtfertigt werden, dass die Worte „,negociis” und „occupato” sich auf beide Personen beziehen: „occupato” bezieht sich sowohl auf „tibi”, als auch auf „michi” und so bezieht sich das von ihm abhängige „,negociis” auf die Tätigkeiten der beiden. Beide sind schwer beschäftigt, sowohl der Bruder als auch Benedetto. Der Unterschied dieser Beschäftigungen wird durch die Gegenüberstellung von ,magnis et laudabilibus” und ,parvis, tamen necessariis” zum Ausdruck gebracht. Man kann davon ausgehen, dass Benedetto, wenn nicht nur die Größenordnung, sondern auch der Ort dieser Be-

\footnotetext{
718 Wattenbach, de Pileo, S. 227.
} 
schäftigungen unterschiedlich gewesen wäre, auch einen Hinweis auf diesen Unterschied in den Satz eingebaut hätte.

Wie genau die Worte „magnis et laudabilibus” zu interpretieren sind, ist nicht ganz klar. Dass die Tätigkeiten des Bruders ein größeres Prestige haben als die des Benedetto, kann mehreres bedeuten. Weitere Stellen des Briefes könnten vielleicht bei der Interpretation helfen:

$\mathrm{Tu}$, qui cum mortuis sed sempiterne viventibus habitas, me, qui cum vivis sed mortuis versor, ex tuo ingenio iudicas. ${ }^{719}$

Die „mortui sed sempiterne viventes” sind wahrscheinlich Autoren, mit deren Texten sich der Bruder beschäftigt. Es scheint auf Grund der wiederholten Betonung Benedettos plausibel zu sein, dass sein Bruder, was ,poesis” betrifft, besonders kompetent ist.

In hiis enim, que poesim concernunt, aptius et tucius michi videtur tue inherere sentencie, quam meam opinionem defendere. Summa summarum hec est in hoc: Malo vinci, quam vincere. ${ }^{720}$

Ob sich die Worte „magnis et laudabilibus” auch auf ein größeres soziales Prestige beziehen, das einem höheren Amt zu verdanken ist, oder einfach auf die aus humanistischer Sicht löbliche Beschäftigung mit Texten, wird an dieser Stelle nicht weiter erklärt, die oben zitierte Anspielung auf die erlesene Gesellschaft des Bruders („,cum mortuis sed sempiterne viventibus habitas") macht allerdings die Annahme plausibel, dass es um ein Prestige geht, das den Studien des Bruders zu verdanken ist.

Wenn man davon ausgeht, dass der Brief in der Tat an den Bruder gerichtet war, so kann man aus dieser Schrift über ihn folgendes erfahren: er wird von Benedetto als ein arbiter dargestellt, der für ihn in Stilfragen als kompetent galt. Weiterhin kann man auf Grund des Briefes auch nicht ausschließen, dass er sich zum Zeitpunkt des Schreibens ebenfalls in Konstanz aufhielt. Das Briefschreiben wäre auch in diesem Fall begründet: Benedetto beendet seine Schrift mit einem Hinweis darauf, dass er sich außerhalb der Stadt aufhält: „ex meo cubiculo extra Constanciam, ${ }^{, 721}$.

\footnotetext{
719 Wattenbach, de Pileo, S. 228.

720 ebda

721 ebda
} 


\section{Der Libellus penarum}

\subsection{Grundsätzliches}

\subsubsection{Die Struktur und Schreibsituation (nach der Fiktion)}

Der Libellus $^{722}$ ist an Benedettos Brüder, Johannes und Bartholomeus, gerichtet (strenggenommen nicht an beide, sondern an einen der beiden: vgl. „Iohanni vel Bartholomeo”, und die späteren Ansprachen, die in Singular stehen: „Legito frater has omnes et habebis tertiam et ultimam partem proposite divisionis". ${ }^{723}$ ). Die Widmung an die Adressaten kündigt die Aufteilung des Werkes auf drei Bücher an:

Volens tibi Iohanni vel Bartholomeo fratri meo partem passionum narrare, quas in Alimanie finibus passus, hoc opusculum edidi, quod a sua materia libellum penarum appellari volo. Divideris ipsum in tres particulas prima nuntius, secunda narratio, tercia supplicatio dicitur. ${ }^{72}$

Der erste Teil, der „nuntius” (f. 208r-224r) ist in elegischen Distichen verfasst, die „narratio” $(224 r-229 v)$ ist in Prosa geschrieben und die „supplicatio” (230v-246v) enthält sowohl Versals auch Prosateile.

Die „narratio” beschreibt den Weg, den das Büchlein vor sich hat, wenn es Benedettos Brüder aufsucht. Dementsprechend redet der Autor in diesem Teil seines Werkes das Büchlein an. Alle die Städte und alle die Freunde, die in diesen Städten wohnen, sind hier beschrieben, die das Buch unterwegs nach Piglio, Benedettos Heimatsstadt, aufsuchen soll.

In der auf die Wegweisung folgenden ,narratio” erzählt Benedetto die Geschichte seiner Gefangenschaft ab dem Tag der Ankunft in Neufchâtel bis zu einem geheimnisvollen Besuch eines gelehrten Mannes, der nach einem kurzen Gespräch mit dem Gefangenen sich für Benedetto einsetzt und erreicht, dass er sich manchmal nachmittags auf dem zweiten Stockwerk des Turmes aufhalten darf und mit besserem Essen und Trinken versorgt wird. Nachdem er wieder etwas zu Kräften gekommen sei, habe er an die Königin Barbara, die Frau Sigismunds, den Grafen von Neufchâtel, seinen Sohn und viele andere Briefe verfasst:

Sic pedetentim resumpto vigore primo domine Barbare Serenissime regine, ac domino Comiti filioque suo, qui cum eo morabatur in quodam castro Germanie duorum dierum iam itinere destanti a loco, in quo detenebar, deinde his, qui dicto

\footnotetext{
722 Der Libellus wird hier nach dem Wiener Codex zitiert, auch an den Stellen, die in Wattenbachs Artikel veröffentlicht wurden, und nicht nach Wattenbachs Schreibweise, der den Text nach der Gewohnheit seiner Zeit in der klassizisierenden Schreibweise wiedergibt.

723 CVP. 3529, 209v

724 CVP. 3529, 208r.
} 
subiecti $^{725}$ sunt comiti, quibusdam insuper additis, scripsi epistulas infrascriptas, que michi magnum in civibus prebuere favorem. Legito, frater, has omnes, et habebis tertiam et ultimam partem proposite divisionis. ${ }^{726}$

Mit diesem Absatz fasst der Autor den Inhalt des dritten Teiles, der supplicatio zusammen, die hauptsächlich seine Briefe enthält. Die Erzählung über seine Gefangenschaft wird aber fortgesetzt: Benedetto berichtet zwischen den Abschriften seiner Briefe über die Situation, in der er sich beim Schreiben des jeweiligen Schriftstückes befunden hat. Durch die chronologische Anordnung der Briefe und die Berichte über den jeweiligen Auslöser des Schreibens der Briefe ist es möglich, den Lebensweg Benedettos bis zu seiner Befreiung aus der Gefangenschaft zu verfolgen.

\subsubsection{Die Zeit der Entstehung des Buches}

Was den Zeitpunkt betrifft, zu dem das Werk geschrieben wurde, muss man zunächst zwischen dem tatsächlichen Zeitpunkt des Verfassens und dem fiktionalen, vom Narrator angedeuteten Zeitpunkt unterscheiden. Auf Zeitpunkt und Ort, wann und wo Benedetto, der Autor, sein Werk in endgültiger Form zu Papier brachte, bekommt man keinen Hinweis aus dem Paratext. Die Angabe des Jahres im Explicit wird unterbrochen, die des Ortes fehlt gänzlich: „Benedicti de Pileo ad fratrem libellus penarum explicit Millesimo quadringentesimo."727 Wahrscheinlich schrieb Benedetto den Libellus, nachdem er nach Konstanz zurückgekehrt war. Die Zusammenstellung des von der gleichen Hand abgeschriebenen Teils des Codex zeigt nämlich das Interesse eines auf dem Konzil weilenden Gelehrten: unmittelbar auf den Libellus folgt der auf den 14. Februar 1415 datierte Brief Benedettos an seinen Bruder mit der Beschreibung der Konzilsstadt; dann ein im Namen des Königs Ferdinand von Aragon geschriebener Brief für seinen Gesandten Antonio de Caxal $(250 \mathrm{v})^{728}$, ebenfalls der Niederschlag eines Ereignisses in der Konzilsstadt; und auch für die Verbreitung der ironisierenden Verse des Heinrich von Würzburg über den römischen Klerus (De statu curie romane) (252r-267v) stellte das Konzil den idealen Kontext dar. Die einzige Schrift in diesem Teil des Codex, die nichts mit dem Konzil von Konstanz zu tun hat, ist ein

\footnotetext{
Im Codex steht ,subiecto”.

CVP. 3529, 229v-230r.

CVP. 3529,f. 246v.
}

728 Der Text des Briefes ist auch in Hardts Ausgabe der Konzilsakten veröffentlicht worden. Vgl. Hardt, Magnum Concilium, Bd. 4, S. 815-816. Dieser Ausgabe des Briefes diente aber eine andere Fassung als Vorlage. Im Text des Wiener Codex wird der „primogenitus” des Königs Ferdinand als Aussteller des Briefes genannt, mit der Begründung, dass der König selbst abwesend (,nicht verfügbar”: „et propter indispositionem persone nostro signata manu nostri primogeniti”) war. In der von Hardt veröffentlichten Fassung wird der Brief von „Rex Alfonsus” unterschrieben, und auf den 6. Juni 1416 datiert, während die Wiener Fassung auf den Januar des Jahres 1416 datiert wurde. 
wahrscheinlich unterbrochenes Cicero-Zitat (Cic. Sen. 21. 78) über die Unsterblichkeit der Seele (250r). Man kann also davon ausgehen, dass der Teil des Codex, der die oben erwähnten Schriften enthält, die von der gleichen Hand geschrieben worden sind wie der Libellus und in seiner unmittelbaren Nähe stehen, auf dem Konzil abgeschrieben wurde, was ein terminus ante quem für die Entstehung des Libellus bedeuten würde. Dass der den Libellus enthaltende Teil des Codex noch in Konstanz entstand (und es sich nicht um eine Abschrift von einer in Konstanz gefertigten Vorlage handelt), ist deswegen wahrscheinlich, weil ein späterer Kopist das Cicero-Zitat und den Begleitbrief des Königs Ferdinand wahrscheinlich nicht mit abgeschrieben hätte.

Wenn man nach dem Zeitpunkt sucht, der in der Erzählung des Narrators impliziert wird, so bekommt man auch keine definitive Antwort. Die Perspektive ändert sich oft. An manchen Stellen der narratio findet man Hinweise darauf, dass Benedetto sich im Moment des Schreibens noch in Gefangenschaft befunden hat. Das personifizierte Buch bekommt den Auftrag, in Rom in die Wand des Vespasians-Bogens die folgende an den Kardinal Stefaneschi gerichtete Botschaft einzugraben:

Ecce tuos famulos, septem sunt ordine menses, Pretentos turri pena metusque tenet. ${ }^{729}$

An einer Stelle, in der der Erzähler über die Schwierigkeit reflektiert, die ihm das Einfügen eines Namens in den Text verursacht, wünscht er sich, dass er mit anderen Schwierigkeiten genau so gut klarkommen könnte, wie mit diesem textuellen Problem. Dann würde er sich nicht in einer solch erbärmlichen Lage befinden, wie es in diesem Moment der Fall ist:

Non ego nocturno semper contendere bello

Conarer variis vermibus esca datus,

Non ego cenarem semper sine lumine tristis,

Et nec pranderem plenus ubique malis

Non ego nunc starem cavee conclusus in antro. ${ }^{730}$

Mit diesen Versen wird offensichtlich seine Gefangenschaft beschrieben. Die an diesen Stellen implizierte Schreibsituation (das Schreiben des Buches im Gefängnis) wird aber von der Funktion des sog. nuntius untergraben. Der nuntius erzählt nicht die eigentliche, an die Brüder adressierte Geschichte. Der erste Teil des Werkes fungiert als Bote, der eine Mitteilung trägt. Das Instruieren des Boten (was in diesem Fall in der Beschreibung des zurückzulegenden Weges besteht) geschieht meistens, wenn die Botschaft selbst schon „fertig” ist. Bene-

729 CVP. 3529, 213r; Wattenbach, B. d. P., S. 109.

730 CVP. 3529, 211v. 
detto behält im Text des nuntius ansonsten konsequent das Kommunikationsschema „Absender (Benedictus) - Empfänger (die Brüder: Iohannes oder Bartholomeus) - Botschaft (die Leidensgeschichte des Benedictus, beschrieben in der narratio und supplicatio) - Bote (der nuntius)" bei. Dementsprechend dürfte man davon ausgehen, dass nach der inneren Logik der Selbstfiktion des Libellus (die selbstverständlich nicht unbedingt mit der tatsächlichen Schreibsituation übereinstimmen muss) im Moment des Schreibens des nuntius der Rest des Werkes schon fertig sein sollte. Dies kann nur nach der Befreiung der Fall sein, weil die Gefangenschaft erst dann als eine vollendete Geschichte erzählt werden kann.

Die Perspektive der narratio ist nicht so kompliziert wie die des nuntius. Sie ist als eine Erzählung vergangener Geschehnisse gestaltet. Aus welcher Perspektive, das wird gleich im ersten Satz verraten: „Fortune gratum habeo, frater, si tibi hec dederit, ut ignoraveris me apud inferos diu fuisse ac nunc demum scias cum inde iam redii." ${ }^{, 731}$ Der Bruder werde über die Leiden Benedettos erst erfahren, wenn diese schon vorbei seien.

In der supplicatio wird die gleiche Perspektive beibehalten. Die Briefe, die der Gefangene aus seinem Kerker an verschiedene potentielle und tatsächliche Gönner richtet, werden im Nachhinein als Selbstzitate von den Vorlagen abgeschrieben. In den kleinen Texten, die diese Fragmente kurz kommentieren und zu einer fließenden Erzählung auffädeln, wird immer auf die Schreibsituation des jeweiligen Originals reflektiert:

Scripta hec fuerunt a me Benedicto cum calamo palee et atramento confecto de carbone et aqua in cavea, die prima Septembris; ${ }^{732}$

und später:

Prescriptas supplicationes formavi et scripsi septimo septembris die ac sequente ad eos, quos suprascriptiones indicant per custodem carceris. Decimo vero dicti mensis die, quia dicti cappellani ac nobilis viri Mathei de Corteis rerum dicti comitis precuratoris opera summoque studio factum erat, ut papirum ceteraque ad scribendum necessaria haberem. In quo papiro precedentes ac subsequentes litteras scripsi ad eundem cappellanum. Primo deinde ad ipsum Matheum, ut sequntur, verba feci. ${ }^{733}$

Zusammenfassend kann man feststellen, dass der Erzähler die Geschehnisse überwiegend in der Form eines Rückblicks vergegenwärtigt. Er nutzt diese Perspektive allerdings nicht ganz konsequent, weil sich im ersten Teil Stellen befinden, die so formuliert sind, als wenn der Erzähler im Moment des Schreibens sich immer noch in Gefangenschaft befinden würde.

\footnotetext{
731 CVP. 3529, 224r.

732 CVP. 3529, 231v

733 CVP. 3529, 233r.
} 
Diese uneinheitliche Perspektive wird vom Autor teilweise mit den Hinweisen (vor allem in der supplicatio) auf die Tatsache erklärt, dass der endgültige Text aus Schreibstücken entstanden ist, die schon in der Gefangenschaft konzipiert worden sind. Dieser Umstand hätte aber dem Autor die Möglichkeit offengelassen, sein Werk mit einer einheitlichen Perspektive zu versehen, indem er die Teile, die er in der Gefangenschaft geschrieben hatte, als Selbstzitat in seinen Text einfügt, wie er dies in der supplicatio gemacht hat. In der narratio nutzt er diese Technik nicht, er wechselt einfach die Perspektive, ohne diesen Akt zu signalisieren und zu erklären. Die Tatsache, dass der Kopist das Datum nicht vollständig angegeben hat („millesimo quadringentesimo”), könnte ein Zeichen dafür sein, dass er von der Wechselhaftigkeit der Referenzen über die Position des Erzählers selbst verunsichert wurde.

\subsubsection{Fiktion oder Realität?}

\subsubsection{Ovid, das Modell}

Im Folgenden soll die Frage erörtert werden, ob der Libellus eine „wahre Geschichte” erzählt, oder ob es sich hier ausschließlich um die Umsetzung eines literarischen Modells handelt. ${ }^{734}$ Dass die Tristia des Ovid das wichtigste literarische Modell für Benedettos Buch waren, wurde schon von Wattenbach, Sabbadini und Grayson festgestellt. ${ }^{735}$ Die Reminiszenzen an Ovid sind so eindeutig, dass es genügt, die auffälligsten zu nennen, um jeden Zweifel zu zerstreuen, dass es sich hier um eine bewusste Nachahmung des ovidianischen Modells handelt.

Benedetto schickt sein Buch genauso wie Ovid in seine Heimat, zu seinen Freunden und seiner Familie, um ihnen über seine Lage zu berichten. Allein diese gemeinsame Ausgangssituation erzeugt viele Elemente, die sich in beiden Werken auffinden lassen. Die Personifizierung des Buches und seine ständige Anrede ist die erste und auffälligste Konsequenz dieser Erzählsituation. Ein wesentlicher Unterschied liegt aber in der Struktur der beiden Werke und dieser macht sich auch in den Anreden der jeweiligen Bücher kenntlich. Die Tristia haben im Unterschied zum Libellus keine auffällige Aufteilung (außer der Aufteilung auf Bücher, selbstverständlich), der Libellus wurde aber von seinem Autor, wie schon oben

734 Die gleiche Frage wird von der Forschung auch für die Tristita selbst gestellt. Einen Überblick über die Debatte über die Historizität oder Fiktionalität von Ovids Verbannung bietet: Martin Amann, Komik in den Tristien Ovids, Schweizerische Beiträge zur Altertumswissenschaft 31 (Basel: Schwabe Verlag, 2006), [im Weiteren: „Komik”], S. (46-47), und Anna Julia Martin, Was ist Exil? Ovids Tristia und Epistulae ex Ponto, Spudasmata 99 (Hildesheim, Zürich, New York: Georg Olms Verlag, 2004). S. 25-27.

735 Vgl. Wattenbach, B. d. P., S. 104: „Wir wollen ... uns seinen Tristien zuwenden, den Distichen in welchen er Ovid nachahmend sein Buch anredet, welches den Freunden in der Heimath Nachricht bringen soll", und Sabbadini, Le scoperte, Bd. 1. S. 154, auch Grayson nennt neben Boethius auch Ovids Tristia als das wichtigste Modell für den Libellus: Grayson, Benedetto, S. 444. 
beschrieben, in drei Teile gegliedert. Dementsprechend gestalten sich auch die Anreden der beiden Schriften: während in den Tristia die Anrede des Buches sich nicht auf einen gut isolierbaren Textblock beschränkt (die Buchrolle wird im ganzen Werk immer wieder angesprochen), wird das Buch im Libellus nur im ersten Teil, im sogenannten nuntius angesprochen. In dieser ganzen Texteinheit richtet der Autor seine Rede konsequent an das Buch. Im Gegensatz zu Benedettos detaillierter Wegweisung bekommt Ovids Büchlein keine zusammenhängende, konsequente Wegbeschreibung von seinem Autor. Der antike Autor erzählt seine Geschichte in als (im Vergleich mit Benedettos Erzählung) fragmentarisch beschreibbaren Stücken: die Geschichte entsteht hier aus kleinen, von einander teilweise unabhängigen Bildern. Der Grund für diesen Unterschied ist wahrscheinlich in der Funktion der Wegweisung Benedettos zu suchen, die später erörtert wird.

Um einige von den direkten Übernahmen zu nennen, kann man auf folgende Stellen hinweisen:

Non equidem invideo, nam si michi fata favebunt,

Teque meosque alios curo videre brevi."

schreibt Benedetto gleich am Anfang seiner Anrede. Er beneide sein Buch dafür, dass es in seine Heimat, nach Italien laufen kann, angeblich genauso wenig, wie Ovid seine Buchrolle um die ihrige Reise angeblich nicht beneidet:

Parve (nec invideo) sine me, liber ibis in urbem ei mihi, quod domino non licet ire tuo!"737

Benedetto nennt den Grund, warum er sein Buch nicht beneidet, im Gegensatz zu Ovid explizit. Er drückt seine Hoffnung auf seine eigene Wiederkehr aus. Ovid lässt dagegen die Frage in der Schwebe, er meint einerseits, dass er sein Büchlein nicht beneide, andererseits gibt er aber in der zweiten Zeile auch seiner Trauer Ausdruck. Es ist zwar schwierig, die poetischen Qualitäten von Texten miteinander auf eine exakte Weise zu vergleichen und eine Rangordnung festzulegen, man könnte es hier vielleicht trotzdem riskieren, und zwar mit der Feststellung, dass die Spannung, die Ovid dabei schafft, vieldeutiger ist und deswegen auch interessanter, als Benedettos pragmatische Begründung.

Benedetto klagt in der Form eines Bescheidenheitstopos über die Unmöglichkeit, unter den miserablen Umständen, in denen er sich befindet, schreiben zu müssen:

CVP. 3529, 208v; Wattenbach, B. d. P., S. 104.

Ov. trist. 1, 1, 1-2. 
O si sic alios possem michi demere morbos, Ut valeo dictum pellere convicium!

und einige Zeilen später:

$$
\begin{aligned}
& \text { Non ego nunc starem cavee conclusus in antro } \\
& \text { Carmina non canerem, que tibi rauca sonant. }{ }^{738}
\end{aligned}
$$

Auch bei Ovid wird der Demutstopos des Öfteren in Zusammenhang mit der Klage über die eigene Lage benutzt. Auf die Unvereinbarkeit von Schreiben und Exil bei den „Barbaren” gibt es in den Tristia immer wieder zerstreute Hinweise, das Gedicht 5, 12 ist aber ganz diesem Thema gewidmet. Der Kontrast von diesem Bescheidenheitstopos und dessen mit offensichtlicher Sorgfalt gestalteten Form sei nach Amanns überzeugender Deutung dieser Stelle für sich allein zwar nicht als komisches Element deutbar, jedoch sei er ein Mittel, mit dem der Dichter eine Distanz herstellt, die Komik überhaupt möglich macht. Die Komik selbst ist nach dieser Interpretation in den Versen 57-58 auch deutlich vorhanden: „ipse mihi videor iam dedidicisse Latine: / nam didici Getice Sarmaticeque loqui”, wo Ovid mit Hilfe einer bewussten Kakofonie den Inhalt der Verse einerseits illustriert, andererseits aber (durch das Geschick des Sich-Verstellens) auch untergräbt. ${ }^{739}$ Die Frage, ob es auch Benedetto gelingt, seinen Bescheidenheitstopos durch einen brillanten Stil zu untergraben, wird in meiner Analyse später erörtert.

\subsubsection{Die Historizität von Benedettos Geschichte}

Weil für Benedettos Gefangenschaft außer seinem Libellus keine Aussagen zur Verfügung stehen, kann man die Frage nach dem Wahrheitsgehalt des Textes vorläufig (bis vielleicht einmal neue Quellen auftauchen) mit einer bloß plausiblen Antwort abschließen. Diese könnte lauten: Es scheint wahrscheinlich zu sein, dass Benedettos Geschichte keine erfundene ist. Wenn es das Hauptanliegen des Autors gewesen wäre, eine Paraphrase der ovidianischen Tristia zu schreiben, so wäre er seinem Modell vielleicht konsequenter gefolgt, als es im Libellus der Fall ist. Auch die Fülle und Vielfältigkeit der Briefe der supplicatio lässt sich nur damit erklären, dass diese Schriften in der Tat aus einem konkreten, realen Anlass entstanden sind. Für eine reine Stilübung macht der Libellus einen viel zu heterogenen Eindruck. Obwohl die endgültige Fassung des Textes nicht im Kerker entstanden ist, ist davon auszugehen, dass die Gefangenschaft, der Anlass zum Schreiben des Buches, keine Fiktion ist, das ovidianische

CVP. 3529, 211v.

Amann, Komik, S. 248. 
Modell (hauptsächlich für den nuntius) hat sich als ein selbstverständlicher Rahmen der Erzählung angeboten, nicht aber die Hauptrolle bei der Entstehung des Textes gespielt.

\subsection{Die dreifache Zielsetzung des Buches}

\subsection{1. „Eripe nos a penis”: Schreiben für das Überleben/1.}

Die Briefe, die Benedetto vom Ort seiner Gefangenschaft abgeschickt hatte und deren Abschrift den größten Teil der supplicatio bildet, waren Hilfeschreie: sie sollten dazu dienen, ihren Adressaten über das jammervolle Schicksal Benedettos $\mathrm{zu}$ berichten und sie dazu bringen, dem Gefangenen zu helfen. Dass Lesen-und-Schreiben-Können gegebenenfalls Leben retten kann, gehörte zur mittelalterlichen Realität. Es handelt sich hier nicht allein um die den Alphabetisierten gegebene Möglichkeit, sich gegebenenfalls durch das Schreiben von Briefen Hilfe zu holen. Im Philobiblon beschreibt Bury eine Szene, in der ein Kleriker sein Leben durch das Lesen des Psalters retten kann. ${ }^{740}$ In diesem Fall diente das Vorlesen-Können als Beweis für den Klerikerstatus des Delinquenten. Obwohl Burys Worte in einem ironisierenden und sogar satirischen Kontext eingebettet sind und gewiss nicht die alltägliche Praxis wiedergeben, haben sie selbst durch diese Übertreibung eine gewisse Aussagekraft über den Status, mit dem das Schreiben-und-Lesen-Können im 14. Jahrhundert verbunden war. Obwohl zu Benedettos Zeit die von Bury beschriebene Situation nicht mehr gültig war (die Unterscheidung zwischen litteratus und illitteratus lässt sich in dieser Zeit nicht mehr mit der Unterscheidung zwischen Laien und Klerikern ${ }^{741}$ gleichsetzen), bleibt die Tatsache, dass das Schreiben-Können, besonders auf Lateinisch, das Privileg einer begrenzten Gruppe blieb. Benedetto also schreibt und fleht seine Adressaten um Hilfe an. Die Tatsache selbst, dass er die Honoratioren anschreibt, zeichnet ihn in den Augen der Adressaten als einen „Gleichrangigen” aus. Er gehöre zur gleichen Gruppe wie die Sekretäre, Notare und Kuriengeistlichen, an die er die meisten seiner Briefe schreibt, und könne mit ihnen auf Augenhöhe kommunizieren.

Das Schreiben des Buches beziehungsweise eines Teiles dessen, diente im engsten Sinne des Wortes Benedettos Überleben. Seine Briefe sollten dafür sorgen, dass er aus seiner Gefangenschaft befreit werde. Benedetto war davon überzeugt, dass sie diese Funktion auch

\footnotetext{
740 Bury, Philobiblon (in Altamuras Ausgabe), S. 85-86.

741 Über die Geschichte der Verkoppelung und Entkoppelung der Ausdrücke ,illitteratus” - „idiota” - und „laicus” vgl. Grundmanns Studie: Herbert Grundmann, „Litteratus-illitteratus. Der Wandel einer Bildungsnorm vom Altertum zum Mittelalter”. In Herbert Grundmann, Ausgewählte Aufsätze (Stuttgart: Anton Hiersemann, 1978), 1-66.
} 
erfüllt haben. Er bemerkt am Ende der narratio über seine Briefe: „que michi magnum in civibus prebuere favorem" ${ }^{, 742}$.

\subsection{2. „otium sine litteris mors est”: Schreiben für das Überleben/2.}

Um Überleben geht es im Libellus nicht nur im oben geschilderten, konkreten Sinne des Wortes. Schreiben soll Benedettos Überleben auch auf einer anderen Ebene erleichtern: es sollte dem Gefangenen die Zeit im Kerker erträglicher machen. Der literarische Gemeinplatz schlechthin für diese Funktion des Lesens und Schreibens ist der berühmte Satz von Seneca: „Otium sine litteris mors est et hominis vivi sepultura.” (Ep. Mor. 82, 3) Als Grund der Entstehung seines Buches gibt Benedetto außer seinem Wunsch, seinen Bruder zu benachrichtigen, auch folgendes an: „Atque michi verba dedi, ut tarde labentes fallerem dies ac ne otio marcerem vivusque sepultus essem." ${ }^{, 73}$ Diese Stelle lässt sich als eine Paraphrase von Senecas Satz lesen. Die Metapher, die das Schreiben mit dem Leben und das NichtSchreiben-Können mit dem Tod identifiziert, taucht auch in der Erzählung der supplicatio auf. In einem Brief bedankt er sich bei dem Kaplan, der ihm Papier und Tinte geben ließ.

Habitanti michi in tenebris, et in regione umbre mortis, optime cappellane, tunc lux est orta, cum tua diligenti opera papyrus, penna et atramentum michi date sunt. Tum visum michi est a mortuis surrexisse. Tum redditam michi vitam putavi. ${ }^{744}$

Dass es aber in diesem Fall nicht um das Überleben im Senecaschen, im also übertragenen, sondern in dessen ganz konkretem Sinne geht, geht aus der Fortsetzung deutlich hervor: „Dedisti enim forte ac validum iter, per quod ad salutem venire spero."745 Leben und Tod sind plötzlich auch ganz konkret und nicht nur metaphorisch zu verstehen: Benedetto will sich mit Hilfe der Tinte und des Papiers frei schreiben.

Die zwei Ebenen der Darstellung des Schreibens als Überlebensstrategie überlappen sich. Diese Überlappung ist mit der oben erwähnten Implikation des Schreiben-Könnens und seiner Ostentation zu erklären. Benedettos Bitten sollten nicht nur durch deren Inhalt wirken, sie sollten auch einen guten Eindruck machen. Zu diesem „guten Eindruck” gehörte das Schaffen des Bildes eines Gelehrten, der seine Zeit am liebsten mit Schreiben und Lesen verbringt, und für den ein Leben ohne Schreiben ,den Tod” bedeutet.

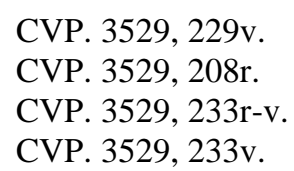




\subsection{3. „fama per Italiam clara perennis erit”: Schreiben für das Überleben/3}

Benedetto hat sein Büchlein, nachdem er freigelassen worden war, gründlich umgearbeitet. Der Text in seiner endgültigen Form hatte eine ganz andere Funktion, als seine im Kerker entstandenen Vorlagen. Er sollte Benedettos Ruhm begründen. Dies scheint nicht nur wegen Benedettos Lebenslage plausibel zu sein und auch nicht nur wegen der Tatsache, dass wahrscheinlich jeder literarische Text unter anderem auch diese Funktion hat. Benedettos Hintergedanke wird auch von seinen eigenen Worten verraten. In seiner Danksagung an den Kaplan, der ihm Weintrauben geschenkt hatte, meint er, dass er den Namen seines Wohltäters in seinen Versen verewigen wird. Er leitet den Gedanken mit einem vergilianischen Echo (Aen. IX. 446) ein:

Nam tua, si vivam, ac si quid mea carmina possunt, Fama per Italiam clara perennis erit. ${ }^{746}$

und etwas später setzt er so fort:

Nomine sic magnas intrabis clarus in urbes, Et fies scriptis undique nota meis. ${ }^{747}$

Obwohl der im Untertitel zitierte Pentameter sich nicht direkt auf Benedettos fama bezieht, sondern auf die des Kaplans, geht es in diesen Versen auch um Benedettos Ruhm. Sein Libellus soll nach diesen Zeilen in ganz Italien gelesen werden. Auch wenn der Autor hier, um seiner Danksagung noch mehr Nachdruck zu verleihen und dem Kaplan zu schmeicheln, die zukünftige Aufnahme seines Werkes mit noch optimistischeren Tönen beschrieben hatte, als er es vielleicht selbst für realistisch hielt, ließ er letzten Endes diese Verse, die seiner Schrift eine solche glänzende Zukunft prophezeien, auch in der umgearbeiteten Fassung stehen. Er hielt also diese Zukunft nicht für ganz unrealistisch, andernfalls hätte er die Zeilen weglassen können, um sich nicht der Lächerlichkeit auszusetzen. ${ }^{748}$

Es gibt eine Stelle über die heilende Kraft des Schreibens, die auf allen drei Ebenen interpretierbar ist. Am Anfang des nuntius, bevor er die italienischen Gelehrten Revue passieren lässt, legt Benedetto dem Büchlein seine allgemeine, an alle gerichtete Nachricht in

746 CVP. 3529, 336r.

747 CVP. 3529, 336v.

748 Diese verschiedenen Ebenen des Nutzens des Schreibens lassen sich auch in den Tristia finden: In den letzten 17 Zeilen der Elegie 4, 10. bedankt sich Ovid bei seiner Muse, die ihm das Leben unter unmenschlichen Verhältnissen gerettet und die ihm Ruhm bereitet habe, sogar bereits in seinem Leben, was den meisten erst nach deren Tod zuteil wird. Für die erste Ebene, auf der das Schreiben als eine ganz konkrete Bitte um Hilfe benutzt wird, gibt es auch Beispiele bei Ovid in den Briefen, in denen er um Mitleid und Hilfe bittet (die bekannteste Stelle ist am Ende des 2. Buches. Hier bittet Ovid Augustus, ihn nach einem sichereren Verbannungsort zu schicken). 
den Mund: es ginge ihm geistig gut, obwohl er für lange Zeit zu körperlicher Untätigkeit verdammt war:

Mentis enim compos existo, corpore quamvis

Torpuerim multo tempore semper iners.

Spero tamen Christi virtute iuvante salutem

Visere, consilii nec minus artis ope. ${ }^{749}$

Es geht nicht ganz eindeutig aus dem Text hervor, wie man „salus” genau verstehen sollte. Es kann sich ganz einfach auf die körperliche Gesundheit Benedettos beziehen. In den ersten zwei Zeilen wird das Thema angesprochen (corpore torpuerim). Wenn die Kunst (ars) des Autors, mit Christi Hilfe, ihm bei dem Wiedergewinnen seiner (körperlichen) Gesundheit helfen soll, so versteht sich hier das Anliegen von Benedettos Schreibkunst auf der ersten Ebene: sie soll die Adressaten dazu bringen, dem Gefangenen zu helfen und ihn möglichst bald aus seinem Kerker zu befreien. „Salus” kann sich aber auch auf Benedettos „mentalen” Zustand beziehen. Nach dieser Lesart würde „mentis compos” zwar bedeuten, dass der Gefangene seinen Verstand bewahren, womit er sich aber doch nicht ganz zufriedengeben konnte. Er wünscht vom Schreiben, dass es ihm im Senecaschen Sinn helfe. Wenn „,salus” in einem allgemeineren Sinne das Wohl bedeuten sollte, so kann man die Kunst Benedettos als Überlebensstrategie auf der dritten Ebene interpretieren. Sie soll ihm Ruhm bescheren, welcher seinen Wert natürlich nicht nur in sich habe, sondern für die Verbesserung der Lebenslage des Autors insgesamt von großer Bedeutung wäre. ${ }^{750}$

\subsection{Benedettos Publikum}

\subsubsection{Die Adressaten der Briefe der supplicatio}

Seinen verschiedenen Funktionsebenen entsprechend muss man das vom Libellus anvisierte Publikum differenziert analysieren. Die Briefe der supplicatio wurden nach der Fiktion des Libellus ursprünglich in der Gefangenschaft an verschiedene Adressaten geschrieben. Benedetto schrieb des Öfteren an den Pfarrer des Ortes, mehrere seiner Briefe sind an alle Kleriker und Amtsträger von Neufchâtel gerichtet, in einem Brief spricht er die Frauen des Ortes an und rechnet mit deren Gutmütigkeit, er bedankt sich in einem Brief auch bei einem Jungen, der ihm Weintrauben gebracht hat, um nur einige Beispiele für die

749 CVP. 3529, 208v; Wattenbach, B. d. P. S. 104.

750 Obwohl Benedetto seinen salus mit Christi Hilfe erreichen möchte, geht es hier um eines ganz gewiss nicht: um das Heil im christlichen Sinne des Wortes. Das Seelenheil mittels „,consilium” und ,ars” erreichen zu wollen, wäre im Hinblick auf das Wesen von Benedettos Schreiben (es handelt sich um keine religiöse Thematik), eher überraschend. 
Adressaten der supplicatio zu nennen. ${ }^{751}$ Diese einzelnen Personen oder Gruppen sind aber in den meisten Fällen nicht Adressaten des Buches als ganzes.

Wahrscheinlich entstanden aber einige Briefe der supplicatio nicht in der Gefangenschaft, sondern erst später. Hier ist an das den dritten Teil einleitende Gedicht an die Königin Barbara und das die Reihe der Briefe und Gedichte abschließende Gedicht auf das Konstanzer Konzil zu denken. Diese zwei den Rahmen der supplicatio bildenden Gedichte sind wahrscheinlich erst in Konstanz entstanden. Im Fall der Danksagung an das Konzil kann diese Annahme einfach mit der Logik der Chronologie, bzw. mit der Tatsache begründet werden, dass diese Lobschrift auf das Gedicht folgt, das Benedettos Befreiung aus seiner Gefangenschaft feiert. So ist sie im Gegensatz zu den meisten Briefen der supplicatio nicht als ein Selbstzitat zu verstehen, durch das Benedetto eine früher verfasste Schrift in sein Buch später einfügt. Das Gedicht wurde ausschließlich für den Libellus verfasst und spricht das von Benedetto angepeilte Publikum an: die Öffentlichkeit des Konzils.

Königin Barbaras Lob verfasste Benedetto aller Wahrscheinlichkeit nach auch nicht im Kerker. Die Vorstellung, dass Benedetto darauf gehofft haben könnte, sein „Brief” an Barbara würde aus dem Kerker in Neufchâtel nach Konstanz gelangen, ist nicht besonders realitätsnah. Selbst wenn er das Gedicht im Kerker geschrieben hatte, war dieser nicht als missilis gedacht, sondern eher als ein für das spätere Buch gemeintes Schriftstück. Dieses Gedicht hatte mit der Ansprache seiner Adressatin, Barbara, eine wichtige Funktion: es musste nach Benedettos Absicht seinen Autor als „Schützling” der Königin und des Königs darstellen. Im Gedicht kommt nämlich auch die Figur des Königs vor, Benedetto „wünscht” auf indirekte Weise, also mittels der Ansprache an die Königin, dass Sigismund vom Papst zum Kaiser gekrönt werde (,sumentem summo a pastore coronam”,752). Benedettos Adressatin ist deswegen die Königin, weil der König selbst zur Zeit der Entstehung des Gedichtes auf Reisen war. Was die Abwesenheit des Königs betrifft, macht es keinen Unterschied, ob man die von Benedetto angegebene Datierung des Gedichtes (es seien sechs Monate vergangen, seitdem er eingekerkert wurde: „Nos miseri turri six iam sunt ordine menses”,753) für die tatsächliche Entstehungszeit hält, oder ob man für eine spätere Entstehungszeit plädiert: Sigismund war im Oktober 1415 (also sechs Monate nach der Gefangennahme Benedettos) in Perpignan ${ }^{754}$, in Konstanz findet man ihn erst ab dem 27. Januar 1417 wieder. Demzufolge

\footnotetext{
751 In den letzten beiden Fällen mag man bezweifeln, ob die sogenannten Adressaten die jeweiligen Briefe jemals gelesen haben, die deswegen eher in die Kategorie der fiktiven Briefe fallen.

752 CVP. 3529, 230v.

753 ebda

754 Zu Sigismunds Reisewegen und Aufenthaltsorten vgl. Hoensch, Sigismund, S. 625.
} 
konnte Benedetto, wenn er das Gedicht erst nach seiner Rückkehr nach Konstanz verfasste, immer noch über einen abwesenden König schreiben.

Benedetto musste, weil er keinen richtigen Befürworter hatte, die Strategie anwenden, (wenn schon von Seite der Mächtigen keine Ermutigung kam), seine eigenen Initiativen, diese Mächtigen angeschrieben zu haben, als Zeichen von deren (erhoffter) wohlwollender Unterstützung darzustellen. Durch sein Lobgedicht auf die Königin Barbara am Anfang des dritten Teiles des Libellus steht gleichsam die ganze supplicatio unter königlicher Ägide.

\subsubsection{Benedettos Brüder als Adressaten des Libellus}

Der Text in seiner endgültigen Fassung ist, laut Benedettos Aussage, an seine Brüder gerichtet. Die Frage, welchen Stellenwert Benedettos diesbezügliche Aussagen haben, ob also die Brüder als Leser des Buches tatsächlich in Frage kamen oder Teil der Fiktion des Libellus sind, wurde bereits angesprochen und darauf hingewiesen, dass Benedettos Bruder Johannes sich zum Zeitpunkt des Schreibens des Libellus möglicherweise auch in Konstanz aufhielt. Hier soll lediglich bestärkt werden, dass die Selbstaussagen des Libellus kritisch zu betrachten sind.

\subsubsection{Benedettos „Freunde": Eine Lesergemeinschaft}

\subsubsection{Allgemeines}

Die Freunde Benedettos, die das Büchlein auf seinem Weg in die Heimat zu begrüßen hat, werden oft als Leser des Buches dargestellt. Bei manchen weist Benedetto ganz konkret darauf hin, dass sie das Buch korrigieren sollen. Selbst bei den Freunden, zu denen der Autor keinen solchen Hinweis gibt, soll man die Metapher des reisenden Buches, das Freunde und Bekannte aufsucht und grüßt, in diesem Sinn verstehen. Die zu begrüßenden Personen stellen also eine Liste der potentiellen Leser des Buches dar. Wenn man versucht, die von ihm erwähnten Namen zu identifizieren, wird man auf die folgende Struktur aufmerksam. Die großen Namen sind mit den Städten Bologna, Rom und Florenz verbunden. Es handelt sich entweder um Leute, die Benedetto in der Tat persönlich gut gekannt haben musste (wie zum Beispiel seinen Unterstützer in Bologna, Johannes de Loddovicis, oder Bartholomeus de Regno, bei dem Benedetto wahrscheinlich die klassischen Autoren gelesen hatte), oder um Personen, bei deren Beschreibung er sich etwas vorsichtiger ausdrückt und schreibt, es könnte sein, dass sie nicht Zeit für das Büchlein haben (wie im Fall von Leonardo Bruni). In Tivoli, Anagni und Piglio nennt er viele Bekannte und meistens ohne die Vorwarnung, dass das Büchlein seine Worte sehr gründlich überlegen sollte, also ohne eine ehrenvolle Distanz 
zwischen sich selbst und den Angesprochenen anzudeuten. Hier sind die Verhältnisse manchmal sogar andersherum: Er selbst, Benedetto, ist derjenige, der den anderen großzügig an seiner Freundschaft beteiligt (wie im Fall von Johannes Chamicius in Tivoli, vgl. Anm. 818). Seine „Leser” sind also sehr unterschiedlich, was die Hierarchie innerhalb der jeweiligen Bekanntschaften betrifft. Benedetto hat hier jeden aufgelistet, mit dem er auf irgendeine Weise bekannt war und der als Leser in Frage kommen konnte.

Mit der Enumeration seiner Freunde im nuntius kreiert Benedetto eine Lesergemeinschaft, einen Kreis von Freunden, der nach der humanistischen Gepflogenheit die Werke seiner Mitglieder liest und mit Ratschlägen und Korrekturen nicht geizt.

Die Darstellung der Freunde, die teils Rechtsgelehrte, teils Poeten waren, des Öfteren sogar beides, also ehemalige Poeten, die sich später der Rechtswissenschaft widmeten, ist Teil von Benedettos Selbstdarstellung. Die hier angewandte Selbstdarstellungsstrategie funktioniert ähnlich wie die des Lobgedichtes an die Königin Barbara. Es ist Benedetto, der diese Personen auf seine Liste setzt und sich auf diese Weise mit ihnen in Verbindung bringt. Die Tatsache, dass er diese Gelehrten als Leser anspricht, soll dafür sorgen, dass sein eigenes Renommee, sein „soziales Kapital”, einen Zuwachs erfährt. ${ }^{755}$

\subsubsection{Die Öffentlichkeit des Konstanzer Konzils}

Wie schon durch das Gedicht an das Konzil am Ende des Buches deutlich wurde, war die auch durch die Auflistung der Freunde konzipierte Selbstdarstellung Benedettos wahrscheinlich an das Publikum des Konstanzer Konzils gerichtet. Benedetto hat gehofft, hier einen zukünftigen Brotherren zu finden. Dieses plausible Anliegen lässt das Motiv des zu den Brüdern geschickten Buches als literarischen Topos interpretieren, der nicht unbedingt für bare Münze genommen werden sollte. Dies würde bedeuten, dass es sich auch mit der repräsentativen Liste der Freunde nicht anders verhalten kann. Die Reise des Buches durch Italien nach Piglio hat mehr mit Fiktionalität als mit Realität zu tun. Die Grenzen zwischen diesen zwei Bereichen sind allerdings voneinander nicht so scharf zu trennen: Benedetto kann es sich gewünscht haben, dass sein Libellus in ganz Italien gelesen wird. Das Entscheidende ist hier nicht die Tatsache, dass dies sehr wahrscheinlich nicht der Fall war, sondern die plausible Annahme, dass Benedetto vielleicht gar nicht vorhatte, das Buch von Konstanz nach Piglio zu schicken. Des Büchleins Reise durch Italien ist wahrscheinlich auch als ein Zeichen von Benedettos Wunschdenken zu verstehen, nach dem der Libellus von Konstanz aus eine

755 Eine Liste mit Benedettos Freunde, die das Büchlein aufsuchen soll befindet sich im Anhang 4. Hier folgen auch reichlich Zitate aus der narratio. 
große Verbreitung erfahren sollte: Wenn der Libellus in der Konzilsstadt großes Interesse erweckt hätte, so wären dort zahlreiche Kopien entstanden, was zu einem möglichen Erfolg auch in Italien hätte führen können. Die italienische Erfolgsgeschichte wird durch die Wegweisung des Autors an sein Buch lediglich vorweggenommen. Die Lesergemeinschaft des Konstanzer Konzils ist das eigentliche Publikum, an das der Libellus in erster Linie gerichtet war und das über das Schicksal des Büchleins und teilweise auch über das seines Autors entscheiden sollte.

Wie aus der im Anhang 4 erstellten Skizze über Benedettos Freunde anschaulich hervorgeht, gibt es auch Überlappungen zwischen den im nuntius genannten Namen und dem Konstanzer Publikum. Die bekanntesten der Freunde, die das Buch besuchen soll, Cencio Romano in Rom und Bartolomeus da Montepulciano in Florenz, waren zur Zeit des Konzils in Konstanz, ebenso wie auch Leonardo Bruni, wenigstens bis zum Zeitpunkt des päpstlichen Fluchtversuches. ${ }^{756}$ Welche weiteren Freunde Benedettos, die das Büchlein in Italien aufsuchen sollte, sich zur Zeit der Entstehung des Buches in Konstanz aufhielten, kann nicht gesagt werden. Nachdem man bei den drei vielleicht bekanntesten Persönlichkeiten auf Benedettos Liste gleich erfährt, dass sie um diese Zeit in der Konzilsstadt waren, und man im Zusammenhang weiterer, in der Kurie tätiger Freunde, den gleichen Verdacht schöpft, gerät man in Versuchung zu denken, dass es vielleicht bei allen Adressaten der Fall sein könnte. Wie es im Anhang 4 „Die biographischen Personen von Benedettos Lesergemeinschaft” anschaulich gemacht wird, gab es unter Benedettos Freunden viele, die als apostolische Notare und Sekretäre ihr Brot verdienten, und die sich demzufolge zur Zeit der Entstehung des Libellus sehr wahrscheinlich in Konstanz aufhielten.

Somit hätte Benedetto durchaus damit rechnen können, dass seine schmeichelnden Zeilen von seinen Bekannten in der Tat gelesen werden konnten, andererseits hätte er so auf gewitzte Weise zwei Lesergemeinschaften, die fiktive und die reale, ineinander geblendet bzw. wäre seine fiktive Lesergemeinschaft keine fiktive mehr gewesen, sondern nur ihr Aufenthaltsort. Eine hundertprozentige Überlappung der zwei Gruppen ist allerdings eher unwahrscheinlich, vor allem was die Freunde in Piglio, Anagni und Tivoli betrifft. Es ist eher unwahrscheinlich, dass allein von Benedettos ehemaligen Schülern so viele an dem Konzil teilgenommen hätten. Die Wahrheit liegt wohl irgendwo in der Mitte. Der Autor hat bestimmt sämtliche Freunde, die sich auf dem Konzil aufhielten, in seinen nuntius aufgenommen und diese Liste, um den ganzen nach Piglio führenden Weg beleben zu können, mit weiteren Bekannten ergänzt. Dass außer Leonardo Bruni, Cencio Romano und Bartolomeus da Monte-

\footnotetext{
756 Diese „Inkonsequenz” wurde schon von Max Lehnerdt bemerkt. Vgl. Lehnerdt, Cencio, S. 294, Anm. 3.
} 
pulciano auch noch andere Bekannte Benedettos für eine gewisse Zeit in Konstanz aufzufinden waren, kann man vielleicht auch auf Grund der hohen Anzahl von Graduierten für wahrscheinlich halten. ${ }^{757}$ Eines kann mit Sicherheit gesagt werden: Er hat die Namen der in Konstanz weilenden Bekannten nicht aus Versehen in Italien situiert und auch nicht in der Hoffnung, dass sein „Fehler” seinen Lesern nicht auffallen würde, denn dafür sind diese Namen zu bekannt gewesen. Es handelt sich hier eher um einen bewusst angewandten Kunstgriff, der von den Konzilsteilnehmern als ein spielerisches Ineinanderblenden der Gelehrtentopographie des Konzils mit Benedettos italienischer Freundestopographie verstanden werden sollte.

\subsection{Benedettos Selbstpositionierung mit seinem Libellus: Unter Sigismunds Ägide?}

\subsubsection{Benedettos Sigismund im Libellus}

Sigismund wird im Libellus nicht nur in Barbaras Lobgedicht erwähnt. Er wird an zwei weiteren Stellen als legitimierende Instanz benutzt.

In der folgenden, an den Kaplan gerichteten Passage der supplicatio stellt Benedetto offensichtlich seine eigene Initiative, an den König zu schreiben, als einen Beweis für das königliche Wohlwollen dar:

Porro tua pia ac diligenti opera spero coram domino comite gratiam invenire. Primo ob reverentiam dei; secundo, quia de laude imperatoris Sigismundi aliqua meis in carminibus scripsi; tertio, quia ubicumque ero, me servum dicti comitis pronuntiabo; quarto, quia sum pauper clericus; ultimo cardinalis redemptionem meam inter curas suas non habet. ${ }^{758}$

Als Grund seiner Hoffnung, vom Grafen günstig behandelt zu werden, verweist er gleich nach der Gottesfurcht auf seine Lobschriften auf Sigismund. Hier verwendet Benedetto also die gleiche Strategie wie in dem Fall des für die Königin verfassten Lobgedichtes.

Das andere Beispiel für eine Erwähnung Sigismunds befindet sich in einer Schrift der supplicatio, in der Benedetto den Sohn des Grafen von Neufchâtel anspricht. Hier wird impliziert, dass dieser die Gunst und die Liebe des Königs unter anderem durch solche Wohltaten wie die Benedetto geleistete Hilfe erreichen könnte. Benedetto stellt sich also auch in dieser Passage unter der königlichen Ägide dar:

\footnotetext{
757 Joseph Riegel, Die Teilnehmerlisten des Konstanzer Konzils. Ein Beitrag zur mittelalterlichen Statistik. Inaugural-Dissertation (Freiburg: Caritas-Druckerei, 1916), hier S. 69. 
Ita deus det tibi diu in hac vita florere, ac Hectorem militia imitari, et hac aliisque bonis artibus lucrari gratiam et amorem gloriosissimi principis Sigismundi Romanorum et Ungarie Regis illustris. ${ }^{759}$

\subsection{2. „O si nunc Caesar consurgere posset ab umbris" - Benedettos Rom-Invektive}

Außer bei den oben angeführten Erwähnungen Sigismunds macht Benedetto seine Sympathie für den römisch-deutschen König auch in indirekter Weise deutlich.

Wenn das Büchlein Rom durch die Porta Maggiore verlassen haben werde, soll es noch einmal zurückblicken und folgende Worte an die Stadt richten:

$\mathrm{O}$, patria antiqua multos dominata per annos!

$\mathrm{O}$, superum sedes, quo ruis arte dolo?

O, caput, o mundi, quondam memorabile solum!

Constat nunc nomen famaque nota tibi!

$\mathrm{O}$, si nunc Cesar consurgere posset ab umbris, Psalleret ${ }^{760}$ indignos percutiens baculo!

Diceret: „Ignavi nunc hinc migrate coloni! ${ }^{761}$

Hic locus est aliis dignus ubique viris!" 762

Wenn man diese Klageworte mit den im Mittelalter üblichen Rom-Invektiven vergleicht, so fällt sofort auf, dass Benedettos Romklage sich nicht in die Reihe der die Kurie kritisierenden Schriften fügt. Er spezifiziert zwar die Adressaten seiner Kritik an dieser Stelle nicht, das Heraufbeschwören Cäsars ist aber ein klares Zeichen dafür, dass der Autor hier unter dem ehemaligen Ruhm der Stadt nicht den des christlichen Roms versteht. Was er hier beklagt, ist das antike Rom. Im Entstehungskontext seiner Schrift, auf dem Konzil, hätte sich ein anderes Modell viel selbstverständlicher ergeben: die Gegenüberstellung des Klerus seiner eigenen Zeit mit dem Ideal der apostolischen Zeiten. ${ }^{763}$ In einem ähnlichen Kontext, 1406, hielt Pier Paolo Vergerio seine Oratio pro redintegranda uniendaque ecclesia über das Schisma an die römischen Kardinäle. ${ }^{764}$ In dieser Rede spielt Vergerio mit der Idee, was passieren würde, wenn Peter und Paul auferstehen würden:

\footnotetext{
759 CVP. 3529, 213r.

760 Im Codex steht ,psalleret”, dies wurde von Wattenbach (stillschweigend) auf ,pelleret” korrigiert.

761 Verg. Ecl. IX. 4

762 CVP. 3529, 214r; Wattenbach, B. d. P., S. 110.

763 Über die Romkritik im Mittelalter vgl. Josef Benzinger, Invectiva in Romam. Romkritik im Mittelalter vom 9. bis zum 12. Jahrhundert (Lübeck und Hamburg: Matthiesen Verlag, 1968).

764 Die oratio wurde veröffentlicht in: Carlo Combi, „Un discorso inedito di P. P. V. il Seniore di Capodistria”, Archivio Storico per Trieste, l'Istria e il Trentino 1 (1882): 351-374, [im Weiteren: „Un discorso”], der Text der oratio befindet sich auf den Seiten 360-374.
} 
Mihi quidem videtur, si nunc, voluntate Dei, Petrus et Paulus resurgerent a mortuis, huc intra venientes, Ecclesiam hanc non recognoscerent; opinor, ne magis [eam] pro sua reciperent, quam ipsi reciperentur a nobis. ${ }^{765}$

Das Argument von Vergerios Rede, die für die Aufhebung des Schismas plädiert und dementsprechend die Kirche insgesamt kritisiert und nicht die römischen Verhältnisse im Allgemeinen, würde mit Benedettos Bild des auferstandenen Cäsars natürlich nicht funktionieren. Vergerios Wahl der Apostel als Vergleichs- und Kontrollinstanzen war also eine Selbstverständlichkeit. Warum Benedetto seinerseits Cäsar für seine Invektive aussucht, bedarf aber einer Erklärung. Seine Wahl, bei der Erwähnung des verlorenen Ruhms von Rom nicht auf das auch in der mittelalterlichen Tradition verbreitete Muster der Gleichsetzung von Rom- und Kirchenkritik zu rekurrieren, sondern gerade Cäsar zu evozieren, ist vielleicht mit seiner Intention zu erklären, Sigismund auf dem Konstanzer Konzil als advocatus ecclesiae und als den möglichen Wiederhersteller der guten alten Zeiten anzusprechen. Man darf diese Geste andererseits natürlich auch nicht überbewerten, denn sie ist keineswegs mit den Petrarcaschen Briefen an Karl IV. zu vergleichen, die eine direkte, wenn auch für den heutigen Leser anachronistisch erscheinende Aufforderung enthalten, Rom wieder zum Zentrum des Reiches zu machen. ${ }^{766}$ Bei Benedetto handelt es sich noch weniger als bei Petrarca um ein politisches Programm, was die Rolle Roms in der Geschichte des Reiches betrifft. Als Geste ist aber das Evozieren Cäsars nicht zu unterschätzen.

Benedettos Rom-Klage bekommt einen Akzent, den man als „humanistisch” bezeichnen könnte. ${ }^{767}$ Dass er hier das antike Rom meint, ist auch dem unmittelbaren Kontext seiner Klageworte an die Stadt zu entnehmen. Seine Attacke auf das neue Rom (bzw. auf die neuen Bewohner Roms) als Verschwender des kostbaren Erbes ${ }^{768}$ fängt nämlich schon früher an. Das Büchlein wird in Rom die Klage des Kolosseums hören:

Tunc dabitur querulis laniantem se Coliseum

Vocibus audiri, parve libelle, suis

Dicentem: „Quid me manibus permittis iniquis

Avelli, patiens, improba Roma, tuis?!

O, cives, cives! Michi nil donastis, et ergo

\section{Combi, Un discorso, S. 396.}

Vgl. Bayley, Petrarch, Charles IV.

Es wäre selbstverständlich nicht richtig, Humanismus und Religion als entgegengesetzte, einander ausschließende Diskurse darzustellen, dies ist hier auch nicht gemeint. Die Tatsache aber, dass Benedetto in einem Kontext, in dem andere Akzente selbstverständlicher gewesen wären, statt über die Kuria zu schreiben, den Glanz des antiken Rom zurückwünscht, ist meines Erachtens im Kontext der humanistischen Antikenbegeisterung zu betrachten.

768 Benedetto verwendet hier den gleichen Topos wie Bruni in seiner Beschreibung der Stadt von Konstanz: die Bewohner der Stadt als Vergeuder des antiken Erbes ihrer Stadt. Vgl. das Unterkapitel IV. 1.3.1. „Benedettos Brief an seinen Bruder”. 
Cur rapitis, verus quod dederat populus?

Non pudet ignavos veterum monimenta virorum

Perdere?" Et alterius, sed probitate dolent.

Hunc cum tu videas laniatum corpore toto

Suspirans, dicas: „O, miser alte ruis,

Qui totiens populumque tuo gaudere theatro

Vidisti, atque senes, nomina magna, viros!

Roma quibus vacua est, ac mundi fece repleta

Fert male cum sociis te, miserande, rapi.,"769

Mit dem „verus populus” ist hier offensichtlich die antike Bevölkerung Roms gemeint, weil es um das Volk geht, das das ,theatrum” erbaut hat. Das Kolosseum als Symbol für die ganze Stadt ist aus dem Beda zugeschriebenen Satz bekannt, nach dem die Stadt Rom so lange stehe wie das Kolosseum und die Welt so lange wie Rom: „Quandiu stat Colisaeus, stat et Roma; quando cadet Colisaeus, cadet Roma. Quando cadet Roma, cadet et mundus."770 Diesen Satz könnte Benedetto gekannt haben: Seine Wahl der Ansprache des Kolosseums als der antiken Ruine Roms schlechthin war möglicherweise auch durch diesen Spruch beeinflusst. Dies würde bedeuten, dass die scharfe Trennung zwischen der Sehnsucht nach dem antiken Rom und dem Bejubeln des christlichen Roms nicht vorstellbar ist. Im Pseudo-Beda-Satz geht es, obwohl dessen Autor eine antike Ruine als Sinnbild der Standhaftigkeit der Stadt wählt, dennoch um das christliche Rom. ${ }^{771}$ Bei Benedetto ist aber Roms Ruhm schon längst Vergangenheit und durch das Erwähnen des „verus populus”, Cäsars und der Senatoren eindeutig in der Antike angesiedelt.

\subsubsection{Der geheimnisvolle Besucher}

In seinem Kerker bekommt Benedetto einmal einen mysteriösen Besuch. Der Besucher fragt nach Benedettos Namen und als er ihn erfährt, sagt er, dass er vom Gefangenen schon gehört habe, als er in Konstanz gewesen sei. Er wundere sich, sagt der Besucher, warum Benedetto bei einem solch ungebildeten Menschen ausharre wie dem Kardinal Stefaneschi. Benedettos Antwort und die Fortsetzung des Gespräches malen kein schmeichelhaftes Bild von den Betroffenen, dem Kardinal und dem Papst Johannes XXIII.:

\footnotetext{
769 CVP. 3529, 13v; Wattenbach, B. d. P., S. 109-110.

770 Pseudo Beda Venerabilis, Excerptiones patrum (Migne, PL 94), Sp. 543.

771 Hier sei angemerkt, dass das Kolosseum auch später, vom Papst Eugen IV., als Sinnbild für die ewige Stadt und sogar die Garantie des Fortbestehens von Rom und des ganzen Erdkreises gehalten wurde. Der Papst hat diejenigen mit Strafe bedroht, die den kleinsten Stein des Kolosseums abtragen würden. Vgl. Ludwig von Pastor, Geschichte der Päpste im Zeitalter der Renaissance bis zur Wahl Pius II.; Martin V., Eugen IV., Nikolaus V., Kalixtus III (Freiburg, Br.: Herder, 1925, 5. Aufl.), S. 366.
} 
„Miror, quid tu manes cum homine imperito, qualis est cardinalis sancti Angeli.” Ad hec ego: „Non est”, inquam, ,ita indoctus, ut dicis. Sed ab ea, si quam habet imperitia, se redimit vite ac morum honestate, virtutisque multiplicibus donis, quibus inter illustres eminet viros.” „Non quidem”, inquit ille, „virtuosus et bonus esse potest, qui Baldassarem Coxam, quondam papam Iohannem nuncupatum, sequutus est. Nam ista non cadunt simul, nec sese compatiuntur, aliquem bonum virum esse, ac eundem Baldassarem diligere simoniacum, fallacem, scelestum, inhumanum, homicidam, corruptorem, stupratorem, incestum, adulterum et, quod abominabilius erat, olim inter Cives Sogdome principalem.

Benedetto verteidigt den Kardinal, aber diese Verteidigung ist vielleicht noch giftiger als die Worte des Besuchers. Mit „sed ab ea si quam habet imperitia” gibt Benedetto praktisch zu, dass er Stefaneschi auch nicht für besonders gebildet hält. Dass es ausgerechnet die moralische Haltung (,vite ac morum honestate”) des Kardinals sein soll, die für einen Ausgleich für seine mangelnde „Bildung” sorgen soll, bildet den Gipfel von Benedettos durch Ironie verschleierter Attacke. Im nuntius macht Benedetto seine Meinung über das Verhalten des Kardinals, der seine Leute im Stich gelassen hatte, eindeutig. Er vertraut seinem Büchlein folgende Nachricht an den Kardinal an, die er in den Vespasians-Bogen eingravieren soll:

Eloquar, an sileam? Loquar, et tibi, grate capellum, Qui geris, et cardi nomina nalis habes.

Ecce tuos famulos, septem sunt ordine menses, Pretentos ${ }^{773}$ turri pena metusque tenet.

Quid facis, o, bone vir? Tibi nummus dormit in arca, Et vermis comedit parva pulexque tuos,

Tuque voluntates gratas tibi perficis omnes, At miseros torquet noxque diesque tuos!

Omnes fecisses salvos, si tempore primo Esset, et ipsorum plena rogata salus.

Effudere preces pro solis verbaque rebus Non pro personis, impia turba, tuis.

Da tibi posse homines nunc comptis fallere verbis, Nunquid cernentem fallere cuncta potes?

Hic tibi pro meritis tribuet quecunque mereris, Hic tibi, si fallis, premia digna dabit. ${ }^{774}$

Dem Leser des Libellus muss Benedettos Meinung über die „Tugend” Stefaneschis in den oben zitierten Zeilen des nuntius, des ersten Teiles des Buches, beim Lesen der Besucherszene in der narratio bereits bekannt sein. Demzufolge kann Benedettos Verteidigung des Kardinals nur ironisch gedeutet werden.

\footnotetext{
772 CVP. 3529, 229r; Wattenbach, B. d. P., S. 117.

773 In der Handschrift steht pretenti.

774 CVP. 3529, 213r-213v; Wattenbach, B. d. P., S. $108 \mathrm{f}$.
} 
Auch sein Gegenargument, das Baldassare Cossas Kritik betrifft, wirkt sehr blass, wenn man sie mit der Vehemenz der Attacke des Besuchers vergleicht:

Tunc ego: „Bone domine,” inquam „fama in his maior est vero. Non semper est fame credendum, que mendax frequentius existens prava ficta penitusque falsa pronuntiat. Nec omni spiritui fides prestanda. Nam summis viris et si nullos inimicos iniuria, multos tamen invidia peperit.",775

Es war offensichtlich nicht Benedettos Absicht, den ehemaligen Papst Johannes XXIII., in dessen Obedienz sein Kardinal gehörte, vor den Schmähungen zu schützen. Man könnte sogar davon ausgehen, dass die Schilderung des Besuches eine fiktive Szene ist, was den von Benedetto „zitierten” Schmähungen des Kardinals und des Papstes eine besondere Bedeutung verleiht. Was die Fiktionalität der Szene wahrscheinlich macht, sind folgende Besonderheiten der Beschreibung: Es scheint eher unwahrscheinlich zu sein, dass jemand plötzlich ganz zufällig im Kerker von Neufchâtel auftaucht, der nicht nur über die Geschehnisse des Konzils bestens informiert ist, sondern sogar Benedetto mit Namen kennt. Der Name des Besuchers wiederum, wie auch seine Herkunft, werden nicht verraten, seine Figur bekommt nicht einmal die vagesten Konturen. Die Einfügung der Szene wäre vielleicht damit zu erklären, dass Benedetto seine Kritik des Kardinals noch einmal etwas nachdrücklicher formulieren und sie mit einer Attacke gegen den ehemaligen Papst Johannes XXIII. verbinden wollte, dem in Konstanz der Prozess gemacht wurde. Mit Hilfe der Besuchsszene konnte er diese Kritik in Anführungsstrichen zum Ausdruck bringen. Dies konnte für Benedetto wichtig sein, weil er es sich in seiner Situation nicht leisten konnte, für oder gegen jemanden auf solch kämpferische Weise Stellung zu nehmen.

Andererseits musste Benedetto auch seine eigene Stellung in der Geschichte klären. Er wollte sich wahrscheinlich gegenüber dem möglichen Vorwurf verteidigen, den er seinem Besucher in den Mund legte, dass kein Mensch, der dem ehemaligen Johannes XXIII. gedient habe, tugendhaft sein könne (,,non quidem, inquit ille, virtuosus et bonus esse potest, qui Baldassarem Coxam, quondam papam Iohannem nuncupatum, sequutus est.") Dieser Satz bezieht sich zwar auf den Kardinal, unmittelbar betrifft er aber auch Benedetto. Er will dementsprechend klare Grenzen zwischen dem Kardinal, in dessen Gefolge er nach Konstanz gezogen war, und Baldassare Cossa ziehen:

„Sane dominus meus Cardinalis eundem colebat et honorabat ut dominum. Sua vero, si qua erant mala opera, odio semper habuit. Nec multum sibi amicabatur. Et cum

775 CVP. 3529, 229r; Wattenbach, B. d. P., S. 117. 
idem electus assumptusque in summum pontificem, idem Cardinalis ab eligentibus clare dissensit, prout omnibus illo tempore patuit."776

Er belässt es aber nicht dabei. Auf die Geschichte, dass der Kardinal seine Leute im Stich gelassen und nicht alles getan habe, sie wieder befreien zu lassen, will Benedetto (durch die Zwischenschaltung des Besuchers) noch zurückkommen:

„Cur ergo" inquit ille ,a tam sacro cetu Constantie congregato hic tuus magister discesserat? Mercenarium quidem se esse monstravit, et indignum, cui ovium Christi commiteretur, venientem enim fugerat lupum."

Benedetto „versucht” hier den Kardinal von dieser schweren Anklage zu dispensieren und sagt:

„Abiit” inquam „et, ne ovis una periret, succurrere properabat. Timebat enim, ne Roma sua patria ac Petri sedes precipua contra regimen ecclesie in tanto discrimine rebellaret. Abiit” inquam ,petita et obtenta ab Imperatore licentia intendens volensque singulis concilii sacri censuris obedire ac per omnia consentire."

Die Aussage, Stefaneschi habe sich Mühe gegeben, zu helfen, dass keines der Schafe verloren gehe, klingt nach der langen Klage, die der Libellus in den Vespasian-Bogen eingravieren soll, wenig überzeugend. Der Besucher lässt es auch nicht dabei bewenden, sondern setzt seine Invektive umgehend fort:

„Tunc ille discessit” inquit „ut Rome suas voluptates impleret. Tu te damnas, si ipsum defendere pergis. Studia enim sua Constantie pro notoriis divulgata sunt" ${ }^{779}$

Diesen Anschuldigungen setzt Benedetto nichts entgegen, er schließt seine „Apologie” mit dem bereits angewandten, allgemeinen Argument, nach dem man nicht jedem Gerücht Glauben schenken sollte:

Respondi talia dicentibus non esse credendum, esseque nonnullos ipsum cardinalem non suo, sed ipsorum vitio habentes, odio falsa pro veris de eo loquentes. His dictis ab ea materia divertens recommendavi me sibi. ${ }^{780}$

Benedettos zwiespältige Haltung dem Kardinal gegenüber zeigt sich noch einmal am Ende des nuntius, nach dem an das Konzil gerichteten Gedicht. Mit folgenden Zeilen entschuldigt er sich für seine harten Worte über den Kardinal:

\footnotetext{
776 CVP. 3529, 229r-229v; Wattenbach, B. d. P., S. 117.

777 CVP. 3529, 229v; Wattenbach, B. d. P., S. $117 \mathrm{f}$.

778 CVP. 3529, 229v; Wattenbach, B. d. P., S. 118.

779 ebda

780 ebda
} 
Parce michi, domine, multum enim in carcere maledixi tibi et his, qui te impulerunt, ut abires Constancia. Nunc autem benedicens benedicam, et id mali, quod diu passus sum, fortune imputo mee. Datum erat in fatis, evitari non poterat. ${ }^{781}$

Benedetto tut hier so, als ob er nicht die Möglichkeit gehabt hätte, seinen Text nach der Gefangenschaft noch einmal zu korrigieren und die Passagen, die er im Nachhinein nicht richtig fand, zu streichen. In der Tat wollte er die den Kardinal kritisierenden Zeilen in seinem Text beibehalten, er wollte sich für sie aber auch entschuldigen. In der Besucher-Szene konnte er beide seiner Vorhaben gleichzeitig verwirklichen.

Der Gesamteindruck der Szene, die Benedettos mysteriösen Besuch darstellt, ergibt, dass es sich hier um eine Fiktion handelt, die es Benedetto ermöglichte, seine frühere Position im Gefolge des ehemaligen Papstes zu klären (also unmissverständlich zu machen, dass die Tatsache, zu Stefaneschis Gefolge zu gehören, nicht eine kritiklose Loyalität dem abgesetzten Papst gegenüber bedeutete), andererseits seine Kritik am Kardinal und dem Papst Johannes XXIII. in noch schärferer Form (durch die Aussagen des Besuchers) zu formulieren. Drittens zeigt das oben dargestellte Verhalten den Gefangenen als einen gutmütigen und, wenn man seine Situation bedenkt, in welcher er den Kardinal verteidigte, großzügigen Menschen. Die Szene lässt alle Möglichkeiten offen, macht die Distanzierung Benedettos vom päpstlichen Fluchtversuch eindeutig, ohne dass er seinen früheren Brotherren - abgesehen von ein paar Seitenhieben - vehementer Kritik unterwerfen wollte.

Der Ton der Darstellung der Besucherszene lässt sich schwer definieren. Es handelt sich nicht nur um das doppelte Spiel, das hier von Benedetto gespielt wird, also nicht nur um die Frage, was seine Meinung über Stefaneschi und Cossa besser ausdrückt, die in imaginären Anführungsstrichen geschilderten Schmähungen des Besuchers oder Benedettos Verteidigung. Es gibt auch andere Aspekte des Textes, die es schwierig machen, Benedettos Distanz oder Nähe zu den hier Dargestellten genau einzuschätzen. Benedettos Vorlage für seinen Libellus war außer Ovid auch Boethius. Die Schreibsituation (der Autor im Gefängnis) und die Form (das Wechseln zwischen Vers und Prosa ${ }^{782}$ ) machen den Zusammenhang zwischen den zwei Texten (Benedettos Libellus und Boethius' Consolatio) eindeutig. Dementsprechend kann Benedettos Besucherszene vor der Folie des Besuchs der Philosophia in Boethius' Gefängnis gelesen werden. Ein kurzer Vergleich der jeweiligen Sujets der Beschreibungen der Besuche ergibt viele Ähnlichkeiten: Wenn Benedettos Besucher dem Gefangenen vorwirft, dass er sich zu unwürdigen Menschen gesellt habe, dann kann dieser

781 CVP. 3529, 246r; Wattenbach, B. d. P., S. 123.

782 Diese Frage wird später, im Unterkapitel IV. 2.5.3. „Der Libellus als Prosimetrum” ausführlicher erörtert. 
Vorwurf dem Leser die Vorwürfe der Philosophia in Erinnerung rufen ${ }^{783}$, die sie an den gefangenen Erzähler richtet: der Besuch der Musen sei unerwünscht und sogar schädlich, zweitens habe der Kranke der Consolatio seiner selbst vergessen und sie, Philosophia, könne dabei helfen, ihm sein wahres Wesen in Erinnerung zu rufen. Ähnlich wie Philosophia will auch Benedettos Besucher mit seinen schmähenden Worten über den Kardinal und den ehemaligen Papst dem Gefangenen die Augen öffnen.

Wie die Philosophia will auch Benedettos Besucher dem Gefangenen helfen. Während aber die Philosophia ihren Zögling in einem langen, mäeutischen Gespräch zu therapieren versucht, ist Benedettos Besucher etwas pragmatischer. Er versucht nur die strengen Bedingungen von Benedettos Gefangenendasein zu mildern:

Qui vere misericors atque pius efficacem operam dedit, ut uno et aliquando duobus diebus post meridiem qualibet ebdomada in secundo turris tabulatu mansurus emitterer cavea. Hic multum et satis ultra, quod merear, verbis extulit, ac commendatur suis urgentibus persuasionibus effecit, ut michi deinceps cibus et potus bonus afferretur in copia. ${ }^{784}$

Dass die Consolatio Philosophiae als Folie für seinen eigenen Text wirken könnte, musste Benedetto bewusst sein. Die boethianische Tradition war im 14. und am Anfang des 15. Jahrhunderts eine wohl bekannte, sie diente auch als Rahmen für mehrere Texte, die ein Lehrgespräch inszenierten. Um ein Beispiel von Petrarca zu nennen: die Gesprächssituation des De secreto conflictu curarum mearum ${ }^{785}$ folgt auch eindeutig dem boethianischen Muster.

Eine andere mögliche Folie, die in Benedettos Besucherszene evoziert wird, ist die Vita des Heiligen Antonius. ${ }^{786}$ Unmittelbar vor der Schilderung der Ankunft des Besuchers schreibt Benedetto über seinen erbärmlichen Zustand im Gefängnis und vor allem über seine Visionen, die er im Schlaf und auch im wachen Zustand empfangen hat.

Quos et quot lemures, quas et quam informes, que nunquam in sensu fuerunt imagines, per somnum et interdum vigilans viderim, que comminantium fulmina audiverim, quot et quales penas illic subiverim, reminisci piget. ${ }^{787}$

Die Erzählung der Ankunft des Besuchers fängt gleich im nächsten Satz an:

\footnotetext{
783 Für die Vertreibung der Musen vgl. Boeth. Cons. Phil. 1, 1, 25-39, für Philosophias Diagnose des kranken Gefangenen: 1, 2, 1-16.

784 CVP. 3529, 229v.

785 Francesco Petrarca, Secretum, hrsg. v. Enrico Fenzi (Mailand: Mursia, 1992).

786 Die lateinische Übersetzung des Evagrius, in der die Vita Antonii des Athanasius im lateinischen Mittelalter gelesen wurde, jetzt ed.: Pascal Bertrand, „Die Evagriusübersetzung der Vita Antonii. Rezeption Überlieferung - Edition. Unter besonderer Berücksichtigung der Vitas patrum - Tradition" (PhD Diss., Universiteit Utrecht, 2006), [im Weiteren: „Vita Antonii”] und ist unter folgender Adresse abrufbar: http://igitur-archive.library.uu.nl/dissertations/2006-0221-200251/index.htm. 
Saltem post dictos dies quidam satis doctus a deo, ut puto, missus ad me venit, et loqui cepit. ${ }^{788}$

Die Inszenierung der Ankunft des gelehrten Mannes folgt hier dem Muster der Erzählung der Vita Antonii. Auch der Eremit hat mit der „multifaria turba demonum” seinen Kampf kämpfen müssen. ${ }^{789}$ Antonius' Kampf mit den Dämonen endete mit der Epiphanie Jesu Christi, der den Kampf des Heiligen verfolgt und ihn wegen seiner Tapferkeit und Ausdauer davon vergewissert habe, dass er fortan ihm immer zur Seite stehen würde. ${ }^{790}$ Obwohl Leiden und Hilfe in Benedettos Text keine ausgesprochen religiöse Bedeutung haben, ist das Grundschema der Erzählung dem der Heiligenvita recht ähnlich.

Benedetto verwendet einen Satz, der den Leser ebenfalls an die Vita Antonii erinnern musste: als er die erste Welle der Attacken seines Besuchers abwehrt, baut er auch den Satz „Nec omni spiritui fides prestanda” in seine „Verteidigung” ein. Der Satz, der auf den ersten Blick etwas fehl am Platz zu sein scheint, weil es hier nicht um Dämonen, sondern um Gerüchte geht, hat aber im Kontext des Konstanzer Konzils doch eine Bedeutung, die sogar in diesem Kontext des Libellus wirken kann. Die Praxis der discretio spirituum, auf die dieser Satz hinweist und deren berühmteste Schilderung sich in der Vita Antonii befindet, ${ }^{791}$ wurde auf dem Konzil des Öfteren thematisiert. Eines der Werke des Jean Gerson, die sich mit der Frage der discretio spirituum befassen, ist auf dem Konzil entstanden. ${ }^{792}$ Der Anlass zum Schreiben seines De probatione spiritum war die Frage der Dekanonisation von Brigitte von Schweden. ${ }^{793}$ Gerson weist auch auf die Tatsache hin, dass zu der Zeit mehrere Traktate zum Thema zur Verfügung standen. ${ }^{794}$ Wenn man den Konstanzer Kontext beachtet, so erscheint Benedettos Stelle, die die Frage der Diskreditierung einer Person (des ehemaligen Papstes) mit einem aus dem Diskurs der discretio stammenden Ausdruck formuliert, nicht mehr so merkwürdig. Die Theorie und Praxis der discretio wurde auf dem Konzil als ein politisches Instrument benutzt. Es mag natürlich auch sein, dass er diesen Ausdruck an dieser Stelle ohne weitere und tiefere Überlegungen verwendet, die Verknüpfung ist aber sehr wahrscheinlich

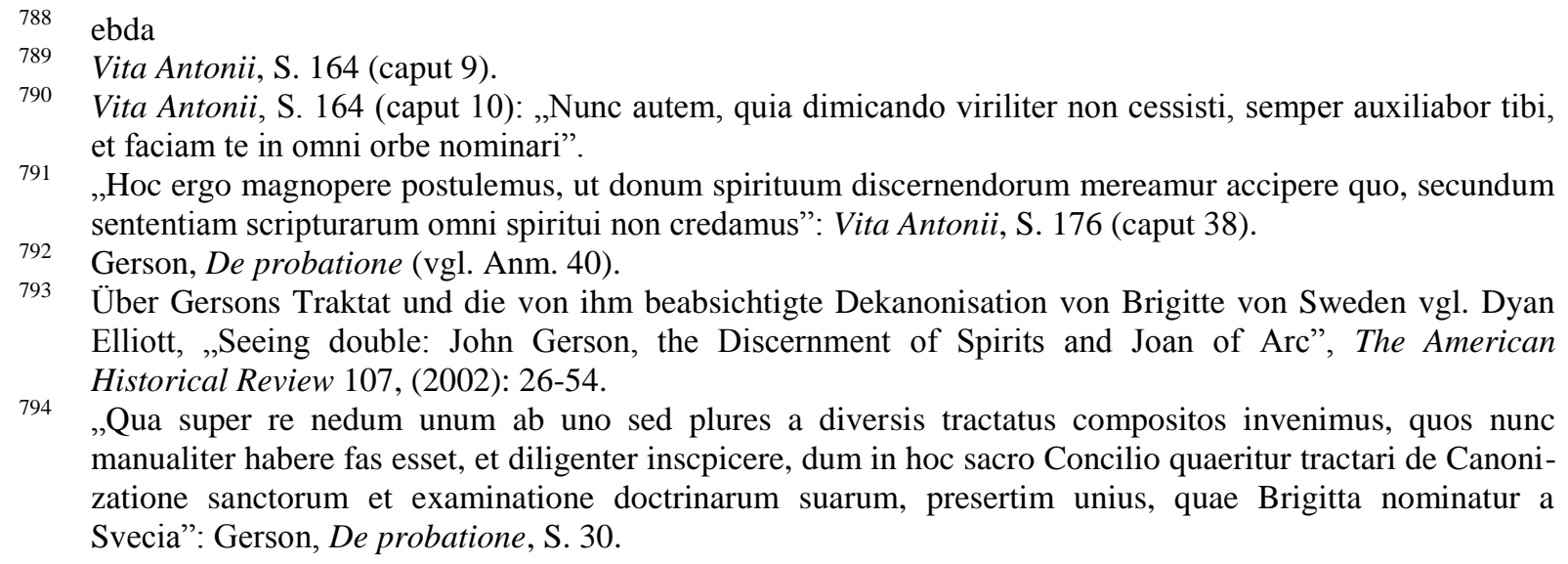

791 „Hoc ergo magnopere postulemus, ut donum spirituum discernendorum mereamur accipere quo, secundum sententiam scripturarum omni spiritui non credamus": Vita Antonii, S. 176 (caput 38).

792 Gerson, De probatione (vgl. Anm. 40).

793 Über Gersons Traktat und die von ihm beabsichtigte Dekanonisation von Brigitte von Sweden vgl. Dyan Elliott, „Seeing double: John Gerson, the Discernment of Spirits and Joan of Arc”, The American Historical Review 107, (2002): 26-54.

794 „Qua super re nedum unum ab uno sed plures a diversis tractatus compositos invenimus, quos nunc manualiter habere fas esset, et diligenter inscpicere, dum in hoc sacro Concilio quaeritur tractari de Canonizatione sanctorum et examinatione doctrinarum suarum, presertim unius, quae Brigitta nominatur a Svecia": Gerson, De probatione, S. 30. 
dem Konstanzer Kontext zu verdanken, in dem Fragen, die die Glaubwürdigkeit bestimmter Personen betrafen, mit Hinweis auf diese Praxis entschieden werden konnten. Benedettos Hinweis auf diese Tradition konnte der zeitgenössische Leser des Textes mit der Vita Antonii in Zusammenhang bringen, unabhängig davon, ob Benedetto dies beabsichtigt hatte oder nicht. Wenn man die Szene konsequent vor dieser Folie liest, so erscheint der Besucher in Benedettos Kerker als ein Geist, der dem Gefangenen erscheint und der wahrscheinlich nicht zu den guten, vertrauenswürdigen Visionen gehört, denn er verbreitet Nachrichten, denen man eher kein Vertrauen schenken sollte (der auf die discretio hinweisende Satz bezieht sich im Text auf die üblen Nachreden über den Papst). Diese Lesart untergräbt allerdings die Interpretation, nach der die eigentliche Meinung Benedettos über den Kardinal und den Papst in den Mund des Besuchers gelegt worden ist, bzw. stellt einen möglichen Rahmen für die oben geschilderten Manöver der Verunsicherung dar, was den Stellenwert der Aussagen des Besuchers betrifft.

Die zwei Folien, vor denen die Darstellung der Besucherszene des Libellus sich interpretieren lässt, wirken komisch, wenn sie mit Benedettos Text parallel „mitgelesen” werden. Diese Komik wird von der Spannung zwischen der Pragmatik des Libellus und der philosophischen Tiefe der Consolatio einerseits, und zwischen der Profanität von Benedettos Text und der Sakralität der Heiligenvita andererseits generiert. Ob die Komik Benedettos Absicht war oder nicht, kann nicht eindeutig entschieden werden. Was auf jeden Fall auffällt, ist die Unentschiedenheit des Tons der Darstellung, was bestimmt nicht dem Zufall zuzuschreiben ist. Benedetto konnte oder wollte (je nach dem, wie viel Intentionalität man diesen verunsichernden Elementen zuschreibt) sich in der Frage über den Kardinal und den ehemaligen Papst nicht eindeutig festlegen.

\subsection{Komische Elemente im Libellus penarum?}

\subsubsection{Der Libellus als Prosimetrum}

Der komische Effekt im Libellus entsteht durch die Bezugnahme auf verschiedene literarische Traditionen: entstellte oder im neuen Kontext verwirrend wirkende Zitate, der Hinweis auf literarische Vorlagen, die aber auf verschiedene Weisen verfremdet werden, sind bekannte Techniken der literarischen Parodie. Als ein extremes Beispiel für den durch Zitate 
erzeugten komischen Effekt kann die Centoliteratur genannt werden, die das intertextuelle Spiel bis zu einem nicht überschreitbaren Grad steigert. ${ }^{795}$

Die Literaturform Prosimetrum ist ein wichtiges Stichwort, das im Zusammenhang mit Komik und Ironie angesprochen werden muss. Umso mehr muss es geschehen, weil der Libellus zu dieser Gattung gehört. Selbst wenn man die von Pabst mit Strenge festgestellten Kriterien der Zugehörigkeit zur Gattung übernimmt, kann man behaupten, dass der Libellus mit Recht in dieser literarischen Tradition unterzubringen ist. Pabsts Definition lautet: „Prosimetrum als 'Schreibweise' ist eine literarische Darstellungstechnik, die allein auf der bewußten Entscheidung eines Autors beruht, die (unterschiedlichen) Gestaltungsmöglichkeiten von Prosa und Vers innerhalb einer Sinneinheit, die kleiner ist als das Werk (bzw. Buch) als ganzes, nebeneinander zu nutzen." ${ }^{796}$ Der Autor erläutert diese Definition etwas näher, und begünstigt damit ihre Anwendung auf den Fall des Libellus. Der Wille des Autors als einzig möglicher Anlass für die Mischung von Prosa und Vers ist wichtig, weil so ,funktionale Zitate poetischer Texte in prosaischer Umgebung” ausgeklammert werden, ebenso wie „Schmuckzitate aus bekannten poetischen Autoritäten, die meist auf das Bestreben, Bildung und Gelehrsamkeit zu demonstrieren, zurückgehen." Auch jene Texte werden mit dieser Definition ausgegrenzt, in denen der Wechsel von Prosa- und Versteilen ,äußeren Notwendigkeiten einer bestimmten Literaturform und nicht der Entscheidung des Verfassers entspringt”. Der Libellus entspricht diesem Kriterium: Es gibt keinen den von Pabst beschriebenen Beispielen ähnlichen, zwingenden Umstand, außer der Entscheidung des Autors, weswegen er seinen Text als Wechsel von Prosa und Versteilen hat gestalten müssen.

Die zweite Bestimmung ist das Erfordernis, dass „Prosa und Vers innerhalb einer Sinneinheit, die kleiner ist als das Werk als ganzes, nebeneinander eingesetzt werden”. Wenn man es streng nimmt, entspricht Benedettos Werk dieser Bestimmung nur zum Teil. Es ist erst im dritten Buch, in der supplicatio, wo Vers und Prosa innerhalb einer Sinneinheit, die kleiner als das Ganze ist, nebeneinander auftauchen. Das erste Buch, der nuntius, ist ganz in elegischen Distichen, während das zweite, die narratio, ausschließlich in Prosa verfasst worden ist. Wenn man aber versteht, welche Textsorten mit dieser Bestimmung Pabst

795 Obwohl es in Benedettos Fall nicht um diese Technik geht, ist sie als ein extremes Beispiel für die in intertextuellen Beziehungen immanente komische Möglichkeit trotzdem zu nennen. Über literarische Parodien im Mittelalter vgl. Fidel Rädle, „Zu den Bedingungen der Parodie in der lateinischen Literatur des hohen Mittelalters", in Literaturparodie in Antike und Mittelalter, Bochumer Altertumswissenschaftliches Colloquium 15, hrsg. v. Wolfram Ax, Reinhold F. Glei (Trier: Wissenschaftlicher Verlag, 1993), 171-85. Zur Centoliteratur: Theodor Verweyen, Gunther Witting, „The Cento. A Form of Intertextuality from Montage to Parody", in Intertextuality, hrsg. v. Heinrich F. Plett (Berlin, New York: de Gruyter, 1991), 165-77.

796 Bernhard Pabst, Prosimetrum. Tradition und Wandel einer Literaturform zwischen Spätantike und Spätmittelalter, 2 Bde., Ordo. Studien zur Literatur und Gesellschaft des Mittelalters 4 (Köln, Weimar, Wien: Böhlau, 1994), [im Weiteren: „Prosimetrum”], hier Bd. 1, S. 12. 
ausgrenzen wollte, so wird klar, dass der Libellus nicht zu den auszugrenzenden Texten gehört: „Der Sinn dieses Postulats wird sofort deutlich, wenn man die Erscheinungen betrachtet, die durch es ausgegrenzt werden. $\mathrm{Zu}$ nennen sind zunächst einmal Sammlungen ursprünglich unabhängiger, zum Teil rein prosaischer, zum Teil in rein poetischer Form verfasster Texte, in denen durch die Zusammenstellung nachträglich ein akzidenteller Wechsel zwischen Prosa und Vers zustande kommt." ${ }^{\text {797 }}$ Die andere auszugrenzende Textsorte sei das Opus geminum, in dem „die formal verschiedenen Passagen unverbunden gleichsam als Alternativen nebeneinander [stehen], beim Prosimetrum tragen die Partien jeweils nur einen Teil zur Gesamtaussage bei, so daß - und sei es nur stofflich - stets eine Aufgabenverteilung zwischen ihnen vorliegt." ${ }^{798}$ Eine Aufgabenverteilung liegt im Fall Benedettos auf jeden Fall vor: das erste Buch beschreibt den Weg des Buches nach Hause, während der zweite Teil Benedettos Geschichte erzählt. Im dritten Teil befinden sich manchmal Anflehungen, die in beiden Formen verfasst worden sind: der in Prosa verfassten Bitte folgt in diesen Fällen eine an dieselben Personen gerichtete Bitte in Versen mit demselben Inhalt. In manchen Fällen handelt es sich aber auch in der supplicatio um eine Aufgabenverteilung: der in Vers verfasste Brief folgt manchmal dem in Prosa geschriebenen Teil, der die Entstehungsumstände erläutert. Dementsprechend hält die Qualifikation des Textes als Prosimetrum stand.

Die Gattung der menippeischen Satire gehört auch zu dieser Literaturtradition, da die meisten antiken Stücke, die die Form des Prosimetrums aufweisen, menippeische Satiren sind. Seit Michail Bachtin konzentriert sich die Forschung dieser Gattung auf die Fragen der Parodie, Ironie und der Suche nach der dem Suchenden immer wieder entgleitenden Wahrheit als die wichtigsten Themen und Merkmale der menippeischen Satire. In diesem Sinn betrachtet Relihan ${ }^{799}$ das parodistische Element als Hauptmerkmal dieser Gattung und interpretiert mehrere Texte völlig neu. Nach seiner Lesart seien zum Beispiel De nuptiis Mercurii des

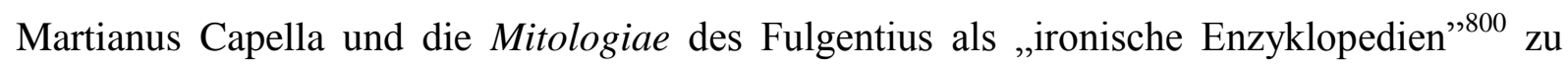
deuten. Sogar der Consolatio des Boethius wird die Möglichkeit einer ironischen Lesart zugesprochen. ${ }^{801}$

797 Hier könnte man bemerken, dass diese Abgrenzung vielleicht mehr zu dem ersten Erfordernis passt, das heißt, dass es sich bei dem „Mischen” von Prosa- und Versteilen um einen bewussten Akt des Autors handeln muss.

798 Pabst, Prosimetrum, Bd. 1, S. 14.

799 Seine Dissertation von 1985 über die Geschichte dieser Gattung wird von Pabst erbarmungslos kritisiert.

800 Joel C. Relihan, Ancient Menippean Satire (Baltimore, London: The Johns Hopkins University Press, 1993), hier S. 137-163.

801 Im Fall vieler Beispiele der menippischen Satire (wie zum Beispiel Werke des Menippos, des Lukians, oder in Senecas Apocolocyntosis) ist die Absichtlichkeit der Komik in Form von Parodie und Ironie von Seiten 
Pabst hält die Idee, nach der ,jedes in prosimetrischer Form verfaßte Werk eine Parodie von Literatur an sich darstelle, die jede Möglichkeit von Wahrheitsvermittlung in Frage stelle und per se auch die vordergründig in ihr vertretenen Ansichten selbstparodistisch negiere" 802 für unhaltbar, weil, wie er bemerkt, die Komik ,hier nicht aus der Mischung von Prosa und Poesie an sich, sondern aus dem Kontrast zwischen epischem und tragischem Verspathos und banalem Kontext" resultiere. ${ }^{803}$ Obwohl Relihans Argumentation an manchen Stellen vielleicht etwas forciert zu sein scheint, ist die Idee der von ihm vorgeschlagenen unorthodoxen Lesarten dennoch nicht einfach vom Tisch zu wischen.

Die Wahrheit liegt vielleicht irgendwo in der Mitte: Obwohl es richtig ist, dass in dieser Gattung nicht die Mischung von Vers- und Prosateilen an sich Träger von Komik ist, ist das episch-tragische Verspathos von der Form, in der es zumeist vermittelt wird, nicht zu trennen. Die Wahrscheinlichkeit, dass zwischen einem einen banalen Inhalt vermittelnden Prosateil und einem Verszitat, das in den Text eingebaut wird, eine gewisse Spannung, und durch die Plötzlichkeit und die Enttäuschung der Erwartungen der Leser eine gewisse Komik erzeugt wird, ist nicht zu unterschätzen. Die Entscheidung über die Haltbarkeit einer ironischen Lesart von Capella, Boethius und Fulgentius ist nicht Aufgabe dieser Arbeit. Das komisch-ironisch-selbstironische Potential ist jedenfalls in vielen prosimetrischen Texten präsent, die zu derselben Literaturform gehören wie der Libellus.

\subsubsection{Die als komisch oder selbstironisch deutbaren Stellen im Libellus penarum}

\subsubsection{Im nuntius}

Um zu der früher angefangenen Reihe der ovidianischen Reminiszenzen kurz zurückzukommen, beginne ich mit der Schilderung der komischen Elemente, die von Ovids Tristia übernommen wurden. Aus den von Amann als komisch etikettierten Elementen übernimmt Benedetto diejenigen, die mit der übertriebenen Vermenschlichung des Büchleins spielen und diese Vermenschlichung in einem übertriebenen Maß verbildlichen. Das markanteste und vielleicht spielerischste von diesen Bildern ist die Darstellung des ,,hinkenden” Buches: „Eine vertraute Gegebenheit (das alternierende Versmaß) wird in einen ungewohnten Zusammenhang gestellt (das Buch als Mensch) und erfährt dadurch eine neue Deutung (das Distichon als Illustration des Hinkens), die man in dieser Form nicht erwartet hat und aus

des Autors ganz eindeutig. Im Fall von Martianus, Boethius und Fulgentius wiederum gibt es in der Forschung keinen Konsens über die ironisierende Lesart des Werkes. 
diesem Grund in dieser Konstellation eine spürbare Anomalie darstellt." ${ }^{\text {} 804}$ Es geht um die folgenden Verse des Ovid:

Clauda quod alterno subsidunt carmina versu Vel pedis hoc ratio, vel via longa facit. ${ }^{805}$

Auch Benedetto spielt mit der Möglichkeit, sein Buch als „hinkend” darzustellen:

Ibis in italicas claudo pede tardius urbes

Claraque continges, parve libelle, loca. ${ }^{806}$

Die aus der Vermenschlichung des Buches stammende Komik zieht sich durch den ganzen nuntius hindurch und erreicht ihren Höhepunkt in den Versen, in denen die Ankunft des Büchleins in Piglio, bei Benedettos Familie geschildert wird. Am Abend seiner Ankunft soll das Buch von den Familienmitgliedern, die ihm zu essen und zu trinken geben werden, mit Küssen empfangen werden:

Interea solito sternetur et ordine mensa.

$\mathrm{Tu}$ vacuus ventrem tende replere tuum!

Multa tibi et pater et gaudens dabit oscula mater.

Haud vidisse semel te sibi sufficient.

At, ubi depositum videas, aut noveris unctum

Gausipe, iam marcens, ebrius ipse satis,

Incipe, rana loquax, facta et non facta referre!

Dedecet hic non te dicere quanta voles. ${ }^{807}$

Das Buch werde sich also wahrscheinlich etwas betrinken und davon geschwätzig werden, aber das passe zur Situation, ermutigt Benedetto das Buch. Diese Ermutigung gefährdet die Glaubwürdigkeit der vom Büchlein getragenen Geschichte, die auf diese Weise schwer vom Geschwätz eines Frosches zu trennen ist. Das abendliche Gerede des Büchleins ist allerdings nicht mit der Erfüllung seiner ursprünglichen Aufgabe gleichzusetzen, weil es zu diesem Akt erst ganz am Ende des ersten Teiles kommt:

Et sic hic dicas: „Frater Benedictus in antro

Conclusus cavee carmina multa dedit.

Nescio quid raucus iam multis scripsit inepte,

Hic ego depono, vos tamen accipite!

Penas ipse suas in nobis narrat, ut infra

\footnotetext{
804 Amann, Komik, S. 131-132.

805 Ov. Tr. 3.1. 11f.

806 CVP. 3529, 208v; Wattenbach, B. d. P., S. 104.

807 CVP. 3529, 219v; Wattenbach, B. d. P., S. 112.
} 
Cernere erit vobis, sunt michi dicta satis."

Das Büchlein setzt seine Last erst jetzt ab und die Brüder können nun erst anfangen, die von Benedetto niedergeschriebene Geschichte zu lesen. Dies bedeutet, dass das vorherige Geschwätz des Buches nicht als die Vollendung seiner Mission zu deuten ist. Nichtsdestotrotz ist die Ermutigung des Buches zum Erzählen von Ereignissen, die sich teilweise gar nicht ereignet haben, ein Detail, das die Vertrauenswürdigkeit des Trägers der Geschichte Benedettos zumindest abschwächen kann und deswegen auch als eine selbstironisierende Erzählstrategie verstanden werden könnte.

Eine andere, vom Autor eindeutig gewollt komische Stelle befindet sich in der Beschreibung der Verwüstung von Benedettos Garten in Piglio. Der historische Kontext und die Ursache dieses Unglücks werden vom Autor erst später erörtert: es ist die Einnahme Piglios durch Adinulfus de Comite mit Hilfe des Priesters Johannes Christianus. Es ist bemerkenswert, wie detailliert der Garten und die Gartenarbeiten beschrieben werden. All diese Arbeiten waren jedoch umsonst. Nach der Zerstörung des Gartens liegen die Äpfel und Birnen auf dem Boden. Wegen des Unterschieds zwischen den Perspektiven der in den Mund des Kolosseums gelegten, eher klischeehaften Klage über Roms Schicksal einerseits und der viel persönlicheren, weil detaillierteren Schilderung der Verwüstung von Benedettos Garten andererseits, scheint der Schmerz über diesen letzteren ein viel größerer zu sein. Umso überraschender ist es, wenn Benedetto gerade hier ein Wortspiel in seine Beschreibung des traurigen Anblickes einbaut:

Quotque mee mali terram petiere cadentes!

Hanc mali penam non meruere pati. ${ }^{809}$

Der Auslöser von Komik in der zweiten Zeile ist die doppelte Bedeutung von „mali”. Das Wortspiel würde hier folgenden Sinn haben: normalerweise seien es die „Bösen” (mali), die eine Strafe verdienen, die Apfelbäume (māli) haben hingegen ihr trauriges Schicksal nicht verdient. ${ }^{810}$ Dass es hier um die Apfelbäume geht, wird durch das Pronominalattribut „mee“ klar (,,meine Apfelbäume“). Der Kontex (vgl das Wortfeld „Strafe“: pena, merere, pati) macht

\footnotetext{
CVP. 3529, 223v.
}

CVP. 3529, 218r.

810 In Boethius' Consolatio, Benedettos anderem, möglichem Modell für seinen Libellus, befindet sich eine längere Erörterung über die Strafe der Bösen: „Quae cum ita sint, de malorum quoque inseparabili poena dubitare sapiens nequeat; nam cum bonum malumque, item poenae atque praemium aduersa fronte dissideant, quae in boni praemio uidemus accedere eadem necesse est in mali poena contraria parte respondeant. Sicut igitur probis probitas ipsa fit praemium, ita improbis nequitia ipsa supplicium est. Iam uero quisquis afficitur poena malo se affectum esse non dubitat.” (Boeth. Cons. Phil. 4, Prosa 3) Die Möglichkeit, dass Benedettos Wortspiel eine Anspielung auf diese Stelle wäre, ist nicht sehr wahrscheinlich, aber auch nicht ganz auszuschließen. 
wiederum eine Assoziation auf „malus“ als Böse plausibel. Durch die Anspielung auf den Titel (durch das Wort „pena”) gewinnt die Komik dieser Stelle eine weitere Bedeutungsebene: nicht nur Benedetto musste seine Strafe erleiden, sondern sogar die von ihm gepflanzten Äpfel und Birnen.

\subsubsection{In der narratio}

Benedetto versuchte aus seiner Gefangenschaft zu fliehen, er wurde aber von den Einwohnern von Neufchâtel gefangen und zurück in das Gefängnis geschleppt. Über diesen gescheiterten Fluchtversuch berichtet er in der narratio. In die Erzählung dieser traurigen Episode mischen sich jedoch Stimmen, die dem Leser ermöglichen, sie an manchen Stellen als komisch zu empfinden. Zuerst soll aber die Geschichte von Benedettos Ausbruch aus dem Turm zusammengefasst werden.

Seine Flucht hatte Benedetto gut vorbereitet: er hörte oft, dass der Wächter, wenn er aus dem Turm gegangen war, die Schlüssel in ein Versteck außerhalb des Turmes legte. Der Gefangene konnte die genaue Stelle auf Grund der Geräusche identifizieren: „Multotiens hoc notavi sonum clavium lapidumque, quibus ipsas tegebat, aure percipiens. "811 Außerdem gab es eine Öffnung in der Mauer, die von außen gesehen weit genug, von innen aber für Benedetto zu eng war. Es schien aber möglich zu sein, sie nach dem Entfernen einiger Steine breit genug zu machen, so dass seine Leidensgenossen, die offensichtlich kleiner waren, durch diese Öffnung hinausklettern konnten.

Insuper foramen erat iuxta secundum tabulatum in muro ipsius turris, quod ab exteriore parte satis videbatur mediocrem hominem capere, sed ab interiore parte arctum. Amotis tamen aliquot lapidibus largum fieri poterat: huius altitudinem ac latitudinem sepe mensus fui cum corporibus sociorum: facile ipsos recipere videbatur. Me autem aliquanto latiores humeros sociis ipsis habentem nullatenus admittebat. ${ }^{812}$

Eines Tages, am 21. Juli, war es soweit: die Gefangenen haben aus der Öffnung der Mauer einige Steine entfernt. Ein Mitgefangener Benedettos konnte so hinausklettern, um den Schlüssel zu holen, und seine Mitbewohner zu befreien. Es war auch für den Fall, wenn er die Schlüssel nicht finden sollte, vereinbart, dass er das Holzbrett, das die Tür zuhielt, entfernen wird. Der aber hat gar nicht daran gedacht, die anderen, die im Turm geblieben sind, zu befreien, sondern ist allein geflohen, ohne den Schlüssel zu holen, die Tür zu öffnen oder das Holzbrett von der Tür zu entfernen:

811 CVP. 3529, 227r.

812 ebda 
Captato tempore, cum omnes castrenses essent in prandio, Iulii primo ac vigesimo die per foramen ipsum amotis, per vim et ingenium multis lapidibus unum ex sociis predictis emisi. Admonens eum, ut claves quereret, ac ipsis inventis turris hostium apperiret. Id si casu non posset, amoveret tandem lignum, quod cum cathena quadam ferrea $a b$ exteriore parte fores turris tenebat immobiles. At bonus socius immemor mei utrumque neglexit. Nam nec claves, quas ibi fuisse certissimum est perquirens, nec lignum amovens saltu se proiciens extra muros castri de quadam satis alta fenestra, quantumque in ipso fuit; me, alium socium morti tradidit. ${ }^{813}$

Benedetto stieg am Ende mit viel Mühe selbst durch das Fenster hinaus und begann zu rennen. Der dritte Gefangene wollte auch fliehen, als er aber erkannte, dass er seine Sachen nicht mitnehmen kann, hat er seine Flucht aufgegeben und angefangen, laut nach den Wächtern zu rufen und vom Turm aus den Weg der Flüchtlinge zu zeigen.

Tum ego futurum periculum metuens rursus id foramen agredior, et summa virum ac ingenii ope tria insuper evulsi saxa. Inde sola indutus camisia foramen exivi, dentibus ipsius in mei corporis partibus miserabiliter laceratus de dicta fenestra prosilui. Deinde nemine sentiente quandam vineam intravi, expectabam stultus alium socium. Ille vero videns non posse secum ferre sarcinulas ignavus cacumen turris ascendit, altaque voce clamans vocabat custodem carceris sociorum fugam denuntians, quodque dampnabilius est, ostendens. ${ }^{814}$

Die Jagd nach Benedetto nimmt jetzt ihren Anfang. Der Fliehende versucht zu rennen, dies fällt ihm aber nicht leicht, da sein rechtes Knie seit einem Unfall im Gefängnis (er ist ausgerutscht und vom zweiten Stock in den ersten hinuntergestürzt) verletzt war. ${ }^{815}$ Weiterhin war es auch noch warm, was durch das Rennen noch viel mehr zu spüren war. Benedetto gelang es, da er nur ein Hemd anhatte, schneller zu sein als die ihn verfolgenden Leute. Ab diesem Punkt zeigt die Erzählung verwirrende, eigentlich nur als komisch deutbare Elemente:

Populus concitatur. Ego, quamvis claudus, satis tamen pedibus fidens currere cepi. Totus populus sequebatur. „Estus erat magnusque labor geminaverat illum”. Facile michi erat cum sola camisia cursu totum populum superare. ${ }^{816}$

Der Hinweis auf die durch körperliche Anstrengung doppelt so stark spürbare Hitze ist ein Zitat aus Ovids Metamorphoses ${ }^{817}$ Im Originalkontext findet man den Vers in der Erzählung von Arethusas Geschichte (5. 586). Arethusa war eine der Nymphen. Ihre Schönheit empfand sie selbst immer als eine Last und ihr erschien es sogar als eine Sünde, den anderen zu

\footnotetext{
813 CVP. 3529, 227r-227v.

814 CVP. 3529, 227v.

815 CVP. 3529, 225v

816 CVP. 3529, 227v; Wattenbach, B. d. P., S. 116.
}

817 Das Zitat wurde schon von Wattenbach identifiziert: S. 116, er hat auch auf die Tatsache hingewiesen, dass im Originaltext das letzte Wort ,aestum” ist, und dass der Vers seit Heinsius so gelesen wird: ,aestus erat, magnumque labor geminaverat aestum". 
gefallen. Diese wunderschöne Jungfrau wollte, als sie einmal aus dem Wald zurückkehrte und ihr heiß war, in einem Fluss baden. Das Ende der Geschichte ist wohl bekannt: Auf ihre Bitte hin wurde sie von Artemis in eine Quelle verwandelt, damit sie in dieser Form dem liebeswütigen Alpheos entfliehen konnte. Der von Benedetto zitierte Vers beschreibt Arethusa in dem Moment, als sie aus dem Wald zurückkehrte.

Wenn man Benedettos Geschichte weiterliest, so findet man auch in dieser Erzählung, wenn schon keinen richtigen Fluss, so doch wenigstens einen Graben mit Wasser. Das dort wachsende Gebüsch schien Benedetto ein gutes Versteck zu bieten. So bewegte er sich hier im Graben auf allen vieren fort:

Sed ecce complures equites precurrentes quorundam collium cacumina conscenderunt. Horum oculos fugiendo fallere nullo modo dabatur. Est ampla altaque ac longa fossa, non manu facta, sed ab ipsa rerum natura formata, dumis arbustis densisque fructibus plena, ut predicitur fugienti propinqua, per cuius fundum aqua decurrit, que castrum predictum per medium scindit. Hec satis oportuna et idonea latebris videbatur. Huc descendi, atque, ut sequentes circumvenirem astutiaque deciperem, pedibus ac minibus ambulans fere per medium miliare cucurri, sequens versus castrum decursus aquarum, meque frondentibus ramis tegens nemine perpendente delitui. ${ }^{818}$

Benedettos Flucht ist, wenn man sie in dem vom Zitat gebildeten Kontext sieht, fast als parodistisch zu bezeichnen. Auf der einen Seite hat man die wunderschöne, keusche Nymphe, die ihre Kleidung (mollia velamina) zum Baden auszieht, auf der anderen einen hinkenden Mann mit vielen Wunden und Ungeziefer (im Gefängnis hatte er ganze Scharen von allen möglichen Insekten auf seiner Haut ${ }^{819}$ ), der in seinem Hemd auf allen vieren zu fliehen versucht. Diese Gegenüberstellung scheint überhaupt nicht so an den Haaren herbeigezogen zu sein, wenn man bedenkt, dass Benedettos Leser (sowohl die Adressaten seines Büchleins, also seine Brüder, als auch das Publikum, das der Autor beim Schreiben sonst noch im Auge haben konnte) mit dem Text der Metamorphoses vertraut waren und beim Lesen des Zitats die Stelle leicht identifizieren konnten. Durch die Spannung zwischen dem Originalkontext und dem neuen, in den der Vers hineingebaut wurde, entsteht eine gewisse Komik. Ovids epischelegische Erzählung als Folie setzt einen besonderen Akzent auf die prosaische Darstellung des Benedetto.

Seine Tarnung war allerdings nicht perfekt, der dritte Gefangene hat ihn entdeckt und den Leuten, die nach ihm jagten, Bescheid gesagt. So wurde Benedetto von seinen Verfolgern eingeholt und umzingelt:

818 CVP. 3529, 227v-228r; Wattenbach, B. d. P., S. 116,

819 CVP. 3529, 226v; Wattenbach, B. d., P., S. 115. 
Tunc, postquam me vidit turba querentium, magno clamore facto ac impetu me circumdedere. Et, ut noster Virgilius ait: „Scinditur incertum studia in contraria vulgus". Hic me salvum fieri debere clamabat. Ille lancia, alius gladio, hic fuste, ille pugno me percutere minabatur. Alius me dignum furca dicebat, quia carcerem fregeram. Alius me vitam finire in facto foramine iudicabat. ${ }^{820}$

Das Vergil-Zitat stammt aus der Aeneis (2.39) und beschreibt die Unschlüssigkeit des Volkes von Troja dem Pferd gegenüber, das von den Griechen vor die Mauer ihrer Stadt gestellt wurde. Die einen wollten es in die Stadt führen, die anderen ins Meer werfen oder anzünden oder wenigstens durchbohren. Dieser Originalkontext konnte dem Leser bei dieser Stelle Benedettos schon deswegen einfallen, weil es teilweise auch dort um Vernichtungsmethoden ging, wie im Fall Benedettos. Der ursprüngliche, epische Kontext steht wieder in Spannung mit der neuen, prosaischen Umgebung des Zitats.

Benedetto bemerkt an dieser Stelle, dass es eigentlich um eine verzeihliche Sünde gehe:

Culpa levis erat et, ut idem Virgilius dicit: , Ignoscenda quidem, scirent si ignoscere manes". Deinde dum traherent me rursus in turrim, piissime loci illius domine me videntes lacerum, sanguine manantem omnes inconsolabiter flebant. ${ }^{821}$

Diesmal wird zum Ausschmücken der Erzählung ein Vers aus den Georgica (IV. 489) zitiert. Der Satz bezieht sich auf Orpheus' dementia, die ihn, Orpheus, dazu gebracht hatte, auf seinem Heimweg mit Eurydice aus der Unterwelt doch nach hinten, sich doch nach seiner Geliebten umzuschauen. Eurydice darf nicht mit Orpheus zurück nach oben, an das Tageslicht, sie muss in die Unterwelt zurückkehren. Auch Benedetto muss zurück in das Gefängnis.

Die drei oben gezeigten Stellen können aus dem gleichen Grund nicht als frei von einer gewissen Komik gedeutet werden. Die Diskrepanz zwischen dem Originalkontext und dem von Benedetto geschaffenen neuen Kontext ist nicht nur groß, sondern sie hat immer die gleiche Richtung. Das episch-elegische Verspathos steht in scharfem Kontrast zur Welt, die in Benedettos Prosa vergegenwärtigt wird. In allen drei Fällen kann man davon ausgehen, dass der Originalkontext den Lesern bekannt war. Die Assoziation mit den antiken Texten wird jedes Mal auch durch bestimmte gemeinsame Elemente des jeweiligen antiken Textes und Benedettos Erzählung in Gang gesetzt. In der Arethusa-Episode sind es die Flucht selbst und das Wasser, im Fall des trojanischen Pferdes ist es die Unschlüssigkeit des Volkes, welche Maßnahme zu ergreifen sei (dem Pferd oder Benedetto gegenüber), im dritten Fall sind es das

820 CVP. 3529, 228v; Wattenbach, B. d. P., S. 116.

${ }^{821}$ CVP. 3529, 228v; Wattenbach, B. d. P., S. 116-117. 
Motiv der gescheiterten Flucht und die Rückkehr in die Gefangenschaft. Diese Gemeinsamkeiten verhindern es, die Zitate ganz unabhängig von deren ursprünglichem Kontext als sprichwortähnliche Textbausteine zu lesen. Das Durchschimmern des Originalkontextes ist in allen drei Fällen die Voraussetzung des komischen Effektes.

\subsubsection{Die Peinlichkeiten des Libellus}

\subsubsection{Fehler}

Zuerst soll die Frage der allgemeinen Textqualität des Libellus angesprochen werden. Der Text des Libellus im Wiener Codex ist mit Sicherheit kein Autograph. Dies wird nicht einfach durch die Zahl der Schreibfehler bewiesen, da es nicht unmöglich ist, dass der Autor selbst grammatikalische Fehler begangen oder Namen inkonsequent geschrieben hatte. Es gibt aber Fehler, die der Urheber des Textes auf keinen Fall begangen hätte. Ein solcher Fehler ist zum Beispiel, ,phebriam” statt „phebeam” (210v-211r: „O clari cives, concedite per sua laurum / tempora phebriam serpere quam meruit”), „dicona” statt „elicona” (214r: „sepeque conscendit sitiens dicona virentem”), oder „psalleret” statt ,pelleret” (214r: „O si nunc Caesar consurgere posset ab umbris, / psalleret indignos percutiens baculo") zu schreiben. Wenn man davon ausgeht, was auf Grund des ähnlichen ductus mit großer Wahrscheinlichkeit zu vermuten ist, nämlich, dass von den drei Händen, die die Glossen geschrieben haben, die eine identisch mit der des Schreibers des Textes ist, dann kommen weitere offensichtliche Beweise $\mathrm{zu}$ den obengenannten Schreibfehlern hinzu, wie zum Beispiel das Wort „Coliseum” (213v), das mit der interlinearen Glosse ,illum deum” erklärt wird. Weiterhin wäre die Art von Erläuterungen, die diese Hand zum Text liefert, von seiten des Autors etwas ungewöhnlich. Diese sind nämlich Schulglossen ähnliche Glossen, die meistens nur Synonyma zu den Wörtern oder das Verständnis erleichternde Ergänzungen zu den Namen liefern: „oratii” für „flacci” (209v), ,illius dei” zu „,mercurii” (210v), „,de more” zu ,rite” (209v), ,vitia” zu ,maculos” (210v).

Die oben aufgelisteten Fehler, mit Sicherheit vom Schreiber stammend, sagen nichts über die Sprachqualität von Benedettos Text. Es gibt aber Ungeschicklichkeiten, von denen man mit großer Wahrscheinlichkeit vermuten kann, dass sie schon in der Vorlage, also im Text vorhanden waren, wie ihn möglicherweise Benedetto gestaltet hatte.

\subsubsection{Ungeschicklichkeiten im nuntius}

Im Folgenden werden diejenigen Formulierungen angesprochen, deren Status nicht ganz eindeutig ist. Sie könnten theoretisch auch als Träger der Komik verstanden werden, 
weil sie den Sinn ihrer unmittelbaren Textumgebung plötzlich in sein Gegenteil verwandeln. Eine gewisse interpretatorische Willkür spielt gewiss eine Rolle bei der Entscheidung, was als komisch und was als fehlerhaft (also ohne die Absicht des Autors zum Lachen erregend) etikettiert wird. Aus dem hermeneutischen Zirkel könnte man aber sonst überhaupt nicht ausbrechen. Für die Entscheidung, ob die Zitate vom Autor als komisch gemeint worden sind oder nicht, werden zum Vergleich andere Stellen herangezogen, um einen Gesamteindruck vom Text zu bekommen. Diese Stellen können aber meistens wiederum auf verschiedene Weisen verstanden werden: als fehlerhaft oder als gewollt komisch-ironisch. Weil aber der Gebrauch der folgenden zweideutigen Formulierungen nicht konsequent ist, ist wahrscheinlich doch davon auszugehen, dass sie als „Fehler” und nicht als bewusst eingesetzte komische Elemente zu verstehen sind. Benedettos Latein ist kein Spottlatein, es fehlt das übertriebene Maß an Fehlern, das den Lesern eindeutig zeigen würde, dass es hier um ein bewusstes Spiel geht. Im Folgenden führe ich einige Beispiele an, die mit höchster Wahrscheinlichkeit auf Benedettos eigene Ungeschicklichkeit zurückzuführen sind.

Eine Verwechslung von „prefidus” und „perfidus” verursacht an einer Stelle eine äußerst ungeschickte Zweideutigkeit des Textes. Der Autor schreibt über einen Freund in Rom, Angelottus geheißen, den das Büchlein unbedingt aufsuchen solle. Dieser werde es gerne als Gast in sein Haus aufnehmen: „Angelus accipiet perfidus mente domoque.” ${ }^{\text {„22 }}$ Aus dem hoch geschätzten Freund, dem der Autor so sehr schmeicheln wollte und über den er seinen Lesern ein überaus schmeichelhaftes Bild zeichnen wollte, wird aus Ungeschicklichkeit ein „treuloser Engel”. In diesem Fall ist mit Sicherheit auszuschließen, dass es sich um einen Schreibfehler des Kopisten handelt. Die Hand, die den Text mit interlinearen Glossen versehen hat (die mit der Hand, die den Text geschrieben hat, wahrscheinlich identisch ist), gibt an dieser Stelle als Synonyme „valde fidus” an, was darauf schließen lässt, dass der Schreiber dieser Stelle mehr Aufmerksamkeit geschenkt hat, zumindest, dass er sie nicht, ohne ihr einen weiteren Gedanken geschenkt zu haben, quasi en passant kopiert hatte. Dass er die Verwendung des Wortes im positiven Sinne für etwas ungewohnt gehalten haben sollte, wird von einer weiteren Glosse bestätigt: In der von der gleichen Hand stammenden Randglosse zum Wort steht: „sonat in bonam partem”. Es handelt sich also um keinen Schreibfehler, der Schreiber hat das Wort schon in seiner Vorlage in dieser Form gefunden. Das Wort „perfidus” für die Bezeichnung des Angelottus stammt dementsprechend wahrscheinlich von Benedetto selbst, auf keinen Fall aber vom Kopisten des Wiener Codex. 
In einem weiteren Beispiel für die Kategorie „Ungeschicklichkeiten” will Benedetto einen Freund aus Florenz rühmen und sagt:

Dum serum pergis, cernis, si forte Iohannem

Montis in ornato, qui studet eloquio. ${ }^{823}$

Die Ungeschicklichkeit der Stelle besteht in der Zweideutigkeit der Wortgruppe „,in ornato qui studet eloquio". Gemeint ist hier selbstverständlich, dass der Freund sich dem Studium der „geschmückten Rede” widme, dass er also ein Experte auf dem Gebiet der Rhetorik sei. Die andere Funktion des ,in”, und zwar als negierendes Präfix: inornato, ermöglicht aber eine andere Lesart, im entgegengesetzten Sinne der gemeinten Lesart. Diese zweite Lesart wird durch die inkonsequente Schreibart von Präfixen und Präpositionen ermutigt, und durch die Tatsache, dass studere auch mit einem blossem Dativ stehen kann, nicht nur mit der Präposition „,in“. Trotzdem bleibt die Frage, um welches ,in” es sich in diesem Fall handele, im Prozess des Lesens offen, wenigstens so lange, bis man den Satz zu Ende gelesen und festgestellt hat, welche Bedeutung in diesem Fall ,in” haben kann. Dass beim Lesen kurz die andere, den Sinn des Satzes in seinen Gegenteil wendende Bedeutung des „in” als möglich erscheint, ist auch der Tatsache geschuldet, dass das Wort ,inornatus” im Zusammenhang mit Redekunst in der klassischen Literatur über Rhetorik des öfteren vorkommt, ${ }^{824}$ allerdings meistens in pejorativer Bedeutung. Auch in diesem Fall kann man mit der gleichen Begründung wie im Fall von ,perfidus” davon ausgehen, dass es sich nicht um eine vom Autor beabsichtigte Zweideutigkeit handelt.

Über einen bestimmten Angelus sagt Benedetto zudem:

Angelus angelicam servans per secula vitam,

Et michi precipuus rex simul atque deus,

Cui clemens opto: tollat deus ipse podagram. ${ }^{825}$

Was hier etwas fehl am Platz scheint, ist, wie es bei Benedetto des öfteren der Fall zu sein scheint, das plötzliche Wechseln vom erhabenen Stil zu den sehr konkreten Begebenheiten. Angelus, der in der ersten Zeile noch selbst als „deus” bezeichnet wird, muss in der dritten Zeile mit Gottes Hilfe seine Gicht loswerden. Aus ähnlichen Gründen wie das Missgeschick bei dem als „perfidus” titulierten Angelottus in Rom kann auch diese Dissonanz nicht als beabsichtigt verstanden werden: es spricht nichts dafür, dass Benedetto mit der Krankheit seines Freundes Angelus gescherzt haben sollte.

\footnotetext{
823 CVP. 3529, 209r.

824 Vgl. die Stellen des ThLL: Bd. 7, 1, fasc. 1, S. 1762 f.

${ }^{825}$ CVP. 3529, 215r; Wattenbach, B. d. P., S. 111.
} 
Um weitere Ungeschicklichkeiten zu nennen, kann man die fast mechanisch erscheinende Wiederholung von Bildern anführen. Die Freunde Benedettos scheinen alle die musischen Berge zu bevölkern, bei jeder poetischen Quelle findet man einen engen Freund des Autors, der den singenden Musen zuhört oder Blumen pflückt. Über Johannes de Loddovicis heißt es:

Sepe solet cupidis Musas audire canentes ${ }^{826}$;

über Bartholomeo:

Famosum iuvenem, cui mons est Politianus Patria, sed novit Menalus ipse virum; ${ }^{827}$

über Leonardo Aretino:

Fonte Caballino iam bonus haurit aquas, Vel viridi flores Parnaso colligit inde, ${ }^{28}$

sowie zum zweiten Mal über ihn:

Ergo age, si talem redeuntem culmine Cyrre Videris aut Nyse, concide, flecte genu; ${ }^{829}$

desweiteren über Angelottus:

Sepe fuit visus musis in colle Liceii

Et carpens flores, o bona Cyrra, tuos; ${ }^{830}$

und über Cencio:

cui pulchra Camena

Claraque castalias sepe ministrat aquas.

O mirum doctumque virum, cui pulcher Apollo

Menalium montem sepe videre dedit; ${ }^{831}$

über Johannes Chamicius:

Sepeque conscendit sitiens dicona ${ }^{832}$ virentem,

\footnotetext{
826 CVP. 3529, 209r; Wattenbach, B. d. P., S. 105

827 CVP. 3529, 210v.

828 ebda

829 CVP. 3529, $211 \mathrm{r}$.

830 CVP. 3529, 212r.

831 CVP. 3529, 212v.

832 statt, ,elicona“
} 
Sepe Caballinis fontis inivit aquas; ${ }^{833}$

über Paulus Capranicensis:

Sepeque cantantes audivit monte Camenas

Parnaso, et doctus iam sapit ipse bene; ${ }^{834}$

über Antonius Tuzarelli:

gustavit Eliconis aquas ${ }^{835}$;

über Johannes Lelli:

O, quotiens illum Phebus per carmina ductus

Artium in montem deliciasque dedit. ${ }^{836}$

\subsubsection{Die Durchsuchung: eine peinliche Szene und eine missglückte Stelle in der narratio}

Am Anfang seiner narratio erzählt Benedetto, wie er und seine Leidensgenossen von den Leuten, die sie festgehalten hatten, ausgezogen und durchsucht worden sind. Trotz des Mitleids, das sogar der hartherzigste Leser mit dem Erzähler hat, findet er eine Stelle dieser Beschreibung wegen der Diskrepanz zwischen dem üppigen mythologischen Arsenal, das hier benutzt wird, und der ungeschminkten Wahrheit der Situation überraschend unpassend und deswegen möglicherweise komisch:

Pape, dicti turpitudine loqui prohibeor, sed propter rei novitatem tacere non possum. Inventus est aliquis, qui in unius ex meis sociis ano submerso ac circumducto digito argentum vel aurum quesivit in fistula stercorum. O, dii morum! Si divitias Cleopatre, si thesaurus Sichei, aut opes Pigmalionis, si aurum Migde, si tributum, pro quo Iulio se Metellus opposuit reperire spes esset, locus ille tangendus non erat! ${ }^{837}$

Nicht nur der für die Veranschaulichung eines großen Reichtums obligatorisch zu nennende Midas wird hier erwähnt, sondern auch auf die Geschichte des Sychaeus und des Pygmalion wird hingewiesen (Aen, I, 346-364). Der Erzähler nimmt auch aus der römischen Geschichte ein Beispiel. Er deutet auf die auch in Lucans Pharsalia (III, 114-153) beschriebene Episode

\footnotetext{
833 CVP. 3529, 212v-213r.

834 CVP. 3529, 215v; Wattenbach, B. d. P., S., 111

835 CVP. 3529, 216r.

836 CVP. 3529, 217r.

837 CVP. $3529,224 \mathrm{v}$.
} 
des Bürgerkrieges hin, als Cäsar trotz des Widerstandes des Caecilius Metellus den Staatsschatz aus dem Saturntempel plünderte. Die Erwähnung von Kleopatras Namen in diesem Zusammenhang ist auch nicht ganz selbstverständlich: Kleopatra wurde in der Literatur in erster Linie nicht unbedingt für ihren Reichtum zitiert. ${ }^{838}$ Das zehnte Buch der Pharsalia beschreibt beide Eigenschaften Kleopatras (sowohl ihre weibliche Verführungskraft als auch ihren Reichtum) ausführlich. Es ist wahrscheinlich, dass Benedetto die Beispiele der Kleopatra und des von Cäsar geraubten aerariums aus den Pharsalia genommen hat, die er auf dem Konzil auch vorgelesen hatte. Sammelte Benedetto alle die von ihm bekannten Beispiele für das Thema „Reichtum”, um diese von ihrem Inhalt her zum niedrigsten Register gehörende Stelle seines Textes mit mythologisch-literarischen exempla etwas zu veredeln und scheiterte aber dabei wegen der allzu großen Spannung zwischen dem Aufwand der Beispiele und der Brutalität des Sachverhaltes oder hat er die Spannung absichtlich entstehen lassen, um damit Komik zu erzeugen? In diesem Fall würde man vielleicht davon ausgehen, dass es sich hier nicht um einen vom Autor erzielten komischen Effekt handelt, sondern eher um den ersten Fall, also um Benedettos gescheiterten Versuch, die Brutalität des Geschriebenen durch seine mythologischen und historischen Beispiele in ein literarisches Register zu erheben. Grund für diese Annahme sind das hohe Maß der geschilderten Brutalität und die Tatsache, dass Fäkalhumor und ähnliche Grobianismen sonst nicht zu Benedettos Welt zu gehören scheinen.

\subsubsection{Ein Versuch im Stil der „Bewanderten”. Stilistisches Scheitern in der supplicatio: die declamatio ${ }^{839}$}

\subsubsection{1. „suavis et ponderosa oratio"}

Im dritten Teil des Libellus, in der supplicatio, bewertet Benedetto den bisherigen Stil seiner Briefe derart, dass er, obwohl er in gehobenem Stil schreiben hätte müssen, sich einfach ausgedrückt habe:

Hactenus, viri optimi, cum latino utens eloquio debuissem pleno ac pro meo ingenii modulo sublimi dicendi genere scribere, stilo brevi ac infimo, profane et metrice vobis scribens verbis communibus rudibusque pro tempore usus sum. ${ }^{840}$

\footnotetext{
838 In der Divina Commedia wird Cleopatra unter denen dargestellt, die mit Wollust (lussuria) sündigten (Inf. 5, 63). In Petrarcas De rerum memorandorum libri wird sie als ein Beispiel für die unbeständige Ehegattin erwähnt (De inpudica uxore).

839 Der Text der „declamatio” befindet sich im Anhang 3. dieser Arbeit.

C40 CVP. 3529, 237r.
} 
Diesmal wolle er seine Leser, also die schon häufiger angeschriebene Geistlichkeit, die Vasallen, Räte und Sekretäre, in Prosa, in einer angenehmen und würdevollen Form, soweit möglich, ansprechen. Dies sei die Redeweise, die den „Versierten” immer mehr gefalle:

Nunc autem soluta suavique ac, quantum michi datur, ponderosa oratione quadam, quasi declamatorio more vos alloquor. Quod utique genus dicendi magis ac magis solet placere peritis. ${ }^{841}$

Mit dem Wort „peritis” ist hier wahrscheinlich die Gruppe der Gelehrten gemeint, die sich die neue Schreibweise angeeignet haben. Diese Annahme ist erstens deswegen plausibel, weil Benedetto hier anscheinend über eine sich damals stark verbreitende Tendenz (,,magis ac magis") schreibt. Zweitens kann man davon ausgehen, dass es ihm auffallen musste, dass die Oratorik eines der von den Humanisten intensiv gepflegten Gebiete war. Dementsprechend meint er, wenn er über den „declamatorius mos” schreibt, wahrscheinlich die neue, oft in der Oratorik verwendete Schreibweise. Der Text, den er mit diesen Bemerkungen einleitet, kann demzufolge als ein Versuch von Seiten seines Autors verstanden werden, die humanistische Schreibweise zu imitieren.

Wie hat Benedetto den neuen Stil wahrgenommen? Was waren die Merkmale, die er für spezifisch gehalten haben konnte? Seine explizite Bewertung muss hier an erster Stelle noch einmal erwähnt werden. Sein Stil, den er im Folgenden nachahmen wollte, sei „suavis” und ,ponderosa”.

Die „angenehme” Redeweise wird von Cicero mit der Erwartung verbunden, die Zuhörerschaft zum Staunen zu bringen. Die Rede ist nach Ciceros Ratschlag ,suavis”, wenn der Redner etwas „Unübliches”, „Unerhörtes” oder „Neues” sagt: „Fiet enim suavis oratio, cum aliquid aut inusitatum aut inauditum aut novum dicas. Delectat etiam quidquid est admirabile, maximeque movet ea, quae motum aliquem animis ciet." ${ }^{\$ 42}$ Ob Benedetto das Wort in diesem Sinn benutzt, also ob er das ciceronische Postulat des Zum-Staunen-Bringens damit assoziiert, ist nicht ganz sicher. Andererseits kann Benedetto das Wort „suavis” auch so benutzt haben, dass er die Cicero-Stelle der Partitiones zwar im Blick hatte, ohne aber die Lehre über die Wichtigkeit des ,admirabile” damit in Verbindung zu bringen. In diesem Fall steht „suavitas” in Benedettos Gebrauch einfach als ein Merkmal der „narratio ornata”, die bei Cicero die Rahmentugend ist und unter der ,suavitas” erörtert wird. Einem im rhetorischen Schrifttum

841 ebda

842 Cic. Part. 22. 
belesenen Publikum waren Ciceros Partitiones jedenfalls geläufig, und so war es für einen zeitgenössischen Leser möglich, Benedettos „suavis” mit Ciceros Lehre zu assoziieren. ${ }^{843}$

Unter ,suavis” konnte der Autor aber auch einfach den Anspruch verstanden haben, eine unterhaltsame, ,angenehme” Rede zu halten, welcher wegen der humanistischen Wiederaufwertung der Rhetorik als ein humanistisches Merkmal gelten durfte.

Das zweite von Benedetto benutzte Adjektiv ist „ponderosa”. Dieses Wort ist kein ausgeprägter rhetorischer terminus technicus. Am nächsten verwandt scheint „pondus” mit den in der Rhetorik geläufigeren Begriffen von ,auctoritas” und ,gravitas” zu sein. ${ }^{844}$ Außerhalb der rhetorischen Fachliteratur wird das Wort in der Bedeutung von „gewichtig” oder „inhaltsschwer” benutzt. Benedetto hatte ,ponderosus” wahrscheinlich nicht als rhetorischen Fachterminus verwendet. Beide von ihm benutzten Wörter bezeichnen nach Benedettos Intention wahrscheinlich einfach eine kunstvoll gestaltete Rede und keine weiteren, spezifischen Textqualitäten. Benedetto wollte diesmal etwas „Schönes” schreiben.

Im einleitenden Teil bemerkt er, dass er sich bislang sehr einfach ausgedrückt habe, und begründet diese Schlichtheit mit einem Zitat aus Cassiodor, der im Prolog zu seinen Varia schreibt, es sei auch ein Zeichen von rhetorischem Können, zu vermeiden, was den Gelehrten gefällt: „Interdum enim, ut ait Cassiodorus in prologo Variorum, genus peritie est vitare quod placeat doctis. ${ }^{, 845}$ Es sei angemerkt, dass Cassiodors Aussage in ihrem Originalkontext sich auf den Fall bezieht, wenn der Redner/ Autor die einfachsten Menschen als Zuhörer/ Leser hat. In diesem Fall müsse er seinen Stil an die Bildung seines Publikums anpassen, damit er verstanden werden kann. Mit dem Zitat von Cassiodor impliziert Benedetto eigentlich, dass er bis zu diesem Punkt sich deswegen so einfach ausgedrückt habe, weil er sich an das Niveau der Empfänger seiner Briefe anpassen wollte. $\mathrm{Ob}$ es tatsächlich Benedettos Absicht war, seinen Lesern einen solchen Seitenhieb zu versetzen, kann nicht mit Sicherheit entschieden werden.

Er behauptet jedenfalls, dass er in dem auf diese Entschuldigung folgenden Text das Gegenteil versuchen wolle. Sein Vorhaben, sich diesmal in erhabenerem Stil auszudrücken, ist eigentlich unlogisch, wenn man annimmt, dass Benedetto die verschiedenen Stilebenen nach cassiodorischen Prinzipien, also abhängig von Stand und Bildung seiner Leserschaft,

\footnotetext{
843 Über die Rezeptionsgeschichte der Partitiones vgl. Giuseppe Billanovich, „Petrarca e i retori latini minori”, Italia Medioevale e Umanistica 19 (1962): 103-64, und Otto Zwierlein, ,Zur Methodik der Emendatio in Ciceros Partitiones oratoriae", Zeitschrift für Papyrologie und Epigraphik 144 (2003): 87-99, hier S. 87-90.

844 Quintilian benutzt das Wort einmal als Synonym für „auctoritas” (Quint. Inst. 4, 2, 125), und einmal im Sinne von ,gravitas" (Quint. Inst. 6.1.2). 
benutzen wollte. Er richtet seine declamatio nämlich an die gleichen Leser, an die er auch seine vorherigen Briefe gerichtet hatte.

\subsection{Benedettos Stilversuch}

Als erstes fällt auf, dass der Text der declamatio in Gegensatz zu Benedettos vorherigen Briefen sehr reich an Zitaten ist. ${ }^{846}$ Auf das Zitat von Cassiodor folgt eine ganze Reihe von weiteren Zitaten und literarischen Anspielungen: man trifft im Text Ovid, Seneca, Hieronymus und Franciscus de Sarzana.

Für die Unterhaltsamkeit soll gleich eine Fabel sorgen, mit der Benedetto seine declamatio eröffnet. Nach eigener Angabe habe er diese selbst geschrieben. Sie erzählt die Geschichte der Freundschaft zwischen dem Wolf und dem Pferd. Die beiden Tiere haben einen Freundschaftspakt geschlossen. Der Wolf ist eine Nacht in einen Schafstall eingebrochen, und hat ein Lamm erbeutet. Der den Stall hütende Hund hat mit seinem Bellen die anderen Hunde und den Hirt geweckt, der Wolf wurde umzingelt und von den Hunden heftig gebissen, so dass er kaum entfliehen konnte. Als er zu Hause ankam, legte er sich in der Höhle, wo er mit dem Pferd lebte, hin und bewegte sich gar nicht mehr. Vom langen Liegen, vom Hunger und vom Durst wurde er ganz kraftlos. Als er in diesem jämmerlichen Zustand seinen Freund erblickte, der neben ihm lag, biß er das Pferd. Dieses wurde wach, erschrak und fragte wütend:

„Quid est hec fides?” inquit. „Mentem etiam egram habes. Ubi societas, ubi fides, ubi pactum, ubi lex, ubi iuramentum? Hec omnia uno momento fregisti”. 847

Die Antwort des Wolfes bringt die Geschichte endlich auf den Punkt, der Leser erfährt nämlich erst jetzt, warum die Fabel erzählt wurde:

Lupus avulso sanguinolento dente suam causam defendens ait: „Socie, necessitas non habet legem. Plus ipsa potest ad impellendum, ut aliquid fiat, quam lex ad prohibendum, ne fiat. Magna et imperiosa domina est, non est sub lege." 848

Die Fabel soll also dazu dienen, das Sprichwort „necessitas non habet legem” zu exemplifizieren. Wie diese Sentenz zu Benedettos Lage passt, erklärt er auch:

Quin etiam multa in hac fabula contenta michi promittere impertinentia censeo. Solam illam clausulam capio, que pro mee intentionis fundamento satis michi

\footnotetext{
846 Der Text der ,declamatio” befindet sich im Anhang 3.

847 CVP. 3529, 238r.

848 ebda
} 
sufficere puto. Lupus dixit: „Necessitas non habet legem.” Proposueram, ut per alias meas litteras, per aures vestras amplius meis indigestis clamoribus non obtundere. Sed neccessitas me in contrarium rapit. ${ }^{849}$

Die Aktualität der Geschichte besteht für Benedetto in der Ähnlichkeit der aussichtslosen Lage des Wolfes und seiner eigenen Situation, die beide dazu zwingt, das gegebene Wort zu brechen (im Fall des Wolfes den Freundschaftseid, im Fall Benedettos das Versprechen, keine Bitten mehr zu verfassen und hinauszuschicken). Die Entschuldigung dafür sei in beiden Fällen die Notlage der Betroffenen: Not kenne bekannterweise kein Gebot.

Benedetto bemerkt zwar, dass es in der Fabula vieles gäbe, das nicht zu seinem Fall passe, damit kann er aber die Verwunderung der Leser wahrscheinlich nicht ganz dämpfen: warum identifiziert sich der Autor gerade mit einer so unsympathischen Figur der Fabeltierwelt wie dem Wolf? Der Wolf hat in der antiken und christlichen Literatur keine gute Konnotationen. In dem Benedetto verfügbaren Erzählgut ${ }^{850}$ ist er keineswegs ein Sympathieträger. Sein einziges Merkmal, mit dem sich Benedetto leicht identifizieren konnte, ist die Tatsache, dass er fast immer den Kürzeren zieht. Wenn aber Benedetto schon eine eigene Fabel für seine declamatio geschrieben hatte, wie er behauptet, warum hat er keine Geschichte geschrieben, in der die Identifikation des Darstellers mit dem Autor für den Leser weniger verwirrend ist? Wenn sein Anliegen mit der Geschichte darin bestand, Mitleid zu erregen, so scheint der das Blut seines Freundes trinkende Wolf $\mathrm{zu}$ diesem Vorhaben nicht recht zu passen. Der Wolf als negative Figur kommt sogar im Libellus selbst vor: „nec michi mille meos nudis in collibus agnes / frange(re)t errantes dentibus ipse lupus” ${ }^{\text {,51, }}$, schreibt Benedetto in seinem nuntius. Der böse Wolf steht hier für den Zerstörer der Scherben, auf die der Autor seine Gedichte geschrieben hatte, erfährt man aus der Randglosse zur Textstelle. Weiterhin, in der suplicatio, wird der Kardinal Stefaneschi als schlechter Hirt dargestellt, der, als der Wolf kam, entflohen sei.

Benedettos Fabel sollte das exordium der Rede darstellen. Auf diese Funktion deutet nicht nur die Tatsache hin, dass sie am Anfang des Textes steht, sondern sie geht auch aus Benedettos Worten eindeutig hervor. Er leitet seine Fabel folgendermaßen ein: „Et exordiar ab apologo”. ${ }^{852}$ Den Ratschlag, die Rede „ab apologo” anzufangen, konnte Benedetto aus der Rhetorica ad Herennium entnehmen. Der Autor dieser Schrift schlägt vor, die Rede auf diese

\footnotetext{
${ }^{849}$ CVP. 3529, 238v.

850 Hier kommen die literarischen Werke, die Benedetto geläufig gewesen sein dürften (Tierepen, Tierfabeln), als Träger dieses Erzählgutes in Frage, genauso wie auch weitere Übermittlungskanäle, wie zum Beispiel die in die Predigten eingebauten exempla. 
Weise anzufangen, wenn die Zuhörer schon müde sind. ${ }^{853}$ Diese Motivation passt eigentlich zu Benedettos Schreibsituation: Benedetto belästige wahrscheinlich seine Leser, weil er sich schon häufiger an sie gewendet habe. Etwas später im Text der Rhetorica beschreibt der Autor die möglichen Fehler, die man im exordium unbedingt vermeiden sollte: ,,item vitiosum est $[\ldots]$ si nimium longum est, et quod non ex ipsa causa natum videatur, ut proprie cohaereat cum narratione, et quod neque benivolum, neque docilem, neque adtentum facit auditorem." 854 Wenn man Benedettos exordium nach diesen Richtlinien unter die Lupe nimmt, so kann man feststellen, dass er sich zwar bemüht hat, seine Einleitung laut dem Ratschlag der Rhetorica ad Herennnium „ab apologo” zu schreiben, beging aber dabei fast alle möglichen vitia eines exordiums: seine Fabel ist zu lang und scheint wenig mit Benedettos Fall zu tun zu haben. Die Sympathie der Zuhörer (Leser) weckt sie wegen der unglücklichen Identifikationsfigur des Wolfes auch nicht. ${ }^{855}$

In dem Teil, den man als narratio identifizieren könnte, beschreibt Benedetto seine eigene Lage. Er befindet sich in Gefangenschaft und es geht ihm schlecht. Die näheren Gründe für seine üble Lage sind die Umstände, die Folgen der Gefangenschaft sind: dass er keine frische Luft zum Atmen hat, dass er keine Gesprächspartner hat und, was er als den Gipfel seiner Probleme bezeichnet, dass sein Körper wegen des Mangels an Bewegung schlicht eingeht.

Beweise für die These, die man als „Gefangenschaft schadet der Gesundheit” zusammenfassen könnte, sind in die Darstellung von Benedettos Lage inseriert. Die von Benedetto zitierten Autoren stehen alle als Autoritäten, die diese These bekräftigen sollen. Dafür, dass die Abwesenheit der Freunde und Gesprächspartner eine traurige Angelegenheit ist, steht ein Satz des Predigers: „Ait sapiens vae soli, qui non habet relevantem” ${ }^{, 556}$ und Verse von Ovids Tristia: „Quamobrem in libro de tristibus inquit: nonqui soletur nec qui labentia tarde tempora narrando fallat amicus adest." ${ }^{, 857}$

Für die schädliche Wirkung des Mangels an Bewegung steht an erster Stelle Franciscus de Sarzana: „exercitium corporis membra consolidans superfluum digerit humidum calorem naturalem mirabiliter refocillans” ${ }^{858}$; dann Ovid: „cernis, ut ignavum

Rhet. Her. 1.6.10.

854 Rhet Her. I. 7. 11.

855 Laut Quintilian passe der Vortrag von erfundenen Fabeln eher zu einem einfacher geschnittenen Publikum: „Illae quoque fabellae [...] ducere animos solent praecipue rusticorum et imperitorum, qui et simplicius quae ficta sunt audiunt, et capti voluptate facile iis quibus delectantur consentiunt." (Quint. Inst. 5, 11, 19). 
corrumpant otia corpus, ut capiant vitium, ni moveantur aque ${ }^{, 859}$; der ,philosophus in ethicis”, also eine Stelle der nikomachischen Ethik (2,2 1104a): „Superflua exertitia aut diminuta formam sanitatis corrumpant” ${ }^{\$ 60}$; und Seneca: „hec duo miscenda sunt: et agenti quiescendum est, et quiescenti agendum"861.

Von Seneca wird sogar eine weitere Stelle zitiert, die aber den Leser etwas verwirrt, weil es um ein entstelltes Zitat geht. Diese Seneca-Stelle ist der berühmte und bereits erwähnte Satz („Otium sine litteris...”). Sie scheint Benedetto am Anfang seines Libellus noch zu kennen. Als Grund für die Entstehung seines Buches gibt er nämlich außer seinem Wunsch, seinen Bruder zu benachrichtigen, weiterhin an: „Atque michi verba dedi ut tarde labentes fallerem dies ac ne otio marcerem vivusque sepultus essem" ${ }^{\text {"862 }}$. Das Nutzen des Seneca-Zitats ist im Fall der im Libellus dargestellten Schreibsituation „Schreiben im Gefängnis” beinahe eine Selbstverständlichkeit. Umso erstaunlicher wirkt es auf den Leser, wenn er den Satz Senecas in diesem Werk später in entstellter Form wiederfindet. Der Satz von Seneca ist in Benedettos Beweisführung in folgender Form $\mathrm{zu}$ finden: „otium sensualitatis mors est ac vivi hominis sepultura" ${ }^{863}$. Der Grund, warum Benedetto diesen wohlbekannten, oft zitierten und in seiner ursprünglichen, richtigen Form zum Kontext des Libellus so perfekt passenden Satz hier in dieser veränderten Form zitiert, ist nicht ganz klar. Ein einfacher Kopierfehler kann daher ausgeschlossen werden, weil der ursprüngliche Satz, in seiner unveränderten Form, hier nicht zu der Beweisführung der declamatio gepasst hätte. Könnte es sein, dass Benedetto sein Gedächtnis einfach im Stich gelassen hat? Dagegen könnte aber die oben zitierte Stelle über den Grund seines Schreibens sprechen. Wollte er das Zitat an seine Beweisführung anpassen, in der es um die Folgen der körperlichen, nicht der

859 CVP. 3529, 239r. Ov. Ep. Ex Pont. 1.5.5.

860 CVP. 3529, 239r. Benedetto zitiert den Satz vielleicht aus dem Kopf, ohne eine Übersetzung als Vorlage benutzt zu haben, es konnte keine wörtliche Übereinstimmung des Satzes mit einer der überlieferten Übersetzungen festgestellt werden. In der Translatio antiquissima lautet der Satz: „Superflua enim ginnasia et indigencia, corrumpunt virtutem.”: Renatus Antonius Gauthier, Hrsg., „Ethica Nicomachea. Translatio Antiqissima", in Aristoteles Latinus Bd. 26, 2 (Brüssel, Leiden: Desclée de Brouwer, 1972), hier S. 7; in der Translatio Roberti Grosseteste Lincolniensis: „Superhabundantia enim gignasia et deficiencia corrumpunt sanitatem.”. Vgl. Renatus Antonius Gauthier, Hrsg., „Ethica Nicomachea. Translatio Roberti Grosseteste Lincolniensis”, in Aristoteles Latinus, Bd. 26, 3 (Brüssel, Leiden: Desclée de Brouwer, 1972), hier S. 165; in Leonardo Brunis Übersetzung: „Excessus enim et defectus laborum vires corrumpunt.” Vgl. Aristoteles, „Ethica Nicomachea”, übersetzt von Leonardo Bruni in Leipziger Universitätsbibliothek, Arist 96/3 (Paris: H. Stephanus, 1510), hier Le, 5r. Obwohl Bruni seine Übersetzung erst zwischen März 1416 und März 1417 fertiggestellt hatte, war es sinnvoll, Benedettos Version mit seiner Übersetzung zu vergleichen, weil Bruni mit der Übertragung der Nikomachischen Ethik wahrscheinlich, wie Hanna Barbara Gerl nachgewiesen hat, spätestens 1413 angefangen hat: Hanna-Barbara Gerl-Falkowitz, Philosophie und Philologie, Humanistische Bibliothek 1, 42 (München: Wilhelm Fink Verlag, 1981), hier S. 154-157. Eine Übereinstimmung zwischen Benedettos Zitat und Brunis Übersetzung wäre allerdings eher eine Überraschung gewesen, aber auch nicht ganz auszuschließen.

CVP. 3529, 239v; Sen. Ep. Mor. 1.3.

CVP. 3529, 208r.

CVP. 3529, 239v. 
geistigen „Untätigkeit” geht? Dieser Satz war aber dafür zu bekannt, Benedetto musste deswegen damit rechnen, dass sein Leser sein Entstellungsmanöver erkennt. Als letzte Möglichkeit würde noch das bewusste Spiel des Autors bleiben: dementsprechend hätte man es mit einem Erzähler zu tun, den der Autor mit dieser Geste als nicht besonders vertrauenswürdig, weil - möglicherweise von der langen Gefangenschaft - als etwas abgestumpft darstellt. $\mathrm{Ob}$ ein solches selbstironisches Spiel, das zwischen dem Autor und dem Narrator unterscheidet und letzteren als des Vertrauens nicht würdig darstellt, von Benedetto beabsichtigt sein konnte, ist freilich schwer zu entscheiden.

Als nächstes und letztes wird ein Zitat von Ambrosius angeführt, das angeblich auf Hieronymus zurückgeht: „corporis virtus exertitatione augetur et inexercitata minuitur. Plurimi enim exercitii dissuetudines etiam naturalem corrumpere virtutem" ${ }^{\text {} 864}$.

Mit ,igitur” leitet Benedetto den Satz ein, der den Inhalt seiner declamatio zusammenfassen soll: „Igitur in me qui aere qui hominum conversatione, qui exertitio careo corporalis, corrupta est salus et gravius reor viventis integritas diminuita." ${ }^{\prime 85}$ Die Zusammenfassung wird mit einem Hinweis auf Hiobs Figur noch einmal bildlich und nachdrücklich gemacht:

Iam in me video, quod beatus Hiob in se accidisse conquestus est. „Pelli mee consumptis carnibus adhesit os meum" ${ }^{\text {, }}$, enim vero caro, que media erat inter pellem ac ossa mea, ut unicuique vestrum patere possit, consumpta est, quod est signum magis mortis, quam vite. ${ }^{867}$

Der Hinweis auf Hiobs Geschichte durch die Paraphrase der Beschreibung des abgemagerten Körpers Hiobs ist vielleicht das passendste Mittel vom Benedettos literarischen Arsenal.

In der peroratio fleht der Autor seine Leser erneut an, für ihn und seine Leidensgenossen zu beten und ihnen zu helfen.

\subsection{Benedettos Perspektive}

Die gesamte declamatio macht den Eindruck, dass sich Benedetto bemüht hat, seine Prosa möglichst reich zu schmücken, um den erhabenen, neuen Stil nachzuahmen, wobei er aber dabei eher gescheitert ist. Weniger wäre vielleicht mehr gewesen: Die einleitende Fabel ist zu lang und tut nur wenig zur Sache, der Aufwand der Zitate für den Beweis von Benedettos Anliegen scheint ebenfalls übertrieben zu sein. Man könnte feststellen, dass die

CVP. 3529, 239v; Ambr. De Cain et Abel, 2.6.22.

CVP. 3529, 239v.

Iob 19, 20.

ebda 
Art seines Versuches verrät, dass sein Verhältnis zur neuen Kultur eher als das eines Outsiders zu beschreiben ist.

Seine Außenseiterperspektive will er eigentlich auch nicht ganz verbergen, seine Worte („Quod utique genus dicendi magis ac magis solet placere peritis”) zeigen ihn als jemanden, der sich in einem Stil ausprobiert, der nicht sein eigener ist. Er schreibt über den erhabenen Stil von außerhalb.

\subsubsection{Benedettos Reflexionen über die Qualität des eigenen Textes}

Benedettos Reflexionen über die Qualität des eigenen Textes sind in der Regel als Bescheidenheitstopoi zu deuten. Die Häufigkeit der Verwendung verleiht ihnen aber einen besonderen Akzent und erweckt den Verdacht, dass sie nicht nur Topoi sind. Bereits am Anfang, in den einleitenden Zeilen schickt Benedetto voraus, dass er über die Männer, die er in seinem Werk vergegenwärtigt, nicht so, wie sie es verdient hätten, sondern nur, wie er kann, schreibt.

Utinam tam efficaciter, quam libenter descripsisem vos, o, viri optimi, de quibus huic nuntio locutus sum! Sed feci, quod potui, non quod debui. ${ }^{86}$

Über Angelottus, den das Buch in Rom aufsuchen soll, meint er:

Vellem posse suos equare et carmine mores, Et prosa; menti deficit ingenium. ${ }^{869}$

Am Ende des nuntius muss der Buchbote seine Botschaft Benedettos Brüdern überreichen und ihn folgendermaßen zusammenfassen:

Et sic hic dicas: „Frater Benedictus in antro

Conclusus cavee carmina multa dedit.

Nescio quid raucus iam multis scripsit inepte,

Hic ego depono, vos tamen accipite!"870

Der Autor weist an diesen Stellen auf seine eigene Situation hin, mit der er die mangelnde Qualität seines Textes entschuldigt. Obwohl es schwierig ist, die Schreibsituation genau zu identifizieren, wird eines durch Benedettos Bemerkungen eindeutig hervorgehoben. Er habe sein Werk unter keinen günstigen Verhältnissen verfasst. Wenn er nicht in der Gefangen-

\footnotetext{
868 CVP. 3529, 208r.

869 CVP. $3529,212 \mathrm{v}$

870 CVP. 3529, $223 \mathrm{v}$.
} 
schaft wäre, würde er keine Lieder singen, die roh klingen: „carmina non canerem que tibi rauca sonant". 871

Nicht nur wegen deren Häufigkeit und auch nicht nur wegen der plausiblen Entschuldigung für die mangelnde Qualität des Textes sind die Anwendungen des Bescheidenheitstopos mehr als ein Topos. An manchen Stellen bekommt er eine besondere Funktion und Dynamik. An der Stelle, wo Benedetto sich für seine Unfähigkeit entschuldigt, über Angelottus, dem Gegenstand seines Lobes, nicht würdig genug zu schreiben, verwandelt sich der Text in eine Rede über den Text selbst. Der Anlass zu den längeren Überlegungen ist die Tmesis, die er in eine Zeile einbaut, mit der Begründung, er habe den Namen des Angelottus nicht anders in seinen Vers einbauen können:

In quibus angelicum viris prius Angequeloctum

Appello munitus carminis imperio.

Hoc quamquam nomen, si vellem ponere iambum

In tertio possem nempe referre pede.

Sed, quia perrarum conceditur, hoc ego vito.

Accipias mentem, care libelle, meam.

Quod si forte velis me sanum scribere nomen,

Dicas, ut sequitur, tunc bene letus erit:

Iam florens Angelottus sit commemorandus,

In primis, civis nobilis atque bonus.

$\mathrm{O}$ si sic alios possem michi demere morbos,

Ut valeo dictum pellere convicium!

Nam tibi nec ventus nec nunc mala lingua nocere,

$\mathrm{Nec}$ te iam posset ledere livor edax ${ }^{872}$,

Nec michi mille meos nudis in collibus agnos

Frange[re]t errantes dentibus ipse lupus.

Non ego nocturno semper contendere bello

Conarer variis vermibus esca datus.

Non ego cenarem semper sine lumine tristis,

Et nec pranderem plenus ubique malis. ${ }^{873}$

Benedetto simuliert, dass er den Leser in die Geburt seiner Zeilen einweiht: er wirft eine von ihm eben realisierte Möglichkeit, den Namen Angelottus in seinen Text einzubauen, weg, schlägt eine zweite vor, die er aber nicht verwirklicht (,,sed quia perrarum conceditur hoc ego vito”), um am Ende eine dritte Version auszuführen (,dicas ut sequitur tunc bene letus eris / iam florens Angelottus sit commemorandus").

Mit Geschick wechselt er in der Rede zu seiner Situation. Wenn er auch die anderen Übel so leicht beseitigen könnte wie die eben gelöste Schwierigkeit mit dem Namen des

\footnotetext{
871 CVP. 3529, $211 \mathrm{v}$.

872 Ov. am 1, 15.

873 CVP. 3529, 211r-211v.
} 
Angelottus, wäre das Büchlein nicht dem Wind, den bösartigen Meinungen und dem Neid ausgeliefert und er selbst müsste auch nicht in der Nacht mit Ungeziefer kämpfen und wäre nicht gezwungen, ohne Licht traurig sein Abendbrot und das Mittagessen kummervoll zu verzehren. Die Rede über die Qualität seines Textes benutzt Benedetto dazu, über seinen eigenen Zustand zu schreiben. Durch das Evozieren des Horaz mit „livor edax” erstellt Benedetto einen mutigen Vergleich zwischen dem horatianischen und seinem eigenen Euvre. Diese Geste kann in Benedettos Fall entweder ausgesprochen naiv oder selbstironisch gedeutet werden.

An einer Stelle der narratio wechselt Benedetto seine Taktik und schreibt, dass er diesmal absichtlich kunstlos schreibe:

Quartodecimo dicti mensis die, in quo fuerat festum crucis, sequentes versiculos aliquibus additis porrigi feci complectens omnes, ad quos prius scripseram, in quibus versiculis hoc solum curavi, ut penultima sillaba ultime dictionis versiculi brevis esset. Ac de industria artem metricam non servavi, ut experirer, an facti sine lege plus efficaciem habituri essent, quam facti cum lege. ${ }^{874}$

Der Autor meint hier, dass er ausprobieren wolle, ob seine Fürbitten nicht wirksamer seien, wenn er sie weniger kunstvoll gestalte. Er habe lediglich darauf geachtet, dass am Versende die vorletzte Silbe kurz sein sollte. Er habe sich absichtlich (de industria) nicht um die Metrik (ars metrica) gekümmert. Auch diese etwas verbittert ironisierende Reflexion über die eigene Schreibweise kann als ein Beispiel dafür angeführt werden, dass die Selbstaussagen über Form und Qualität des Textes an manchen Stellen in einem selbstironischen Sinn interpretierbar sind, was für ein bewusstes Nutzen des komisch-ironischen Potentials der von Benedetto gewählten Gattung sprechen würde. ${ }^{875}$

Wie aus diesem Überblick hervorgeht, lassen Benedettos eigene Reflexionen auf die Qualität seines Textes mehrere Möglichkeiten offen. Der Bogen spannt sich von einer ernsten, sich durch das Paradoxon der Bescheidenheitstopoi behauptenden auktorialen Haltung bis zu einer ironischen Geste, die das Schreiben als ein spielerisches Ausprobieren der eigenen Talente in allen möglichen Registern zeigt.

CVP. 3529, 234r.

Auch im Fall der declamatio in der supplicatio kann Benedettos Begründung seiner Wahl der Form seines Werkes (oder jedenfalls von einem Teil des Werkes) als eine selbstironische Geste gedeutet werden, weil die angekündigte „oratio ponderosa” die vom Autor erweckten Erwartungen der Leser nicht erfüllt. Diese Lesart hat natürlich nur in dem Fall ihre Gültigkeit, wenn man die Ungeschicklichkeit der declamatio wenigstens teilweise als absichtlich versteht. 


\subsubsection{Lachbilanz}

Die eben gezeigte Unsicherheit, inwiefern man den Text als selbstironisch betrachten kann, und welche die Stellen sind, die einfach Benedettos Mangel an sprachlich-stilistischer Kompetenz zu verdanken sind, regt zum Weiterdenken des Problems an. Man könnte dafür argumentieren, dass man es auch an den auf den ersten Blick fehlerhaften, ungeschickten Stellen mit bewusster Selbstironisierung oder Ironisierung zu tun hat. Die Kategorie „Ironie” ist aber deswegen gefährlich, weil man sie überall anwenden kann. Zu jedem Text können die ironisierenden Anführungsstriche hinzugedacht werden, was zu einem inflationären Gebrauch dieser Kategorie und damit zu einem Bedeutungsverlust derselben führen kann. Diese Feststellung will jedoch der Lese- und Interpretationslust im Allgemeinen keine Grenzen setzen. In einer Untersuchung aber, die sich als historische versteht und die beabsichtigt, die zeitgenössische Wahrnehmung eines Textes (die mögliche Wahrnehmung des Libellus durch seine Leser auf dem Konzil) oder eines Phänomens (die Wahrnehmung des Humanismus durch Benedetto), wenn nicht zu rekonstruieren, dann wenigstens in ihren Konturen zu skizzieren, muss sich auf das Plausible beschränken.

Wie bereits angemerkt wurde, ist das Latein des Libellus kein Spottlatein, nicht im humanistischen und auch nicht im mittelalterlichen Sinne. ${ }^{876}$ Konsequenz und Übertreibung sind die wesentlichen Merkmale eines Lateins, das in einer, im Vergleich zu dem gängigen Sprachgebrauch, absichtlich verdorbenen Form benutzt wird. Ohne diese Merkmale könnte sich der Autor nicht sicher sein, dass sein Witz oder Spott als solcher verstanden wird und würde damit sein eigenes Renommee gefährden. Wenn man eine Ubiquität der vom Autor beabsichtigten Ironie und Selbstironie im Fall des Libellus als historisch unplausibel ausschließt, dann kann man die Bilanz mit der Behauptung schließen, dass Benedetto oft einfach etwas ungeschickt war, besonders an Stellen, an denen er seinen Text mit üppigem rhetorischen Ornament zu schmücken versuchte.

Wie steht es mit den anderen, nach aller Wahrscheinlichkeit absichtlich komischen und ironischen Stellen des Textes? Wie lassen sie sich in den für den heutigen Leser mit Komik unvereinbaren Kontext fügen? Man kann bei dieser Frage wahrscheinlich Dronke zustimmen, der das Relativierende an der menippeische Satire als ein ständiges Oszillieren beschrieben hat, als einen Prozess des „Testens der Wahrheit”. Der Punkt, an dem der

876 Bei den Humanisten denke ich zum Beispiel an die Dunkelmännerbriefe: Aloys Bömer, Hrsg., Epistolae obscurorum virorum, 2 Bde., Stachelschriften, Ältere Reihe 1, (Heidelberg: Weissbach, 1924, ND: Scientia: Aalen 1978 (2 Bände in 1 Bd.), im Fall des Mittelalters z. B. an das „Quondam fuit factus festus”: Wilhelm Meyer, „Quondam fuit factus festus”: ein Gedicht in Spottlatein”, Nachrichten von der Königlichen Gesellschaft der Wissenschaften zu Göttingen. Philologisch-historische Klasse 1 (1908), 406429. 
englische mittellateinische Philologe anders vorgeht als zum Beispiel Bachtin, ist seine Bemerkung, dass in dieser Gattung alles relativiert wird, und dementsprechend auch die ironisierenden Stellen, die den ernsten Diskurs in Frage stellen, keinen Fixpunkt bilden: „Nor does the undermining itself provide a fixed point of repair: always the dialectic continues." Dronke betont, dass das Wesentliche an der menippeischen Satire das Wechseln von Ernst und Scherz ist, das aber ernste Einsichten ermöglicht. ${ }^{878}$ Dronke behauptet, dass Ernst und Scherz sich nicht ausschließen und dass das Ironische, welches das Ernste untergräbt, nicht die endgültige Lesart des Textes, keinen Ruhepunkt der Interpretation bedeuten muss. Interpreten, die eine ironisierende Lesart ganz ausschließen, erwecken den Eindruck, als wenn sie Angst davor hätten, dass die Ironie das Ernste im Text ganz zerstören könnte. ${ }^{879}$ Radikale Ironiebefürworter wiederum neigen dazu, das Subversive im Text zu verabsolutisieren. ${ }^{880}$

Obwohl Dronkes Bemerkungen sich auf die philosophischen Prosimetra beziehen und man mit dem „Testen der Wahrheit” bei dem Libellus etwas übertreiben würde, kann man trotzdem davon ausgehen, dass das Prinzip, nach dem man innerhalb desselben Textes Ernst und Scherz mischen kann, auch Benedetto nicht fremd war.

Auf die Frage, welcher der früher beschriebenen Grundvarianten der Zusammenhänge zwischen der Intention des Autors und der Wahrnehmung des Publikums Benedettos Text zuzuordnen ist, kann keine definitive, für den ganzen Text gültige Antwort gegeben werden. An manchen Stellen ist eher damit zu rechnen, dass Benedetto keinen komischen Effekt erzeugen wollte, dass er aber manche seiner Leser doch zum Lachen brachte. Ob dieses Lachen ein böses oder ein wohlwollendes war, hing davon ab, ob der Leser die Komik als ein von Benedetto absichtlich verwendetes Stilmittel interpretiert hatte, oder eben als Missgeschick. An manchen Stellen dagegen kann man vielleicht von Benedettos bewusstem Verwenden der komischen oder ironisierenden Mittel ausgehen. Wie diese Stellen von seinem Publikum wahrgenommen wurden, variierte bestimmt auch von Leser zu Leser. ${ }^{881}$

Benedettos Oszillieren zwischen fast bravourhaft komisch gestalteten Stellen (man denke zum Beispiel an sein Wortspiel ,hanc mali penam non meruere pati”: Anm. 914) und Malheuren (wie z. B. im Fall der Schilderung der Durchsuchungsszene) zeichnet ihn als einen

877 Peter Dronke, Verse with Prose. From Petronius to Dante. The Art and Scope of the Mixed Form (Cambridge, Massachusetts, London: Harvard University Press, 1994), [im Weiteren: „Verse with Prose”], hier S. 31.

878 „A significant element of that Menippean mingling of earnest and game, that spoudogeloion, by which serious insights are arrived at in ways more complex than didactic, ways that never exclude the presence of unserious, playful perspectives." Dronke, Verse with Prose, S. 31.

879 Zum Beispiel Pabst.

880 Zum Beispiel der bereits zitierte Relihan.

881 Die etwas tentative Art, diese Frage zu beantworten, hängt wahrscheinlich mit der Tatsache zusammen, dass die Verfasserin dieser Arbeit eigentlich auch nur eine der Leserinnen des Textes ist, und diesen nicht aus einer unabhängigen, allwissenden Perspektive liest. 
gut trainierten Grammatiker mit einer gewissen Bewandertheit in klassischen Texten aus, der sich offensichtlich Mühe gibt, sein Wissen zu mobilisieren. Diese Bemühungen verleihen aber dem Text manchmal einen etwas angestrengten Ausdruck und erreichen so genau das Gegenteil des angestrebten Effekts.

\subsection{Benedettos Rekurs auf humanistische Praktiken}

\subsubsection{Der Diskurs der Dichterkrönung im Libellus und sein Florentiner Kontext}

Um seine Rom-Klage stilgemäß zu formulieren, legt Benedetto mit den Worten „migrate coloni” (Verg. Ecl. 9. 4) sogar eine vergilianische Reminiszenz in Cäsars Mund. Streng genommen passt sie nicht ganz zu ihrem neuen Kontext, weil diese Worte in ihrem ursprünglichen Kontext ein ausgesprochen negatives Vorzeichen haben: Moeris zitiert sie von den Veteranen, die ihn von seinem Gut vertrieben haben. ${ }^{882}$ Es verstärkt aber auf jeden Fall den Eindruck, dass Benedetto seine Rom-Klage so formulieren wollte, dass er dabei auf das antike Rom Bezug nehmen konnte. Der fernere Kontext von Moeris' Worten war wiederum passend zu Benedettos Situation: die Eklogen wurden seit der Antike als autobiografische Elemente enthaltende Schriften gelesen. Nach dieser Interpretation spreche in jeder der Eklogen das alter ego des Dichters, der im Bürgerkrieg selbst sein Landgut verloren und es von Octavianus schließlich zurückbekommen habe; es sei Vergil, der unter der Maske der Hirten über sein Schicksal klage bzw. sich für Octavians Hilfe bedanke. Vergil war eine perfekte Identifikationsfigur für einen „Dichter” wie Benedetto, der sich in einer veränderten Lebenslage um das kaiserliche Wohlwollen bemühte. Vergil galt als der kaiserliche Dichter schlechthin, der vom Kaiser sogar zum Dichter gekrönt worden sei. Dass der historische Vergil kein poeta laureatus war, dass er also auf dem Kapitol nicht, wie es dank der erfolgreichen humanistischen Fiktion selbst heute oft behauptet wird, gekrönt wurde, ändert nichts an der Tatsache, dass Benedetto und seine Zeitgenossen dieses Bild vom augusteischen Dichter hatten. Das Bild Vergils als ein „kaiserlicher” Dichter machte ihn zu einem Modell, dessen Imitation bzw. das Zitieren seiner Eklogen für Benedetto als passend erscheinen musste. ${ }^{883}$

882 Heute wird der Satz ,veteres migrate coloni” immer auf unfaire Situationen bezogen verwendet, wird also im Einklang mit seiner ursprünglichen Konnotation benutzt. Für die Antwort auf die Frage, ob dies schon im 15. Jahrhundert der Fall war, habe ich keine Belege gefunden.

883 Die sich auf Grund seiner Biografie anbietenden Möglichkeiten einer konsequenteren Bezugnahme auf Vergils Figur hat Benedetto allerdings nicht benutzt. An der Stelle z. B., an der es um die Zerstörung seines Gartens geht, hätte er die Möglichkeit ergreifen und seinen Text mit vergilianischen Reminiszenzen schmücken können. 
Die Institution der Dichterkrönung selbst wird im Libellus auch angesprochen. Bei der Erwähnung von Leonardo Bruni bemerkt Benedetto, dass das Büchlein den Florentinern sagen soll:
O clari cives, concedite per sua laurum
Tempora Phebriam ${ }^{884}$ serpere, quam meruit!
Et vacuum exornate locum, iuxtaque Petrarcham
Aut tria cantantem regna locate virum ${ }^{885}$,
Quamvis non agitent tales sua pectora cure,
Vitat enim pompas moribus ipse gravis. ${ }^{886}$

Die in Florenz zu haltende Rede des Buches enthält Benedettos Vorschlag, dass die Florentiner Bruni zum Dichter krönen sollten. Eine Glosse ${ }^{887}$ erklärt, dass es in Florenz ein „Haus” gäbe, in dem die Bilder der gelehrtesten Männer hängen und dass ein Platz freigelassen wurde mit der Unterschrift ,per chi lo meritara”. Der Verfasser der Glosse ist, weil es hier um eine Erläuterung einer in den Versen etwas knapp gefassten Stelle geht („Et vacuum exornate locum, iuxtaque Petrarcham / Aut tria cantantem regna locate virum"), wahrscheinlich der Autor selbst. Die Glosse verweist offensichtlich auf einen uomini famosi-Zyklus.

Wenn man nach einem solchen Zyklus aus dieser Zeit in Florenz sucht, so stellt man fest, dass es zur Zeit der Entstehung des Libellus wenigstens zwei uomini famosi-Zyklen gab $^{888}$. Der eine war der schon im späten Trecento ausgeführte Zyklus, der sich in der aula minor des Palazzo Vecchio befand und während späterer Bauarbeiten im Palast zerstört worden ist. Die von Salutati verfassten Epigramme zu den Bildern sind aber überliefert worden. ${ }^{889}$ Nach diesen Epigrammen wurden in der aula minor insgesamt zweiundzwanzig berühmte Männer dargestellt, von denen dreizehn in Petrarcas Zusammenstellung berühmter Männer in seinem De viris illustribus enthalten sind. Das Florentiner Bildprogramm ist als eine Mischform zu betrachten. Neben den antiken Figuren waren auch die Berühmtheiten der Lokalgeschichte abgebildet. Die fünf Literaten, die auf den Fresken der aula minor zu sehen waren, sind die fünf Dichter, deren Leben und Werke Villani am Anfang seines De origine civitatis Florentiae et eiusdem famosis civibus erörtert, also: Claudian, Dante, Petrarca

\footnotetext{
884 Steht wahrscheinlich für „Phebeam”, wie auch von Wattenbachs Korrektur vorgeschlagen wird.

885 iuxta virum tria regna cantantem: also neben Dante

886 CVP. 3529, 210v-211r; Wattenbach, B. d. P., S. 107.

887 Die Randbemerkung f. 211 r.

888 Über diese Zyklen berichtet: Maria Monica Donato, „Famosi cives" Testi, frammenti e cicli perduti a Firenze fra Tre e Quattrocento”, Ricerche di storia dell'arte 30 (1986): 27-43, [im Weiteren: „Famosi cives"].

889 Die tituli dieses Zyklus wurden veröffentlicht: Teresa Hankey, „Salutati's Epigrams for the Palazzo Vecchio at Florence", Journal of the Warburg and Courtauld Institutes 22, (1959): 363-365.
} 
Boccaccio und Zanobi da Strada. ${ }^{890}$ In der Person von Salutati, der Villanis Text korrigierte $^{891}$, gibt es auch eine direkte Verbindung zwischen Villanis Text und dem Bildprogramm, das wahrscheinlich von Salutati suggeriert wurde.

Der andere Zyklus, dessen tituli von Domenico Silvestri stammen ${ }^{892}$, befand sich im Palazzo dell'Arte dei Giudici e Notai. Der Kern dieses Zyklus' wurde von den Figuren von Dante, Petrarca, Boccaccio und Zanobi da Strada gebildet. 1406 wurde der Maler Ambrogio Baldese für zwei weitere Porträts bezahlt: für die des Claudian und des Salutati. Zu Benedettos Zeit bestand der Zyklus also aus sechs Porträts.

Da Benedetto den Zyklus im Libellus als etwas Offenes darstellt, das erweitert werden sollte, kann man vielleicht davon ausgehen, dass er im Libellus den Zyklus des Palazzo dell'Arte dei Giudici e Notai meinte, der offensichtlich so ausgeführt wurde, dass spätere Erweiterungen des Zyklus möglich und sogar geplant waren. ${ }^{893}$

Ein interessantes Detail in Benedettos Erwähnung des Zyklus' besteht darin, dass er im Text und in der Glosse das Thema Dichterkrönung eng mit der bildlichen Darstellung des Zyklus verknüpft. Um diese Verknüpfung Benedettos mit der zeitgenössischen Wahrnehmung der in den Zyklen dargestellten Dichter vergleichen zu können, sollte man die Frage beantworten, inwieweit es Überschneidungen in der zeitgenössischen Wahrnehmung zwischen dem Diskurs der Dichterkrönung und dem der in den uomini famosi-Zyklen dargestellten Dichter gab. Waren die Dichter, die auf dem von Benedetto erwähnten Fresco dargestellt waren, gekrönte Dichter? Fünf Persönlichkeiten aus den zwei Zyklen sind gemeinsam, der einzige Unterschied ist Salutatis Figur, die nur im Zyklus des Palazzo dell'Arte dei Giudici e Notai vorzufinden ist. ${ }^{894}$ Diese fünf gemeinsamen Figuren der zwei Bilderreihen waren nicht einfach nur Literaten, sondern teilweise auch gekrönte Dichter: Zanobi da Strada und Petrarca wurden zu ihren Lebzeiten zu Dichtern gekrönt und in Villanis Text als poetae laureati bezeichnet.

Auch die anderen drei Dichter konnten aber für einen Leser des frühen 15. Jahrhunderts als Persönlichkeiten erscheinen, die mit dem Diskurs der Dichterkrönung in Verbindung

\footnotetext{
890 Filippo Villani, De origine civitatis Florentiae et eiusdem famosis civibus, hrsg. v. Gustavo Camillo Galletti (Florenz: Joannes Mazzoni, 1847), [im Weiteren: „De origine”].

891 Über Salutatis Korrekturen vgl. Berthold Louis Ullman, „Filippo Villani’s copy of his History of Florence”, in Studies in the Italian Renaissance (Rom: Edizioni di Storia e Letteratura, 1955), 241-247.

892 Die tituli wurden veröffentlicht: Angelo Maria Bandini, Catalogus codicum manuscriptorum Bibliothecae Mediceae Laurentianae, 5 Bde., (Florenz: s. n., 1764-1778), Bd. 3, S. 714ff.

893 Der Zyklus wurde auch später durch Andrea del Castagnos Porträts erweitert.

894 Man kann vielleicht davon ausgehen, dass die Figur Claudians auch zu Salutatis Ehren in den Zyklus aufgenommen wurde. Nach seinem Tod 1406 wollte man ihn vielleicht nicht nur durch seine Aufnahme in den Zyklus ehren, sondern auch dadurch, dass man den Zyklus des Palazzo dell'Arte dei Giudici e Notai mit der Aufnahme von Claudians Figur dem Programm des von Salutati iniziierten Zyklus annäherte.
} 
gebracht werden konnten. Über Dantes Krönung, die post mortem erfolgte, berichtet Boccaccio in seinem Trattatello in laude di Dante:

Fece il magnanimo cavaliere Guido Novel da Polenta ${ }^{895}$, il morto corpo di Dante d'ornamenti poetici sopra uno funebre letto adornare. ${ }^{896}$

Auch Claudianus zählte in der späteren florentinischen Tradition offensichtlich als gekrönter Dichter: Cristoforo Landino stellt ihn als einen gekrönten Dichter dar. Er behauptet in seinen Kommentaren zu Dantes Commedia, dass Petrarca in einer seiner Reden Claudianus als den letzten gekrönten Dichter des antiken Imperiums erwähnt habe. Er, Petrarca, sei nach langer Zeit der erste gewesen, dem diese Ehre wieder zuteil geworden sei, weil Dante seine Krönung zurückgewiesen habe, da sie nicht in Florenz hatte erfolgen können, und er aus diesem Grund erst nach seinem Tod gekrönt wurde:

Solo affermo poche chose essere in quella che non sieno comuni al poeta et all'oratore. Crebbono queste due spetie di scriptori crescendo lo 'mperio latino, et vennono al suo colmo in Virgilio et in Cicerone. Dipoi diminuendo quello anchora epse declinorono; et finalmente sobmersa Italia da varie inondationi di barbariche nationi, al tutto perirono. Ma questo ad che proposito? Meffé, accioché buona gratia consequiti da tutta Italia el fiorentino popolo per due cagioni. Prima perché chome in una sua oratione scrive el Petrarca, l'ultimo poeta laureato, che in prezo rimanessi in lingua Latina, fu el fiorentino Claudiano, et dipoi perché el primo che dopo la resurrextione della facultà poetica prendessi laurea corona fu el Petrarca, perché Dante dinegò prendere tale honore se non lo prendessi nel baptisterio fiorentino. Fu adunque la nostra città l'ultima, nella quale si spegnessi tale facultà, et la prima nella quale si riaccendessi. ${ }^{897}$

In Cristoforo Landinos Kommentaren werden, bis auf Boccaccio, alle die in Villanis Text erörterten Dichter erwähnt. Florenz erscheint in diesem Konstrukt mit der Erwähnung von Claudians Krönung als letzte in der Tradition der Dichtung und Redekunst, die sich bemüht, diese Tradition wiederzuerwecken. Man musste die Tatsachen ein wenig manipulieren, um diese Traditionslinie herstellen zu können: Petrarca war zwar in Florenz geboren, seine Krönung war aber kein florentinisches Ereignis. Claudian wurde nicht nur nicht zum Dichter gekrönt, er wurde auch nicht von dem von Landino zitierten Petrarca für einen gekrönten Dichter gehalten. ${ }^{898}$ Die Linie wird von Landino weitergesponnen. Etwas später werden

895 Der Herr von Ravenna.

896 Giovanni Boccaccio, „Trattatello in laude di Dante”, in Opere, hrsg. v. Pier Giorgio Ricci (Mailand, Neapel: Riccardo Ricciardi Editore, 1965), 565-650, hier S. 597.

897 Cristoforo Landino, Comento sopra la Comedia, hrsg. v. Paolo Procaccioli (Rom: Salerno Editrice, 2001), hier S. 236 (Proemio, IV, Fiorentini excellenti in eloquentia).

898 Man sucht vergebens nach einer Stelle in Petrarcas Reden, in der er über Claudianus als poeta laureatus reden würde. Auch in den Fußnoten zur Ausgabe des Textes Landinos steht, dass Landino hier wahrscheinlich die Collatio laureationis meint, dass aber ein Vergleich zeige, dass der Hinweis nicht stimmt. Der Text 
Boccaccio und Zanobi da Strada, Coluccio Salutati, Leonardo Bruni und Poggio Bracciolini erwähnt. ${ }^{899}$ Landinos Narrative ist zwar wesentlich später entstanden, als die Zeitspanne, in die Benedettos Libellus zu datieren ist, kann aber trotzdem wenigstens als ein Beweis für die spätere Existenz einer florentinischen Traditionslinie der gekrönten Dichter dienen, die sogar bis zu der Antike zurückgeführt wurde, und auf den Fresken der uomini famosi zum Ausdruck gekommen ist.

Um auf den einzigen Dichter der Fresken zurückzukommen, der selbst bei Landino, der sich darum bemüht, die florentinischen Berühmtheiten in einer klaren Traditionslinie darzustellen, nicht als poeta laureatus dargestellt ist, also auf Boccaccio, so kann man feststellen, dass er, obwohl er kein gekrönter Dichter war, mit dem Diskurs der Dichterkrönung bereits bei Villani in Verbindung gebracht wurde. Villani meint, dass Boccaccio es verdient hätte, zum Dichter gekrönt zu werden:

Debuit sane vir tantus vatum laurea coronari, sed tristis temporum miseria, quae temporalium rerum dominos turpi foenore labefactaret, eiusque paupertas hoc penitus vetuerunt; verumtamen quae composuit laureanda volumina pro myrto hederaque suis fuere temporibus. ${ }^{900}$

Obwohl Villani selbst nur über zwei der fünf Dichter als poeta laureatus schreibt, deutet er in seiner Einleitung zu den Lebensbeschreibungen dieser Männer an, dass er den Diskurs über Dichter in engster Verbindung mit dem der Dichterkrönung sieht:

Sane post Caesares, poetas invenimus summo honore apud Gentiles fuisse susceptos, ita ut pariter ambo triumphantes, hedera atque lauro tempora redimerent, eo quod, quae illi corporis animique viribus egregie peregissent, hi arte et scribendi studio deperire non sinerent. ${ }^{901}$

Die Krönung mit Efeu und Lorbeer erscheint hier nicht als etwas Akzidentielles, sondern als etwas, das das Wesen der Aufgabe der Dichter zum Vorschein bringt. Dementsprechend hätte man, wenn man Villanis Logik folgt, alle fünf großen Dichter, die er als größte Gestalten der florentinischen Vergangenheit darstellt, mit dieser Auszeichnung ehren sollen.

Um die Beantwortung der Frage auch auf die sechste Person, auf Coluccio Salutati zu erweitern, kann man feststellen, dass auch er, wie Dante, post mortem, auf seinem Begräbnis

stamme von einer indirekten, nicht identifizierten Quelle, so der Herausgeber des Comento. Dieser „Fehler” trägt aber auf jeden Fall dazu bei, dass eine Florentiner Traditionslinie der Dichterkrönung entstehen konnte, die auf Antike zurückführt.

899 Die Figur des Krönenden spielt bei Landino scheinbar überhaupt keine Rolle: als der Initiator und Ausführer von Zanobis Krönung wird zum Beispiel statt Kaiser Karl IV. der Papst genannt.

900 Villani, De origine, S. 18.

901 Villani, De origine, S. 6. 
zum Dichter gekrönt wurde. ${ }^{902}$ Seine Aufnahme in den Zyklus des Palazzo dell'Arte dei Giudici e Notai bedeutete dementsprechend auch die Fortsetzung der Reihe der florentinischen gekrönten Dichter.

Auf Grund dieser Beispiele des florentinischen Diskurses der Dichterkrönung kann man behaupten, dass Benedettos Verbindung der zwei Themen - der Dichterkrönung und der Aufnahme des jeweiligen Dichters in die Reihe der uomini famosi - wahrscheinlich ziemlich genau den zeitgenössischen Diskurs wiederspiegelt, der diese zwei Formen der Verehrung miteinander auch verknüpfte ${ }^{903}$ und der die Offenheit und den Fortsetzungsdrang dieser Traditionslinie der Dichterkrönungen nachdrücklich betonte. ${ }^{904}$

Über Benedettos Dichterkrönung hat man außer dem Kolophon im Berliner Codex keine weiteren Informationen. Obwohl man davon ausgehen kann, dass die Krönung wahrscheinlich gar nicht stattgefunden hat und es sich um einen rein bürokratischen Akt von Seiten Sigismunds handelte, ist die Tatsache, dass Benedetto im Kontext seiner Declamation von Valerius Maximus als poeta laureatus bezeichnet wird, ein Beweis dafür, dass er diesen Titel führte und sich bei seinen Deklamationen als gekrönten Dichter dargestellt haben muss. Es ist leider nicht möglich, zu entscheiden, ob Benedetto den Libellus und so die Stelle über gekrönte Dichter nach oder vor seiner eigenen Dichterkrönung geschrieben hatte. ${ }^{905}$ Wenn er die Stelle bereits als poeta laureatus konzipierte, so kann sie durchaus als eine Anspielung auf seinen eigenen Titel gelesen werden.

\subsubsection{Benedettos Epitaphien}

Benedetto vertraut dem Büchlein zwei Epitaphien für zwei seiner Freunde an, die zum Zeitpunkt der Italienreise des Buchboten bereits gestorben waren.

Das erste ist Bartholomeus Appulus gewidmet:

902 In seiner Ausgabe der Briefe Salutatis veröffentlichte Novati auch die literarischen Dokumente, die aus dem Anlass von Salutatis Tod entstanden. So befinden sich im Anhang an das Epistolario mehrere Epigramme, die Salutatis Krönung bezeugen. Vgl. Salutati, Epistolario, S. 484-487.

903 In Donatos Artikel wird ein Beispiel erwähnt, das als ein weiterer Beweis für die Verflechtung der zwei Diskurse dienen kann: Santi di Valiana, der Kanzler des Robert Novello da Battifolle, wendet sich an Salutati wegen eines für seinen Herren zu verwirklichenden Bilderzyklus, der 14 gekrönte Dichter darstellen sollte. Donato, Famosi cives, S. 35.

904 Die Tatsache, dass Bruni nach seinem Tod in der Tat zum Dichter gekrönt wurde und sogar sein Bildnis in den Zyklus des Palazzo dell'Arte dei Giudici e Notai aufgenommen wurde, soll nicht den Verdacht einer vaticinatio ex eventu erwecken. Der Text des Libellus zeigt sonst keine Spur von späteren Hinzudichtungen und die Zeit seiner Entstehung (vgl. das Unterkapitel: IV. 2.1.2. „Die Zeit der Entstehung des Buches”) und Abschrift konnte auch mit großer Wahrscheinlichkeit auf die Zeit des Konzils gelegt werden.

905 Das Kolophon, in dem Benedetto als poeta laureatus bezeichnet wird und das so einen terminus ante quem für seine Krönung bedeutet, ist auf 1416 datiert. Benedettos Gefangenschaft, ein terminus post quem für die Konzipierung des Libellus, fällt zwischen April und November 1415. Dementsprechend ist die Möglichkeit nicht auszuschließen, dass Benedetto bei dem Schreiben dieser Stelle bereits über den Titel des poeta laureatus verfügte. 
Hic quoque Pieridum pater optimus et michi

Et tibi dilectus rite videndus erat.

Sed postquam a superis concessit, carmine nostro

Signetur tumulus, quo situs ille fuit:

„Appulus et minimo contentus Bartholomeus

Dilectus musis hac tumulatus humo est."

Quis iam doctiloqui referabit gesta Maronis?

Quis Flacci numeros? Dona quis, Lyee, tua?

Carmina quis nobis varias mutantia formas,

Cesaris et pugnas? Carmina quis Statii?

Quis satyras exinde dabit? Cantus quoque ville?

Tulli, quis nobis et tua scripta canet?

Historiasque tuas, quis, Maxime clare, docebit?

Insimul atque graves, o Paduane, tuas?

Rarus ei similes surget, qui talia possit,

Hoc oritur raro tempore clarus homo. ${ }^{906}$

In diesem Fall ist es nicht ganz klar, wo der Text des Epitaphiums aufhört und wo Benedettos Klage anfängt. Die mit „Quis iam doctiloqui” anfangenden Zeilen könnten auch zum Text des Epitaphiums gehören. Dass die Grenze etwas fließend zu sein scheint, ist der Fiktionalität der Situation zu geschuldet. Die Zeilen waren von vornherein nicht als ein Entwurf für eine Grabinschrift konzipiert, sie bringen durch dieses literarische Spiel einfach Benedettos Trauer zum Ausdruck, deswegen müssen sie auch keine klaren Konturen gewinnen und vom übrigen Textteil eindeutig abgegrenzt werden.

Das zweite Epitaphium soll den Ruhm eines Johannes aus Piglio verewigen:

Nescio, quid possim tibi plus dare; suscipe carmen,

Quod vestro valeo sculpere mansolio:

„Hic iacet in tumulo carus iustusque Iohannes.

Moribus hic florens ac pietate fuit.

Matre Columnense natus, patre Anthioceno

Lugendus cunctis clauditur hoc lapide."907

Das Sammeln und Dichten von Epitaphien und Inschriften aller Art hat eine lange mittelalterliche Tradition: fiktive Epitaphien auf antike Dichter wurden auch im Mittelalter geschrieben $^{908}$, Inschriften wurden kopiert und gelesen, manche Sammlungen haben dabei

906 CVP. 3529, 209v-210r, Wattenbach zitiert die letzten zwei Zeilen: B. d. P., S. 106.

907 CVP. 3529, 219r.

908 Über das Nachleben von Vergils Grabepigramm vgl. Irene Frings, „Mantua me genuit - Vergils Grabepigramm auf Stein und Pergament", Zeitschrift für Papyrologie und Epigraphik 123 (1998): 89-100; und für seine humanistischen Nachdichtungen: Elisabeth Klecker, Dichtung über Dichtung. Homer und Vergil in lateinischen Gedichten italienischer Humanisten des 15. und 16. Jahrhunderts, Wiener Studien 20, Arbeiten zur mittel- und neulateinischen Philologie 2 (Wien: Verlag der Österreichischen Akademie der Wissenschaften, 1994), hier S. 189-196. 
sogar ähnlich wie Reiseführer funktioniert und große Verbreitung gefunden. ${ }^{909}$ Was als novum ab dem 15. Jahrhundert zählen dürfte, ist erstens das Ausmaß dieser Tätigkeit, so wie der Inhalt der Inschriften, die für die neuen Gelehrten interessant waren. Es wurden größtenteils antike Inschriften gesammelt. ${ }^{910}$ Zweitens, was das Dichten von Epitaphien betrifft, war das Zunehmen der eulogischen, die Gelehrsamkeit des Verstorbenen lobenden Elemente dieser Grabinschriften auch ein Merkmal, das die Forschung für gewöhnlich mit der neuen Kultur verbindet. ${ }^{911}$

Das Schreiben von Epigrammen für das Grab eines gelehrten Freundes zählte zu den im Kreis der Humanisten gepflogenen Freundschaftsdiensten. Das in diesen Epigrammen stattgefundene Lob der humanistischen Studien hatte eine repräsentative, selbstrepräsentative sowie gruppenidentitätsstiftende Funktion. Dass diese Epitaphien nicht nur in deren Originalform, auf dem Grabstein, sondern auch im handschriftlichen Verkehr zu lesen waren, lässt sich mit beiden Komponenten derer doppelten Funktion erklären. So konnte der Ruhm des Verstorbenen, aber auch der des Urhebers des Epitaphs effektiver verbreitet werden. Wegen der Kompetitivität der humanistischen Kultur des Totenkultes kam es oft dazu, dass für ein Grab mehrere Epitaphien gedichtet worden sind und demzufolge manche nur in handschriftlicher Überlieferung existierten. ${ }^{912}$ Weitere Beispiele von Inschriften in Handschriften stellen nicht realisierte, aber für eventuelle Realisierung gedachte Entwürfe von „Inschriften” dar.

Es sind also für die in Handschriften kursierenden Epitaphien mehrere Stufen der Fiktionalität festzustellen. Es gab die Epitaphien, die in der Tat auf dem Grabstein standen, also deren Abschriften in Handschriften die Kopien von etwas Primärem (des Epitaphiums des Grabsteins) sind, das die ihm zugewiesene Funktion in der Tat erfüllt. Zweitens gab es die Texte, die aus einem konkreten Anlass geschrieben worden sind und die zwar nicht realisiert

909 Als Beispiel kann man hier die Epigrammata Damasiana nennen. Vgl. Antonius Ferrua, Hrsg., Epigrammata Damasiana (Città del Vaticano: Pontificio Istituto di Archeologia Christiana, 1942). In der Einleitung gibt der Autor auch einen Überblick über die Verbreitung dieser Inschriften: S. 13-17.

910 Über die ersten humanistischen Beschreibungen von antiken Ruinen vgl. Angelo Mazzocco, „Petrarca, Poggio, and Biondo: Humanism's Foremost Interpreters of Roman Ruins”, in Francis Petrarch, Six Centuries Later. A Symposium, hrsg. v. Aldo Scaglione (Chicago: Chapel Hill and The Newberry Library, 1975), 353-363. Die ersten umfangreichen humanistischen Sammlungen von Inschriften sind die folgenden: Cola di Rienzos Sammlung von 1347 (veröffentlicht in: Eugen Bormann und Wilhelm Henzen, Hrsg., Inscriptiones urbis Romae Latinae, Corpus Inscriptionum Latinarum, 6, pars 1 (Berlin: Reimer, 1862-1925), [im Weiteren „CIL 6”], S. XVI-XXVI; Poggios Sammlung von 1429 (heute verfügbar im CIL, VI 1, S. XXIX-XL), und Ciriaco d'Anconas Inschriftensammlung. Über Ciriacos Reisen und Sammeltätigkeit vgl. Scalamonti, Vita Kyriaci (Anm. 75).

911 Vgl. Iiro Kajanto, Classical and Christian. Studies in the Latin Epitaphs of Medieval and Renaissance Rome, Annales Academiae Scientiarum Fennicae 203 (Helsinki: Suomalainen Tiedeakatemia, 1980), hier S. 124-129.

912 Um ein Beispiel zu nennen: die für Salutati verfassten Epitaphien sind veröffentlicht im Anhang der Ausgabe seines Epistolario: Salutati, Epistolario, Bd. 4, S. 484-487. 
worden sind, aber nicht von vornherein nur für das Papier oder Pergament als Schriftträger gedacht worden sind: die Entwürfe von Inschriften. Beispiele für diese Fiktionalitätsstufe sind etwas schwieriger zu nennen: es kann nur schwer entschieden und bewiesen werden, dass der Autor mit der Möglichkeit gerechnet hat, dass seine Zeilen in Stein gehauen werden könnten. Die Mehrstufigkeit der Arbeit an einer Inschrift, die Tatsache also, dass man sie nicht gleich im haltbarsten Material fixiert hat, lässt aber darauf schließen, dass in der handschriftlichen Tradition auch nicht realisierte Entwürfe überliefert worden sind. Die Epitaphien, die als konkurrierende Versionen für ein bereits existierendes Monument erzeugt worden sind, lassen sich auf die dritte Stufe der Fiktionalität stellen. Der Hinweis auf ein (Grab-)Monument als Schriftträger gehört in diesem Fall ganz in den Bereich der Fiktion. Als ein Beispiel dafür können die auf antike Dichter gedichteten Epitaphien genannt werden. Dass die handschriftliche Form nicht immer nur als Kopie, also als etwas Sekundäres diente, sondern dass sie in ihrer Materialität selbst als Monument verstanden werden konnte, kann hier auf Grund des folgenden Falles vermutet werden: Das von Bruni gedichtete Epitaph für Salutati ist nach Angabe Novatis nicht auf Papier geschrieben worden, sondern auf ein Pergamentblatt, das im Nachhinein in den Papiercodex eingefügt wurde. ${ }^{913}$ Da Pergament ein wert- und prestigevollerer Schriftträger war als Papier, war im Zeitalter der Papierhandschriften seine Nutzung mit bestimmten Funktionen verbunden, und so bekam es in diesem Fall wahrscheinlich den Rang eines für den Toten gesetzten Monumentes.

Benedettos Epitaphien, die von seinem nuntius getragen sind, stellen nur insofern eine weitere Fiktionalisierungsstufe dar, als dass hier der ganze Rahmen fiktional ist, was die Möglichkeit eines späteren Medienwechsels für den Leser ganz eindeutig ausschließt. Vor dem Hintergrund der oben kurz zusammengefassten humanistischen Praktiken, die nicht in jedem Fall eine klare Trennung zwischen dem Fiktionalen und dem Realen zulassen, scheint das von Ovid übernommene literarische Motiv nicht nur als solches zu interpretieren sein, sondern als ein Hinweis auf die humanistischen Gepflogenheiten. Mit anderen Worten: Benedettos Epitaphien sind zwar einerseits als Imitation eines Modells zu betrachten, aber nicht ausschließlich als das. Es hätte theoretisch sein können, dass Benedetto für die Grabmonumente seiner Freunde Epitaphien gedichtet hat und diese mit der Absicht, dass sie als reale Monumente verwirklicht werden, in die Städte geschickt hat.

Im Wiener Codex befinden sich nach dem Explicit des Libellus (246 v.) folgende zwei Zeilen:

913 Salutati, Epistolario, S. 485, Anm. 1. 
Qua potui, vivens sublimia semper amavi,

Hac igitur moriens iussi me sede locari. ${ }^{914}$

Die Randglosse verrät, dass es sich hier um Benedettos eigenes Pytaphium handelt. Wattenbach nimmt auf Grund dieser Zeile an, dass Benedetto „,noch auf dem Konzil gestorben ist, man würde auch sonst doch wohl noch etwas mehr von ihm gehört haben". 915

Man könnte aber vielleicht eher davon ausgehen, dass es sich hier um ein von Benedetto und seinem Modell Ovid inspiriertes Spiel des Kopisten handelt: Benedettos Epitaphien im Text und die Tatsache, dass Ovid in seinen Tristien (Benedettos offensichtlicher Vorlage für die Form seiner Leidensgeschichte) sein eigenes Epitaphium gedichtet hatte, ${ }^{916}$ könnte den Kopisten zu diesem literarischen Spiel geführt haben, das nicht ganz ohne Ironie ist. Das Wort „sublimia” könnte im doppelten Sinn verstanden werden und sich sowohl auf die Stilblüten Benedettos als auch auf den Ort seiner Gefangenschaft, den Turm beziehen lassen. Es könnte sich hier sogar um ein geradezu böses Spiel handeln: Wenn der Urheber dieses Spiels sich schon ein maliziöses Ausschlachten der Doppeldeutigkeit des Wortes „sublimia” erlaubt, so könnte man sich auch vorstellen, dass das Benedetto in den Mund gelegte Selbstlob (die Behauptung, dass er sich gern mit erhabenen Dingen beschäftigte) eher als Ironie zu verstehen wäre. Dies würde eine spielerisch-ironische Reflexion auf das eben kopierte Werk bedeuten, das nach der Intention des Autors offensichtlich etwas Erhabenes darstellte. Außer der auch als ironisch deutbaren Formulierung des Pytaphiums kann man vielleicht auch den Rahmen des maliziösen Spiels des Kopisten, also die Tatsache, dass er seine ironisierende Prosopopoeia in der Form eines Epitaphiums dem Libellus beigefügt hatte, als Teil seiner Ironisierungsstrategie deuten. Mit dieser Geste hat der Kopist möglicherweise Benedettos Vorliebe, Epitaphien in seinen Text einzubauen, karikiert.

\subsubsection{Die Aufforderung zur Korrektur}

Die Funktion der Konstruierung des Leserkreises $^{917}$ des Libellus wurde bereits erörtert. Auch die mit diesem halb-fiktiven Leserkreis verbundene Aufforderung, dass Benedettos Leser seine Schrift korrigieren sollten, kann als ein humanistischer Topos verstanden werden. Ähnlich wie bei dem Bescheidenheitstopos fällt auch bei diesem Topos im Libellus auf, dass er von Benedetto sehr intensiv benutzt wird. An seinen Bruder schreibt er ganz am Anfang, in den ersten Zeilen des Libellus: „Perlege cum sociis et corrige, si qua

CVP. 3529, 246v.; Wattenbach, B. d. P., S. 128.

Wattenbach, B. d. P., S. 128.

Ov. Tr. 3.3. 73-76.

Vgl. dazu das Kapitel Benedettos „Freunde”: eine Lesergemeinschaft, und den Anhang 4. 
videbis"918, um etwas später diese Bitte auch in Prosa $\mathrm{zu}$ formulieren: „Corrigite limate mutate minimite addite ut libet"919. In Florenz soll das Büchlein zuerst von Bartolomeus da Montepulciano korrigiert werden:

Eger in hospicio sibi te committe videndum, Ut tollat maculas providus ille tuas. ${ }^{920}$

Auch Leonardo Bruni soll den Libellus von einigen Fehlern befreien:

Si te dignetur parvum timidumque videre, Exora, vitium demat ut ille tuum. ${ }^{921}$

In Rom soll das Buch seine Wunden dem Angelottus zeigen:

Tu plagas ostende tuas, miserebitur ille,

Et cum consilio conferet artis opem. ${ }^{922}$

Um ein Beispiel dafür zu geben, wie unterschiedliche Funktionen dieser Gemeinplatz in verschiedenen Kontexten haben kann, werde hier Benedettos Nutzung des Topos mit einer Stelle von Petrarcas Brief XXII, 2 an Boccaccio verglichen. In diesem Brief schreibt Petrarca seinem Freund über das von ihm selbst bevorzugte Prinzip der imitatio:

Sum, quem similitudo delectet, non identitas, et similitudo ipsa quoque non nimia, in qua sequacis lux ingenii emineat, non cecitas non paupertas; sum qui satius rear duce caruisse, quam cogi per omnia ducem sequi. ${ }^{923}$

Er zitiert auch Stellen aus seinen eigenen Schriften, die er den antiken Vorbildern allzu ähnlich konzipiert habe. Diese Übereinstimmungen jedoch seien ihm erst im Nachhinein bewußt geworden. Ein Vergehen, das ihm nun als fehlerhaft erscheint. Am Ende seines Briefes fordert Petrarca seinen Freund auf, ähnliche „Fehler” in seinem Text (im Bucolicum Carmen) zu korrigieren, falls er noch weitere finden würde:

Et ex hoc quidem genere duo hec sunt, que modo aderant; tu si plura notaveris, vel iure tuo corrige, vel me familiariter admone. Michi enim nil gratius, aut tu potes, aut omnino quisquam amicorum, quam in reprehensionibus meis vere amicum et liberum et intrepidum animum habere. Nulla vero hac acceptior, nisi sola morum potest esse reprehensio; equissimo animo paratus sum et stilum et vitam non tantum

CVP. 3529, 208r.

ebda

CVP. 3529, 210v.

CVP. 3529, 211r.

CVP. 3529, 211v.

Petrarca, Le familiari, (Brief 22, 2), Bd. 4, S. 108. 
amicorum vocibus moderari, sed etiam latratibus emulorum, si modo inter invidie tenebras scintillam aliquam veritatis aspexero. ${ }^{924}$

Dass Petrarcas Worte nicht für bare Münze genommen werden sollten, bemerkte bereits Guido Martellotti in seiner Studie über den Brief. ${ }^{925}$ In seiner Interpretation schlägt er vor, dass man den Brief als eine höflich verschleierte Kritik an Boccaccios Umgang mit den antiken Vorbildern verstehen sollte. Petrarca habe die von ihm angegebenen Stellen absichtlich so formuliert, dass sie sehr direkt mit den antiken Stellen assoziiert werden konnten. Mit fingierter Selbstkritik habe er eigentlich Boccaccio einen Ratschlag erteilen wollen. Man kann vielleicht außer der von Martellotti vermuteten auch noch eine andere Intention Petrarcas aus seinem Text heraushören. Seine Klage darüber, dass er manchmal entgegen seinem Willen antike Textstellen zitiert, kann auch als verdeckter Stolz gelesen werden: er müsse sich anstrengen, um nicht so zu schreiben, wie die antiken Vorbilder. Manche Schriften habe er sich so absolut zu eigen gemacht, dass er sie nicht mehr als fremd wahrnehme ${ }^{926}$. Am Ende seines Briefes schreibt er über Vergil als Imitator. Nach Martellotti ist dieser Hinweis auch als eine Höflichkeitsgeste zu verstehen, denn mit dieser Geste habe er den „Fehler” seines Freundes etwas veredeln wollen. Auch hier könnte man eine Lesart vorschlagen, die diesen Hinweis als Mittel von Petrarcas Selbststilisierung versteht: Er habe die Antiken nicht nur manchmal sogar unbewusst - imitiert, sondern sogar der Akt des Imitierens selbst folge dem Modell antiker Autoren.

Ob man den Brief als einen versteckten Ratschlag an den Freund liest oder als verstecktes Selbstlob: Beide Lesarten von Petrarcas Brief zeigen das Nutzen des Topos „Aufforderung zur Korrektur des eigenen Textes” als ein Instrument der Selbstdarstellung. Im ersten Fall zeigt sich Petrarca als arbiter, im zweiten Fall als einen Nachahmer antiker Autoren, deren Nachahmung nicht als etwas Gewolltes, Erzwungenes, sondern als notwendige Folge der perfekten Verinnerlichung antiker Texte zu betrachten sei.

924 Petrarca, Le familiari, Bd. 4, S. 109.

925 Guido Martellotti, „Similitudo non identitas. Alcuni varianti petrarchesche”, Rivista di cultura classica e medioevale, 19 (1977): 491-503.

926 „Legi apud Virgilium, apud Flaccum, apud Severinum, apud Tullium; nec semel legi sed milies, nec cucurri, sed incubui, et totis ingenii nisibus immoratus sum; mane comedi, quod sero digererem, hausi puer quod senior ruminarem. Hec se michi tam familiariter ingessere et non modo memorie, sed medullis affixa sunt unumque cum ingenio facta sunt meo, ut etsi per omnem vitam amplius non legantur, ipsa quidem hereant, actis in intima animi parte radicibus, sed interdum obliviscar auctorem, quippe qui longo usu et possessione continua quasi illa prescripserim diuque pro meis habuerim, et turba talium obsessus, nec cuius sint certe nec aliena meminerim. Hoc est ergo, quod dicebam, notiora magis fallere, que si quando forsan ex more recursantia in memoriam redeunt, accidit ut nonnunquam occupato et in unum aliquid vehementer intento animo non tantum ut propria sed, quod miraberis, ut nova se offerant." Petrarca, Le familiari, Bd. 4, S. 106. 
Der Kontrast zwischen Petrarcas und Benedettos Umgang mit dem Topos ist offensichtlich. Bei Benedetto geht es erstens um den konkreten Bedarf an nachträglichen Korrekturen. Seine häufigen Bemerkungen bezüglich der mangelnden Textqualität machen den Eindruck, dass diese nicht nur als Bescheidenheitstopoi zu verstehen sind.

Seine Aufforderungen an seine Freunde, seinen Text zu korrigieren sind außerdem, wie es bereits angedeutet wurde, ebenfalls als Bausteine seiner Selbstdarstellung zu verstehen, allerdings auf einer anderen Stufe als bei Petrarca. Benedettos Anliegen mit dem Topos war es, sich als Mitglied einer humanistischen corona darzustellen. Der Unterschied zu Petrarca ist nicht nur, dass bei Benedetto die Kluft zwischen dem Dargestellten und dem Wirklichen wahrscheinlich größer ist als bei Petrarca, sondern auch, dass der Status, den er mit seiner Selbstdarstellungsstrategie anvisiert, ein bescheidener ist. Er muss seine Zugehörigkeit überhaupt beweisen, während Petrarca sich einer führenden Rolle sicher sein kann.

Zur möglichen Wahrnehmung von Benedettos Topoi, mit denen er seine Freunde auffordert, seinen Text zu korrigieren, kann angemerkt werden, dass der zeitgenössische Leser vielleicht etwas irritiert war und möglicherweise eine Spannung zwischen seinen Erwartungen bezüglich der Toposmäßigkeit dieser Aufforderungen und der textuellen Realität des Libellus spüren müsste, die die tatsächliche Unumgänglichkeit der Korrekturen außer Zweifel stellte. Auch diese Spannung konnte auch eine bestimmte Komik erzeugen.

\subsubsection{Benedettos Schüler}

Im nuntius werden auch ehemalige Schüler Benedettos erwähnt: Nicolaus de Nicoleschis, Paulus de Capranica, die Ferrogerii Brüder und Nicolaus Antonii. Von welcher Art genau Benedettos Schule war, kann nicht genau gesagt werden. Die Grenzen zwischen einem „grammatista” und einem Humanisten waren auch später fließend, als das Wort „humanista” bereits für eine solche Unterscheidung zur Verfügung stand. ${ }^{927}$ Benedetto stellt seine Lehrtätigkeit so dar, dass man an beide Möglichkeiten denken könnte. Aus seinen Hinweisen auf seine Lehrtätigkeit im Libellus kann man immerhin entnehmen, dass er die Autoren mit seinen Schülern gelesen hat. Dies kann auch auf einer unteren Stufe passiert sein und bedeuten, dass er als Grammatiklehrer sein Geld verdiente. Mit dem Hinweis auf die Autorenlektüre wertet er aber seine Tätigkeit auf, er lässt jedenfalls auch die Möglichkeit offen, dass ihn seine Leser für einen Humanisten halten.

927 Über die Unterscheidung zwischen diesen verwandten Begriffen vgl. Billanovich, Auctorista. Robert Black bietet einen kurzen Überblick über die Sekundärliteratur zur Frage. Er zitiert in seinen Fußnoten auch einige spätere Texte, in denen eine klare Abgrenzung von Seiten der Humanisten gegenüber den einfachen Grammatiklehrern ausformuliert wird. Vgl. das erste Kapitel seiner Monographie: Black, Humanism and education, S. 12-33, besonders S. 31-32. 


\subsubsection{Zusammenfassung: Benedettos Haltung gegenüber dem Humanist-Sein}

Wenn man auch den Stil als einen Ausdruck von Benedettos Haltung gegenüber $\mathrm{Hu}-$ manismus und Humanist-Sein betrachtet, so konnte man feststellen, dass er sich auf dieser Ebene wahrscheinlich manchmal der Kritik derer ausgeliefert hatte, die im humanistischen Diskurs eine zentrale Position einnahmen. Die üppigen Zitate, manchmal durchaus fehl am Platz, mussten für einen Leser, der sich auf diesem Gebiet etwas sicherer bewegt hatte, manchmal einen komischen Effekt erzeugt haben.

Über seinen expliziten Rekurs auf als humanistisch geltende Themen kann auch festgestellt werden, dass an einigen Stellen eine gewisse Irritation und vielleicht sogar Benedettos Lächerlichwerden bei seinen Lesern nicht ausgeschlossen werden kann. Sein übermäßig häufiges Benutzen bestimmter Topoi (wie der Aufforderung zur Korrektur oder des Dichtens von Epitaphien) musste bei manchen seiner Leser ein ironisches Lächeln hervorrufen.

Benedettos Hinweise auf diese Praktiken beinhalten andererseits eine Zweideutigkeit. Er wollte sich nicht als eine zentrale Figur der humanistischen Gemeinschaft darstellen: dies wäre nicht nur nicht realistisch, sondern auch nicht klug von ihm gewesen. Er wusste, dass er riskiert hätte, sich lächerlich zu machen, wenn er etwas vorgegeben hätte, was mit der Wahrnehmung seiner Leser überhaupt nicht übereinstimmte. In der Zusammenstellung der Liste seiner Freunde zeigt sich z. B. gut die vorsichtige Haltung Benedettos. Er nennt dort mehrere Humanisten nicht, die er auch aus der Kurie gekannt haben sollte, man denke an Poggio Bracciolini oder Antonio Loschi. Wenn er sie nicht auf seine Liste setzte, so kann man davon ausgehen, dass er in seinem nuntius tatsächlich nur die Personen genannt hat, zu denen er eine freundschaftliche Beziehung hatte oder bei denen er wenigstens nicht Angst haben musste, von ihnen wegen der Bezeichnung als „Freunde” für lächerlich oder unverschämt gehalten zu werden.

\section{Benedetto nach dem Konzil}

Zum Schluß freue ich mich noch über Benedickt von Piglio mittheilen zu können, daß er sein Leiden glücklich überstanden hat, und bei Papst Martin V. Secretär geworden ist, wie er auch schon früher als Schreiber und Abbreviator bei Alexander V. am 25. Febr 1410 in Bologna erscheint. Das meldet uns Marini, Degli archiatri pontificii (Romae 1784), wie der Professor Bahlen mir freundlich nachwies. ${ }^{928}$

\footnotetext{
928 Dieser Nachtrag zu Wattenbachs früherem Artikel über Benedetto befindet sich in einer kurzen Notiz in: Zeitschrift für die Geschichte des Oberrheins, 23, 1871, S. 38.
} 
Mit diesen Worten korrigiert Wattenbach seine frühere Vermutung, Benedetto sei auf dem Konzil gestorben. Auf diesen Gedanken war der Wissenschaftler auf Grund von Benedettos Schweigen nach dem Konzil gekommen. Der Grund dieses Schweigens war aber keineswegs der Tod des Autors, sondern eine glückliche Wendung seiner Karriere. Im Gegensatz zu Poggio, dem das Konzil und der neue Papst zuerst einen Prestigeverlust bedeutet haben, wurde Benedetto bei dem neuen Papst als Sekretär eingestellt, seine Tätigkeit an der Kurie lässt sich bis zum Jahr 1423 bezeugen. ${ }^{929}$

Der Status eines apostolischen Sekretärs war hoch begehrt, er bedeutete nicht nur ein sicheres Einkommen, sondern auch die Möglichkeit eines weiteren Aufstiegs. Die übliche kuriale Karriere fing mit dem Posten des Schreibers an und konnte sogar zum höchsten Rang führen. ${ }^{930}$ Um einen der lukrativen Posten in der Kuria zu erhalten, brauchte der Kandidat die Unterstützung eines Patrons. ${ }^{931}$

Auf die Frage, welche Rolle das Humanist-Sein in einer kurialen Karriere gespielt haben konnte, antwortet Partner mit der Bemerkung, dass es zwar zur Verbesserung der eigenen Position beitragen konnte, das Bewandert-Sein in den lateinisch-griechischen Studien jedoch eher für „ornamental” als für nutzbringend gehalten wurde. ${ }^{932}$ Wenn man die letzten zwei Aussagen aufeinander bezieht (dass humanistische Studien eher eine ornamentale Rolle gespielt haben und dass man, um an eine Stelle herankommen zu können, einen Patron brauchte) und sie auf Benedettos Fall anzupassen versucht, so könnte man annehmen, dass seine Selbstdarstellung im Libellus hauptsächlich an seine möglichen Patrone gerichtet war. Es war für ihn weniger wichtig, seine eigentlichen Kompetenzen an und für sich zu beweisen, als möglichst viele Befürworter für sich zu gewinnen.

Diesem Zweck vor allem diente höchstwahrscheinlich sein Libellus. Benedetto stellte sich nicht nur unter Sigismunds Ägide dar, sondern schmeichelte im nuntius mehreren möglichen Befürwortern. Um nur drei Beispiele zu nennen: Floriano Sampieri war nicht einfach ein ehemaliger Rechtsprofessor Benedettos, sondern einer der den neuen Papst begrüßenden oratores der Stadt Bologna. Angelotto Foschi war nicht nur ein im fernen Rom weilender, angeblich guter Freund Benedettos, sondern ebenfalls anwesend auf dem Konzil. Als lateranensischer Domherr war er zudem auch ein Bekannter Benedettos, der Einfluss in der

929 Frenz kennt ein Breve vom Jahr 1423 von ihm: Frenz, Das Eindringen, Teil 2, S. 434.

930 Diesbezüglich vgl. die Statistiken, die von Partner auf der Basis von 22 kurialen Karrieren erstellt wurden. Peter Partner, The Pope's Men. The Papal civil Service in the Renaissance (Oxford: Clarendon Press, 1990), [im Weiteren: „The Pope's Men”], hier S. 47-81.

931 Partner, The Pope's Men, S. 150-182.

932 Partner, The Pope's Men, S. 89. Der Autor unterstützt seine Aussage leider mit keinen einschlägigen Beweisen. Es sei angemerkt, dass eine solche Aussage auch schwer positiv zu beweisen ist. Der Eindruck ergab sich wahrscheinlich aus Partners Untersuchungen der Karrieremuster. 
Kurie hatte. Bartolomeus da Montepulciano galt später als derjenige, dem der Papst am meisten Vertrauen schenkte. Wenn diese gute Beziehung zu Oddo di Colonna, dem zukünftigen Papst, bereits aus dieser Zeit datieren würde, so wäre er auch ein idealer Patron für Benedetto gewesen. Benedetto musste aber nicht nur schmeicheln, sondern sich auch als jemanden darstellen, der „dazu gehört”. Das Kreieren der humanistischen Lesergemeinschaft diente diesem Zweck. Die Tatsache, dass viele der von ihm im nuntius dargestellten „Dichter” nicht nur, um hier einen Bildbruch Benedettos aufzugreifen, aus dem Helikon geschöpft haben, sondern gleichzeitig in der Kurie gearbeitet haben, lässt Benedettos Dichter-Sein auch in einem anderen Licht erscheinen. Die Tatsache, dass er sich als Mitglied der von ihm kreierten Dichter- und Humanistengemeinschaft darstellt, kann als ein Hinweis verstanden werden, mit dem sich Benedetto einen Platz in einer Gruppe vindiziert, in der er nicht nur als „Dichter”, sondern auch als kurialer Amtsträger zu Hause war und zu Hause bleiben wollte. „Dichter-Sein” dient hier also als Ausdruck der Zugehörigkeit zu einer reellen, sich auf Grund von gemeinsamen beruflichen Kompetenzen und Interessen organisierenden Gruppe auf einer symbolischen Ebene. ${ }^{933}$

Vieles scheint im Libellus zu schweben. Nicht nur der Ton, sondern auch die Erzählperspektive, die Figur des Erzählers und die angestrebte Zuhörerschaft sind Aspekte dieses Textes, die keine scharfen Konturen bekommen. Wozu dieses Schweben, dieser unentschlossene Ton des Libellus? Als Benedetto nach seiner Gefangenschaft nach Konstanz zurückkehrte, wusste er nicht, bei wem er für sich eine Anstellung erhoffen könnte. Er wollte sich wahrscheinlich für möglichst viele potentielle Leser salonfähig machen. In seinem Libellus, in dem es manchmal auch zur persönlichen Kritik kommt, wollte sich Benedetto vielleicht der narrativen Verantwortung entziehen. Er kritisiert und klagt, aber er tut es in Anführungsstrichen, in den Anführungsstrichen der Vergangenheit oder in denen der Rede anderer Personen, in denen der Ironie und in denen eines geschwätzigen Froschbuches, das er angeblich nur seinem Bruder geschrieben hatte.

933 Man könnte die Botschaft des Libellus auch folgendermaßen zusammenfassen: wenn er schon mit den anderen gemeinsam die Blumen auf dem Helikon pflückt, warum dürfte er nicht auch in der Kurie deren Kollege bleiben? 


\section{Konklusion}

\section{Eine Vorbemerkung: Das Paradoxon des Humanismus}

Was die Unterscheidung humanistischer Strategien von den „nicht-humanistischen” besonders erschwert und sie sogar als eine fragwürdige Praktik ausweist, ist ein grundlegendes Paradoxon des Humanismus. Wenn man die Hypothese akzeptiert, dass die Betonung eines Bruches mit der alten Kultur, die Behauptung also, neu zu sein und das Alte zu ersetzen, ein wesentliches Merkmal dieser neuen Kultur ist, so wird eine Zwiespältigkeit des HumanistSeins sichtbar: Trotz des Anspruchs der Agenten der neuen Kultur auf Ausschließlichkeit, sollen die studia der Humanisten sich in deren Anwendung in das Alte integrieren. Deswegen ist Humanismus ungreifbar: sein eindeutigstes Merkmal, nämlich etwas komplett Neues darzustellen, wird in der Praxis vernichtet, weil dort genau diese Ausschließlichkeit verschwinden muss.

\section{1. Über die Personen}

Die Karrieren und Schicksale der Protagonisten dieser Geschichte zeigen verschiedene Muster. Poggio Bracciolini bekam im Rahmen der großen Umordnung von 1418 den Posten des apostolischen Sekretärs, auf den er so gehofft hatte, erst einmal nicht. Benedetto da Piglio dagegen, nachdem er ohne Brotherren geblieben ist und seine Suche eine Zeit lang offensichtich in Sigismunds Nähe fortsetzte, bekam genau eine solche Stelle, die von Poggio so heiß begehrt wurde. Pier Paolo Vergerio wiederum gelangte von der Kurie in Sigismunds Hof in Buda.

Die drei Personen nehmen auch im humanistischen Diskurs und im Diskurs über Humanismus unterschiedliche Positionen ein. Es ist Poggio, dessen Zugehörigkeit zur res publica litteraria am wenigsten hinterfragt wurde, sowohl von seinen Zeitgenossen als auch von der Forschung. Die Geschichte von Vergerios Beurteilung zeigt einen deutlichen Bruch. Nachdem er Sigismund nach Ungarn gefolgt war, war seine Zugehörigkeit zu den humanistischen Kreisen nicht mehr so eindeutig, in Italien wurde er sogar für tot gehalten. Benedetto, die dritte Figur, ist einer, der sich in den humanistischen Diskurs offensichtlich von außerhalb hineinzuschreiben versuchte. Dies wird nicht nur von der Tatsache gestützt, dass man bei seinen Zeitgenossen gar keine Erwähnung von ihm findet, sondern auch von seiner Strategie, sich darzustellen. Diese ist als zwiespältig zu beschreiben: Einerseits betont er seine Zugehörigkeit, andererseits behält er seine Außenseiterperspektive gewissermaßen bei. 
Die Kontextbezogenheit humanistischer Selbstdarstellungsstrategien konnte ich am markantesten durch die Beispiele von Vergerio und Benedetto exemplifizieren. Von beiden hört man recht wenig, nachdem sie eine stabile Anstellung gefunden haben. Beide wurden (Vergerio von seinen Zeitgenossen, Benedetto von Wattenbach) wegen ihrer mangelnden Aktivität vor ihrem Tod bereits für tot gehalten. Die eindeutige Zäsur in ihrer Textproduktion erweckt den Eindruck, dass sie es in einer festen Position nicht mehr für nötig gehalten hatten, sich als Humanisten darzustellen. ${ }^{934}$

Durch die Beispiele der untersuchten Texte konnte ich auch für das von Black betonte Merkmal des Humanismus, d. h. für seine universale Verwendbarkeit argumentieren. In Poggios Rede werden die Kirche zur patria und Zabarella, der Kardinal, zum pater patriae stilisiert. Auch Vergerios ganz andere Eigenschaften betonende, weil von anderen politischen Präferenzen motivierte Zabarella-Darstellung hat eine antike Folie: Ciceros De amicitia. Vergerios Widmung seiner Übersetzung der Alexander-Vita Arrians hatte Sigismund nicht nur zum Überflügeln von Alexanders Taten ermutigt, sondern ihn auch, was seinen Lesestoff betrifft, als einen humanistische Interessen hegenden Herrscher dargestellt. Auch Benedettos Libellus, in dem der Autor sich unter Sigismunds Aegide stellt, konnte mit als humanistisch gedachten Strategien operieren. Ob in kurialen oder imperialen Kontexten, antike Folien erscheinen stets wirksam verwendbar zu sein.

\section{Wer ist Humanist? Wahrnehmung und Zuschreibung}

In einer Konzilspredikt über die schlimmen Zustände der Kirche liest man Folgendes:

Quinto sunt hic plures Pharisaei, qui se occupant in scientiis, sed non divinis, sed Poetarum, Philosophorum, et maxime Juristarum, servitium Dei totaliter relinquentes. Sed notum vobis facio, quod in eorum oratoriis nihil fit sine pecuniis. Loquor de malis officiariis, auditoribus, judicibus, officialibus, advocatis, procuratoribus, notariis. In quibus est fons et lacus totius iniquitatis. Audivi enim noviter, hic unum notarium lucratum fuisse isto anno mille florenos. Consumunt enim pauperes, usque ad cerebrum. Haec vos clare videtis, sed nullum remedium apponitis. Sed qui potest capere, capiat. Haec non requirit justitia. Nec dubito, quin tales cum beato Hieronymo horribiliter reprehendantur, ac triplici peccato puniantur. Primo, quia sermo incultus in libris divinis non placet eis. Secundo, quia rectum finem non habent in talibus scientiis acquirendis. Tertio, quia non utuntur talibus scientiis in

934 In Vergerios Fall muss man diese Aussage selbstverständlich etwas modifizieren, seine Zeit in Buda verging nicht ganz ohne literarische Tätigkeiten. Er hat die Alexander-Vita Arrians übersetzt. Diese Übersetzung als einziger Text aus dieser Zeit ist aber immer noch recht wenig für die 26 Jahre, die er hier verbrachte. 
negotiis peragendis, sed de pane lucrando, istum vel istum decipiendo. Vos tamen clare videtis, quem fructum ipsi faciant. A fructibus eorum cognoscetis eos. ${ }^{935,936}$

Der Vorwurf gegen die poetae, philosophi und juristae ist deren gottlose und geldgierige Schönrederei. Diese zornigen Worte lesend, denkt man sofort an die Gruppe, die von Benedetto als sein Freundeskreis dargestellt wurde: Personen, die von Benedetto manchmal als poetae, manchmal als juristae bezeichnet werden, meistens aber sogar als beides, und die oft als Notare in der Kurie tätig waren. Die Perspektive im oben zitierten Text ist der Benedettos entgegengesetzt. Eine Ähnlichkeit gibt es allerdings zwischen den beiden Beschreibungen dieser Gruppe: die Juristen und die mit den Worten poetae und philosophi beschriebenen Personen sind in beiden Texten unter einen Hut genommen.

Wo sind Benedettos Freunde einzuordnen, über die er schreibt, dass sie sich zuerst der Dichtung widmeten, um sich später der Rechtswissenschaft zuzuwenden? ${ }^{937}$ Wenn man fragt, wie das von Benedetto aufgezeichnete Phänomen zu verstehen sei, so kann man vielleicht sagen, dass es sich ganz einfach um Studenten der Rechtswissenschaft handelt, die am Anfang des Studiums auch Rhetorik und Grammatik studieren mussten. Diese einleitenden Studien erscheinen in Benedettos Wahrnehmung als Studien, die um ihrer selbst willen wertvoll sind. Die von ihm suggerierte hohe Zahl der ehemaligen Dichter, die später Rechtsgelehrte geworden sind, muss keinen richtigen Aufschwung humanistischer Interessen bedeuten, wenigstens nicht in dem Sinne, dass Benedettos Freunde in der Tat sich auf einer bestimmten Stufe von ihrem Studium als Dichter verstanden hätten. Die Tatsache aber, dass Benedetto sie als solche darstellte, setzt ein verändertes Verständnis vom Status dieser Studien voraus.

In Benedettos Betrachtung sind seine Freunde als Humanisten oder wenigstens als humanistische Interessen hegende Gelehrte dargestellt. Benedetto geht mit dieser Zuschreibung ausgesprochen großzügig um. Im Libellus werden viele als Dichter und Gelehrte der antiken Literatur dargestellt, die bei den etablierten Humanisten nicht als solche anerkannt

935 Bernhardus Baptisatus Ordinis S. Benedicti de Gasconia, „In corruptum illo tempore clerum, in Constantiensi Concilio emendandum”, in Hardt, Magnum Concilium, Bd. 1, 877-893, hier Sp. 886.

936 Matthaeus 7. 16.

937 Es geht hier selbstverständlich nicht um eine sich unter dem Einfluss des Humanismus erneuernde Rechtswissenschaft. Auf die Frage, wie man den Einfluss des Humanismus auf die Jurisprudenz einschätzt, kann und soll hier nicht eingegangen werden. Selbst wenn man von einer solchen Erneuerung der Rechtswissenschaft ausgeht, würde dieses Phänomen mehr auf das 16. Jahrhundert zu datieren sein. Der Klassiker zur Frage ist Guido Kisch, der zahlreiche Studien dem Thema humanistischer Rechtswissenschaft gewidmet hat. Es seien hier nur zwei genannt, die auch zur allgemeineren Orientierung dienen können: Guido Kisch, Humanismus und Jurisprudenz. Der Kampf zwischen mos italicus und mos gallicus an der Universität Basel (Basel: Helbing \& Lichtenhahn, 1955), und von demselben Autor: Gestalten und Probleme aus Humanismus und Jurisprudenz (Berlin: Walter de Gruyter 1969). Für eine Betrachtung der Frage einer humanistischen Rechtwissenschaft, die statt den Bruch die Kontinuität zwischen mittelalterlicher und humanistischer Rechtswissenschaft betont vgl. Hans Erich Troje, Humanistische Jurisprudenz. Studien zur europäischen Rechtswissenschaft unter dem Einfluss des Humanismus (Goldbach: Keip Verlag, 1993). 
worden wären. Benedettos Perspektive ist die einer Randfigur oder sogar eines Außenseiters, der sich, unter anderem durch die Darstellung seiner Freunde als Humanisten oder der Humanisten als seine Freunde, in den Diskurs hineinzuschreiben versucht. Es ist dieses Außenseitersein, in dem man den Grund für das Verwischen der Grenzen zwischen Juristen und Humanisten in beiden Texten - in Benedettos Freundesliste, und im oben zitierten Ausfall - suchen muss. Für einen Außenseiter war die Abgrenzung dieser zwei Gruppen voneinander nicht eindeutig. Dies ist ein Beweis dafür, dass die Rhetorik des Bruches meistens von Seiten der Humanisten benutzt wurde und dass man einen tatsächlichen Bruch zwischen dem Alten und dem Neuen, bzw. eine eindeutige Abgrenzung zwischen Humanisten von Nicht-Humanisten von außerhalb nicht immer wahrgenommen hatte. Die Gründe bzw. Motivationen für die fehlende Wahrnehmung des Bruches von außen her sind natürlich unterschiedlich: Benedetto will sich der Gruppe annähern, deswegen ist eine großzügigere Interpretation der Grenzen seinerseits logisch. Der Autor der Rede über die schlimmen Umstände der Kirche wiederum ist an einer differenzierteren Analyse einfach nicht interessiert.

Die Perspektive derjenigen, die sich einen Ruf als Humanisten bereits gesichert haben, ist eine völlig andere und sie produziert dementsprechend eine entgegengesetzte Haltung. Diese Personen müssen ihre Position innerhalb des Feldes schützen, was einen sparsameren Umgang mit Bezeichnungen, die man mit Humanismus in Verbindung setzen könnte, verlangt. Um sich als eine über besondere Kompetenzen verfügende Gruppe verstehen und vermitteln zu können, müssen klare Grenzen gezogen werden, die die Außenseiter eindeutig von den Hinzugehörenden unterscheiden. Die Dynamik der Selbstdarstellung entsteht aus der Spannung zwischen der Selbstabgrenzung von den Außenseitern - wie im Fall von Brunis Umgang mit Bartolomeus da Montepulciano - und Gemeinschaftsbildung mit den „Sinnesgleichen”, wofür auf der synchronen Achse Zabarellas Darstellung als Humanist bei Poggio und Vergerio, und diachron gesehen, Vergerios Petrarca-Kult, aber auch die ganze Antikenschwärmerei der Humanisten als Beispiele genannt werden können.

Die Grenzen werden von jeder einzelnen Person anders gezogen, weil sie von persönlichen Interessen und Begebenheiten beeinflusst werden (hier kann man wieder auf die Kontextbezogenheit hinweisen). Die unterschiedlichen Einschätzungen von Montepulciano, der für Benedetto eine Autorität, für Bruni ein verachteter Möchtegern-Humanist war, ist ein gutes Beispiel dafür. Manchmal sind die Grenzen nicht ganz eindeutig. Vergerios Autorität als Humanist wird von der nächsten Generation nicht ganz hinterfragt, er wird nicht gänzlich 
kritisiert und sogar diese Kritik wird dadurch entschärft, dass die Latinität der kritisierten Übersetzung mit Sigismunds Unkultur erklärt wird.

Man könnte einen Vergleich zwischen den ständig wechselnden Zuschreibungen oder des In-Frage-Stellens von Humanist-Sein und dem Funktionsmechanismus der Etikette „Häretiker” riskieren, mit dem einzigen Unterschied, dass „Häretiker” immer nur als Negativum, also für die Bezeichnung der Feinde funktionieren kann, während die Etikettierung von jemandem als Humanist von beiden Seiten kommen kann. Meistens wird sie aber selbstverständlich von den Mitgliedern der Gruppe benutzt, weil die von den Humanisten behaupteten Trennlinien von ausserhalb nicht immer sichtbar oder interessant waren). Auf dem Konzil hat man mit beiden Arten der Zuschreibung operiert. Als Häretiker wurden nach Hus und den Hussiten mal Sigismunds Leute, mal die Mitglieder der Kardinalspartei abgestempelt. Für eine Zuschreibung als Humanist kann das Beispiel der Zabarella-Darstellungen genannt werden. Vergerio wiederum, nach seinem Engagement für Sigismund, empfindet, wie es aus seinem Brief an seinen in Italien verweilenden Freund hervorging, dass es nötig ist, seinen Status als Mitglied der humanistischen Gemeinschaft zu betonen, was eventuell darauf schließen lässt, dass er seinen Ruf als Humanist gefährdet sah.

\section{Wie wurde die Rhetorik des Bruches vermittelt?}

\subsection{Prosopopoeia}

Um den Bruch zwischen dem Neuen und dem Alten eindeutig zu machen, muss sich der Humanist nicht nur als Wiederentdecker der antiken Kultur zeigen. Das würde für eine Abgrenzung von den vorherigen Generationen nicht ausreichen. Er muss sich als den einzig berechtigten Hüter einer Erbschaft darstellen, er muss manchmal sogar die Toten erwecken, muss mit deren Stimme sprechen. In die Rhetorik übersetzt, heißt diese Geste die Anwendung der Figur der Prosopopoeia, einer Figur, die in den Analysen oft zum zentralen Begriff wurde. Es ist diese Figur, mit der man die Haltung der Humanisten gegenüber der Antike generell modellieren kann. Nicht nur die konkreten Beispiele können hier erwähnt werden (man zitiert nicht Cicero, man schreibt in seinem Namen eine Antwort an Petrarca, oder man verwandelt sich durch eine doppelte Verwandlung in den Reden haltenden Cicero). Auch die Geste, genau die Sprache zu schreiben und zu sprechen, die in den antiken Schriften tradiert wurde, ruft eine prosopopoetische Situation hervor: man setzt eine Maske auf und redet oder schreibt eine Sprache einer längst „gestorbenen” Kultur. 


\subsection{Diskurs der Dichterkrönung: Ein Schlüsseldiskurs am Anfang des 15. Jahrhun- derts?}

Die oben angesprochene fehlende Trennung zwischen Humanisten und Nicht-Humanisten von Seiten der Außenseiter ist wahrscheinlich ein zeittypisches Phänomen. Eine vergleichende Untersuchung zwischen den Zuschreibungsmechanismen am Anfang des 15. Jahrhunderts und jener späterer Jahrzehnte würde wahrscheinlich die Tendenz zeigen, dass der von den Humanisten immer wieder suggerierte Bruch auch von Außenseitern öfter wahrgenommen wurde. In diesem Vorgang spielt der Titel des gekrönten Dichters vermutlich eine erhebliche Rolle, den man, in Anlehnung an Schirrmeisters Untersuchungen, wenn nicht unbedingt als identitätsstiftende Instanz, so doch wenigstens als einen der wichtigen humanistischen Diskurse sehen dürfte. Wie steht es mit diesem Titel in der von mir untersuchten Zeitspanne? Die Spuren des Diskurses über den poeta laureatus konnten in den untersuchten Texten rekonstruiert werden. Als einen Unterschied zu Schirrmeisters Untersuchungsgegenstand muss man aber über den Titel des poeta laureatus zu dieser Zeit feststellen, dass er, wegen des geringen Ausmaßes in dem er verwendet wurde ${ }^{938}$, eine viel labilere Legitimierungsinstanz war, als in der von Schirrmeister untersuchten Zeitspanne. Die Seltenheit dieses Titels ist nicht nur der niedrigen Zahl der Krönungen zu verdanken, sondern auch dem seltenen Benutzen des Titels durch dessen Träger. Wenn man sich kurz erlaubt, mit Bourdieuschen Konzepten zu argumentieren, so kann man behaupten, dass die meisten sogenannten Humanisten des frühen 15. Jahrhunderts eher dem Autodidakten nahestanden (nicht im Sinne eines Qualitätsurteils, sondern im Bourdieuschen Sinne), der den Wert seines Kulturkapitals ständig neu beweisen muss. Der Titel des poeta laureatus funktionierte zu dieser Zeit nämlich noch keinesfalls als ein schulisch sanktionierender, rechtlich garantierender Titel. ${ }^{939}$

Zwei von den drei hier ausführlicher erörterten Figuren (Vergerio und Benedetto) wurden auf dem Konzil zu Dichtern gekrönt. ${ }^{940}$ Weil über eine Zeremonie der Krönung nichts überliefert wurde und weil es bei Sigismunds Krönungen immer der Fall gewesen zu sein

\footnotetext{
938 Es gibt Hinweise, so weit es mir bekannt ist, über folgende Dichterkrönungen von Seiten Sigismunds: Benedetto da Piglio (vgl. dazu das einleitende Unterkapitel III. 1.1. „Allgemeines”), Pier Paolo Vergerio (vgl. das Unterkapitel II. 3.2.3. „Der utriusque iuris ac medicine doctor und gekrönte Dichter”), Tommaso Cambiatore (vgl. den Artikel im DBI: Guglielmo Gorni, „Tommaso Cambiatore”, in DBI, Bd. 16, 132-133, hier S. 132.); Antonio Beccadelli (vgl. Altmann, RI, Bd. 11/2, S. 213-214, 9129 und S. 219, 9208, für sein Dichterkrönungsdiplom vgl. Anm. 391 dieser Arbeit) und Ugolino Pisano (vgl. Anm. 639 dieser Arbeit).

939 Bourdieus Worte über das kulturelle Kapital des Autodidakten von Schirrmeister, Triumph, S. 12.

940 John L. Flood erwähnt diese zwei Krönungen nicht. In seinem voluminösen Werk über die gekrönten Dichter des Heiligen Römischen Reiches behauptet er, dass Beccadellis Krönung 1432 die erste kaiserliche Dichterkrönung seit Zanobi da Stradas Krönung 1355 war. Vgl. John L. Flood, Poets Laureate in the Holy Roman Empire, 4 Bde. (Berlin, New York: Walter de Gruyter, 2006), hier Bd. 1, S. 145.
} 
scheint $^{941}$, kann man vielleicht davon ausgehen, dass es um rein bürokratische Angelegenheiten ging, dass also Sigismund keinen besonderen Wert darauf legte, die Krönungen als solche zu inszenieren. Diese ,rasche Entwertung des von den Humanisten so hoch besungenen Lorbeerkranzes" 942 bedeutet trotzdem nicht, dass der Titel ohne jegliche Bedeutung war. Die Tatsache, dass der Titel überhaupt überliefert worden ist, bedeutet, dass er in der zeitgenössischen Wahrnehmung nicht ganz unbemerkt geblieben ist. Sigismunds Passivität, was die Zeremonie der Krönung betrifft, erweckt den Eindruck, dass die Initiative womöglich sogar von den zu krönenden Gelehrten ausging und dass Sigismund für diese eher als Projektionsfläche fungierte.

\section{Humanismus: Reines Kalkül?}

Mein Akzent auf den Selbstdarstellungsstrategien der Humanisten scheint auf den ersten Blick vielleicht ein Verständnis von Humanismus zu implizieren, das diesen zu einem auf bewusstem Kalkül beruhenden Geschäft reduziert. Mir ist durchaus bewusst, dass eine solche Reduktion dem Gegenstand meiner Arbeit, dem Humanismus, nicht gerecht würde. Meine Beispiele erwecken wahrscheinlich trotzdem in manchen Fällen den Eindruck, dass die Wahl des Habitus meiner Protagonisten, also ihre Wahl, sich als Humanisten zu profilieren, ausschließlich mit Kalkül zu begründen wäre. Auf jeden Fall zu beachten ist die Tatsache, dass meine Fallbeispiele aus einem - was den Neuorientierungszwang der Akteure betrifft zugespitzten Kontext stammen. Die persönliche Präferenz und Entscheidung für den Habitus, den ein Humanist für sich wählte, war aber bestimmt nicht nur und nicht bei jedem eine Frage der Strategie. Eine hundertprozentige Kalküllosigkeit ist aber im Fall der Humanisten Anfang des 15. Jahrhunderts nur schwer vorstellbar. Unschuld ist laut Bourdieus geistreicher Formulierung ,das Privileg derer, die in ihrem Bereich wie Fisch im Wasser sind”. ${ }^{943} \mathrm{Da}$ Humanist-Sein in der von mir untersuchten Zeitspanne einen Habitus darstellte, dessen Konturen noch nicht ganz festgelegt waren, also Humanismus Anfang des 15. Jahrhunderts etwas Neues darstellte, kann man schwierig über Akteure sprechen, für die diese neue Kultur eine Selbstverständlichkeit bedeutete.

\footnotetext{
941 Voigt, Die Wiederbelebung, Bd. 2, S. 278.

942 Karl Schottenloher, „Kaiserliche Dichterkrönungen im Heiligen Römischen Reiche deutscher Nation”, in Papsttum und Kaisertum. Forschungen zur politischen Geschichte und Geisteskultur des Mittelalters, hrsg. v. Albert Brackmann (München: Verlag der Münchner Drucke, 1926), 648-673, hier S. 650.

943 Bourdieu, Kapital, S. 195.
} 


\section{Stat Roma pristina nomine?}

Meine Überlegungen mögen an manchen Stellen auch den Eindruck erwecken, als ob „gutes" Latein und Stilsicherheit und allgemein die Bewandertheit in der antiken Literatur überhaupt keine Rolle in den Zuschreibungen gespielt hätten und alles nur von Interessen gesteuert gewesen wäre. So war es gewiss nicht. Die Zuschreibungsmechanismen könnte man am besten in ihrer Mehrdimensionalität beschreiben. Ähnlich wie die von Girgensohn beschriebenen Kriterien, nach denen jemand zum Kardinal gewählt wurde, kann man sich die Kriterien für die Zuschreibungen des Humanisten-Seins vorstellen. Lateinkenntnisse und Bewandertsein in der antiken Literatur gehörten selbstverständlich zu den sine qua non-Voraussetzungen, die man erfüllen musste, um als „Humanist“ gesehen zu werden. Wenn man etwas zynisch ist, könnte man behaupten, dass diese Kenntnisse wenigstens deswegen wichtig waren, weil sonst die betroffene Person keinen Anlass zur Stilisierung hätte bieten können. Eine solche Sichtweise drängt sich auf, wenn man an Poggios in dieser Arbeit zitierten Brief denkt, in dem er bedauert, dass er statt für Zabarella nicht eher für Chrysoloras eine Totenrede halten durfte: er hätte mehr Anlass zum Loben gehabt. „Uberior enim dabatur in laudibus suis vagandi campus." Der Mensch wird in diesem Fall zu einem Schnittpunkt der in einer humanistischen Rede applizierbaren Topoi, zu einem Feld (campus), auf dem der Redner im Kampf für Ruhm seine Fähigkeiten als Orator am besten glänzen lassen kann. Andererseits müssen diese in den Topoi dargestellten Eigenschaften im Gegenstand des Lobes offensichtlich trotzdem auch in der Wirklichkeit vorhanden sein, sonst würde es keinen Unterschied machen, über wen der Orator seine Rede hält.

$\mathrm{Ob}$ man diese Situation so beschreibt, dass das tatsächliche Vorhandensein, also das Leben oder mit anderen Worten, die Geschichte, an sich das Wesentliche ist, um das es geht, und dessen rhetorisierte Form nur etwas Sekundäres, oder umgekehrt von einer Situation ausgeht, in der man nur die rhetorisierte, erzählte Form als Sicheres in der Hand hat und das Dahinter im Wesentlichen immer ununtersuchbar bleibt, gehört zu den Fragen, die wahrscheinlich nie entschieden werden. 


\section{Anhang 1: Die meist benutzten Tropen in Poggios narratio}

(Die Seitenzahlen beziehen sich auf die in der Dissertation benutzte Ausgabe des Textes. Ich verwende der Einfachheit halber die in Lausberg ${ }^{944}$ erhaltenen Benennungen der Tropen.)

Adiunctio: Nemo enim liberius in hoc consilio locutus est unquam, nemo fidentius. (255), qui et celeriter res animo comprehendere, et faciliter posset concilio explicare (255)

Allocutio: Quare vobis peto patres conscripti, ut cum pauca de ipsius vita et moribus pro ut tempus fert dixero, me de virtutibus suis dicentem benigne sicut coepistis, attenteque audiatis.(252) Nam sic habetote P. C. certum esse atque exploratum (257) Attendite nunc, ad eam quaeso. (259)

Anaphora: „Non enim postulantibus amicis, non patriae quaerenti, non imaginibus maiorum" (254) quae cohortationes suae fuerunt, quae preces, quae monitiones (gleichzeitig auch adiunctio) (255) Audistis... Audistis (256); Nulla quidem societas hominum, nulla coniunctio, nulla civitas constare posset (256) Legum magistri magistratus, legum interpretes iudices, legum denique omnes servi sumus, (257)

Annominatio: precibus aut precio (254)

Antitheton: Legum denique omnes servi sumus, ut liberi esse possimus (257). Solent hi sublimes honores...inflare homines... At vero Franciscus noster longe abfuit ab istorum perversitate. (254) non in fastu, non in pompa (254)

Asyndeton: „precibus, divitiis, ambitione” (254); (gleichzeitig auch homoeoptoton), „integritas, continentia, gravitas” (253); „quos fovebat, erudiebat, enutriebat” (253) (gleichzeitig auch homoeoteleuton).

Chiasmus: Audiebat benigne omnes, comiter respondebat. (253) Cibi fuit parcissimus, et modici somni. (gleichzeitig auch adiunctio) (253), tum verborum copia, tum gravitate sententiarum (256) (gleichzeitig auch anaphora)

Gradatio: Nihil praeclarius excogitare potuit vir sapinetissimus, nihil divinius (256) gleichzeitig auch anaphora und adiunctio)

944 Heinrich Lausberg, Handbuch der literarischen Rhetorik (Stuttgart: Steiner, 1990). 
Interrogatio: Quis enim in exquirendis consiliis acutior fuit, solertior in capiendis? (gleichzeitig auch adiunctio und chiasmus) (257) Quid loquar de liberalitate eius ac beneficentia? (258)

Metaphora (gleichzeitig auch comparatio): Audistis non orationem, sed quasi fluvium quendam redundantem (256)

Metonymia: qui aures in ea re satis habent eruditas (256) radices schismatum (255) potissimam partem exoptatissimae unionis, quam manibus ipsis iam tenemus (255) haec tam ampla iecisset fundamenta (255)

Percursio: indagavit, cognovit, praecepit (256)

Personificatio: fata interceperunt (255)

Polysyndeton: Mens et animus, et consilium et sententia civitatis (257)

Reticentia: [...] quamobrem pertransibo ea quae ad singulas spectant, et cum alio festinet animus, ea solum percurram quae pertinent ad publicam causam. (255) quos honoris causa taceo (258)

Similitudo: Ut corpora nostra sine mente, sic civitas sine lege suis partibus, ut nervis et sanguine et membris uti non potest (gleichzeitig auch polysyndeton) (257); Imitatus agros fertiles, qui plus semper reddunt quam acceperunt. (258); ex ipsius schola veluti ex uberrimo fonte sapientiae (253); ut omnium videretur quasi communis parens (253), non secus ac boni frugique parentes solent (253)

Superlatio: et sapientia et prudentia fuit tanta, quanta huius seculi nemo fere alter (256) Concurrebant ad eum undique ex toto fere terrarum orbe (253) ex eius ore melle dulcior (sicut de Nestore inquit Homerus) fluere videretur oratio. (253)

Synonymia: Immortalem sibi gloriam et sempiternum nomen paratum (256) 


\section{Anhang 2: Vergerios und Facios Übersetzung der Praefatio, und der ,zweiten Praefatio" der Alexander-Vita Arrians ${ }^{945}$}

\section{Vergerios Übersetzung}

(Paris Bibl Nat, Nouv. Acq. Lat. 1302)

\section{Praefatio}

(2r) Quaecunque quidem Ptolemeus Lagi et Aristobolus Aristoboli eadem ambo de Alexandro Philippi conscripserunt, illa ego tanquam prorsus vera describo, in quibus vero non convenient, ex illis ea, quae visa sunt mihi probabiliora ac digniora narratu scribenda mihi, elegi. Alii quidem alia de Alexandro iam ante scripserunt, nec est, de quo plures, aut magis invicem discordantes scripserint, sed mihi Ptolemeus et Aristobulus fide digniores visi sunt in narratione. Aristobolus quidem, quia militavit cum rege Alexandro. Ptolemeus autem praeter id, quod cum eo militavit, insuper etiam, quoniam fuit rex, cui turpius erat mentiri, quam alteri. Ambo autem, quia defuncto iam Alexandro conscripserunt, quando ipsis neque necessitas, neque merces erat, ut aliter, quam sicut contigerat, scriberent. Sunt autem aliqua etiam ab aliis conscripta, quae quando visa sunt mihi digna narratione et non penitus sine fide, illa sola tanquam dicta de Alexandro, non tanquam vera conscripsi. Siquis autem mirabitur, quam ob rem post tot scriptores mihi quoque in mentem venerit ista conscriptio, ille postquam omnia illorum scripta relegerit, ad nostra haec veniens, tunc miretur.

\section{Die ,zweite Praefatio"}

(11r) Dicunt etiam aliqui, quod ipse Achillis sepulchrum (,nominavit” expungiert) coronavit, felicemque in hoc eum dixit, quod in memoriam apud posteros Homerum preconem habuerit. Et sane erat Alexandro non minime propter hoc beatificandus Achilles, quam sibi locus iste respectu residue felicitatis defectuose contigit, neque enim Alexandri opera iuxta dignitatem eorum sunt in vulgus edita, neque metro, neque soluta oratione, nec in musicis cantatur Alexander, sicut Hieron et Gelon et Theton ac multi alii, in nullo similes Alexandro. Itaque multo minus cognoscuntur Alexandri opera, quam vilia gestarum antiquorum nam et ascensus (11v) illorum decem milium cum Cyro ad regem Artaxersem, et

945 Ich lege die Texte (Anhang 2 und 3) nach folgenden Editionsprinzipien dar: die Schriftweise (zum Beispiel der Diphthonge ae und oe, oder die Verwechslung $\mathrm{c}$ für $\mathrm{t}$ ) habe ich in der Form beibehalten, wie ich sie in den Handschriften gefunden habe. Um eine bessere Lesbarkeit der Texte zu erreichen verwende ich Großund Kleinschreibung nach den modernen Regeln, und ich verwende die moderne Interpunktion. 
infortunia Clearchi eorumque, qui cum ipso captivi fuerunt. Ac descensus illorum ipsorum decem milium, quos Xenophon reduxit, multo clariores sunt apud homines, primus Xenophontis causa, quam Alexander, aut Alexandri opera. Atqui Alexander non militavit sub alio, neque fugiens magnum regem eos vicit, qui impedimentum praestabant descensu versus mare, sed nec est aliquis alius unus homo, qui tot, aut talia opera multitudine vel magnitudine in Graecis aut barbaris, quemadmodum Alexander (hinc: exp) effecerit. Hinc et ego motum esse me dico in hanc conscriptionem faciendam, non indignum me existimans manifesta facere apud homines opera Alexandri. Quis autem sim, qui talia de me sentio, non indigeo nomen praescribere, non enim ignotum est inter homines, neque, quae est mihi patria, aut genus meum, neque, si quem magistratum in patria mea gessi. Sed illud praescribo, quod mihi et patria est et genus ac magistratus, facultas autem sermonis et est, et usque a iuventute fuit. Et propter hoc non indignum me iudico esse inter primos, qui Graeca oratione valuerunt, si quidem et Alexander est primus inter eos, qui armis excelluerunt.

\section{Facios Übersetzung}

(Vatikanstadt, BAV Cod Vat. Lat. 5268)

\section{Praefatio}

(3r) Ex omnibus Alexandri rerum scriptoribus, quae Ptolemeus Lagi et Aristobolus Aristoboli de rege ipso consentientes memoriae prodiderunt, utpote verissima litteris mandavi. In quibus vero eos discrepare animadverti: ex iis delegi, quae probabiliora ac narratu digniora existimavi. Alii autem de Ale (3v) xandro alia scripsere. Nec vero quisque est, de quo aut plures, aut minus inter se consentientes scripserint. Ceterum ii duo in ipsis rebus enarrandis mihi ceteris probabiliores visi sunt. Aristobolus, quoniam regiae expeditionis socius fuit, Ptolemeus, quoniam praeter quam, quod et ipse regem eo bello secutus est, regiam dignitatem tenuit: cuius rei gratia longe turpius illi futurum fuerat, si a veritate discessisset. Uterque vero quoniam mortuo iam Alexandro ea scripserunt, quandoquidem neque necesitudine, neque mercede ulla adducti videntur, ut haec aliter atque contigerunt litteris mandarent. Quaedam praeterea et ab aliis scripta, quae ipse narratu digna iudicavi, tanquam non penitus improbabilia, sed quod de Alexandro tradita sunt adieci. Siquis vero fortasse miretur, cur post tam multos Alexandri rerum scriptores ego quoque res eius scribere aggressus sim, is rursus perlectis omnibus postquam haec (4r) nostra legerit, sibi admirationis causam non fuisse intelliget. 


\section{Die ,zweite Praefatio"}

(20r) Fertur quoque Achillis sepulchrum coronasse: et ob id felicem dixisse, quod Homerum rerum suarum preconem nactus esset. Fuit haud dubie Alexandro non parum fortunatus Achilles ob eam rem existimandus, namque haec una pars tanto regi ad cumulum felicitatis videtur defuisse. Neque enim eius res gestae aut carmine, aut soluta oratione pro dignitate litteris prodite sunt. (20v) Neque musicis decantatur Alexander, quemadmodum Hieron et Gelon, Theton et alii plerisque rebus gestis et gloria haudquam pares, ita est factum, ut nobis minus notae sunt Alexandri res magnae atque praeclarae, quam multorum veterum infimae exiguaeque. Nam et illorum decem milium cum Cyro adversus Artaxerxem expeditio et Clearchi ac sociorum captivitas eorum denique decem milium Xenophonte duce in maritinam oram Tedicum haud dubie Xenophontis scriptis longe illustriores facti, quam aut ipse Alexander, aut res ab eo gestae. At quamvis neque alieno ductu militaverit, neque Persarum Regem fugiens vicerit, qui obstabant quominus in maritinam regionem descenderet, tamen alius nemo mortalium est, sive Graecus sive barbarus, vel multitudine rerum gestarum, vel magnitudine conferendus. Qua primum causa adductus sum, ut eius res licet a pluribus scriptas scirem, et ipse (21r) litteris mandarem, haud indignum me arbitratus, qui res ab eo gestas conscriberem. At ipse sim, qui ita de me sentiam, nomen profiteri non oportere existimo, neque enim obscurum est, neque item patria, neque genus meum, uti arbitror, neque item, quos honores in civitate mea adeptus sim. Illud dixisse satis fuerit, mihi patriam, familiam, magistratus ac bonas artes esse, et a puero semper fuisse. Qua ut re non indignus fortasse, qui inter primos Graecae linguae autores enumerer, non secus atque Alexander inter eos, qui in re militari praestiterunt. 


\section{Anhang 3: Der Text von Benedettos declamatio}

(Wien, ÖNB, CVP 3529 237r-239r)

(237r) Hactenus, viri optimi, cum latino utens eloquio debuissem pleno ac pro mea ingenii modulo sublimi dicendi genere scribere, stilo brevi ac infimo profane et metrice vobis scribens verbis communibus rudibusque pro tempore usus sum. Interdum enim, ut ait Cassiodorus in prologo Variorum: "Genus peritie est vitare, quod placeat doctis"946. Nunc autem soluta suavique ac, quantum michi datur, ponderosa oratione quadam, quasi de clamatorio more vos alloquor. Quod utique genus dicendi magis ac magis solet placere peritis. Et exordiar ab apologo. ${ }^{947}$

Equus quondam et lupus inter se societatem contraxerant; fide bona data atque accepto pacto legem iuramento firmaverant sese invicem socios et amicos esse. Mansit hec diu societas incorrupta. Lapsu temporis lupus nocte cibum querens suo more intravit ovile, fortuitu pinguem ac magnum ceperat agnum. Retiaque sepesque, quibus oves nocte clauduntur $(237 \mathrm{v})$, pondere gravatis faucibus saltu transire non potuit. Grex territus magno strepitu facto ad latus inimico vacuum se condensavit. Canis quidam naribus sagax lupum sentiit, latratu socios excitat. Opilio tugurium exit. Canes omnes in lupum suo clamore hortatur, instigat, provocat. Hac audacia unus ex canibus lupum mordet in collo, deinde cetera canum turba quisque pro viribus, hic limbum, ille costam, hic coxam sinistram, ille dextram capientes raptorem laniant. Raptor nunc in hunc, nunc in illum frendens nunc hunc, nunc illum perstringens suo forti dente defensus evasit. Rediens iuxta socium in lustro recubuit. Incipit lingua vulnera lingere. Sic diebus aliquot iacens putrescentibus iam vulneribus, nervis ac ossibus suas operationes ammittentibus adeo actenuatus ac debilitatus est, ut non solum non ire raptum, sed vix in lustro poterat se movere siti ac fame perditus. Socium videns pinguem, pulcrum, securum prope cubantem, ipsum momordit in coxa. Equus somno gravis vix debilem morsum sensit. Sed notato vulnere (238r) caput erexit, vidensque socium contra bonum et equum facientem. "Quid est hec fides?" inquit. "Mentem etiam egram habes? Ubi sotietas, ubi fides, ubi pactum, ubi lex, ubi iuramentum? Hec omnia uno momento fregisti!" Lupus avulso sanguinolento dente suam causam defendens ait: "Socie, necessitas non habet legem. Plus ipsa potest ad impellendum, ut aliquid fiat, quam lex ad prohibendum, ne fiat. Magna et imperiosa domina est, non est sub lege. Preterea, quod tam pinguis, tam nitidus, tam securus es, meum est donum, pascis enim hoc pratum, bibis hunc fontem, vigilas, dormis

\footnotetext{
946 Cassiod. var. praef. 15.

947 Vgl.: Rhet. Her. 1, 6, 10: Si defessi erunt audiendo, exordiemur ab apologo.
} 
tutus mea tutela. Lupi, ursi ceteraque ferarum genera meas fugiunt fauces. Patere ergo me leviter te mordere calidumque cruorem ex morsu manantem sugere, ut sic aliquot diebus recollectis paulatim viribus artem meam rursus invadam, manente inter nos eadem, que diu fuit bona societas. Denique accedit ad causam meam, quod tu, si in aliquo diminutus fueris, non habeas longius ire; fons, herba, omnia, quibus vita nutritur ac servatur tua, vicina sunt $(238 v)$, satieberis facile."

Talibus multisque aliis verbis ultro citroque habitis fabula valde longior fuit, quod ut hic comprehendi possit. Ac ex ea pulcra et utilis solet emanare moralitas. Sed tempus breve meique corporis egritudo me in ea ulterius morari non sinunt. Quinetiam multa in hac fabula contenta michi promittere impertinentia censeo. Solam illam clausulam capio, que pro mee intentionis fundamento satis michi sufficere puto: Lupus dixit: "necessitas non habet legem". Proposueram, ut per alias meas litteras aures vestras amplius meis indigestis clamoribus non obtundere. Sed neccessitas me in contrarium rapit. Sentio enim me de die in diem paulatim deficere atque siccari, tanquam lignum, quod abscisum est ab arbore sua. Nam, ut preclarum est, ego a communibus michi donis divisus et amarus sum. Aer, quo cuncta super terram viventia foventur et conservantur, inesse michi in hac tenebrosa cavea denegatus est. Careo hominum conversationem, que miseros satis ac satis consolari solet. Ait sapiens: "Ve soli, qui non habet relevantem!" ${ }^{948}$ Sulmonensis Ovidius, inter illustres poetas maximus, cum in Ponto insula, a qua Pylatus agnominatur Pontius, relegatus esset, inter cetera (239r), que illic patiebatur incommoda, non minimum putavit se sociis amicisque carere. Quamobrem in libro de tristibus inquit: Non qui soletur, nec qui labentia tarde tempora narrando fallat amicus adest." ${ }^{949}$ Hic etiam ad mea mala cumulus accedit, quod exercitio corporis privatus sum, brevi enim cohortatus limite corpus meum movere non possum. Quas autem utilitates consequantur, Franciscus de Sarzana in suo Florifrondio super Cathone breviter enumerat dicens exercitium corporis membra consolidans: superfluum digerit humidum, calorem naturalem mirabiliter refocillans. Lacus hic vester tam amenus, tam clarus si aerem non videret, si a ventis non commoveretur, si semper in se novas confluentes non admitteret, aquas brevi tempore putrescet, malas pestilentesque nebulas exhalaret. Hec omnia clare novit prenominatus Ovidius cum in libro de pontho dixit: "Cernis, ut ignavum corrumpant otia corpus / ut capiant vitium ni moveantur aque." ${ }^{950}$ Philosophus in ethicis superfluitatem ac diminutionem exercitii vitandam censuit, cum dicebat: superflua exertitia aut diminuta formam sanitatis corrumpunt. Moralis Seneca notans scripsit: "Hec duo miscenda sunt: et agenti quiescendum est, et

\footnotetext{
948 Pred. 4, 10.

949 Ov. trist. 3, 3, 10.

950 Ov. Pont. $1,5,5$.
} 
quiescenti agendum." 951 Et in declamationibus ait "otium sensualitatis mors est ac vivi hominis sepultura". Hoc sensit, qui nichil ignoravit, Ieronimus dicens: corporis virtus exertitatione augetur et inexercitata minuitur. Plurimi enim exercitii dissuetudines etiam naturalem corrumpere virtutem. Ex hac auctoritate colligitur, quod non dumtaxat accidentalia, sed etiam que a natura nobis insunt, amittimus, nisi ab exercitio conserventur. Si quis enim naturaliter velox aut fortis vel sanus existat, si corpus non exercit, in tardum debilem et infirmum convertitur. Igitur in me, qui aere, qui hominum conversatione, qui exertitio careo, corporalis corrupta est salus et gravius reor mentis integritas diminuita. Iam in me video, quod beatus Hiob in se accidisse conquestus est. "Pelli mee consumptis carnibus adhesit os meum" 952 , enim vero caro, que media erat inter pellem ac ossa mea, ut unicuique vestrum patere possit, consumpta est, quod est signum magis mortis, quam vite. Que omnia etiam sociis meis attingere non ambigo.

Talia, viri optimi, sinunt, qui me contra propositum venire suadent. Urgente namque necessitate rupi silentium et aures vestras (240r) meis verbis quantum potui honestis iterum iterumque pulsavi. Eya ergo, viri prudentes, audite gemitus infirmorum, non avertatis aures a clamoribus supplicum pauperum. Ex ista enim pena, quam patimur, ex egritudine aut morte, quod absit, nostra magnifico domino comiti novicastri boni nichil accrescit. Agite itaque, porrigite vestras orationes ac preces ad deum dominum, ut socios meos et me innocentes liberet ab his malis, succurrite, dum est tempus, succurrite miseris, ut in necessitatibus vestris ille vobis succurrat, qui in secula seculorum eternus cum patre et spiritu sancto vivit et regnat. Amen.

\footnotetext{
951 Sen. epist. 3,6.
}

952 Iob 19, 20 


\section{Anhang 4: Die biographischen Personen der Lesergemeinschaft Benedettos}

Um ein klareres Bild davon zu bekommen, welche Personen Benedetto als seine Freunde darstellt, soll hier eine Liste folgen, mit den Namen derer, die der Libellus aufzusuchen hatte. Leider war die Identifikation der Freunde nur in wenigen Fällen möglich. ${ }^{953}$ Wenn die konkrete Person nicht identifizierbar ist, so wird wenigstens die Identifikation der Familie versucht. Die Identifikation der Personen erfolgt nach der Reihenfolge der Städte, wie sie Benedetto im Libellus angibt.

\section{Bononia}

\section{Johannes de Loddovicis}

Johannes de Loddovicis ist der erste, den das Büchlein in Bologna grüßen soll. Bei Wattenbach wird er als Mäzen Benedettos genannt, was sich wahrscheinlich auf Benedettos Worte stützt:

Hic ego per multos uno cum cive moratus Annos, sum servus tempus in omne suus. Milite ab egregio natum hunc populusque Johannem

Appellat mitem pauperibusque pium.

De Loddovicis hic est cognomine dictus,

Virtutum numeris solus in urbe nitet.

Nobilis et carus vir semper largus amicis,

Mente domo recipit quemlibet ipse sua. ${ }^{954}$

Benedetto erwähnt auch seine literarischen Interessen:

Sepe solet cupidis musas audire canentes

Auribus in silva, Naso poeta, tua,

Quin etiam tragicos solitus percurrere campos,

Militat in castris maxime sepe tuis. ${ }^{95}$

953 Wattenbach hielt es für wichtig, in seinem Artikel alle die von Benedetto aufgelisteten Namen zu erwähnen. Ich habe versucht, ohne den Anspruch einer prosopographischen Bearbeitung des Stoffes, mehr von ihnen zu identifizieren, als es Wattenbach möglich war. Ich habe auch bei den Personen, die Wattenbach identifiziert hatte, nach weiteren Angaben gesucht, allerdings ohne die Verwendung der lokalen Spezialliteratur, einfach um herauszufinden, ob sie nicht auf der Kurie als scriptores oder secretarii eingestellt waren und demzufolge vielleicht ebenfalls auf dem Konzil von Konstanz erschienen. In manchen Fällen bestätigte sich mein Verdacht. Wenn ich keinen weiteren Hinweis auf die jeweilige Person finden konnte, habe ich wenigstens Benedettos Beschreibung der Person zitiert. 
Benedettos Beschreibung lässt vermuten, dass er Loddovicis gut kannte, er scheint nicht daran zu zweifeln, dass der Libellus von ihm mit Interesse gelesen werden wird, und dass die dort beschriebenen Ereignisse sein Mitleid erregen werden:

Hunc adeas, postquam magnas transiveris Alpes,

Et secum maneas, ut volet ipse diu.

Dic sibi, quid portas, quamvis audire dolebit,

Sepeque suspirans dixerit ore: „tace!",956

Johannes de Loddovicis wurde 1375 in Bologna geboren. ${ }^{957}$ Er hatte enge Beziehungen zu Kardinal Baldassare Cossa, den er 1406 nach Rom zum Konklave begleitet hat, das Gregor XII. zum Papst wählte. Denselben Kardinal begleitete er auch 1408 nach Florenz. Nach 1412 war er länger fern von Bologna. 1419 findet man ihn in Neapel wieder, wo er als Stellvertreter des camerarius Lorenzo Colonna genannt wurde. 1420 wurde er von Martin V. zum vicarius von Cento ernannt, 1423 zum römischen Senator. Er könnte mit dem Johannes Ludovici identisch sein, den Martin V. zum scriptor registri supplicationum ernannt hatte. ${ }^{958}$ Wenn er mit dem 1418 ernannten Sekretär identisch wäre, so könnte man davon ausgehen, dass er sich einige Zeit in der Konzilsstadt aufhielt.

\section{Johannes Montis}

Man kann aus Benedettos Text nicht auf die Art der Beziehung zwischen ihm und Johannes Montis folgern. Man erfährt über ihn nur folgendes:

Dum serum pergis, cernis si forte Johannem Montis, in ornato qui studet eloquio. ${ }^{959}$

Das Wort „studet” verrät auch nicht, in welchem Status er sich den Studien der Rhetorik widmet. Vielleicht war er ein Kommilitone Benedettos in Bologna, aber noch nicht so weit mit seinen Studien wie der Autor, deswegen werden seine Studien als ,rhetorische” bezeichnet.

956 CVP. 3529, 209r; Wattenbach, B. d. P., S. 105.

957 Für die Familie bzw. für eine Kurzbiografie vgl. Giovambattista Crollalanza, Dizionario storico-blasonico delle famiglie nobili e notabili italiane estinte e fiorenti, 3 Bde., (Pisa, La Direzione del Giornale Araldico, 1886-1890), [im Weiteren: „Dizionario”], Bd. 1, S. 28-29. Giorgio Tamba, „Giovanni Ludovisi”, in DBI, Bd. 66 (2006), S. 456 f. Der Artikel gibt zwar Hinweise auf die Sekundärliteratur an, aber leider nicht in Verbindung zu den jeweiligen Informationen. Dementsprechend ist nicht immer klar, auf welche Quellen die einzelnen Behauptungen zurückgehen. nach 1412 schreibt Tamba, dass Johannes in Bologna für längere Zeit abwesend war. 


\section{Marcus Caldarinus ${ }^{960}$}

Marcus Caldarinus wird auch nur erwähnt, ihn soll das Büchlein auch nur kurz grüßen.

Ad Caldarinum Marcum dic: „Mille salutes

Vobis transmittit, qui meus extat herus".961

\section{Florianus}

Dass es hier um eine andere, ehrenvollere Beziehung geht als im Fall der letzteren zwei Personen, zeigen Benedettos Zweifel, ob der Professor überhaupt ansprechbar sein wird:

Hic dominus Florianus ${ }^{962}$ vix cernitur: illum

Iusque utrumque trahit per iuga montis herum.

Scevola nunc Paulus Marcellus Papinianus

Iuris consulti, et cetera docta manus

Ipsum sepe movent a turba, sepe videri

Non datur. ${ }^{963}$

Benedetto preist den Rechtsprofessor in mehreren Zeilen, die Haltung des Büchleins ihm gegenüber soll dementsprechend ehrenvoll sein:

hic miro nunc nitet eloquio.

Eximius doctor nunc florentissimus orbi, Quem natura dedit moribus esse ducem.

Hic est ille bonus, nasci quem Lucius inquit,

Quingentis annis vix semel ipse virum.

Rarus et antiquis par pollens atque modernis

Excellens fenix hic benedictus erit.

Rara avis in terris nigroque simillima cigno ${ }^{964}$

Exorta est; sileo: vincor ab ingenio.

Hunc si forte liber donet fortuna videndum,

Pronus adorato, meque fer esse suum. ${ }^{965}$

Es handelt sich um Floriano Sampieri, wie bereits Wattenbach festgestellt hat, ${ }^{966}$ einen angesehenen Rechtsprofessor in Bologna. ${ }^{967}$ Benedetto kannte ihn wahrscheinlich noch von

Die Familie wird bei Crollalanza erwähnt: Crollalanza, Dizionario, Bd. 1, S. 198 f.

CVP. 3529, 209r.

Vers gestört (bzw. das i im Namen Florianus müsste lang ausgesprochen werden).

CVP. 3529, 209r-v; Wattenbach, B. d. P., S. 105 f.

Iuv. Sat. 6. 165.

CVP. 3529, 209v; Wattenbach, B. d. P., S. 106.

Wattenbach, B. d. P., S. 105.

Die Familie wird von Crollalanza erwähnt (Crollalanza, Dizionario, Bd. 2, S. 476-477), und auch Floriano erwähnt ihn, allerdings als Professor in Siena und Ferrara. In den Rotuli findet man aber seinen Namen wieder: Umberto Dallari, Hrsg., I rotuli die lettori legisti e artisti dello studio Bolognese dal 1384 al 1799, 4 Bde., Dei Monumenti istorici pertinenti alla provincia della Romagna: Serie 2, Carte 2 (Bologna: Merlani, 1888-1924), [im Weiteren: „Rotuli”], hier S. 6 und S. 9. Nach Mazzetti unterrichtete er ab 1383 
seiner Zeit als Student der Rechte in Bologna. Es gibt Quellen für Sampieris Auftritt auf dem Pisanum, zudem soll er mit einer Delegation der Stadt Bologna, die dem neu erwählten Papst gratulieren sollte, auch nach Konstanz geschickt ${ }^{968}$ und auch in weiteren Angelegenheiten als Orator mit diplomatischen Aufgaben beauftragt worden sein. Benedettos Lob seiner Beredsamkeit ist dementsprechend mehr als nur ein Topos. Ob er sich vielleicht bereits früher in Konstanz aufhielt, kann nicht bewiesen werden, ist aber auch nicht auszuschließen.

\section{Bartholomeus Appulus ${ }^{969}$}

Ein anderer Benedetto bekannter Professor schließt die Reihe der Freunde, die das Buch in Bologna aufsuchen soll. Ihn findet der Libellus aber nicht mehr am Leben, er soll sein Grab mit einem Epitaph versehen.

Hic quoque Pieridum pater optimus et michi ${ }^{970}$ multum Et tibi dilectus rite videndus erat.

Sed postquam a superis concessit, carmine nostro Signetur tumulus, quo situs ille fuit:

„Appulus et minimo contentus Bartholomeus

Dilectus musis hac tumulatus humo est."

Quis iam doctiloqui referabit gesta Maronis? ${ }^{971}$

Quis Flacci ${ }^{972}$ numeros? Dona quis, Lyee ${ }^{973}$, tua?

Carmina quis nobis varias mutantia formas? ${ }^{974}$

Cesaris et pugnas, carmina quis Statii?

Quis satyras exinde dabit, cantus quoque ville? ${ }^{975}$

Tulli $^{976}$, quis nobis et tua scripta canet?

Historiasque tuas, quis, Maxime clare, docebit? ?77 $^{977}$

Insimul atque graves, o Paduane ${ }^{978}$, tuas?

kanonisches Recht an der Universität von Bologna: Serafino Mazzetti, Repertorio di tutti i professori antichi, e moderni della famosa università e del celebre istituto delle scienze di Bologna (Bologna: Tipografia di San Tommaso d'Aquino, 1847), [im Weiteren: „Repertorio”], hier S. 279.

Vgl. Giovanni Fantuzzi, Notizie degli Scrittori Bolognesi (Bologna: D’Aquino, 1781-1794), hier Bd. 7, S.

302. In der Fußnote zum Satz über Florianos Tätigkeit auf dem Konstanzer Konzil verweist Fantuzzi auf „Labbe XV, Col 1370”: Philippe Labbé, Ab anno MCCCCXIV usque ad annum MCCCCXVIII, Sacrosancta concilia, 15 (Venedig: Coleti, 1728-1733). An dieser von Fantuzzi angegebenen Stelle bei Labbe geht es aber um einen Auftritt Floriano Sampieris auf dem Pisanum im Jahre 1409. Fantuzzi selbst schreibt auch über Florianos Auftritt auf dem Pisanum, (auf S. 301-302), mit dem Vermerk, dass dieser Auftritt bei Labbé nicht erwähnt wird.

$\mathrm{Zu}$ Bartholomeus de Regno / Appulus vgl den CA.L.M.A. Artikel: „Bartholomeus de Regno Apuliae” , C.A.L.M.A. Bd.2, 2008, S. 49.

Das Wort „michi” steht nur als Nachtrag in der Interlinearglosse.

971 Vergil.

972 Horaz.

973 Lyaeus: Bacchus, es geht um Tragödien (Gaben des Bacchus), „tragedias“ steht als Interlinearglosse zum Wort „dona“. Der Vers ist prosodisch nicht korrekt.

974 Ovids Metamorphosen.

975 In der Interlinearglosse stehen die Namen Terentius und Plautus.

976 Cicero.

977 Valerius Maxemius.

978 Livius. 
Rarus ei similes surget, qui talia possit,

Hoc oritur raro tempore clarus homo. ${ }^{979}$

Wie aus Benedettos Zeilen, aber auch aus anderen Quellen hervorgeht, unterrichtete Bartholomeus Appulus (Bartholomeus de Regno) Grammatik und Rhetorik an der Universität Bologna. Nach Alidosi ${ }^{980}$ ist er 1419 noch am Leben. Der Autor seiner Kurzbiografie, Guido Martellotti, geht vorsichtig mit diesem Widerspruch um und will die Frage, ob man eher Alidosi oder Benedetto glauben soll, nicht ganz eindeutig entscheiden. ${ }^{981}$ Über Appulus Lehraktivität berichten die Rotoli der Universität Bologna. ${ }^{982}$ Er richtete wahrscheinlich eine Lobschrift an Salutati, heute hat man nur Salutatis Antwort. ${ }^{983}$ Benedetto kannte ihn wahrscheinlich aus den Jahren seines Studiums in Bologna.

\section{Florentia}

\section{Marinus de Guadagnis}

Der erste, den der Buchbote in Florenz begrüßen soll, ist Marinus de Guadagnis. Benedetto widmet ihm acht Zeilen. Aus der Beschreibung des möglichen Treffens mit ihm kann man darauf schließen, dass die beiden sich näher kannten.

Prospice per cives, videas si forte Marinum,

Quem de Guadagnis optima fama notat.

Hic michi pro meritis est pura mente colendus,

Et collaudandus constat ubique finis.

Hunc, age, compertum flexa cervice saluta,

Et partem pene perge referre mee!

Cum lacrimas solvet multum pius ipse, memento

Dicere: non plores, nam valet ille bene! ${ }^{984}$

Bei Crollalanza wird der aus der großen florentinischen Familie stammende Marinus als apostolischer Protonotar und Sekretär des Johannes XXIII erwähnt. ${ }^{985}$ Walser erwähnt seinen Namen in Verbindung mit Poggio: Letzterer soll zusammen mit Bartolomeo da Montepul-

CVP. 3529, 209v-210r. Wattenbach zitiert nur die letzten zwei Zeilen: Wattenbach, B. d. P., S. 106. Giovanni Nicolao Pasquali Alidosi, Li dottori forestieri che in Bologna hanno letto teologia, filosofia, medicina et arti liberali (Bologna: Tebaldini, 1623), hier S. 13.

„sembra, dalla testimonianza di un suo scolaro, Benedetto da Piglio, che nel 1415 fosse già morto; sarebbe falsa, dunque, la notizia data dall'Alidosi, che lo fa attivo nello studio fino all' anno 1419": Guido Martellotti, „Bartolomeo del Regno”, DBI, Bd. 6 (1964), 764-765.

Dallari, Rotuli, S. 5, 7, und S. 10.

Salutati, Epistolario, Bd. 2, S. 343-354.

CVP 3529, 210r.

Crollalanza, Dizionario, Bd. 1, S. 505. Bei Frati steht die Information, dass die Familie über eine große Büchersammlung verfügte. Vgl. Carlo Frati, Dizionario bio-bibliografico die bibliotecari e bibliofili italiani: dal secolo XIV al XIX, Biblioteca di bibliografia italiana 13 (Florenz: Olschi, 1933), hier S. 271. 
ciano als procurator Marino de Guadagnis in einer strittigen Angelegenheit in Konstanz geholfen haben. Das von Walser veröffentlichte Dokument, in dem Marinus seine Stellvertreter in Konstanz ernennt, ist 1416 in Florenz ausgestellt worden. Man kann also davon ausgehen, dass Marinus sich um diese Zeit in Florenz aufhielt. Benedetto kannte ihn wahrscheinlich aus der Zeit, die er an der Kurie verbrachte. ${ }^{986}$

\section{Bartolomeus da Montepulciano}

Bartolomeus de Montepulciano wird von Benedetto als ein Dichter beschrieben, der sich später der Rechtswissenschaft widmete und dem die Musen deswegen nachtrauern.

At si Mercurii dono olim Bartholomeum

Carum Calliope sistere, cernis ibi,

Famosum iuvenem, cui mons est Politianus

Patria, sed novit Menalus ipse virum,

Quem flerunt nimphe raptum sibi iuraque valde

Legesque oderunt, est quibus ille datus,

Quem qondam latine ${ }^{987}$ multum flevere camene,

Namque futurus erat miles in arma potens.

Quemque etiam si quando velit pulsare theatrum

Euterpes, recipi pulcer Apollo iubet. ${ }^{988}$

Dass Benedetto ihn für einen kompetenten Latinisten hält, verrät er auch mit der Bitte, seinen Text zu korrigieren. ${ }^{989}$

Auch Bartolomeus war apostolischer Sekretär, nach der Angabe des Artikels im DBI seit 1411, nach de la Mare erst ab $1414 .{ }^{990}$ In Konstanz schloss er sich Poggio an und begleitete ihn auf seinen Entdeckungsreisen: In einem Brief an Ambrogio Traversari berichtet er aus Konstanz über seine Funde. Er bittet Traversari darum, dass er ihm den Brief an Niccoli zeigt, dem er nur dann persönlich schreiben wolle, wenn er über einen Fund berichten

\footnotetext{
Vgl. Walser, Poggius, S. 42 und S. 333. In dem von Walser veröffentlichten Dokument wird Marinus als scriptor apostolicus bezeichnet.

987 Prosodischer Verstoß im Wort „latine“.

988 CVP 3529, 210v.

989 Benedettos Aufforderungen zur Korrektur an seine Freunde werden ausführlicher erörtert im Unterkapitel: IV. 2.6.3. „Die Aufforderung zu Korrektur”.

990 Der Artikel im DBI erschien ohne die Angabe des Autors: vgl. DBI, Bd. 3, S. 686-688. Über diese Angabe, über das genaue Datum also, wann er das erste Mal in diesem Status erwähnt wurde, ist die Autorin einer anderen Kurzstudie über Bartolomeo, de la Mar, skeptisch. Vgl. Albinia Catherine de la Mare, The Handwriting of Italian Humanists (Oxford: Oxford University Press, for the Association Internationale de Bibliophilie, 1973), hier S. 85-90.; S. 89 empfiehlt sie dem Leser, den Artikel des DBI mit Skepsis zu lesen. Hofman erwähnt Bartolomeo das erste Mal als Sekretär 1414. Vgl. Hofman, Forschungen, Bd. 2, S. 109. Nach Ottenthal ist er erst ab 1418 Scriptor: Ottenthal, Bullenregister, S. 475. Er wird auch bei Frenz erwähnt: Thomas Frenz, „Das Eindringen humanistischer Schriftformen in die Urkunden und Akten der päpstlichen Kurie im 15. Jahrhundert, 1-2", Archiv für Diplomatik 19 und 20 (1973 und 1974): 287-418 und 384-506, [im Weiteren: Das Eindringen], hier Teil 2, S. 430 f.
} 
könne, der Niccoli würdig sei. ${ }^{991}$ Er war auch unter Martin V. ab dem Jahr 1418 als scriptor, ab 1421 als Sekretär und referendarius tätig. ${ }^{992}$

Die Beurteilung dieser Figur fällt bei seinen Zeitgenossen sehr unterschiedlich aus. Er erfährt sogar nach seinem Tod eine heftige Attacke von Seiten Brunis in einem Brief an Poggio $^{993}$. Die verbale damnatio memoriae fängt mit der Beschreibung einer Szene an, deren Augenzeuge Bruni in der Nähe von Arezzo wurde. Einige Männer versuchten, die Teile eines Grabmonuments mit Wagen fortzuschaffen. Als Bruni sie fragte, was sie machten, antwortete man ihm mit einer Klage: „Di perdant, inquit, poetas omnes et qui fuerunt unquam, et qui futuri sunt." ${ }^{994}$. Nachdem Bruni nach dem Grund dieser Aufregung fragte, erfuhr er, dass der Dichter Bartolomeus de Montepulciano in Rom gestorben sei, und dass er in seinem Testament die Aufstellung eines Grabmonuments verordnet habe. Der zweite Teil des Briefes enthält eine kurze historische Lektion über die drei großen Herrscher Cyrus, Alexander und Cäsar, die es gar nicht für wichtig hielten, ein Grabmal für sich errichten zu lassen. Der dritte Teil ist eine gnadenlose Attacke gegen Bartolomeus, geführt in der zweiten Person Singular. Einige Zeilen aus dieser hasserfüllten Ansprache illustrieren Brunis Ton: „Tu marmora tibi ex longinquo portari, tu sepulcrum fieri et statuas tibi ipsi collocari testamento iubes? Quo merito, quaeso? An scientia, quae in te nulla fuit? An litteris, quarum vix quatuor tenebas?"995 Die Ahnen Bartolomeus werden folgendermaßen beschrieben: „[dignumque...facit] natum ex patre mercatore circumforaneo, avia obstetrice, matre fanatica." $" 996$ Im letzten Satz des Briefes bemerkt er, dass der Möchtegerndichter in seinem Testament besser verordnet hätte, dass er so vergraben werden sollte, wie er das (gestohlene) Geld vergrub, (also schnell und heimlich), damit seine Eitelkeit und sein Ehrgeiz den Leuten keinen Grund zum Lachen lieferten. ${ }^{997}$ In Brunis vituperatio wird also alles an Bartolomeus geschmäht: seine Herkunft, seine Taten und Fähigkeiten, seine Moral.

991 Ambrosius Traversari, Latinae epistolae, hrsg. v. Pietro Cannetti, Lorenzo Mehus (Florenz: Typogr. Caesareum, 1759), hier Brief XXIV. 9, S. 981-985.

992 Vgl. Piccolominis Beschreibung von ihm als Referendar, dem gegenüber Papst Martin V. das größte Vertrauen hatte: „quem Martinus papa in secretarium recepit atque adeo dilexit, ut unicum eum referendarium habuerit illique soli omnia crederet.": Piccolomini, De viris, S. 36.

993 Bruni, Epistolae, Brief VI. 5, Bd. 1, S. 45-48.

994 Bruni, Epistolae, Bd. 1. S. 45.

995 Bruni, Epistolae, Bd. 1, S. 47.

996 Bruni, Epistolae, Bd. 1, S. 47 f.

997 Die Antipathie Brunis gegenüber Bartolomeo scheint Georg Voigth in seinem Urteil etwas beeinflusst zu haben, er hält ihn nämlich auch für ,ein(en) Mann von sehr untergeordneten Talenten, der sich für einen Philosophen hielt, weil er einige antike Sentenzen über die Freundschaft und über das höchste Gut aufgefangen, für einen Dichter, weil er einst die Schule des Chrysoloras genossen, und zu Costnitz mit dessen Jünger Cenci de' Rustici verkehrte, und für ein wichtiges Glied der literarischen Kreise, weil es ihm gelungen mit Männern wie Guarino, Barbaro und Traversari in Briefwechsel zu treten". Voigt, Wiederbelebung, Bd. 1, S. 137. 
Der Adressat des Briefes, Poggio, hatte allerdings eine ganz andere Meinung von Bartolomeus. Er schreibt an Niccoli über Bartolomeus Tod als Verlust eines ihm lieben Menschen: „Turbatus enim eram et conterritus ex morte Bartholomei de Monte Politiano, viri clarissimi mihique in primis carissimi." 998

Die Tatsachen, dass er Poggio auf seine Entdeckungsreisen begleitet hatte und nach dem Konzil einen Posten in der Kurie erhielt, machen plausibel, dass er sich während des Konzils in der Konzilstadt aufhielt.

\section{Leonardus Aretinus}

Das Büchlein soll auch Leonardo Bruni aufsuchen, dessen Name also gleich auf den des von ihm so vehement geschmähten Bartolomeus folgt. In Bezug auf Bruni drückt sich Benedetto ähnlich aus wie im Fall von Floriano Sampieri. Seine Worte bezeugen eine Beziehung, die eher als distanziert bezeichnet werden kann und wahrscheinlich eher auf Benedettos Reverenz Bruni gegenüber beruhte. Benedetto ist sich gar nicht sicher, ob es dem Büchlein möglich sein wird, Bruni zu treffen.

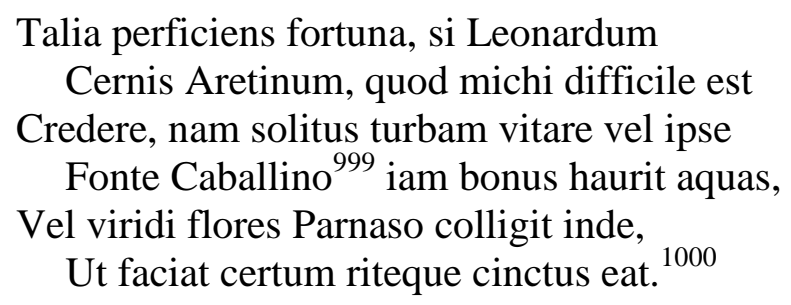

Er drückt seine Bewunderung für Bruni auch durch seine Aufforderung an die Florentiner aus, Bruni zum Dichter zu krönen ${ }^{1001}$. Seine Hoffnung, dass dieser angesehene Humanist seinen Libellus vielleicht lesen und korrigieren würde, drückt Benedetto sehr vorsichtig aus:

Cetera, que vellem super his tibi dicere verba, Non posses dorso singula ferre tuo.

Ergo, age, si talem redeuntem culmine Cyrre

Videris, aut Nyse concide flecte genu,

Cumque manum dabit ille suam, tu porrige dextram

Amplectens leva, si potes, ipse pedes, Inde nichil dicas, sed si rogat ipse benignus,

Que foveris, narra paucaque verba refer.

Si te dignetur parvum timidumque videre,

Exora, vitium demat ut ille tuum. ${ }^{1002}$

\footnotetext{
998 Poggio, Lettere, Bd. 1, S. 210.

999 fons Caballinus: Hippokrene.

1000 CVP. 3529, 210v.

1001 Das Thema „Dichterkrönung” im Libellus wird später ausführlich im Unterkapitel IV. 2.6.1. erörtert.
} 
Benedetto kannte Bruni wahrscheinlich von der päpstlichen Kurie her, wo dieser seit dem Jahr 1405 tätig war. ${ }^{1003}$ Bis zu dem Fluchtversuch des Papstes Johannes XXIII., in dessen Gefolge er auf dem Konzil weilte, war er auch in der Konzilsstadt. ${ }^{1004}$

\section{Roma}

\section{Angelottus}

In Rom soll das Büchlein zuerst Angelottus begrüßen.

Hic michi non inter minimos venerandus amicos Pro domino colitur, proque suo merito. ${ }^{1005}$

Auch er wird von Benedetto als Dichter dargestellt:

Sepe fuit visus Musis in colle Liceii Et carpens flores, o bona Cyrra, tuos. ${ }^{1006}$

Angelotto wird dem Buch mit Interesse zuhören, ihm für die Nacht Unterkunft geben und sogar seine „Wunde heilen”:

Hunc, ubi romuleos muros intraveris hospes,

Alloquere, et casus ordine pande meos!

Suspirans imoque trahens a pectore vocem

Audiet, extinctum me reputabit homo.

Tum tu solicitus, tum tu facundus amico

Perspicuo dicas: „Quid gemis? Ipse valet,

Et rogat, ut fesso pietas michi sepe cadenti

Nunc tua nocturnum prebeat hospicium!"

Hec te, parve liber, demissa voce loquentem,

Namque interrumpet cetera verba tibi,

Angelus accipiet perfidus mente domoque,

Dicet complectens: „Requiesce diu!”

Tu plagas ostende tuas, miserebitur ille,

1002 CVP. 3529, $211 \mathrm{r}$.

1003 Er wurde erst unter Innozenz VII., dann Gregor XII., Alexander V. und schließlich Johannes XXIII. angestellt. Für eine kurze Zusammenfassung von Brunis Leben vgl. Cesare Vasoli, „Leonardo Bruni”, in DBI, Bd. 14 (1972): 618-633. Für eine Bibliographie der Sekundärliteratur über Bruni: James Hankins, Repertorium Brunianum. A critical guide to the writings of Leonardo Bruni, Fonti per la storia dell'Italia medievale 5 (Rom: Istituto Storico Italiano per il medio Evo, 1997), LIII-LXXVI. Für seine Ämter vgl. Hofman, Forschungen, Bd. 2, S. 107.

1004 Über Brunis Flucht aus der Konzilsstadt berichtet Vespasiano da Bisticci in seiner Biographie Brunis: „Misesi indosso una cappa d'uno frate; et messer Lionardo, et lui et altri che gli andavano apresso, uscirono fuori di Gostanza a piè, et andarono a una badia, et dice ch'egli istettono tre dì che non mangiorono se non pere rugine, per non avere altro, et per non iscoprirse, chè sarebono stati presi." Vgl. Vespasiano da Bisticci, Le Vite, hrsg. v. Aulo Greco (Florenz: Nella sede dell'Istituto Palazzo Strozzi, 1970), hier S. 468. 
Et cum consilio conferet artis opem. ${ }^{1007}$

Angelotti wurde bereits von Wattenbach als Angelotto Foschi identifiziert. ${ }^{1008}$ Seine kuriale Karriere wird ausführlich dargestellt im Artikel des DBI. ${ }^{1009}$ Er tritt zum ersten Mal unter Gregor XII. als abbreviator und scriptor apostolicus 1408 in Erscheinung. Seit 1412 findet man ihn in der Kurie von Johannes XXIII. Seine Anwesenheit auf dem Konzil ist durch mehrere Dokumente bezeugt. ${ }^{1010}$ Auch ihn kannte also Benedetto von der gemeinsamen kurialen Vergangenheit. Ab 1418 ist er der Bischof von Anagni. ${ }^{1011}$

\section{Cencius}

Auch Cencio de Rustici soll in Rom gegrüßt werden:

Cencius hic querendus erit, cui pulchra Camena Claraque castalias sepe ministrat aquas.

$\mathrm{O}$ mirum doctumque virum, cui pulcher Apollo Menalium montem ${ }^{1012}$ sepe videre dedit.

Da michi Nasonem: tantum describere civem Vix possem! Fama mutor ab ipse sua!

Hunc pete, nec dubites sibi pandere casus,

Et circumspicias cum ratione loqui!

Nam latina grecaque valet pro singula lingua,

Hos binos cives, Romule, cerne tuos! $!^{013}$

Cencio Romano war apostolischer scriptor unter Johannes XXIII. seit $1411^{1014}$ und wurde 1417 zum Sekretär ernannt. Auch er begleitete Poggio auf seinen Entdeckungsreisen. ${ }^{1015}$ Benedetto hebt die Tatsache hervor, dass er auch Griechisch konnte. Er war in der Tat einer der Schüler des Chrysoloras. Bartolomeus da Montepulciano behauptete in einem Brief an Traversari, nach Chrysoloras Tod von Cencio Griechisch gelernt zu haben. ${ }^{1016}$ Auch ihn kannte Benedetto aus der Kurie Johannes` XXIII.

1007 CVP. 3529, 212r.

1008 Wattenbach, B. d. P., S. 107.

1009 Wolfgang Decker, „Angelotto Foschi”, in DBI, Bd. 49 (1997): 429-431. Die folgenden Daten sind dieser Darstellung entnommen.

1010 Vgl. dafür Deckers Artikel im DBI.

1011 Ferdinando Ughelli, Italia Sacra sive de Episcopis Italiae, 10 Bde. (Venedig: Apud Sebastianum Coleti, 1717), [im Weiteren: „Italia sacra”, hier Bd. 1, Sp. 320.

1012 Mons Maenalus: Berg in Arkadien.

1013 CVP 3529, 212v.

1014 Vgl. Hofman, Forschungen, Bd. 2, S. 110, und Ottenthal, Bullenregister, S. 473.

1015 Für Cencios Leben vgl. Max Lehnerdt, „Cencio und Agapito de’ Rustici”, Zeitschrift für vergleichende Literaturgeschichte 14 (1901): 147-72; 289-318, [im Weiteren: „Cencio”].

1016 Über seine Griechischstudien vgl. Thorn-Wickert, Chrysoloras, S. 92 und S. 109-111, und Lehnerdt, Cencio, passim. Über die Griechischstudien von Bartolomeo de Montepulciano vgl. den skeptischen Bericht von Thorn-Wickert, Chrysoloras, S. 93-94, wo die Autorin auch die weiterführende Literatur zur Frage liefert. 
Die nächsten vier Personen lässt Benedetto zusammen grüßen, ihre Namen werden nur flüchtig hintereinander aufgelistet:

Post hec, si Paulum Marganem, sive Iohannem

De Venetinis videris inque simul,

Et de Sanguineis hic cernas et Leonardum, Ignotos alios preteriturus eris.

Hos tres, precipio, summissa voce saluta, Cum Stephano, clarum quem Catilina facit. ${ }^{1017}$

\section{Paulus Marganis}

Paulus Marganis konnte ich nicht genau identifizieren. Es scheint sicher zu sein, dass er der großen römischen Familie der Margani entstammte. ${ }^{1018}$ Poggio erwähnt ihn außerdem in einem Brief an Niccoli. Paulus de Marganis habe ihn laut diesem Brief um einen Gefallen gebeten. Poggio bittet Niccoli darum, dass er für ihn diesen Freundschaftsdienst erledige und nennt so Paulus de Marganis auf indirekte Weise einen Freund („,hoc onus post mea sume et rem confice pro me, ut opere tuo satisfaciam amicis meis"). ${ }^{1019}$

\section{Iohannes de Venetinis}

Er war der Sohn des Notars und Senators Nardus de Venetinis (Venectinis), ${ }^{1020}$ und erhielt von Bonifaz IX. 1400 ein Kanonikat an der Basilica San Giovanni in Laterano. ${ }^{1021}$

\section{Iohannes de Sanguineis}

Die dritte Person der Gruppe, Iohannes de Sanguineis, kann vielleicht mit jenem Johannes Sanguineis identifiziert werden, der am 13. September 1395 zum scriptor penitentiariae ernannt wurde. ${ }^{1022}$ In diesem Fall wäre davon auszugehen, dass Benedetto auch ihn in der Kurie kennengelernt hatte.

1017 CVP. 3529, 212v.

1018 Über die Familie: Carlo Cecchelli, I Margani, i Capocci, i Sanguigni, i Mellini, Le grandi familglie romane 4 (Rom: Reale Istituto di Studi Romani Editore, 1946), S. 7-20.

1019 Poggio, Lettere, Bd. 1, S. 76-77.

1020 Jörg Garms, Die mittelalterlichen Grabmäler in Rom und Latium vom 13. bis zum 15. Jahrhundert, 2 Bde. (Wien: Verlag der Österreichischen Akademie der Wissenschaften, 1981-1994), [im Weiteren: „Die Grabmäler"], hier Bd. 1, S. 201.

1021 Ottorino Montenovesi, „Roma agli inizi del sec. XV e S. M. Nova”, Rivista Storica Benedettina 17 (1926): 240-347, hier S. 254.

1022 Hofman, Forschungen, Bd. 2, S. 1. 


\section{Stephanus de Catilinis}

Stephanus de Catilinis konnte ich nicht identifizieren. Laut Crollalanza gibt es mehrere Familien, die in Frage kommen könnten: die Catelini von Velletri, die Catelani von Bologna oder die Catellini von Florenz. ${ }^{1023}$

\section{Nicolaus de Nicoleschis}

Der aus Velletri stammende Nicolaus war anscheinend ein Schüler Benedettos, der sich später der Rechtswissenschaft widmete:

Hunc ego per flores et amena virentia duxi

Dum iuvenis fuerat, Mantua, sepe, tuos.

Hinc petiit leges non inferiora sequutus, Iam floret verbis, Iustiniane, tuis.

Quem fortuna virum varios evolvere casus

Impulit inmeritum, fortis ubique fuit. ${ }^{1024}$

Von Benedetto erfährt man noch, dass Nicolaus Benedettos Bruder aufgenommen hatte, als Benedetto seine Heimat verlassen musste.

Hic fratrem magno quondam suscepit honore,

Cum michi per silvas contigit ire, meum,

Me quoque. Non inter dubios in amore sodales

Prestat, et est solitus semper habere suos. ${ }^{1025}$

Mazzetti erwähnt einen Nicolò Nicoletti d'Imola, der 1410 in Bologna die Decretalen gelesen haben soll. ${ }^{1026}$

\section{Nicolaus Gayetanus}

Auch ein Abkömmling der berühmten Familie Gaetani (oder Caetani) soll begrüßt werden. Dass die beiden sich gut kennen mussten, geht aus Benedettos Bitte an das Büchlein hervor, es soll Nicolaus darum bitten, dass er auf seine Bücher, die er gerettet hatte (die Glosse interpretiert „Instante ruina” als Ladislaus’ Eintritt in die Stadt) aufpasse.

Hinc pete, si Rome Gaytanus sit Nicolaus,

Quem flevisse patet meque meumque malum.

Nobilis, egregius, clarisque parentibus ortus,

\footnotetext{
1023 Crollalanza, Dizionario, Bd. 1, S. 262.

1024 CVP. 3529, 212v; Wattenbach, B. d. P., S. 108

1025 CVP. 3529, 213r; Wattenbach, B. d. P., S. 108.

1026 Mazzetti, Repertorio, S. 222.
} 
Et iuvenis fervens arte, Thalia tua,

Et si dicetur, quid sit, tunc ibis ad illum,

Nam te suscipiet conspicietque satis.

At dabit amplexus, sed tu tum ante saluta

Ingenuum puerum, meque valere refer!

Et si sunt libri, quos ipse instante ruina

Eripuit, salvi, dic, bene servet eos. ${ }^{1027}$

\section{Tibur}

\section{Iohannes Chamicius}

In Tivoli sollen Johannes Chamicius und sein Bruder gegrüßt werden. Er scheint ein alter Freund Benedettos zu sein, der auch literarische Interessen hegte oder wenigstens mit Benedetto zusammen die antiken Autoren gelesen hatte.

Hic habitat primis multum me cultus ab annis,

Dignus amicitia, frater et ille, mea.

Nomine patris erat Chamicius, ipse Iohannes

Dicitur. $\mathrm{O}$ bene rem nominis ille tenet,

Sepeque conscendit sitiens Elicona ${ }^{1028}$ virentem,

Sepe Caballini ${ }^{1029}$ fontis inivit aquas.

Hunc audax adeas, hunc tota mente saluta

Et maneas secum totus, ut ipse volet. ${ }^{1030}$

\section{8.-19.Petrarca und Johannes}

Über diese Brüder erfährt man nichts Näheres:

Post hec Petrarcam germanos atque Iohannem

Vise sono vocis, non sine mente dato.

Hi michi sunt cives multum multumque colendi,

Proque suis meritis his ego servus ero,

Dum celo stelle, dum pisces equore, dumque

Spiritus hic membris et bona mentis erunt. ${ }^{1031}$

1027 CVP. 3529, 213 r.

1028 Im Codex steht ,dicona”.

1029 Im Codex steht „caballinis”.

1030 CVP. 3529, 214r-v.

1031 CVP. 3529, 214v. 


\section{Paulellus Sarromanus}

Ähnlich wenig erfährt man über Pauluellus:

Nec Sarromanum Paulellum visere vites,

Pre cunctis hic me semper amare solet. ${ }^{1032}$

\section{Anticholum}

\section{1-22. Nardus und Johannes}

In Anticoli sind Nardus und Johannes, Vater und Sohn, zu grüßen, über die man aus der Beschreibung nur erfährt, dass sie enge Freunde Benedettos sein mussten:

Troianum Eneam superans pietate Iohannes

Atque suus genitor conspicietur ibi.

Nardus odoriferam vincens et †inania Nardum

Casta quoque et coniunx, semper amica dei.

Hos proferre viros non possum semper amantes.

Effugiunt molles, hi bene semper amant.

Effugiunt molles adversa concita vento

Equora, consistant tempus in omne boni.

Quid referam, quanto soliti sunt munera voto

Mittere perque alios se quoque ferre michi?

Clauderet ante diem vesper bis, terque quaterque,

Quam possem tantos ipse referre viros.

Hos tu convenias, hos tota amplectere mente,

Hos mirare duos, hos cole sepe duos!

Hi te suscipient alacres multumque rogabunt:

Quid de me sentis, singula rite refer! ${ }^{1033}$

\section{Genezanum}

\section{Angelus}

In Genazzano soll das Buch Angelus aufsuchen, den Wattenbach als Angelus Afflitti, den Bischof von Anagni, identifiziert hat, der 1401 als solcher ernannt wurde. ${ }^{1034}$

Filius hic Febi ${ }^{1035}$ sapiens magnusque sacerdos Incolit ac largus, nec minus ille pius. ${ }^{1036}$

\footnotetext{
1032 ebda

1033 CVP. 3529, 214v-215r.

1034 Wattenbach, B. d. P., S. 111, und Ughelli, Italia sacra, Bd. 1, Sp. 320, als Angelus de Afflictis oder Anglonus oder Polymnianensis.

1035 Apollon.
} 
Er dürfte mit Benedetto gut befreundet gewesen sein, andernfalls hätte der Autor die Szene des Besuches des Büchleins wahrscheinlich nicht so ausführlich erörtert. Der Autor scheint sogar von der Gicht des Bischofs gewusst zu haben.

Angelus angelicam servans per saecula vitam, Et michi precipuus rex simul atque deus.

Cui clemens opto: tollat deus ipse podagram, Ut sibi sit florens nocte dieque quies!

Hunc pete, sed paucis verbis, precor, atque modestis

Utere, cumque viro contrahe fesso moram!

Hunc tamen admoneo genibus cerviceque flexis

Semper adorare, tum sibi verba dabis!

Gaude, talis enim tibi quippe videbitur hospes,

Et Cereris munus letitiamque dei,

Inde cibos alios donabit divite mensa.

Et sic imbutus carpe, viator, iter. ${ }^{1037}$

\section{Paulus de Capranica}

Vom Bischof soll der Libellus zu Paulus Capranica wandern. Benedetto beschreibt ihn als seinen ehemaligen Schüler:

Tum, si forte tuis fortuna offerret ocellis Paulum, quem miro semper amore colo, Tu bene me sentis, quia dico Capranicensem Splendentem fama mentis et arte virum. Sepe meo quondam nutritus lacte benignus, Non fuit ingratus, nam michi multa dedit, Sepeque cantantes audivit monte camenas Parnaso et doctus iam canit ${ }^{1038}$ ipse bene. Dic, si conspicias ipsum: „Tibi mille salutes

Mandavit, qui me iussit adire domum!"” Paulus ad hec multum cupidus te multa rogabit,

Tu secum confer, verbaque certa dato. ${ }^{1039}$

Der Bruder des Kardinals Domenico Capranica war aber nicht nur ein Schüler Benedettos, sondern ab 1417 auch sein Kollege in der Kurie. ${ }^{1040}$ Auf Grund seiner Ernennung zum Sekretär kann man davon ausgehen, dass er in Konstanz anwesend war.

1036 CVP. 3529, 215r; Wattenbach, B. d. P., S. 111.

1037 CVP. 3529, 215r; Wattenbach zitiert die ersten vier Zeilen: B. d. P., S. 111.

1038 Wattenbach korrigiert stillschweigend „canit” auf, ,sapit”: Wattenbach, B. d. P., S. 111.

1039 CVP. 3529, 215r-215v; Wattenbach zitiert vier Zeilen (sepe cantantes-adire domum) B. d. P., S. 111.

1040 Laut Ottenthal war er von 1417 bis 1425 apostolischer Sekretär. Vgl. Ottenthal, Bullenregister, S. 473. Laut Frenz ist er ab dem 9. Januar 1418 als Sekretär Martins V. nachweisbar. Vgl. Frenz, Das Eindringen, Teil 2, S. 430. 


\section{Anagnia}

\section{5-26-27. Antonius und Andreas und Johannes Thomasii}

In Anagni hat Benedetto viele Freunde, als erste von diesen sollen die Brüder Antonius und Andreas, die Benedettos Verwandte zu sein scheinen, aufgesucht werden:

Hec [Anagnia] adeunda tibi est, florens Anthonius illic

Et meus Andreas hanc habitare solent.

Hi duo sunt nobis et mente et sanguine iuncti, Conspicui cives, optimi et arte pares. ${ }^{1041}$

Näheres erfährt man über sie nicht, außer, dass deren Vater, der ein wohlhabender Mann gewesen sein muss, Johannes hieß (,Thomasii” steht nur in der Glosse).

Germani natique viro, qui nempe Iohannes, Gratia, quod nomen per bona sepe sonat, Appellabatur quondam dum vita manebat, Hic factus dives cum probitate sua est.

His tu ne dubita circumdare brachia collo, Pressaque conventis oscula ferre viris, Dicque meos casus, secum maneasque bibasque

Et comedas, donec noveris esse satur. ${ }^{1042}$

Ottenthal erwähnt einen A. Anagninus, der in den Jahren 1423-25 als Sekretär in Erscheinung tritt. ${ }^{1043}$ Eine Identifikation dieses Sekretärs mit einem der Brüder ist nicht auszuschließen.

\section{Antonius Tuzarelli}

Über Antonius Tuzarelli erfährt man, dass er ebenfalls, wie so viele Freunde Benedettos, ein Dichter war, sich aber später dem Rechtsstudium widmete, welches (das Zivilrecht) er schnell abschließen konnte:

Hic Tuzarelli residens Antonius, olim Qui fuerat socius: nunc meus est dominus. Gustavit Eliconis aquas, meliora sequuntur: Est legum victor, doctor et egregius.

Res miranda quidem, tam parvo tempore vicit Civiles leges, rem bene difficilem.

Sed tamen ingenio studio animoque labore, Ipse quibus pollet, pondera magna levat.

\footnotetext{
1041 CVP. 3529, 215v.

1042 CVP. 3529, 216r.

1043 „ich kann den Mann nicht weiter nachweisen” - fügt er hinzu: Ottenthal, Bullenregister, S. 475.
} 
Multa viri virtus clari me vincit et inde

Tutius hec nobis esse tacere puto.

Hunc quere et rerum nostrarum pande tenorem! ${ }^{1044}$

Ihn kennt Benedetto noch aus Studententagen („olim qui fuerat socius”). Worauf sich das „nunc meus est dominus” genau bezieht, ist nicht klar.

\section{9-30. Franciscus Zoni und Andreas Iacobi}

Auch diese Brüder waren Benedettos Schüler:

Ac ferrogerii bini querantur, et a te

Sponte salutentur, care libelle, mei!

Franciscum Zoni fratrem Andreamque notabis, Andream Iacobi, discipulosque meos. ${ }^{1045}$

\section{Jacobus de Zancatis}

Jacobus de Zancatis soll mit gebeugten Knien gegrüßt werden:

Postquam sic animo fuerisque et mente refertus, Antistes Iacobus rite petendus erit.

Hic de Zancatis clarus magnusque sacerdos

Iam pater est nobis melitus et dominus.

Hunc capere et genibus flexis de more saluta, Et dic me letum prosperitate sua. ${ }^{1046}$

Er wurde von Wattenbach als der Bischof von Anagni (bis 1401) identifiziert. ${ }^{1047}$ Sein Nachfolger war der bereits erwähnte Angelus Afflitti. Wattenbach macht über die chronologischen und geographischen Unstimmigkeiten die folgende ironische Bemerkung: „Ughelli berichtet, daß er 1401 zum Bischof von Chalcedon ernannt sei und den oben erwähnten Angelus zum Nachfolger erhalten habe. Offenbar hat er aber seinen Platz nicht sogleich zu räumen für gut befunden." 1048 Die Tatsache, dass Benedetto immer noch Anagni als seinen Aufenthaltsort bestimmt, muss nicht unbedingt bedeuten, dass er schlecht informiert war. Es ist eher ein

1044 CVP. 3529, $216 r$.

1045 ebda

1046 CVP. 3529, 216v.

1047 Ughelli, Italia sacra, Bd. 1, Sp. 320. Benedetto grüßt insgesamt drei aufeinanderfolgende Bischöfe: Jacobus de Zancatis, Angelus und Angelottus.

1048 Wattenbach, B. d. P., S. 112. 
Zeichen dafür, dass er seine Freunde oft an den Orten darstellt, an denen er sie kennengelernt hatte. $^{1049}$

\section{Nicolaus Antonii}

Es handelt sich um einen weiteren Schüler Benedettos:

Et civis Antoni natus non est Nicolaus Hos inter cives pretereundus homo.

Perfida quem fortem magnos fortuna labores Ac varios casus sepe subire dedit.

Hunc ego perdocui, quid posset Turnus in armis, Quid pius Eneas, bella latina simul. ${ }^{1050}$

Auch dieser Schüler wurde später Rechtsstudent:

Ex hinc ad leges cupidus se transtulit equas,

Discipulus florens, Papiniane, tuus.

Hic te suscipiet non egra mente benignus,

Sepe rogans dicet: Quid facit alter ego ${ }^{1051}$

\section{Johannes Lelli}

Dieser Mann wird als Benedettos benefactor bezeichnet. Auch er wird als ein literarisch interessierter Mensch dargestellt, der Recht studierte.

Ad benefactorem nostrum tunc perge Iohannem Lelli permeritum, quicquid in orbe nitet.

Hic bonus est civis doctusque et iure peritus,

Hic michi de rebus sepe suis placuit.

O quotiens illum Phebus per carmina ductus ${ }^{1052}$

Artium in montem, deliciasque dedit,

Quas sors campano nulli donaverit olim!

O meritum civem quis bene te caneretur? ${ }^{1053}$

Hic tibi non egra civis sit mente videndus,

I liber, i, compta voce loquare viro. ${ }^{1054}$

\footnotetext{
1049 Auch dies macht er aber nicht konsequent.

1050 CVP. 3529, 216v.

1051 CVP. 3529, 216v-217r; Wattenbach, B. d. P., S. 112.

1052 Statt „ductus” sollte eigentlich ,ductum” stehen.

1053 Auch hier handelt es sich um einen Fehler: es sollte hier „caneret” stehen.

1054 CVP. 3529, $217 \mathrm{r}$.
} 


\section{Castrum Vici}

\section{Pascalis}

In Vico soll ein bestimmter Pascalis aufgesucht werden, ein weiterer Rechtsgelehrter, der sich zuerst der Dichtung gewidmet hat.

Hic est Pascalis dominus iam lege peritus,

Ante maroneo ${ }^{1055}$ se dedit ingenio. ${ }^{1056}$

Das Büchlein wird hier ein opulentes Essen bekommen:

$\mathrm{O}$, quot complexus, o quot tibi grandia cernis Conferri et plenis dona ministeriis!

Edus et agnellus, porcus carnesque salite, Caseus et pullus non tibi deficient.

Autumno mensam toto splendere videbis, Accedet vultus singula ad ista bonus. ${ }^{1057}$

\section{Castrum Pilei}

\section{Johannes}

In Piglio soll der Libellus zuerst das Grab des Johannes aufsuchen, dessen Vater Anthiocenus hieß und dessen Mutter aus der Familie Colonna stammte:

Hic iacet in tumulo carus iustusque Iohannes,

Moribus hic florens ac pietate fuit.

Matre Columnense natus, patre Anthioceno,

Lugendus cunctis clauditur hoc lapide. ${ }^{1058}$

\section{Benedettos Familie und Freunde}

Jetzt soll das Buch Benedettos Familie und Freunde besuchen.

Inde valde dicto ${ }^{1059}$ studeas utrumque parentem

Visere, tum fratres tende videre meos!

Post hec sunt omnes michi caro sanguine iuncti

\footnotetext{
1055 vom Namen Maro (Vergil), es geht also um Dichtung.

1056 CVP. 3529, 217r-v.

1057 CVP. 3529, 217v

1058 CVP. 3529, 219r.

1059 Prosodischer Verstoß
} 
Visendi, in primis sit tibi prima soror.

Hinc et vicinos caros et adibis amicos. ${ }^{1060}$

Interessant ist hier die Benutzung des Wortes ,amici”, da auch die bis zu diesem Punkt beschriebenen Personen als Freunde bezeichnet wurden. Jetzt versteht er unter „Freunde” eine bestimmte engere, bzw. eine andere Gruppe. In den vorangehenden Textteilen bezeichnete er damit die Freunde, die er von seinem „Beruf” her kannte: seine Schüler, Lehrer und Kollegen.

\section{Iacobus Soranus}

$\mathrm{Zu}$ Iacobus Soranus soll das Büchlein am Tag nach dem Besuch bei seiner Familie kommen:

At cum lux oritur sobrius et fueris, Tum tibi precipio: Iacobi contende Sorani, Presulis ingenui visere rite domum! Hunc genibus flexis clarum longeque verendum

Alloquere, et dominum respice corde tuum $!^{1061}$

Wie Wattenbach festgestellt, handelt es sich um einen Bischof. ${ }^{1062}$

\section{Die Anthioceni}

Auch diese Familie muss aufgesucht werden (es handelt sich offensichtlich um die Familie, der auch der verstorbene Johannes angehörte). Hier wird der Libellus Iohannes, Corradin, Petrus, Ludovicus und Philippus antreffen. Benedetto unterwirft sich dieser Familie als seinen „Herren”, die Glosse bezeichnet sie als „domini pilei”.

Hinc tu discedens de more videre Iohannem At Corradinum iuribus ipse stude.

Et Petrum pariter Lodovicum sive Philippum, Anthio quos cenos ${ }^{1063}$ edidit una domus.

Hos omnes dominos tibi plena mente colendos Mando, si sanus vixeris ipse, meos.

Predictis et vitam, et res, et quidquid ubique Possideo, dona daque subesse simul. ${ }^{1064}$

1060 CVP. 3529, 219r.

1061 CVP. 3529, 219v.

1062 Es handelt sich wahrscheinlich um den Jacobus, den Ughelli 1399-1404 als den Bischof von Sora erwähnt, mit der Bemerkung, dass er vielleicht auch später diesen Titel hatte. „Reperitur enim anno 1406 die 28 mensis octobris solitum subsidium Camerae Apostolicae adpromisisse. Hic Jacobus sub V. Martino Altarista cooptatus est majoris altaris Basil. Principis Apostolorum. Decessit autem 1420." Ughelli, Italia sacra, Bd. 1, Sp. $1246 \mathrm{f}$.

1063 Hier scheint sich Benedetto keine Sorge um die unelegante Tmesis zu machen. 
Wie die Liste gezeigt hat, kannte Benedetto die von ihm dargestellten Personen aus verschiedenen Kontexten. Je näher das Büchlein auf seiner Reise an Piglio herankommt, desto größer ist die Wahrscheinlichkeit, dass es die beschriebenen Personen in der Tat in Italien und nicht auf dem Konzil auffinden könnte. Die Herren von Piglio oder seine eigene Familie würde es wahrscheinlich in dem von Benedetto angegebenen Ort auffinden. ${ }^{1065}$ Die meisten in der Kurie tätigen Humanisten sind wahrscheinlich, ebenso wie Benedetto, in der Konzilsstadt. ${ }^{1066}$ Auch manche seiner ehemaligen Schüler sollte man besser in Konstanz suchen, weil viele von ihnen eine ähnliche Karriere gemacht haben wie Benedetto selbst: Paolo Capranica ist ein Beispiel für einen ehemaligen Schüler Benedettos, der später in der Kurie Karriere machte.

Der Unterschied zwischen dem eben rekonstruierten Adressatenkreis des nuntius und der supplicatio soll an dieser Stelle kurz angesprochen werden. Es wäre möglich, eine andere Liste zusammenzustellen, und zwar von den Personen, an die die Briefe der supplicatio gerichtet worden sind, und diese zwei Personenlisten miteinander zu vergleichen. Weil auf dieser anderen Liste noch weitaus mehr Namen stehen würden, deren Identifikation wahrscheinlich nicht gelingen würde, habe ich auf einen ausführlichen Vergleich verzichtet. Aber selbst ohne eine detaillierte Analyse wird man auf einen wesentlichen Unterschied aufmerksam werden. Während die im nuntius genannten Personen gleichzeitig als von Benedettos Fiktion kreierte ideale, und als, jedenfalls nach Benedettos Absicht, reelle Leser fungieren, sind die Adressaten der Briefe, mit Ausnahme der Königin Barbara, eher nur reelle Leser, deren Aufnahme in den Libellus als ein Akt der Fixierung historisch-autobiographischer Sachverhalte zu betrachten ist. Ihr Leserstatus bezieht sich aber nur auf begrenzte Segmente des Buches, deren Originalfunktion eine völlig andere war als die Rolle, die sie im neuen Kontext erfüllen müssen. Demgegenüber sind die im nuntius aufgezählten Personen als Leser des ganzen Buches als eines literarischen Werkes dargestellt. Aus diesem funktionellen Unterschied erklärt sich die Tatsache, dass sich die im nuntius dargestellten Leser mehr einem Ideal von Lesern annähern als die der supplicatio. Sie sind eigentlich von ihrem Beruf her Leser oder mit anderen Worten: sie stellen eine Gruppe dar, die am Anfang des 15. Jahrhunderts auf ihrem Weg zur Professionalisierung war.

\footnotetext{
1064 CVP. 3529, 219v-220r.

1065 Vielleicht mit Ausnahme seines Bruders Bartolomeo.

1066 Vgl. dazu das Kapitel „Die Öffentlichkeit des Konstanzer Konzils”.
} 


\section{Bibliographie}

\section{Primärliteratur}

\subsection{Handschriften}

Berlin, Staatsbibl. P. K. Lat. Fol. 585.

Leipzig, Universitätsbibliothek, Lat. 1316.

München, Bayerische Staatsbibliothek, clm 5596.

Paris, Bibliothèque Nationale de France, Nouv. Acq. Lat. 1302.

Vaticanstadt, Biblioteca Apostolica Vaticana, Cod. Vat. Lat. 5268.

Wien, ÖNB, CVP 3529.

\subsection{Drucke}

\subsubsection{Werke einzelner Autoren}

Alberti, Leon Battista. „Canis.” In Apologhi ed elogi, hrsg. v. Luigi Malerba, 142-169. Genua: Costa \& Nolan, 1982.

—. „Musca.” In Aploghi ed elogi, hrsg. v. Luigi Malerba, 172-195. Genua: Costa \& Nolan, 1982.

—. „Defunctus.” In Dinner Pieces, hrsg. v. David Marsh, 98-125. Binghamton: Medieval and Renaissance Texts and Studies in conjunction with the Renaissance Society of America, 1987.

Aurispa, Giovanni. Carteggio. Hrsg. v. Remigio Sabbadini. Rom: Tipografia del Senato, 1931.

Barbaro, Francesco. Epistolario, 2 Bde., Istituto nazionale di studi sul Rinascimento / Carteggi umanistici 5-6, hrsg. v. Claudio Griggio. Florenz: Leo S. Olschki Editore, 1999. 
Bernhardus Baptisatus Ordinis S. Benedicti de Gasconia, „In corruptum illo tempore clerum, in Constantiensi Concilio emendandum." In Magnum oecumenicum Constantiense Concilium de universali ecclesiae reformatione, unione, et fide VI. tomis comprehensum, hrsg. v. Hermann von der Hardt, Bd. 1,877-893. Frankfurt: In officina Genschii, 1697.

Bisticci, Vespasiano da. Le Vite. Hrsg. v. Aulo Greco. Florenz: Nella sede dell'Istituto Palazzo Strozzi, 1970.

Boccaccio, Giovanni. „Trattatello in laude di Dante.” In Opere, hrsg. v. Pier Giorgio Ricci, 565-650. Mailand, Neapel: Riccardo Ricciardi Editore, 1965.

Bracciolini, Poggio. „Oratio in funere domini Francisci cardinalis Florentini.” In Opera omnia, 3 Bde., hrsg. v. Riccardo Fubini, Bd. 1, 252-261. Turin: Bottega d'Erasmo, 1964.

—. Facezie. Biblioteca Universale Rizzoli L 418. Hrsg. v. Marcello Ciccuto. Mailand: Rizzoli, 1983.

- Lettere, 3 Bde., Istituto nazionale di studi sul Rinascimento / Carteggi umanistici 1-3. Hrsg. v. Helene Harth. Florenz: Leo S. Olschi, 1984-1987.

Bruni, Leonardo. Epistolarum libri VIII, 2 Bde. Hrsg. v. Lorenzo Mehus. Florenz: Paperinus, 1741, ND hrsg. v. James Hankins (Rom: Edizioni Storia e Letteratura, 2007).

- Humanistisch-philosophische Schriften. Mit einer Chronologie seiner Werke und Briefe, hrsg. v. Hans Baron. Berlin, Leipzig: Teubner, 1928, ND Wiesbaden: M. Sandig, 1967.

Dialogi ad Petrum Paulum Histrum, Istituto Nazionale di Studi sul Rinascimento / Studi e testi 35, hrsg. v. Stefano Ugo Baldassarri. Florenz: Leo S. Olschi, 1994. 
Bury, Riccardo da. Philobiblon, hrsg. v. Antonio Altamura. Neapel: Fausto Fiorentino Libraio, 1954.

Castiglione, Baldassare. Il libro del Cortegiano, hrsg. v. Giulio Preti. Turin: Einaudi, 1965.

Castiglione, Matteo. Elogi historici. Mantua: Osanna, 1606.

Cortesi, Paolo. De hominibus doctis dialogus. L’ippogrifo 1, hrsg. v. Maria Teresa Graziosi. Rom: Bonacci, 1973.

Cuspinianus, Johannes. De Caesaribus atque imperatoribus romanis opus insigne. Strassburg (Argentorati): Mylius, 1540.

Decembrio, Angelo Camillo. De politia litteraria, Beiträge zur Altertumskunde 169, hrsg. v. Norbert Witten. München/Leipzig: K. G. Saur, 2002.

Donato, Pietro. „Oratio in exequiis Domini Francisci Zabarellae.” In Bibliotheca codicum manuscriptorum monasterii S. Michaelis Venetiarum prope Murianum, hrsg. v. Iohannes-Benedictus Mittarelli, Venedig: Typ. Fentiana, 1779. col. 1236.

Epistolae obscurorum virorum, 2 Bde., hrsg. v. Bömer, Aloys, Stachelschriften, Ältere Reihe 1. Heidelberg: Weissbach, 1924, ND Scientia: Aalen 1978 (2 Bände in 1 Bd.).

Facio, Bartolomeo. „Le invettive di Bartolomeo Facio contro Lorenzo Valla.” Hrsg. v. Robert Valentini, und I. Guidi. Rendiconti della Reale Accademia dei Lincei. Classe di scienze, morali, storiche s. 5.15 (1906): 493-550.

Fillastre, Guillaume. „Gesta concilii Constantiensis.” In Acta Concilii Constantiensis, hrsg. v. Heinrich Finke, Johannes Hollnsteiner und Hermann Heimpel, Bd. 2. 13-170. Münster i. W.: Regensberg, 1896-1928, ND 1981.

Gerson, Johannes. „De probatione spirituum.” In Magnum oecumenicum Constantiense Concilium de universali ecclesiae reformatione, unione, et fide VI. tomis 
comprehensum, hrsg. v. Hermann von der Hardt, Bd. 3, 28-38. Frankfurt: In officina Genschii, 1697.

Hieronymus. „Brief an Pammachius.” Übersetzt v. Wolfgang Buchwald. In Das Problem des Übersetzens, Wege der Forschung 8, hrsg. v. Hans Joachim Störig, 1-13. Darmstadt: Wissenschaftliche Buchgesellschaft, 1963.

Landino, Cristoforo. Comento sopra la Commedia. Hrsg. v. Paolo Procacciali. Rom: Salerno Editrice, 2001.

Petrarca, Franesco. Africa. Edizione Nazionale delle Opere di Francesco Petrarca 1, hrsg. v. Nicola Festa. Florenz; Sansoni, 1926.

—. Le Familiari, 4 Bde. Edizione Nazionale delle Opere di Francesco Petrarca 10-13, hrsg. v. Vittorio Rossi. Florenz: Sansoni, 1865-1938.

—_. „Invectiva contra medicum.” In Invectives, I Tatti Renaissance Library 11. Hrsg. v. David Marsh, 2-179. Cambridge, Massachusetts; London: Harvard University Press, 2003.

—. „Epistola Posteritati.” Hrsg. von Enenkel, Karl A. E. In Modelling the Individual. Biography and Portrait in the Renaissance, Studies in Literature 23, hrsg. v. Betsy De Jong-Crane, Karl A. E. Enenkel und Peter Liebregts, 243-282. Amsterdam, Atlanta: Rodopi, 1998.

Piccolomini, Enea Silvio. „Commentarii in libros Antonii Panormitae poetae de dictis et factis Alfonsi regis.” In Opera quae extant omnia, 387-471. Basel: H. Petri, 1551.

. De viris illustribus, Studi e Testi, 341, hrsg. v. Adrianus Van Heck. Città del Vaticano: Biblioteca Apostolica Vaticana, 1991.

De Europa, Studi e Testi 398, hrsg. v. Adrianus van Heck. Città del Vaticano: Biblioteca Apostolica Vaticana, 2001. 
Richental, Ulrich von. Das Konzil zu Konstanz, 2 Bde., hrsg. v. Otto Feger. Starnberg: Keller/Thorbecke, 1964.

Salutati, Coluccio. Epistolario. Hrsg. v. Francesco Novati. Rom: Tipografi del Senato, 4 Bde. 1891-1911.

Scalamonti, Francesco. Vita clarissimi et famosissimi Kyriaci Anconitani. For Promoting Useful Knowledge 86, hrsg. v. Charles Mitchell und Edward W. S.J. Bodnar. Philadelphia: American Philosophical Society, 1996.

Segovia, Joannes de. Historia gestorum generalis synodi basiliensis, Monumenta conciliorum generalium seculi decimi quinti, Tomus. 3., pars 5 und Tomus 4, hrsg. v. Ernestius Birk. Wien: Typis C. R. Officinae Typographicae Aulae et Status, 1873.

Tomasini, Giacomo Filippo. Petrarcha redivivus. Padua Frambotto, 1650.

Traversari, Ambrosius. Latinae epistolae, hrsg. v. Pietro Cannetti, Lorenzo Mehus. Florenz: Typogr. Caesareum, 1759.

Vergerio, Pier Paolo. Epistolario. Fonti per la storia d'Italia. Epistolari. Secolo XIV-XV 74. Hrsg. v. Leonardo Smith. Rom: Istituto Storico Italiano, 1971.

—. „De ingenuis moribus et liberalibus adolescentiae studiis liber.” In Humanist educational treatises, I Tatti renaissance Library 5, hrsg. v. Craig Kallendorf, 2-91. Cambridge, Massachusetts, London: Harvard University Press, 2002.

Veronese, Guarino. L'epistolario. Miscellanea di storia veneta 11. Hrsg. v. Remigio Sabbadini. Bd. 1. Venedig: R. Deputazione Veneta di Storia Patria, 1915.

Villani, Filippo. De origine civitatis Florentiae et eiusdem famosis civibus. Hrsg. v. Gustavo Camillo Galletti. Florenz: Joannes Mazzoni, 1847.

Vitez de Zredna, Johannes. Opera quae supersunt, Bibliotheca Scriptorum Medii Recentisque Aevorum 3, hrsg. v. Iván Boronkai. Budapest: Akadémiai Kiadó, 1980. 


\subsubsection{Weitere Textausgaben}

Altmann, Wilhelm, Johann Friedrich Böhmer, Hrsg. Die Urkunden Kaiser Sigismunds (14101437), 2 Bde., Regesta Imperii 11. Hildesheim: Olms, 1968, Nd. 1896-1900.

Beckmann, Gustav, Hrsg. Deutsche Reichstagsakten unter Kaiser Sigmund. Sechste Abteilung. 1435-1437. Göttingen: Vandenhoeck \& Ruprecht, 1957 (1901).

Bormann, Eugen und Wilhelm Henzen, Hrsg. Inscriptiones urbis Romae Latinae, Corpus Inscriptionum Latinarum, 6, pars 1. Berlin: Reimer, 1862-1925.

Dallari, Umberto, Hrsg. I rotuli die lettori legisti e artisti dello studio Bolognese dal 1384 al 1799, 4 Bde., Dei Monumenti istorici pertinenti alla provincia della Romagna: Serie 2, Carte 2. Bologna: Merlani, 1888-1924.

Ferrua, Antonius, Hrsg. Epigrammata Damasiana. Città del Vaticano: Pontificio Istituto di Archeologia Christiana, 1942.

Finke, Heinrich, Johannes Hollnsteiner und Hermann Heimpel, Hrsg. Acta Concilii Constantiensis, 4 Bde. Münster i. W.: Regensberg, 1896-1928, ND 1981.

Gauthier, Renatus Antonius, Hrsg. „Ethica Nicomachea. Translatio Antiqissima.” In Aristoteles Latinus, Bd. 26, 2, Brüssel, Leiden: Desclée de Brouwer, 1972.

—, Hrsg. „Ethica Nicomachea. Translatio Roberti Grosseteste Lincolniensis.” In Aristoteles Latinus, Bd. 26, 3. Brüssel, Leiden: Desclée de Brouwer, 1972.

Hardt, Hermann von der, Hrsg. Magnum oecumenicum Constantiense Concilium de universali ecclesiae reformatione, unione, et fide VI. tomis comprehensum. Frankfurt: In officina Genschii, 1697. 
Meyer, Wilhelm. „Quondam fuit factus festus”: ein Gedicht in Spottlatein.” Nachrichten von der Königlichen Gesellschaft der Wissenschaften zu Göttingen. Philologischhistorische Klasse 1 (1908), 406-429.

Palacky, Franz, Hrsg. Urkundliche Beiträge zur Geschichte des Hussitenkrieges, 2 Bde. Prag: Tempsky, 1873, ND. Osnabrück: Biblio-Verlag, 1966.

Solerti, Angelo, Hrsg. Le vite di Dante, Petrarca e Boccaccio scritte fino al secolo decimosesto, Storia letteraria d'Italia 54. Mailand: Vallardi, 1905.

Wolkan Rudolf. Der Briefwechsel des Eneas Silvio Piccolomini, 4 Bde, Fontes Rerum Austriacarum, Abt. 2, Bd. 61, 62, 67, 68. Wien: Hölder, 1909-1918.

Zonta, Gaspare und Giovanni Brotto, Hrsg. Acta Graduum Academicorum Gymnasii Patavini ab anno MCCCCVI ad annum MCCCCL. Padua: Typis Seminarii, 1922.

\section{Sekundärliteratur}

\subsection{Monographien}

Alföldi, Andreas. Der Vater Des Vaterlandes Im Römischen Denken, Libelli 261. Darmstadt: Wissenschaftliche Buchgesellschaft, 1972.

Alidosi, Giovanni Nicolao Pasquali. Li dottori forestieri che in Bologna hanno letto teologia, filosofia, medicina et arti liberali. Bologna: Tebaldini, 1623.

Amann, Martin. Komik in den Tristien Ovids, Schweizerische Beiträge zur Altertumswissenschaft 31. Basel: Schwabe Verlag, 2006.

Ampére, Jean-Jacques. Histoire littéraire de la France avant le douzième siècle. Paris: Hachette, 1839.

Baron, Hans. The Crisis of the Italian Renaissance. Civic Humanism and Republican Liberty in an Age of Classicism and Tyranny. Princeton, New Jersey: Princeton University Press, 1955. (2. Aufl. 1968) 
Beinhoff, Gisella. Die Italiener am Hof Kaiser Sigismunds (1410-1437), Geschichte und ihre Hilfswissenschaften 620. Frankfurt am Main, Berlin, Bern, New York, Paris, Wien: Peter Lang, 1995.

Bentley, Jerry H. Politics and Culture in Renaissance Naples. Princeton: Princeton University Press, 1987.

Benzinger, Josef. Invectiva in Romam. Romkritik im Mittelalter vom 9. bis zum 12. Jahrhundert. Lübeck und Hamburg: Matthiesen Verlag, 1968.

Bertrand, Pascal. „Die Evagriusübersetzung der Vita Antonii. Rezeption - Überlieferung Edition. Unter besonderer Berücksichtigung der Vitas patrum - Tradition.” PhD Diss., Universiteit Utrecht, 2006.

Billanovich, Giuseppe Gli inizi della fortuna di Francesco Petrarca. Rom: Edizioni di Storia e Letteratura, 1947.

Black, Robert. Humanism and Education in Medieval and Renaissance Italy: Tradition and Innovation in Latin Schools from the Twelth to the Fifteenth Century. Cambridge: Cambridge University Press, 2001.

Botley, Paul. Latin Translation in the Renaissance. The Theory and Practice of Leonardo Bruni, Giannozzo Manetti and Desiderius Erasmus. Cambridge: Cambridge University Press, 2004.

Brandmüller, Walter, Hrsg. Das Konzil von Konstanz 1414-1418, Konziliengeschichte Reihe A. 2 Bde. Padernborn, München, Wien, Zürich: Ferdinand Schöning, 1991, 1997.

Burdach, Konrad. Aus Petrarcas ältestem deutschen Schülerkreise. Texte und Untersuchungen, Vom Mittelater zur Reformation 4. Berlin: Weidmannsche Buchhandlung, 1929. 
Classen, Carl Joachim. Die Stadt im Spiegel der Descriptiones und Laudes urbium in der antiken und mittelalterlichen Literatur bis zum Ende des zwölften Jahrhunderts. Hildesheim, Zürich, New York: Georg Olms Verlag, 1986.

Cecchelli, Carlo. I Margani, i Capocci, i Sanguigni, i Mellini, Le grandi famiglie romane 4. Rom: Reale Istituto di Studi Romani Editore, 1946.

Csapodi - Gárdonyi, Klára. Die Bibliothek des Johannes Vitéz. Budapest, Akadémiai Kiadó, 1984.

Copeland, Rita. Rhetoric, Hermeneutics and Translation in the Middle Ages. Academic Traditions and Vernacular Texts. Cambridge: Cambridge University Press, 1991.

de la Mare, Albinia Catherine. The Handwriting of Italian Humanists. Oxford: Oxford University Press, for the Association Internationale de Bibliophilie, 1973.

Dronke, Peter. Verse with Prose. From Petronius to Dante. The Art and Scope of the Mixed Form. Cambridge, Massachusetts, London: Harvard University Press, 1994.

Fantuzzi, Giovanni. Notizie degli Scrittori Bolognesi. Bologna: D’Aquino, 1781-1794.

Fera, Vincenzo. Antichi editori e lettori dell'Africa, Itinerari Eruditi 2. Messina: Centro di Studi Umanistici, 1984.

Finke, Heinrich. Bilder vom Konstanzer Konzil. Neujahrsblätter der badischen Histor. Kommission: Heidelberg, 1903.

Flood, John L. Poets Laureate in the Holy Roman Empire. 4 Bde. Berlin, New York: Walter de Gruyter, 2006.

Folts, James Donald. „In Search of the „Civil Life": An Intellectual Biography of Poggio Bracciolini.” PhD Diss., University of Rochester, 1976. 
Fried, Johannes. „Geschichte und Gehirn: Irritationen der Geschichtswissenschaft durch Gedächtniskritik.” Abhandlungen der Geistes- und Sozialwissenschaftlichen Klasse / Akademie der Wissenschaften und der Literatur 7 (2003): 5-43.

—. Der Schleier der Erinnerung. Grundzüge einer historischen Memorik. München: C. H. Beck, 2004.

Garms, Jörg. Die mittelalterlichen Grabmäler in Rom und Latium vom 13. bis zum 15. Jahrhundert, 2 Bde. Wien: Verlag der Österreichischen Akademie der Wissenschaften, 1981-1994.

Girgensohn, Dieter. Peter von Pulkau und die Wiedereinführung des Laienkelches. Leben und Wirken eines Wiener Theologen in der Zeit des großen Schismas, Veröffentlichungen des Max-Planck-Instituts für Geschichte 12. Göttingen: Vandenhoeck\&Ruprecht, 1964.

Greenblatt, Stephen. Renaissance Self-Fashioning: From More to Shakespeare. Chicago ; London: University of Chicago Press, 1980.

Grendler, Paul F. Schooling in Renaissance Italy: Literacy and learning 1300-1600. Baltimore: Johns Hopkins University Press, 1989.

- The Universities of the Italian Renaissance. Baltimore und London: The Johns Hopkins University Press, 2002.

Hankins, James. Repertorium Brunianum. A critical guide to the writings of Leonardo Bruni, Fonti per la storia dell'Italia medievale 5. Rom: Istituto Storico Italiano per il medio Evo, 1997.

Haskins, Charles Homer. The Renaissance of the Twelth Century. Cambridge: Harvard University Press, 1927.

Haye, Thomas. Lateinische Oralität. Gelehrte Sprache in der mündlichen Kommunikation des hohen und späten Mittelalters. Berlin, New York: Walter de Gruyter, 2005. 
Hedrick, Charles W. History and Silence: Purge and Rehabilitation of Memory in Late Antiquity. Austin: University of Texas Press, 2000.

Hirschi, Caspar. Wettkampf der Nationen. Konstruktionen einer deutschen Ehrgemeinschaft an der Wende vom Mittelalter zur Neuzeit. Göttingen: Wallstein, 2005.

Hoensch, Jörg K. Kaiser Sigismund. Herrscher an der Schwelle zur Neuzeit. München: Beck, 1997.

Hofman, Walther von. Forschungen zur Geschichte der kurialen Behörden: vom Schisma bis zur Reformation, 2 Bde. Rom: Verlag von Loescher\& C., 1914.

Huszti, József. Janus Pannonius. Pécs: Janus Pannonius Társaság [Janus Pannonius Gesellschaft], 1931.

Janko, Richard. Aristotle on Comedy. Towards a Reconstruction of Poetics II. Berkeley and Los Angeles: University of California Press, 1984.

Kajanto, Iiro. Classical and Christian. Studies in the Latin Epitaphs of Medieval and Renaissance Rome, Annales Academiae Scientiarum Fennicae 203. Helsinki: Suomalainen Tiedeakatemia, 1980.

Kardos, Tibor. A magyarországi humanizmus kora [Das Zeitalter des ungarischen Humanismus]. Budapest: Akadémiai Kiadó, 1955.

Kisch, Guido. Humanismus und Jurisprudenz. Der Kampf zwischen mos italicus und mos gallicus an der Universität Basel. Basel: Helbing \& Lichtenhahn, 1955.

- Gestalten und Probleme aus Humanismus und Jurisprudenz. Berlin: Walter de Gruyter 1969. 
Klaniczay, Tibor. A Magyarországi akadémiai mozgalom elötörténete [Die Vorgeschichte der ungarischen akademischen Bewegungen], Humanizmus és Reformáció 20. Budapest: Balassi Kiadó, 1993.

Klecker, Elisabeth. Dichtung über Dichtung. Homer und Vergil in lateinischen Gedichten italienischer Humanisten des 15. und 16. Jahrhunderts, Wiener Studien 20, Arbeiten zur mittel- und neulateinischen Philologie 2. Wien: Verlag der Österreichischen Akademie der Wissenschaften, 1994.

Lipking, Lawrence. The Life of the Poet. Beginning and Ending Poetic Careers. Chicago, London: The University of Chicago Press, 1981.

Martin, Anna Julia. Was ist Exil? Ovids Tristia und Epistulae ex Ponto, Spudasmata 99. Hildesheim, Zürich, New York: Georg Olms Verlag, 2004.

Mazzetti, Serafino. Repertorio di tutti i professori antichi, e moderni della famosa università e del celebre istituto delle scienze di Bologna. Bologna: Tipografia di San Tommaso d'Aquino, 1847.

Mályusz, Elemér. Das Konstanzer Konzil und das königliche Patronatsrecht in Ungarn, Studia Historica 18. Budapest: Akadémiai Kiadó, 1959.

—. Zsigmond király uralma Magyarországon 1387-1437, [König Sigismund in Ungarn 1387-1437]. Budapest: Gondolat, 1984.

Menzel, Wolfgang. Geschichte der Deutschen bis auf die neusten Tage. Stuttgart, Tübingen: Cotta, 1837 (3. Aufl).

McManamon, John M. „Innovation in Early Humanist Rhetoric: The Oratory of Pier Paolo Vergerio the Elder." Rinascimento 2. s. 22 (1982): 3-32. 
- Pierpaolo Vergerio the Elder. The Humanist as Orator, Medieval and Renaissance Texts and Studies 163. Tempe: Arizona Center for Medieval and Renaissance Studies, 1996.

- Pierpaolo Vergerio the Elder and Saint Jerome: An Edition and Translation of „Sermones pro Sancto Hieronymo”, Medieval and Renaissance Texts and Studies 177. Tempe: Arizona Center for Medieval and Renaissance Studies, 1999.

Mommsen, Theodor E. Petrarch's Tetstament. Ithaca, New York: Cornell University Press, 1957.

Morrissey, Thomas Edward. „Franciscus de Zabarellis (1360-1417) and the conciliarist traditions.” PhD. Diss., Cornell University, 1973.

Muhlack, Ulrich. Geschichtswissenschaft im Humanismus und in der Aufklärung. Die Vorgeschichte des Historismus. München: C.H. Beck, 1991.

Müller, Harald. Habit und Habitus. Mönche und Humanisten im Dialog. Spätmittelalter und Reformation, N. R. 32. Tübingen: Mohr Siebeck, 2006.

Nighman, Chris. „Reform and Humanism in the Sermons of Richard Fleming at the Council of Constance (1417).” PhD Diss., University of Toronto, 1996.

Oschema, Klaus. Freundschaft und Nähe im spätmittelalterlichen Burgund. Studien zum Spannungsfeld von Emotion und Institution, Norm und Struktur 26. Köln, Weimar, Wien: Böhlau Verlag, 2006.

Pabst, Bernhard. Prosimetrum. Tradition und Wandel einer Literaturform zwischen Spätantike und Spätmittelalter, 2 Bde., Ordo. Studien zur Literatur und Gesellschaft des Mittelalters 4. Köln, Weimar, Wien: Böhlau, 1994.

Paparelli, Gioacchino. Callimaco Esperiente (Filippo Buonaccorsi). Salerno: Edizioni Beta, 1971. 
Paré, Gérard; Adrien Brunet und Pierre Tremblay. La Renaissance du xiie siècle. Les écoles et l'enseignement. Ottawa und Paris: Vrin, Institut d'études médiévales, 1933.

Pastor, Ludwig von. Geschichte der Päpste im Zeitalter der Renaissance bis zur Wahl Pius II.; Martin V., Eugen IV., Nikolaus V., Kalixtus III. Freiburg (Br.): Herder, 1925, 5. Aufl.

Patschovsky, Alexander. Der italienische Humanismus auf dem Konstanzer Konzil (14141418). Konstanz: Universitätsverlag Konstanz GMBH, 1999.

Quadlbauer, Franz. Die antike Theorie der genera dicendi im lateinischen Mittelalter. Wien: Hermann Böhlaus Nachf., 1962.

Rathmann, Thomas. Geschehen und Geschichten des Konstanzer Konzils. Chroniken, Briefe, Lieder und Sprüche als Konstituenten eines Ereignisses, Forschungen zur Geschichte der älteren deutschen Literatur 20. München: Wilhelm Fink Verlag, 2000.

Reali, Mauro. Il Contributo Dell'epigrafia latina allo studio dell'amicitia: Il caso della Cisalpina, Pubblicazione della Facoltà di lettere dell’Università degli studi di Milano, 176. Florenz: La Nuova Italia Editrice, 1998.

Relihan, Joel C. Ancient Menippean Satire. Baltimore, London: The Johns Hopkins University Press, 1993.

Rico, Francisco. Vida u obra de Petrarca. I. Lectura del Secretum. Padua: Antenore, 1974.

Riegel, Joseph. Die Teilnehmerlisten des Konstanzer Konzils. Ein Beitrag zur mittelalterlichen Statistik. Inaugural-Dissertation. Freiburg: Caritas-Druckerei, 1916.

Rüegg, Walter. Cicero und Humanismus. Formale Untersuchungen über Petrarca und Erasmus. Winterthur: Buchdruckerei Winterthur AG., 1946.

Sabbadini, Remigio. Le scoperte dei codici latini e greci ne'secoli XIV e XV, 2 Bde. Florenz: Casa Ed. Le lettere, 1905-1914, ND Florenz 1967. 
_. Il metodo degli umanisti. Florenz: Le Monnier, 1920.

. Storia e critica di testi latini. Padua: Antenore, 1971.

Schirrmeister, Albert. Triumph des Dichters. Gekrönte Intellektuelle im 16. Jahrhundert. Frühneuzeitstudien N. F. 3. Köln, Weimar und Wien: Böhlau, 2003.

Steinherz, Samuel. Ein Fürstenspiegel Karls IV., Quellen und Forschungen aus dem Gebiete der Geschichte 3. Prag: Verlag der Deutschen Gesellschaft der Wissenschaften und Künste für die Tschechoslowakische Republik, 1925.

Stewart, Alan. Close Readers: Humanism and Sodomy in Early Modern England. Princeton, N.J.: Princeton University Press, 1997.

Stump, Philip H. The Reforms of the Council of Constance. Studies in the History of Christian Thought 53. Leiden, New York, Köln: Brill, 1994.

Tanner, Marcus. The Raven King. Matthias Corvinus and the Fate of His Lost Library. New Haven, London: Yale University Press, 2008.

Thorn-Wickert, Lydia. Manuel Chrysoloras (Ca. 1350-1415). Eine Biographie des byzantinischen Intellektuellen vor dem Hintergrund der hellenistischen Studien in der italienischen Renaissance, Bonner romanistische Arbeiten 92. Frankfurt am Main, Berlin, Bern, Bruxelles, New York, Oxford, Wien: Peter Lang, 2006.

Troje, Hans Erich. Humanistische Jurisprudenz. Studien zur europäischen Rechtswissenschaft unter dem Einfluss des Humanismus. Goldbach: Keip Verlag, 1993.

Vedova, Giuseppe. Memorie intorno alla vita ed alle opere del cardinale Francesco Zabarella. Padua: Coi tipi della Minerva, 1829.

Vermeer, Hans J. Skizzen zu einer Geschichte der Translation. Anfänge von Mesopotamien bis Griechenland. Rom und das frühe Christentum bis Hieronymus, 2 Bde., Translato- 
risches Handeln - Wissenschaft 6. Frankfurt am Main: Verlag für Interkulturelle Kommunikation, 1992.

Voigt, Georg. Die Renaissance: Die Wiederbelebung des classischen Alterthums, 2 Bde. Berlin: Aretz, 1932.

Voigt, Klaus. Italienische Berichte aus dem spätmitteralterlichen Deutschland. Von Francesco Petrarca zu Andrea de 'Franceschi. Stuttgart: Ernst Klett Verlag, 1973.

Walser, Ernst. Poggius Florentinus. Leben und Werke, Beiträge zur Kulturgeschichte des Mittelalters und der Renaissance 14, hrsg. v. Walter Goetz. Leipzig, Berlin: Teubner, 1914.

Wilson, Nigel Guy. From Byzantium to Italy. Greek Studies in the Italian Renaissance. London: Duckworth, 1992.

Witt, Ronald G. In the Footsteps of the Ancients, Studies in Medieval and Reformation Thought 74. Leiden: Brill, 2000.

Zemplényi, Ferenc. Az európai kultúra és a magyar irodalom, [Die europäische Kultur und die ungarische Literatur], Historia Litteraria 4. Budapest: Universitas, 1998.

Ziliotto, Baccio. La cultura letteraria di Trieste e dell'Istria, Trieste: Vram, 1913.

\subsection{Artikeln in Zeitschriften und Sammelbänden}

Aurigemma, Marcello. „Il „Sermo de vita Francisci Petrarchae" di Pier Paolo Vergerio.” In Studi filologici, letterari e storici in memoria di Guido Favati, hrsg. v. Giorgio Varanini. 33-53. Padua: Antenore, 1977.

Avesani, Rino. „La Professione dell’ „Umanista" nel Cinquecento.” Italia Medioevale e Umanistica, 13 (1970): 205-232. 
Baron, Hans. „Bruni's Laudatio Florentinae Urbis.” In Hans Baron, From Petrarch to Leonardo Bruni. Studies in Humanistic and Political Literature, 232-263. Chicago und London: The University of Chicago Press, 1968.

Bayley, Charles Calvert. „Petrarch, Charles IV, and the „Renovatio Imperii".” Speculum 17 (1942): 323-341.

Bánfi, Florio. „Pier Paolo Vergerio Il Vecchio in Ungheria 1-2.” Archivio di Scienze, Lettere ed Arti della Società Italo-Ungherese 1 und 2 (1939-1940): 1-30 und 17-29.

Bertalot, Ludwig. „Benedictus de Pileo in Konstanz.” In Ludwig Bertalot, Studien zum italienischen und deutschen Humanismus, 2 Bde., Storia e Letteratura, Studi e Testi 130. Hrsg. v. Paul Oskar Kristeller, 305-310. Rom: Edizioni di Storia e Letteratura, 1975.

Billanovich, Giuseppe. „Petrarca e i retori latini minori.” Italia Medioevale e Umanistica 19 (1962): 103-164.

„Auctorista, Humanista, Orator.” Rivista di cultura classica medioevale 7 (1965): 143-163.

Birnbaum, Marianna D. „Humanism in Hungary.” In Renaissance Humanism. Foundations, Forms and Legacy, hrsg. v. Albert Rabil, Bd 2, 293-334. Philadelphia: University of Pennsylvania Press, 1988.

Black, Robert. „Humanism.” In The New Cambridge Medieval History c. 1415- c. 1500, The New Cambridge Medieval History 7, hrsg. v. Christopher Allmand, 243-277. Cambridge: Cambridge University Press, 1998.

Blatt, Franz. „Die letzte Phase der lateinischen Sprache.” Archivium Latinitatis Medii Aevi 40 (1975): 65-75.

Borzsák, István. „Exegi Monumentum Aere Perennius...” Antik Tanulmányok 11 (1964): 4956. 
Boskoff, Priscilla F. „Quintilian in the Middle Ages.” Speculum 27 (1952): 71-78.

Bourdieu, Pierre. „Ökonomisches Kapital, kulturelles Kapital, soziales Kapital.” In Soziale Ungleichheiten, Soziale Welt, Sonderband 2, hrsg. v. Reinhard Kreckel, 183-198. Göttingen: Verlag Otto Schwartz\& Co., 1983.

Calcaterra, Carlo. „Sant Agostino nelle opere di Dante e Petrarca.” In Nella selva del Petrarca, 291-306. Bologna: Editore Licinio Cappelli, 1942.

Campana, Augusto. „The Origin of the Word „Humanist".” Journal of the Warburg and Courtauld Institutes 9 (1946): 60-73.

Clark, Albert C. „The Literary Discoveries of Poggio.” Classical Review 13 (1899): 119-130.

Combi, Carlo. „Un discorso inedito di P. P. V. il Seniore di Capodistria.” Archivio Storico per Trieste, l'Istria e il Trentino 1 (1882): 351-374.

Csapodi, Csaba. „A magyar könyvkultúra Zsigmond korában [Ungarische Buchkultur im Zeitalter von Sigismund]", Magyar Könyvszemle 111 (1995): 1-14.

Decker, Wolfgang. „Angelotto Foschi.” In Dizionario Biografico degli Italiani, Bd. 49 (1997): 429-431. Rom: Treccani, 1960-.

Donato, Maria Monica. „Famosi cives" Testi, frammenti e cicli perduti a Firenze fra Tre e Quattrocento.” Ricerche di storia dell'arte 30 (1986): 27-43.

Elliott, Dyan. „Seeing double: John Gerson, the Discernment of Spirits and Joan of Arc.” The American Historical Review 107, (2002): 26-54.

Enenkel, Karl A. E. „Modelling the Humanist: Petrarch's Letter to Posterity and Boccaccio’s Biography of the Poet Laureate." In Modelling the Individual. Biography and Portrait in the Renaissance, Studies in Literature 23, hrsg. v. Betsy De Jong-Crane, Karl A. E. Enenkel und Peter Liebregts, 11-49. Amsterdam, Atlanta: Rodopi, 1998. 
Erkens, Franz-Rainer. „Über Kanzlei und Kanzler König Sigismunds. Zum Kontinuitätsproblem in der deutschen Königskanzlei unter dem letzten Luxemburger." Archiv für Diplomatik 33 (1987): 429-458.

Festa, Nicola. „Prefazione”, in Francesco Petrarca, Africa, Edizione Nazionale delle Opere di Francesco Petrarca 1, hrsg. v. Nicola Festa, XI-LXX. Florenz: Sansoni, 1926.

Fink, Karl August. „Die Wahl Martins V.” In Das Konstanzer Konzil, Wege der Forschung 415, hrsg. v. Remigius Bäumer, 306-322. Darmstadt: Wissenschaftliche Buchgesellschaft, 1977.

Finke, Heinrich. „Das Quellenmaterial zur Geschichte des Konstanzer Konzils.” Zeitschrift für die Geschichte des Oberrheins 70 (1916): 253-275.

Firnhaber, Friedrich. „Petrus de Pulka, Abgesandter der Wiener Universität am Concilium zu Constanz.” Archiv für österreichische Geschichte 15 (1856): 1-70.

Flood, John L. „Viridibus lauri ramis et foliis decoratus. Zur Geschichte der kaiserlichen Dichterkrönungen.” In Reichspersonal. Funktionsträger für Kaiser und Reich, hrsg. v. Anette Baumann, Peter Oestmann, Stephan Wendehorst and Siegrid Westphal, 353377. Köln, Weimar, Wien: Böhlau, 2004.

Frenken, Ansgar. „Pier Paolo Vergerio (der Ältere).” In Biographisch-Bibliographisches Kirchenlexikon, hrsg. v. Friedrich Wilhelm Bautz (ab Band 3 fortgeführt von Traugott Bautz), Bd. 14, Spalten 1572-1576. Herzberg: Verlag Traugott Bautz, 1975-.

—. „Die Quellen des Konstanzer Konzils in den Sammlungen des 17. und 18. Jahrhunderts.” Annuarium Historiae Conciliorum 30, (1998): 416-439.

Frenz, Thomas. „Das Eindringen humanistischer Schriftformen in die Urkunden und Akten der päpstlichen Kurie im 15. Jahrhundert, 1-2.” Archiv für Diplomatik 19 und 20 (1973 und 1974): 287-418 und 384-506. 
Frings, Irene. „Mantua me genuit - Vergils Grabepigramm auf Stein und Pergament.” Zeitschrft für Papyrologie und Epigraphik 123 (1998): 89-100.

Fubini, Riccardo. „Un’ orazione di Poggio Bracciolini sui vizi del clero scritta al tempo del concilio di Costanza." Giornale storico della letteratura italiana 142 (1965): 24-33.

—. „Il „teatro del mondo" nelle prospettive morali e storico-politiche di Poggio Bracciolini." In Poggio Bracciolini 1380-1980. Nel VI. Centenario della nascita, Studi e testi / Istituto Nazionale di Studi sul Rinascimento 8, hrsg. v. Riccardo Fubini und Cesare Vasoli, 1-135. Florenz: Sansoni, 1982.

Gallo, Rodolfo. „Due informazioni sullo studio di Padova della metà del Cinquecento.” Archivio Veneto, 73, s. 5 (1963): 17-100.

Gerl-Falkowitz, Hanna-Barbara. Philosophie und Philologie, Humanistische Bibliothek 1, 42. München: Wilhelm Fink Verlag, 1981.

Gilli, Patrick. „L'humanisme français au temps du concile de Constance.” In Humanisme et culture géographique à l'époque du concile de Constance autour de Guillaume Fillastre, Actes du Colloque de l'Université de Reims 18-19 Novembre 1999, History of the Representation of Space in Text and Image 3, hrsg. v. Didier Marcotte, 41-62. Turnhout: Brepols, 2002.

Girgensohn, Dieter. „Die Universität Wien und das Konstanzer Konzil.” In Das Konzil von Konstanz. Beiträge zu seiner Geschichte und Theologie. Festschrift unter dem Protektorat seiner Exzellenz des hochwürdigsten Herrn Erzbischofs Dr. Hermann Schäufele, hrsg. v. August Franzen und Wolfgang Müller, 252-281. Freiburg, Basel, Wien: Herder, 1964.

. „Wie wird man Kardinal? Kuriale und außerkuriale Karrieren an der Wende des 14. zum 15. Jahrhundert." Quellen und Forschungen aus italienischen Archiven und Bibliotheken 57 (1977): 138-162. 
—. „Francesco Zabarella aus Padua. Gelehrsamkeit und politisches Wirken eines Rechtsprofessors während des großen abendlandischen Schismas.” Zeitschrift der Savigny-Stiftung für Rechtsgeschichte, Kanonistische Abteilung 79=110=123 (1993): 232-277.

—. „Studenti e tradizione delle opere di Francesco Zabarella nell'Europa centrale.” In Studenti, università, città nella storia padovana. Atti del convengno, Padova 6-8 febbraio 1998, Contributi alla storia dell'Università di Padova 34, hrsg. v. Francesco Piovan und Sitran Rea Luciana, 127-176. Triest: Lint, 2001.

—_ .Die Stellung Francesco Zabarellas im Humanismus." In Prusy - Polska - Europa. Studia $z$ dziejów sredniowiecza $i$ czasów nowozaytnych. Prace poswiecone profesorowi Zenonowi Hubertowi Nowakowi w szesndziesieciopieciolecie urodzin $i$ czterdziestolecie pracy naukowej, hrsg. v. Anrzej Radziminski und Janusz Tandecki, 57-72. Torun: Wydawnictwo Naukowe Umk, 1999.

Goetz, Hans-Werner. „Wahrnehmung” der Arbeit als Erkenntnisobjekt der Geschichtswissenschaft." In Arbeit Im Mittelalter, hrsg. v. Verena Postel, 21-35. Berlin: Akademie Verlag, 2006.

Gombrich, Ernst H. „Antike Regeln und objektive Kriterien. Von der Schrift- und Sprachreform zur Kunst der Renaissance: Niccolo Niccoli und Filippo Brunelleschi.” In Die Entdeckung des Sichtbaren. Zur Kunst der Renaissance Bd. 3., 114-135. Stuttgart: Klett, 1987 (1967).

Gordan, Phyllis Goodhart. „Poggio at the Curia.” In Umanesimo a Roma nel Quattrocento, hrsg. v. Paolo Brezzi und Maristella de Panizza Lorch, 113-127. Rom, New York: Istituto di Studi Romani, Barnard College, 1984.

Gorni, Guglielmo. „Tommaso Cambiatore.” In Dizionario Biografico degli Italiani, Bd. 16, S. 132-133. Rom: Treccani, 1960-

Gray, Hannah H. „Renaissance Humanism: The Pursuit of Eloquence.” Journal of the History of Ideas 24, (13): 497-514. 
Grayson, Cecil. „Benedetto da Piglio.” In Dizionario Biografico degli Italiani, Bd. 8. 443444. Rom: Treccani, 1960-.

Green, Dennis H. „Alieniloquium. Zur Begriffbestimmung der mittelalterlichen Ironie.” In Verbum et Signum. Beiträge zur mediävistischen Bedeutungsforschung. Studien zu Semantik und Sinntradition im Mittelalter, 2 Bde., hrsg. v. Hans Harms, Wolfgang Fromm, und Uwe Ruberg, Bd. 2, 119-159. München: Wilhelm Fink, 1975.

Grendler, Paul F. „Reply to Robert Black.” Journal of the History of Ideas 52, no. 2 (1991): 335-337.

—. „Education and Society in Florentine Tuscany: Teachers, Pupils and Schools, C. 1250-1500 (Besprechung).” Renaissance Quarterly 61 (2008): 509-511.

Grundmann, Herbert. „Litteratus-illitteratus. Der Wandel einer Bildungsnorm vom Altertum zum Mittelalter.” In Herbert Grundmann, Ausgewählte Aufsätze, 1-66. Stuttgart: Anton Hiersemann, 1978.

Gumbert, Johann Peter. „Italienische Schrift - Humanistische Schrift - Humanistenschrift.” In Renaissance und Humanistenschriften, Schriften des Historischen Kollegs Kolloquien 13, hrsg. v. Johanne Autenrieth, 63-71. München: R. Oldenbourg Verlag, 1988.

Hankey, Teresa. „Salutati's Epigrams for the Palazzo Vecchio at Florence.” Journal of the Warburg and Courtauld Institutes 22, (1959): 363-365.

Hankins, James. „The „Baron Thesis" After Forty Years and Some Recent Studies of Leonardo Bruni." Journal of the History of Ideas 56 (1995): 309-338.

—. „Renaissance Crusaders. Humanist Literature in the Age of Mehmed II.” Dumberton Oaks Papers 49 (1995): 111-207. 
—. „Manuel Chrysoloras and the Greek Studies of Leonardo Bruni.” In Humanism and Platonism in the Italian Renaissance, 2 Bd., Storia e letteratura 215, 220, ders., Bd. 1, 243-266. Rom: Edizioni di Storia e Letteratura, 2003.

Harth, Helene. „Überlegungen zur Öffentlichkeit des humanistischen Briefs am Beispiel der Poggio-Korrespondenz." In Kommunikationspraxis und Korrespondenzwesen im Mittelalter und in der Renaissance, hrsg. v. Heinz-Dieter Heimann und Ivan Hlaváček, 127-137. Paderborn: Ferdinand Schöningh, 1998.

Helmrath, Johannes. „Kommunikation auf den spätmittelalterlichen Konzilien.“ In Die Bedeutung der Kommunikation für Wirtschaft und Gesellschaft, hrsg. v. Hans Pohl, 116-172. Stuttgart: Franz Steiner Verlag, 1989.

—. „Pius II. und die Türken.” In Europa und die Türken in der Renaissance, hrsg. v. Bodo Guthmüller und Wilhelm Kühlmann, 79-137. Tübingen: Max Niemeyer Verlag, 2000.

. „Diffusion des Humanismus. Zur Einführung.” In Diffusion des Humanismus, hrsg. v. Johannes Helmrath, 9-29. Göttingen: Wallstein Verlag, 2002.

—. „Vestigia Aeneae imitari. Enea Silvio Piccolomini als „Apostel" des Humanismus. Formen und Wege seiner Diffusion.” In Diffusion des Humanismus, hrsg. v. Johannes Helmrath, 99-141. Göttingen: Wallstein Verlag, 2002.

- „Diffusion des Humanismus und Antikrezeption auf den Konzilien von Konstanz, Basel und Ferrara/Florenz.” In Die Präsenz der Antike im Übergang vom Mittellater zur Frühen Neuzeit. Bericht über Kolloquien der Kommission zur Erforschung der Kultur des Spätmittelalters 1999-2002, Abhandlungen der Akademie der Wissenschaften zu Göttingen, Philologisch-Historische Klasse, 3. Folge, 263, hrsg. v. Ludger Grenzmann, Klaus Grubmüller, Fidel Rädle und Martin Staehlin, 8-56. Göttingen: Vandenhoeck \& Ruprecht, 2004. 
—. „Der europäische Humanismus und die Funktionen der Rhetorik.” In Funktionen des Humanismus. Studien zum Nutzen des Neuen in der humanistischen Kultur, hrsg. v. Thomas Maissen und Gerrit Walter, 18-48. Göttingen: Wallstein, 2006.

Hobbins, Daniel. „The Schoolman as Public Intellectual: Jean Gerson and the Late Medieval Tract." The American Historical Review 108 (2003): 45 pars. 2 Mar. 2008, http://www.historycooperative.org/journals/ahr/108.5/hobbins.html.

Hollnsteiner, Johannes. „König Sigismund auf dem Konstanzer Konzil. Nach den Tagebuchaufzeichnungen des Kardinal Fillastre.” Mitteilungen des Österreichischen Instituts für Geschichtsforschung 41 (1926): 185-200.

Hruza, Karel. „Propaganda, Kommunikation und Öffentlichkeit im Mittelalter.” In Propaganda, Kommunikation und Öffentlichkeit (11.-16. Jahrhundert), Forschungen zur Geschichte des Mittelalters 6, hrsg. v. Karel Hruza, 9-25. Wien: Verlag der Österreichischen Akademie der Wissenschaften, 2002.

Huszti, József. „Pier Paolo Vergerio és a magyar humanizmus kezdetei [Pier Paolo Vergerio und die Anfänge des ungarischen Humanismus].” Filológiai Közlöny, 1 (1955): 521533.

Ianziti, Gary. „Bruni on Writing History.” Renaissance Quarterly 51 (1998): 367-391.

IJsewijn, Jozef. „Mittelalterliches Latein und Humanistenlatein.” In Die Rezeption der Antike. Zur Problem der Kontinuität zwischen Mittelalter und Renaissance, Wolfenbütteler Abhandlungen zur Renaissanceforschung 1, hrsg. v. August Buck, 71-83. Hamburg: Hauswedell, 1981.

Jeudy, Colette. „La bibliothèque de Guillaume Fillastre.” In Humanisme et culture géographique à l'époque du concile de Constance autour de Guillaume Fillastre, Actes du Colloque de l'Université de Reims 18-19 Novembre 1999, History of the Representation of Space in Text and Image 3, hrsg. v. Didier Marcotte, 245-291. Turnhout: Brepols, 2002. 
Jocelyn, Henry David. „Petrarch and the Classical Drama.” In Petrarca e la cultura europea, hrsg. v. Luisa Rotondi Secchi Tarugi, 31-54. Mailand: Nuovi Orizzonti, 1997.

Kardos, Tibor. „Petrarca e la formazione dell'umanesimo ungherese.” In Italia ed Ungheria. Dieci secoli di rapporti letterari, hrsg. v. Mátyás Horányi und Tibor Klaniczay, 67-89. Budapest: Akadémiai Kiadó, 1967.

Kristeller, Paul Oskar. „The Humanist Bartolomeo Facio and His Unknown Correspondence.” In From the Renaissance to the Counter-Reformation, Essays in the honour of Garrett Mattingly. Hrsg. v. Charles H. Carter, 56-74. New York: Random House, 1965.

—. „Humanism and Scholasticism.” In Renaissance Thought and Its Sources, hrsg. v. Michael Mooney, 85-105. New York: Columbia University Press, 1979.

Lehmann, Paul. „Konstanz und Basel als Büchermärkte während der großen Kirchenversammlungen." In Erforschung des Mittelalters. Ausgewählte Abhandlungen und Aufsätze, 5 Bde., hrsg. v. Paul Lehmann, Bd. 1. 253-280, (Stuttgart: Hirsemann, 19411962).

Lehnerdt, Max. „Cencio und Agapito de’ Rustici.” Zeitschrift für vergleichende Literaturgeschichte 14 (1901): 147-72; 289-318.

Lytle, Guy Fitch. „Friendship and Patronage.” In Patronage, Art, and Society in Renaissance Italy, hrsg. v. Francis W. Kent und Patricia Simons, 47-61. Oxford, Canberra: Humanities Research Center, Clarendon Press 1987.

Magni, Domenico. „Gasparino Barzizza, una figura del primo umanesimo.” Bergomum, 31 (1937) 104-118, 143-170, und 205-222.

Martellotti, Guido. „Bartolomeo del Regno.” in Dizionario Biografico degli Italiani. Bd. 6 (1964): 764-765. Rom: Treccani, 1960-. 
Mertens, Dieter. „Zu Sozialgeschichte und Funktion des poeta laureatus im Zeitalter Maximilians I.” In Gelehrte im Reich. Zur Sozial- und Wirkungsgeschichte akademischer Eliten des 14. Bis 16. Jahrhunderts, hrsg. v. Rainer Christoph Schwinges, 327348. Berlin: Duncker\&Humblot, 1996.

Miethke, Jürgen. „Die Konzilien als Forum der öffentlichen Meinung im 15. Jahrhundert“, DA 37 (1981) 736-773.

—_. „Die großen Konzilien des 15. Jahrhunderts als Medienereignis: Kommunikation und intellektueller Fortschritt auf den Großtagungen." In University, Council, City. Intellectual culture on the Rhine (1300-1559), hrsg. v. Laurent Cesalli und Nadja Germann, 291-322. Turnhout: Brepols, 2007.

Moles, J. L. „The Interpretation of the „Second Preface" in Arrian's Anabasis.” The Journal of Hellenic Studies 105 (1985): 162-168.

Mommsen, Theodor E. „Petrarch's Conception of the 'Dark Ages'.” Speculum 17 (1942): 226-242.

Montenovesi, Ottorino „Roma agli inizi del sec. XV e S. M. Nova.” Rivista Storica Benedettina 17 (1926): 240-347.

Morrissey, Thomas Edward. „The Decree Haec Sancta and the Cardinal Zabarella: His Role in Its Formulation and Interpretation.” Annuarium Historiae Conciliorum 10 (1978): 145-176.

—. „Emperor-Elect Sigismund, Cardinal Zabarella, and the Council of Constance.” The Catholic Historical Review 69, (1983): 353-370.

—. „The Call for Unity at the Council of Constance: Sermons and Addresses of Cardinal Zabarella, 1415-1417." Church History 53 (1984): 307-318. 
Mücke, Rudolf. „Die Ülzener Handschrift zu Senecas Briefen”. In Jahresbericht über die Königliche Klosterschule zu Ilfeld,. 1-43. Nordhausen: C. Kirchner's Buchdruckerei, 1895.

Necchi, Elena. „Una silloge epigrafica padovana: gli epigrammata illustrium virorum di Iohannes Hasenbeyn.” Italia Medioevale e Umanistica 35 (1992): 123-177.

Németh, András. „Az Egyetemi Könyvtár Cod. Lat. 20. kódexének új vizsgálata és a benne szereplő Phalarisz-levél fordítása [Die neue Untersuchung des Codex Nr. 20 der Universitätsbibliothek von Budapest und die Übersetzung des in dem zu befindenden Phalaris-Briefes]." Az Egyetemi Könyvtár Évkönyvei [Die Jahrbücher der Universitätsbibliothek von Budapest] 12 (2005): 61-92.

Ouy, Gilbert. „Discovering Gerson the Humanist.” In A Companion to Gerson, Brill's Companions to the Christian Tradition 3, hrsg. v. Brian Patrick McGuire, 79-132. Leiden, Boston: Brill, 2006.

Pajorin, Klára. „A magyar humanizmus Zsigmond-kori alapjai [Die Anfänge des Ungarischen Humanismus im Zeitalter von Sigismund von Luxemburg].” In Müvészet Zsigmond korában 1387-1437 [Kunst im Zeitalter von Sigismund von Luxemburg], hrsg. v. László Beke, Ernő Marosi, Tünde Wehli, 193-211. Budapest: Müvészettörténeti Kutatócsoport, 1987.

—_. „Vitéz János müveltsége [Die Bildung von Vitéz János].” Irodalomtörténeti Közlemények [Literaturhistorische Mitteilungen] 108 (2004): 533-540.

Papy, Jan. „Creating an Italian Friendship: From Petrarch’s Ideal Literary Critic „Socrates" to the Historical Reader Ludovicus Sanctus of Berlingen." In Petrarch and his Readers in the Renaissance, Intersections: Yearbook for Early Modern Studies 6, hrsg. v. Karl A. E. Enenkel und Jan Papy, 13-30. Leiden, Boston: Brill, 2006.

Rathmann, Thomas. „Beobachtung ohne Beobachter? Der schwierige Umgang mit dem historischen Ereignis am Beispiel des Konstanzer Konzils.“ In Die Konzilien von Pisa 
(1409), Konstanz (1414-1418) und Basel (1431-1449), hrsg. v. Heribert Müller und Johannes Helmrath, 95-106. Ostfildern: Thorbecke, 2007.

Rädle, Fidel. „Zu den Bedingungen der Parodie in der lateinischen Literatur des hohen Mittelalters." In Literaturparodie in Antike und Mittelalter, Bochumer Altertumswissenschaftliches Colloquium 15, hrsg. v. Wolfram Ax, Reinhold F. Glei, 171-185. Trier: Wissenschaftlicher Verlag, 1993.

Robey, David. „P. P. Vergerio the Elder: Republicanism and Civic Values in the Work of an Early Humanist." Past and Present 58 (1973): 3-37.

Sabbadini, Remigio. „Note filologiche sul Secretum del Petrarca.” Rivista di Filologia e di istruzione classica 45 (1917): 24-37.

—. „Dalle nuove lettere di Gasparino Barzizza.” Rendiconti del R. Istituto Lombardo di Scienze e Lettere 62 (1929): 881-890.

Schmidt, Paul Gerhard. „Mittelalterliches und humanistisches Städtelob.” In Die Rezeption der Antike. Zum Problem der Kontinuität zwischen Mittelalter und Renaissance, edited by August Buck, 119-29. Hamburg: Dr. Ernst Hauswedell \& Co., 1981.

Schottenloher, Karl. „Kaiserliche Dichterkrönungen im Heiligen Römischen reiche deutscher Nation." In Papsttum und Kaisertum. Forschungen zur politischen Geschichte und Geisteskultur des Mittelalters, hrsg. v. Albert Brackmann, 648-673. München: Verlag der Münchner Drucke, 1926.

Schreiner, Peter. „Giovanni Aurispa in Konstantinopel. Schicksale griechischer Handschriften im 15. Jahrhundert." In Studien zum 15. Jahrhundert. Festschrift für Erich Meuthen, 2 Bde., hrsg. v. Johannes Helmrath und Heribert Müller, Bd. 2. S. 623-633. München: Oldenbourg, 1994.

Schullian, Dorothy M. „Valerius Maximus.” In Catalogus Translationum et Commentariorum: Mediaeval and Renaissance Latin Translations and Commentaries, 
hrsg. v. F. Edward Cranz, Paul Oskar Kristeller, Bd. 5. (1984), 287-403. Washington D. C.: The Catholic University of America Press, 1960-.

Seigel, Jerrold E. „'Civic Humanism' or Ciceronian Rhetoric? The Culture of Petrarch and Bruni." Past and Present 34 (1966): 3-48.

Singer, Wolf. „Wahrnehmen, Erinnern, Vergessen.” In Eine Welt - Eine Geschichte? 43. Deutscher Historikertag in Aachen 26. Bis 29. September 2000. Berichtsband, hrsg. v. Max Kerner, 18-27. München: Oldenbourg Wissenschaftsverlag, 2001.

Solymosi, Milán. „Pier Paolo Vergerio e Coluccio Salutati.” Verbum. Analecta Neolatina 4 (2002): 147-163.

Sottili, Agostino. „La questione ciceroniana in una lettera di Francesco Zabarella a Francesco Petrarca." Quaderni per la storia dell'università di Padova, 6 (1973): 25-59.

Speroni, Mario. „Lorenzo Valla a Pavia: Il Libellus Contro Bartolo.” Quellen und Forschungen aus italienischen Archiven und Bibliotheken 59 (1979): 453-467.

Stadter, Philip A. „Arrianus.” In Catalogus Translationum et Commentariorum: Mediaeval and Renaissance Latin Translations and Commentaries, hrsg. v. F. Edward Cranz, Virginia Brown und Paul Oskar Kristeller, Bd. 3, 1-20. Washington D. C.: The Catholic University of America Press, 1960-, 1976.

Studt, Birgit. „Tamquam organum nostre mentis. Das Sekretariat als publizistisches Zentrum der päpstlichen Außenwirkung.” In Kurie und Region, hrsg. v. Brigitte Flug, Matheus Michael, Andreas Rehberg, 73-92. Stuttgart: Franz Steiner Verlag, 2005.

Tamba, Giorgio. „Giovanni Ludovisi.” in Dizionario Biografico degli Italiani, Bd. 66 (2006), S. 456-457. Rom: Treccani, 1960-.

Thomson, Ian. „Manuel Chrysoloras and the Early Italian Renaissance.” Greek, Roman and Byzantine Studies 7 (1966): 63-82. 
Trapp, Joseph Burney. „The Owl's Ivy and the Poet's Bays. An Enquiry into Poetic Garlands.” Journal of the Warburg and Courtauld Institutes 21 (1958): 227-255.

Ullman, Berthold Louis. „Some Aspects of the Origin of Italian Humanism.” In Studies in the Italian Renaissance, Storia e Letteratura 51, hrsg. v. Berthold Louis Ullman. 27-40. Rom: Edizioni di Storia e Letteratura, 1955.

Ullman, Berthold Louis. „Filippo Villani’s copy of his History of Florence.” In Studies in the Italian Renaissance, 241-247. Rom: Edizioni di Storia e Letteratura, 1955.

Vasoli, Cesare. „Leonardo Bruni.” in Dizionario Biografico degli Italiani. Bd. 14 (1972): 618-633. Rom; Treccani, 1960-.

Verweyen, Theodor und Gunther Witting. „The Cento. A Form of Intertextuality from Montage to Parody.” In Intertextuality, hrsg. v. Heinrich F. Plett, 165-177. Berlin, New York: de Gruyter, 1991.

Wattenbach, Wilhelm. „Benedictus de Pileo.” In Festschrift zur Begrüßung der 24. Versammlung deutscher Philologen zu Heidelberg, 97-131. Leipzig: Engelmann, 1865.

Wattenbach, Wilhelm. „Sigismund Grossembrot als Vorkämpfer der Humanisten und seine Gegner." Zeitschrift für die Geschichte des Oberrheins 25 (1873): 36-69.

—_. „Benedictus de Pileo.” Anzeiger für Kunde der Deutschen Vorzeit 62 (1879): 225228.

Weiss, Roberto. „Greek in Western Europe at the End of the Middle Ages”, in Medieval and Humanist Greek, ders., 3-12. Padua: Antenore, 1977.

White, Peter. „Amicitia and the Profession of Poetry in Early Imperial Rome.” The Journal of Roman Studies 68 (1978): 74-92. 
Wiesiołowski, Jacek. „Gli amici e i mecenati di Callimaco in Polonia.” In Callimaco Esperiente. Poeta e politico del '400, hrsg. v. Gian Carlo Garfagnini, 91-104. Florenz: Leo S. Olschi Editore, 1987.

Winterbottom, Michael. „Fifteenth-Century Manuscripts of Quintilian.” The Classical Quarterly n. s. 17 (1967): 339-369.

Wootton, David. „The True Origins of Republicanism: The Disciples of Baron and the Counter-Example of Venturi.” In Il repubblicanesimo moderno. L'idea di repubblica nella riflessione storica di Franco Venturi, serie Studi 31, hrsg. v. Manuela Albertone, 271-305. Neapel: Bibliopolis, 2006.

Worstbrock, Franz Josef. „Hartmann Schedels „Index Librorum". Wissenschaftssystem und Humanismus um 1500." In Studien zum 15. Jahrhundert. Festschrift für Erich Meuthen, Hrsg. v. Johannes Helmrath, Heribert Müller, und Helmut Wolff, 697-715. München: Oldenbourg, 1994.

Zwierlein, Otto. „Zur Methodik der Emendatio in Ciceros Partitiones oratoriae.” Zeitschrift für Papyrologie und Epigraphik 144 (2003): 87-99.

\section{Nachschlagewerke, Lexika, Kathaloge}

Bandini, Angelo Maria. Catalogus codicum manuscriptorum Bibliothecae Mediceae Laurentianae, 5 Bde. Florenz: s. n., 1764-1778.

Compendium Auctorum Latinorum Medii Aevi (500-1500), Florenz: SISMEL, Edizioni dell Galluzzo, 2000-.

Crollalanza, Giovambattista. Dizionario storico-blasonico delle famiglie nobili e notabili italiane estinte e fiorenti, 3 Bde. Pisa, La Direzione del Giornale Araldico, 1886-1890.

Dizionario Biografico degli Italiani. Rom: Treccani, 1966-. 
Frati, Carlo. Dizionario bio-bibliografico die bibliotecari e bibliofili italiani: dal secolo XIV al XIX, Biblioteca di bibliografia italiana 13. Florenz: Olschi, 1933.

Jaumann, Herbert. Handbuch Gelehrtenkultur der Frühen Neuzeit, Band 1: Bio-bibliographisches Repertorium. Hrsg. v. Herbert Jaumann, 667. Berlin, New York: Walter de Gruyter 2004.

Kristeller, Paul Oskar. Hrsg. Iter Italicum: a Finding List of Uncatalogued or Incompletely Catalogued Humanistic Manuscripts of the Renaissance in Italian and other Libraries 6 Bde. London: The Warburg Institute und Leiden: Brill, 1963-1992.

Lausberg, Heinrich. Handbuch der literarischen Rhetorik. Stuttgart: Steinerer, 1990.

Legrand, Emile Louis Jean, Louis Petit, Hubert Octave Pernot, Hrsg. Bibliographie Hellénique ou, Description raisonnée des ouvrages publiés par des Grecs aux XV et XVI siècle. Paris, G. P. Maisonneuve \& Larose, 1885.

Ottenthal, Emil von. „Die Bullenregister Martin V. und Eugen IV.” Mittheilungen des Instituts für Österreichische Geschichtsforschung 1. Ergänzungsband (1885): 401-589.

Smith, Joseph. Bibliotheca Smithiana: seu catalogus librorum D. Josephi Smithii Angeli per cognomina authorum dispositus. Venedig: Typis Jo. Baptistae Pasquali, 1755.

Thesaurus Linguae Latinae. Stuttgart und Leipzig: Teubner (bis 1999), München und Leipzig: KG Saur Verlag (bis 2006), Berlin und New York: Walter de Gruyter (ab 2007).

Thesaurus Proverbiorum Medii Aevi, 13 Bde. Berlin-New York: Walter de Gruyter, 19962007.

Ughelli, Ferdinando. Italia Sacra sive de Episcopis Italiae, 10 Bde. Venedig: Apud Sebastianum Coleti, 1717. 


\section{Elektronische Ressourcen}

Inventario die Manoscritti della Biblioteca Guarneriana di San Daniele del Friuli. http://www.guarneriana.it/inventario-manoscritti.html, letzte Einsicht am 03. 01. 2017. 